\title{
Design of an Actinide Burning, Lead or Lead-Bismuth Cooled Reactor that Produces Low Cost Electricity FY-01 Annual Report
}

Jacopo Buongiorno

Cliff Davis

Steve Herring

Philip MacDonald

Eric Loewen

Galen Smolik

Kevan Weaver

Ron Ballinger

Ken Czerwinski

Chris Larson

Michael Driscoll

Vaclav Dostal

Pavel Hejzlar

Jeongyoun Lim

Mujid Kazimi

Neil Todreas

October 2001 
INEEL/EXT-01-01376

MIT-ANP-PR-083

\title{
Design of an Actinide Burning, Lead or Lead-Bismuth Cooled Reactor that Produces Low Cost Electricity
}

\author{
FY-01 Annual Report \\ Report compiled and edited by \\ P. E. MacDonald and J. Buongiorno \\ MIT Principal Investigators \\ Ron Ballinger -Material Studies \\ Ken Czerwinski -Polonium Technology \\ Chris Larson - Polonium Technology \\ Michael Driscoll -Neutronics \\ Vaclav Dostal -Reactor Design \\ Pavel Hejzlar -Neutronics \\ Jeongyoun Lim-Materials \\ Mujid Kazimi -Reactor Design \\ Neil Todreas - Project Leadership \\ INEEL Principal Investigators \\ Jacopo Buongiorno, Reactor Design \\ Cliff Davis -Reactor Design \\ Steve Herring -Neutronics \\ Philip MacDonald - Project Leadership \\ Eric Loewen -Materials Studies \\ Galen Smolik -Materials Studies \\ Kevan Weaver -Neutronics
}

October 2001

\author{
Idaho National Engineering and Environmental Laboratory \\ Idaho Falls, Idaho 83415 \\ Prepared for the \\ U.S. Department of Energy \\ Under DOE Idaho Operations Office \\ Contract DE-AC07-99ID13727
}




\section{Table of Contents}

TABLE OF CONTENTS ................................................................................................................. II

EXECUTIVE SUMMARY ……....................................................................................................

1. PROJECT OVERVIEW ......................................................................................... 1

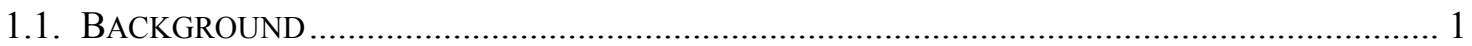

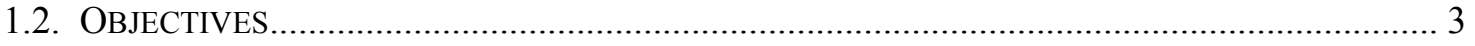

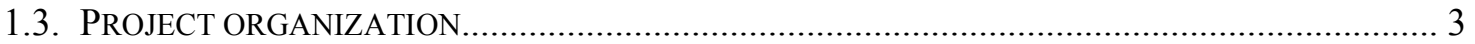

2. CURRENT RESEARCH DIRECTION .................................................................... 5

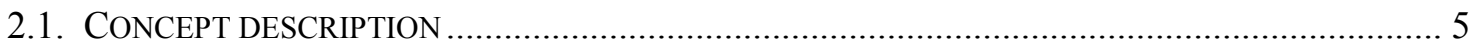

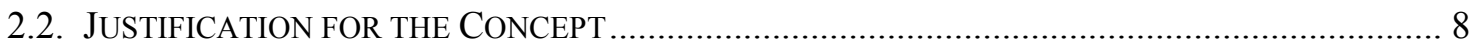

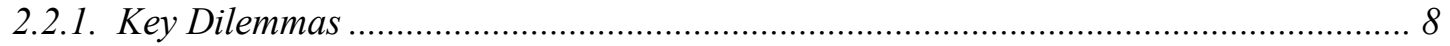

2.2.2. Design Strategy and Constraints...................................................................... 12

2.2.3. General Design Choices …………………………………………………. 15

3. RESULTS OF REACTOR CORE NEUTRONICS STUDIES …….................................... 20

3.1. TEMPERATURE DEPENDENT CRoss-SeCtION LIBRARIES ................................................ 21

3.1.1. Performance of New Library (minacxs 1) ............................................................. 21

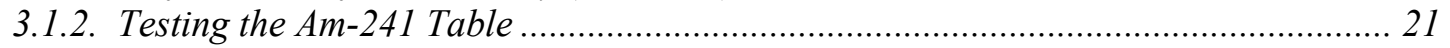

3.2. PARAMETRIC StUdies ON THE AFFeCt OF POWER ON BURNUP ……………………...... 22

3.2.1. Analysis Tools ........................................................................................... 22

3.2.2. Fuel Parameters.............................................................................................. 22

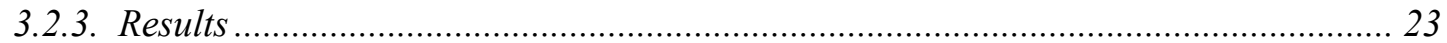

3.2. Comparison of the Neutronic Performance of Cores with Sodium and Pb-Bi

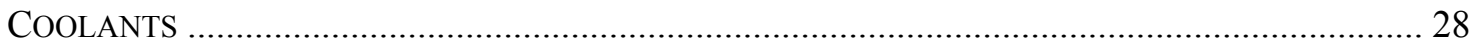

3.3.1. Fuel Parameters.............................................................................................. 29

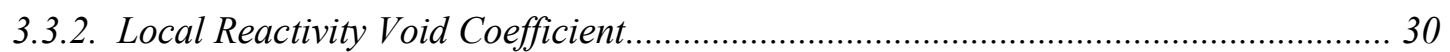

3.3.3. Doppler Reactivity Coefficient ........................................................................... 31

3.3.4. Reactivity Swing with Burnup ………………………………………………….... 31

3.3.5. Actinide Destruction and Generation Rates........................................................ 35

3.3.6. Actinide Discharge .................................................................................. 40

3.3.7. Plutonium Content ………………………………………................................ 40

3.4. CORE CONCEPT FOR MINOR ACTINIDE BURNING.......................................................... 41

3.4.1. Key Reactor Physics Challenges..................................................................... 42

3.4.2. Venue For Fertile-Free, Low-Reactivity Swing, Critical Burner Core...................... 43

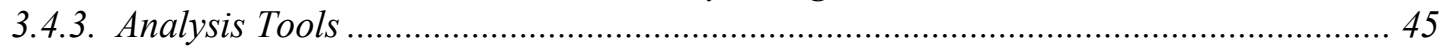

3.4.4. Achievement of Negative Coolant Void Worth ………………………………….... 46

3.4.5. Burnup Performance and Minor Actinide Destruction Rate..................................... 47

3.4.6. Coolant Reactivity Performance ……………………………………………..... 50

3.4.7. Core Power Distribution ………………………………………………………..... 51

3.4.8. Fuel Temperature Coefficient ……………………………………………….... 53

3.4.9. Delayed Neutron Fraction ……………………………………………………..... 59

3.5. CORE CONCEPT OPTIMIZED FOR BOth ACTINIDE BURNING AND ECONOMIC ELECTRICITY

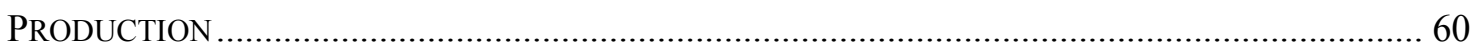

3.5.1. Key constraints and philosophy of the neutronic design....................................... 60 


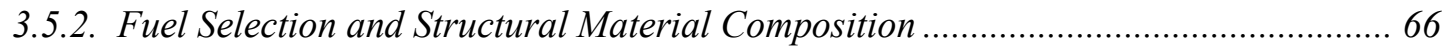

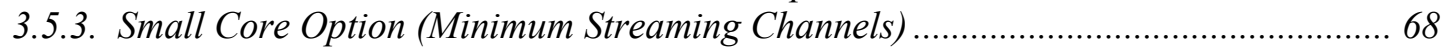

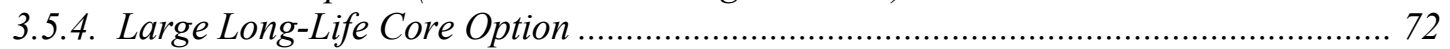

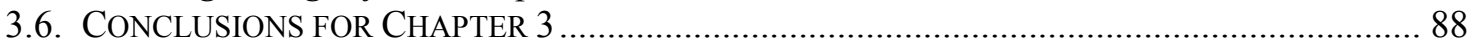

3.6.1. Summary and Conclusions of the Cross-Section Work ......................................... 88

3.6.2. Conclusions of the Parametric Studies on Power and Burnup ................................ 88

3.6.3. Conclusions of the Lead-Bismuth and Sodium Comparison ...................................... 88

3.6.4. Conclusions on Minor Actinide Burning Concept .................................................... 90

3.6.5. Conclusions from the MIT Study to Optimize both Actinide Burning and Low-Cost

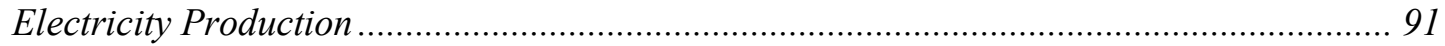

4. RESULTS OF THE PLANT ENGINEERING AND ECONOMICS STUDIES..............93

4.1. Thermal and BuRnup Limits For the Cladding And Metal Fuel .......................... 93

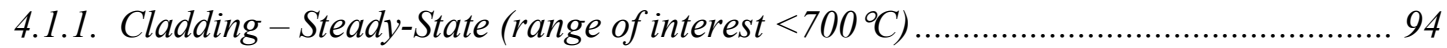

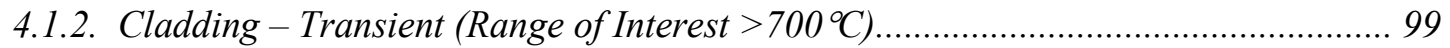

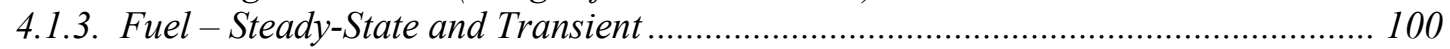

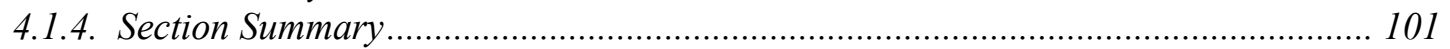

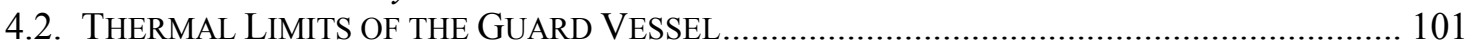

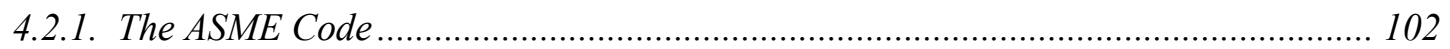

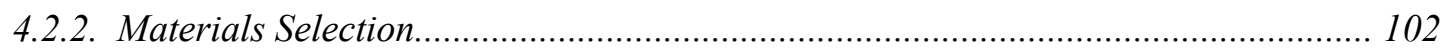

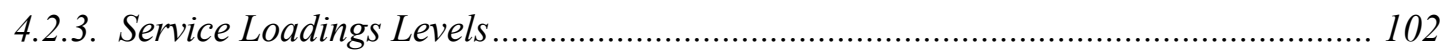

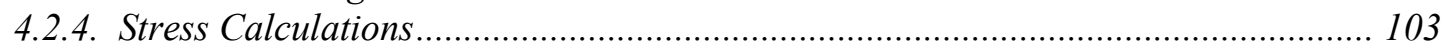

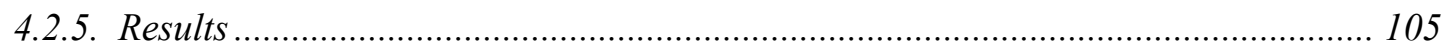

4.3. TECHNICAL/ECONOMICAL OPTIMIZATION OF THE PRIMARY CIRCUIT AND POWER

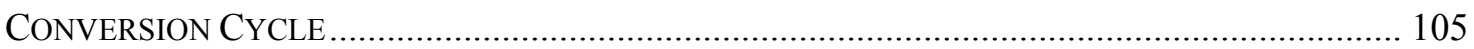

4.3.1. Thermal Hydraulic Analysis of the Core with Forced Circulation ............................ 106

4.3.2. Intermediate Heat Exchangers and Steam Generators ...................................... 110

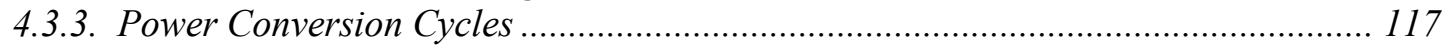

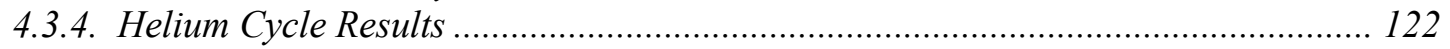

4.3.5. Economic Comparison of the Power Conversion Cycles....................................... 127

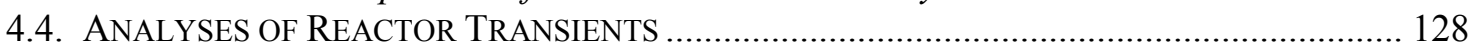

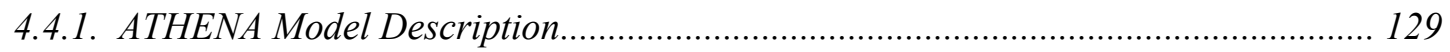

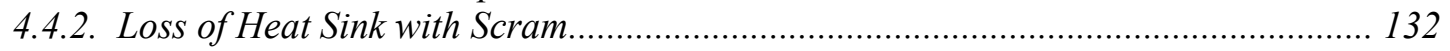

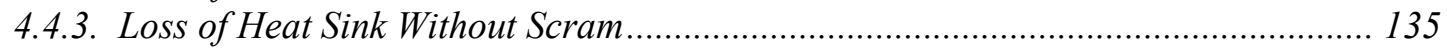

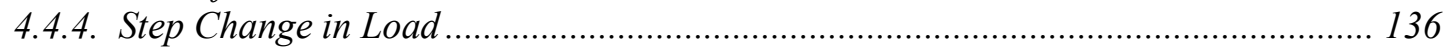

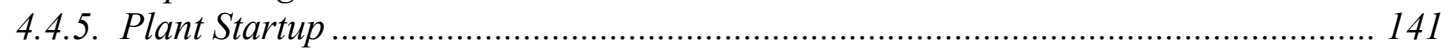

4.4.6. Control Rod Ejection Accident Without Scram................................................... 144

4.4.7. Large Rupture of the Secondary System Outlet Piping Without Scram .................... 147

4.4.8. Primary Coolant Pump Seizure Without Scram................................................. 150

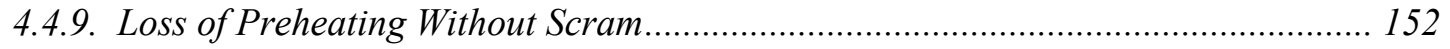

4.4.10. Heat Exchanger Tube Rupture Without Scram ................................................... 155

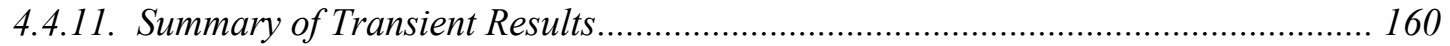

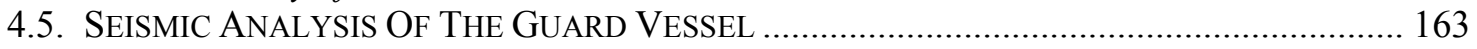

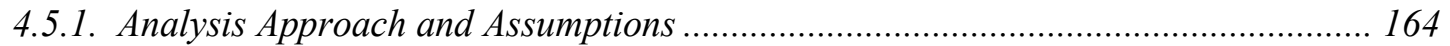

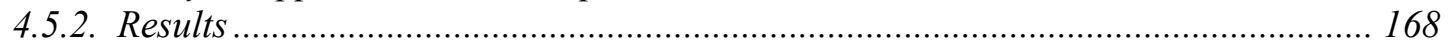

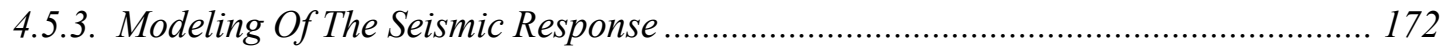

4.5.4. Applications Of The Correlations To The Reactor Guard Vessel ........................... 179

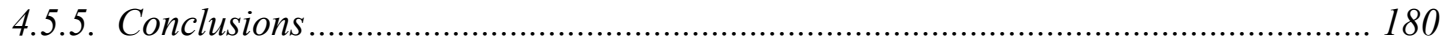

5.0. RESULTS OF THE MATERIALS STUDIES.................................................................. 181

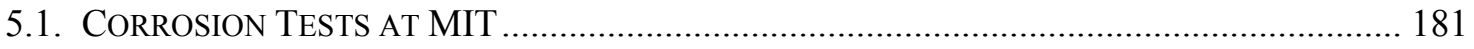




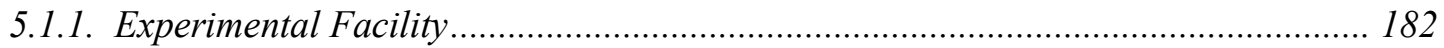

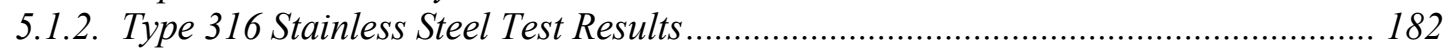

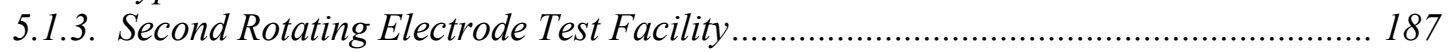

5.1.4. Sensor Development and Calibration ................................................................... 188

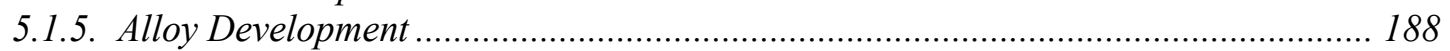

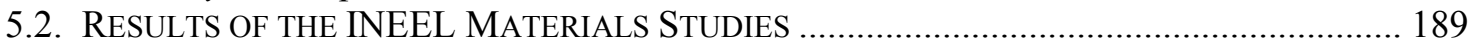

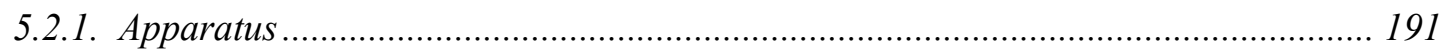

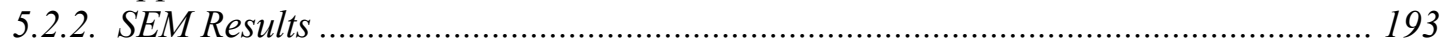

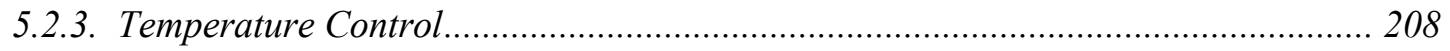

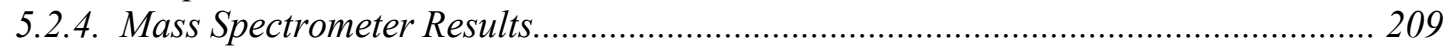

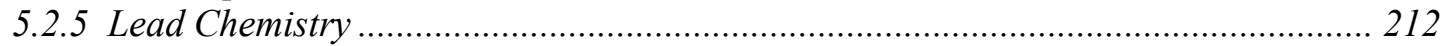

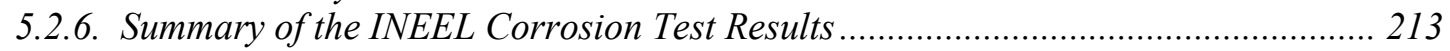

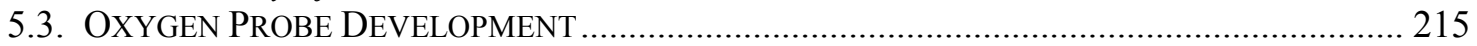

5.3.1. Test Results from Initial $\mathrm{Y}_{2} \mathrm{O}_{3}$-stabilized Zirconia Probe ...................................... 215

5.3.2. Design of Probes Using Automotive Oxygen Sensors............................................ 216

5.3.3. Experimental Results from the Newly Designed Oxygen Sensors............................ 217

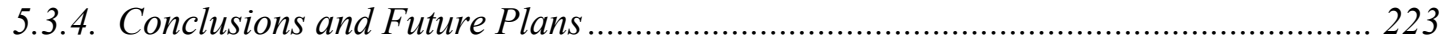

6. RESULTS OF THE COOLANT ACTIVATION STUDIES....................................... 224

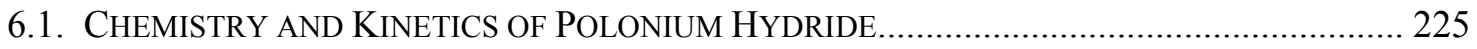

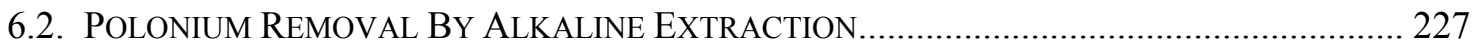

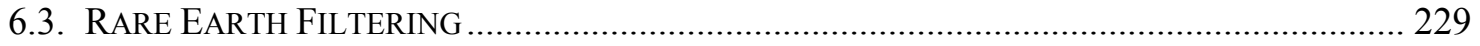

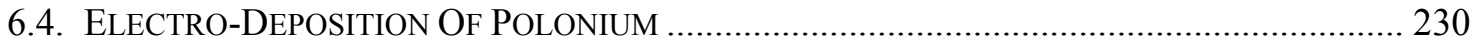

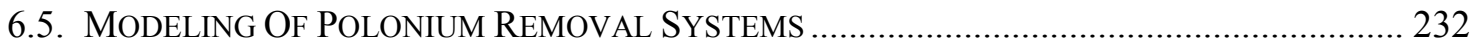

6.5.1. Figures Of Merit Of A Polonium Removal System................................................... 232

6.5.2. Simplified Analysis Of A Polonium Hydride Exchanger ........................................... 233

7. SUMMARY OF THE ACCOMPLISHMENTS TO DATE AND PLANS FOR FY-02. 240

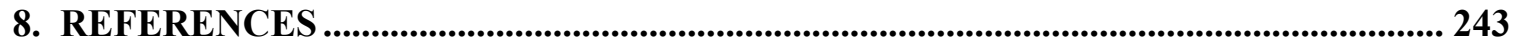

APPENDIX A. PUBLICATION HISTORY OF THE LEAD-COOLED ACTINIDE BURNING REACTOR PROJECT ............................................................................................. 251

APPENDIX B. THE STRAIN AND STRESS MODEL IN THE CLADDING ................... 255

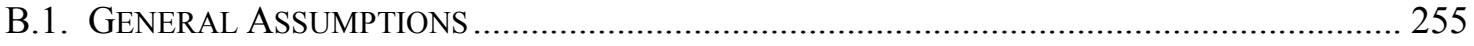

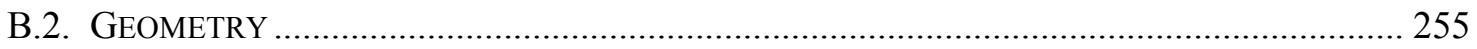

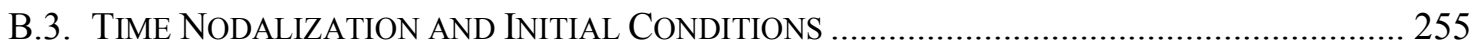

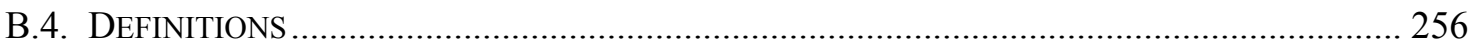

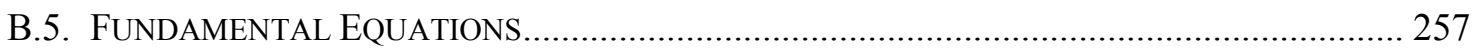

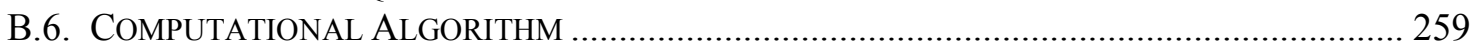

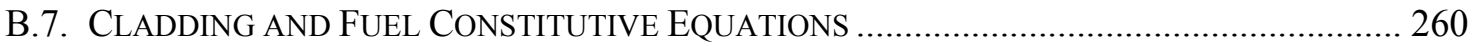

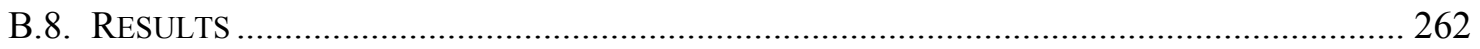




\section{Executive Summary}

The purpose of this collaborative Idaho National Engineering and Environmental Laboratory (INEEL) and Massachusetts Institute of Technology (MIT) Laboratory Directed Research and Development (LDRD) project is to investigate the suitability of lead or lead-bismuth cooled fast reactors for producing low-cost electricity as well as for actinide burning. The goal is to identify and analyze the key technical issues in core neutronics, materials, thermal-hydraulics, fuels, and economics associated with the development of this reactor concept. Work has been accomplished in four major areas of research: core neutronic design, plant engineering, material compatibility studies, and coolant activation. The publications derived from work on this project (since project inception) are listed in Appendix A.

Core Neutronic Design. Core designs that were optimized for minor actinide burning, and economic electricity production were produced. The major drawback of the design optimized for minor actinide burning was the small effective delayed neutron fraction, which cannot be increased in a fertile-free core, because it is primarily determined by the transuranics (TRUs), which are to be destroyed. This resulted in a reactor that was hard to control. In addition, the core optimized for economic electricity production, while having better controllability and long core life, was found to produce a weapons usable plutonium in the discharged fuel.

The concept of a safe and economic $\mathrm{Pb}-\mathrm{Bi}$ cooled critical reactor that will destroy actinides from spent LWR fuel was also evaluated. The analyses were performed for thorium metal-based fuel (Th-U-Pu-MA-Zr) in a once-through cycle. The reactivity swing was small, the actinide destruction rate was $63 \%$ of that expected for the ATW, an eight year refueling period was identified as feasible, a negative coolant void coefficient was obtained with streaming assemblies, the Doppler and fuel thermal expansion coefficients were negative, and the isotopics in the discharged fuel were virtually weapons unusable. This concept is the main candidate to be further developed in FY-2002.

Temperature dependent cross-section tables were produced for the $\mathrm{Np}, \mathrm{Am}$, and $\mathrm{Cm}$ isotopes. The importance of having temperature dependent cross-section data is related to the safety evaluations of the reactor concepts. If the net result of the reactivity coefficients is negative, a strong claim for passive safety can be made based on reactivity feedback mechanisms.

A comparison of different pin powers and their effect on burnup was performed in order to help in the optimization of the core design. Calculations show that a higher pin power, while decreasing the effective-full-power-days of operation, will increase the reactivity limited burnup due to the residence time of the fuel in the reactor, where the decay of the $\mathrm{Pu}-241$ is the major player.

The burnup and isotopics of non-fertile and fertile fuel in a lead-bismuth and in a sodium cooled fast reactor were calculated, with an emphasis on the fuel cycle life and isotopic content. The calculations show that the average actinide burn rate for the fertile free fuel is similar for both the sodium and lead-bismuth cooled cases, but when using the same parameters, the sodiumcooled case went sub-critical after 0.2 to 0.8 effective full power years, whereas the lead-bismuth cooled case was critical for 1.5 to 4.5 effective full power years. For the fertile fueled cores, the calculations show that the core life can extend beyond 20 years, and the average actinide burn rate is similar for both the sodium and lead-bismuth cooled cases. 
Plant engineering. The steady state and transient temperature limits were estimated for the fertile and fertile-free metallic fuel and cladding. It was found that the steady-state cladding temperature limit ranges from 580 to $620^{\circ} \mathrm{C}$ depending on the cladding diameter and thickness, on the gas-plenum-to-fuel length ratio, and on the fuel burnup. On the other hand, the transient cladding limit was determined to be $725^{\circ} \mathrm{C}$. Finally, the fuel temperature limit was determined to be $1000^{\circ} \mathrm{C}$ for both steady state and transient conditions.

The thermal limits were determined for the guard vessel (containment vessel) of a reactor with a Reactor Vessel Auxiliary Cooling System (RVACS) -type of decay heat removal system. The guard vessel normal operating temperature needs to be maintained below $430^{\circ} \mathrm{C}$ if the anticipated reactor lifetime exceeds 34 years. On the other hand, remarkably high temperatures $\left(>700^{\circ} \mathrm{C}\right)$ can be tolerated by thick vessels $\left(\mathrm{t}_{\mathrm{v}}>10 \mathrm{~cm}\right)$ under ASME Service Level C conditions for shorter times $(<1,000$ hours) typical of loss-of-primary-heat-sink situations.

Work was performed to optimize the primary circuit heat transfer and also the power conversion cycle. The thermodynamic efficiency of the power conversion cycle is one of the key parameters that affect the bus-bar cost of electricity. In order to achieve the highest possible efficiency it was first necessary to maximize the average core outlet temperature. The results for the case of forced circulation are very promising. The average lead-bismuth outlet temperature is less than $50^{\circ} \mathrm{C}$ lower than the cladding temperature limit. Three power generating system options (steam, helium and supercritical $\mathrm{CO}_{2}$ cycles) that might be used with a lead-bismuth cooled reactor were then evaluated. Assessment of the heat exchanger and steam generator designs determined that the configuration with the lead-bismuth in the shell performs better than the configuration with the lead-bismuth in the tubes. Assessment of the cycle and net efficiencies determined that the supercritical $\mathrm{CO}_{2}$ cycle achieves the best efficiencies. Therefore, it was concluded that the supercritical $\mathrm{CO}_{2}$ recompression Brayton cycle should be the cheapest option.

The performance of three different plant configurations of the actinide-burner reactor (natural circulation of the primary coolant and a steam power conversion system, forced circulation of the primary coolant and steam on the secondary side, and natural circulation of the primary coolant and helium on the secondary side) was evaluated with the ATHENA computer code during a wide range of transients, including loss of secondary heat sink with reactor scram, loss of secondary heat sink without scram, step change in load, plant startup, control rod ejection, large rupture of the secondary coolant system, primary coolant pump seizure, loss of preheating of the secondary coolant, and heat exchanger tube rupture. All three configurations of the actinideburner reactor have acceptable safety characteristics. Each configuration can be designed to meet the thermal limits for all of the transients evaluated. However, the peak cladding temperatures are generally lowest for the configuration with forced circulation of the primary coolant and steam on the secondary side and highest for the configuration with natural circulation of the primary coolant and helium on the secondary side.

A seismic linear-elastic analysis for the guard vessel of a heavy-liquid-metal reactor was undertaken based on the Design Response Spectrum approach and a $0.5 \mathrm{~g}$ earthquake. Four support types were analyzed and it was found that the (typical PWR) roll support exhibits the best overall performance. It was also found that the frequency of the first normal mode increases with increasing guard vessel diameter and thickness, while the total peak stress intensity decreases with increasing guard vessel thickness and is roughly independent of the guard vessel diameter. It was found that a $25 \mathrm{~cm}$ thickness ensures adequate seismic performance. 
Material compatibility studies. Experimental apparatuses for the investigation of the flowassisted dissolution and precipitation (corrosion) of potential fuel cladding and structural materials were designed and built at both the INEEL and MIT. The INEEL forced convection corrosion cell consists of a small heated vessel with a shroud and gas flow system. The gas flow rates, heat input, and shroud and vessel dimensions have been adjusted so that a controlled coolant flow rate, temperature, and oxygen potential are created within the down-comer located between the shroud and vessel wall. The two MIT test rigs are rotating electrode-type facilities. The oxygen potential and flow velocity can be more accurately controlled and measured in this type of apparatus.

The corrosion cells at the INEEL are being used to test structural materials that are commercially available in the United States to temperatures of about $650^{\circ} \mathrm{C}$. These materials included zirconium alloys, stainless steels, and iron-base alloys. Seven tests were completed during FY-01. The zirconium alloy material was found to perform best. The MIT test facilities are being used to test material that can be used to relatively high temperatures. One test was completed at MIT during FY-01. The results of testing a Type 316 stainless steel sample show grain boundary attack and selective removal of the nickel along the grain boundaries.

Coolant activation. Five chemical/physical mechanisms of PbPo removal from leadbismuth are being evaluated in this project, including formation of the volatile polonium hydride from the reaction of hydrogen gas with polonium, direct high temperature evaporation of the lead polonide, formation and separation of sodium polonide from the reaction of molten sodium hydroxide with polonium, deposition of the lead polonide induced by the application of an electric field, and removal of polonium by forming solid polonide species with praseodymium or thulium.

Experimental work was conducted in the areas of polonium hydride stripping, alkaline extraction, and formation of rare-earth polonides. Moreover the relevant figures of merit for a generic polonium extraction system were identified, and the performance of an extraction system based on polonium hydride stripping was modeled.

The kinetics of polonium hydride formation and release from a high-temperature molten leadbismuth bath was investigated in the Po reaction cell at MIT. It was found that typical time constants for the reaction range between 40 and 45 minutes depending on the temperature and gas conditions. A reaction cell was designed and constructed at the INEEL for investigation of the alkaline extraction technique. The cell can accommodate up to 4 crucibles simultaneously, and has a gas-injection system equipped with a mass spectrometer for control of the oxygen potential in the cell. Two test runs were conducted to confirm the expected performance of the cell components (e.g., heaters, gas injectors, gas spectrometer, thermocouples), and assess the interaction of the lead-bismuth/sodium hydroxide melt with the crucibles. Equilibrium and kinetic data on the chemical reactions of interest will be collected in FY-02. Preliminary measurements of the interaction between the lead-bismuth melt and praseodymium were performed at MIT in view of a more systematic investigation of the rare-earth methodology for Po extraction to be conducted in FY-02.

A simple mass-balance analysis of a generic polonium extraction system was conducted to identify the relevant figures of merit for such a system. It was found that the Po clean-up factor depends mainly on the product of the Po removal efficiency in the system times the lead-bismuth flow rate in the system. Finally, the performance of an extraction system based on polonium stripping was studied. It was found that such a system would be rather effective in reducing the 
specific activity of the lead-bismuth coolant, but serious technological and safety problems need to be resolved, because the system makes use of high-pressure hydrogen. 


\section{Project Overview}

\subsection{Background}

While considerable design work has been done in the United States, Europe, and Japan on fast reactors, including actinide-burners, it has mostly been done for sodium cooled reactors. A lead-bismuth cooled fast reactor was considered in the United States in the 1950s. However, it was abandoned in favor of sodium cooling for two reasons:

(1) Lead-bismuth coolant at the temperatures of interest can be very corrosive to structural materials; and

(2) The doubling time of sodium cooled fast reactors can be significantly shorter than that of lead-bismuth cooled reactors as a result of the higher power density achievable in sodium cooled cores.

Whereas a short doubling time was considered an important performance characteristic in the 1950 's, it is of little significance today, as we do not foresee a depletion of low cost uranium resources in the near future, and we have a significant inventory of actinides that can be burned in a fast reactor. Regarding the material compatibility issue, the Russians adopted lead-bismuth for use in their most advanced nuclear submarines, the so-called "Alpha" class submarines, which are the fastest in the world. The Russians have built and operated seven lead-bismuth reactors in submarines and two on-shore prototypes. More recently, they have studied the design of a variety of lead and lead-bismuth reactors for electric power generation, some of which can operate with one core loading for many years and do not require any fuel reprocessing.

Elsewhere, very long-lived core, lead-bismuth cooled, fast reactors have continued to be investigated in Japan, Korea, and in the United States at the University of California at Berkeley. A lead-bismuth cooled, accelerator-driven, sub-critical actinide-burner (labeled ATW) is a possible candidate proposed by the Los Alamos National Laboratory (LANL) for burning the actinides and long-life fission products from spent light water reactor fuel. It is envisioned that the reactors investigated in this study could operate in concert with ATWs in a program to both burn the waste from the current generation of light water reactors and produce low-cost electricity. It should also be noted that there exists a synergy between the development of the ATW and a lead or lead-bismuth cooled critical reactor system: they share similar coolant and fuel technologies with the result that either system can greatly benefit from improvements achieved for the other.

Rationale for use of lead-alloy coolant. Liquid-metal cooled fast reactors have the following advantageous characteristics:

- Their excellent heat transfer capacity enables compact, high power-density cores. This attribute is essential to developing a relatively small (and economic) core.

- Their excellent capability for natural circulation, especially for lead-alloy cooled fast reactors with an open (loose pitch) core, provides important safety advantages and offers significant potential for heat transport system simplification.

- They have unique passive safety and autonomous operability characteristics attributable to the fast neutron energy spectrum, which enables:

(a) A relatively high conversion ratio and weak fission product poisoning, thereby minimizing burnup reactivity loss and the associated need for active control and the potential for reactivity insertion accidents, and 
(b) Favorable neutronic (when properly designed) and thermo-structural feedback characteristics allowing passive adjustment of the fission power generation to the system heat rejection.

Among the different liquid metals, the choice of lead or lead-bismuth for the reactor coolant in a fast reactor offers enhanced safety and reliability. The advantages of lead-alloy over sodium as a coolant are related to the following basic material characteristics: chemical inertness with air and water; higher atomic number; low vapor pressure at operating temperatures; and high boiling temperature. The basic properties of lead, lead-bismuth, and sodium are compared in Table $\mathbf{1}^{1}$.

Table 1. Basic characteristics of liquid metal coolants.

\begin{tabular}{|c|c|c|c|c|c|}
\hline Coolant & Mass \# & $\begin{array}{c}\text { Neutron Absorption } \\
\text { Cross Section }(\mathrm{mb})\end{array}$ & $\begin{array}{c}\text { Melting Point } \\
\left({ }^{\circ} \mathrm{C}\right)\end{array}$ & $\begin{array}{c}\text { Boiling } \\
\text { Point }\left({ }^{\circ} \mathrm{C}\right)\end{array}$ & $\begin{array}{c}\text { Chemical Reactivity } \\
\text { (with air and water) }\end{array}$ \\
\hline $\mathrm{Pb}-\mathrm{Bi}$ & $\sim 208$ & 3.82 & 125 & 1670 & Inert \\
\hline $\mathrm{Pb}$ & 207 & 2.75 & 327 & 1737 & Inert \\
\hline $\mathrm{Na}$ & 23 & 2.35 & 98 & 883 & Highly reactive \\
\hline
\end{tabular}

These basic properties lead to the following potential advantages for lead-bismuth coolant:

- Harder neutron spectrum and better reflection properties (with little moderation), which results in an improved neutron economy, especially when burning actinides from spent LWR fuel, and makes it possible to get a good conversion ratio even without blankets (neutron economy is vital to achieving long core lifetimes while minimizing burn up reactivity loss and excessive control requirements).

- The high boiling temperature $\left(1670^{\circ} \mathrm{C}\right)$ and high heat of vaporization of lead and leadbismuth coolants (versus $883^{\circ} \mathrm{C}$ for sodium), which eliminates boiling and related loss of cooling as a realistic accident scenario.

- Significantly lower reactivity (in fact, negative reactivity with certain designs) associated with hypothetical voiding of the coolant. The positive reactivity effect of coolant voiding is a concern with sodium-cooled fast spectrum systems.

- Lead-alloy coolant does not react energetically with air and water (eliminating fires and the necessity of employing an intermediate heat transport loop, thereby reducing plant capital costs).

- Possibility of using relatively high outlet temperatures and high efficiency heat transfer cycles. With proper control of the coolant chemistry and choice of cladding and structural materials, it is likely that relatively high coolant temperatures can be obtained; in addition, there is potential for coupling of the reactor to other energy conversion and distribution systems of the future.

- High solubility of the actinides in the coolant, which prevents re-criticality events upon core melting.

\footnotetext{
1 Thermophysical properties of pure lead, Pb-Bi eutectic and sodium from [Lyon 1952, Kutateladze 1958], cross sections from [BNL 2000].
} 
Because lead or lead-bismuth has not been used as a reactor coolant outside of Russia, important technology issues (e.g., structural material corrosion, coolant chemistry control, filtration of impurities, coolant activation) must be addressed. There are also other disadvantages to the use of lead or lead-bismuth for cooling an actinide fast reactor in addition to the material compatibility problems. These include: high material cost; higher melting temperature $\left(125^{\circ} \mathrm{C}\right.$ for lead-bismuth versus $98^{\circ} \mathrm{C}$ for sodium); and the production of Po-210. But probably most important, the relative cost of the various design alternatives that have been proposed earlier must be substantially improved.

\subsection{Objectives}

The purpose of this Idaho National Engineering and Environmental Laboratory (INEEL) and Massachusetts Institute of Technology (MIT) Laboratory Directed Research and Development (LDRD) project is to investigate the suitability of lead-bismuth cooled fast reactors for producing low-cost electricity as well as for actinide burning. The goal is to identify and analyze the key technical issues in core neutronics, materials, thermal-hydraulics, fuels, and economics associated with the development of this reactor concept. The goal is also to identify the most promising approach for designing such a reactor.

Considerable attention has been given in this project to the strategic objectives for this fast reactor concept since these dictate both the potential future interest in the product $\&$ the potential cost of the product. Hence, three major directions for the neutronic design of a lead-bismuth cooled reactor core have been studied: (1) a fertile free actinide burner, (2) a high conversion concept that does not require reprocessing, and (3) an economical actinide burner that employs fertile fuel to reduce the reactivity swing and increase the core lifetime. In addition, plant designs have been studied that include direct contact between the liquid metal and the secondary side coolant (water/steam), indirect contact with natural circulation of the primary system coolant, and indirect contact with forced convection of the coolant. A variety of secondary side heat transport schemes have also been investigated.

\subsection{Project organization}

INEEL and MIT are carrying out this investigation in a cooperative, coordinated manner in four discipline-based areas (core neutronic design, material compatibility studies, coolant activation, and plant engineering). The distribution between INEEL and MIT lead responsibilities in these disciplinary areas is as follows:

(1) Neutronics-MIT has examined core designs to achieve the two limiting objectivesmaximum actinide consumption and minimization of electricity cost while the INEEL and MIT together have examined a core designed to optimize both objectives simultaneously.

(2) Structural Materials-INEEL is performing circulation corrosion studies while MIT is performing static autoclave studies with spinning test sections. Further, INEEL's studies focus on commercially available materials while MIT focuses on more advanced materials. Both INEEL and MIT are also developing the capability to fabricate oxygen potential measurement probes for both the materials and polonium investigations.

(3) Polonium - MIT has been obtaining fundamental chemical data characterizing the release mechanisms of polonium from a lead-bismuth primary coolant. The INEEL activity is aimed at selecting a coolant purification process. 
(4) Plant Engineering - The INEEL has assessed the transient plant performance while MIT has assessed steady state plant performance. In both cases, the focus has been on determining the maximum allowable plant power and the associated plant capital cost for the following plant system options: primary coolant under natural versus forced-circulation; and a steam, helium or supercritical carbon dioxide secondary coolant system. The INEEL has also analyzed the fuel performance and the reactor vessel and guard vessel structural behavior.

The project has been active in disseminating its results through preparation of topical reports and technical papers in journals and technical conferences. These publications are listed in Appendix A. 


\section{Current Research Direction}

This research project investigates the suitability of lead-bismuth cooled fast reactors for producing low-cost electricity as well as for actinide burning. While these two goals are the primary thrust in the development of a conceptual design, proliferation resistance and safety are also important aspects to be incorporated in the design process. Thus, this concept will address all objectives of the Generation IV program: favorable economics, proliferation resistance, enhanced safety and waste minimization.

Section 2.1 presents a brief description and schematic figures of the current most promising design to familiarize the reader with the concept that will be further developed in FY-2002. The concept strives for balance between the actinide destruction rate, economic electric power generation, and excellent safety characteristics. Section 2.2 discusses the dilemmas, constraints and design strategy that lead to this design.

\subsection{Concept description}

A schematic of the reactor primary coolant system and the reactor vessel auxiliary cooling system (RVACS) (the decay-heat removal system) is illustrated in Figure 1. The whole primary circuit operates at atmospheric pressure and is contained within a single vessel. This results in an integrated, more compact system and essentially eliminates the possibility of any type of loss-ofcoolant accident (LOCA) because the primary coolant does not flow in external pipes. The annulus between the core barrel and the reactor vessel is used to accommodate the intermediate heat exchangers and the circulation pumps.

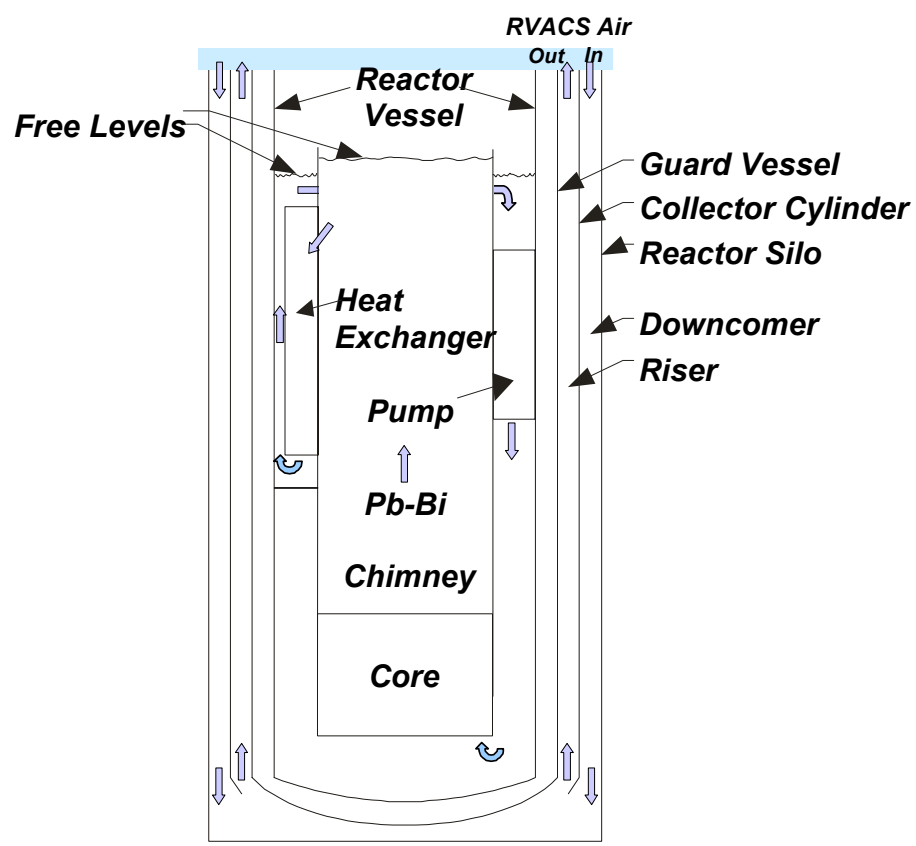

Figure 1. Layout of the reactor with the circulation scheme for the primary coolant and for the reactor vessel auxiliary cooling system (RVACS).

Circulation of the primary coolant within the pool is based on a dual-free-level approach. The primary coolant flows from the core outlet to the hot free level. From there it flows through 
the intermediate heat exchanger and surfaces again at the cold free level, from which it is pumped down to the core inlet. This circulation scheme prevents dragging of gas bubbles into the core in the case of a heat-exchanger-tube-rupture event, which could otherwise cause undesirable reactivity perturbations.

A guard vessel surrounds the main reactor vessel and is welded to the reactor compartment. Both the guard vessel and the reactor compartment are sealed thus effectively forming the reactor containment. In a hypothetical loss-of-primary-heat-sink event, the residual heat is removed by the RVACS passive decay heat removal system, i.e., the decay heat is discharged through the vessel and the guard vessel to air in natural circulation on the outer surface of the guard vessel. The gap between the vessel and the guard vessel is filled with liquid lead-bismuth to enhance heat transfer. Also a perforated cylinder is placed around the guard vessel to increase the heat transfer surface to the air. The RVACS is a completely passive system and for the reference dimensions of the vessel, it can safely remove the decay heat from a 875-MWth core without violating the temperature limits of the fuel, cladding and vessel.

The core employs 157 streaming fuel assemblies as illustrated in Figure 2, fueled with a metal alloy of thorium, uranium, zirconium, plutonium, and minor actinides or, alternatively, mono-nitride thorium, uranium, plutonium and minor actinides. These fuels enable achievement of satisfactory actinide burning rates, and exhibit adequate reactivity coefficients. As shown in both Figures 1 and 2, the space between the core barrel and the vessel is used to place two intermediate heat exchangers and reactor coolant pumps. The intermediate heat exchangers are designed with the lead bismuth flow on the shell side and high-pressure $\mathrm{CO}_{2}$ inside the tubes.

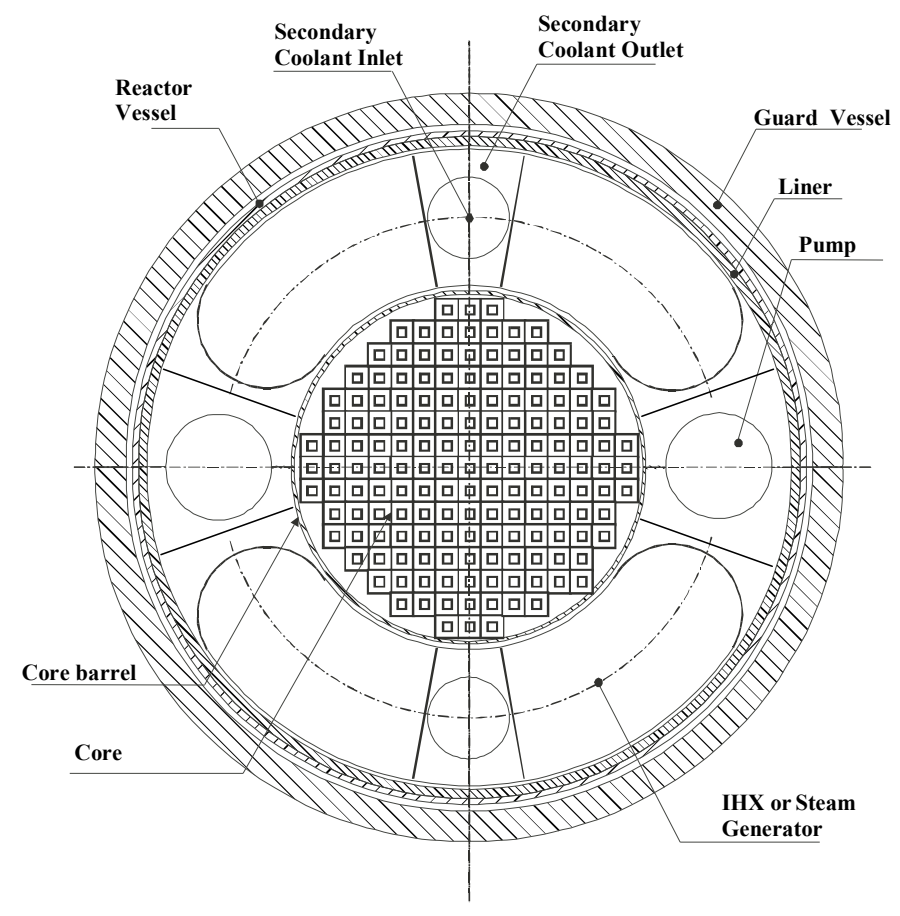

Figure 2. Top view of the vessel with core and intermediate heat exchanger layout.

Figure 3 shows the Brayton power cycle with supercritical $\mathrm{CO}_{2}$ working fluid and the current design values. The pressures, temperatures, enthalpies, entropies, and densities in Figure 3 are listed by numbered location in Table 2 . This cycle achieves high cycle efficiency at relatively 
low temperatures compatible with the cladding temperature constraints and is significantly simpler than the Rankine cycle. The proposed cycle employs a split recuperator design with flow recompression to avoid a negative pinch point. Only about half of the total flow enters the main compressor to proceed to the low temperature recuperator. The main stream is merged with the recompressed stream prior to entering the high temperature recuperator. The total mass flow is then heated in the high temperature recuperator and subsequently in the intermediate heat exchangers. Following the expansion in the high and low-pressure turbines, the working fluid enters the high temperature recuperator and, subsequently, the low temperature recuperator. After leaving the low temperature recuperator the flow is split. About half of the flow is recompressed in the recompression compressor. The remaining flow is cooled in the pre-cooler prior to entering the main compressor. The cycle achieves a thermal efficiency of $44.6 \%$.

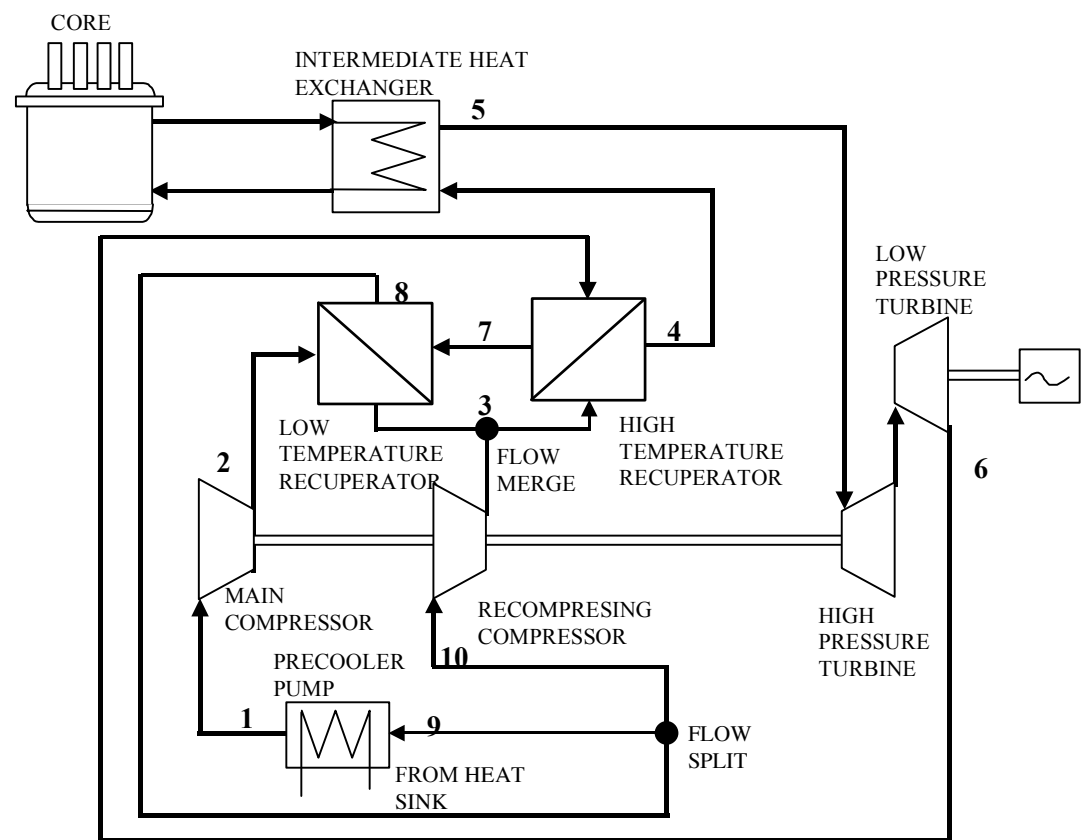

Figure 3. Brayton power cycle with supercritical $\mathrm{CO}_{2}$.

Table 2. Pressures, temperatures, enthalpies, entropies, and densities in Figure 3 listed by numbered location.

\begin{tabular}{|c|c|c|c|c|c|}
\hline \multirow{2}{*}{ Location } & Pressure & Temperature & Enthalpy & Entropy & Density \\
\cline { 2 - 6 } & $\mathbf{( k P a )}$ & $\left({ }^{\circ} \mathbf{C}\right)$ & $\mathbf{( k J / k g )}$ & $\mathbf{( k J / k g K )}$ & $\mathbf{( k g / m 3 )}$ \\
\hline 1 & 7600.00 & 32.00 & 315.08 & 1.376 & 557.5 \\
\hline 2 & 19000.00 & 63.62 & 336.89 & 1.387 & 681.97 \\
\hline 3 & 18971.50 & 156.41 & 537.95 & 1.923 & 297.3 \\
\hline 4 & 18943.04 & 408.02 & 861.67 & 2.520 & 146.2 \\
\hline 5 & 18864.11 & 550.00 & 1035.94 & 2.753 & 117.61 \\
\hline 6 & 7627.95 & 445.53 & 920.952 & 2.777 & 56.04 \\
\hline 7 & 7616.49 & 161.54 & 597.23 & 2.205 & 102.7 \\
\hline 8 & 7605.07 & 68.87 & 478.61 & 1.8975 & 162.7 \\
\hline Pressure ratio & & & \multicolumn{3}{|c|}{2.5} \\
Recompression fraction \\
Compressor efficiency \\
Turbine efficiency \\
Cycle Efficiency
\end{tabular}


The important reactor system design parameters are listed in Table 3.

Table 3. Reactor design parameters.

\begin{tabular}{|c|c|c|c|}
\hline \multirow{2}{*}{\multicolumn{3}{|c|}{ 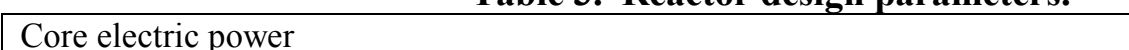 }} & \\
\hline & & & $300-350 \mathrm{MW}_{\mathrm{e}}$ \\
\hline \multicolumn{3}{|c|}{ Core thermal power } & $700-875 \mathrm{MW}_{\text {th }}$ \\
\hline \multicolumn{3}{|c|}{ Cycle efficiency } & $43-46 \%$ \\
\hline \multirow{7}{*}{$\begin{array}{l}\text { Reactor } \\
\text { vessel } \\
\text { geometry }\end{array}$} & \multirow{3}{*}{ Guard vessel } & Outer diameter & $6.15 \mathrm{~m}$ \\
\hline & & Inner diameter & $5.65 \mathrm{~m}$ \\
\hline & & Wall thickness & $25 \mathrm{~cm}$ \\
\hline & \multirow{3}{*}{ Vessel } & Outer diameter & $5.55 \mathrm{~m}$ \\
\hline & & Inner diameter & $5.45 \mathrm{~m}$ \\
\hline & & Wall thickness & $5 \mathrm{~cm}$ \\
\hline & \multicolumn{2}{|c|}{ Liner-to-vessel gap } & $7.5 \mathrm{~cm}$ \\
\hline \multirow{8}{*}{ Fuel pin } & \multicolumn{2}{|c|}{ Fuel outer diameter } & $5.48 \mathrm{~mm}$ \\
\hline & \multicolumn{2}{|c|}{ Cladding inner diameter } & $6.32 \mathrm{~mm}$ \\
\hline & \multicolumn{2}{|c|}{ Cladding outer diameter } & $7.52 \mathrm{~mm}$ \\
\hline & \multicolumn{2}{|c|}{ Cladding thickness } & $0.6 \mathrm{~mm}$ \\
\hline & \multicolumn{2}{|c|}{ Fuel heated length } & $1.3 \mathrm{~m}$ \\
\hline & \multicolumn{2}{|c|}{ Fission-gas plenum height } & $2.47 \mathrm{~m}$ \\
\hline & \multicolumn{2}{|c|}{ Cladding material } & $\begin{array}{l}\text { HT-9, EP-823, or ODS } \\
\text { martensitic/ferritic steels }\end{array}$ \\
\hline & \multicolumn{2}{|l|}{ Gap bond } & liquid $\mathrm{Pb}$ \\
\hline \multirow{8}{*}{ Core geometry } & \multicolumn{2}{|c|}{$\begin{array}{l}\text { Number of positions ( } 1 \text { external and } 5 \text { internal rows } \\
\text { are voided) in assembly }\end{array}$} & $21 \times 21$ \\
\hline & \multicolumn{2}{|c|}{ Pitch to diameter ratio (square pitch) } & 1.3 \\
\hline & \multicolumn{2}{|c|}{ Number of fuel assemblies } & 157 \\
\hline & \multicolumn{2}{|c|}{ Core equivalent outer diameter } & $2.92 \mathrm{~m}$ \\
\hline & \multicolumn{2}{|c|}{ Number of rods per fuel assembly } & 312 \\
\hline & \multicolumn{2}{|c|}{ Fuel assembly pitch } & $206.3 \mathrm{~mm}$ \\
\hline & \multicolumn{2}{|c|}{ Core Barrel Outer Diameter } & $3.20 \mathrm{~m}$ \\
\hline & \multicolumn{2}{|c|}{ Core Barrel Thickness } & $20 \mathrm{~mm}$ \\
\hline \multicolumn{3}{|l|}{ Fuel type } & $\begin{array}{l}\text { U-Th-Pu-MA nitride } \\
\text { U-Th-Pu-MA-Zr metal }\end{array}$ \\
\hline
\end{tabular}

\subsection{Justification for the Concept}

\subsubsection{Key Dilemmas}

The design was driven by the emphases placed on the individual Generation IV goals. The Generation IV goals, once translated into actual design concepts, result in a number of competing requirements, which makes it impossible to satisfy each to the maximum possible extent. Therefore, a delicate balance among individual objectives is necessary. Seven key dilemmas affecting the choice of current design direction are discussed next.

Waste reduction versus safety dilemma. If the primary goal is to minimize waste from the LWR fleet, maximization of the actinide destruction rate is desirable. This implies a fertile-free core. Although it is feasible to design critical, fertile-free actinide burners, the achievable safety level is penalized. This has been shown for a fertile-free actinide burner reactor design [Hejzlar 2001a] where a large number of control rods had to be employed to compensate for the large reactivity swing of a fertile-free core. This problem can be avoided if the reactor is optimized for 
minor actinide (i.e., TRUs of atomic number higher than $\mathrm{Pu}$ ) burning, as shown by Hejzlar et al., [2001b] for a Minor Actinide Burner (MABR) design, where a very small reactivity swing can be achieved in a fertile-free core utilizing the attractive properties of Np-237 and Am-241 whose progeny exhibit significantly higher fission to capture ratio cross section. However, these reactors lack a sufficient Doppler coefficient and exhibit a small delayed neutron fraction making the reliance on inherent reactivity feedbacks very difficult. Relaxing the requirement on maximum actinide destruction rate allows the introduction of fertile material into the core and hence an improvement of the safety characteristics. It is important, however, to strike a balance between the actinide annihilation rate and the inherent safety so that a sufficient transuranic (TRU) destruction rate can be attained while maintaining a high level of safety.

Waste reduction versus cost dilemma. Reduction of the waste from the LWR spent fuel requires reprocessing of both the LWR fuel and reprocessing of the discharged fuel from the actinide burner reactor. However, reprocessing, and in particular multiple reprocessing of the spent actinide burner reactor fuel where high recovery efficiencies above $99.9 \%$ are required (see top scheme on Figure 4) significantly increases the fuel cycle cost. The projected fuel cost of a recycling-mode system where fuel from the actinide burner reactor is recycled until almost all the TRUs are destroyed was found to be two to four times larger than the current LWR fuel costs [Driscoll and Kim, 2000, Kim et. al., 2000]. The cost imposed by appending the burner fuel cycle to the LWR fuel cycle would make LWR electric power uncompetitive with fossil-fired power if the additional cost is charged to the LWRs, or make actinide burner reactors too costly should this expenditure be incurred as part of actinide burner reactor fuel cycle cost. Clearly, there is an acute need to significantly reduce the fuel cycle cost of any transmutation system before that technology can be commercially deployed. One possibility for compromise, should the transmutation systems be deployed before new and substantially cheaper technologies become available, is a once-through actinide burner reactor approach. The LWR fuel would be reprocessed once to extract the transuranics to fuel the actinide burner reactors, where their isotopics would be degraded before disposing the actinide burner reactor spent fuel in a repository or placing the potentially valuable spent fuel in long term storage (see bottom scheme on Figure 4). This way, the LWR TRU inventory is reduced, albeit not totally eliminated, and the cost of reprocessing could be maintained at a reasonable level, since only LWR fuel reprocessing without the need for separation of individual transuranics is required.

Cost versus proliferation resistance dilemma. The most promising approach for economical production of electricity is a once-through (hence no reprocessing costs) fuel cycle of extended length achieved by in-situ breeding and in-situ burning of fissile material. Such a reactor can be fueled with enriched uranium without the need for reprocessing, have a very small reactivity swing over a long core life, and exhibit attractive safety characteristics, as shown in Hejzlar et al., [2001c]. This cycle, suggested recently by Toshinski [1997], also offers better utilization of uranium resources than the LWR once-through cycle, albeit not as good as the fast breeder reactor cycles with reprocessing. In addition, waste generation per MWth produced in this once-through concept can be significantly reduced in comparison to the current LWRs. However, plutonium in the discharged fuel of such reactors has a very high content of Pu-239 making the spent fuel a potential proliferation threat.

Monolithic vs. Modular Design Dilemma. Large-power monolithic plants take full advantage of the economy of scale by minimizing materials, land and staff requirements per unit power generated. However, their construction usually requires large initial capital investments, and significant on-site welding and assembling, which result in high financial risk and long construction times, respectively, even though some of their systems/structures can be 
modularized, too. On the other hand, small-power modular reactors will have a less favorable economy of scale, but present the following advantages:

- They can be fully fabricated in a factory and readily shipped as modules to the site for quick and economic assembling,

- Because for a given electricity demand they are fabricated in larger number, they can take full advantage of cost reduction from learning,

- They require smaller initial capital investments and shorter construction time, which reduces the financial risk associated with the project,

- Additional generating capacity can be gradually installed at the plant by adding small modules, which enables closely matching the electricity demand of the utility customers, prevents market saturation, and ultimately maintains the price of electricity stable,

- Because of their smaller power they can be designed with simpler and more reliable passive safety systems.

\section{Multi Fuel Recycle Scheme}

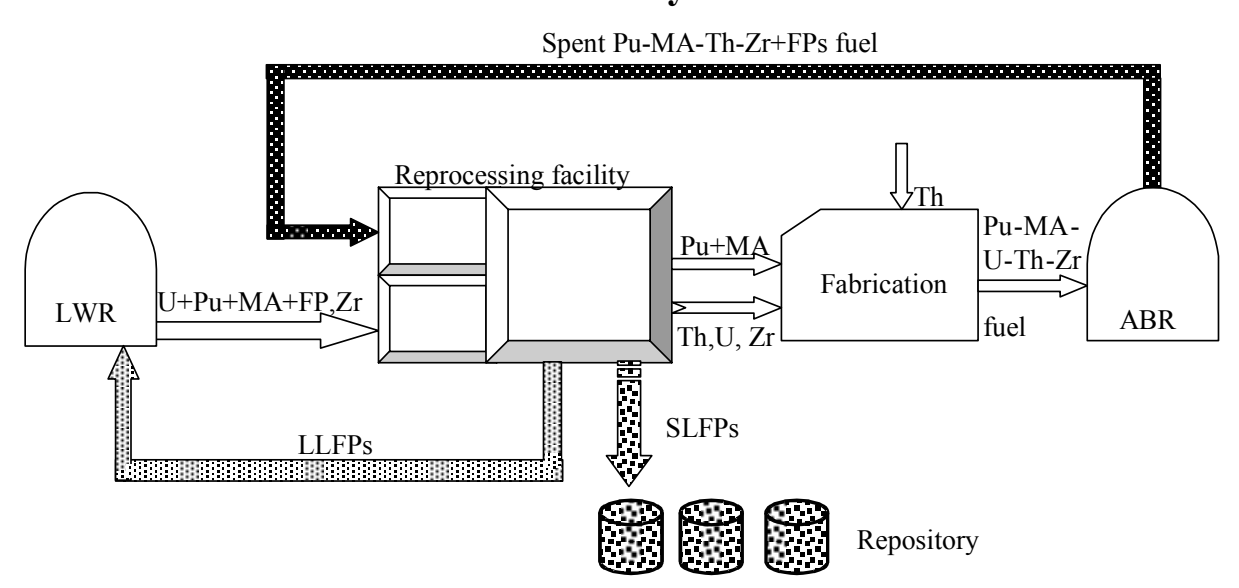

$\mathrm{ABR}=\mathrm{LBE}$ cooled Actinide Burning Reactor

LLFP - Long-Lived Fission Products

SLFP - Short-Lived Fission Products

Once Through Fast Reactor Fuel Cycle Scheme

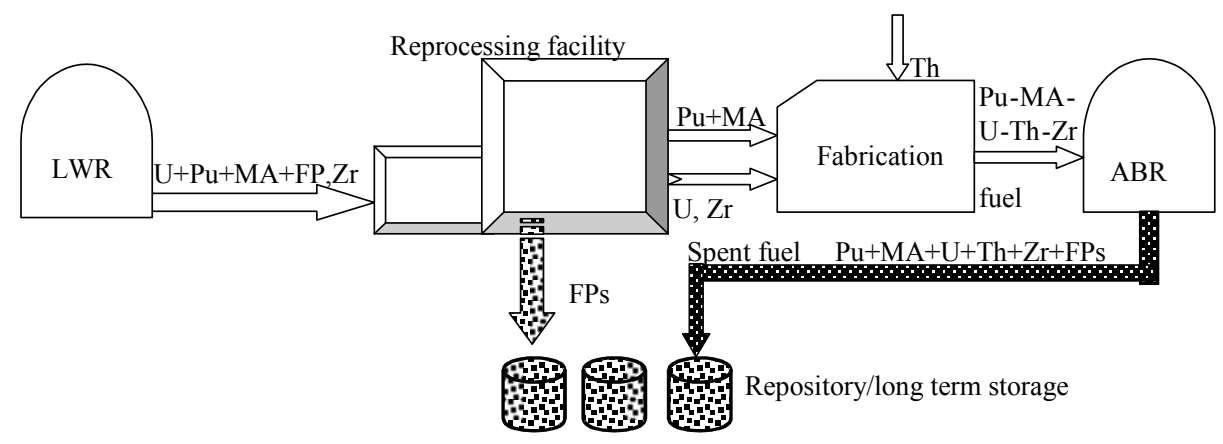

Figure 4. Fuel cycle schemes with lead or lead-bismuth cooled fast reactors.

Active vs. Passive Safety Dilemma. While current commercial LWRs (designed and licensed in the 70s and 80s) rely on active and redundant safety systems, in the last two decades an effort was made to design nuclear reactors in which the consequences of accidents are coped 
with by systems based solely on the basic laws of physics, e.g., thermal radiation, natural circulation. The use of passive safety systems reduces the need for operator intervention under accidental conditions, thus decreasing the possibility of human errors, which significantly contributed to the development of the Chernobyl and Three Mile Island accidents. In addition, passive systems are generally simpler and less capital-intensive than active systems, e.g., they do not need diesel generators and/or dedicated pumps. While it is challenging to design large-power reactors with fully-passive safety systems, it is relatively easy to equip small modular reactors with such systems.

Forced vs. Natural Circulation Dilemma. Forced circulation of the primary coolant under normal operating conditions enables design of a tighter and neutronically more economic core, minimizes the coolant temperature rise across the core (which, for given outlet temperature, results in higher temperatures of the secondary coolant and thus in higher thermal efficiencies), and facilitates reactor control during start-up and other operational transients. On the other hand, natural circulation eliminates the need for primary coolant pumps, which results in both a capital and operating cost reduction, but requires a large relative elevation between the core and the heat sink (making the whole system less compact), and requires a relatively loose core, which negatively affects the neutron economy.

The Power Cycle Dilemma. Three power conversion cycles are considered in this project: a Rankine steam cycle, a Brayton helium cycle, and a Brayton supercritical-carbon-dioxide cycle. At temperatures typical of lead-bismuth-cooled reactors (i.e., $500-600^{\circ} \mathrm{C}$ ), the steam and the $\mathrm{CO}_{2}$ cycles can achieve thermal efficiencies up to $45-46 \%$, while the helium cycle exhibit efficiencies around 33\%. Clearly, the helium cycle is the least attractive of the three. Although a mature technology, the steam cycle is a large and relatively complicated system with high capital cost and maintenance requirements. On the other hand, the supercritical $\mathrm{CO}_{2}$ cycle, more compact and with fewer components, has the potential for capital cost reduction, although it is a much less established technology and needs to be operated at very high pressures (i.e., up to $20 \mathrm{MPa}$ ).

Although there are many other dilemmas involved, the above issues, in particular the first three were the most influential factors shaping the design direction we have now embraced for the development of the lead or lead-bismuth cooled reactor. We adopted the following postulates in selecting and pursuing our future reactor design:

1. The concept must be economic and effectively compete with other alternatives of electricity generation.

2. Safety is of paramount importance with no compromises to be made.

3. The concept must help in the reduction of transuranics from spent LWR fuel, or generate significantly less waste than current LWRs.

4. Because transmutation of LWR actinides necessarily implies reprocessing, it is recognized that these systems cannot be as proliferation resistant as LWRs. Nevertheless, maximization of the barriers to diversion of fissile materials will be pursued as an important goal for this fuel cycle. In addition, the proliferation resistance of discharged spent fuel from an actinide burner reactor must be at least as good as for the LWR oncethrough cycle, and preferably better. 


\subsubsection{Design Strategy and Constraints}

This section presents key parameters and constraints used in the development of the lead or lead-bismuth-cooled reactor concept and briefly describes the underlying logic behind the process that lead to each key parameter/constraint. These constraints and parameters are summarized in Table 4.

\section{Design Approach}

Considering the economy of scale in modular reactors, transportability options, and current utility interests in plant sizes to be deployed, the target electric power rating was set between 300 to $350 \mathrm{MW}_{\mathrm{e}}$. Using the electric power output as a starting point, thermal power can be determined for an assumed power conversion cycle efficiency. The thermal power sets the vessel diameter necessary to passively dissipate decay heat to the air flow around the guard vessel. A seismic analysis also has to be performed to set the thickness of the guard vessel (which in turn affects the decay heat transfer rates) to withstand the design base earthquake event. Based on the vessel diameter from decay heat removal and seismic analyses, the area between the vessel and the core barrel to accommodate the intermediate heat exchangers or steam generators, pumps and other reactor internals can be calculated, which also yields the area available for the core. Finally, the core design, which needs to fit in these dimensions is then optimized for neutronic and thermal hydraulic performance.

Table 4. Design constraints*.

\begin{tabular}{|c|c|c|c|c|c|c|}
\hline \multirow{3}{*}{ Cladding limits } & \multirow{2}{*}{\multicolumn{2}{|c|}{ Thermal }} & \multirow{2}{*}{\multicolumn{2}{|c|}{$\begin{array}{l}\text { Membrane temperature } \\
\text { Inner temperature }\end{array}$}} & Steady state & $600^{\circ} \mathrm{C}$ \\
\hline & & & & & Transient & $725^{\circ} \mathrm{C}$ \\
\hline & \multicolumn{5}{|c|}{ Fluence $(\mathrm{E}>0.1 \mathrm{MeV})$} & $4 \times 10^{23} \mathrm{n} / \mathrm{cm}^{2}$ \\
\hline \multirow[t]{4}{*}{ Fuel limits } & \multirow{2}{*}{\multicolumn{3}{|c|}{\begin{tabular}{l|} 
Maximum \\
temperature
\end{tabular}}} & \multicolumn{2}{|c|}{ Metallic } & $1000^{\circ} \mathrm{C}$ \\
\hline & & & & & $>1000^{\circ} \mathrm{C}$ \\
\hline & \multirow{2}{*}{\multicolumn{3}{|c|}{ Peak burnup }} & & & $200 \mathrm{MWd} / \mathrm{kg}$ \\
\hline & & & & \multicolumn{2}{|c|}{ Nitride } & $200 \mathrm{MWd} / \mathrm{kg}$ \\
\hline \multirow[t]{2}{*}{ Vessel limits } & \multicolumn{3}{|c|}{ Steady state } & \multicolumn{2}{|c|}{ Maximum membrane temperature } & $430^{\circ} \mathrm{C}$ \\
\hline & \multicolumn{3}{|c|}{ Transient } & \multicolumn{2}{|c|}{ Maximum membrane temperature } & $750^{\circ} \mathrm{C}$ \\
\hline \multicolumn{6}{|c|}{ Maximum coolant velocity ${ }^{* *}$} & $2 \mathrm{~m} / \mathrm{s}$ \\
\hline \multirow{5}{*}{\multicolumn{2}{|c|}{ Neutronics constraints }} & \multirow{2}{*}{\multicolumn{2}{|c|}{ Proliferation }} & \multicolumn{2}{|c|}{$(\mathrm{U}-233+0.6 \mathrm{U}-235) / \mathrm{U}_{\text {total }}$} & $\leq 12 \%$ \\
\hline & & & & \multicolumn{2}{|c|}{$\mathrm{Pu}$ isotopic composition } & Worse than LWR \\
\hline & & \multirow{3}{*}{\multicolumn{2}{|c|}{$\begin{array}{l}\text { Reactivity } \\
\text { coefficients }\end{array}$}} & \multicolumn{2}{|c|}{$\mathrm{A} / \mathrm{B}^{* * *} \mathrm{~T}$} & $\leq 1$ \\
\hline & & & & \multicolumn{2}{|c|}{$\mathrm{C} \Delta T_{c} / \mathrm{B}^{* * *}$} & $\in<1 ; 2>$ \\
\hline & & & & \multicolumn{2}{|c|}{$\Delta \rho_{T O P} / \mathrm{B}^{* * *}$} & $\leq 1$ \\
\hline \multirow{3}{*}{\multicolumn{2}{|c|}{$\begin{array}{l}\text { Vessel rail } \\
\text { transportability }^{* * * *}\end{array}$}} & \multicolumn{4}{|c|}{ Outer vessel diameter } & $6.1 \mathrm{~m}$ \\
\hline & & \multicolumn{4}{|c|}{ Vessel height } & $19 \mathrm{~m}$ \\
\hline & & \multicolumn{4}{|c|}{ Vessel weight } & 880 ton \\
\hline
\end{tabular}

${ }^{*}$ For justification of criteria see text ${ }^{* *}$ Currently, the limit of $2 \mathrm{~m} / \mathrm{s}$ is used, but higher velocities up to $4 \mathrm{~m} / \mathrm{s}$ will be also explored, should the corrosion experiments with advanced protective films yield favorable data at higher velocities. ${ }^{* * *}$ For description of nomenclature see text. ${ }^{* * * *}$ On a special Schnabel car with limited access within the U.S.

\section{Reactor Vessel}

A Reactor Vessel Auxiliary Cooling System analysis was performed to evaluate the minimum vessel/containment size enabling passive removal of the reactor decay heat from a 875 
$\mathrm{MW}_{\text {th }}$ core. Assuming a $40 \%$ thermal efficiency, this power level corresponds to the electric output target of $350 \mathrm{MW}_{\mathrm{e}}$. The decay heat is removed by a passive RVACS with:

- A liner between the heat exchangers and the vessel (to bypass the heat exchangers in case of loss of the normal heat sink),

- Liquid lead-bismuth in the vessel/containment gap as a thermal bond,

- Fins on the outer surface of the containment, and,

- A perforated plate in the collector annulus.

The Reactor Vessel Auxiliary Cooling System heat removal capability during the loss-of-normalheat-sink event (i.e., loss of feedwater in the steam generators) was calculated assuming that the peak cladding temperature during the transient reaches its maximum acceptable limit of $725^{\circ} \mathrm{C}$ (limit derived for the HT-9 cladding on the basis of fuel-clad-chemical-interaction considerations).

For the reference guard-vessel conditions, it was found that the guard-vessel thickness needs to be at least $25 \mathrm{~cm}$ to meet the ASME requirements for safe shutdown after an earthquake. This sets the guard vessel outer diameter to $6.15 \mathrm{~m}$ and inner diameter to $5.65 \mathrm{~m}$. The reactor vessel outer diameter is then $5.55 \mathrm{~m}$, the reactor vessel thickness is $5 \mathrm{~cm}$, and its inner diameter is 5.45 $\mathrm{m}$. The liner width is $7.5 \mathrm{~cm}$. The guard vessel thermal limits were identified to be $430^{\circ} \mathrm{C}$ for the steady state and around $750^{\circ} \mathrm{C}$ for transients.

Modularity and reactor transportability is an important part of the design and the reactor vessel size must fall within the envelope of transportability requirements. From industry experience, the biggest rail transportable vessel (by means of a special Schnabel car with limited access within the U.S.) is $6.1 \mathrm{~m}$ in diameter, $19 \mathrm{~m}$ high, weighting 800 tons. The reference vessel for this design lies within this envelop and will be rail transportable.

\section{Reactor Core}

After eliminating fertile-free fuels because of controllability and economic issues, and U-Pubased fuels because of proliferation issues, it was established that only two fuel materials will be explored in the future: U-Th-Pu-Ma nitride and U-Th-Pu-Ma-Zr metal fuels. The steady-state and transient temperature limits for the metal fuel were identified as about $1000^{\circ} \mathrm{C}$. The temperature limit for the nitride fuel has not been identified yet, but is expected to be significantly higher than $1000^{\circ} \mathrm{C}$.

The dimensions of the fuel rods are determined to a large extent by cladding performance under stresses from fission gas pressure and temperature loads, allowing for protective oxide layers. Cladding performance analysis shows that the target peak burnup of $15-20$ at $\%$ can be achieved with: a fuel pellet outer diameter $5.48 \mathrm{~mm}$, a cladding inner diameter $6.32 \mathrm{~mm}$ (resulting in a smeared density of $75 \%$ ), a cladding thickness $0.6 \mathrm{~mm}$, a cladding outer diameter $7.52 \mathrm{~mm}$, a fuel slug length $1.3 \mathrm{~m}$, and a fission gas plenum length $2.47 \mathrm{~m}$ (total fuel pin length $3.77 \mathrm{~m}$ ).

These data are based on HT-9 (or EP-823) cladding. The thermal bond in the gap between the fuel slug and the cladding will be pure liquid lead. The steady state cladding limit (derived from mechanical considerations for the target peak burnup of 15-20 at \%) for these conditions is $600^{\circ} \mathrm{C}$ and is set on the radial average cladding temperature. The transient cladding limit (derived from fuel-clad-chemical-interaction considerations) is $725^{\circ} \mathrm{C}$ and is set on the inner surface of the clad. Both the steady state and transient temperature limits based on corrosion considerations are not known at this time and should be provided by the corrosion team in the near future. 
Structural materials undergo damage under neutron irradiation, which limits their lifetime in a neutron flux, in particular in fast reactors where the fraction of neutrons at high energies, which are primarily responsible for lattice changes, is high. Therefore, fluence on the in-core materials, in particular on the cladding at the location of highest neutron flux, can limit their residence in the core. The fluence limit for the low-swelling cladding HT-9 steel alloy, $3.8-4.0 \times 10^{23} \mathrm{n} / \mathrm{cm}^{2}$ $(\mathrm{E}>0.1 \mathrm{MeV})$ or about 165 dpa [Hill et. al., 1999], developed for the U.S. fast reactor program was adopted as the guiding fluence parameter for in-core stainless steel structures.

Another important constraint to be considered is the maximum burnup that the fuel rods can withstand without significant swelling and fission gas pressures that challenge the cladding integrity. As mentioned above, the fuel rods were designed for $15-20 \%$ peak burnup, which, therefore, is also the burnup constraint, i.e., core power and fuel management are maintained in such a way as to not exceed a peak burnup of $20 \%$ at. Note that the possibility of achieving these burnup levels was demonstrated for ternary (UPuZr) metal alloy pins in HT-9 ferritic cladding [Hill et. al., 1999]. The same burnup limit was adopted for both the metal and nitride fuels. However, it is to be noted that the experience base for nitride fuels is very limited and their actual burnup limit is unknown, and will have to be established. For the current work, we have assumed the same performance and fuel parameters (i.e., fuel smear density and fission gas plenum height) as for the metal fuel.

Neutronics constraints have been introduced under the safety paragraph in Section 2.2.2. It is desirable that the Doppler coefficient, fuel expansion coefficient, radial expansion and control rod driveline expansion coefficients are negative, and the coolant temperature coefficient is negative or only slightly positive. The actual numerical values must fall within ranges that satisfy selfcontrol requirements. Wade and Hill [1997] showed that for sufficiently large margins between the operating point and safety limits, one can design a core with reactivity feedback ratios assuring passive self-control if the following ranges for the reactivity coefficients expressed in terms of measurable integral reactivity parameters are met:

1. $\mathrm{A} / \mathrm{B} \leq 1$, where $\mathrm{A}$ is the net power reactivity coefficient and $\mathrm{B}$ represents the power/flow coefficient of reactivity, which controls the asymptotic temperature rise in an unprotected loss of flow transient. In case of natural circulation at full power, this criterion can be relaxed.

2. $1 \leq \frac{C \Delta T_{c}}{B} \leq 2$, where $\mathrm{C}$ characterizes the inlet temperature coefficient of reactivity and $\Delta T_{c}$ is full-power, steady-state coolant temperature rise. The term ensures an inherent balanced response to an unprotected loss of heat sink transient and coolant inlet freezing.

3. $\frac{\Delta \rho_{T O P}}{|B|} \leq 1$, where $\Delta \rho_{T O P}$ is the reactivity vested in a single control rod.

The above three criteria were adopted as top-level requirements for the core neutronic design. Reactivity coefficients will be required to have values which satisfy these three criteria.

Proliferation resistance criteria involve requirements on plutonium and uranium vectors to prevent misuse of these materials for weapons production. There is no rigorous international standard for a truly proliferation risk free plutonium vector, hence we imposed the requirement that the composition of plutonium isotopes in spent fuel from the actinide burner reactor be worse 
(more diluted by fertile Pu isotopes) than that for LWR spent fuel. In addition, the content of (U$233+0.6 \mathrm{U}-235$ ) in total uranium must be below the 12\% limit [Forsberg et. al., 1999].

With lead-based coolant, corrosion and erosive wear of core structural materials are intensified as coolant velocity increases, and hence the coolant velocity must be limited. The maximum coolant velocity of $2 \mathrm{~m} / \mathrm{s}$ was selected based on Russian experience [Fomitchenko, 1998], since adequate corrosion data are not yet available. However, the possibility to use higher velocities up to $4 \mathrm{~m} / \mathrm{s}$ will be explored in the future. To protect the cladding from corrosion an oxide layer is intentionally formed on the surface of the cladding. For thermo-hydraulic calculations, this layer is assumed to be $0.01 \mathrm{~mm}$ thick with a thermal conductivity of $2 \mathrm{~W} / \mathrm{mK}$ [Samsonov. 1973].

The reactor core performance was evaluated for $700 \mathrm{MW}_{\text {th. }}$. The fuel assemblies consist of 21 x 21 positions, of which 5 center and 1 outside external rows are voided and sealed to enhance neutron streaming and thus reduce the coolant temperature and void coefficients. The pitch to diameter ratio was selected to be 1.3 (square pitch) based on coolant void worth and thermal hydraulic considerations. Both in the forced and natural circulation cases, the total reactor thermal power is limited by the loss-of-heat-sink transient, not by the steady-state. There is no benefit to go to smaller pitch to diameter ratio, as this would reduce the decay-heat-removal capability of the RVACS and thus the reactor power (regardless of whether the steady-state mode of operation is forced or natural circulation).

The power conversion cycle efficiencies were evaluated to vary from $43 \%$ to $46 \%$ depending on the power conversion cycle and power conversion cycle component performance.

\subsubsection{General Design Choices}

The key design approaches adopted to address the cardinal Generation IV objectives while maintaining the four postulates of Section 2.2.1 and conforming to the design constraints of Section 2.2.2 will be as follows:

\section{To improve economics}

- Adopt a chemically-stable heavy liquid metal (i.e., lead-bismuth) as the reactor coolant. This enables elimination of the intermediate heat transport loop, simplification of the containment design (because the possibility of fires and explosion is eliminated), and improvement of the neutron economy.

- Reduce capital cost through simplified design and selection of sufficiently large power rating. Measures incorporated include:

$\circ$ The aforementioned elimination of an intermediate heat transport loop allowed by the chemical stability of lead-bismuth coolant with air or steam,

- Achievement of high thermal efficiencies at low turbine inlet temperatures (dictated by corrosion and creep-related temperature limits on cladding) by introducing a supercritical $\mathrm{CO}_{2}$ Brayton cycle, which also allows for significant simplification of the balance of plant,

- Modular design, which can be manufactured with desired high quality at a factory and transported to the site, reducing construction time and cost, and,

- Selecting a sufficiently high power rating to capitalize on economy of scale within the constraints imposed by modularity.

- Adopt forced circulation for the primary coolant. Forced circulation of the primary coolant under normal operating conditions enables design of a tighter and neutronically 
more economic core, minimizes the coolant temperature rise across the core (which, for given outlet temperature, results in higher temperatures of the secondary coolant and thus in higher thermal efficiencies), and finally facilitates reactor control during start-up and other operational transients.

- $\quad$ Reduce operating and maintenance cost. Key strategies implemented involve

(1) An increased intra-refueling time up to 8 years to decrease plant downtime, and

(2) A significantly simplified design using a supercritical $\mathrm{CO}_{2}$ Brayton cycle, which will require less operating staff.

- $\quad$ Reduce fuel cycle costs through increased burnup. Ultimately, the fuel cycle costs will depend on the cost of reprocessing, which is currently high. Therefore, one option to be investigated will involve a once-through cycle, which will significantly reduce the TRU inventory from LWRs, but does not consider multiple recycle of spent fuel from fast reactors - see Figure 4. Future developments will have to focus on significant reductions in the fuel reprocessing costs. Low-cost innovative fuel reprocessing technologies will be required independently of this reactor concept, should actinide and long lived fission product destruction strategies be successful.

\section{To increase proliferation resistance}

- $\quad$ Reduce the plutonium and minor actinide inventory from LWR spent fuel by burning the fissile isotopes with high efficiency. This will require cores with a minimum amount of fertile materials or cores with fertile isotopes (thorium) that do not breed plutonium. However, reprocessing of the LWR spent fuel (with separation of $\mathrm{Pu}$ and minor actinides) is necessary in this fuel cycle.

- $\quad$ Produce plutonium isotopics unsuitable for weapons production. The goal is to obtain a dirtier plutonium composition at discharge compared to spent LWR fuel. In addition, fissile isotopes in the discharged fuel, such as U-235 or U-233, if present, will have to be diluted so that their concentrations satisfy internationally accepted proliferation standards.

- Minimize fuel movements and access to core. The main measure will be a significantly longer operating cycle duration and, possibly, on-site fuel reprocessing and fabrication.

\section{To enhance safety}

- Design self-controllable reactor core so that its response to ATWS transients always leads to a safe shutdown state without exceeding the limits assuring core integrity. Key design features to be pursued include:

$\circ$ Establish the limits ensuring core integrity and assure that these limits are not exceeded during unprotected loss of flow (ULOF), unprotected loss of heat sink (ULOHS), and unprotected transient overpower (UTOP) conditions,

- Rely on inherent safety features, in particular neutronic feedbacks (Doppler coefficient, fuel expansion, coolant density change, radial expansion) and heat transfer mechanisms (e.g., natural convection, radiation, etc.) to achieve a safe shutdown state, and

- Rely on passive safety features (examples are the use of enhanced thermal expansion materials, a gas expansion module, a very low reactivity swing, and other passive reactivity feedback mechanisms) to assist the other inherent feedbacks in the achievement of a self-controllable reactor state in ATWS scenarios. 
Note that conventional active safety systems can also be used, but they will not be credited for self-controllability, i.e., the reactor has to be able to achieve a safe shutdown state without reliance on active safety systems. The categorization of safety features versus self-control is shown in Figure 5. Because inherent features provide a high degree of confidence because they function independent of human or machine actions, the primary thrust of the design effort will be directed to maximum reliance on such features.

- Ensure reliable removal of the decay heat. A Reactor Vessel Auxiliary Cooling System (RVACS) is adopted, that can remove $100 \%$ of the decay heat in a fully passive fashion, even in case of total loss of the normal heat sink (i.e., the heat exchangers). In the RVACS the heat generated in the core is conveyed to the reactor vessel by natural circulation of the primary coolant, is conducted across the vessel and guard vessel, and is finally discharged to atmospheric air naturally flowing on the outer surface of the guard vessel.

- Make self-termination of severe accidents part of the design. In the extreme and hypothetical case of a severe accident when the core integrity is not maintained, the system has to be designed to:

- Prevent a reactivity excursion due to core compaction, and,

- Reach a stable defined state without release of radioactive fission products to the environment, relying on natural phenomena and barriers.

\section{To reduce waste}

- $\quad$ Reduce the TRU inventory from spent LWR fuel by burning the fissile isotopes with high efficiency - same as first bullet under proliferation resistance.

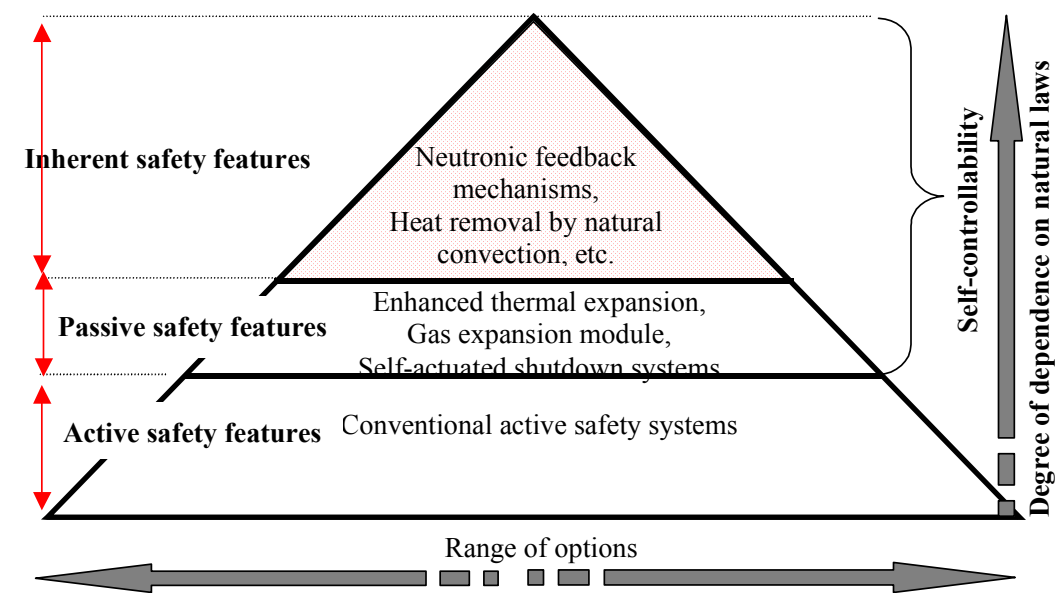

Figure 5. Hierarchy of safety features versus self-controllability (adapted from Kuraishi et al. 2001).

\section{The Selected Design Approach for FY-2002}

Using the guiding principles outlined above, pure TRU burners fueled with reprocessed spent LWR fuel were discarded from further development because achievement of excellent safety is difficult due to the absence of sufficiently negative inherent reactivity feedbacks. A uraniumfueled, once-through, high-conversion ratio reactor was also dismissed, despite of its good 
economic promise, because of the proliferation potential of the spent fuel and because it does not address the goal of transmutation of the actinides in LWR spent-fuel.

As a result, the concept to be pursued is a TRU burner fueled by reprocessed spent LWR fuel and optimized for economic electricity generation, while having relatively high net TRU destruction rates (goal is at least 50\% of that of pure TRU burners) and excellent safety. To reduce the fuel cycle costs, it is assumed that in the transition period, before new cheaper reprocessing technologies are developed, the concept will operate in a once-through path. An alternative version to be investigated later is a TRU burner with multiple recycling. The oncethrough path requires that the discharged fuel from the TRU burner is proliferation resistant. To achieve this goal, plutonium production from U-238 captures is minimized by using:

- Thorium as the major fertile material,

- Minor actinides mixed together with plutonium to increase the generation of $\mathrm{Pu}-238$ (from neutron captures in Np-237) with high decay heat levels, making construction of weapons without sophisticated cooling extremely difficult,

- High-burnup fuels to dilute the plutonium vector, and

- Natural uranium to denature the bred-in U-233.

Excellent safety standards are pursued through self-control and self-termination, as discussed above. In this year's investigations, a core design with acceptable reactivity feedbacks was identified. Future design efforts will optimize the core to achieve self-control at least as good as the Integral Fast Reactor (IFR) core. Self-control also requires that the decay heat is removed by natural circulation of the coolant and dissipation of the heat into the ultimate heat sink (air will be used) by natural phenomena without crediting active systems. A decay heat removal system similar to that of the PRISM is used to achieve this goal as discussed in Section 2.1 above.

Selection of lead bismuth eutectic as a coolant brings a number of advantages as discussed in Section 1 and in the previous annual report [MacDonald et. al, 2000], but also brings challenges that need to be overcome for successful deployment of lead-bismuth-cooled power reactors. These involve materials corrosion issues related to the fact that most metals have a finite solubility in lead or lead-bismuth and generation of undesirable Polonium 210 by neutron capture from Bismuth 209. Regarding the corrosion issue, the maximum coolant operating temperatures, as well as of materials in contact with coolant (in particular of cladding, which in addition undergoes thermal and irradiation creep from the pressure of gaseous fission products), are limited, reducing plant efficiency, because the solubility is a strong function of temperature. Two approaches are pursued to overcome this challenge:

1. Development of a system in which the structural material is insoluble in the coolant and/or of a material which forms a stable, self healing, protective film at oxygen potentials below that for the formation of $\mathrm{PbO}$ at reasonably high temperatures, and

2. Development of a power cycle that can attain high cycle efficiencies at relatively low temperatures. Three power cycles are evaluated - the traditional Rankine cycle with steam superheat, a helium-cooled cycle, and the supercritical $\mathrm{CO}_{2}$-cooled Brayton cycle. Because the supercritical $\mathrm{CO}_{2}$ Brayton cycle can achieve the highest cycle efficiency for low temperatures compatible with lead-bismuth corrosion related material issues, the primary thrust of power cycle development is in this direction. In addition, this cycle is much simpler than the Rankine cycle offering significant benefits in capital cost. 
The second issue related to lead-bismuth coolant is generation of Polonium 210 (an extremely toxic alpha-emitter of approximately 140 days half-life) from ${ }^{209} \mathrm{Bi}$ by neutron capture. Therefore, part of the research effort is also directed to understanding polonium chemistry and behavior. The formation of volatile Po species is being examined and quantified. Studies on the removal of Po from the $\mathrm{Pb}-\mathrm{Bi}$ melt using chemical reactions, volatility and rare-earth solids are being performed. 


\section{Results of Reactor Core Neutronics Studies}

This chapter discusses a number of core neutronic design subjects. Work at the INEEL on the creation and evaluation of temperature dependent cross-sections is discussed in Section 3.1. The importance of having temperature dependent cross-section data is related to the safety evaluations of the reactor concepts. If the net result of the reactivity coefficients is negative, a strong claim for passive safety can be made based on reactivity feedback mechanisms. In addition to the existing temperature dependent cross-section sets that were processed previously at the INEEL and the University of Texas at Austin, a new library of minor actinides (Np, Am, and $\mathrm{Cm}$ ) was also processed.

Section 3.2 presents a comparison performed at the INEEL of different pin powers and their effect on burnup. In order to optimize the core design, the fuel constituents (fissile and fertile components) and power density need to be optimized to allow for the maximum burnup. Calculations show that a higher pin power, while decreasing the effective-full-power-days of operation, will increase the reactivity limited burnup due to smaller residence time of the fuel in the reactor, which is not sufficient to allow decay of $\mathrm{Pu}-241$ as in the low-power case

The neutronics of non-fertile and fertile fuel in a lead-bismuth and in a sodium cooled fast reactor are discussed in Section 3.3, with an emphasis on the fuel cycle life and isotopic content. The INEEL calculations show that the average actinide burn rate for the fertile free fuel is similar for both the sodium and lead-bismuth cooled cases, ranging from 1.02 to $1.16 \mathrm{~g} / \mathrm{MWd}$, compared to a typical LWR actinide generation rate of $0.303 \mathrm{~g} / \mathrm{MWd}$. However, when using the same parameters, the sodium-cooled case went sub-critical after 0.2 to 0.8 effective full power years, whereas the lead-bismuth cooled case was critical for 1.5 to 4.5 effective full power years. For the fertile fueled cores, the calculations show that the core life can extend beyond 20 years, and the average actinide burn rate is similar for both the sodium and lead-bismuth cooled cases.

This chapter also presents in Sections 3.4 and 3.5 the results of the neutronic designs performed at MIT for two core concepts. The first involves the core optimized for minor actinide burning, the second covers the concept optimized for both actinide burning and economic electricity production. The major drawback of the design optimized for minor actinide burning was the small effective delayed neutron fraction, which cannot be increased in a fertile-free core, because it is primarily determined by the TRUs, which are to be destroyed. This resulted in a reactor that was hard to control.

The concept of a safe and economic $\mathrm{Pb}-\mathrm{Bi}$ cooled critical reactor that will destroy actinides from spent LWR fuel was also evaluated at MIT and is discussed in Section 3.5. The analyses were performed for metal thorium-based fuel (Th-U-Pu-MA-Zr) in a once-through cycle. The reactivity swing was small, the actinide destruction rate was $63 \%$ of that expected for the ATW, an eight year refueling period was identified as feasible, a negative coolant void coefficient was obtained with streaming assemblies, the Doppler and fuel thermal expansion coefficients were negative, and the isotopics in the discharges fuel were virtually weapons unusable. This concept is the main candidate to be further developed in FY-2002. 


\subsection{Temperature Dependent Cross-Section Libraries (INEEL, Dr. Kevan Weaver)}

In order to account for the prompt temperature coefficient (i.e., the Doppler effect) in the calculations, the computer codes need to have temperature dependent, continuous, point-wise cross-section libraries (tables) for the minor actinides that are present in the fuel being analyzed. The cross-section libraries that were developed for MCNP (Briesmeister et al. 1997) contain values for $0^{\circ} \mathrm{K}$ and/or room temperature $\left(273^{\circ} \mathrm{K}\right)$ only, with the exception of a few of the uranium isotopes. Thus, other library tables were added, when available, and a selected minor actinide library was created from the Evaluated Nuclear Data File (ENDF6) data sets for those tables that did not exist elsewhere. The NJOY (MacFarlane and Muir 1994) code was used to create the new cross-section tables (the new library tables are called minacxs1). New cross-section tables were created for the following minor actinides at the temperatures listed:

- $\quad \mathrm{Np}-237$ at 600,900 , and $1200^{\circ} \mathrm{K}$

- $\quad$ Am-241 at 900 and $1200^{\circ} \mathrm{K}$

- $\quad \mathrm{Am}-242$ at 900 and $1200^{\circ} \mathrm{K}$
- $\quad A m-242 \mathrm{~m}$ at 900 and $1200^{\circ} \mathrm{K}$

- $\quad \mathrm{Cm}-242$ at 900 and $1200^{\circ} \mathrm{K}$

- $\quad \mathrm{Cm}-244$ at 900 and $1200^{\circ} \mathrm{K}$

The new cross-section tables were chosen based on the fuel constituents that were used in our studies. The $600^{\circ} \mathrm{K}$ tables for Am-241 through Cm-244 already existed, and were previously generated for Oak Ridge National Laboratory (ORNL) by the INEEL. However, not all ORNL libraries used the ENDF6 data sets; ENDF5, JENDL, JEF, BROND, or other data sets were also used. Other temperature dependent, isotope cross-section data (other than those mentioned above) have also been produced at the University of Texas at Austin (Abdelrahman and Abdurrahman 1998).

\subsubsection{Performance of New Library (minacxs1)}

All of the tables appear to correlate well with previous data (i.e., the reactivity change with temperature behaves as expected), with the exception of the Am-241 tables. These tables appear to be inconsistent, where the effective multiplication factor increases with temperature using the Am-241 tables, rather than decreasing as one would expect. In order to resolve this issue, discussions with the group at Los Alamos National Laboratory (LANL) were held. The results of these discussions revealed that the ENDF5 data set at $300^{\circ} \mathrm{K}$ for $\mathrm{Am}-241$ (95241.50c) is unreliable. As such, other data sets may also be unreliable and a test of the existing data for Am241 was performed.

\subsubsection{Testing the Am-241 Table}

A study using MCNP was performed using a thermalized fission neutron spectrum to verify our findings. The study was performed by building a simple sphere made of Am-241 in MCNP, and surrounding this sphere with a water sphere. The boundary of the water sphere was reflective to prevent neutron leakage. A neutron source with a Maxwellian fission energy distribution was also placed in the water sphere next to (but not in) the Am-241 sphere. The (n, $\gamma$ ) reaction rate was tallied using 100,000 histories.

Results of the Am-241 test confirmed that the ".50c" file extension library processed from the ENDF5 data set, and the ".97c" file extension library processed from ORNL data set 128, are not consistent with the ENDF6 data. The results of the test are summarized in Table 5. 
Table 5. Results of the Am-241 tests.

\begin{tabular}{|c|c|c|c|c|}
\hline $\begin{array}{c}\text { Base Library } \\
\text { Extension }\end{array}$ & $\begin{array}{c}\text { Comparison } \\
\text { Library } \\
\text { Extension }\end{array}$ & Data Set & Temperature & $\begin{array}{c}\text { \% Difference } \\
\text { in Captures }\end{array}$ \\
\hline \hline $.50 \mathrm{c}$ & - & ENDF5 & $300 \mathrm{~K}$ & - \\
\hline & $.60 \mathrm{c}$ & ENDF6 & $300 \mathrm{~K}$ & $1.23 \%$ \\
\cline { 2 - 5 } & $.97 \mathrm{c}$ & 128 & $600 \mathrm{~K}$ & $0.35 \%$ \\
\cline { 2 - 5 } & $.82 \mathrm{c}$ & ENDF6 & $900 \mathrm{~K}$ & $0.79 \%$ \\
\cline { 2 - 5 } & $.83 \mathrm{c}$ & ENDF6 & $1200 \mathrm{~K}$ & $0.70 \%$ \\
\hline \hline $.60 \mathrm{c}$ & - & ENDF6 & $300 \mathrm{~K}$ & - \\
\hline & $.97 \mathrm{c}$ & 128 & $600 \mathrm{~K}$ & $-0.87 \%$ \\
\cline { 2 - 5 } & $.82 \mathrm{c}$ & ENDF6 & $900 \mathrm{~K}$ & $-0.44 \%$ \\
\cline { 2 - 5 } & $.83 \mathrm{c}$ & ENDF6 & $1200 \mathrm{~K}$ & $-0.53 \%$ \\
\hline
\end{tabular}

Note that the other higher temperature ENDF6 tables (".82c" and ".83c") show a good response, where an increase in captures are recorded for each step increase in temperature.

\subsection{Parametric Studies on the Affect of Power on Burnup (INEEL, Dr. Kevan Weaver)}

One measure that can be taken to enhance the economics and safety, reduce the waste, and increase the proliferation resistance of the proposed $\mathrm{Pb}$-Bi cooled reactor is to optimize the refueling cycle length. If the cycle lengths are very long, the proliferation resistance and waste reduction are enhanced, but the fuel carrying costs will be high and may diminish any economic advantage. On the other hand, if high power densities are used to shorten the cycle length to reasonable levels, the reactivity swings may be high and will directly impact the safety of the system. The affect of pin power versus burnup was studied to address these issues.

\subsubsection{Analysis Tools}

The current work uses the MOCUP code (Moore et al. 1995) to analyze the reactivity characteristics and isotopic concentrations of unit fuel pins/cells, with 38 actinides and 50 fission products being tracked through the MCNP portion of the analysis. MCNP is a well-known Monte Carlo code capable of calculating fluxes, reaction rates, and eigenvalues in general, 3-D geometry using continuous cross-section data. ORIGEN (Croff 1980) uses a matrix exponential method to calculate the generation and depletion of isotopes, or elements, in a given neutron flux. MOCUP takes specific output data (including cross-section data, fluxes, and reaction rates) from MCNP and passes it to ORIGEN, where new isotopic information is generated and passed back to MCNP for the next calculation. This gives time dependent information about the reactivity swing and isotopics for the specified problem.

\subsubsection{Fuel Parameters}

For the calculations presented here, a pin cell was used with the parameters shown in Table 6. All of the pins contained $20 \mathrm{wt} \%$ plutonium and minor actinides ( $\mathrm{Np}, \mathrm{Am}$, and $\mathrm{Cm})$, and either uranium or thorium as the fertile component. 
Table 6. Parameters of the cylindrical fuel pins.

\begin{tabular}{|l|l|}
\hline Design Parameter & Value \\
\hline \hline Fuel OD & $0.864 \mathrm{~cm}$ \\
\hline Gap Thickness & $0.02 \mathrm{~cm}$ \\
\hline Cladding Thickness & $0.063 \mathrm{~cm}$ \\
\hline Cladding OD & $1.03 \mathrm{~cm}$ \\
\hline P/D & 1.6 \\
\hline Active Fuel Height & $120 \mathrm{~cm}$ \\
\hline $\begin{array}{l}\text { Gas Plenum Height } \\
\text { (metallic fuel only) }\end{array}$ & $90 \mathrm{~cm}$ \\
\hline $\begin{array}{l}\text { Average Coolant } \\
\text { Density }\end{array}$ & $10.25 \mathrm{~g} / \mathrm{cm}^{3}$ \\
\hline
\end{tabular}

\subsubsection{Results}

By increasing the pin power, the effective-full-power-years (EFPY) of operation are decreased due to the increased fission rate (see Figure 6). However, even though the cycle duration was shortened, the calculations show that the reactivity-limited burnup is increased in both the metal and nitride fuels that were studied. Figure 7 shows the reactivity limited burnup for the metal fuels, where the zirconium is $10 \mathrm{wt} \%$ of the fuel.

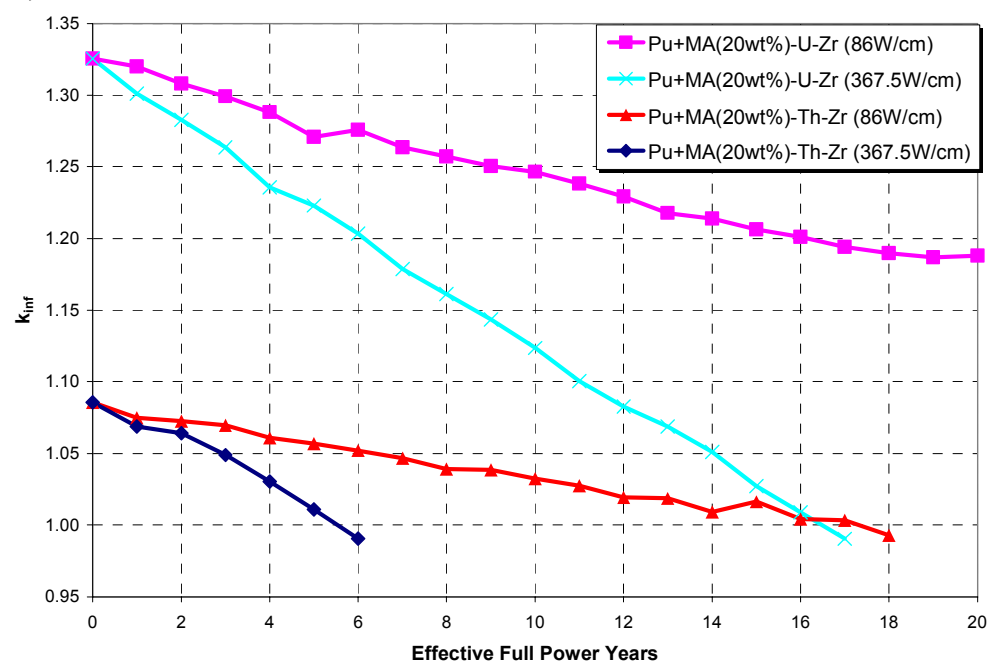

Figure 6. Reactivity versus EFPY for metal fuels.

For the nitride based fuels, the reactivity versus EFPY can be seen in Figure 8 and the reactivity limited burnup can be seen in Figure 9. Again, a higher burnup can be achieved at the higher power level.

The higher burnups at high power are due to the change in fissile material in the fuel. Figures 10-13 show the $\mathrm{Pu}-239$ and $\mathrm{Pu}-241$ content for the uranium and thorium fuels. Figure 14 shows the U-233 content for the thorium based fuels. 


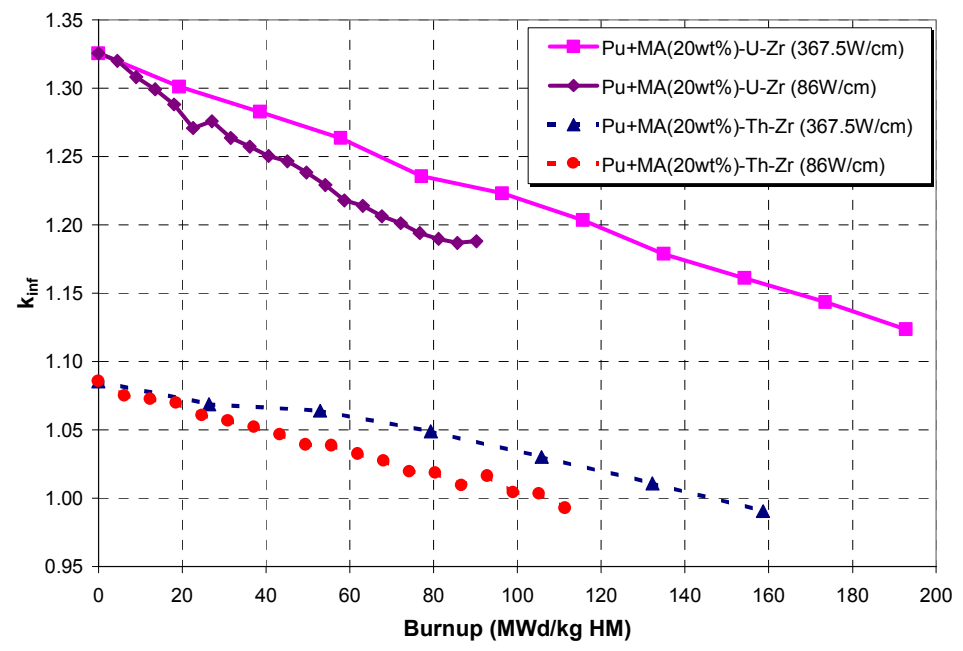

Figure 7. Reactivity limited burnup for the metal fuels.

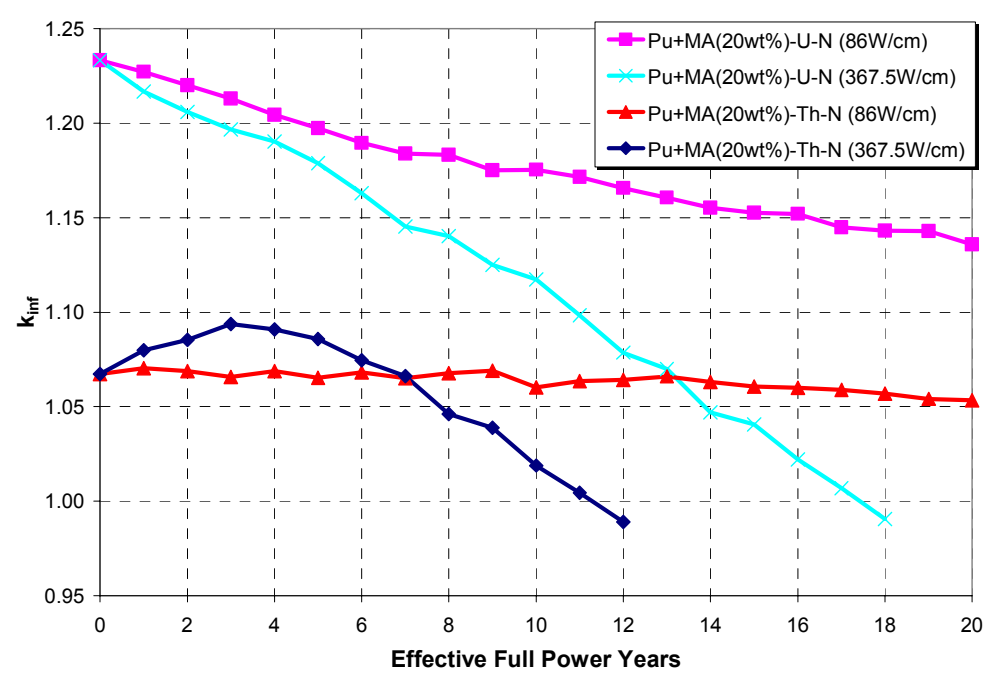

Figure 8. Reactivity versus EFPY for nitride fuels.

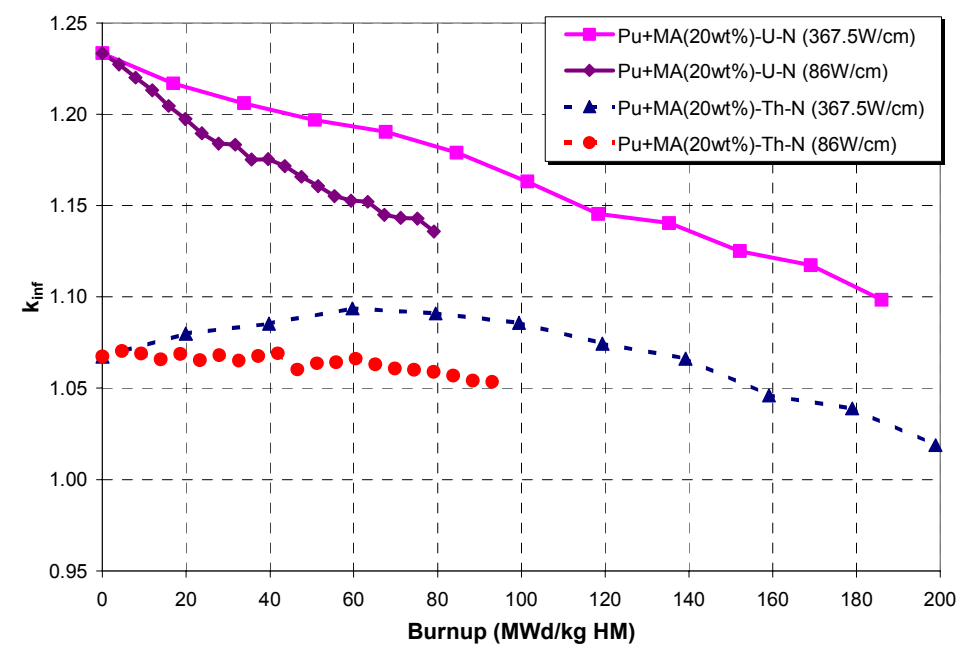

Figure 9. Reactivity limited burnup for the nitride fuels. 


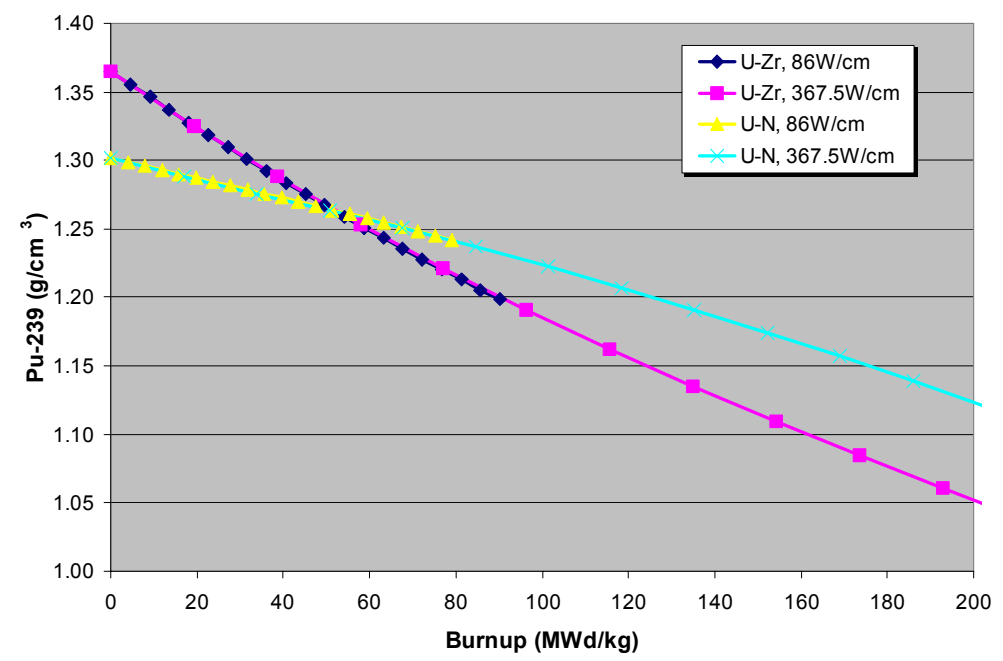

Figure 10. Pu-239 burnup in the uranium fuels.

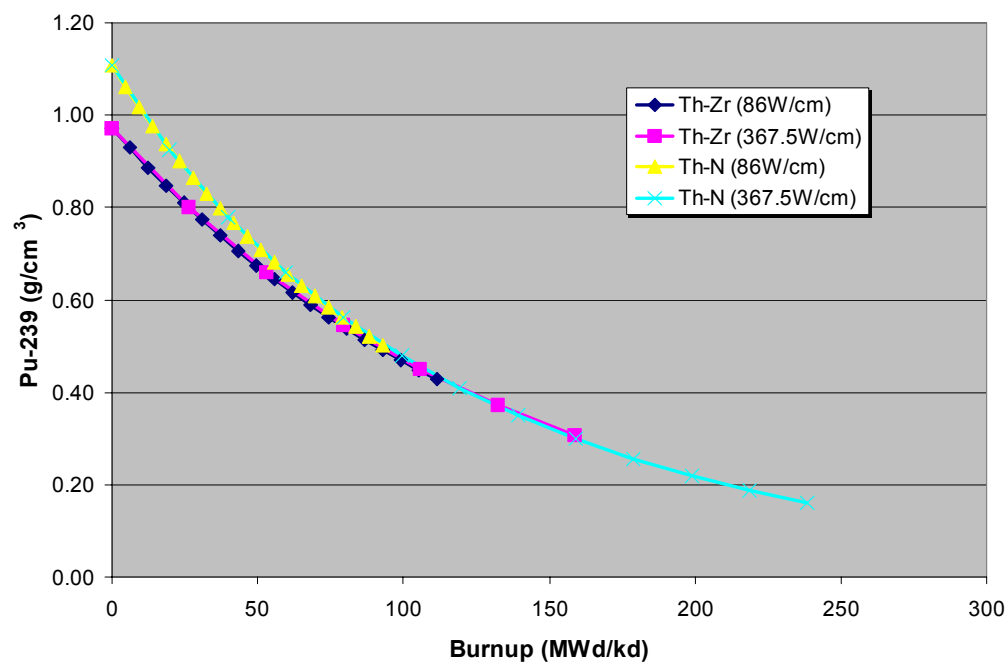

Figure 11. Pu-239 burnup in the thorium fuels.

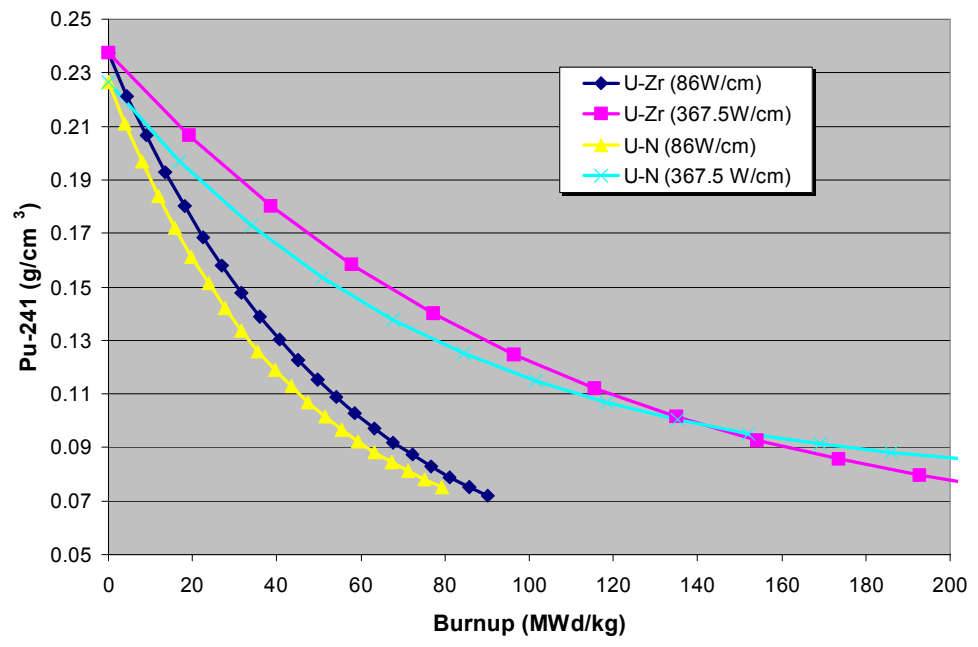

Figure 12. Pu-241 burnup in the uranium fuels. 


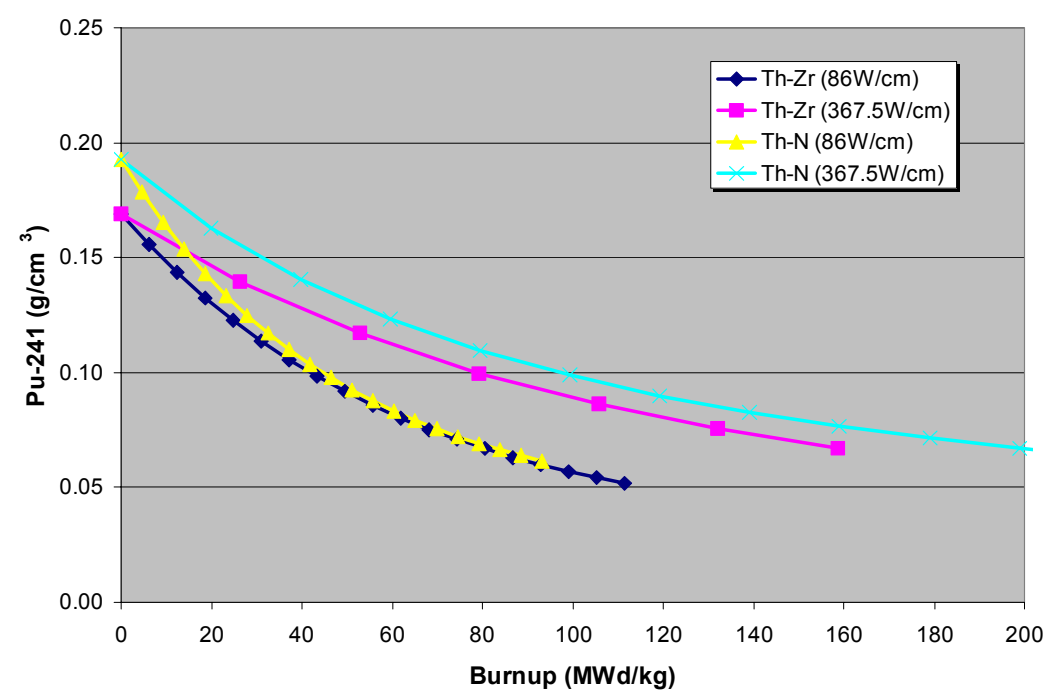

Figure 13. Pu-241 burnup in the thorium fuels.

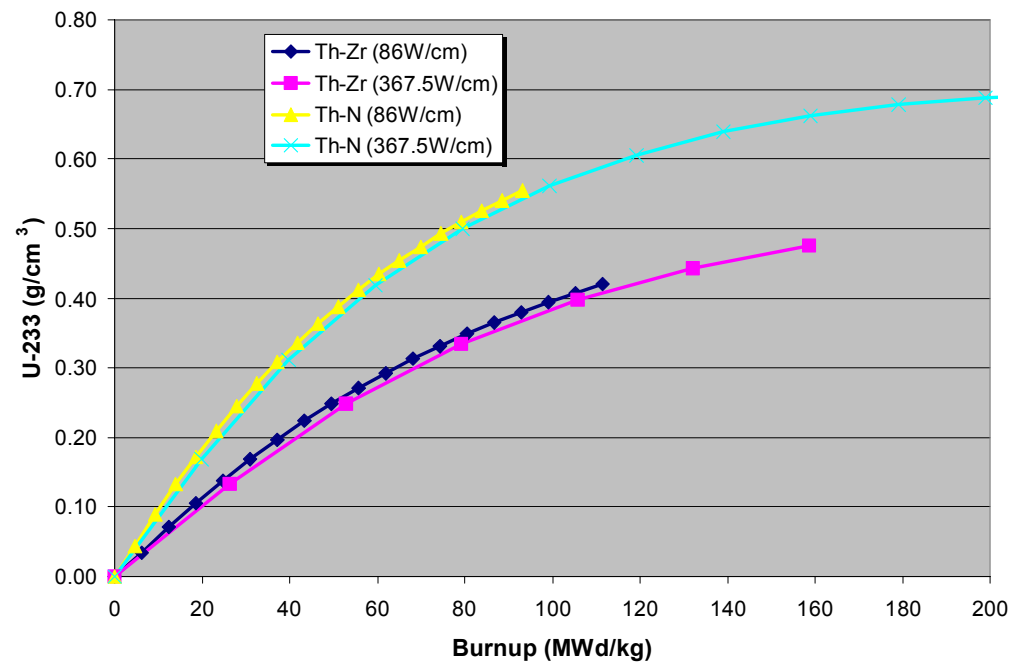

Figure 14. U-233 burnup in the thorium fuels.

As can be seen in the figures above, both the Pu-239 (in the uranium and thorium fuels) and the U-233 (in the thorium fuels) burnup are not dependent on the power level. However, the Pu-241 concentration is dependent on the power level, where the lower power level appears to decrease the Pu-241 concentration faster than at higher power levels. This is due to the longer in-core residence times at the lower power levels ( $>20$ years), where more than half of the Pu-241 (halflife 14.4 years) can decay before the next refueling occurs. Because Pu-241 decays to Np237, which has significantly higher capture to fission cross section ratio than Pu-241, reactivity-limited burnup for low-power levels is reduced." However, this difference in reactivity-limited burnup will not occur if $\mathrm{Pu}$ from spent LWR fuel is loaded after long time of cooling, i.e., 50 years in the intermediate repository.

Also of interest are the end-of-life Pu fractions shown in Table 7. 
Table 7. Plutonium isotopic fractions.

\begin{tabular}{|c|c|c|c|c|c|c|c|}
\hline \multirow{2}{*}{$\begin{array}{c}\text { Fuel } \\
\text { (initial } \\
\text { Pu+MA } \\
20 w t \% \text { ) }\end{array}$} & \multirow[b]{2}{*}{$\begin{array}{l}\text { Linear } \\
\text { Power } \\
\text { (W/cm) }\end{array}$} & \multirow[b]{2}{*}{ EFPY } & \multicolumn{5}{|c|}{ Spent Fuel Pu Isotopic Fractions } \\
\hline & & & Pu-238 & Pu-239 & Pu-240 & Pu-241 & $\mathrm{Pu}-242$ \\
\hline U-Zr & 86 & $>20$ & $5.9 \%$ & $57.8 \%$ & $27.8 \%$ & $3.5 \%$ & $5.1 \%$ \\
\hline U-Zr & 367.5 & 17 & $5.5 \%$ & $56.7 \%$ & $28.5 \%$ & $3.7 \%$ & $5.6 \%$ \\
\hline $\mathrm{U}-\mathrm{N}$ & 86 & $>20$ & $6.4 \%$ & $57.8 \%$ & $27.4 \%$ & $3.5 \%$ & $4.9 \%$ \\
\hline U-N & 367.5 & 18 & $4.9 \%$ & $55.1 \%$ & $30.5 \%$ & $4.4 \%$ & $5.1 \%$ \\
\hline Th-Zr & 86 & 18 & $9.2 \%$ & $41.3 \%$ & $37.1 \%$ & $5.0 \%$ & $7.4 \%$ \\
\hline Th-Zr & 367.5 & 6 & $10.1 \%$ & $34.4 \%$ & $39.3 \%$ & $7.5 \%$ & $8.6 \%$ \\
\hline Th-N & 86 & $>20$ & $10.0 \%$ & $40.4 \%$ & $37.3 \%$ & $4.9 \%$ & $7.3 \%$ \\
\hline Th-N & 367.5 & 12 & $13.4 \%$ & $21.6 \%$ & $45.3 \%$ & $8.0 \%$ & $11.6 \%$ \\
\hline
\end{tabular}

For the uranium fuels, the higher power levels did not "dirty" the plutonium isotopics. However, this was not the case for the thorium fuels, where an increase in the Pu-238 and a decrease in $\mathrm{Pu}-239$ are seen at the higher power level for both the metal and nitride fuel.

While the amount of plutonium and its isotopic fractions are of particular interest for proliferation resistance, the thorium fuels will need to be de-natured due to the buildup of U-233. Figures 15 and 16 show a comparison of the reactivity with effective-full-power-years of operation for the nitride and metal fuels containing separate uranium and thorium, and homogeneously mixed thorium-uranium.

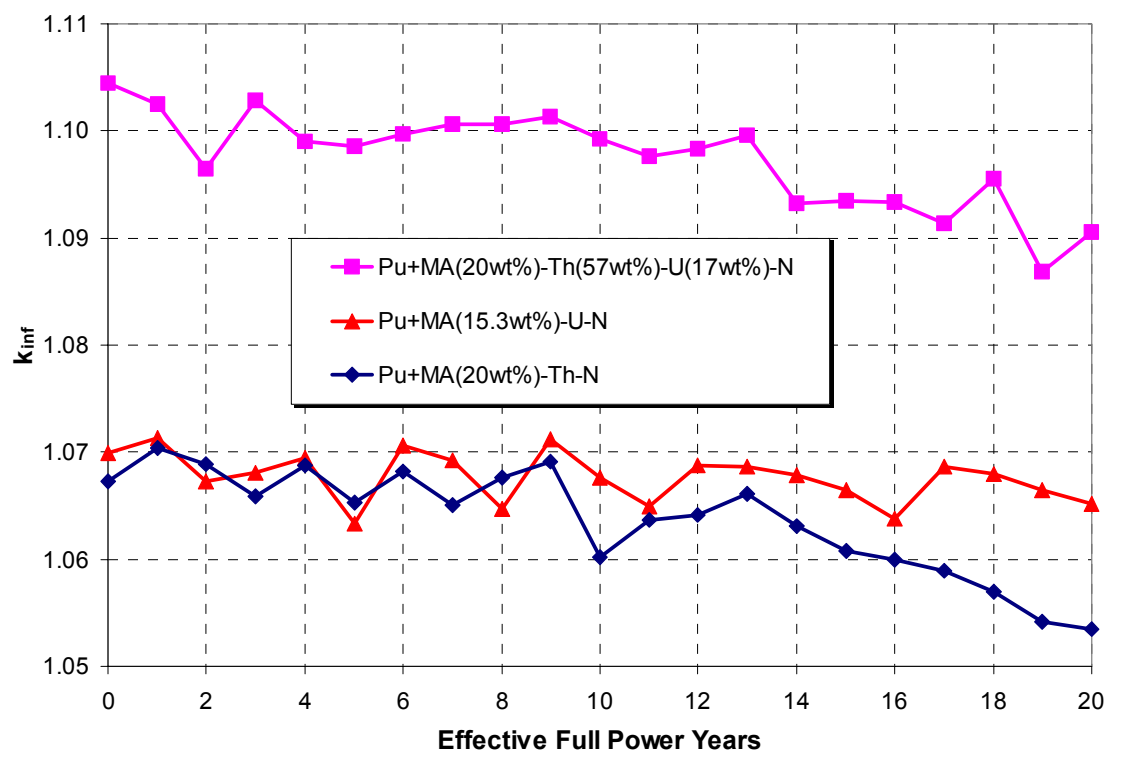

Figure 15. Comparison of separate thorium and uranium, and mixed thorium-uranium nitride fuel. 


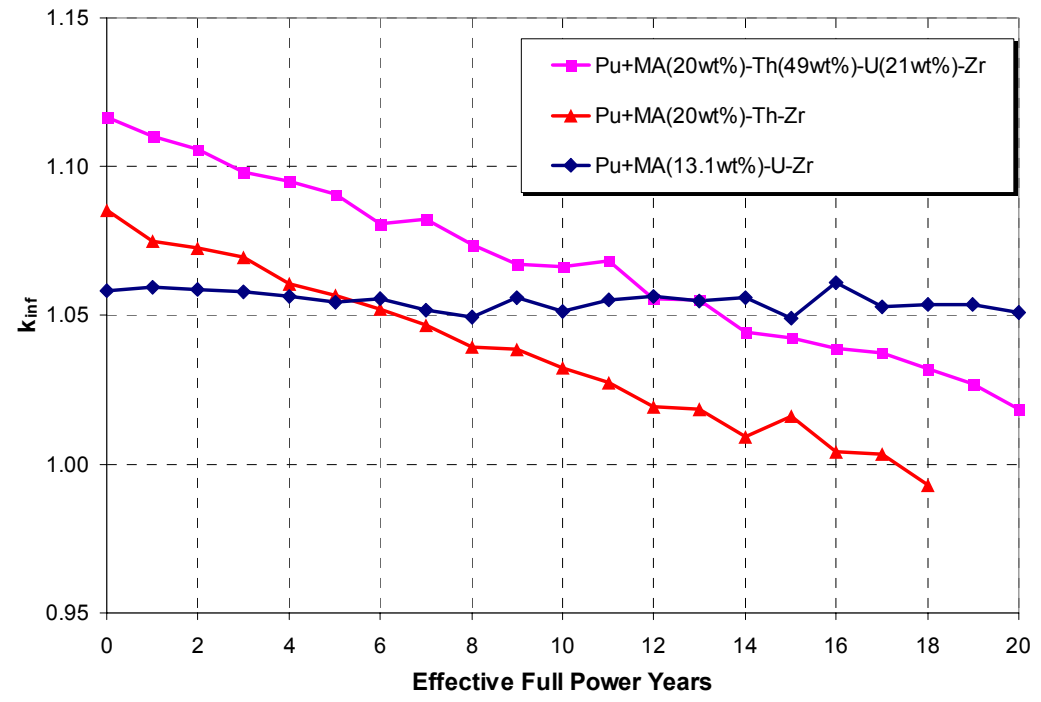

Figure 16. Comparison of separate thorium and uranium, and mixed thorium-uranium metal fuel.

The mixed thorium-uranium nitride fuel appears to have a flat reactivity curve, while the mixed metal fuel has a curve similar to the pure thorium metal fuel. Because the addition of uranium to the fuel will produce more plutonium (even though a net reduction may be obtained), it was assumed that the actinide destruction potential and isotopic fractions of the mixed thoriumuranium fuel would not match that of the pure thorium fuel. However, as can be seen in Table 8, the isotopic fractions are more similar to the pure thorium fuels (compare to Table 7 above), where the plutonium vector is highly degraded. In addition, the mixed fuel transmutation rate is $50 \%$ that of the pure (fertile-free) actinide burner, as compared to $70 \%$ for the pure thorium fuel.

Table 8. Plutonium isotopic fractions for the mixed thorium-uranium fuel.

\begin{tabular}{|c|c|c|c|c|c|c|}
\hline \multirow{2}{*}{$\begin{array}{c}\text { Fuel } \\
\text { (initial }\end{array}$} & & \multicolumn{5}{|c|}{ Spent Fuel Pu Isotopic Fractions } \\
\cline { 3 - 7 } $\begin{array}{c}\text { Pu+MA } \\
\text { 20wt\%) }\end{array}$ & EFPY & Pu-238 & Pu-239 & Pu-240 & Pu-241 & Pu-242 \\
\hline \hline ThU-Zr & $>20$ & $8.4 \%$ & $46.3 \%$ & $34.3 \%$ & $4.2 \%$ & $6.7 \%$ \\
\hline ThU-N & $>20$ & $8.5 \%$ & $46.5 \%$ & $34.2 \%$ & $4.5 \%$ & $6.4 \%$ \\
\hline
\end{tabular}

\subsection{Comparison of the Neutronic Performance of Cores with Sodium and Pb-Bi Coolants (INEEL, Dr. Kevan Weaver)}

The recent resurgence of interest in fast reactors and fast reactor technology has sparked a debate as to the choice of coolant and its attendant benefits. Included in this debate are issues related to transmutation of the long-lived waste (mainly plutonium and minor actinides), where the preference is to use a fast neutron spectrum due to the large fission to capture ratio. Also of interest is the development of new technologies such as the Advanced Accelerator Applications program (formerly called the Accelerator Transmutation of Wastes), and the use of alternative coolants in fast fission reactors. Although the U.S. has significant experience with sodium coolants, other coolants have been used and considered in the past. Two of these are gas (e.g., $\mathrm{He}$ ) and heavy liquid metals such as lead or lead-bismuth. There are benefits and challenges 
associated with all types of fast reactor coolants. However, the neutronic benefits of using as hard a spectrum as possible are clear. Thus the following work compares the neutronics and discharge isotopics of sodium and lead-bismuth cooled fuel using a unit-cell model (i.e., a semiinfinite lattice with axial leakage) to identify if there are neutronic benefits of using LBE instead of sodium.

\subsubsection{Fuel Parameters}

The fuels studied were non-fertile metal fuel, and fertile metal or nitride fuel that had a constant pitch to diameter $(\mathrm{P} / \mathrm{D})$ ratio of 1.6 using a square pitch, and an initial actinide loading (i.e., Pu and minor actinides) of 20-30 wt\%. Table 9 gives a summary of the fuel composition for the non-fertile fuel. Table 10 gives a summary of the TRU composition for all fuels with $20 \mathrm{wt} \%$ plutonium and minor actinides.

A large, square pitch was chosen to assure that the thermalhydraulic resistance in the core would be small, which is an important consideration in minimizing pumping requirements while maximizing natural circulation during loss-of-flow accidents. Typically, very tight pitches are used in fast reactors to minimize neutron moderation and to maintain an acceptable void reactivity coefficient. In addition, core configurations previously used in fast reactors were optimized for high breeding ratios. In this project, we were not interested in high breeding ratios typical of most fast reactors, and it is possible to have a negative void coefficient of reactivity with lead-bismuth coolant in relatively open lattices. Thus while no sodium cooled reactor would ever be built with such a large $\mathrm{P} / \mathrm{D}$ ratio, these preliminary calculations give a qualitative assessment of the performance of these two coolants using the exact same parameters (i.e., only the coolant is changed in the calculations). Further calculations will be performed with tighter pitches to confirm conclusions that might be drawn from the work presented here.

The next consideration in using this fuel is the reactor power level (power density) or linear power, where we used two different linear powers in our analysis at $367.5 \mathrm{~W} / \mathrm{cm}$ and $86 \mathrm{~W} / \mathrm{cm}$ as in the previous section. These two linear powers represent the expected upper and lower bounds of what might work well in a lead or lead-bismuth cooled reactor. The power level becomes important for long-lived cores because the amount of fissile material that will be needed to sustain a critical reactor will have to be optimized. The fissile components used for the current analysis are $\mathrm{Pu}-239$ and $\mathrm{Pu}-241$, and were kept constant at a combined weight percent of $10.88 \%$ for the 20 $\mathrm{wt} \%$ added TRU, and $16.32 \mathrm{wt} \%$ for the $30 \mathrm{wt} \%$ added TRU cases.

Table 9. Beginning-of-
life fuel composition
for non-fertile fuel
\begin{tabular}{|c|c|}
\hline Isotope & wt\% \\
\hline \hline Pu-238 & $0.32 \%$ \\
\hline $\mathrm{Pu}-239$ & $9.28 \%$ \\
\hline $\mathrm{Pu}-240$ & $4.16 \%$ \\
\hline $\mathrm{Pu}-241$ & $1.60 \%$ \\
\hline Pu-242 & $0.64 \%$ \\
\hline $\begin{array}{c}\text { Plutonium } \\
\text { Total }\end{array}$ & $\mathbf{1 6 \%}$ \\
\hline \hline Np-237 & $1.72 \%$ \\
\hline Am-241 & $1.80 \%$ \\
\hline Am-243 & $0.36 \%$ \\
\hline Cm-244 & $0.12 \%$ \\
\hline $\begin{array}{c}\text { Minor } \\
\text { Actinide } \\
\text { Total }\end{array}$ & $\mathbf{4 \%}$ \\
\hline \hline $\begin{array}{c}\text { Zirconium } \\
\text { Matrix }\end{array}$ & $\mathbf{8 0} \%$ \\
\hline
\end{tabular}

Table 10. Beginningof-life TRU composition for all 20 wt\% Pu+MA.

wt \% Pu+MA.
\begin{tabular}{|c|c|}
\hline Isotope & wt $\%$ \\
\hline \hline Pu-238 & $0.32 \%$ \\
\hline Pu-239 & $9.28 \%$ \\
\hline Pu-240 & $4.16 \%$ \\
\hline Pu-241 & $1.60 \%$ \\
\hline Pu-242 & $0.64 \%$ \\
\hline $\begin{array}{c}\text { Plutonium } \\
\text { Total }\end{array}$ & $\mathbf{1 6 \%}$ \\
\hline \hline Np-237 & $1.72 \%$ \\
\hline Am-241 & $1.80 \%$ \\
\hline Am-243 & $0.36 \%$ \\
\hline Cm-244 & $0.12 \%$ \\
\hline $\begin{array}{c}\text { Minor } \\
\text { Actinide } \\
\text { Total }\end{array}$ & $\mathbf{4 \%}$ \\
\hline
\end{tabular}

The current analysis has been limited to IFR type fuel, i.e., cylindrical pins placed in assemblies. The parameters of the pin are the same as in the previous section.

The metal fuel has three interesting properties that are important to this type of fuel: 
- The gas plenum above the fuel,

- The axial expansion, and

- The materials used in the gap between the fuel and the cladding.

The gas plenum is used to store the fission gases as they diffuse from the metal fuel, the axial expansion will result in a negative reactivity insertion, and the gap material enhances the thermal conductivity.

\subsubsection{Local Reactivity Void Coefficient}

While total and partial voiding of the core due to coolant overheating is nearly impossible because of the high boiling temperature of lead and lead-alloys, local voiding could be a possibility. A hypothetical situation could be a steam bubble passing through the core due to a steam tube rupture. Previous work (Weaver et al. 2000, and Weaver et al. 2001) has shown that the local void reactivity worth is $\sim \$ 3$ to $\$ 5$ worth of positive reactivity due to the very small delayed neutron fraction $(\sim 2.5$ times smaller than in an LWR). Table 11 shows the reactivity insertion for voiding the center half of the non-fertile fuel.

Table 11. Calculated local void reactivities at beginning-of-life for the non-fertile fuel.

\begin{tabular}{|c|c|c|}
\hline TRU Loading (wt $\%)$ & Coolant & Void Reactivity $(\% \Delta \mathrm{k} / \mathrm{k})$ \\
\hline 20 & $\mathrm{Na}$ & $1.09 \%$ \\
\hline 20 & $\mathrm{~Pb}-\mathrm{Bi}$ & $0.73 \%$ \\
\hline 30 & $\mathrm{Na}$ & $1.38 \%$ \\
\hline
\end{tabular}

This is a significant insertion of reactivity that could result in cladding failure due to overheating from a super-prompt-critical excursion, if other reactivity coefficients such as fuel expansion can not compensate. Relying solely on void worth for a negative reactivity insertion requires modification of the core or assemblies either passively or mechanically. Hejzlar et al. (1999a) devised a passive "streaming" assembly that allows for neutron leakage in the axial and radial directions (see Figure 17). The design compensates for the reactivity increase, and creates a negative coefficient due to local voiding. 


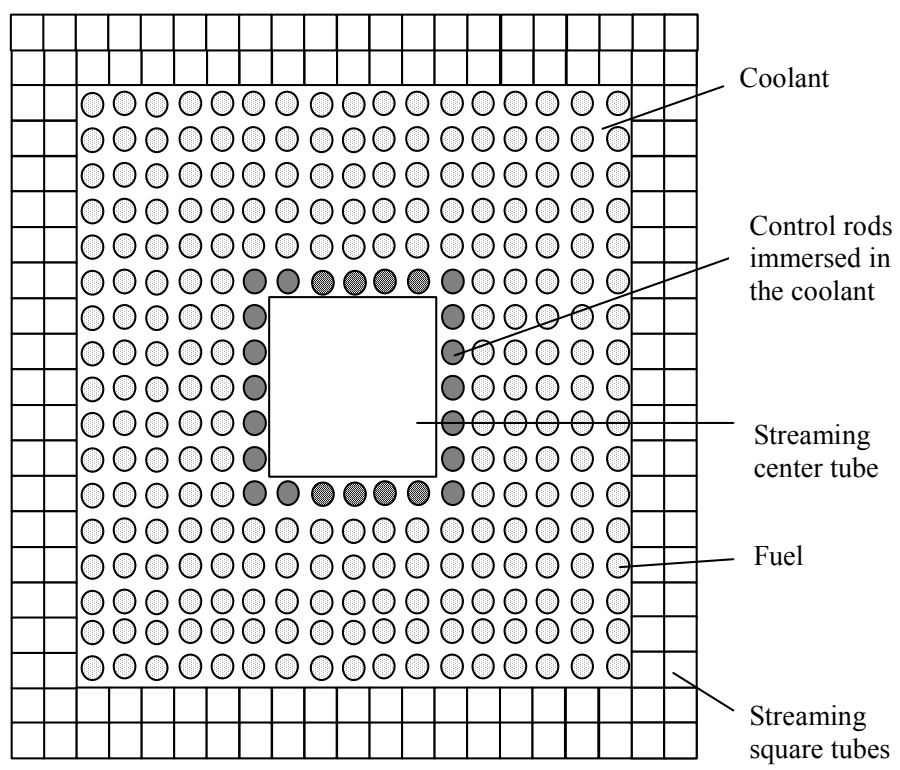

Figure 17. Schematic of Hejzlar streaming assembly.

\subsubsection{Doppler Reactivity Coefficient}

Work done at MIT (Hejzlar et al. 1999b) has shown that, although small, the Doppler coefficient is negative for the fuels we studied. It is important to note that the computational tools used in this analysis (MCNP) take an enormous amount of computer time to calculate this coefficient. Other tools may be more efficient in calculating the Doppler coefficient, and will be sought for future work.

\subsubsection{Reactivity Swing with Burnup}

The burnup time steps taken in MOCUP for all cases were one-year steps with no outages. The results for the non-fertile fuel at linear power of $367.5 \mathrm{~W} / \mathrm{cm}$ are shown in Figure 18. Note the extremely short fuel life in the sodium-cooled case as compared to the lead-bismuth-cooled case. In order to extend the fuel life in the sodium-cooled case to make it comparable to the leadbismuth-cooled case, the TRU content was increased from $20 \mathrm{wt} \%$ to $30 \mathrm{wt} \%$. The consequences of this will be discussed later.

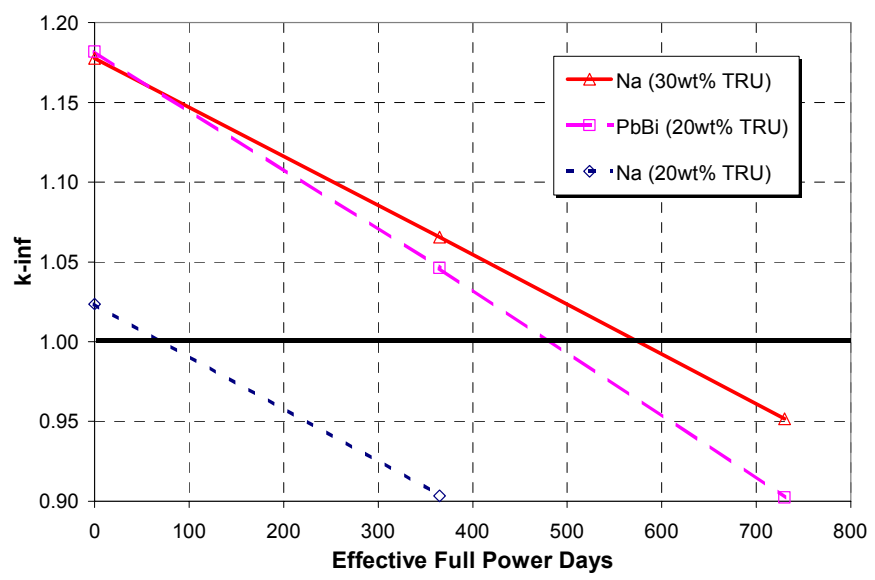

Figure 18. Reactivity comparison at $367.5 \mathrm{~W} / \mathrm{cm}$. 
Figure 19 shows the results for a comparison of a derated linear power at $86 \mathrm{~W} / \mathrm{cm}$. While increasing the overall fuel life, an increase in beginning-of-life TRU is required in the sodium cooled case to extend its life further, and thus increase the total amount of actinides burned in the cycle.

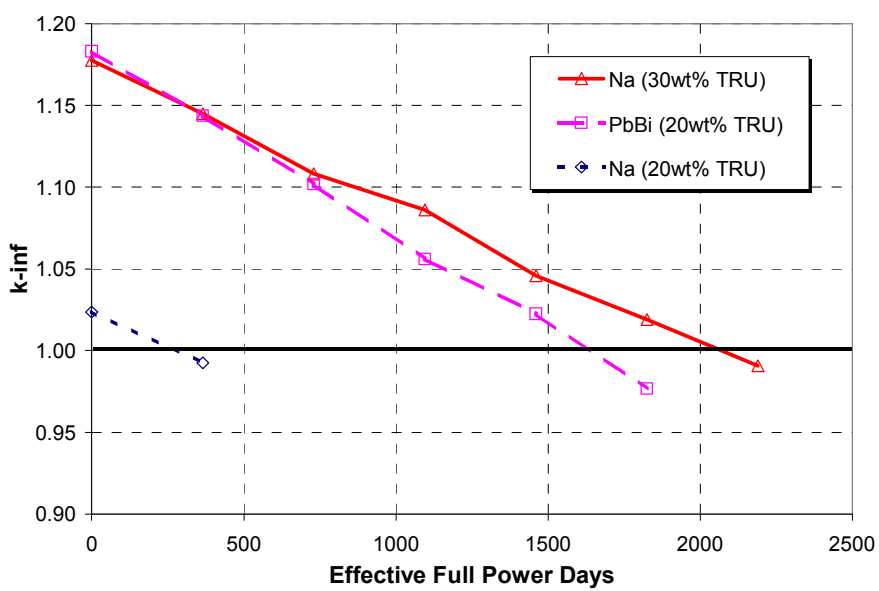

Figure 19. Reactivity comparison at $86 \mathrm{~W} / \mathrm{cm}$.

It is important to note that because these calculations were based on a pin cell with axial leakage only, the radial leakage of these cells was not accounted for and is significant in this type of reactor. Thus the effective-full-power-days that were calculated are an overestimation. However, the semi-infinite lattice parameters assumed in these calculations were kept constant in all cases and thus normalized the results that will be presented in the following sections.

The results for the fertile fuel at a linear power of $367.5 \mathrm{~W} / \mathrm{cm}$ are shown in Figures 20 through 23. Note that the TRU loading was increased from $20 \mathrm{wt} \%$ to $30 \mathrm{wt} \%$ in the Th-Zr based fuel due to the fact that the $20 \mathrm{wt} \%$ loading was not critical. Also note that for similar TRU loadings, the lead-bismuth cooled cases have lifetimes that are $26-65 \%$ longer than the sodium cooled cases. Of particular interest is the reactivity increase for the Th- $\mathrm{N}$ based fuel. This is a result of the high conversion of Th-232 to U-233.

Figures 24 through 27 show the results for a comparison of a derated linear power at 86 $\mathrm{W} / \mathrm{cm}$

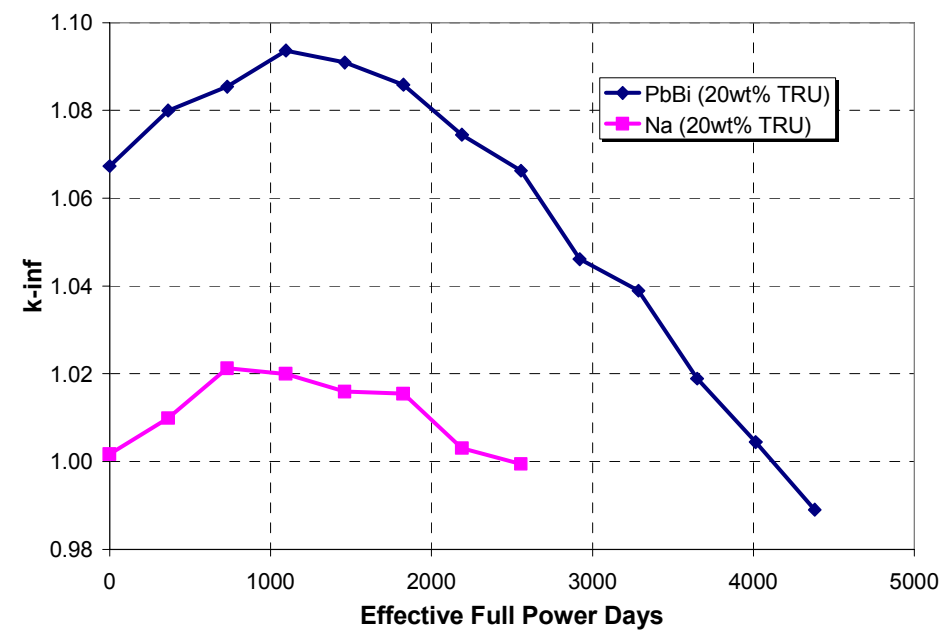

Figure 20. Reactivity comparison at $367.5 \mathrm{~W} / \mathrm{cm}$ for $\mathrm{ThN}$ based fuel. 


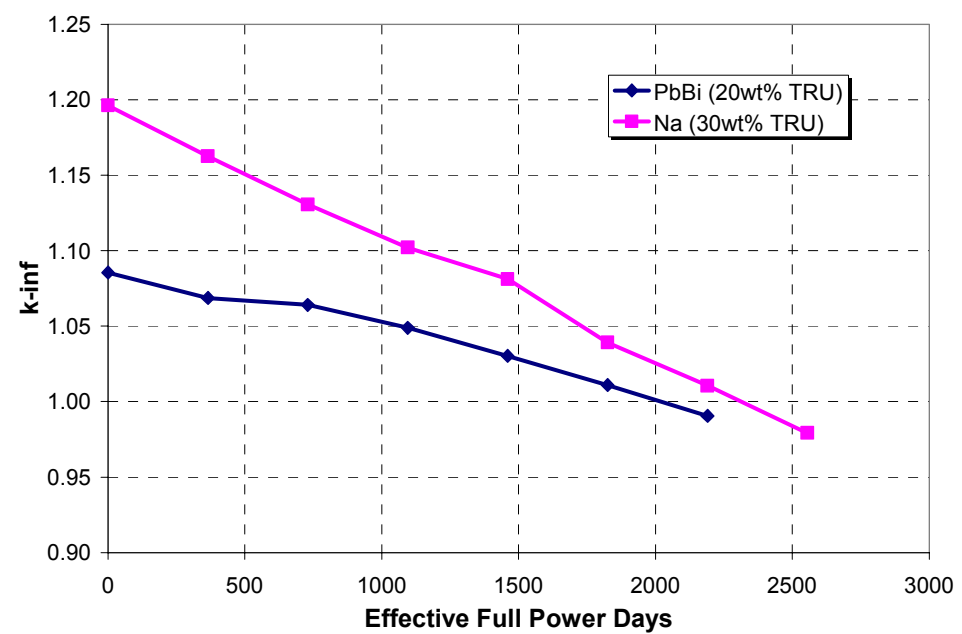

Figure 21. Reactivity comparison at $367.5 \mathrm{~W} / \mathrm{cm}$ for ThZr based fuel.

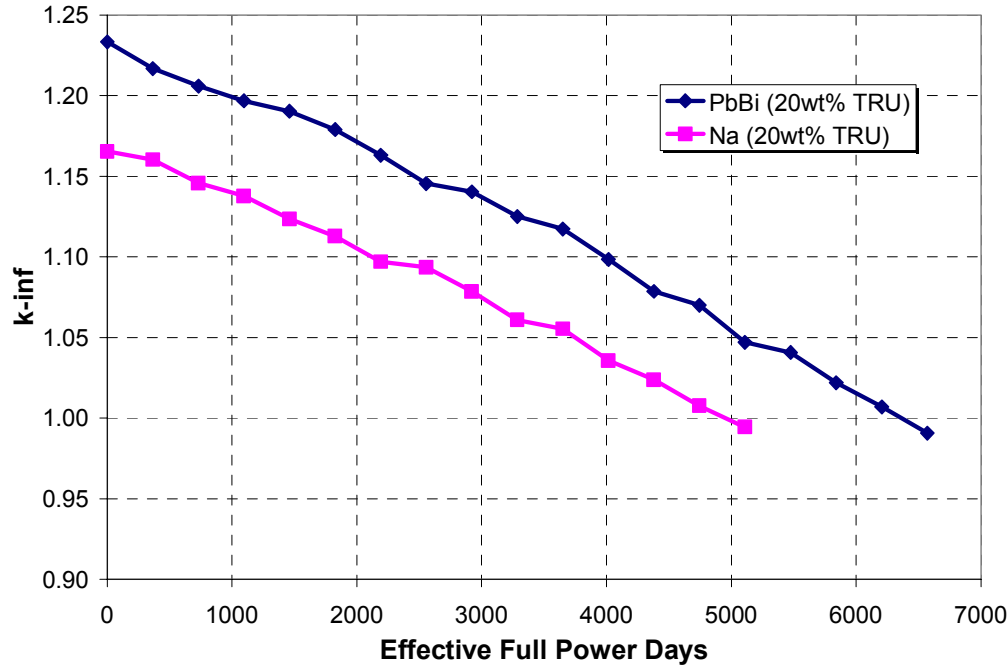

Figure 22. Reactivity comparison at $367.5 \mathrm{~W} / \mathrm{cm}$ for $\mathrm{U}-\mathrm{N}$ based fuel.

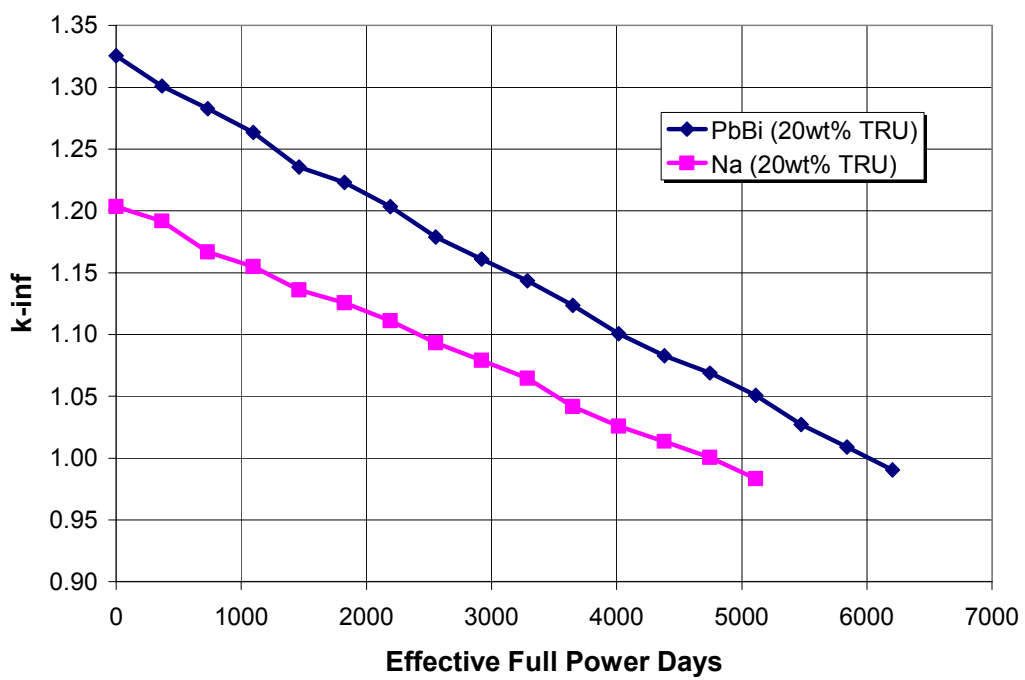

Figure 23. Reactivity comparison at $367.5 \mathrm{~W} / \mathrm{cm}$ for $\mathrm{U}-\mathrm{Zr}$ based fuel. 


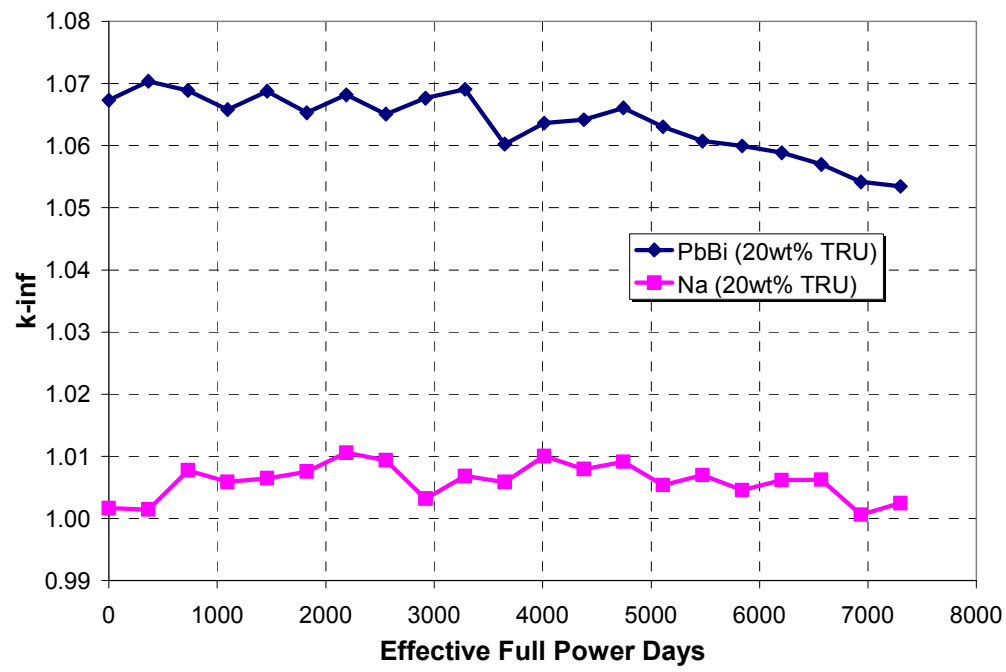

Figure 24. Reactivity comparison at $86 \mathrm{~W} / \mathrm{cm}$ for Th-N based fuel.

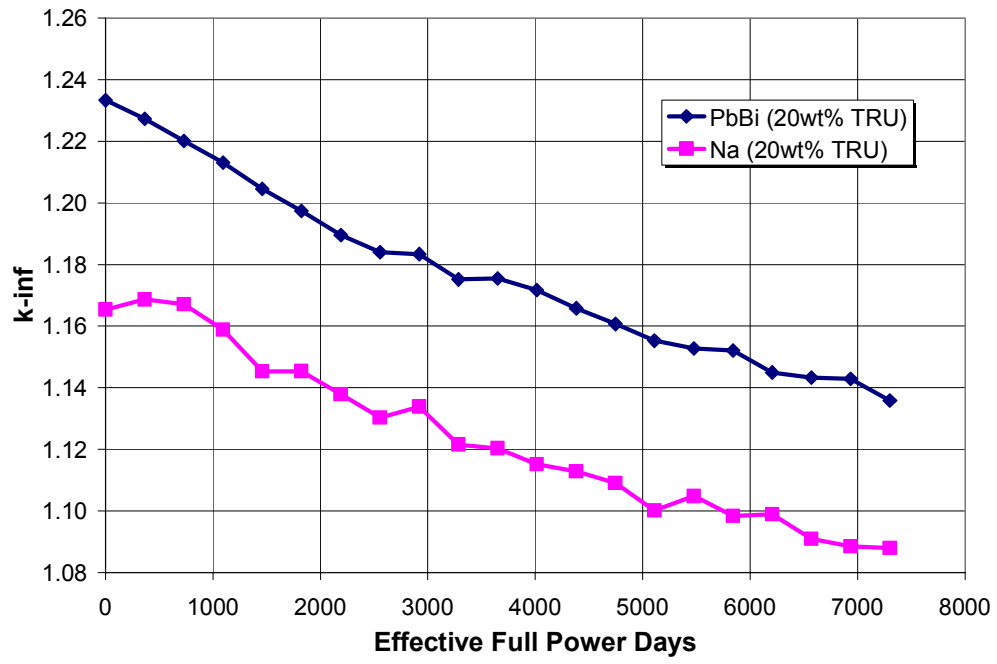

Figure 25. Reactivity comparison at $86 \mathrm{~W} / \mathrm{cm}$ for $\mathrm{U}-\mathrm{N}$ based fuel.

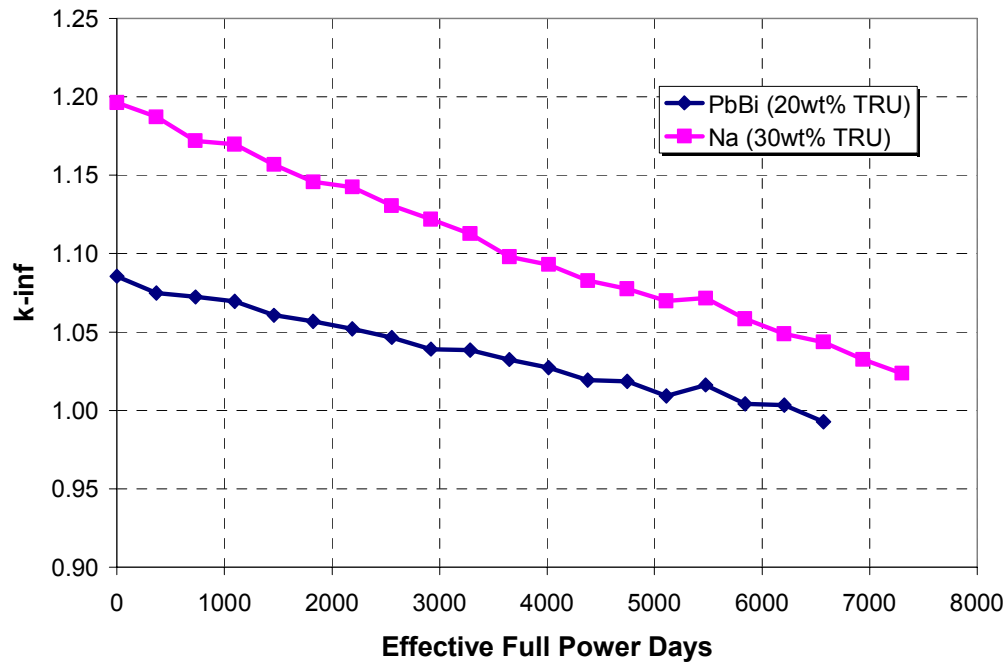

Figure 26. Reactivity comparison at $86 \mathrm{~W} / \mathrm{cm}$ for $\mathrm{Th}-\mathrm{Zr}$ based fuel. 


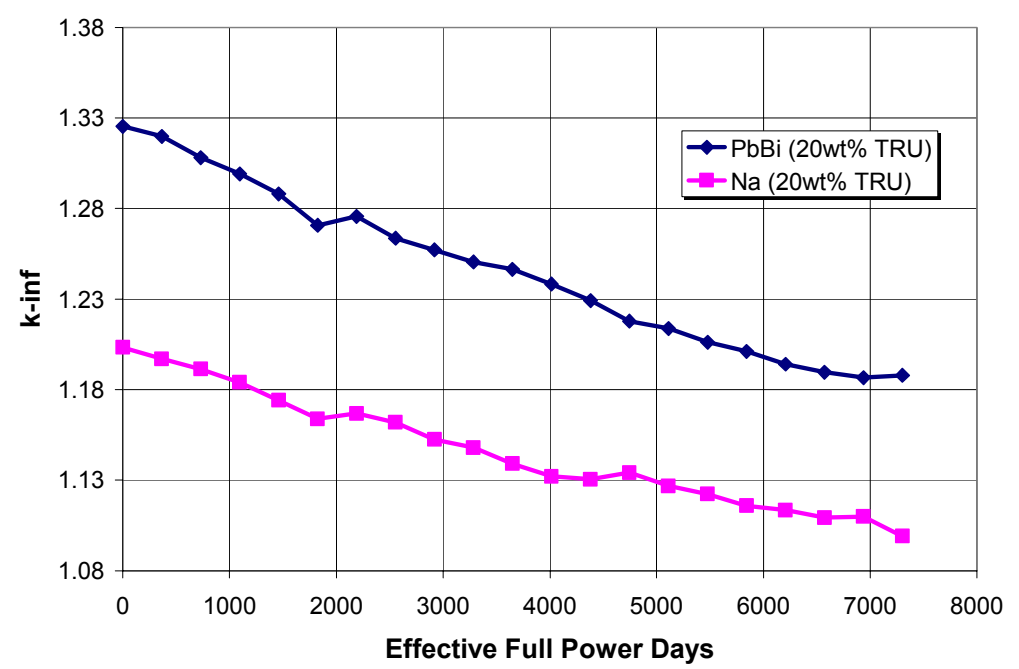

Figure 27. Reactivity comparison at $86 \mathrm{~W} / \mathrm{cm}$ for $\mathrm{U}-\mathrm{Zr}$ based fuel.

Again, the lead-bismuth cooled cases all have longer cycle lengths based on the reactivity versus effective-full-power-day (EFPD) curves. As mentioned above, these calculations were based on a pin cell with axial leakage only; the radial leakage of these cells was not accounted for and is significant in this type of reactor. Thus the effective-full-power-days that were calculated are an overestimation. However, as with the fertile free cases, the semi-infinite lattice parameters assumed in these calculations were kept constant in all cases and thus normalized the results presented.

\subsubsection{Actinide Destruction and Generation Rates.}

As stated previously, the actinide transmutation rate is dependent on whether fertile or non-fertile fuel is used. A higher net actinide destruction rate of the initially loaded plutonium and minor actinides is achieved with the non-fertile fuel, with the sodium and lead-bismuth destruction rates being approximately equal, as can be seen in Figures 28 and 29.

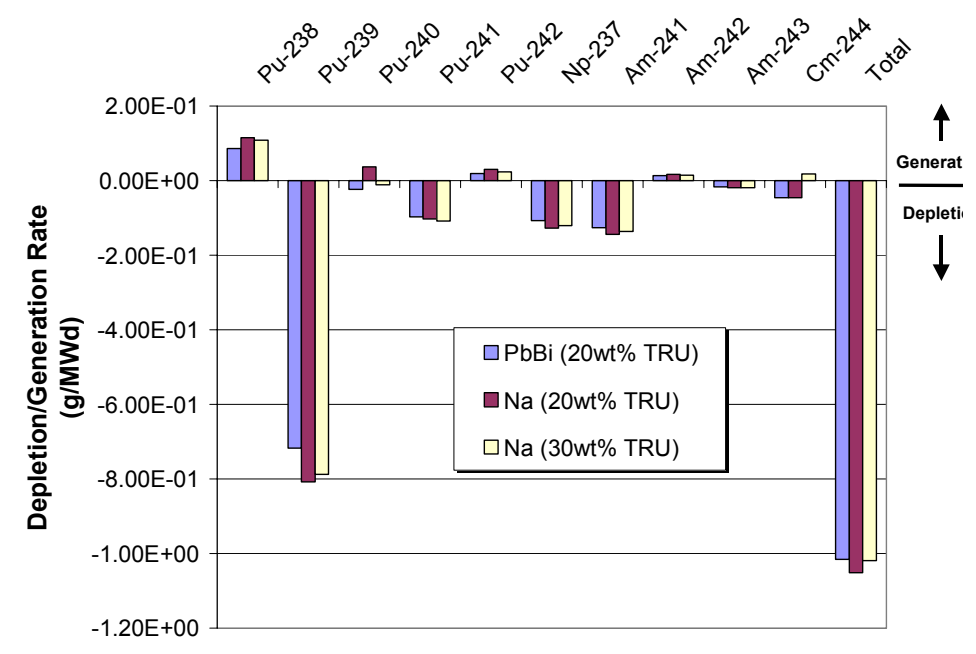

Figure 28. Average isotopic burnup rate at a linear power of $367.5 \mathrm{~W} / \mathrm{cm}$. 


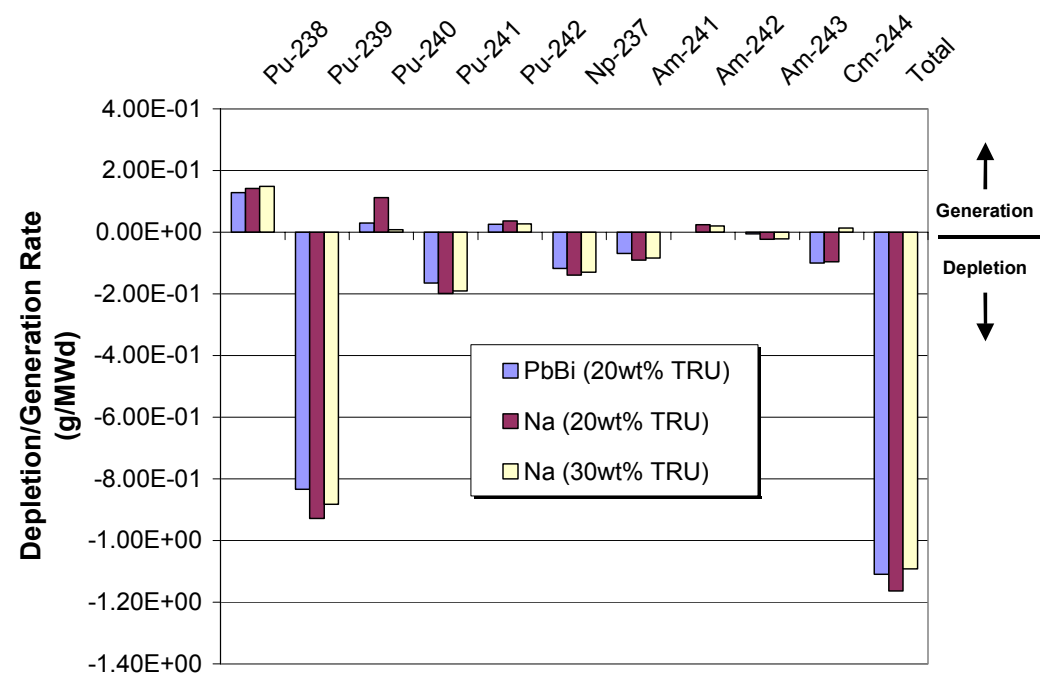

Figure 29. Average isotopic burnup rate at a linear power of $86 \mathrm{~W} / \mathrm{cm}$.

The plutonium destruction rates, particularly the $\mathrm{Pu}-239$, gives a slight advantage to the 20 wt $\%$ loaded, sodium cooled case. However, as was seen previously, the shorter fuel life will not allow this particular case to "burn" enough of the plutonium to be competitive with the leadbismuth cooled reactor design. The overall actinide destruction rate for a 1-batch core can be seen in Figure 30, where the total burnup capability based on burnup rates and total core life are presented. The highest actinide burnup is achieved in the lead-bismuth case at a linear power of $367.5 \mathrm{~W} / \mathrm{cm}$. The non-linearity between the two power levels with respect to the total TRU burned will be discussed later.

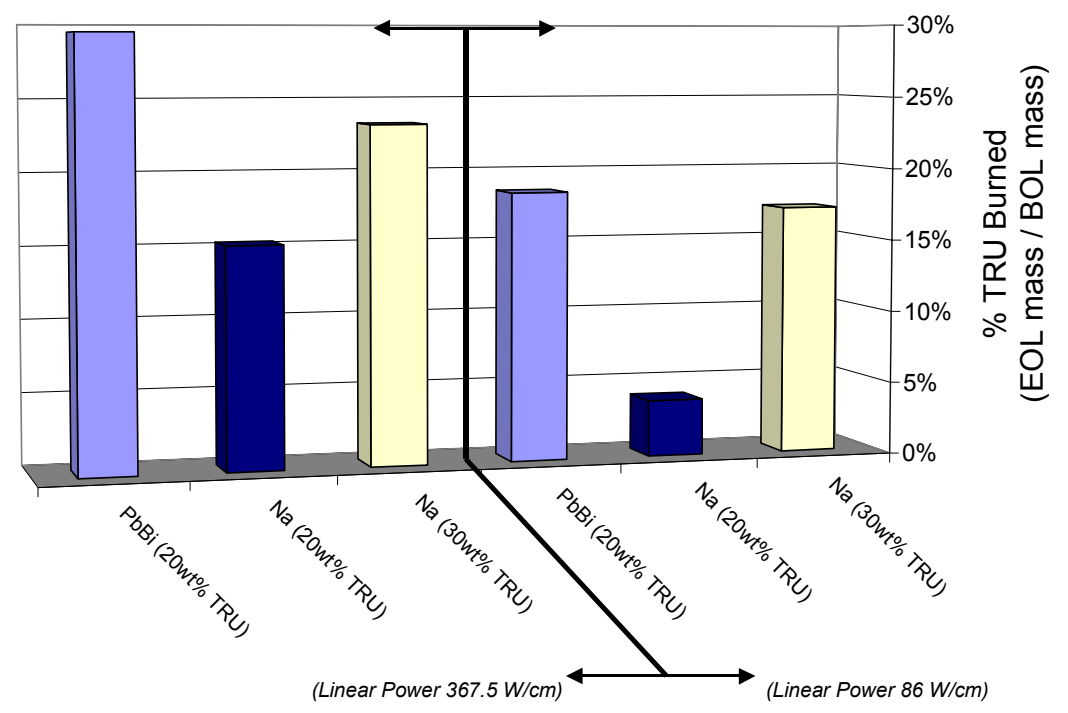

Figure 30. One-batch core actinide burnup comparison.

The hard spectrum in the both lead-bismuth and sodium cooled reactors results in a high fission to capture ratio, making them attractive as an actinide burners. However, the longer core life for comparable initial actinide loadings in the lead-bismuth-cooled reactor appears to make it 
more suitable for actinide burning. The net destruction rates of individual isotopes in the fertile fuel can be seen in Figures 31 through 34.

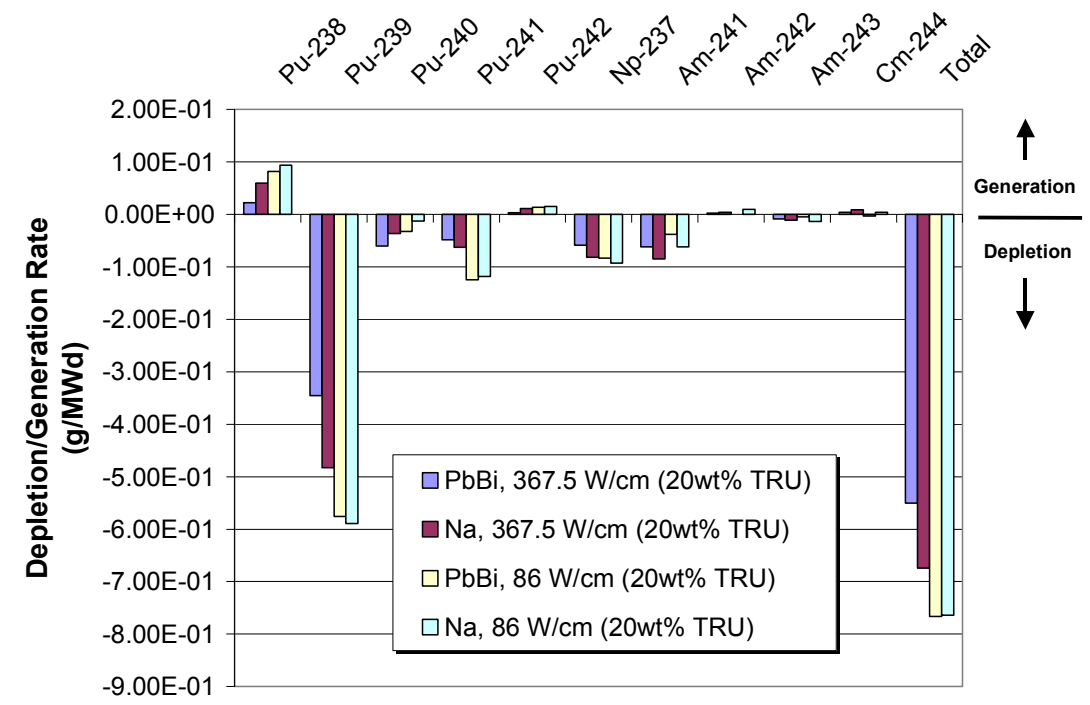

Figure 31. Average isotopic burnup rate for $\mathrm{ThN}$ based fuel.

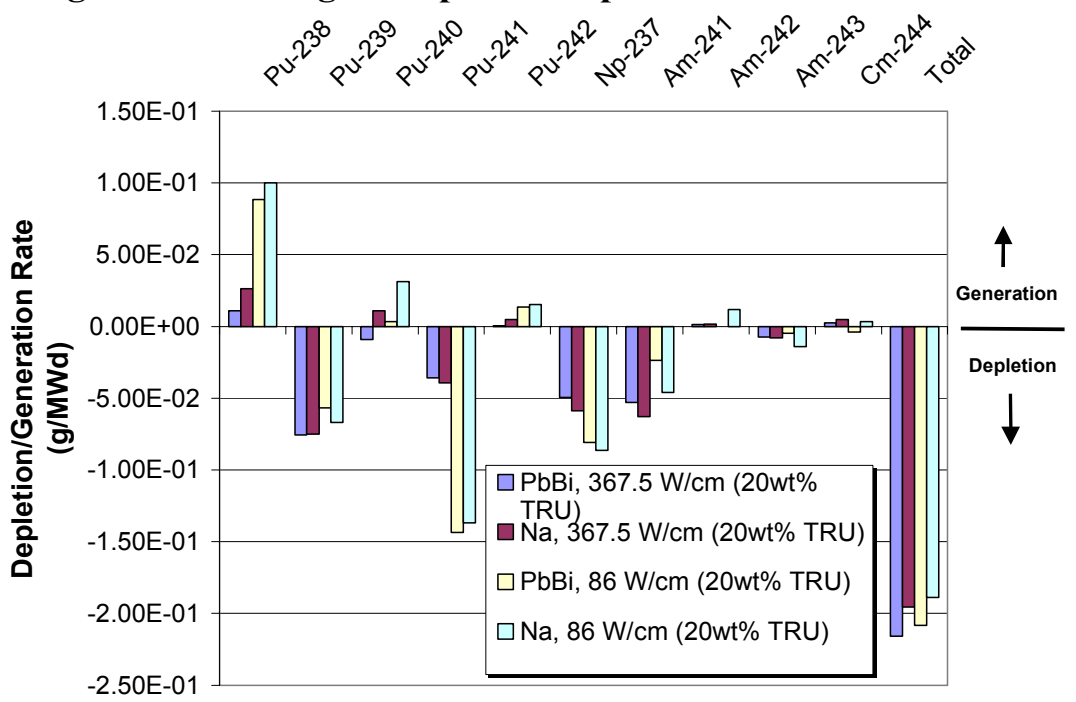

Figure 32. Average isotopic burnup rate for $U-N$ based fuel. 


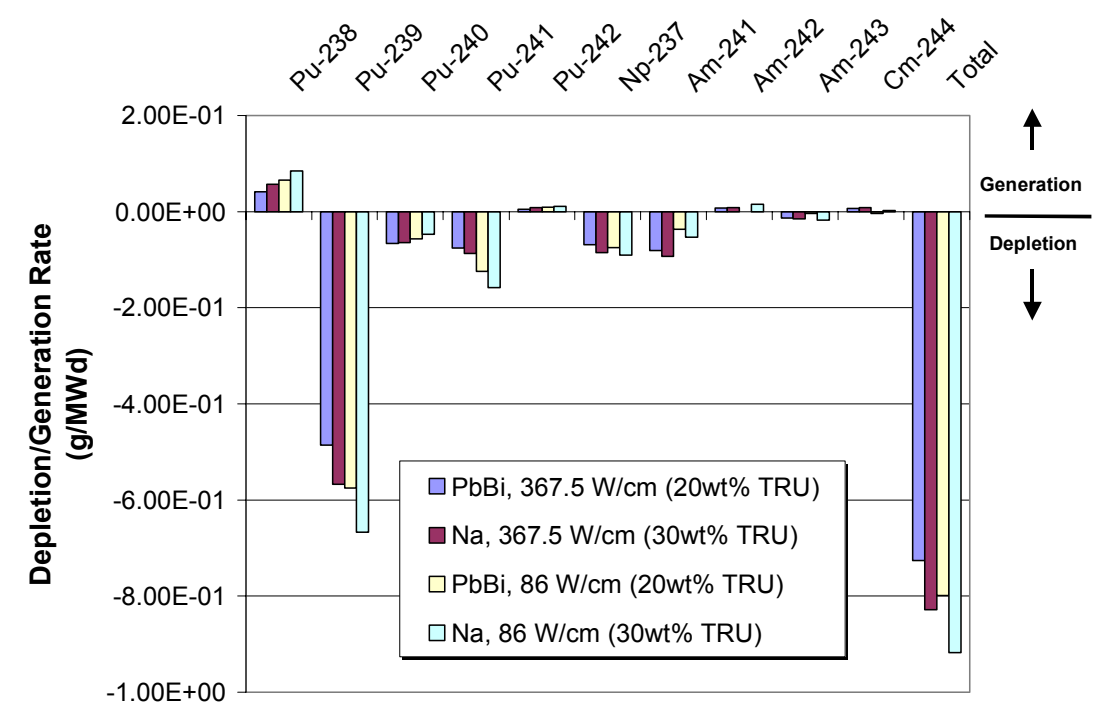

Figure 33. Average isotopic burnup rate for Th-Zr based fuel.

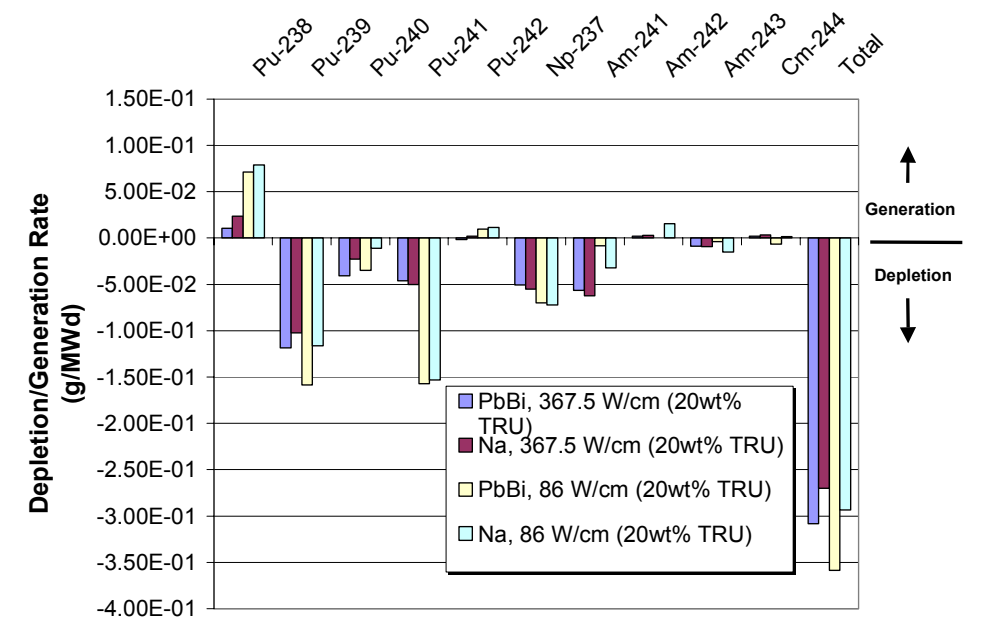

Figure 34. Average isotopic burnup rate for $\mathrm{U}-\mathrm{Zr}$ based fuel.

The depletion rates are approximately the same for both coolants at similar linear powers. However, as was seen previously, the shorter fuel life of the sodium cooled cases with similar TRU loadings will not allow these particular cases to "burn" enough of the plutonium to be competitive with the lead-bismuth cooled reactor designs.

The overall actinide destruction rates for 1-batch cores can be seen in Figures 35 and 36, which compare the total burnup capability based on burnup rates and total core life. 


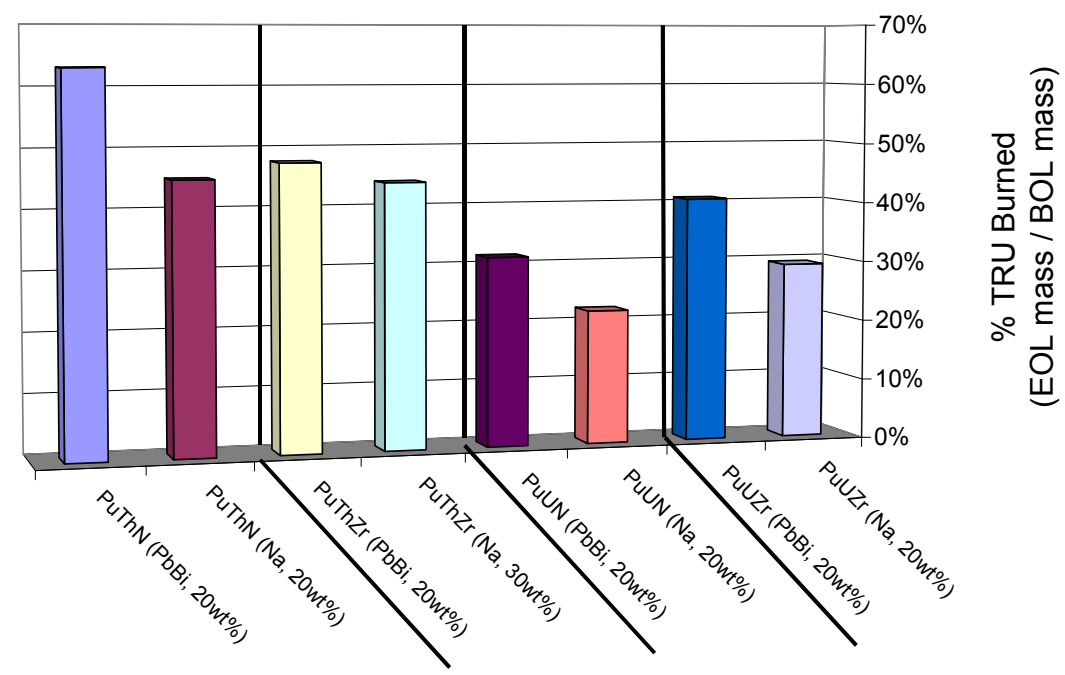

Figure 35. One-batch core actinide burnup comparison at a linear power of $367.5 \mathrm{~W} / \mathrm{cm}$.

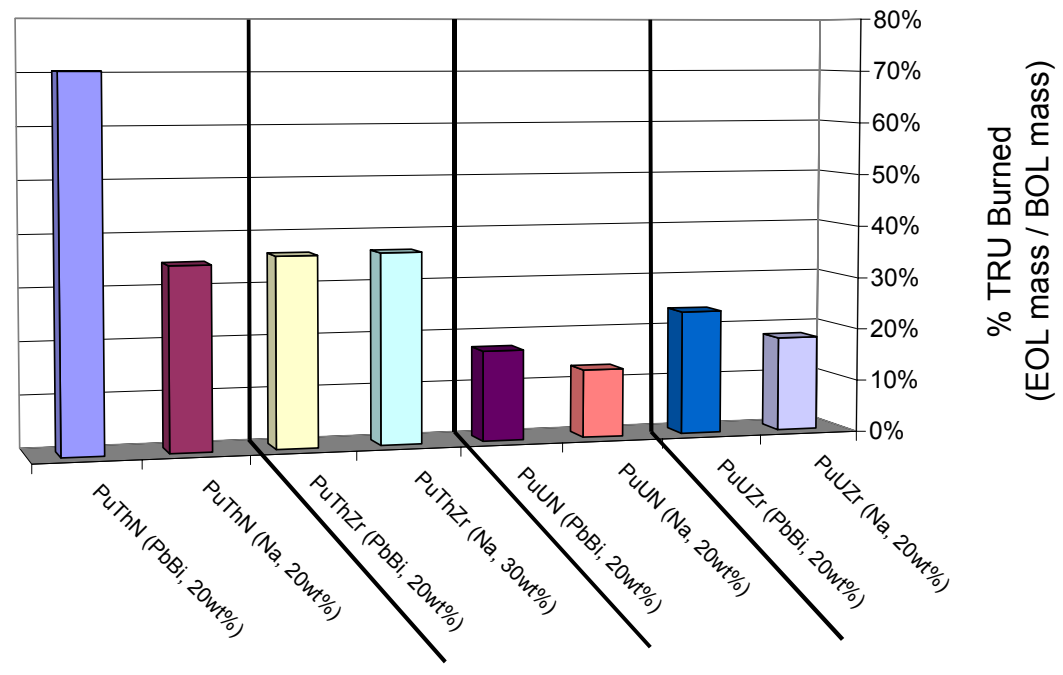

Figure 36. One-batch core actinide burnup comparison at a linear power of $86 \mathrm{~W} / \mathrm{cm}$.

The highest actinide burnup is achieved with the Th-N based fuel in the lead-bismuth case at a linear power of $86 \mathrm{~W} / \mathrm{cm}$. In all cases, the actinide burnup using the lead-bismuth coolant is as good or better than the sodium cooled cases. This is true even in the $(\mathrm{Pu}+\mathrm{MA}) \mathrm{ThZr}$ case where the $\mathrm{Pu}+\mathrm{MA}$ enrichment had to be increased by 1.5 times in the sodium coolant case to become critical, and to match the transmutation capability of the lead-bismuth case. Of particular interest is the generally lower actinide burnup capability at $86 \mathrm{~W} / \mathrm{cm}$ than at $367.5 \mathrm{~W} / \mathrm{cm}$, even though the overall lifetime of the fuel is much longer. This is due to a couple of competing factors: 1) the longer lifetime of the $86 \mathrm{~W} / \mathrm{cm}$ cases allow for more decay and generation of certain actinides based on half-lives, and 2) the actinides typically follow an exponential growth/depletion curve which can be almost linear in the $86 \mathrm{~W} / \mathrm{cm}$ cases depending on the exponential constant. In short, the differences are due to the neutron flux and in-core residence time. Nevertheless, as with the fertile-free fuel, lead-bismuth gives better end-of-life transmutation capability as compared to the sodium-cooled cases due to the longer in-core residence times. 


\subsubsection{Actinide Discharge}

The end-of-life actinide discharge for each case depends highly on the total actinides burned. When scaled on a per year basis, the sodium and lead-bismuth cooled cases are almost identical. But if no reprocessing or fuel shuffling is assumed, the actinide discharge would be considerably less in most cases for the lead-bismuth coolant when using comparable initial TRU loadings. Further reduction of the actinide discharge for a once through (no reprocessing) cycle can be accomplished by using a 3-batch cycle, which would increase the lifetime and, therefore, the total destruction by $50 \%$ (Driscoll et al. 1990). However, the fluence limits would most likely preclude the use of a multi-batch refueling scheme in the fertile fueled reactors. On the other hand, reprocessing would further reduce the actinide discharge of both the non-fertile and fertile fueled reactors.

\subsubsection{Plutonium Content}

Of the total discharged actinides, the plutonium content varies from $76 \mathrm{wt} \%$ to $82 \mathrm{wt} \%$ for the fertile free fuel. For plutonium proliferation concerns, the total plutonium content decreases in all cases, with the fraction (or weight percent) of each plutonium isotope also changing. However, the isotopic fractions are dependent on the coolant and the effective-full-power-days, as can be seen in Table 12.

Table 12. Plutonium isotopics from a once-through cycle using fertile-free fuel.

\begin{tabular}{|c|c|c|c|c|c|c|c|c|}
\hline \multirow[b]{4}{*}{ Coolant } & \multirow{4}{*}{$\begin{array}{c}\text { Initial TRU } \\
\text { Loading } \\
\text { (wt } \%)\end{array}$} & \multirow{4}{*}{$\begin{array}{l}\text { Linear } \\
\text { Power } \\
\text { (W/cm) }\end{array}$} & \multirow[b]{4}{*}{ EFPD } & \multicolumn{5}{|c|}{ BOL Plutonium Fractions, All Cases (wt\%) } \\
\hline & & & & Pu-238 & Pu-239 & Pu-240 & Pu-241 & Pu-242 \\
\hline & & & & $2.0 \%$ & $58.0 \%$ & $26.0 \%$ & $10.0 \%$ & $4.0 \%$ \\
\hline & & & & \multicolumn{5}{|c|}{ EOL Plutonium Fractions (wt \%) } \\
\hline $\mathrm{PbBi}$ & 20 & 367.5 & 482 & $7.3 \%$ & $42.5 \%$ & $34.9 \%$ & $8.7 \%$ & $6.6 \%$ \\
\hline $\mathrm{Na}$ & 20 & 367.5 & 72 & $4.9 \%$ & $49.4 \%$ & $31.0 \%$ & $9.3 \%$ & $5.3 \%$ \\
\hline $\mathrm{Na}$ & 30 & 367.5 & 575 & $6.5 \%$ & $45.5 \%$ & $33.0 \%$ & $9.0 \%$ & $6.1 \%$ \\
\hline$\overline{\mathrm{P}} \mathrm{PbBi}$ & 20 & 86 & "1639 & $5.9 \%$ & $\overline{448.3 \%}$ & $32.5 \%$ & $7.8 \%$ & $5.5 \%$ \\
\hline $\mathrm{Na}$ & 20 & 86 & 276 & $2.7 \%$ & $56.0 \%$ & $27.5 \%$ & $9.5 \%$ & $4.3 \%$ \\
\hline $\mathrm{Na}$ & 30 & 86 & 2070 & $5.9 \%$ & $49.1 \%$ & $31.7 \%$ & $7.7 \%$ & $5.6 \%$ \\
\hline
\end{tabular}

Of special interest is the change in the ratio of both the $\mathrm{Pu}-238$ and $\mathrm{Pu}-239$, where the $\mathrm{Pu}-238$ ratio increases in all cases. The $\mathrm{Pu}-239$ content is depleted significantly in the cases where the linear power is high, and the $\mathrm{Pu}-238$ and $\mathrm{Pu}-240$ contents increase in all cases. The Pu-238 and $\mathrm{Pu}-240$ isotopes are important for non-proliferation concerns because of the decay heat produced by the $\mathrm{Pu}-238$, and the spontaneous neutrons produced by the $\mathrm{Pu}-240$. If significant percentages of these two isotopes are present in the plutonium, it will considerably reduce the yield of a weapon, and make handling of the plutonium difficult.

Of the total discharged actinides in the fertile fuel, the total plutonium content decreases in all cases, with the fraction (or weight percent) of each plutonium isotope also changing. However, as with the fertile-free fuel, the isotopic fractions are dependent on the coolant and the effectivefull-power-days, as can be seen in Table 13. 
Table 13. Plutonium isotopics from a once-through cycle.

\begin{tabular}{|c|c|c|c|c|c|c|c|c|c|}
\hline \multirow[b]{4}{*}{ Fuel } & \multirow[b]{4}{*}{ Coolant } & \multirow{4}{*}{$\begin{array}{c}\text { Initial } \\
\text { TRU } \\
\text { Loading } \\
\text { (wt \%) }\end{array}$} & \multirow{4}{*}{$\begin{array}{l}\text { Linear } \\
\text { Power } \\
\text { (W/cm) }\end{array}$} & \multirow[b]{4}{*}{ EFPD } & \multicolumn{5}{|c|}{ BOL Plutonium Fractions, All Cases (wt\%) } \\
\hline & & & & & $\mathrm{Pu}-238$ & Pu-239 & Pu-240 & Pu-241 & $\mathrm{Pu}-242$ \\
\hline & & & & & $2.0 \%$ & $58.0 \%$ & $26.0 \%$ & $10.0 \%$ & $4.0 \%$ \\
\hline & & & & & \multicolumn{5}{|c|}{ EOL Plutonium Fractions (wt\%) } \\
\hline \multirow[t]{4}{*}{ PuThN } & $\mathrm{PbBi}$ & 20 & 367.5 & 4120 & $13.4 \%$ & $21.6 \%$ & $45.3 \%$ & $8.0 \%$ & $11.6 \%$ \\
\hline & $\mathrm{Na}$ & 20 & 367.5 & 2499 & $12.2 \%$ & $30.6 \%$ & $40.2 \%$ & $8.4 \%$ & $8.7 \%$ \\
\hline & $\mathrm{PbBi}$ & 20 & 86 & 7300 & $10.0 \%$ & $40.4 \%$ & $37.3 \%$ & $4.9 \%$ & $7.3 \%$ \\
\hline & $\mathrm{Na}$ & 20 & 86 & 7300 & $10.7 \%$ & $38.4 \%$ & $38.2 \%$ & $5.4 \%$ & $7.3 \%$ \\
\hline \multirow[t]{4}{*}{ PuThZr } & $\mathrm{PbBi}$ & 20 & 367.5 & 2021 & $10.2 \%$ & $34.5 \%$ & $39.3 \%$ & $\overline{7.4 \%}$ & $8.5 \%$ \\
\hline & $\mathrm{Na}$ & 30 & 367.5 & 2313 & $10.2 \%$ & $35.6 \%$ & $38.5 \%$ & $7.5 \%$ & $8.1 \%$ \\
\hline & $\mathrm{PbBi}$ & 20 & 86 & 6325 & $9.2 \%$ & $41.3 \%$ & $37.1 \%$ & $5.0 \%$ & $7.4 \%$ \\
\hline & $\mathrm{Na}$ & 30 & 86 & 7300 & $8.6 \%$ & $43.4 \%$ & $36.3 \%$ & $4.8 \%$ & $6.9 \%$ \\
\hline \multirow[t]{4}{*}{ 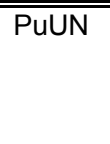 } & $\overline{\mathrm{PbBi}}$ & 20 & 367.5 & 6361 & $4.9 \%$ & 55.1\% & $30.5 \%$ & $4.4 \%$ & $5.1 \%$ \\
\hline & $\mathrm{Na}$ & 20 & 367.5 & 4957 & $6.4 \%$ & $52.6 \%$ & $30.8 \%$ & $5.0 \%$ & $5.3 \%$ \\
\hline & $\mathrm{PbBi}$ & 20 & 86 & 7300 & $6.4 \%$ & $57.8 \%$ & $27.4 \%$ & $3.5 \%$ & $4.9 \%$ \\
\hline & $\mathrm{Na}$ & 20 & 86 & 7300 & $6.8 \%$ & $56.2 \%$ & $28.3 \%$ & $3.8 \%$ & $4.9 \%$ \\
\hline \multirow[t]{4}{*}{ 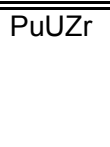 } & $\overline{\mathrm{PbBi}}$ & 20 & 367.5 & 6015 & $5.5 \%$ & $56.7 \%$ & $28.5 \%$ & $3.7 \%$ & $5.6 \%$ \\
\hline & $\mathrm{Na}$ & 20 & 367.5 & 4757 & $6.5 \%$ & $55.2 \%$ & $28.8 \%$ & $4.1 \%$ & $5.4 \%$ \\
\hline & $\mathrm{PbBi}$ & 20 & 86 & 7300 & $5.9 \%$ & $57.8 \%$ & $27.8 \%$ & $3.5 \%$ & $5.1 \%$ \\
\hline & $\mathrm{Na}$ & 20 & 86 & 7300 & $6.0 \%$ & $57.6 \%$ & $27.9 \%$ & $3.5 \%$ & $5.0 \%$ \\
\hline
\end{tabular}

Of special interest is the change in the ratio of both $\mathrm{Pu}-238$ and $\mathrm{Pu}-239$, where the $\mathrm{Pu}-238$ ratio increases in all cases. The $\mathrm{Pu}-239$ content is depleted significantly in the thorium base fuels, and the $\mathrm{Pu}-238$ and $\mathrm{Pu}-240$ contents increase in all cases.

\subsection{Core Concept for Minor Actinide Burning (MIT, Dr. Pavel Hejzlar)}

The investigations in this section are focused on exploring the possibility of burning TRUs from spent LWR fuel in a critical lead or lead-bismuth-cooled fast reactor core. Our earlier analyses have shown that with special streaming fuel assemblies [Hejzlar et. al., 2000],[ Hejzlar et. al., 2001a], [MacDonald et al., 2000] it is possible to design a dedicated lead-bismuth cooled TRU ( $\mathrm{Pu}+\mathrm{MA}$ ) burner core with zirconium-based metal fuel, which exhibits acceptable safety characteristics, specifically negative coolant void and fuel temperature coefficients. The fertilefree fuel was found to require a large beginning-of-life reactivity excess, thus demanding a large number of control rods for reactivity compensation, increasing system complexity, and raising concerns with reactivity accidents from control rod malfunctions. Therefore, various approaches to reduce the reactivity swing during irradiation were investigated. In the absence of effective burnable poisons for hard-spectrum cores, a promising alternative to maintain a small reactivity excess without frequent refueling is a streaming core dedicated for minor actinide (MA) burning. The major plutonium fraction of the TRU is left for incineration in existing PWRs in peripheral fertile-free fuel assemblies. This strategy brings the following key benefits:

1. It significantly reduces the size of the burner system and its associated reprocessing/ refabrication facilities compared to the strategy of transmutation of all-TRUs in one system, and hence decreases the burner program cost. Figure $37^{*}$, shows that the number of dedicated Minor Actinide Burners (MABRs) in such a two-tier system can be reduced by as much as a

\footnotetext{
* The results shown in Figure 37 were calculated for the total waste mass intended for the repository in Yucca Mountain containing 711 MT TRU, from which 594 MT is plutonium and 117 MT minor actinides. Further, it was assumed that $80 \%$ burnup is achieved in peripheral inert matrix PWR assemblies based on the work by Chodak et. al. [1997].
} 
factor of 3 times if all the MAs and none of the plutonium pass through the dedicated MABR units. Correspondingly, the Pu flow through the LWR fleet increases.

2. It can substantially reduce the reactivity swing during burnup due to the attractive combination of fission and capture cross sections of the major MAs - Np-237 and Am-241 and their progenitors in the buildup and decay chains, as discussed in Section 3.4.3 below.

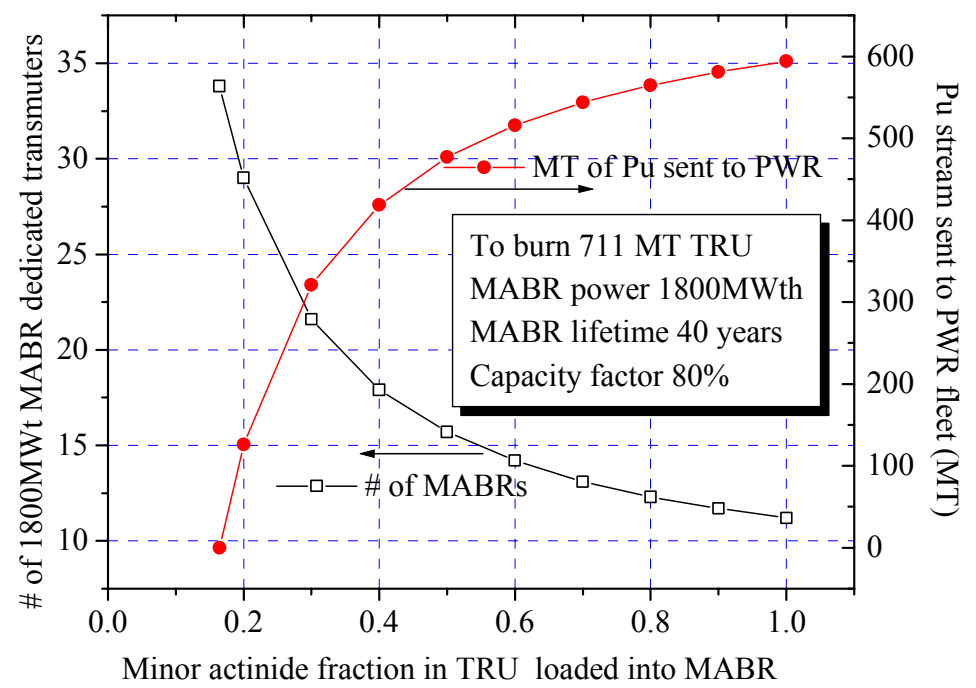

Figure 37. The effect of minor actinide fraction in TRU in the MABR stream on the number of dedicated MABR units and on the Pu stream sent to the PWR fleet.

The objective of this study was to investigate if a critical lead or lead-bismuth-cooled reactor can be designed to: (i) achieve competitive net actinide destruction rate per EFPY with that of accelerator driven transmuters, (ii) achieve a small reactivity swing for a refueling period of about 2 years to be competitive with utility practice and (iii) maintain acceptable safety characteristics.

\subsubsection{Key Reactor Physics Challenges}

However, the design of MA burning fast spectrum cores poses three major challenges:

1. Large positive coolant void worth. A major contribution to the positive coolant void worth comes from the spectral component (the others being leakage and coolant absorption) of the reactivity response to the coolant density reduction. In Pu-driven fast reactor cores, the harder neutron spectrum from coolant voiding leads to reduced fission and capture rates in the major $\mathrm{Pu}$ fissile isotopes, resulting in a net reactivity increase due to the smaller capture-to-fission ratio. Major MAs, such as $\mathrm{Np}-237$ and Am-241, exhibit an increase in their fission rate upon spectrum hardening, as more neutrons appear above the fast fission threshold - similar to the fertile isotope U238. However, because their fast fission cross-section is higher than that of U-238, the effect of the fast threshold fissions is more pronounced. It is also to be noted that contrary to most odd A nuclides, which exhibit a decreasing trend of fission cross section with increasing energy, the cross sections of both Np-237 and Am-241 increase for $\mathrm{E}>0.1 \mathrm{MeV}$ by two orders of magnitude.

Earlier studies by other researchers showed that mixing minor actinides homogeneously in fast reactor cores is possible up to $5 \mathrm{wt} \%$ without an unacceptable 
increase in the sodium void worth [Takano et. al., 1990], [Dobbin et. al., 1993], [Wakabayashi et. al., 1997]. Higher MA loadings up to $10 \%$ were found to be feasible only when many measures were introduced to reduce void worth to $+3 \$$ [Fujimura et. al., 1993]. Dedicated lead and sodium cooled MA burners have been recently investigated by French researchers, both having positive coolant void worth of several $\$$ in the scenario of voiding the whole core while keeping the reflector and shield regions full of coolant [Tommasi et. al., 1998]. Similar results were obtained by Russian investigators [Krivitski,2000] who found a significant shift to a positive coolant void worth when adding minor actinides to plutonium fuels in their BN-600 reactor core calculations. Fuels with increased minor actinide content as a means to extend core life at lower reactivity swing were also investigated by Yamaka and Wakabayashi [1995] and Nikitin et. al. [1999], but for mixed oxide fuels and sodium cooled reactors or tight heavy water lattices, respectively. These prior designs were limited to small MA loadings of $<10 \mathrm{w} / \mathrm{o}$, or used MAs in other reactors primarily as an "inverse burnable poison" rather than an actinide burner per se. In this study, very high MA loadings up to $100 \% \mathrm{w} / \mathrm{o} \mathrm{MA}$ will be evaluated. As reinforced by the Chernobyl accident, a large positive coolant void reactivity coefficient is an important parameter that needs to be avoided in any future reactor design. Thus, one of the primary goals of our efforts was to eliminate by design large positive coolant void worth.

2. Small or zero fuel temperature coefficient. The amount of fertile isotopes in fuel with high MA loadings is very small. Moreover, the hard spectrum of the lead or lead-bismuth-cooled core leads to a decrease in the absorption rate of the resonances. Both of these factors result in a very significant drop in the Doppler effect. Hence other measures to attain a reasonable value of negative fuel temperature feedback must be employed. Addition of absorbers with resonances at high energies, such as natural hafnium or rhodium may be necessary to attain a sufficiently negative Doppler coefficient. Reactivity changes from fuel thermal expansion are also prompt, hence if appreciable negative reactivity insertion from fuel thermal expansion is realized, the required magnitude of a negative Doppler coefficient may be reduced. Various approaches to overcome the challenge of prompt fuel temperature feedback will be investigated.

3. Small effective delayed neutron fraction. This fraction is small since the high-mass number isotopes which fission have a low delayed neutron yield. Moreover, delayed neutrons are emitted at lower energies than prompt neutrons and are thus more likely to be parasitically absorbed in control rods or structural materials, reducing the effective delayed neutron fraction and raising concerns over the controllability of critical reactors.

\subsubsection{Venue For Fertile-Free, Low-Reactivity Swing, Critical Burner Core}

Traditionally, critical reactors employ a large weight fraction of fertile material to maintain a reasonably small reactivity swing and simplify reactor control, and to attain acceptable neutronic feedbacks. However, when the fuel contains fertile isotopes there is a significant reduction in the net actinide destruction rate in incineration systems, since as some actinides are incinerated, others are formed, contradicting somewhat the primary purpose of actinide burners. But, if the fertile material is completely removed and replaced, for example, by an inert matrix, the reactivity swing becomes large. This makes the reactor control difficult and large transient 
overpower (TOP) initiators are possible, or short refueling cycles are required with their associated economic penalties. This dilemma can be resolved when the potential of certain attractive neutronic properties of minor actinides is utilized in a hard-spectrum reactor. Figure 38 shows the minor actinide buildup and decay chains and Table 14 shows the microscopic cross sections of the MAs of interest. The primary MAs (Np-237, Am-241 and to much less extent Am-243) from spent LWR fuel that are to be incinerated are shown in shaded boxes in Figure 38.

Table 14. One-group effective cross sections of key minor actinides and their successors in an lead or lead-bismuth-cooled reactor.

\begin{tabular}{|c|c|c|c|}
\hline Isotope & $\sigma_{c}$ (barn) & $\sigma_{\mathrm{f}}($ barn) & $\sigma_{\mathrm{f}} / \sigma_{\mathrm{c}}$ \\
\hline Np237 & 1.129 & 0.345 & 0.305 \\
\hline Pu239 & 0.425 & $1.751 \downarrow 5 x$ higher & $4.17 \checkmark 13.7 x$ higher \\
\hline $\mathrm{Pu} 241$ & 0.404 & 2.330 & 5.76 \\
\hline Am241 & 1.537 & 0.274 & 0.18 \\
\hline Am242m & 0.328 & $3.641 \nabla 13 x$ higher & $11.1 \checkmark 62 x$ higher \\
\hline $\mathrm{Cm} 242$ & 0.259 & 0.137 & 0.53 \\
\hline Pu238 & 0.645 & 1.119 & $1.73 \checkmark 3.27 \mathrm{x}$ higher \\
\hline
\end{tabular}

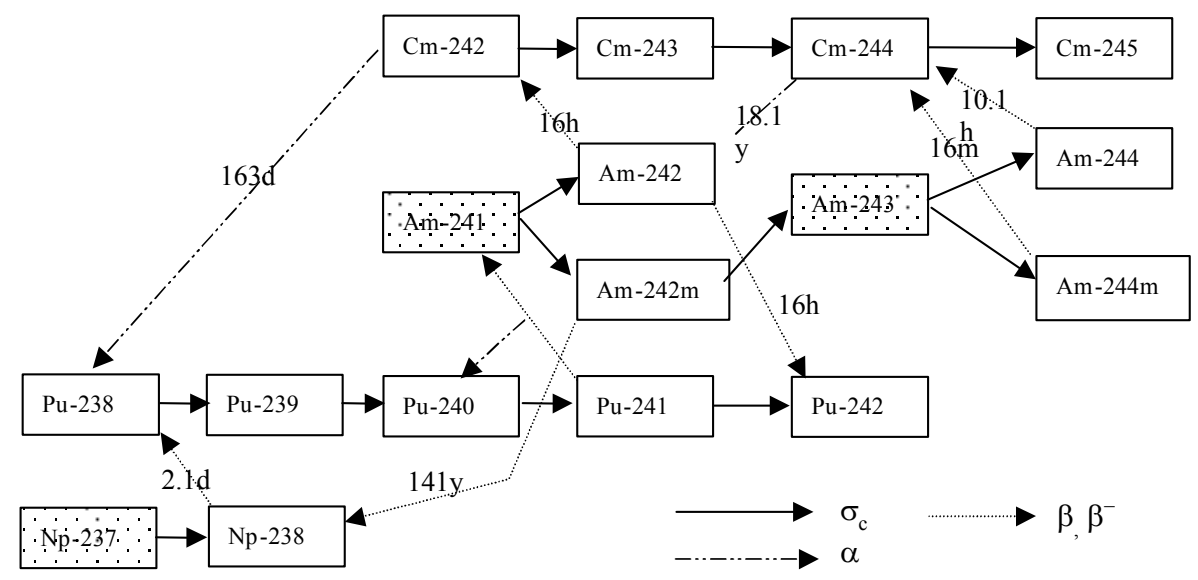

Figure 38. Buildup and decay chains of minor actinides.

There are three important neutron physics aspects to be noted:

1. The capture cross-section of Np-237 is significantly higher than its fission cross-section, thus $\mathrm{Np}-237$ is mainly transmuted to $\mathrm{Pu}-239$ (via $\mathrm{Pu}-238$ ), which is primarily fissioned because of its 13.7 times higher fission to capture cross section ratio than its predecessor.

2. A similar situation occurs with Am-241, which is transmuted upon neutron capture to Am$242 \mathrm{~m}$. Am-242m has a long half-life, therefore it builds up in the core, even though its production from neutron captures on Am-241 accounts only for $20 \%$ of the total Am-241 captures. More importantly, this minor actinide has by far the largest fast fission cross section among all the actinides present resulting in a significant increase of material reactivity. Table 14 shows that in the Am-241-Am-242m chain the fission cross section is increased 13 times and the fission to capture cross section ratio is 62 times higher. In addition, a small fraction of Am-241, which during core residence time decays via Am-242m to $\mathrm{Np}-238$, is eventually fissioned as either $\mathrm{Pu}-238$ or $\mathrm{Pu}-239$ - both nuclides being significantly more reactive than the original precursor, Am-241. All these features indicate that loading the core with a high content of Am-241 will result in a substantial reduction of 
reactivity degradation with burnup or possibly even in reactivity addition. Finally, it is to be noted that the spent LWR fuel contains an appreciable fraction of $\mathrm{Pu}-241$, which $\beta^{-}$decays to Am-241 with a half-life of 14.35 years. Hence, most of the Pu-241 will decay to Am-241 if transmutation of LWR spent fuel begins after more than 30 years of cooling. Considering the fact that most of the existing spent LWR fuel has been sitting in spent fuel pools for decades and will be transferred to intermediate repositories where it will be stored for many years before disposal and the fact that it will take another 10 to 20 years to develop and deploy transmuting systems, 50 years of decay time after the fuel is discharged from a reactor seems to be the time scale of interest. Thus, an appreciable content of Am-241 will build up in the LWR spent fuel before the transmutation process is implemented.

3. Another important aspect of fuels having a high Am-241 content is the delayed reactivity increase from Cm-242 decay. Cm-242 builds up in the core due to rapid Am-242 decay (note that $80 \%$ of neutrons captured in Am-241 yield Am-242 directly). Cm-242 has half life of 163 days, and contributes to reactivity buildup by decaying to the more reactive $\mathrm{Pu}-238$ (about 3 times higher fission to capture cross section than $\mathrm{Cm}-242$ ), which in turn produces $\mathrm{Pu}-239$ upon neutron capture with an even higher fission to capture ratio (8 times) than $\mathrm{Cm}$ 242 and almost 10 times higher than the original Am-241 progenitor. Therefore, the Cm-242 path can contribute to the flattening of the reactivity curve in the longer term, providing the potential for extension of the intra-refueling period. However, the increase of reactivity from the decay of $\mathrm{Cm}-242$ to $\mathrm{Pu}-238$ is an important safety aspect with respect to the maintenance of sufficient control margin in long shutdowns.

These three major transmutation paths lead, in a hard spectrum reactor, to the replacement of the original minor actinides from LWR spent fuel with a high-quality fissionable material. This provides the possibility to design an efficient MA burner core with a small reactivity swing in the absence of traditional fertile materials, provided that a sufficiently high fraction of MAs is present in the core.

\subsubsection{Analysis Tools}

Reactor physics analysis generally requires several successive steps involving few-group cross-section preparation for a homogenized cell and then a de-homogenization procedure to reconstruct the pin by pin power distribution from the homogeneous solution. All these steps can be accomplished in one comprehensive step with the Monte Carlo Method. In addition, the Monte Carlo Method provides a 3-D transport solution that is necessary for the high-leakage cores under investigation. Therefore, the Monte Carlo Neutron Photon Transport (MCNP) code MCNP4B [Briesmeister,1997], developed at Los Alamos National Laboratory, was selected as the main tool for neutron physics analysis, due to its availability, versatility and extensive verification for a variety of applications including heterogeneous lattices for fast reactors. Calculations of the effective delayed neutron fraction cannot be performed accurately using MCNP4B, because the differences between the spectra of delayed neutrons are not accommodated in this version of the code. Therefore, MCNP4C [Briesmeister, 2000] was obtained from the Radiation Safety Information Computational Center (RISCC) to be used for computation of effective delayed neutron fraction.

One MCNP limitation is its inability to calculate core depletion. To perform the burnup calculations, the ORIGEN2.1 code [Croff, 1980], developed at Oak Ridge National Laboratory (ORNL), has been chosen. The coupling between MCNP and ORIGEN2.1 has been attained through the set of coupling utility programs assembled in the MOCUP code [Moore et. al., 1995]. 
Sixty two fission products accounting for $95 \%$ of the absorptions of all the fission products and 37 actinides were tracked in all MOCUP calculations. Some burnup calculations were also performed using MONTEBURNS 1.0 [Poston and Trellue, 1999] - another MCNP-ORIGEN2 coupling program developed at LANL, which in comparison with MOCUP, offers benefits of easier use and CPU time savings due to dynamic tracking of important fission products.

\subsubsection{Achievement of Negative Coolant Void Worth}

The design of the MA burner core is based on the streaming fuel assemblies used in the analysis of the MIT/INEEL critical actinide burner [Hejzlar et. al., 2000, 2001a], shown in Figure 17 in Section 3.3.2 above. The assembly contains $21 \times 21$ positions with 240 fuel rods, 40 peripheral square streaming tubes and a $5 \times 5$ voided box in the fuel assembly center. The streaming tubes are filled with gas and sealed. The voided tubes allow streaming of neutrons in both the radial and axial directions. In addition to their neutron streaming function, they also provide structural support, making the elimination of the tie rods possible. The peripheral tubes also help confine molten fuel in the event of local coolant blockage.

The fuel is a metal alloy of zirconium matrix, minor actinides and plutonium, arranged in a square pitch. Plutonium and minor actinide vectors correspond to those of PWR discharge fuel after 50 years of cooling, but the ratio of MA to $\mathrm{Pu}$ is much higher. The cladding and structural material was assumed to be made of special ferritic-martensitic steel with 12percent chromium, designated EP-823, developed by the Russians for their lead-bismuth cooled reactors. Lead- was selected as a bond between the fuel pellets and stainless steel cladding. The core containing 157 fuel assemblies was assumed to operate at 1800MWth (average linear power of $367 \mathrm{~W} / \mathrm{cm}$ ). The MABR core layout is schematically shown in Figure 39. The major design parameters used in the analyses are summarized in Table 15.

Table 15. Design parameters of neutron transparent core with streaming FAs

\begin{tabular}{|l|l|}
\hline Design parameter & Value \\
\hline Fuel pellet outside diameter & $8.64 \mathrm{~mm}$ \\
\hline Fuel composition & $\begin{array}{l}\text { TRU }=39.6 \mathrm{wt} \%, 34 \mathrm{wt}^{*}{ }^{*}, \text { rest zirconium matrix, } \\
\text { MA/TRU }=59 \mathrm{wt} \%\end{array}$ \\
\hline Pu vector $(\mathrm{Pu} 48 / \mathrm{Pu} 49 / \mathrm{Pu} 40 / \mathrm{Pu} 41 / \mathrm{Pu} 42)$ & $1 / 63 / 29 / 1 / 6 \mathrm{wt} \%^{* *}$ \\
\hline MA vector $(\mathrm{Np} 237 / \mathrm{Am} 241 / \mathrm{Am} 243 / \mathrm{Cm} 244)$ & $30 / 64.5 / 5 / 0.5 \mathrm{wt} \%{ }^{* *}$ \\
\hline Gap thickness (lead bond) & $0.2 \mathrm{~mm}$ \\
\hline Cladding thickness & $0.63 \mathrm{~mm}$ \\
\hline Pin cladding outer diameter & $10.3 \mathrm{~mm}$ \\
\hline Pitch & $12.55 \mathrm{~mm}$ \\
\hline P/D & 1.2 \\
\hline Heated core length & $1.3 \mathrm{~m}$ \\
\hline Gas plenum height & $1.3 \mathrm{~m}$ \\
\hline Number of fuel assemblies & 157 \\
\hline
\end{tabular}

"Reference case for the initial core; the outer core region contains $39.6 \mathrm{wt} \%$ TRU fuel; the inner core region is loaded with $34 \mathrm{wt} \%$ TRU-enriched fuel (37wt $\%$ TRU on core-average basis).

${ }^{* *}$ LWR spent fuel $\left(\mathrm{B}_{\mathrm{d}}=33 \mathrm{MWd} / \mathrm{kg}\right)$ after 50 years of cooling. 


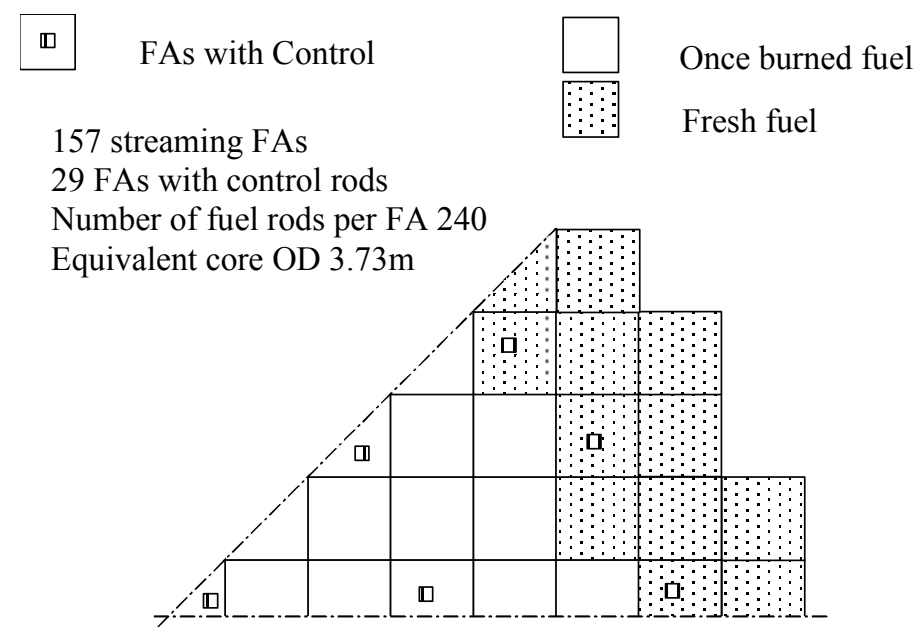

Figure 39. Schematic of MABR core layout

\subsubsection{Burnup Performance and Minor Actinide Destruction Rate}

The effect of minor actinide loading on reactivity in the streaming core is plotted in Figure 40. These curves were calculated using a $1 / 8^{\text {th }}$ core MOCUP model at a linear heat rate of $240 \mathrm{~W} / \mathrm{cm}$. The "ABR" trace depicts the fuel composition of a pure actinide burner [Hejzlar et. al., 2000, 2001a] where the major fissile material is plutonium. As the MA to $\mathrm{Pu}$ ratio is increased in the TRU fuel, dramatic decreases in reactivity swing take place, culminating in a significant reactivity increase when the MA fraction exceeds $80 \mathrm{wt} \%$. This rise in reactivity takes place due to the conversion of the major MAs, Np-237 and Am-241, to their successors, which have significantly higher fission-to-capture cross section ratios. Figure 40 also indicates that there exists a MA loading which would yield a small reactivity swing. Such a fuel contains, for the studied core, about $37 \%$ wt $\%$ TRU/TRU $+Z r$ with $59 w \%$ MA/TRU loading. Figure 41 , which was generated for a reference pin linear heat rate of $367 \mathrm{~W} / \mathrm{cm}$, shows that the reactor could be operated at full power for 700EFPDs (selected to give a refueling interval compatible with current utility practice) at a very small reactivity swing.

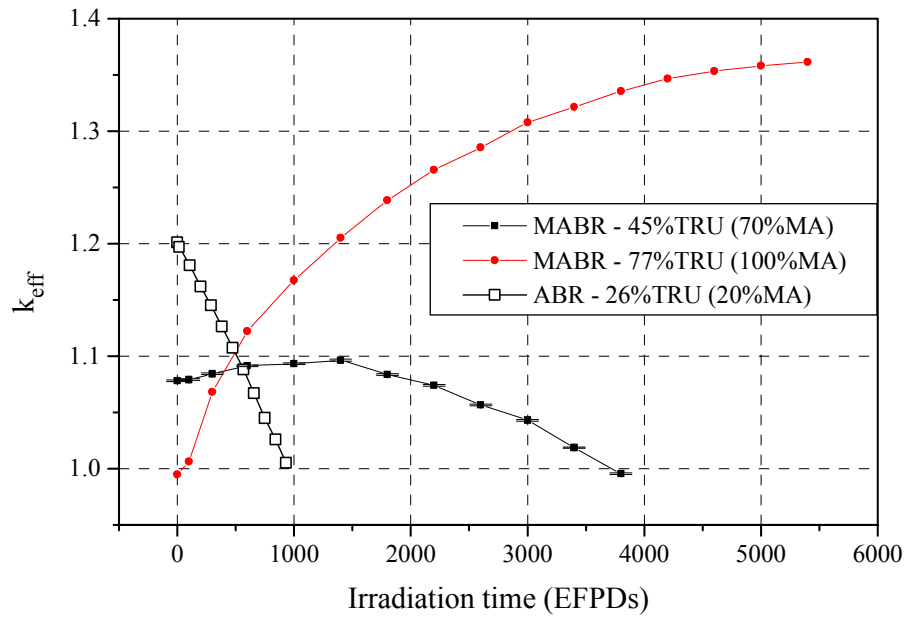

Figure 40. The effect of minor actinide loading on reactivity burnup curve in actinide burning reactors 


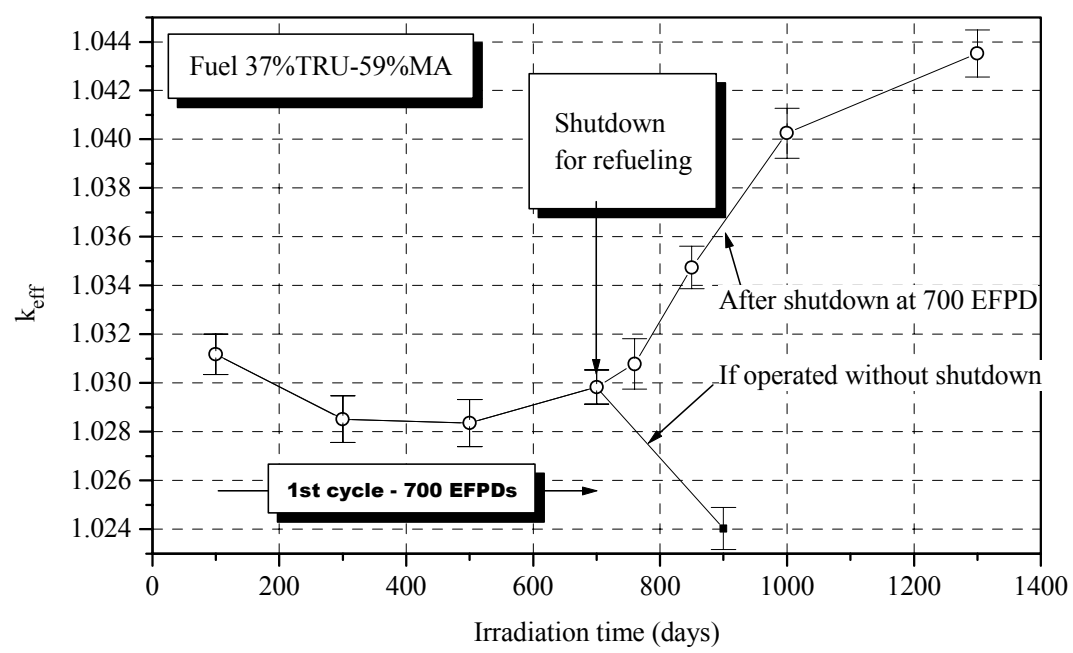

\section{Figure 41. Operation with low reactivity swing and effect of $\mathrm{Cm}-242$ decay on reactivity after prolonged shutdown}

An important safety aspect that needs to be considered for these fuels with high Am-241 content is the delayed reactivity effect from $\mathrm{Cm}-242$ decay to more reactive $\mathrm{Pu}-238$, as discussed earlier. This is also shown on Figure 41 where the upper curve after 700 EFPDs was generated by letting the fuel decay at zero power and keeping all control-rod drives withdrawn from the core. The important safety aspect is the maintenance of sufficient shutdown margin for long downtimes. Several options are possible to assure safety for longer shutdowns. For example, a larger number of control rod drives that are out of the core during normal operation and are inserted and secured in the in-core position only after the reactor is shut down can be employed. An interesting option is to remove some fuel assemblies from the core and replace them with fresh fuel assemblies. The old assemblies can be placed in the plant refueling pool for a long cooling time (note that this fuel is deeply subcritical in water and corrosion is not an issue at low temperatures) and after several years reused to boost reactivity, if the assembly fluence limit has not been reached. Actually, this effect allows new options for fuel management by reusing onceburned assemblies. For higher MA loadings, burning will be limited only by fuel and cladding durability, offering a considerably less expensive mode of recycling, involving primarily fuel refabrication without chemical/electrochemical reprocessing and without intentional fission product removal.

The net destruction rate of all actinides (including plutonium) in a $1800 \mathrm{MWth}$ core is $660 \mathrm{~kg} / \mathrm{EFPY}$, or $42 \mathrm{~kg} / \mathrm{TWh}$. This is comparable to the incineration rate of all actinides in an ATW system or that of the dedicated fast cores for actinide transmutation in a pure MA recycling mode investigated by French researchers [Tommasi and Massara, 1999]. However, the composition of the discharged fuel exhibits a high fraction of $\mathrm{Pu}-238$ (13w/o in total $\mathrm{Pu}$ after 700 EFPD - at a burnup of $141 \mathrm{MWd} / \mathrm{kgHM}$ ). Thus, these results confirm that the objective of achieving high minor actinide destruction rate comparable to that of the ATW system while maintaining small reactivity swing can be accomplished.

Tables 16 shows actinide composition and neutron balance of the heavy metals for the reference case with 59wt\% MA in the TRU (37\%TRU) after an irradiation time of 700 EFPD (1batch refueling, for 2-batch refueling the exposure time would be approximately $4 / 3$ longer). Note that core-smeared number densities are shown (per core volume including the gas plenum and all streaming voids). The fractional number densities are normalized per the total number density of actinides in the core and the fractional capture and fission rates are normalized per the 
total absorption rate in the actinides. Heavy metals with fractional contribution less than $10^{-4}$ are not shown. Table 16 can be used to judge the contribution of the individual actinides to the reactivity. It can be seen that Pu-239 is the most important fission nuclide followed by Am-241, $\mathrm{Np}-237, \mathrm{Pu}-240, \mathrm{Pu}-238$, and Am-242m, which has the highest number of neutrons per fission, thus contributing to reactivity more than the loss per source neutron would suggest.

Table 16. Number density and neutron balance in heavy metal nuclides - case of 37\%TRU/59\%MA after 700EFPDs (141MWd/kgHM)

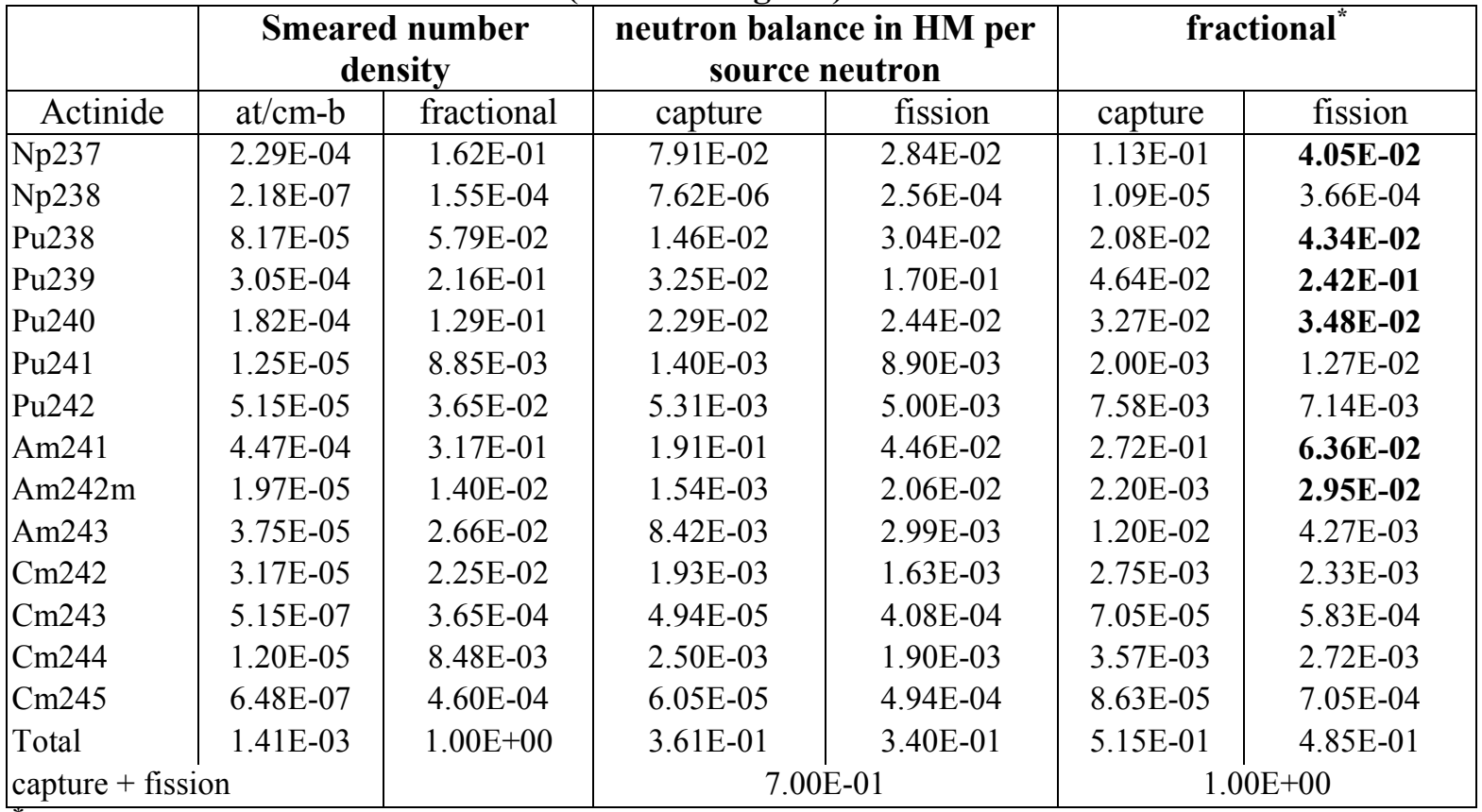

Normalized to total absorption rate in all heavy metal nuclides in the fuel.

Table 17 presents the same characteristics as Table 16, but for the case of 100\%MA loading. Note that the burnup is not reactivity limited in this case, hence the composition was extracted at a long irradiation time of 15 EFPYs, yielding a burnup of $246 \mathrm{MWd} / \mathrm{kgHM}$ (the core contains 26.4tMT of heavy metal, i.e., a $77 \% \mathrm{TRU}$ and $23 \mathrm{wt} \%$ zirconium matrix). The key nuclides driving the reactivity include the Pu-238, Np-237, Am-241 and Am-242m. This is in agreement with the reasoning outlined in Section 3.4.3. The drawback of the very high MA loading is the relatively large amount of curium, which will lead to an appreciable reduction of the delayed neutron fraction. 
Table 17. Number density and neutron balance in heavy metal nuclides - case of $100 \% \mathrm{MA}$ loading after 15EFPY (246MWd/kgHM)

\begin{tabular}{|l|c|c|c|c|c|c|}
\hline & \multicolumn{2}{|c|}{ Number density } & \multicolumn{2}{c|}{$\begin{array}{c}\text { Neutron balance in HM per } \\
\text { source neutron }\end{array}$} & \multicolumn{2}{c|}{ Fractional* $^{*}$} \\
\hline Actinide & at/cm-b & fractional & capture & fission & capture & fission \\
\hline U234 & $4.88 \mathrm{E}-05$ & $1.42 \mathrm{E}-02$ & $3.01 \mathrm{E}-03$ & $4.10 \mathrm{E}-03$ & $3.62 \mathrm{E}-03$ & $4.93 \mathrm{E}-03$ \\
Np237 & $1.11 \mathrm{E}-03$ & $3.24 \mathrm{E}-01$ & $1.50 \mathrm{E}-01$ & $9.61 \mathrm{E}-02$ & $1.81 \mathrm{E}-01$ & $\mathbf{1 . 1 6 E - 0 1}$ \\
Np238 & $2.19 \mathrm{E}-07$ & $6.37 \mathrm{E}-05$ & $2.87 \mathrm{E}-06$ & $9.67 \mathrm{E}-05$ & $3.45 \mathrm{E}-06$ & $1.16 \mathrm{E}-04$ \\
Pu238 & $6.84 \mathrm{E}-04$ & $1.99 \mathrm{E}-01$ & $5.08 \mathrm{E}-02$ & $1.48 \mathrm{E}-01$ & $6.11 \mathrm{E}-02$ & $\mathbf{1 . 7 9 E - 0 1}$ \\
Pu239 & $6.78 \mathrm{E}-05$ & $1.97 \mathrm{E}-02$ & $2.63 \mathrm{E}-03$ & $2.01 \mathrm{E}-02$ & $3.16 \mathrm{E}-03$ & $2.42 \mathrm{E}-02$ \\
Pu240 & $8.28 \mathrm{E}-05$ & $2.41 \mathrm{E}-02$ & $4.17 \mathrm{E}-03$ & $7.52 \mathrm{E}-03$ & $5.02 \mathrm{E}-03$ & $9.04 \mathrm{E}-03$ \\
Pu241 & $3.54 \mathrm{E}-06$ & $1.03 \mathrm{E}-03$ & $1.57 \mathrm{E}-04$ & $1.18 \mathrm{E}-03$ & $1.89 \mathrm{E}-04$ & $1.42 \mathrm{E}-03$ \\
Pu242 & $9.97 \mathrm{E}-05$ & $2.90 \mathrm{E}-02$ & $3.99 \mathrm{E}-03$ & $6.63 \mathrm{E}-03$ & $4.80 \mathrm{E}-03$ & $7.97 \mathrm{E}-03$ \\
Am241 & $8.53 \mathrm{E}-04$ & $2.48 \mathrm{E}-01$ & $1.52 \mathrm{E}-01$ & $6.08 \mathrm{E}-02$ & $1.82 \mathrm{E}-01$ & $7.32 \mathrm{E}-02$ \\
Am242m & $1.05 \mathrm{E}-04$ & $3.07 \mathrm{E}-02$ & $2.60 \mathrm{E}-03$ & $5.25 \mathrm{E}-02$ & $3.13 \mathrm{E}-03$ & $\mathbf{6 . 3 2 E}-02$ \\
Am243 & $1.82 \mathrm{E}-04$ & $5.30 \mathrm{E}-02$ & $1.44 \mathrm{E}-02$ & $1.04 \mathrm{E}-02$ & $1.74 \mathrm{E}-02$ & $1.25 \mathrm{E}-02$ \\
Cm242 & $1.47 \mathrm{E}-05$ & $4.29 \mathrm{E}-03$ & $2.85 \mathrm{E}-04$ & $5.85 \mathrm{E}-04$ & $3.43 \mathrm{E}-04$ & $7.03 \mathrm{E}-04$ \\
Cm243 & $5.81 \mathrm{E}-07$ & $1.69 \mathrm{E}-04$ & $1.95 \mathrm{E}-05$ & $2.21 \mathrm{E}-04$ & $2.35 \mathrm{E}-05$ & $2.66 \mathrm{E}-04$ \\
Cm244 & $1.51 \mathrm{E}-04$ & $4.41 \mathrm{E}-02$ & $1.29 \mathrm{E}-02$ & $1.57 \mathrm{E}-02$ & $1.56 \mathrm{E}-02$ & $1.89 \mathrm{E}-02$ \\
Cm245 & $2.27 \mathrm{E}-05$ & $6.61 \mathrm{E}-03$ & $7.74 \mathrm{E}-04$ & $8.38 \mathrm{E}-03$ & $9.31 \mathrm{E}-04$ & $1.01 \mathrm{E}-02$ \\
Total & $3.43 \mathrm{E}-03$ & $9.99 \mathrm{E}-01$ & $3.98 \mathrm{E}-01$ & $4.33 \mathrm{E}-01$ & $4.78 \mathrm{E}-01$ & $5.21 \mathrm{E}-01$ \\
capture + fission & & & & & & $1.00 \mathrm{E}+00$
\end{tabular}

*Normalized to total absorption rate in all heavy metal nuclides in the fuel

\subsubsection{Coolant Reactivity Performance}

Figure 42 plots the reactivity changes as a function of coolant density for the core with 157 regular square bundles ("No streaming" curve) and the core with the same fuel rod and P/D geometry, but with the streaming fuel assemblies shown in Figure 17. The calculations were performed for beginning-of-life conditions and the coolant density changes were introduced only in the core region (including the fuel gas plenum) while keeping the coolant density in the lower plenum, downcomer and above the core at its original value. Thus, the case with zero coolant density represents the coolant void worth, as typically calculated for fast breeder reactor designs when the whole core is assumed voided. If the regular fuel assemblies are used, the core exhibits a large positive coolant void worth of about $+15 \$$. The reasons for a large reactivity increase upon coolant voiding in cores with high MA loadings were discussed earlier. The introduction of the streaming assemblies significantly improves the coolant void worth performance through enhanced neutron leakage. The coolant void worth for whole core voiding is negative $(-3.7 \$)$. This compares very favorably with other designs [Fujimura et. al, 1993,Tommasi et. al., 1998] that exhibit positive coolant void worth for even smaller MA loadings. 


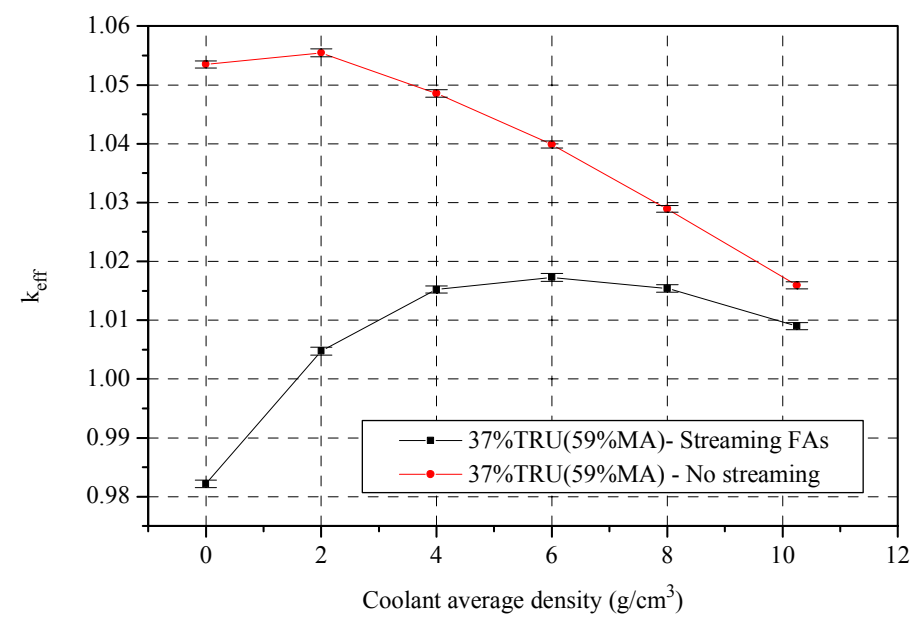

Figure 42. Changes of reactivity with coolant average density

However, a range of coolant core-average densities (between 3 to $10.25 \mathrm{~g} / \mathrm{cm}^{3}$ ) with positive reactivity, which provides a venue for reactivity insertions, still exists for the streaming fuel assemblies with high MA loadings. The largest reactivity increase $(+3.2 \$)$ is reached at a coolant density of about $6 \mathrm{~g} / \mathrm{cm}^{3}$. However, considering the fact that there will be relatively small coolant density changes with temperature and the very high lead-bismuth boiling point $\left(1725^{\circ} \mathrm{C}\right)$, any coolant core-wide reactivity additions due to coolant density changes will be small. An increase of the core-average coolant temperature from the reference value of $450^{\circ} \mathrm{C}$ to $750^{\circ} \mathrm{C}$ (cladding temperature limit) brings a reactivity insertion of only $0.4 \$$. This gives a value for the coolant density coefficient of $+0.16 \mathbb{\$} /{ }^{\circ} \mathrm{C}$ - slightly less than the sodium density coefficient of an IFR reactor. Optimization of the streaming assembly design can be pursued in the future to further reduce the coolant temperature coefficient, should this value not be sufficient to attain selfregulation characteristics during unprotected transients.

\subsubsection{Core Power Distribution}

Figure 43 shows that the proposed core has small radial power peaking (averaged over all fuel pins within each assembly). This is due to the flat neutron flux profile across the core (see Figure 44) and enrichment zoning where fresh fuel is placed in core peripheral assemblies. This flat neutron flux profile is a consequence of a large mean free path and very strong neutronic coupling. The large mean free path and tight coupling have crucial impacts on neutron physics. First, the instabilities in the flux distribution, which can be a problem in large fast reactor cores [Shirakata et. al., 1999] are eliminated and the proposed core concept can be scaled up without concerns about significant changes in the radial flux/power shapes in response to perturbations. Secondly, the space-dependency of the neutron kinetics is significantly reduced and a point kinetics analysis should provide accurate results. The proposed core should be highly stable against the above phenomena and complex measures to mitigate both the instability in flux distribution due to perturbation and the space dependency of kinetics will not be needed, simplifying the design. Eventually, of course, this will have to be confirmed by transient calculations.

The pin power distribution within the hot fuel assembly is depicted in Figure 45. Since the control rods in the center of the fuel assembly depress the flux at this location, the hot pin is located in the corner channel. However, this channel is also challenged thermal hydraulically because it has a somewhat reduced flow due to the presence of the wall of streaming peripheral 
channels. Therefore, measures to improve flow in this channel will be required. The axial power profile also exhibits small peaking, as shown on Figure 46.

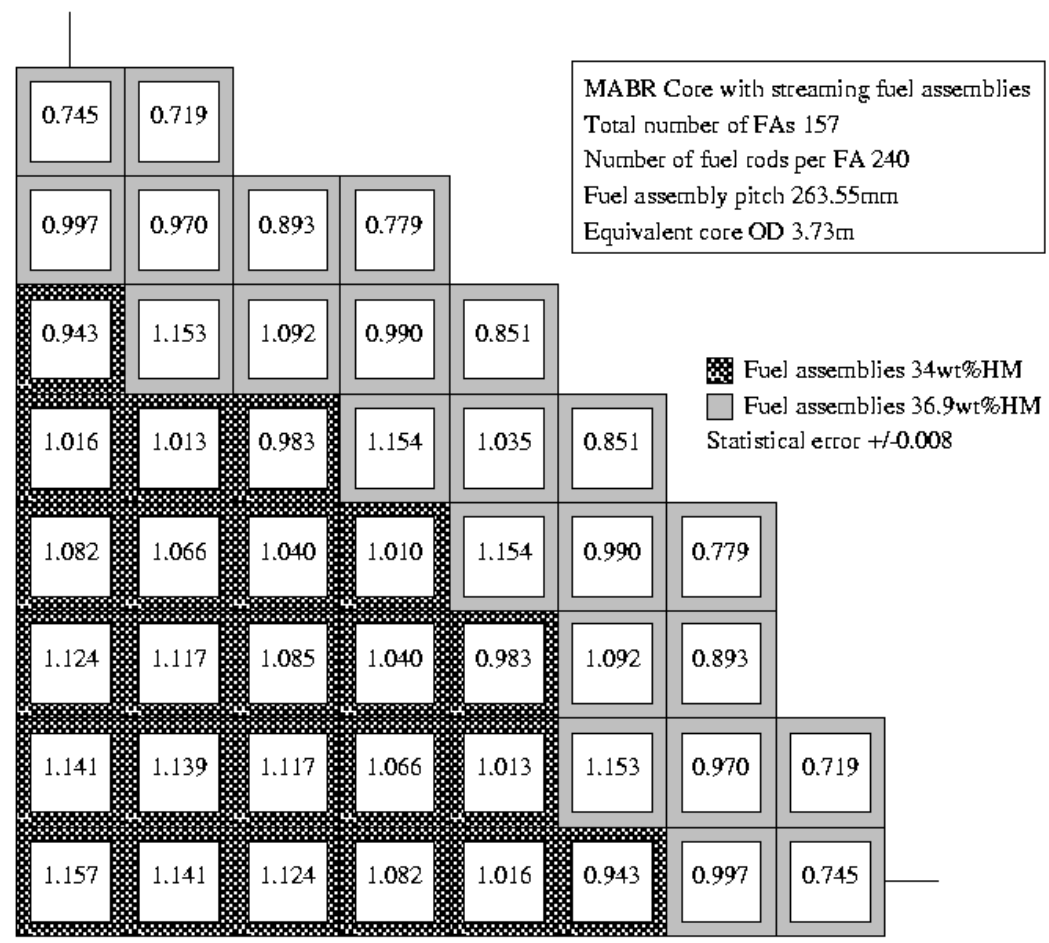

Figure 43. Fuel assembly-averaged power distribution at beginning-of-life

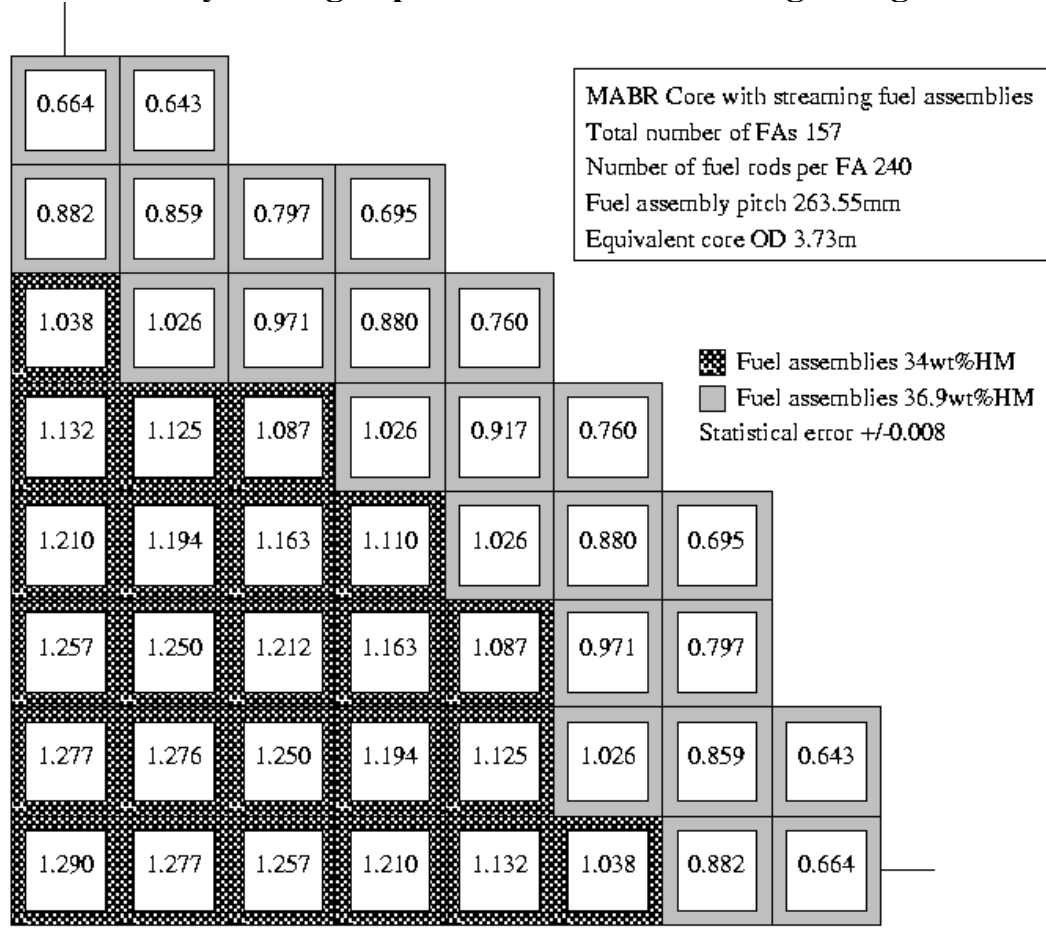

Figure 44. Fuel assembly-averaged neutron flux distribution at beginning-of-life 


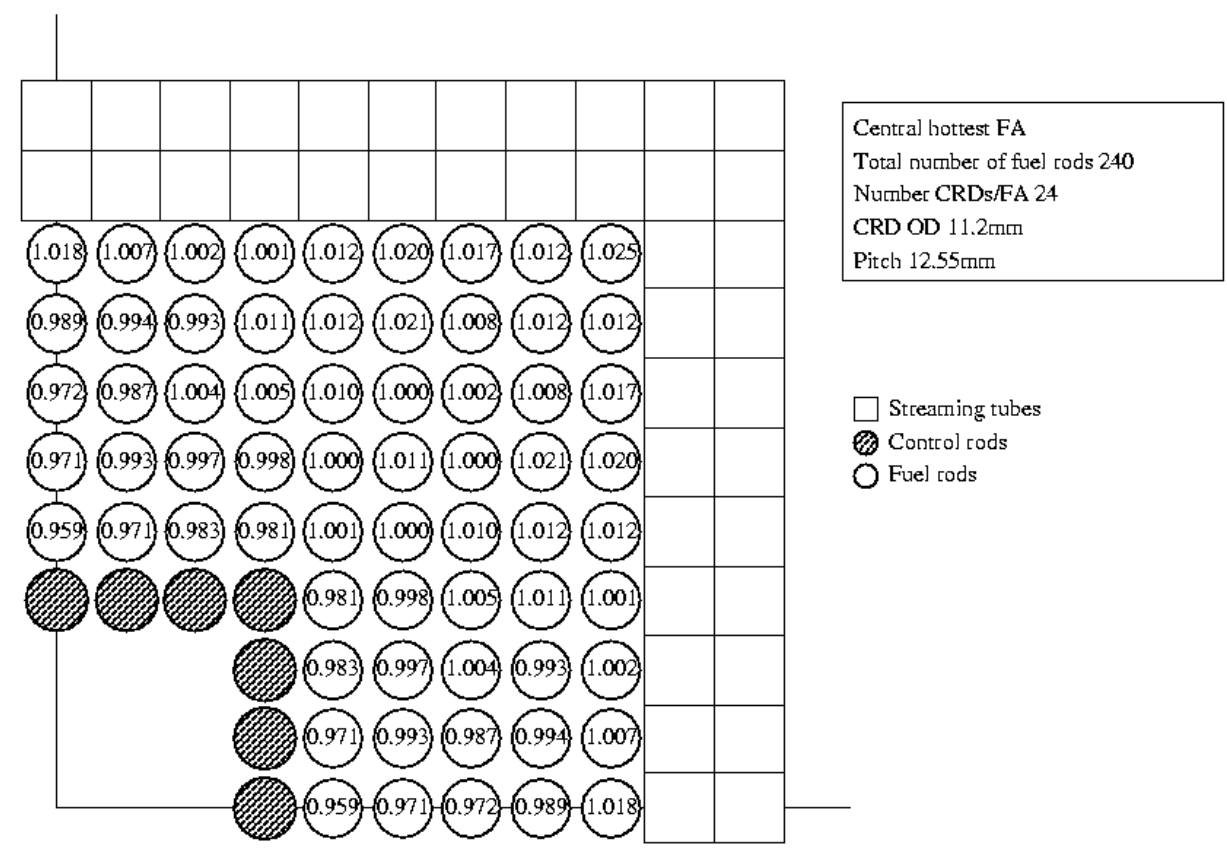

Figure 45. Pin power distribution in the hot fuel assembly at beginning-of-life

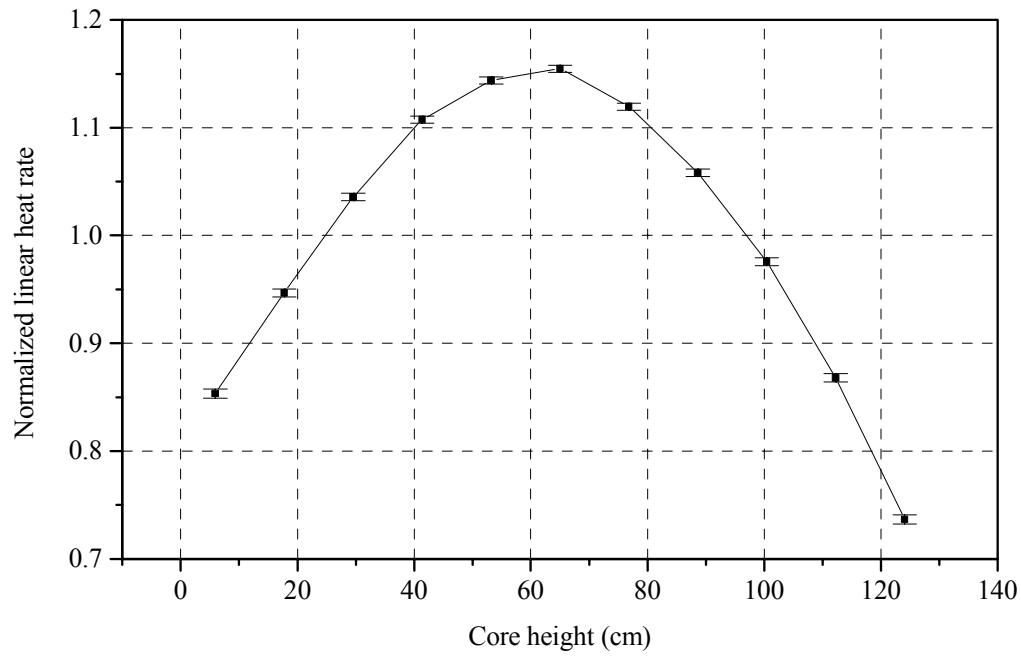

Figure 46. Axial power profile in a hot fuel assembly

\subsubsection{Fuel Temperature Coefficient}

It is desirable that fuel temperature coefficient be prompt and negative to limit the reactivity increase in transients leading to fuel temperature rise. The two key components of the fuel temperature feedback involve the Doppler coefficient thermal expansion coefficient, which will be discussed in Sections 3.4.9.1 and 3.4.9.2, respectively. Approaches to substitute for the lack of negative fuel temperature feedbacks by other prompt mechanisms are investigated in Section 3.4.9.3. 


\subsubsection{Doppler coefficient}

The Doppler coefficient was calculated using the MCNP code with the UTXS temperature dependent cross section libraries imported from the University of Texas [Abdelrahman and Abdurrahman, 1998]. Because these libraries do not contain some minor actinides, specifically $\mathrm{Np}-237$, Am-241, and Cm-244, the temperature dependent libraries for these nuclides generated at INEEL, as discussed in Section 3.1, were used.

The results for the beginning-of-life core using an MCNP4B model of $1 / 8^{\text {th }}$ of the core (see Table 18) show that the Doppler coefficient is about zero, i.e., within the statistical error bounds of the MCNP calculations. These results are somewhat uncertain because of the uncertainties in the temperature dependent libraries for the Am-241 and Np-237, which need verification, and also because of the uncertainties associated with the lack of temperature dependent libraries with resonance probability tables.

Table 18. Doppler coefficients for the fresh core with 37wt\%TRU and 59wt\%Mas.

\begin{tabular}{|l|l|l|}
\hline Case & $\mathbf{k}_{\text {eff }}$ & Doppler $(\mathbf{c} / \mathbf{K})^{*}$ \\
\hline $\mathrm{T}=300 \mathrm{~K}$ & $1.00293 \pm 0.0003$ & \\
\hline $\mathrm{T}=1154 \mathrm{~K}$ & $1.00294 \pm 0.0003$ & \\
\hline Doppler coefficient & & $+0.0005 \pm 0.02$ \\
\hline
\end{tabular}

Assumes $\beta_{\text {eff }}=0.0021$, as calculated in section 3.3.10, the Doppler coefficient is the linearized average value between temperatures 300 and $1154 \mathrm{~K}$.

To explore the effects of the unresolved resonances on the core reactivity, MCNP4C with the latest libraries, which contain the unresolved resonances data to be used with the "Probability Table Method", was run. The libraries with unresolved resonances at a temperature of $300 \mathrm{~K}$ are available for all fuel nuclides present in the fresh core, except for $\mathrm{Cm}-244$, which represents only very small fraction of the TRU loading $(\sim 0.2 \mathrm{at} \%)$. The effect of incorporating the unresolved resonances into the calculations is shown in Table 19. Including the calculations for the unresolved resonances increases the reactivity by only $0.26 \$$, which still within the MCNP error bound. This small effect is the consequence of a very hard spectrum where most of the neutrons are above the upper neutron energy limit for the unresolved resonance data.

This small increase is insignificant in terms of reactivity value. However, because the reactivity increase indicates an increase in the fission to capture ratio, the treatment of unresolved resonances may shift the Doppler effect to more positive values than those calculated based on the results from libraries without the unresolved resonance data. For more accurate estimates of the Doppler effect, unresolved resonances should be included in the Doppler calculations. This indicates the need to generate new sets of temperature dependent libraries with unresolved resonance data.

Table 19. Effect of the inclusion of unresolved resonance probability tables on reactivity.

\begin{tabular}{|l|l|}
\hline Case (all control rod drives out, streaming core) & $\mathrm{k}_{\mathrm{eff}}$ \\
\hline Run without unresolved resonances (ENDF-VI libraries 60c) & $1.0019 \pm 0.0006$ \\
\hline Run with unresolved resonances (ENDF-VI libraries 61c)* & $1.0024 \pm 0.0006$ \\
\hline
\end{tabular}

* Except for $\mathrm{Cm} 244$, where the 60c library was used due to the unavailability of a library with unresolved resonances for this nuclide 


\subsubsection{Fuel Thermal Expansion Coefficient}

A full core model of a streaming core was used to calculate the thermal expansion effect using MCNP4B in a similar manner as described in Hejzlar et. al., [2000]. The results yielded about zero thermal expansion coefficient, i.e., within the MCNP statistical error bounds. Thus, the fuel temperature feedback, which includes both the Doppler and fuel thermal expansion effects is around zero - a significant challenge to be overcome in MABR cores with high MA loadings.

\subsubsection{Measures to Enhance Fuel Temperature Feedback}

Because the lack of prompt fuel temperature feedback in a MABR core poses a significant safety issue, various means to obtain prompt negative feedback during transients with a reactivity increase were explored.

The first possibility is to add a resonance absorber, such as hafnium, to the fuel. However, this method is not effective for this hard-spectrum core because most of the resonance absorbers do not have resolved resonance peaks above $10^{4} \mathrm{eV}$ where the majority of the neutron population occurs. Therefore, most of the resonance captures must occur in the low energy tail. To maintain this tail, some moderator must be present in the core and a zirconium matrix with a large volume fraction of zirconium, which is the third lightest nuclide in the core (after the boron and carbon in the control rod drives), appears to be an important scatterer. Therefore, replacing the zirconium with heavier absorbers is not an efficient method to increase the magnitude of the Doppler feedback. These results are the same as obtained earlier for the actinide burner reactor design [Hejzlar et. al., 2000].

The only absorber with a resonance peak at high energy is Li-6, which has a large $(n, \alpha)$ resonance at $\sim 0.2 \mathrm{MeV}$. The lead-based cooled reactor peaks are almost coincident with the Li- 6 resonance energy. Therefore, the importance of this resonance peak is high and it was hoped that its broadening with a temperature increase may lead to an appreciable reactivity reduction. To overcome problem of the low melting point of the lithium, lithium oxide, with a melting point of $1600^{\circ} \mathrm{C}$ and specific density of $2.013 \mathrm{~g} / \mathrm{cc}$, enriched with Li-6 was used. Two approaches were evaluated - (i) $\mathrm{Li}_{2} \mathrm{O}$ Doppler enhancers placed around the periphery of the central voided region of streaming fuel assemblies and (ii) mixing $\mathrm{Li}_{2} \mathrm{O}$ directly with fuel. However, no appreciable improvement in the reactivity response to the temperature rise over the reference case was achieved. On the contrary, the reactivity slightly increased. Edit of the Li-6 cross section showed that the increase in the absorption cross section upon a temperature increase from 300 to $800 \mathrm{~K}$ was negligible (within the statistical zero band). In other words, because the resonance peak is relatively broad and low, the additional reactivity increase from the broadening at higher temperatures is negligible, even though $\mathrm{Li}_{2} \mathrm{O}$ absorbs a relatively large neutron fraction (reduction of $\mathrm{k}_{\text {eff }}$ from 1.012 to 0.9681 ) prior to the temperature change. On the other hand, a slightly higher fission to capture ratio and a smaller leakage was observed for the high-temperature case, which caused a shift of the Doppler coefficient to a more positive value.

Another possibility is to soften the spectrum by adding a scatterer to the fuel, but this option was not pursued because it leads to an increase in the capture to fission ratios in the TRUs, reducing the effectiveness of the minor actinide burning.

A final approach explored was to use prompt gamma and neutron heating in thermally expandable materials, which expand into the core upon the increased heating, introducing negative reactivity. The voided region in the center of fuel assemblies is a good place for these 
devices. However, they must be capable of withstanding high temperatures because of both the high coolant temperatures and the radiation heating. A number of candidate materials have been explored, such as tungsten, hafnium, tantalum, rhenium, boron-nitride and hafnium-carbide. However, MCNP analyses have shown that only a relatively small negative reactivity is introduced because the thermal expansion of these devices is not sufficient to provide a feedback of desirable magnitude. These efforts lead to the conceptualization of the reactivity feedback device (RFD) shown schematically in Figure 47 [Driscoll and Hejzlar, 2001]. The RFDs are located in selected streaming fuel assemblies around the periphery of the central streaming region, as shown on Figure 48. Fuel assemblies equipped with RFDs are indicated in Figure 49.

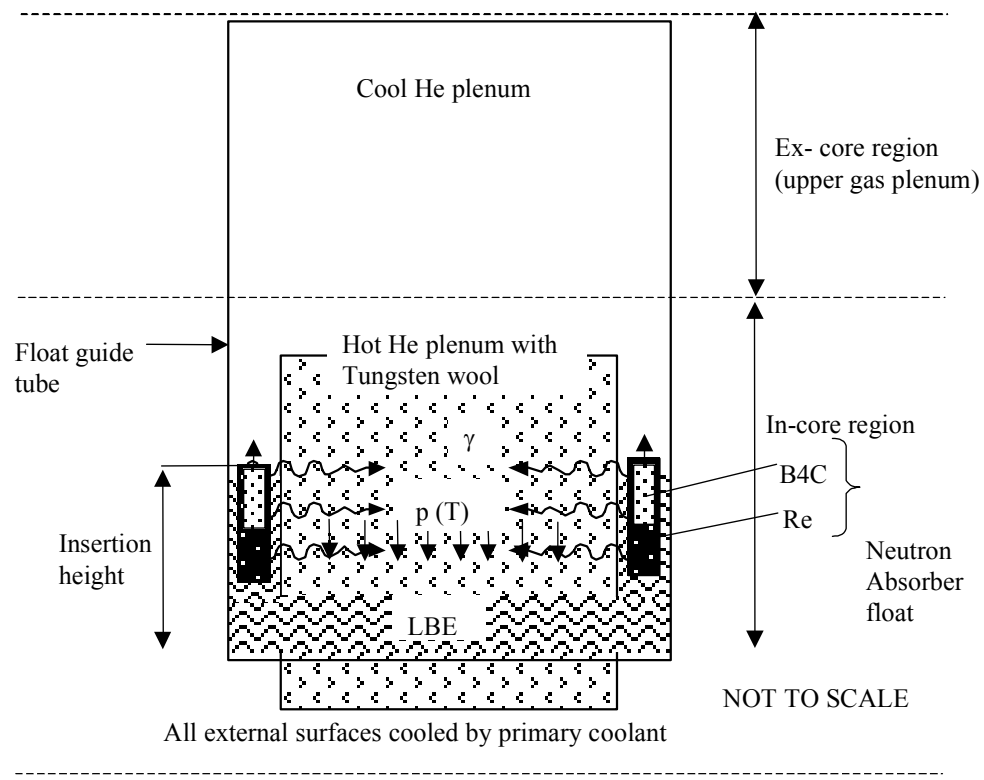

Figure 47. Schematic of self-actuated Reactivity Feedback Device (from Driscoll and Hejzlar 2001).

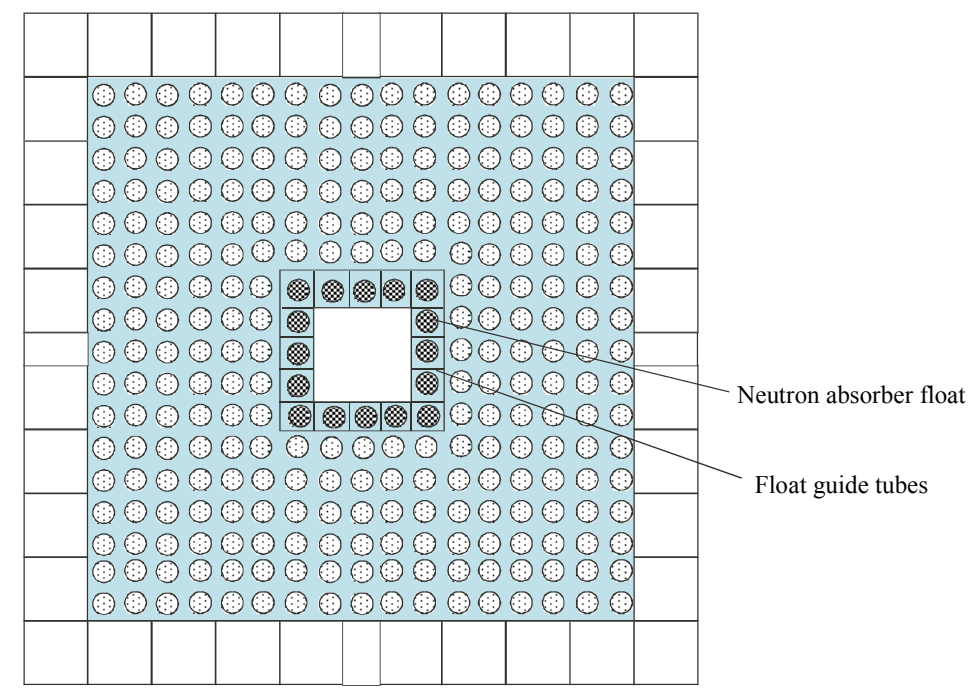

Figure 48. Streaming fuel assembly with neutron absorber floats - top view. 


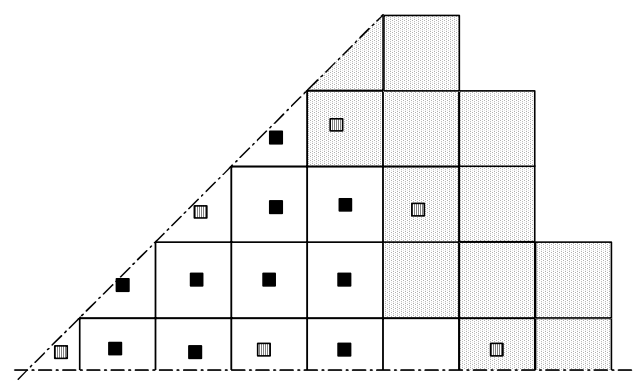

\section{Figure 49. Layout of control rods and RFDs in the MABR core.}

The RFD consists of an in-core flask containing helium gas, tungsten wool, and a small reservoir of lead-bismuth that communicates with the vertical tubes the housing neutron absorber floats. The upper part of these guide tubes contains helium gas that is vented into a separate, cooler ex-core helium gas plenum. The principle of operation is as follows:

- The tungsten wool, hence the helium gas in the in-core plenum, is heated by gammas, and loses heat to the walls by convection and conduction (radiation is feeble for monatomic gases and, in any event, intercepted by the tungsten wool). An energy balance determines the gas temperature, hence pressure: here $10 \mathrm{~atm}$. The energy loss rate can be adjusted by using xenon or a gas mixture in place of helium. The tungsten wool mass, here 1 vol.\% wool, can also be increased to increase gamma heating and further retard convection; alternatively, a Dewar flask could be used in place of the additional wool.

- An increase in core power causes a virtually instantaneous increase in gamma flux, hence gas heatup: the thermal time constant of the tungsten filaments and their surrounding gas film is about $40 \mu \mathrm{sec}$.

- The increased gas temperature is associated with an increased gas pressure, which forces more liquid metal into the float guide tubes: lead-bismuth (density $=10.25 \mathrm{~g} / \mathrm{cc}$ ) will rise about $100 \mathrm{~cm}$ per atmosphere increase in pressure.

- This lifts the floats higher into the core above their equilibrium position at HFP (at maximum differential worth - about one-quarter insertion).

- The increased neutron absorption produces a negative reactivity feedback.

- The surrounding primary coolant keeps all boundaries at nearly constant temperature. The ex-core helium has very low energy absorption, plus good heat transfer (for a gas) which helps maintain constant temperature and pressure (provided that the plenum volume greatly exceeds guide tube volume).

The neutron absorber floats are thin metal tubes that contain a rhenium slug (density = $21 \mathrm{~g} / \mathrm{cc}, 1067 \mathrm{~g}$ per assembly), as a high capture cross section ballast, and an upper section of ${ }^{10} \mathrm{~B}_{4} \mathrm{C}$ pellets (at $2.38 \mathrm{~g} / \mathrm{cc}, 136 \mathrm{~g}$ per assembly). The tops and bottoms of the floats are rounded to guard against sticking inside the riser tubes. The top of the float is vented through a porous disc into the cool helium plenum to allow the helium produced during the B-10 captures to escape. The absorber float is cooled by conduction through the $\mathrm{Pb}-\mathrm{Bi}$ bath, and guide tube wall, into the ambient lead-bismuth primary coolant. 
Whole-core Monte Carlo calculations for RFDs substituted for the central void tube in $20 \%$ of the streaming fuel assemblies in a MABR core (as shown on Figure 49) were performed to evaluate the efficacy of the RFDs. The reactivity worth of the RFDs is plotted as a function of the float insertion in Figure 50. Interestingly, the reactivity is slightly increased during the first $10 \mathrm{~cm}$ displacement before it is reduced. Figure 51 shows that fraction of neutrons captured in the Re half decreases monotonically, while in the B-10 it is slightly reduced at first and then increases. Competing flux and spectrum effects at the core bottom boundary can explain this behavior. When the float is below the core, it resides in a softer spectrum and because the capture cross-section decreases with neutron energy for both the B-10 and Re, the insertion into the core (as the float moves into the harder spectrum region) leads to a reduction of the effective capture cross section. When the insertion is small the flux near the core bottom is also small and the flux increase is not sufficient to compensate for the cross section reduction, yielding a reactivity increase. For larger insertions into the region with a high flux gradient, the increased rate from the differential contribution of the neutron flux prevails over the reduction in the capture cross section. Also, the mass of the in-core part of the slug becomes larger as the slug moves from the out-of-core region. Note that the Re slug remains completely out of the core until an insertion height of $20 \mathrm{~cm}$ is reached while the B-10 part is fully in the core at this point, which explains why the capture rate in the Re is decreasing while the capture rate in the B-10 is increasing. The important conclusion for the RFD design is that the float must be designed to be partially inserted in the core during normal operation.

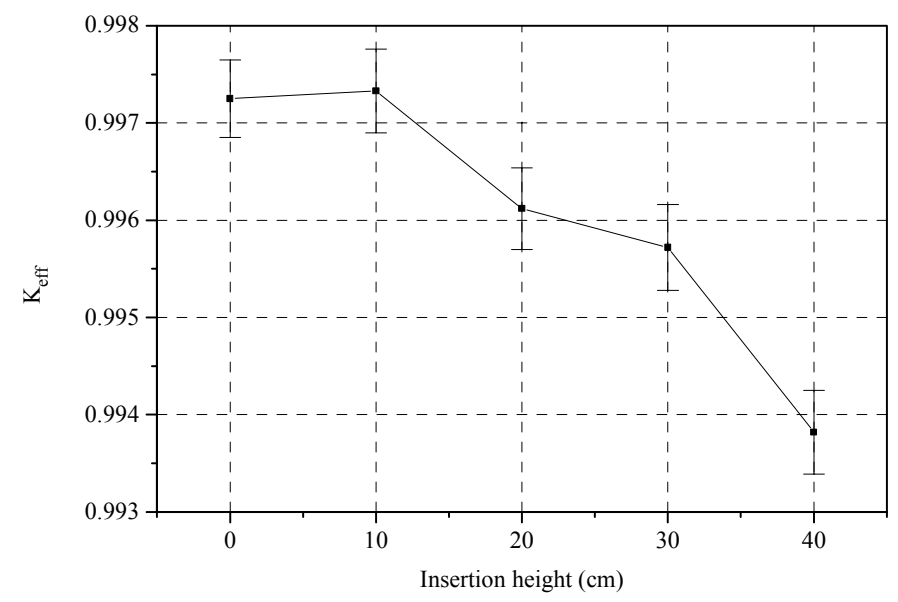

Figure 50. RFD worth as a function of float insertion height.

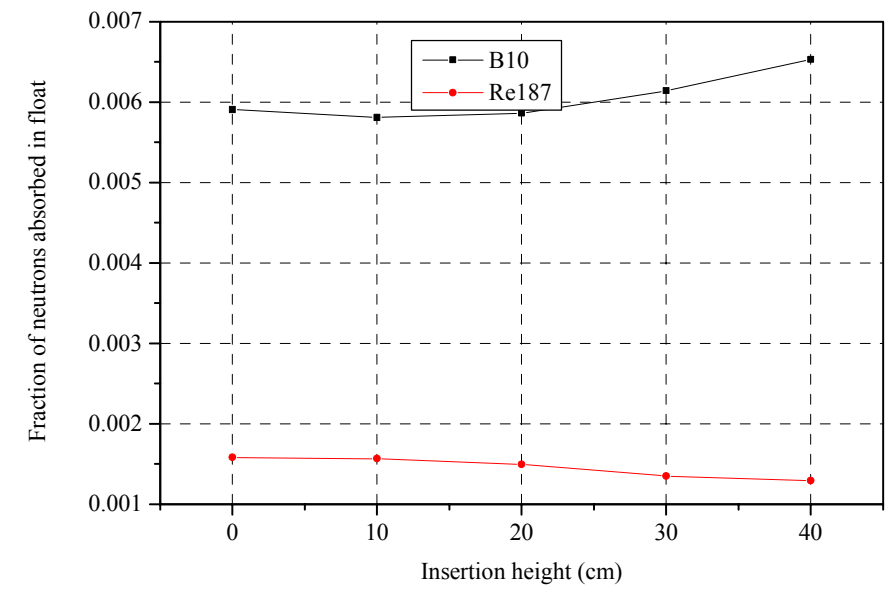

Figure 51. Fraction of neutrons absorbed in Re and B-10 of the float of an RFD. 
The results in Figure 50 indicate a steady-state reactivity power feedback coefficient exceeding $-1 \notin$ per $\%$ power, which is better than that of sodium-cooled IFR-type cores (at approximately $-0.5 \varnothing / \%)$ and about half of that of oxide-fueled FBRs. However, the RFD feedback is considerably slower following a step power increase: preliminary estimates suggest a factor of five slower than the oxide fuel Doppler reactivity insertion rate. Nevertheless, this may be adequate, since the reactors in question can be designed to have no obvious large, rapid reactivity insertion accidents to cope with.

Much remains to be done to refine and optimize this concept. Among the necessary evaluations are the seismic response and the consequences of gas plenum failure and the reactivity insertion due to the automatic RFD withdrawal following a power reduction, safety scram in particular. Nevertheless, it has been shown that it is possible to develop a fast-response reactivity feedback device that can substitute for the lack of a traditional fuel temperature feedback.

\subsubsection{Delayed Neutron Fraction}

The delayed neutron fraction can be estimated using a simple fission fraction-weighted average of the delayed neutron yields of the actinides, as shown in Table 20. A more accurate space-dependent calculation of the effective delayed neutron fraction must include the adjoint function in the weighting procedure and the energy spectrum of delayed neutrons. This can be performed using the MCNP option to turn on and off the effect of delayed neutrons. Earlier benchmarks [Hejzlar et. al, 2000] showed that this simplified method, see Table 20, and MCNP4B direct calculations yielded relatively close results.

Table 20. Simple estimate of delayed neutron fraction for minor actinide burner

\begin{tabular}{|l|l|l|r|r|}
\hline \multicolumn{2}{|c|}{ Fresh core } \\
\hline Nuclide & $\mathrm{Y}_{\mathrm{i}}^{*}$ & $v^{* *}$ & Fission fraction, $\mathrm{F}_{\mathrm{i}}$ & $\beta_{\mathrm{i}}=\mathrm{Y}_{\mathrm{i}} / \nu \mathrm{F}_{\mathrm{i}}$ \\
\hline Np-237 & 0.0114 & 2.935 & 0.099 & $3.8593 \mathrm{E}-04$ \\
Pu-238 & 0.0079 & 3.009 & 0.007 & $1.7904 \mathrm{E}-05$ \\
$\mathrm{Pu}-239$ & 0.0068 & 2.946 & 0.620 & $1.4307 \mathrm{E}-03$ \\
$\mathrm{Pu}-240$ & 0.0081 & 3.024 & 0.071 & $1.8891 \mathrm{E}-04$ \\
$\mathrm{Pu}-241$ & 0.0139 & 2.978 & 0.012 & $5.6889 \mathrm{E}-05$ \\
$\mathrm{Pu}-242$ & 0.014 & 3.075 & 0.011 & $4.7876 \mathrm{E}-05$ \\
$\mathrm{Am}-241$ & 0.005 & 3.402 & 0.169 & $2.4766 \mathrm{E}-04$ \\
Am-242 & 0.007 & 3.361 & 0 & 0 \\
Am-243 & 0.0079 & 3.653 & 0.011 & $2.3059 \mathrm{E}-05$ \\
Cm-242 & 0.0013 & 3.868 & 0 & 0 \\
Cm-244 & $?^{+}$ & 3.743 & 0.002 & 0 \\
Total & - & - & 1.000 & $\beta=\mathbf{0 . 0 0 2 4 0}$ \\
\hline
\end{tabular}

${ }^{*}$ Total delayed neutron yield from Brady and England [Brady M.C. and England,1989].

${ }^{* *}$ Fast fission neutron yield from ORIGEN2.1 computer code.

${ }^{+}$Data not found, assumed zero in the calculations to give conservative $\beta$.

The MCNP4B calculations are subject to an uncertainty embedded in the inability of MCNP4B to apply the correct energy spectrum for delayed neutrons (the delayed neutrons are assumed to have the same energy spectrum as prompt neutrons). However, there is a significant difference because most delayed neutrons are emitted at energies of $0.5 \mathrm{MeV}$ while most of the prompt neutrons have energies around $2 \mathrm{MeV}$. Because the neutrons with lower energies are 
more likely to be captured, i.e., the capture to fission rate in $\mathrm{HM}$ is higher for $0.5 \mathrm{MeV}$ neutrons than for $2 \mathrm{MeV}$ neutrons, the effective fraction of delayed neutrons will be smaller than the fraction that is obtained based on prompt neutron spectra or than the fraction obtained from delayed neutron yields and of individual fissile isotopes.

Recent MCNP developments and new libraries that include delayed neutron spectra have enabled more rigorous calculations of the effective delayed neutron fractions than had been possible prior to the availability of MCNP4C. Therefore, MCNP4C was used to determine an effective delayed neutron fraction. MCNP4C, run with an accurate treatment of delayed neutron spectra, gives for the MABR with reference fuel (37wt $\% \mathrm{TRU}-59 \mathrm{wt} \% \mathrm{MA})$ the effective delayed neutron fraction of

$$
\beta_{\text {eff }}=\frac{k-k_{p}}{k}=\frac{1.00264-1.00053}{1.00264}=0.0021 \pm 0.0003
$$

This compares with $\beta=0.0024$ estimated from delayed neutron yields and normalized fission fractions (based on both prompt and delayed neutrons) or from MCNP4B direct calculations. The dependence of the $\beta_{\text {eff }}$ on burnup was also investigated. No degradation of delayed neutron fraction was observed with burnup, since Am-241, with the smallest $\beta_{\text {eff }}$ of the major actinides present, is replaced by $\mathrm{Am}-242$, which has a $\beta_{\text {eff }}$ comparable to Pu-239. A major concern would arise if the Cm-242, which has a very low $\beta_{\text {eff, }}$ would build up, but its contribution remains small.

The value of 0.0021 is $\sim 40 \%$ less than the $\beta_{\text {eff }}$ of typical oxide-fueled fast reactors or the conventional U-Pu-Zr fueled IFR core $\left(\beta_{\text {eff }}=0.0034\right)$. Such a small $\beta_{\text {eff }}$ raises concerns over the controllability of critical reactors with a dominant fraction of minor actinides and it is a major challenge for the MABR.

\subsection{Core Concept Optimized for both Actinide Burning and Economic Electricity Production (MIT, Dr. Pavel Hejzlar)}

The concept to be reported in this section is the TRU burner fueled by reprocessed spent LWR fuel and optimized for economic electricity generation, while having high net TRU destruction rates (goal is at least $50 \%$ of that of pure TRU burners) and excellent safety. This is the current major design direction for the reasons outlined in Chapter 2. First, the key constraints and philosophy adopted for neutronic design will be discussed in Section 3.5.1, followed by the description of the core designs and their reactor physics characteristics.

\subsubsection{Key constraints and philosophy of the neutronic design}

Targets within constraints drive the neutronic design. The targets specify the desired direction, the constraints the available option space. The key constraints and targets affecting the neutronic design are as depicted on Figure 52. The constraints can be classified into three major categories - safety related, material or burnup related and proliferation related. Four major targets are reactor power rating, length of refueling period, desirable TRU burnup rate and vessel transportability. 

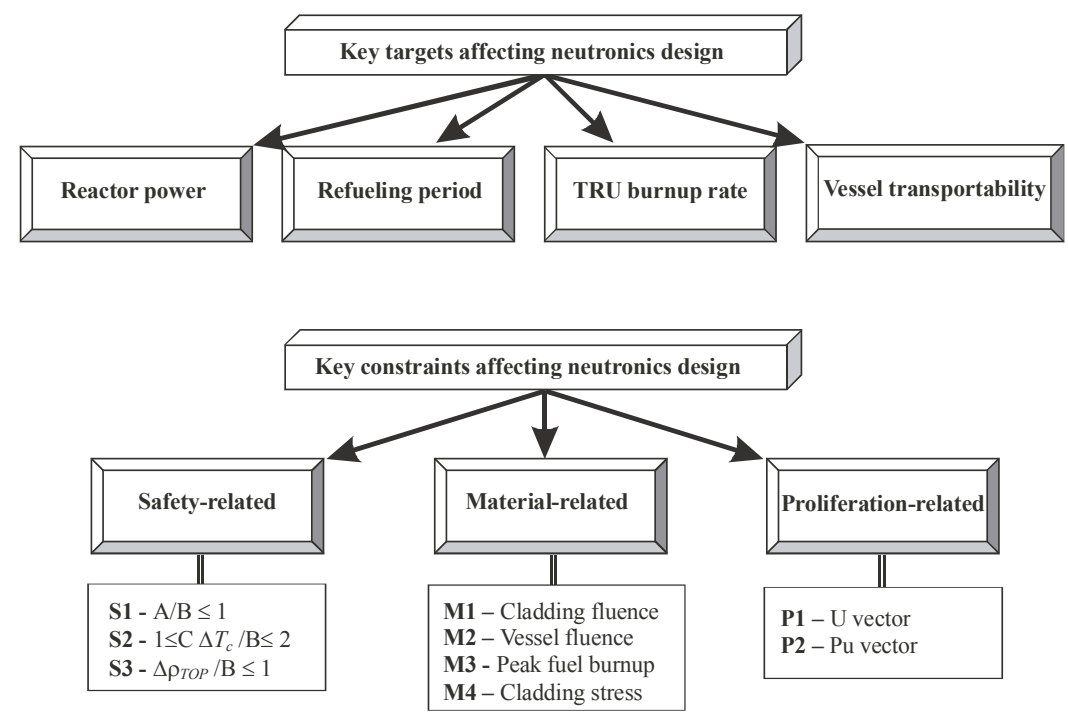

Figure 52. Key targets and constraints affecting neutronic design

\subsubsection{Impact of Design Goals on Neutronics Design Strategy}

Reactor power and vessel transportability are interrelated targets because power removable from a vessel of a given maximum transportable size is limited by the decay heat removal capability of the vessel cavity cooling system, which is directly proportional to vessel dimensions. Therefore, considering the transportability requirement together with the potential economy of scale for modular reactors and the current utility interest in moderate plant sizes, the power was set between $300-350 \mathrm{MW}_{\mathrm{e}}$. Then the thermal power can be determined for a given power conversion cycle efficiency. Based on preliminary analyses of the most promising supercritical $\mathrm{CO}_{2}$ Brayton cycle with efficiencies between 45 and $50 \%$, a thermal power rating of $700 \mathrm{MWth}$ was adopted for the neutronics analyses. Accounting for the area needed between the vessel and the core barrel to accommodate the intermediate heat exchangers or steam generators, pumps and other reactor internals, the area available for the core can be calculated. Using a reactor vessel inside diameter of $5.45 \mathrm{~m}$ (see Table 3 in Section 2) and a down-comer gap thickness of $1.25 \mathrm{~m}$ - sufficient space to place all internals - the maximum core equivalent diameter is $3.2 \mathrm{~m}$. Thus, the core must be designed to fit in these dimensions. This limits the potential for neutronic and economic optimization. Since the number of fuel pins is proportional to core cross sectional area, the maximum number of fuel rods is limited, constraining the option of reducing the fluence on the core structures (see material -related constraints M1) via an increase of heavy metal loading. Conversely, if the core is designed significantly smaller than the limiting diameter, a large space becomes wasted, increasing the cost. Therefore, the core size should be ideally set close to the maximum diameter to use the space effectively and to minimize fluence on cladding.

The refueling period was set to be 8 years to reduce the number of refueling outages and fuel handling and thus the possibility of its diversion. The length of refueling period is a very important target affecting core design. A long refueling period favors high heavy metal loadings, which for fixed core power reduces the neutron flux on the core components and increases the internal breeding ratio, and thus the reactivity limited burnup. In addition, the fuel burnup limit per kg of HM is reached later for higher HM loadings, making it possible to comply with the peak fuel burnup constraint (M3). The heavy metal loadings can be increased by enlarging the fuel 
pins or by adding more pins. The former strategy is limited by material related constraint M3 and the latter one by the maximum core size set by transportability and core power targets (see above). The design option pursued will be to employ the maximum fuel pellet size allowed by constraint M4 and maximize the number of fuel pins to fit within given core dimensions. Note that safety constraints, in particular those depending on the coolant density reactivity coefficient also affect the maximum number of fuel pins, if streaming channels are employed to alleviate coolant void worth challenges.

The target of high TRU burnup rate has a key impact on neutronic design. The net TRU destruction rate depends primarily on the core thermal power and internal conversion ratio. Because the electrical power output is set to $300-350 \mathrm{MWe}$, the only possibility to increase the TRU burnup rate is a reduction of the cycle efficiency and increase in the thermal power. This alternative is unacceptable, because it has a negative impact on plant economy. The maximum TRU incineration rate can, for a fixed core power, be achieved in a fertile-free core. However, the absence of fertile material in critical reactors impairs safety characteristics (all S-criteria). Therefore, the strategy adopted for this study is to use thorium, with some natural uranium for denaturing, as the fertile material. This will reduce the bred-in plutonium and thus increase the net TRU destruction rate in comparison with traditional uranium-plutonium fueled cores. The goal is to attain the TRU destruction rate of at least $50 \%$ of that for a fertile-free core of the same power output.

\subsubsection{Impact of Design Constraints on Neutronics Design Strategy}

\section{Safety related constraints}

Neutronics constraints affecting safety are primarily the reactivity feedbacks that control the passive shutdown characteristics, in compliance with the top-level requirement for reactor selfcontrollability imposed by the objective to attain safety comparable to that of the IFR. Selfcontrollability requires that, in a quasi-static reactivity balance sense, the reactor is inherently shut down to a safe state under the most restricting anticipated transients without scram. There are three external paths through which the core can be compromised:

- Coolant core inlet temperature,

- Coolant flow rate and

- Externally induced reactivity changes, either due to control rod motion or seismically induced core geometry changes.

These all-encompassing paths are embodied in three generic anticipated transients without scram [Wade and Fujita, 1989]: Unprotected Loss of Flow (ULOF), Unprotected Loss of Heat Sink (ULOHS) and Unprotected Transient Overpower (UTOP).

Wade and Hill [1997] showed that for sufficiently large margins between the operating point and safety limits and for a reactor with decay heat removal via natural means, one can design a core with reactivity feedback ratios assuring passive self-control if the following ranges for the reactivity coefficients, expressed in terms of measurable integral reactivity parameters, are met:

- S1: $\mathrm{A} / \mathrm{B} \leq 1$, where $\mathrm{A}$ is the net power reactivity coefficient in cents and $\mathrm{B}$ represents the power/flow coefficient of the reactivity in cents $/ 100 \%$ power/flow, which controls the asymptotic temperature rise in an unprotected loss of flow transient. In the case of natural circulation at full power, this criterion can be relaxed. 
- S2: $1 \leq \frac{C \Delta T_{c}}{B} \leq 2$, where $C$ characterizes the inlet temperature coefficient of reactivity in cents $/{ }^{\circ} \mathrm{C}$ and $\Delta T_{c}$ is full-power, steady-state coolant temperature rise. The term ensures an inherent balanced response to an unprotected loss of heat sink transient and coolant inlet freezing.

- S3: $\frac{\Delta \rho_{T O P}}{|B|} \leq 1$, where $\Delta \rho_{T O P}$ is the reactivity vested in a single control rod.

The above three safety criteria (S-criteria) were adopted as top-level constraints for the core neutronic design. Because the S-criteria are determined by the values and signs of the reactivity coefficients, the latter will be required to fall within the ranges that satisfy these three criteria.

The S1 criterion requires that the net power coefficient A is small and negative. Since A consists of the Doppler and fuel thermal expansion coefficients multiplied by the incremental temperature rise of the fuel relative to the coolant, metal fuel will be preferable, because it has a small fuel temperature coefficient and small temperature rise across the fuel pin. In addition, it is desirable that $B=-[\partial \Delta \rho /(\partial P / F)]$ (where $\mathrm{P}$ represents normalized power and $\mathrm{F}$ normalized flow) is negative and larger than A to satisfy the inequality relation. It comprises, in addition to the fuel temperature coefficient, the coolant density coefficient, the control rod driveline expansion coefficient, and the core radial expansion coefficient, all multiplied by the average coolant temperature rise across the core. Since the control-rod driveline and the core radial expansion coefficients are typically negative, but a positive coolant temperature coefficient leads to a reduction in the negative $\mathrm{B}$ values or even can shift B to the positive side, the key strategy is to achieve a negative coolant temperature coefficient or minimize its positive magnitude. A large $\mathrm{B}$ value also favors a sufficiently high temperature rise across the core. Because, the core outlet temperature is limited by constraints on the cladding temperatures, the only option to enhance this temperature difference is by a reduction of the core inlet temperature. This path also has limits because a low core inlet temperature reduces the $\Delta \mathrm{T}_{\log }$ in the IHX, and thus the plant efficiency and could result in large thermal stresses on the core structure during LOHS events. Thus a compromise must be made.

The S2-criterion provides a proper balance between the ULOHS and the chilled inlet temperature (coolant freezing) inherent responses. The ULOHS favors a large coolant inlet temperature coefficient $C=-\left[\partial \Delta \rho / \partial T_{i n}\right]$, which contains terms due to the Doppler, fuel axial expansion, coolant density and core radial expansion coefficients. Similarly as for the B coefficient, the main effort will be to minimize the reactivity insertion due to any coolant density reduction. Also, the core radial expansion coefficient can be increased through altered grid plane design, if needed.

The S3-criterion favors a large B (discussed under S1 criterion) and a small reactivity insertion from control rod run out events. To minimize the $\Delta \rho_{\mathrm{TOP}}$, the rod worth of the most reactive control rod must be limited so that other inherent reactivity feedbacks from the temperature rise stop the power rise driven by the reactivity insertion due to the withdrawn control rod drives. The principle means to accomplish this task is to design a core for low burnup control swing by maximizing the internal breeding. This can be achieved by (1) maximizing the fertile content in the core, and, (2) maximizing $\eta$ of the fissile material. Because the addition of fertile material reduces the destruction rate of the actinides, which is contrary to one of the key goals of the design, compromises have to be made. The following strategy is applied: (i) thorium 
will be used instead of the traditional U-238 to minimize the buildup of the plutonium, and (ii) a relatively high fraction of minor actinides in the TRU will be loaded to maximize the transmutation of the Am-241 and N-237 to daughters with high fission to capture ratios. $\eta$ maximization will be pursued via a hard spectrum, i.e., use of lead or lead-bismuth coolant and metal or nitride fuel. An increase of the fuel volume fraction in a core is another option to enhance internal breeding. This can be done by enlarging the fuel pin diameter, but this venue is limited by constraints on cladding dimensions to withstand irradiation creep and stress from fission gas pressure, as discussed under material-related constraints. Finally, a high internal breeding ratio favors a low leakage core. Because leakage is essential to the reduction of coolant void worth, a compromise has to be made on this parameter. Note that a simple approach to reduce reactivity vested in one control rod is to employ a large number of control rod drives. However, this increases the probability of control-rod run out accidents and cost. Therefore, the primary thrust of the optimization will be directed to minimization of the $\Delta \rho_{\mathrm{TOP}}$ through a reactivity swing reduction.

\section{Material-related constraints}

Although these constraints are not directly reactor physics limits because they come from the requirements on the materials, they must be considered in the reactor physics design.

The M1 - Criterion requires that peak fast fluence on the cladding remain below a limiting value that would cause unacceptable damage from neutron irradiation. The fluence limit for the low-swelling cladding HT-9 steel alloy, $3.8-4.0 \times 10^{23} \mathrm{n} / \mathrm{cm}^{2}(\mathrm{E}>0.1 \mathrm{MeV})$ or about 165 dpa [Hill et. al., 1999], developed for the U.S. fast reactor program was adopted as the guiding fluence parameter for the in-core stainless steel structures. The peak fluence on the cladding depends, for a fixed reactor thermal power, on four factors: (1) exposure time, (2) the absolute value of the neutron flux, (3) the overall core flux peaking factor, and (4) the fraction of the neutrons that are above a $0.1 \mathrm{MeV}$ threshold. Because the exposure time is fixed for a time interval between refuelings of 8 years, only the last three factors remain as effective paths to reduce the fast fluence. The average neutron flux can be reduced through an increased loading of fissile material. However, this path is limited because increasing the number of fuel pins is possible only until the maximum number allowed by the vessel dimensions (see target 4) is reached; increasing the fuel pin diameter is constrained by the M4-criterion, and an increase in the enrichment is limited by the reactivity excess at beginning-of-life (S3-criterion). The two possibilities left are to maximize the fuel density and use a high-packing core geometry. The high fuel density option is employed using metal or nitride fuel, although the fuel performance limits, which require a smear density of $75 \%$ (see M3 criterion) must be considered. The high packing core option through tight pitch or hexagonal lattice was not pursued for two reasons (i) it challenges thermal hydraulics and increases the pumping power in lead or lead-bismuth-cooled cores (note that heavy metal cooled cores require a loose lattice to keep pumping power reasonably low) - both factors reduce net plant efficiency, which for fixed electric power rating requires higher thermal power, and thus higher flux, and (ii) it leads, for a given fuel composition, to higher peaking factors and thus to higher peak fluence. As can be seen, both these measures are counterproductive to the original goal of minimizing the peak flux. Minimization of neutron flux peaking was adopted as the main venue to reduce the peak fast fluence. This is pursued through (i) introduction of streaming fuel assemblies, which increase the neutron migration area and reduce overall peaking for a fixed enrichment and (ii) enrichment zoning, placing fuel assemblies with a higher enrichment at the core periphery. Finally, spectrum softening to reduce the neutron population above $0.1 \mathrm{MeV}$ was not pursued, because it is counterproductive to the goal of actinide burning. Slightly lower peak fluence can be obtained using nitride fuel. 
The M2 - criterion constrains peak fast fluence on the vessel wall. PWR vessels are typically exposed to fluences of $2 \times 10^{19}(\mathrm{E}>1 \mathrm{MeV}) \mathrm{n} / \mathrm{cm}^{2}$. This value was adopted for the actinide burner reactor design. For a given vessel lifetime, which determines plant life (projected for 60 years), fluence on the vessel wall is determined by peak fast flux. The same four factors as for the M1-criterion apply with the difference that higher leakage from the core (although it reduces in-core peaking) leads to higher flux on the vessel wall. However, because the intermediate heat exchanger and pumps in the downcomer require a large downcomer width, because lead or leadbismuth is good reflector, and because a long-life core requires a de-rated power density, it is not expected that vessel fluence will pose a challenge requiring design modifications. Therefore, the compliance with this constraint will be verified.

The M3 -criterion limits the maximum burnup the fuel rods can withstand without significant swelling and fission gas pressure that would challenge cladding integrity. Since the possibility of achieving burnup levels of 15 to $20 \mathrm{at} \%$ was demonstrated for ternary (U-Pu-Zr) metal alloy pins in HT-9 ferritic cladding [Hill et. al., 1999], the fuel rods were designed for these peak burnups (see M4-criterion), and these values were adopted as the burnup constraint. The same burnup limit was adopted for both the metal and nitride fuels, although the experience base for nitride fuels is very limited and their actual burnup limit will have to be established. The implications of this constraint for neutronics design are that core power and fuel management are maintained in such a way not to exceed a peak burnup of $20 \%$ at. For a fixed target power and refueling time, the only options to reduce the fuel burnup are to (1) increase the heavy metal content in the core and to (2) reduce the core-wide power peaking. The increase of heavy metal loading is limited for the same reasons as discussed under the M1-criterion, i.e., the number of fuel pins is constrained by the vessel dimensions, the fuel pin diameter is constrained by the M4criterion (also a larger pin outside diameter can reduce the achievable burnup limit), the fuel density is limited by the $75 \%$ smear density requirement to accommodate swelling, and a high packing core incurs the thermal hydraulic and peaking challenges as outlined above. Therefore, the strategy adopted was to use the maximum possible number of fuel rods in a given space while maintaining a sufficiently loose lattice and minimizing the power peaking. It will be shown that the burnup constraint is less limiting than the fluence constraint and hence the compliance with the burnup constraint is the less demanding requirement in the actinide burner reactor core design.

The M4-Criterion comes from cladding performance under stresses from fission gas pressure and temperature loadings, allowing for the protective oxide layers. Thus, in addition to burnup related stresses, thermal stresses, irradiation creep, and a reduced allowable stress limit due to elevated operating temperature must be considered. The cladding dimensions are determined by the cladding performance analysis accounting for all these effects (see Table 3 in Section 2). Thus, for a given pin height and target burnup, the fuel pellet outer diameter is fixed at $5.48 \mathrm{~mm}$ and the fission gas plenum length is fixed at $2.47 \mathrm{~m}$. This limits the option space for the neutronics design, because it does not allow for a desirable increase in the heavy metal loading through the use of enlarged fuel pins.

\section{Proliferation-related constraints}

Since TRU burning requires reprocessing with separation of the TRUs from the heavy metal and fission products, a potential for diversion of weapons-usable material exists. This potential is restricted more to the reprocessing facility rather than to the burner reactor. The actinide burner reactor design can influence the proliferation risk by ensuring that the composition of the discharged fuel is proliferation resistant. This is even more important for the once-through actinide burner reactor cycle scheme where the discharged fuel from the actinide burner reactor 
goes to temporary storage. Therefore, the proliferation resistant criteria adopted for the design involves the composition of the plutonium and uranium vectors in the discharged fuel. In addition, to minimize the fuel movements on the plant site, a long refueling time of 8 years was adopted as a target.

The P1 - Criterion sets the requirements on the plutonium vector in the fuel discharged from the actinide burner reactor. There is no rigorous international standard for a truly proliferation risk free plutonium vector. Hence we imposed the requirement that the composition of the plutonium isotopes in the spent fuel from the fast reactor be worse (more diluted by fertile $\mathrm{Pu}$ isotopes) than that for LWR spent fuel. To achieve this goal, $\mathrm{Pu}$ production from the U-238 captures will be minimized by using (i) thorium as the major fertile material, (ii) minor actinides mixed together with the plutonium to increase the generation of the $\mathrm{Pu}-238$ (from neutron captures in the Np-237) (Pu-238 has high decay heat levels making construction of weapons difficult), (iii) high-burnup fuels to dilute the Pu vector.

The P2 - Criterion requires that the amount of fissile uranium isotopes remain within a limit considered as weapons unusable by international standards. This limit is $20 \mathrm{wt} \%$ of the U-235 in the uranium. For the U-233 isotope, which has higher $\eta$, a smaller weight fraction has been recently proposed [Forsberg et. al., 1999], stating that the content of (U-233+0.6U-235) in all uranium must be below $12 \%$. The strategy adopted to satisfy this constraint will be to mix thorium with natural or depleted uranium to denature the bred-in U-233. The negative impacts of the uranium are the reduction of the net TRU incineration rate and a less favorable coolant void worth. Hence the minimum amount of depleted uranium which satisfies the P2-criterion will be sought.

Finally, it is noted that there are also thermal-hydraulic constraints, which affect neutronic design. These are not discussed here, because the de-rated core power to attain long refueling time leads to a significant increase in thermal hydraulic margins in comparison with typical fast breeder reactors, making them of less concern. Thermal hydraulic analysis is performed in Section 4.2.1 and adjustments to core geometry can be made later should thermal hydraulic margins not be met.

\subsubsection{Fuel Selection and Structural Material Composition}

Fertile-free actinide or minor actinide critical burners suffer from a small delayed neutron fraction and a lack of fuel temperature feedback. Both the Doppler coefficient and delayed neutron fraction can be improved by adding fertile material, but this negatively impacts the net TRU destruction rate - one of the targets set for the development of this reactor design. Thus, a compromise must be made. To minimize the generation of the plutonium, and thus to reduce the degradation of the actinide destruction rate, thorium was selected as the major fertile material. The benefits of the thorium-based fuel are the following:

1. It reduces generation of the plutonium, because the amount of uranium in the fuel can be significantly decreased (only a fraction to denature bred-in U-233 is needed).

2. It improves the coolant density reactivity coefficient in comparison with U-238 based fuels. This is due to a smaller increase in the fission to capture cross section ratio (than U-238) from spectrum hardening under the conditions of a lead or lead-bismuth-cooled reactor. Also, the fission cross section of the Th-232 is four times smaller than that of the U-238, hence the threshold effect from an increased fission rate in the fertile material is smaller than in the case of the U-238. In addition, the larger capture cross section of the Th-232 requires a higher 
loading of TRUs, whose major component is $\mathrm{Pu}-239$, the fission to capture cross section ratio of which is reduced upon spectrum hardening, further reducing coolant void worth.

3. It provides breeding of U-233, hence significantly reducing the reactivity swing and requirements for control rods, thereby improving safety.

Two fuel forms were selected for the study - metal fuel (Pu-MA-Th-U-Zr) and nitride fuel (Pu-MA-Th-U-N). Metallic fuel is a primary candidate because of the more extensive experience database with this type of fuel (albeit mostly without MAs and Th) and nitride fuel is a backup fuel form. Only the metal form was the subject of investigations this year; nitride fuel will be studied next year (FY-2002). The fuel composition used in our calculations is given in Table 21 . The fuel considered is a metal alloy of zirconium (10wt\%), thorium, uranium, plutonium and minor actinides, arranged in a square pitch. The isotopic composition of the plutonium and minor actinides corresponds to those of PWR spent fuel 50 years after discharge. The values with asterisk are subject to change, since the TRU loading depends on the core configuration to reach criticality (typically $20-30 \mathrm{wt} \%$ TRU in all metal). The ratio of MAs to TRUs was fixed at $20 \mathrm{wt} \%$ for all cases. The ratio of $U$ to $(\mathrm{U}+\mathrm{Th})$ of $12 \mathrm{wt} \%$ shown in Table 21 was used for the initial small core alternative. Later it was increased to satisfy proliferation resistance requirements for the uranium in the spent fuel.

Table 21. Reference fuel composition.

\begin{tabular}{|l|l|}
\hline Isotope & Weight percent \\
\hline Zirconium & $10 \%$ \\
\hline Heavy metal total & $90 \%$ \\
\hline $\mathrm{Pu}$ & $18.4 \%{ }^{*}$ \\
\hline $\mathrm{MAs}$ & $4.6 \%$ \\
\hline $\mathrm{Pu}+\mathrm{Ma}$ & $23 \%{ }^{*}$ \\
\hline $\mathrm{Th}+\mathrm{U}$ & $67 \%{ }^{*}$ \\
\hline $\mathrm{U}$ & $8.04 \%(12 \%$ of U+Th) \\
\hline Pu composition (50 yrs after discharge) & $\mathbf{1 0 0} \%=\mathbf{1 8 . 4 \%}$ total \\
\hline $\mathrm{Pu}-238$ & $1 \%$ \\
\hline $\mathrm{Pu}-239$ & $63 \%$ \\
\hline $\mathrm{Pu}-240$ & $29 \%$ \\
\hline $\mathrm{Pu}-241$ & $1 \%$ \\
\hline $\mathrm{Pu}-242$ & $6 \%$ \\
\hline MA composition (50 yrs after discharge) & $\mathbf{1 0 0} \%=\mathbf{4 . 6 \%} \% \mathbf{0 t a l}$ \\
\hline $\mathrm{Np}-237$ & $30 \%$ \\
\hline $\mathrm{Am}-241$ & $64.5 \%$ \\
\hline $\mathrm{Am}-242$ & $0 \%$ \\
\hline $\mathrm{Am}-243$ & $5.1 \%$ \\
\hline $\mathrm{Cm}-244$ & $0.4 \%$ \\
\hline
\end{tabular}

*Variable values depending on core design to reach criticality

The cladding is assumed to be made of special stainless steel, designated EP-823, developed by the Russians for their leadbismuth cooled reactors. The composition of EP-823 is summarized in Table 22 to the right. The same steel was used for other core structural materials. The gap between the cladding and fuel requires bonding material to enhance thermal conductivity. The proven bonding material from the IFR program is sodium. However, to avoid having a different material than the coolant in the core, which could lead to potential release of sodium into the $\mathrm{Pb}-\mathrm{Bi}$ coolant, lead-bismuth-tin alloy (33wt\% $\mathrm{Pb}-33 \mathrm{wt} \% \mathrm{Sn}-$

Table 22. Composition of stainless steel EP-823.

\begin{tabular}{|l|l|}
\hline Element & $\mathrm{Wt} \%$ \\
\hline $\mathrm{Fe}$ & 82.62 \\
\hline $\mathrm{Ni}$ & 0.8 \\
\hline $\mathrm{Cr}$ & 12 \\
\hline $\mathrm{Mo}$ & 0.9 \\
\hline $\mathrm{Si}$ & 1.3 \\
\hline $\mathrm{V}$ & 0.4 \\
\hline $\mathrm{Nb}$ & 0.4 \\
\hline $\mathrm{W}$ & 0.8 \\
\hline $\mathrm{C}$ & 0.18 \\
\hline $\mathrm{Mn}$ & 0.6 \\
\hline
\end{tabular}


$33 \mathrm{wt} \% \mathrm{Bi}$ ) was selected as a bond between the fuel pellets and stainless steel cladding. This material was found to be compatible with Zircaloy-4 [Wright et. al.,1996], although for LWR conditions. Therefore, a research program will be required to confirm its compatibility with zirconium-based fuel and stainless steel cladding. Sodium bonding as in EBR-II and IFR is an alternative in case the lead-bismuth-tin alloy does not provide satisfactory performance. In any event, the amount of bonding agent is not large enough to significantly affect neutronics, which are the focus of the present study.

\subsubsection{Small Core Option (Minimum Streaming Channels)}

The number of pins in the core depends on the number of positions used for streaming. The first option to be investigated will be a small core with a minimum number of streaming channels and a large number of fuel pins per assembly. The motivation is to maintain acceptable coolant void worth with a minimum number of streaming channels, and thus have a minimum number of fuel assemblies to reduce the costs. The number of streaming channels to limit the reactivity insertion from a coolant density reduction can be decreased due to the smaller coolant void worth of thorium based fuels and due to the smaller core dimensions expected for a core with significantly smaller power rating in comparison with the MABR (700 versus $1800 \mathrm{MWth})$. The most efficient approach to maximize the number of fuel rods per assembly is to eliminate the peripheral streaming channels, as they occupy a large number of positions taking away space available for the fuel. The fuel assembly proposed for the small core option is shown in Figure 53. It contains 392 pins per assembly and a central streaming channel occupying the center $7 \times 7$ positions. Twenty four positions around the channel periphery are occupied by control rodlets, as indicated on Figure 53. Assuming the core height of $130 \mathrm{~cm}$ (same as for MABR core), the number of fuel assemblies needed to produce 700 Figure 53. Fuel assembly for a small core configuration.

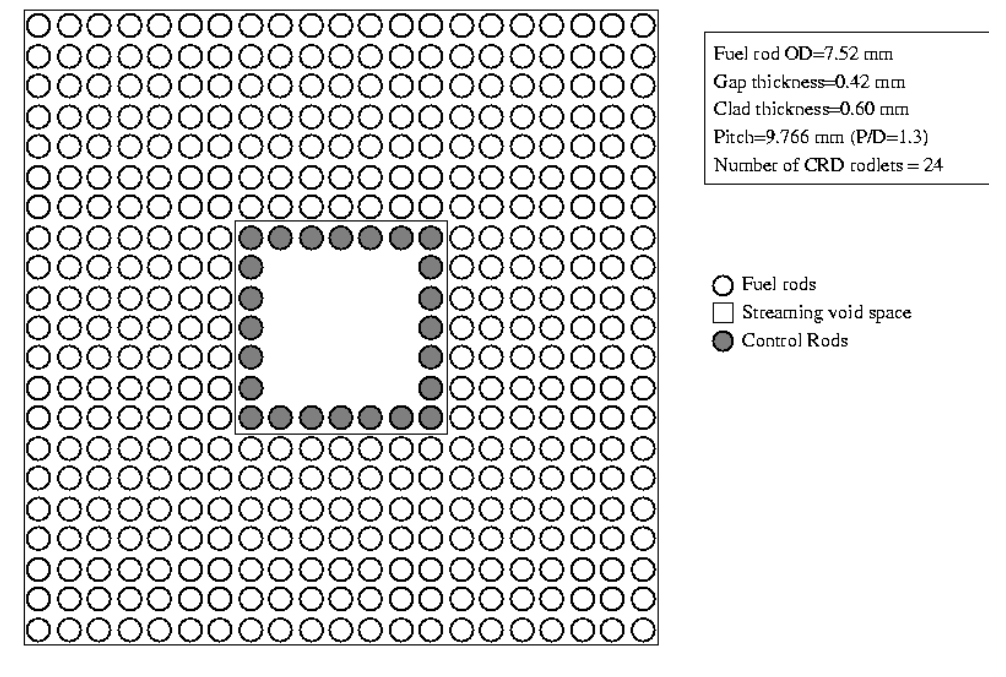
MWth can be thus estimated to be:

$$
\mathrm{N}_{\mathrm{FA}}=700 \mathrm{E} 6 \mathrm{~W} /(170 \text { to } 195 \mathrm{~W} / \mathrm{cm}) / 130 \mathrm{~cm} / 392 \mathrm{pins}=80 \text { to } 70 \text { fuel assemblies. }
$$

A core layout with 69 fuel assemblies is shown in Figure 54. This is a relatively small core with an effective core diameter less than $2 \mathrm{~m}$. Two different enrichments are assumed to flatten the power distribution. Because a relatively small reactivity swing is expected, only a small number of control rods will be required. Thus, the control rods are inserted in the central streaming channels in selected fuel assemblies, as indicated in Figure 54. Cooling of control rods will be provided through radiation. Heat transfer calculations will have to be performed to confirm the feasibility of such a design. The design parameters used in neutronic analyses of the small core option are listed in Table 23. 


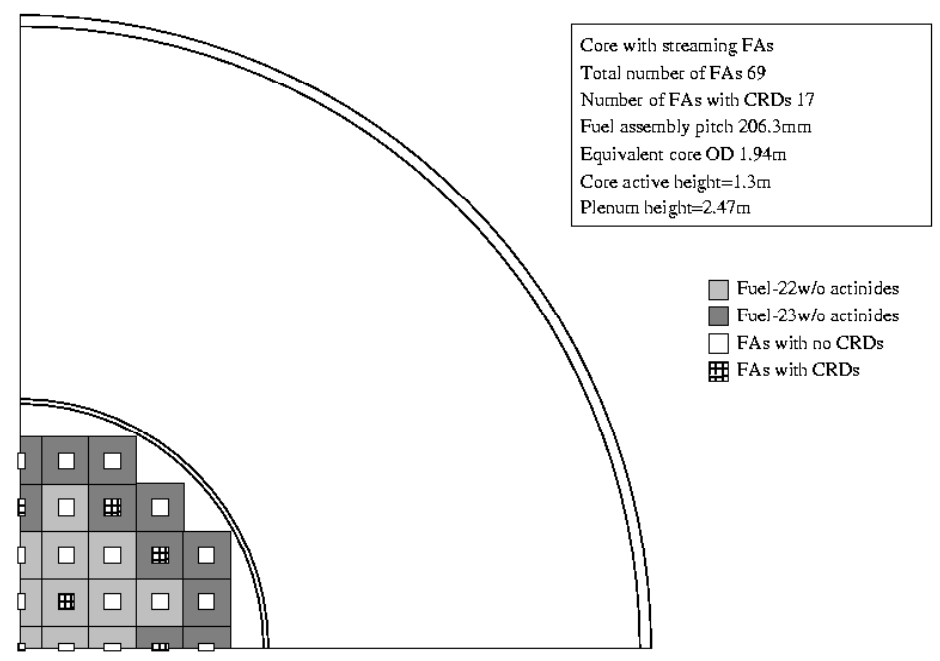

Figure 54. Core layout for small 700MWth core with U-Th-Pu-MA-Zr fuel.

Table 23. Design parameters for small core option (minimum streaming fuel assemblies).

\begin{tabular}{|c|c|}
\hline Design parameter & Value \\
\hline Fuel pellet outside diameter & $5.48 \mathrm{~mm}^{* *}$ \\
\hline Fuel composition & See Table $21^{*}$ \\
\hline Gap thickness (lead bond) & $0.42 \mathrm{~mm}^{* *}$ \\
\hline Cladding thickness & $0.6 \mathrm{~mm}^{* *}$ \\
\hline Pin outer diameter (cladding outer) & $7.52 \mathrm{~mm}^{* *}$ \\
\hline Pitch & $9.776 \mathrm{~mm}$ \\
\hline $\mathrm{P} / \mathrm{D}$ & 1.3 \\
\hline Heated core length & $1.3 \mathrm{~m}$ \\
\hline Gas plenum height & $2.47 \mathrm{~m}$ \\
\hline Number of fuel assemblies & 69 \\
\hline Number of positions in fuel assembly & $21 \times 21$ \\
\hline Number of fuel rods per fuel assembly & $392(21 \times 21$ array $)$ \\
\hline Number of control-rod fingers per fuel assembly & 24 (in selected fuel assemblies around void periphery) \\
\hline Number of void positions in fuel assembly center & $7 \times 7$ \\
\hline Control rod material & $\mathrm{B}_{4} \mathrm{C}(90 \% \mathrm{~B}-10)$ \\
\hline Equivalent core diameter & $1.94 \mathrm{~m}$ \\
\hline Core barrel thickness & $2 \mathrm{~cm}$ \\
\hline Downcomer thickness & $0.8 \mathrm{~m}$ \\
\hline Vessel outside diameter & $5.55 \mathrm{~m}$ \\
\hline Vessel inside diameter & $5.45 \mathrm{~m}$ \\
\hline Thickness of the $\mathrm{Pb}$-Bi layer in lower plenum & $1.5 \mathrm{~m}$ \\
\hline Thickness of the $\mathrm{Pb}-\mathrm{Bi}$ chimney above core & $5 \mathrm{~m}$ \\
\hline Fuel; fuel density & $\mathrm{Pu}+\mathrm{MA}+\mathrm{Th}+\mathrm{U}+\mathrm{Zr} ; 12.1 \mathrm{~g} / \mathrm{cm}^{3}$ (theoretical) \\
\hline Smeared density & $75 \%$ \\
\hline Coolant & $\mathrm{Pb}-\mathrm{Bi}$ \\
\hline Core-average coolant temperature and density & $521^{\circ} \mathrm{C} ; 10.09 \mathrm{~g} / \mathrm{cm}^{3}$ \\
\hline Temperature of $\mathrm{Pb}-\mathrm{Bi}$ coolant in the chimney & $580^{\circ} \mathrm{C}$ \\
\hline Temperature of $\mathrm{Pb}$-Bi coolant in lower plenum & $462^{\circ} \mathrm{C}$ \\
\hline
\end{tabular}


The minor actinide burner core showed acceptable cladding fluence for a core residence time of 3.2 EFPYs, at a pin linear power of $360 \mathrm{~W} / \mathrm{cm}$. To increase the core life for the optimized core design to 7-8 years, the pin linear heat rate has to be de-rated to remain within the fluence and burnup limits. Assuming an $85 \%$ capacity factor, the reduced pin linear heat rate can be calculated as

$$
\left.\mathrm{q}^{\prime}=360 * 3.2 \mathrm{EFPY} /(7 \text { to } 8) / 0.85\right) \mathrm{EFPY}=170 \text { to } 195 \mathrm{~W} / \mathrm{cm} \text {. }
$$

Figures 55, 56, and 57 show the fuel assembly-averaged power distribution normalized to the core-average power, the pin power distribution in the hot fuel assembly, and the axial power profile in the hot fuel assembly. The total power peaking is

$$
\mathrm{k}_{\mathrm{total}}=1.2568(1.20) 1.024=1.54 \text {. }
$$

This power peaking is about 1.25 times higher than in the case of the actinide burner studied earlier [Hejzlar et. al., 2001a] in spite of significantly smaller core outside diameter. This is due to the larger capture rate in the heavy metal, which replaced some of the neutronically transparent zirconium matrix.

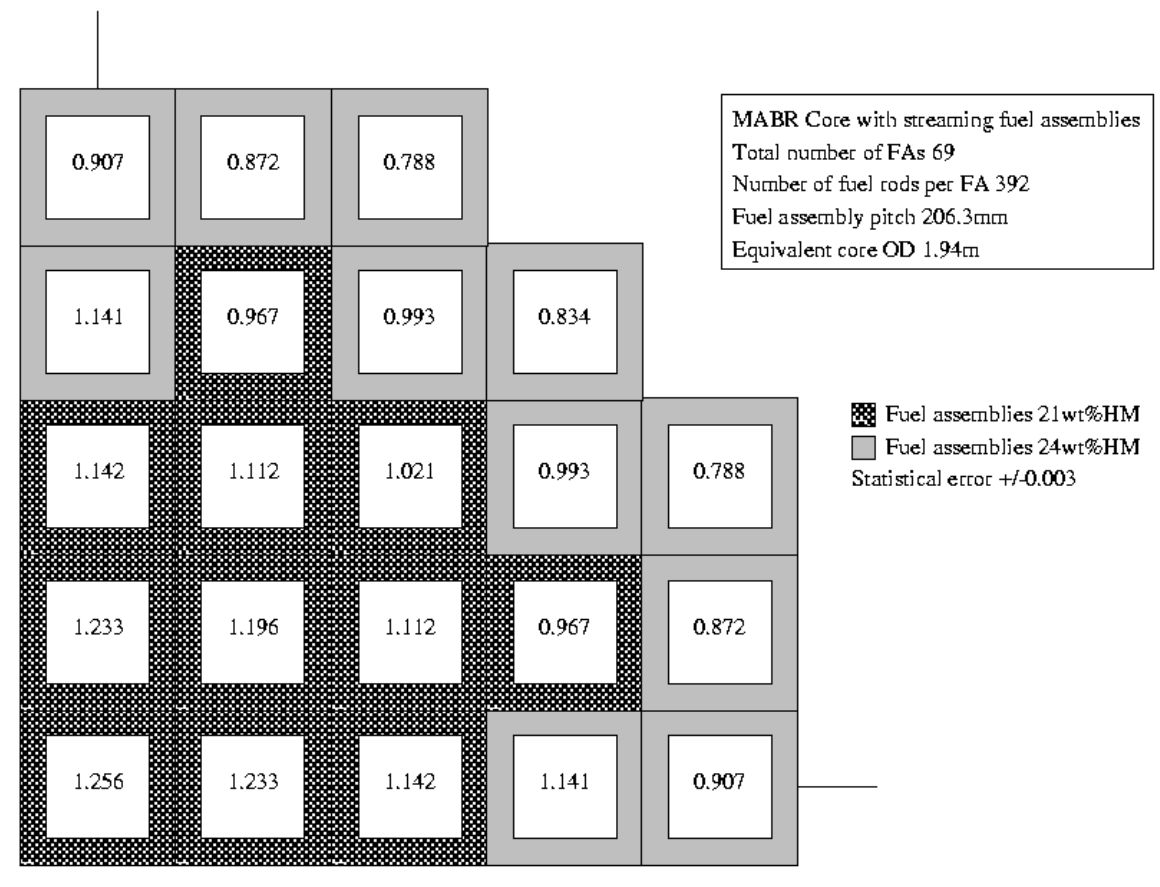

\section{Figure 55. Normalized fuel assembly power distribution for the small core option.}

The reactivity response to the coolant density changes is plotted in Figure 58. The coolant temperature coefficient is negative or zero for the entire range of coolant densities between the reference value and zero (total core voiding while keeping coolant density in the reflectors at the reference value). For the fuel assemblies with no streaming channels at the periphery, reactivity changes between reference coolant density and $8 \mathrm{~g} / \mathrm{cc}$ are approximately zero. For the lower densities, the reactivity is reduced with the coolant density decrease. If one row of streaming channels is introduced on the fuel assembly periphery (for the same core layout), the reactivity reduction with the density decrease is too steep, resulting in an unnecessarily large leakage and 
thus reduced neutron economy. Therefore, the core layout shown in Figure 54 in combination with fuel assemblies shown in Figure 53 provides a very good reactivity performance during coolant density changes. These results confirm the expectations that for small cores, peripheral streaming channels are not needed.

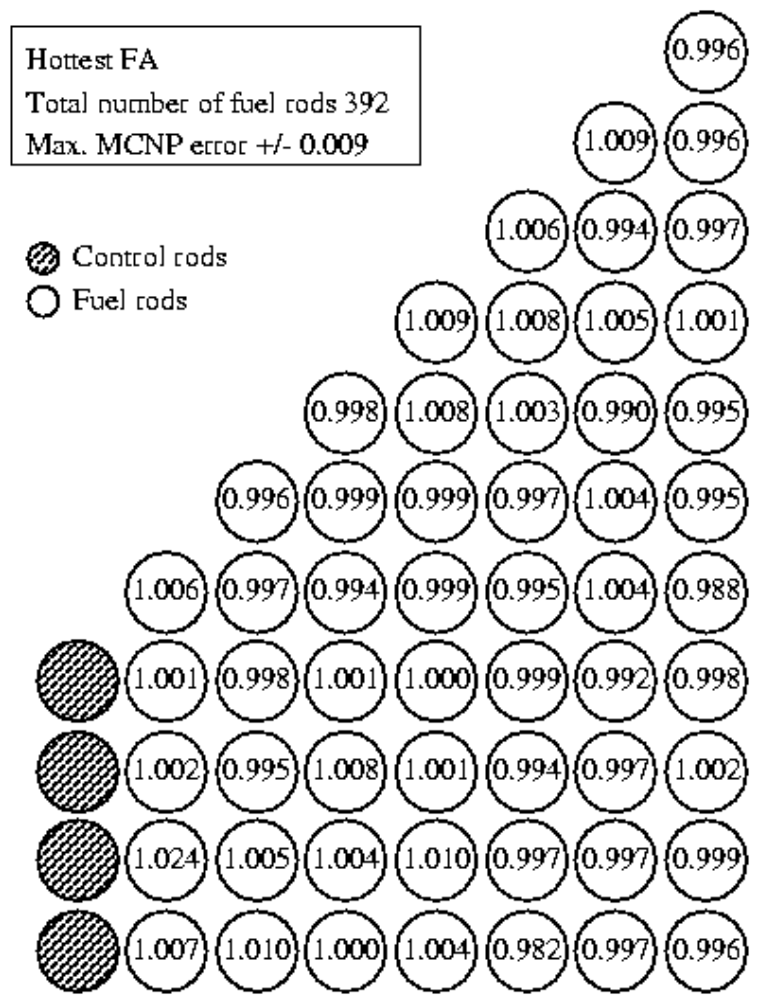

Figure 56. Pin power distribution in the hot fuel assembly for the small core option.

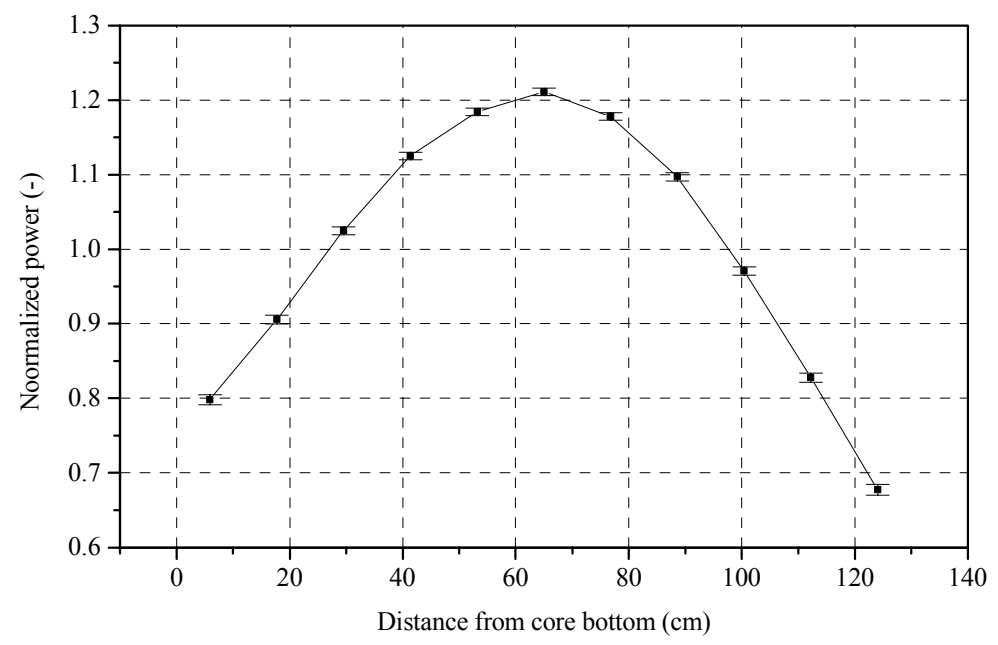

Figure 57. Axial power profile in the hot fuel assembly for the small core option. 


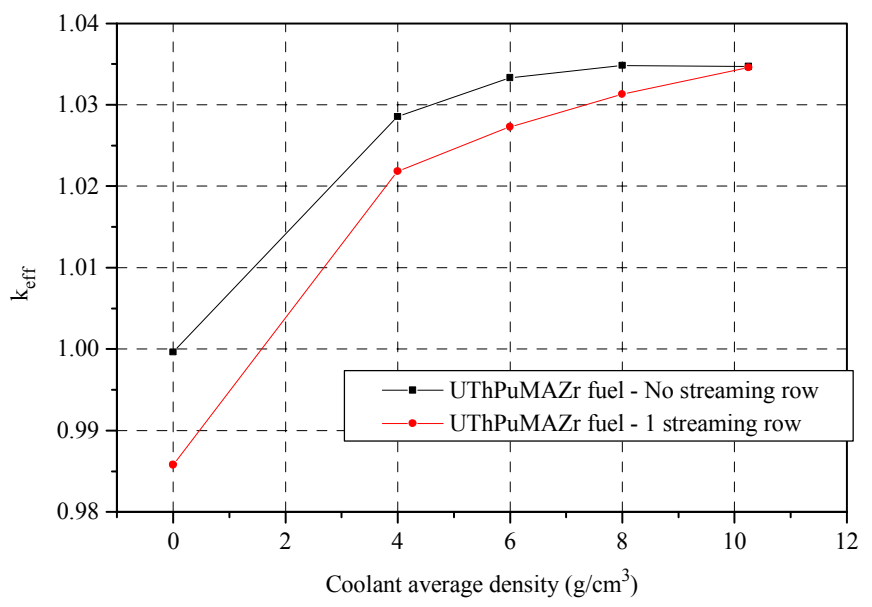

Figure 58. Reactivity response to coolant density changes.

Fast neutron flux on the most exposed fuel pin in the hot fuel assembly $(20 \mathrm{~cm}-1$ ong section at core midplane) was edited from an MCNP run to yield flux:

$$
\phi \max =4.3 \times 10^{15} \mathrm{n} / \mathrm{cm}^{2}-\mathrm{s}(\mathrm{E}>0.1 \mathrm{MeV}) .
$$

If the core operates 8years with capacity factor of 0.85 , the cladding would be exposed to a maximum accumulated fluence of $9.4 \times 10^{23}(\mathrm{E}>0.1 \mathrm{MeV}) \mathrm{n} / \mathrm{cm}^{2}$. This is 2.35 times more than the limiting value of $4.0 \times 10^{23}(\mathrm{E}>0.1 \mathrm{MeV}) \mathrm{n} / \mathrm{cm}^{2}$ for HT-9 steel. This is a significantly higher value than expected, considering the fact that core power density was reduced to extend the core life. One of the reasons for this is the higher power peaking in this core with fertile fuel (1.25 times more than in an MABR). The second reason is the substantial reduction in the fuel pin diameter in comparison to the MABR design (to comply with the M4-criterion), which was not accounted for during the preliminary assessment of the number of fuel pins, which was based on de-rating of pin linear power.

Clearly, the proposed small core cannot meet the target of a refueling interval of 8 years because of the fluence constraint. There are two possibilities to be pursued: (1) Use the small core option from Figure 54 and reduce the refueling time to about 4 years or (2) increase the number of fuel assemblies to further decrease the fast flux. Because the vessel dimensions based on the decay heat removal studies and transportability considerations allow placing more fuel in the vessel, the latter option is to be pursued. In fact this is the only choice to satisfy the targets. However, it is noted that the economic analysis confirming the preference of 8-year cores over cores having shorter life ( $\sim 4$ years) has not been performed. If future economics studies show that the small core design is more economical, the core layout from Figure 54 may be developed further. Finally, it is important to note that the dimensions of this core are too small in relation to the vessel size. To proceed with the design with the 4-year core life alternative would require a significant upgrade of the passive decay heat removal system to reduce vessel dimensions and maintain the same decay heat removal rate.

\subsubsection{Large Long-Life Core Option}

\subsubsection{Core Layout, Fuel Composition and Design Parameters}

To maximize the core lifetime, which is driven by the fluence limit on the cladding, it is desirable to increase the heavy metal loading or increase the number of fuel pins. Considering 
the constraints from Section 3.5.1.2, the preferable strategy to increase heavy metal loading is through the latter option. The maximum number of fuel assemblies must fit within the equivalent diameter of $3.2 \mathrm{~m}$ (see Section 3.5.1.1) to comply with the target for vessel transportability and passive decay heat removal. Thus, the maximum number of $21 \times 21$ fuel assemblies having a fuel assembly pitch of $206.3 \mathrm{~mm}$ is 157 . Because increasing the number of fuel assemblies leads to the deterioration of the coolant void worth, each fuel assembly for the large core version has one row of streaming peripheral channels. Figure 59 shows the new core design to scale and Figure 60 depicts the fuel assembly used with this core layout.

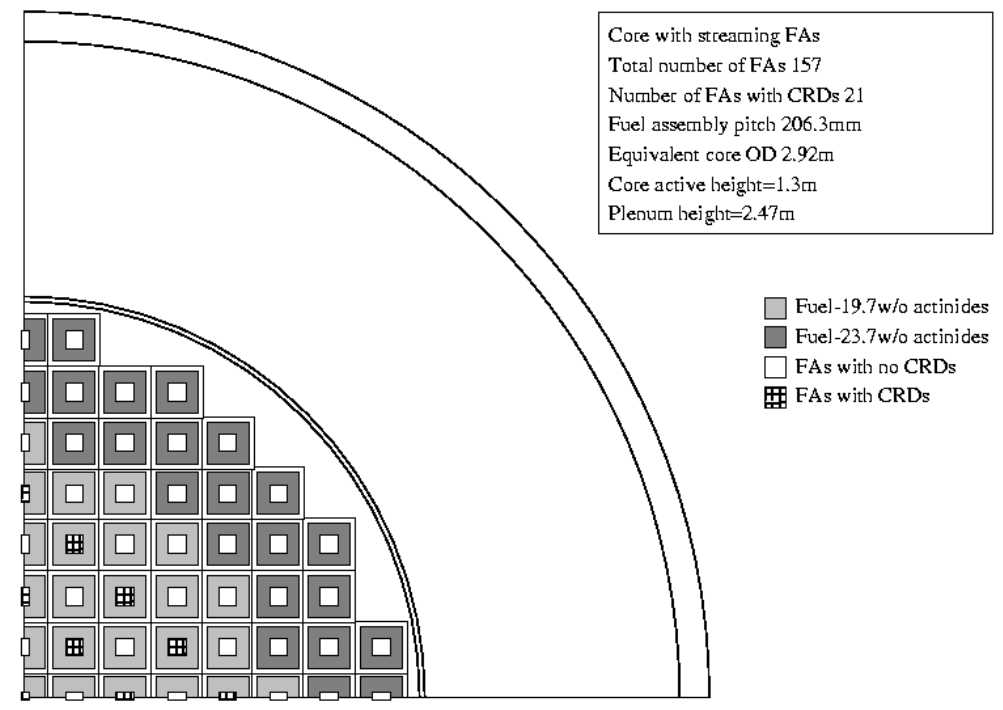

Figure 59. Core layout for the reference design.

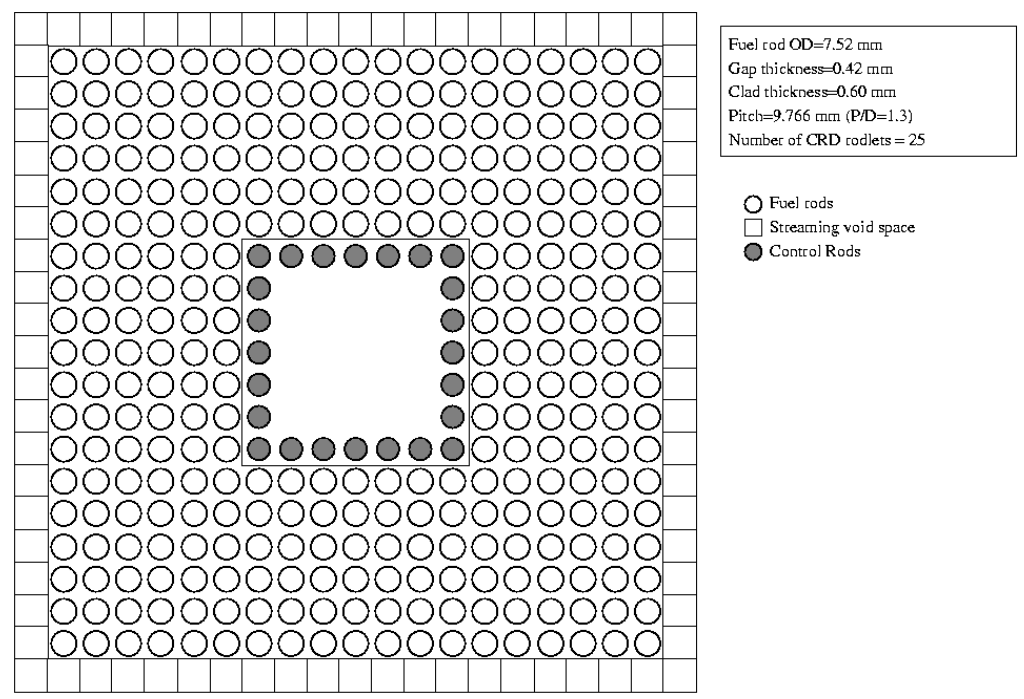

Figure 60. Fuel assembly with 1 row of peripheral streaming channels - reference design

In comparison to the small core option, the number of fuel pins is increased by the ratio $157 / 69=2.3$, i.e., by about the same ratio that the fluence exceeded the allowable limit. However, because more streaming channels per assembly are needed, the ratio based on the number of pins is less. On the other hand, streaming reduces the core-wide peaking, countering to some extent their negative effect on heavy metal loading. In any case, the above ratio suggests 
that it will be challenging to meet the fluence limit on the cladding for the limited core space and given fixed core power.

Burnup analysis of the small core option (not discussed in Section 3.5.1) showed that the content of the U-233 in the discharged fuel is well above the $12 \%$ proliferation resistance limit. Therefore, the fraction of depleted uranium in the fresh fuel needs to be increased at the expense of the Th-232. Table 24 shows the new reference fuel with $30 \mathrm{wt} \%$ uranium in the Th-U heavy metal. The TRU loading is smaller in comparison with Table 21 - a result of a smaller capture rate in the fertile isotopes due to the smaller capture cross section of the U-238 than for the Th-232. The plutonium and minor actinide vectors are the same as shown in Table 21. In the initial core, the outer core region contains $23.7 \mathrm{wt} \%$ TRU-enriched fuel; the inner core region is loaded with $19.7 \mathrm{wt} \%$ TRU-enriched fuel. The design parameters for the reference design are listed in Table 25.

\begin{tabular}{|c|c|}
\hline Isotope & $\begin{array}{l}\text { Weight } \\
\text { percent }\end{array}$ \\
\hline Zirconium & $10 \%$ \\
\hline $\begin{array}{l}\text { Heavy metal } \\
\text { total }\end{array}$ & $90 \%$ \\
\hline $\mathrm{Pu}^{*}$ & $18.4 \%$ \\
\hline $\mathrm{MAs}^{*}$ & $4.6 \%$ \\
\hline $\begin{array}{l}\mathrm{Pu}+\mathrm{Ma} \\
\text { (TRUs) }\end{array}$ & $21.7 \%$ \\
\hline $\mathrm{Th}+\mathrm{U}$ & $78.3 \%$ \\
\hline $\mathrm{U}$ & $\begin{array}{l}23.49 \% \\
(30 \% \mathrm{wt} \% \quad \text { in } \\
\text { ThU mixture) }\end{array}$ \\
\hline
\end{tabular}

Table 25. Design parameters for large core option (with streaming fuel assemblies).

\begin{tabular}{|l|l|}
\hline Design parameter & Value \\
\hline Fuel pellet outside diameter & $5.48 \mathrm{~mm}^{*}$ \\
\hline Fuel composition & see Tables 21 and 24 and Figure 59 \\
\hline Gap thickness (lead bond) & $0.42 \mathrm{~mm}^{*}$ \\
\hline Cladding thickness & $0.6 \mathrm{~mm}^{*}$ \\
\hline Pin outer diameter (cladding outer) & $7.52 \mathrm{~mm}^{*}$ \\
\hline Pitch & $9.776 \mathrm{~mm}$ \\
\hline P/D & 1.3 \\
\hline Heated core length & $1.3 \mathrm{~m}$ \\
\hline Gas plenum height & $2.47 \mathrm{~m}^{*}$ \\
\hline Number of fuel assemblies & 157 \\
\hline Number of positions in FA & $21 \mathrm{x} 21$ \\
\hline Number of fuel rods per FA & $\begin{array}{l}312(21 \mathrm{x} 21 \text { array with central and peripheral } \\
\text { streaming channels) }\end{array}$ \\
\hline Number of control-rod fingers per FA & $\begin{array}{l}24 \quad \text { in selected fuel assemblies on void } \\
\text { periphery) }\end{array}$ \\
\hline Number of void positions in fuel assembly center & $7 \mathrm{x} 7$ \\
\hline Control rod material & $\mathrm{B}_{4} \mathrm{C}(60 \% \mathrm{~B} 10)$ \\
\hline Equivalent core diameter & $2.92 \mathrm{~m}$ \\
\hline Core barrel thickness & $2 \mathrm{~cm}$ \\
\hline Downcomer thickness & $1.0 \mathrm{~m}$ \\
\hline Vessel outside diameter & $5.50 \mathrm{~m}$ \\
\hline Vessel inside diameter & $5.25 \mathrm{~m}$ \\
\hline Thickness of the Pb-Bi layer in lower plenum & $1.5 \mathrm{~m}$ \\
\hline Thickness of the Pb-Bi chimney above core & $5 \mathrm{~m}$ \\
\hline Fuel; fuel density & $\mathrm{Pu}+\mathrm{MA}+\mathrm{Th}+\mathrm{U}+\mathrm{Zr} ; 12.7 \mathrm{~g} / \mathrm{cm}^{3}$ (theoretical) \\
\hline Smeared density & $75 \%$ \\
\hline Coolant & $\mathrm{Pb}-\mathrm{Bi}$ \\
\hline Core-average coolant temperature and density & $521{ }^{\circ} \mathrm{C} ; 10.09 \mathrm{~g} / \mathrm{cm}^{3}$ \\
\hline Temperature of Pb-Bi coolant in the chimney & $580{ }^{\circ} \mathrm{C}$ \\
\hline Temperature of Pb-Bi coolant in lower plenum & $462{ }^{\circ} \mathrm{C}$ \\
\hline Based on INEEL cladding stress and strain evaluations - see Section 4.1. \\
\hline
\end{tabular}




\subsubsection{Power Distribution and Peak Fast Fluence}

Figures 61 through 63 depict normalized assembly-averaged power distribution for the 157 fuel assembly core, pin power distribution in the hot fuel assembly and the axial power profile in the hot FA, respectively. The radial power peaking is reduced compared to 69 -fuel assembly core version - a result of (1) slightly larger enrichment difference between the outer and inner core, (2) increased neutron migration area due to added peripheral streaming channels, and (3) a larger fraction of depleted uranium, which has a smaller capture cross section than the thorium, further increasing the neutron mean free path. Thus, the higher peaking typical of larger cores was effectively mitigated through improved enrichment zoning and streaming design measures. This will also reduce maximum fluence on the cladding. Pin power peaking is also very small, although it should be noted that the statistical error in the pin powers is relatively large, making judgments on the trend of the power profile within fuel assemblies difficult, given the small differences between individual powers, which fall mostly within statistical error. The axial power profile is relatively flat with a maximum peak-to-average ratio of 1.155. Thus the maximum peaking is only:

$$
\mathrm{k}_{\mathrm{tot}}=1.160 * 1.155 * 1.015=1.360 \text {. }
$$

More importantly, peak fast flux on cladding is substantially reduced in comparison with the small core alternative, i.e.,

$$
\phi \max =1.92 \times 10^{15} \mathrm{n} / \mathrm{cm}^{2}-\mathrm{s}(\mathrm{E}>0.1 \mathrm{MeV}),
$$

yielding peak fluence of $4.2 \times 10^{23}(\mathrm{E}>0.1 \mathrm{MeV}) \mathrm{n} / \mathrm{cm}^{2}$. This is close to the limiting value of 4.0 $\mathrm{x} 10^{23}(\mathrm{E}>0.1 \mathrm{MeV}) \mathrm{n} / \mathrm{cm}^{2}$ for HT-9 steel. Therefore, operation without refueling of about 8 years seems feasible based on the fluence limit on core structures. Further optimization and more accurate calculations, including the change of local flux and of the location of the most exposed spot during burnup would be required to determine if actual fluence can be reduced further.

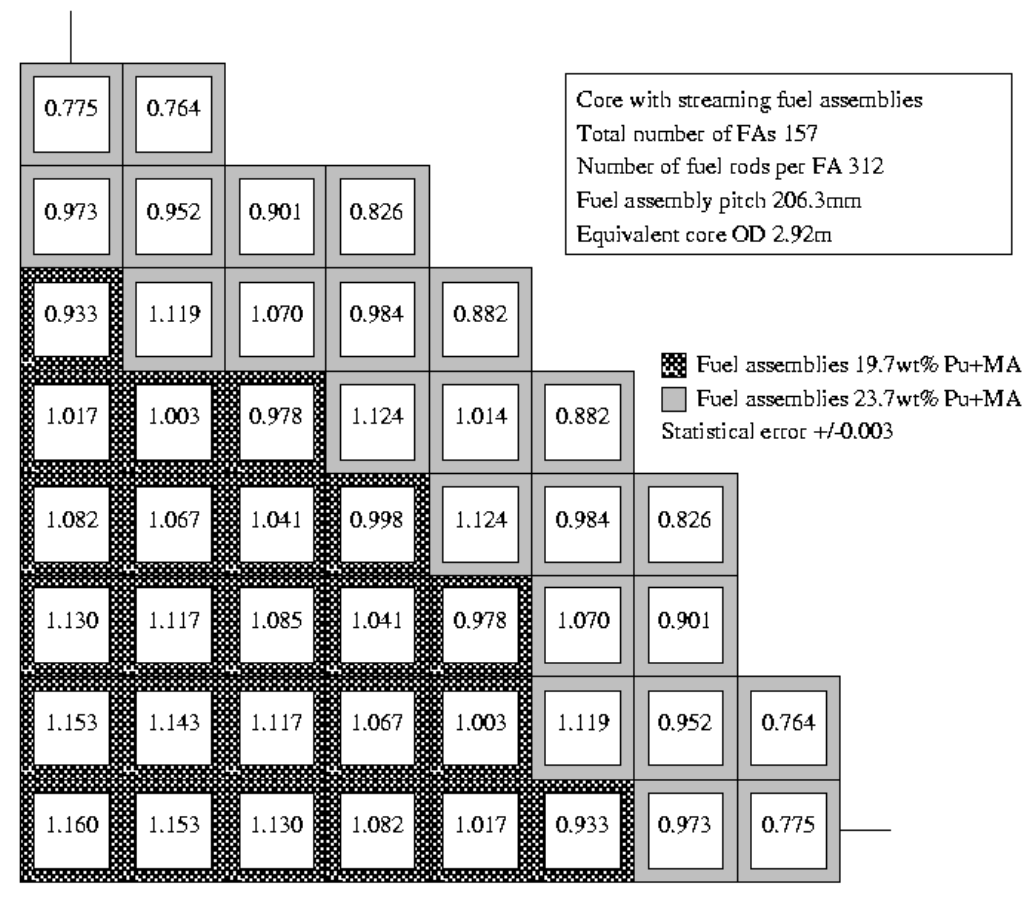

Figure 61. Fuel assembly power distribution for the reference core design. 


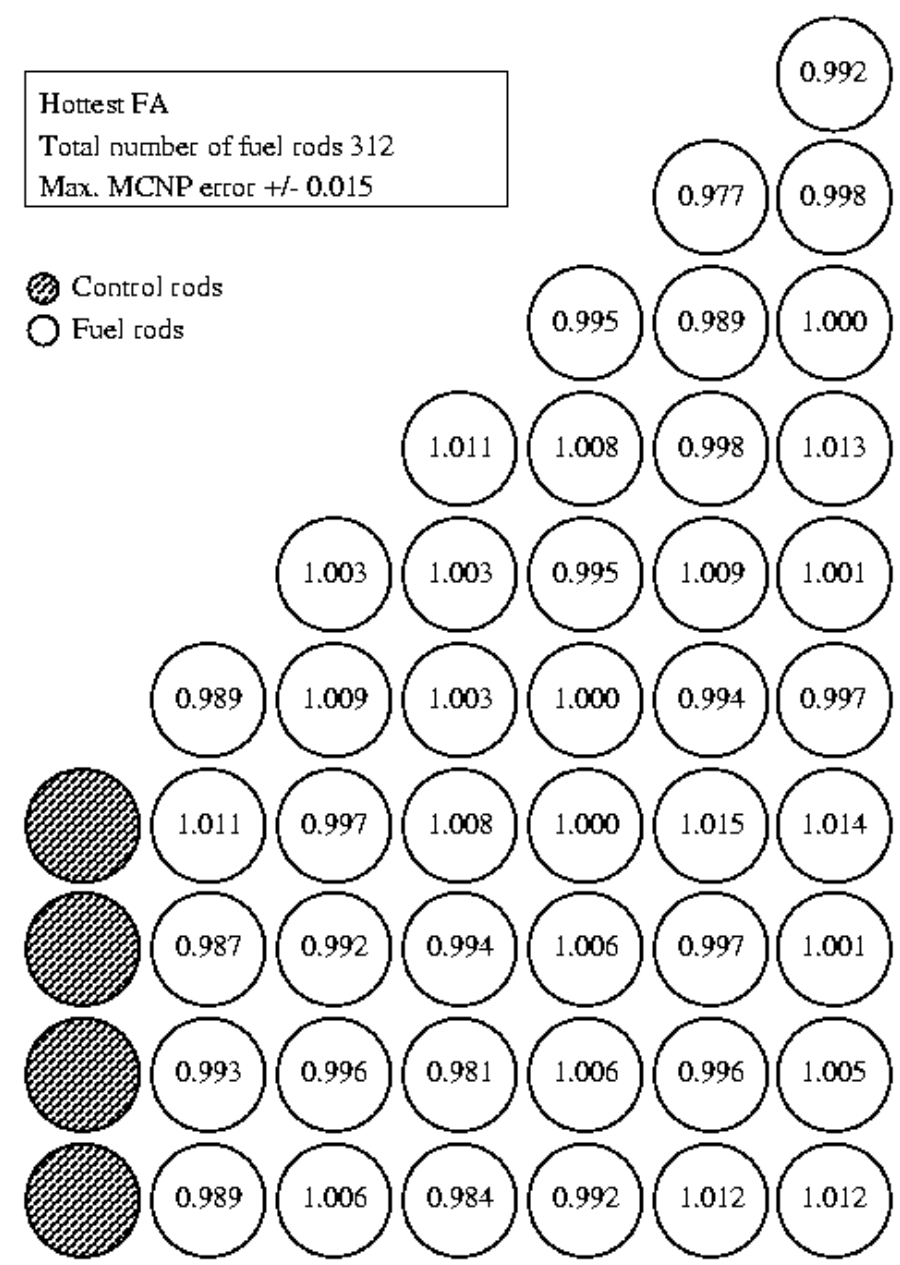

Figure 62. Pin power distribution in hot fuel assembly for the reference design.

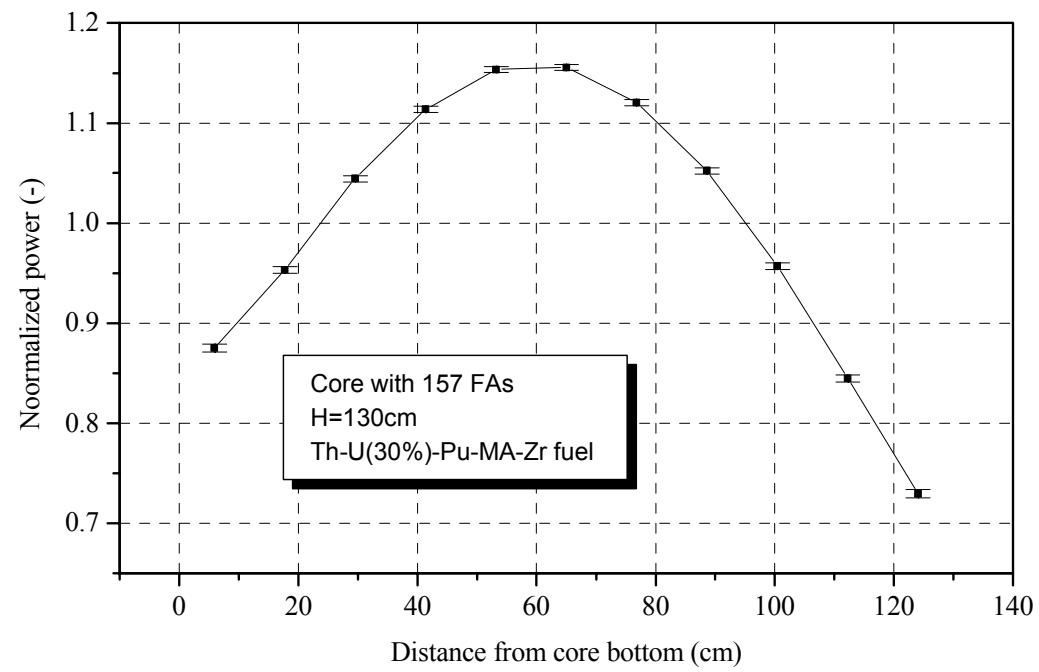

Figure 63. Normalized axial power distribution in hot fuel assembly for the reference design. 


\subsubsection{Reactivity Response to Coolant Density Changes}

Reactivity changes with coolant density are plotted in Figure 64. Coolant void reactivity worth is negative (the case of voiding all coolant in the core corresponds to zero density on Figure 64). If coolant density is decreased homogeneously through the core, reactivity is increased for densities down to $4 \mathrm{~g} / \mathrm{cc}$. In comparison with the small core design where maximum reactivity addition was zero, this slight reactivity increase is a consequence of (1) larger core size and (2) higher U-238 loading. Nevertheless, the maximum reactivity insertion remains less than $1 \$(0.8 \$)$.

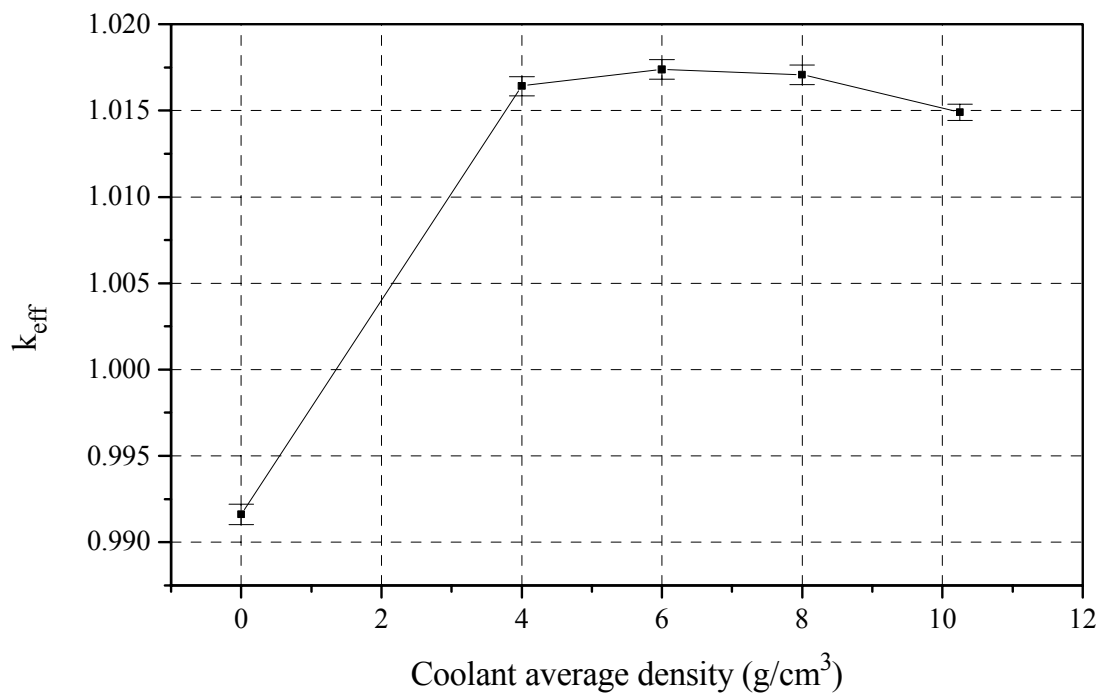

Figure 64. Reactivity response to coolant density changes.

Further, it is to be noted that the density of $6 \mathrm{~g} / \mathrm{cc}$ cannot be effectively reached through coolant heat up, because the density just prior to when the boiling point of $1670^{\circ} \mathrm{C}$ is reached is $8.7 \mathrm{~g} / \mathrm{cc}$, corresponding to a reactivity insertion of $+0.46 \$$. But even this high temperature cannot be reached because the core structural material and fuel would melt first. Therefore, assuming that the maximum allowable coolant temperature is equal to the transient cladding temperature limit, i.e., $725^{\circ} \mathrm{C}$, the minimum density from the coolant temperature changes is $9.85 \mathrm{~g} / \mathrm{cc}$, corresponding to a very small reactivity insertion of $0.08 \$$, or $0.04 \xi /{ }^{\circ} \mathrm{C}$. This is almost 5 times less than the $18 \mathrm{\xi} /{ }^{\circ} \mathrm{C}$ value estimated for a sodium cooled IFR core. Because the IFR was designed to have a self-control capability, the smaller coolant density reactivity coefficient will make it easier to attain self-regulating characteristics for the proposed core. These studies will be subject of future investigations.

Finally, it is to be noted that although a higher positive coolant temperature coefficient may be feasible from a self-control viewpoint, the philosophy adopted for this design was to keep the maximum reactivity insertion less than $1 \$$ to constraint power surges during hypothetical scenarios of gas or steam ingress of bubbles into the core, such as from ruptured tubes of the intermediate heat exchanger, when coolant densities in the core might be below those corresponding to the melting point. Adopting this philosophy, the addition of streaming channels at the fuel assembly periphery is necessary, because the employment of fuel assemblies with central streaming channels only (see Figure 53) in the large core would yield a peak reactivity insertion of $+3.5 \$$. 


\subsubsection{Burnup Performance}

Burnup calculations for the detailed 1/8th 157-fuel assembly core model were performed using the MONTEBURNS MCNP-ORIGEN coupling program. MOCUP was also used for comparative purposes. Because neutron flux across the core is relatively flat and neutron migration area is large, only two core regions were modeling by MONTEBURNS, assuming that each entire region is exposed to a constant region-averaged neutron flux. Sixty-two fission products and 37 actinides were tracked in MOCUP in each region throughout the entire burnup period. MONTEBUNRS automatically selects the key fission products and actinides based on their fractional importance. If any of the following values: atom fraction, weight fraction, fraction of absorption, and fraction of fission are greater than the value of the "fractional importance", the isotope is included in all transfers from ORIGEN to MCNP through the remainder of the run. The fractional importance was assigned to be $0.1 \%$.

A relatively large number of neutron histories $(300,000)$ was chosen in both MOCUP and MONTEBURNS to attain a small MCNP statistical error. The error on neutron flux was less than $0.2 \%$. The error on reaction rates varied from nuclide to nuclide; most of the errors were less than $0.5 \%$ and the largest error for nuclides with very low number density was $1.2 \%$. A time step for the MCNP updates of the cross sections of 400 days was used in the analysis. Sensitivity to the selection of the time step was not evaluated due to the very long running times required (24 hours per 1 step on a 500MHz Digital Alpha Workstation).

Figure 65 shows the trace of $\mathrm{k}_{\mathrm{eff}}$ as a function of irradiation time obtained by MONTEBURNS and MOCUP. Note the significant difference in reactivity trend during the first three burnup steps. This discrepancy can be attributed to MOCUP inaccuracies during the first step due to the long time step. It is expected that shorter MOCUP steps would reduce this discrepancy. While MOCUP uses the cross sections calculated by MCNP at the beginning of each step (macro-step), MONTEBURNS employs a more accurate approach to improve accuracy during the burnup calculations by running ORIGEN2 halfway through the designated burnup step to predict compositions at the step midpoint. MCNP is then run to edit the cross sections at the midpoint, which are then used in the ORIGEN2 re-execution to predict the composition at the end of step. This way, the isotopics at the midpoint (and thus the neutron flux spectrum) is taken as representative for the burnup step calculations rather than the conditions at the beginning of the step. Hence, the MONTEBURNS results in the initial stages of burnup on Figure 65 are assumed to be more accurate than the MOCUP results. Moreover, detailed and rigorous benchmark calculations of MOCUP against CASMO4 on ultra-high burnup LWR lattices, currently ongoing at MIT, show that MOCUP tends to over-predict reactivity at higher burnup. The major reason for this discrepancy was identified to be inaccurate prediction of actinide number densities due to the accumulation of small inaccuracies in the cross section calculations at the beginning of each step, where the spectrum is less representative for the step than for the mid-step conditions. MONTEBURNS, with the mid-point strategy, was found to yield results significantly closer to those of CASMO4. On the other hand other MIT investigations found that MONTEBURNS tends to over predict the reactivity for fuels with a high fraction of americium because it does not provide the possibility to track both the stable and meta-stable isotopes of Am-242 and because it alters the branching ratio between stable and excited states. However, MONTEBURNS was selected for burnup analyses because the amount of the Am-241 is relatively small in comparison to other actinides and because MONTEBURNS is easier to use and consumes less CPU than MOCUP. 


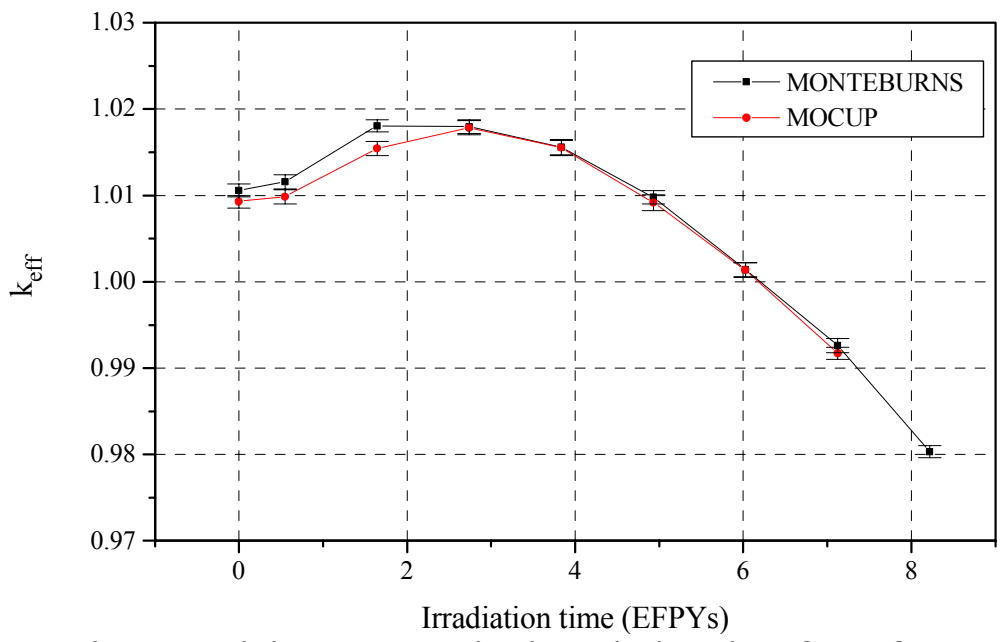

Figure 65. Reactivity change with irradiation time for reference core.

Figure 66 shows the development of the reactivity versus the irradiation time for two different TRU loadings. It can be observed that for a TRU loading of $21.7 \mathrm{wt} \%$, the reactivitylimited irradiation time is about 6.6 EFPYs, or 7.8 years assuming $85 \%$ capacity factor. The maximum reactivity excess of $2.3 \% \Delta \mathrm{k} / \mathrm{k}$, or $8 \$$ is reached at $\sim 2$ EFPYs. Such a small reactivity excess can be easily compensated by a small number of control rods. The proposed number of control rods is 21 (see Figure 59), hence the reactivity vested in one control rod at the peak reactivity excess is on the average $0.4 \$$. Refined analyses will be performed in the future to identify the control rod with maximum worth and design modifications will be made, if necessary, to ensure compliance with the $\mathrm{S} 3$ criterion. The reactivity excess can be reduced by a decrease in the TRU loading, as can be seen by comparing the two curves on Figure 66. However, the loading of $21.5 \mathrm{wt} \%$ TRU achieves a smaller reactivity-limited burnup, hence the $21.7 \mathrm{wt} \%$ loading $(23.7 \mathrm{wt} \%$ outer and $19.7 \%$ inner region) was adopted as the reference case. Further flattening of the burnup curve could be achieved by enlarging the pin diameter, because that would allow an increase of the fractional neutron absorptions in the heavy metal (rather than in the core structures) and thus an increase of the conversion ratio. However, the cladding stress constraint (M4-criterion) limits further increases of cladding diameter.

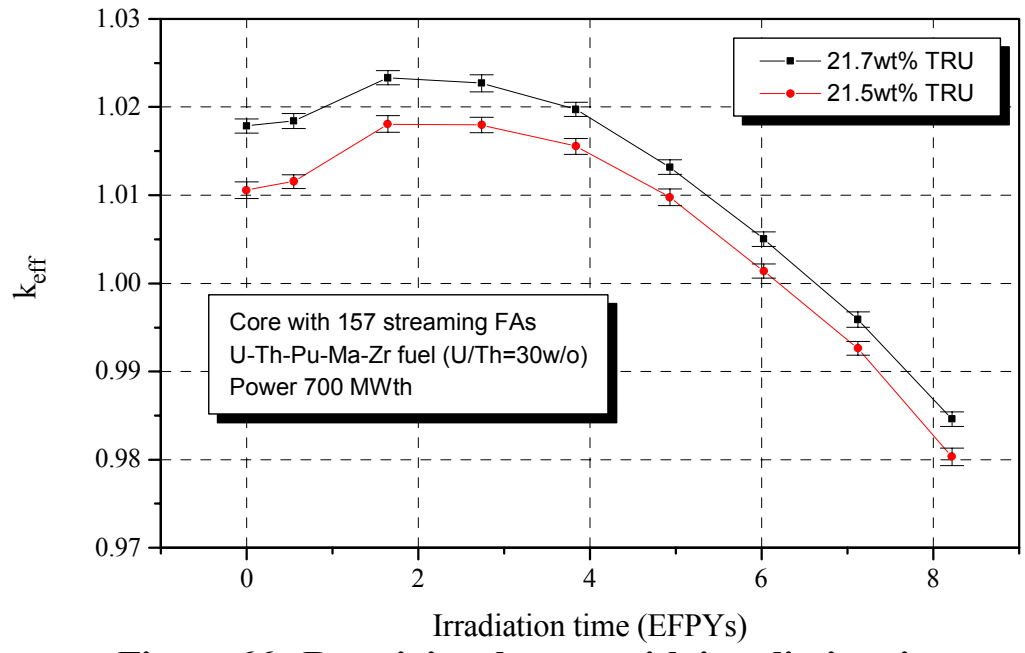

Figure 66. Reactivity changes with irradiation time. 
The fuel burnups in the inner and outer core regions are plotted versus irradiation time on Figure 67. The burnup in the inner core is higher due to the higher neutron flux in this region. The discharge burnup of $140 \mathrm{MWd} / \mathrm{kgHM}$ in the inner core is well within the established experience for metal U-Pu-Zr fuels. Note the burnup shown is region-averaged, hence the peak burnup will be higher. However, because the flux peaking within the inner region is small, it is not expected that peak burnup in the central fuel assembly will exceed $160 \mathrm{MWd} / \mathrm{kgHM}$. Thus, the limit on peak burnup is easy to satisfy in the proposed core design. Note that the core is designed for 1-batch refueling: all fuel is assumed to be removed from the core after 8 years and replaced by fresh fuel.

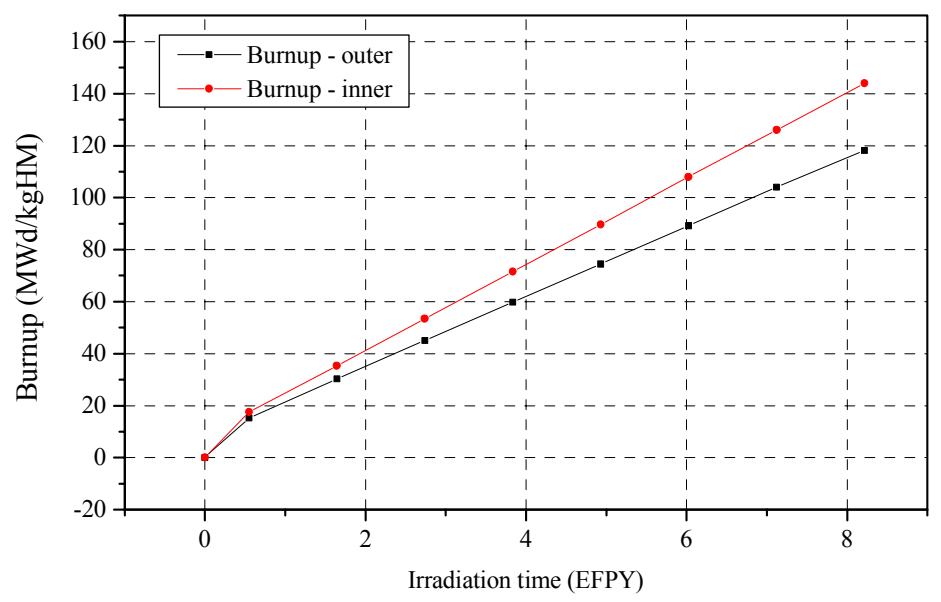

Figure 67. Burnup in the inner and outer core as a function of irradiation time.

The consumption rate of the individual transuranic isotopes per EFPY is depicted on Figure 68. In comparison with the fertile-free actinide burner investigated earlier during this project [Hejzlar et. al., 2001] or the fertile-free MABR discussed in Section 3.4, the TRU destruction rate per MWth is about $35 \%$ less. Hence, the actinide burning penalty for introducing the fertile U238 is relatively small and high TRU burning rates can be achieved. This destruction rate exceeds the target by $10 \%$. It is instructive to compare this TRU consumption rate with that of the ATW. The ATW designers report a destruction of $650 \mathrm{~kg} / \mathrm{y}$ per $2000 \mathrm{MWt}$, or $0.325 \mathrm{~kg} / \mathrm{y}$ per MWt. This compares with $0.24 \mathrm{~kg} / \mathrm{EFPY}$, or $0.204 \mathrm{~kg} / \mathrm{y}$ assuming $85 \%$ capacity factor for this actinide burner reactor design. Thus, the destruction rate per year is $63 \%$ of that of ATW. This is an impressive destruction rate considering the presence of fertile material and comparing the simplicity of the proposed reactor with the complex accelerator-reactor tandem configuration.

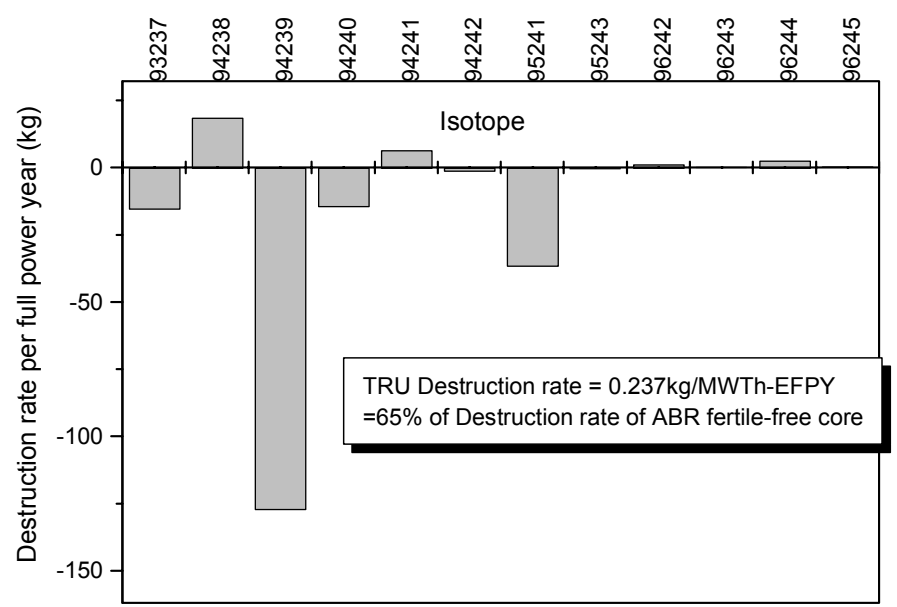

Figure 68. TRU Consumption rate per full power year for reference core. 
Moreover, it should be noted that the assumed capacity factor of $85 \%$ for the actinide burner reactor is a conservative value. With no refueling for 8 years, $95 \%$ capacity factors should be achievable, increasing the destruction rate per year further to about $70 \%$ of that of the ATW. On the other hand, the capacity factor of $75 \%$ for the ATW may be optimistic considering the availability data of current accelerators. This is because: (1) the capacity factor of two systems, which must be operating to maintain the operation of the whole unit is less than the capacity factor of one system and (2) current large accelerators experience frequent trips. The latter reason is a key issue to be resolved in further accelerator development because in current high-power accelerators the time between failures is measured in hours or tens of hours, [Eriksson M. and Piaszczyk, 1998]. Even an increase of the mean time between failures to 100 hours, which is a substantial step forward from current values (by one to two orders of magnitude), is not sufficient for a power production systems required capacity factor of $75 \%$.

Finally, note that current evaluations did not assume reprocessing of the spent actinide burner reactor fuel and recycling it back through the actinide burner reactor to reach equilibrium mass

flows. This is consistent with the philosophy described in Chapter 2. Multi-recycling will be evaluated in the future.

\subsubsection{Proliferation Considerations}

Figure 69 shows that the $12 \%$ proliferation limit on uranium is reached at about 6 EFPY, i.e., at a slightly shorter irradiation time than the reactivity limited timescale. However, the overshoot is small and the content of the depleted uranium can be slightly increased in the future to further reduce the U-233 content in the discharged fuel. Multiple recycling of spent actinide burner reactor fuel was not evaluated. Once this option is introduced in the future, the content of the U238 in total uranium will have to be further increased to satisfy the proliferation constraint at equilibrium. The approximate ratio of atomic densities of U-238 to Th-232 necessary to comply with this constraint can be derived from equality of U-233 generation and destruction in equilibrium, i.e.,

$$
N^{T h 232} \sigma_{c}^{T h 232}=N^{U 233} \sigma_{a}^{U 233}
$$

and the requirement that:

$$
\frac{N^{U 233}}{N^{U 233}+N^{U 238}} \leq 0.12
$$

to yield:

$$
\frac{N^{U 233}}{N^{T h 232}} \geq \frac{\sigma_{c}^{T h 232}}{\sigma_{a}^{U 233}} \frac{0.12}{1-0.12}=\frac{0.251}{2.426+0.223} \frac{0.12}{1-0.12}=0.68, \text { or } \frac{N^{U 238}}{N^{T h 232}+N^{U 238}} \geq 0.41
$$

where the one-group cross sections were edited from the MCNP4B model of the reference core. Therefore, the fraction of $\mathrm{U} /(\mathrm{U}+\mathrm{Th})$ will have to be increased to satisfy the proliferation constraint in multi-recycled fuel from 30 to $42 \%$, making some allowance for the U-235, which was not accounted for in this simplified assessment. 


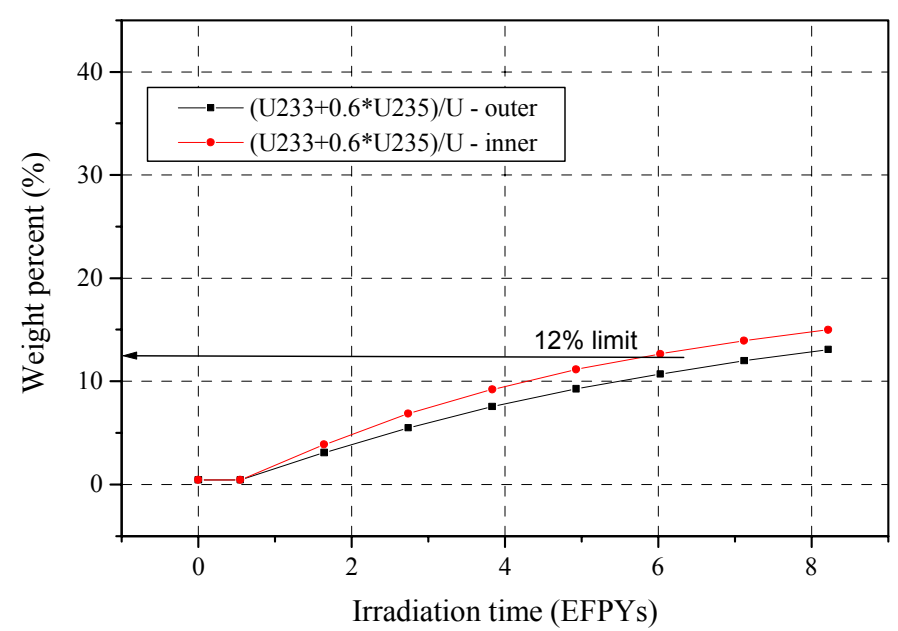

Figure 69. Proliferation index for fissile uranium.

The plutonium isotopics are significantly degraded from that of the PWR spent fuel vector, making it virtually weapons unusable - see Figure 70. Especially noteworthy is that the content of the Pu-238 is very high $(\sim 7 \mathrm{wt} \%)$ due to the $\beta^{-}$decay of the Np-238, which is generated upon neutron capture in the Np-237. Also, the fraction of other even isotopes is very high, i.e., 35 and $7 \mathrm{wt} \%$ for $\mathrm{Pu}-240$ and $\mathrm{Pu}-242$, respectively.

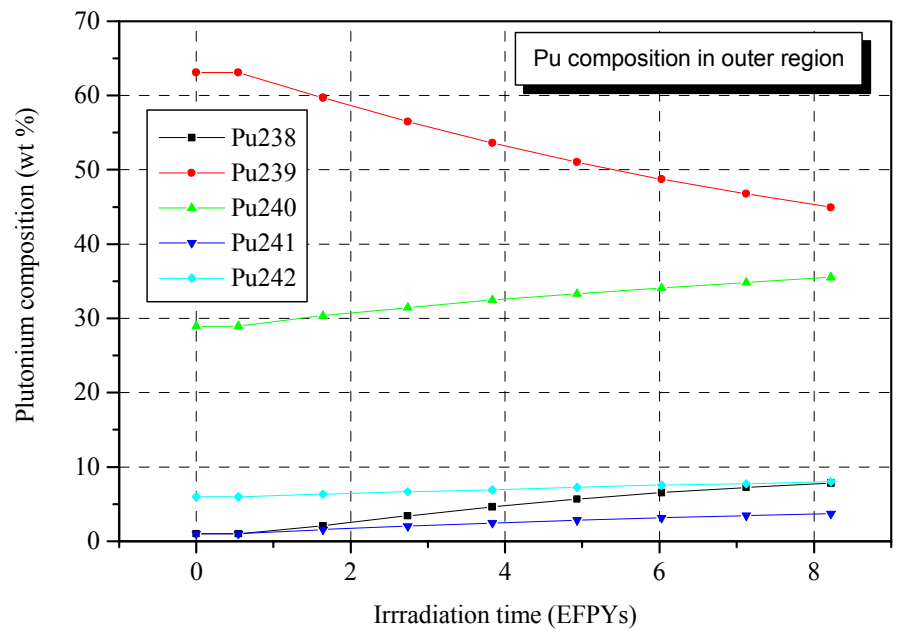

Figure 70. Plutonium vector in the outer core region for fuel with $30 \mathrm{w} / \mathrm{o} \mathrm{U}$.

\subsubsection{Delayed Neutron Fraction}

The effective delayed neutron fraction was calculated using the MCNP4C model of the full core at beginning-of-life to yield:

$$
\beta_{\text {eff }}=\frac{k-k_{p}}{k}=\frac{1.01491-1.01207}{1.01491}=0.0028 \pm 0.0003
$$

where $\mathrm{k}$ is the eigenvalue obtained with all neutrons, i.e., both prompt and delayed, and the $k_{p}$ is the eigenvalue computed using prompt neutrons only. Note that MCNP4C accounts for a 
different spectra for the delayed and prompt neutrons. For consistency, identical libraries accounting for unresolved resonances (61c) were used and the effect of the delayed neutrons in the prompt criticality calculations was turned off through the TOTNU card.

It needs to be noted that the above calculations did not incorporate the effects of the photoneutrons produced outside the fuel. Some of these photo-neutrons are produced by delayed gamma rays contributing to the delayed neutron population. Also, some delayed neutrons will be multiplied by $(n, 2 n)$ and $(n, 3 n)$ reactions in the large mass of coolant. However, it is expected that the contribution from photo-production and $(\mathrm{n}, \mathrm{xn})$ reactions to the total effective yield will be small.

This value is compared with the effective delayed neutron fraction of other fast reactors in Table 26.

Table 26. Comparison of $\beta_{\text {eff }}$ with various fast reactor designs.

\begin{tabular}{|c|c|c|c|}
\hline Reactor & Fuel & $\beta_{\text {eff }}$ & Reference \\
\hline \hline Super Phenix (France) & $\mathrm{UO}_{2}-\mathrm{PuO}_{2}$ & 0.004 & Waltar and Reynolds [1981] \\
\hline CDFR (UK) & $\mathrm{UO}_{2}-\mathrm{PuO}_{2}$ & 0.003 & Waltar and Reynolds [1981] \\
\hline SNR-2 (Germany) & $\mathrm{UO}_{2}-\mathrm{PuO}_{2}$ & 0.004 & Waltar and Reynolds [1981] \\
\hline Conventional IFR core & Metallic U-Pu-Zr fuel & 0.0034 & Hill et. al., [1995] \\
\hline Pure Pu burner core & $\begin{array}{c}\text { Metallic } \mathrm{Pu}-28 \mathrm{Zr}+\mathrm{Hf}-26 \mathrm{Zr} \\
\text { fuel }\end{array}$ & 0.002 & Hill et. al., [1995] \\
\hline Pure MABR & $\mathrm{Pu}-\mathrm{Ma}-\mathrm{Zr}$ & 0.0021 & \\
\hline Optimized core design & U-Th-Pu-MA-10Zr & $\mathbf{0 . 0 0 2 8}$ & - \\
\hline
\end{tabular}

The delayed neutron fraction is less than the values for mixed oxide cores, and also less than $\beta_{\text {eff }}$ for a conventional metal-fueled IFR core. The streaming core contains less weight fraction of fertile isotopes ( $\mathrm{U}$ and $\mathrm{Th}$ ), hence less neutrons are absorbed and fissioned in these nuclides than in an IFR core. Because neutrons from the fertile fissions provide an appreciable contribution to the overall neutron population and because yields of delayed neutrons from fissions of these isotopes is high, the delayed neutron fraction is reduced in low fertile content fuel. In addition, increased neutron leakage out of the core in the optimized streaming core is responsible for an increased loss of delayed neutrons, which are more likely to be absorbed in structural materials outside the core in comparison with prompt neutrons. Thirdly, the higher actinides, in particular the Am-241, have a small delayed neutron yield, contributing to a reduced $\beta_{\text {eff. }}$ Therefore, the optimized core exhibits a smaller delayed neutron fraction than in a conventional IFR.

On the other hand, a significant improvement in comparison to the pure actinide burner and the minor actinide burner designs, investigated earlier, can be observed. Thus, the effect of fertile isotopes proved to be beneficial.

Table 27 shows the delayed neutron fraction calculated from the fission fractions (obtained from MCNP4C) and the delayed neutron yield of the individual species. Comparing this value with the effective delayed neutron fraction, it can be observed that $\beta_{\text {eff }}$ is $12.5 \%$ less than $\beta$. Thus, the differences in delayed and prompt neutron spectra are important in a hard spectrum reactor and use of the MCNP4C code is necessary to calculate $\beta_{\text {eff }}$ with sufficient accuracy. 
Table 27. Estimate of delayed neutron fraction $\beta$ for optimized core.

\begin{tabular}{|c|c|c|c|c|}
\hline \multicolumn{3}{|c|}{ 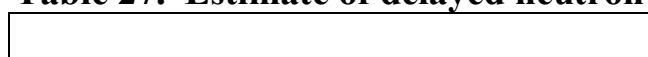 } & \multicolumn{2}{|l|}{ Fresh core } \\
\hline Nuclide & $\mathbf{Y}_{\mathrm{i}}^{*}$ & $\mathrm{v}^{* * *}$ & Fission. fraction, $F_{i}$ & $\beta_{i}=Y_{i} / v F_{i}$ \\
\hline Th232 & 0.0564 & 2.396 & 0.01694 & $3.9883 \mathrm{E}-04$ \\
\hline $\mathrm{U}-235$ & 0.0206 & 2.468 & 0.01018 & 8.4946E-05 \\
\hline $\mathrm{U}-238$ & 0.0405 & 2.776 & 0.03017 & 4.4011E-04 \\
\hline $\mathrm{Np}-237$ & 0.0114 & 2.935 & 0.01916 & 7.4436E-05 \\
\hline $\mathrm{Pu}-238$ & 0.0079 & 3.009 & 0.00818 & 2.1484E-05 \\
\hline $\mathrm{Pu}-239$ & 0.0068 & 2.946 & 0.77058 & 1.7787E-03 \\
\hline $\mathrm{Pu}-240$ & 0.0081 & 3.024 & 0.08336 & $2.2329 \mathrm{E}-04$ \\
\hline $\mathrm{Pu}-241$ & 0.0142 & 2.978 & 0.01562 & $7.4472 \mathrm{E}-05$ \\
\hline $\mathrm{Pu}-242$ & 0.0143 & 3.075 & 0.01200 & $5.5820 \mathrm{E}-05$ \\
\hline Am-241 & 0.0051 & 3.402 & 0.03158 & 4.7337E-05 \\
\hline Am-243 & 0.008 & 3.653 & 0.00191 & $4.1884 \mathrm{E}-06$ \\
\hline $\mathrm{Cm}-244$ & 0.0013 & 3.868 & 0.00032 & $1.0613 \mathrm{E}-07$ \\
\hline Total & - & - & 1.00000 & $\beta=\mathbf{0 . 0 0 3 2 0}$ \\
\hline
\end{tabular}

Total delayed neutron yield from Brady and England [15].

${ }^{* *}$ Fast fission neutron yield from ORIGEN2.1 computer code.

${ }^{+}$Data not found, assumed zero in the calculations to give conservative $\beta_{\text {eff }}$.

\subsubsection{Doppler Coefficient}

In fast reactors fueled by $\mathrm{UO}_{2}-\mathrm{PuO}_{2}$, the major contribution to the Doppler coefficient comes from the increase of the U-238 capture cross section with temperature in the energy range $10 \mathrm{eV}$ to $10,000 \mathrm{eV}$. The lead or lead-bismuth-cooled metal-fueled core has a much harder spectrum than the sodium cooled core, both due to the heavy metal nuclides in the coolant and due to absence of oxygen (which also provides some moderation) in the fuel. Therefore, the fraction of neutrons in the energy range below $100 \mathrm{eV}$ is very small and only the resonances above $100 \mathrm{eV}$ contribute to the Doppler effect in this reactor. Hence, a smaller Doppler effect than in oxidefueled, sodium-cooled fast breeder reactors is expected. The proposed reactor contains much less U-238 than a typical fast breeder reactor since U-238 is replaced mostly by Th-232, which becomes the major fertile nuclide. Thorium has fewer resonances in the energy range 10$10,000 \mathrm{eV}$, but higher peaks at higher energies, hence thorium is an important nuclide contributing to a negative Doppler effect in this hard-spectrum reactor.

The Doppler coefficient was calculated using the MCNP code with the UTXS temperature dependent cross section libraries imported from the University of Texas [Abdelrahman and Abdurrahman, 1998]. For the Am-241, Np-237, and Cm-244 isotopes, libraries generated at INEEL specifically for this project were used (see Section 3.1). The results of the full core (control rod drives withdrawn) calculations at beginning-of-life are presented in Table 28.

Table 28. Doppler coefficients for full core model of the 157 fuel assembly core (at BOL).

\begin{tabular}{|l|l|l|}
\hline Case & $\mathbf{k}_{\text {eff }}$ & Doppler $(\mathbf{c} / \mathbf{K})^{*}$ \\
\hline Case 1- Reference fuel, control rod drives withdrawn, T=300K & $1.01568 \pm 0.0003$ & \\
\hline $\begin{array}{l}\text { Case 1 - Reference fuel, control rod drives withdrawn, } \\
\text { T=1154K }\end{array}$ & & \\
\hline Case 1 - Doppler coefficient & & $\mathbf{- 0 . 0 7 \pm 0 . 0 1}$ \\
\hline
\end{tabular}

${ }^{*}$ Assumes $\beta_{\text {eff }}=0.0028$, as calculated in the previous section, the Doppler coefficient is the linearized average value between the temperatures 300 and $1154 \mathrm{~K}$. 
In typical liquid metal fast breeder reactors, the Doppler coefficient is described by a law of the type [Salvatores, 1986]:

$$
T \frac{d K_{D}}{d T}=A T^{-\alpha}
$$

where $\mathrm{A}$ and $\alpha$ are constants. In practice the Doppler coefficient in a $1200 \mathrm{MWe}$ liquid metal fast breeder reactor varies from $\sim-1.2 \mathrm{pcm} /{ }^{\circ} \mathrm{C}$ at $400{ }^{\circ} \mathrm{C}$ to $\sim-0.5 \mathrm{pcm} /{ }^{\circ} \mathrm{C}$ at $1200^{\circ} \mathrm{C}$ [Salvatores, 1986]. Substituting these values in the above equation, the unknown constants can be calculated to match Doppler coefficients at temperatures of $400^{\circ} \mathrm{C}$ and $1200^{\circ} \mathrm{C}$. This procedure yields the constants. $A=-0.01737$ and $\alpha=-0.11765$. Using the above equation with these constants yields Doppler coefficients for the temperatures used in the MCNP Doppler calculations, i.e., $2.9 \mathrm{pcm} /{ }^{\circ} \mathrm{C}$ at $300 \mathrm{~K}$ and $\sim-0.7 \mathrm{pcm} /{ }^{\circ} \mathrm{C}$ at $1154 \mathrm{~K}$; or using the typical liquid metal fast breeder reactor delayed neutron fraction of 0.0035 , one obtains $\sim-0.83 \phi / \mathrm{K}$ at $300 \mathrm{~K}$ and $\sim-0.2 \phi / \mathrm{K}$ at $1154 \mathrm{~K}$. The linearized Doppler coefficient for our reference fuel between these temperatures is $0.07 \phi / \mathrm{K}$, which is six times less than the above values. Because the dependence of the Doppler coefficient in a hard spectrum reactor is different from that of the oxide-fueled reactors, a more consistent comparison is the reactivity change between the above temperatures. The Superphenix Doppler constant $T d k / d T=0.0086$ [Waltar and Reynolds, 1981]. Since for fast oxide-fueled reactors the temperature dependence of $d k / d T$ is almost exactly $d k / d T=K_{D} / T$, the change of reactivity from the temperature increase between $558 \mathrm{~K}$ and $1154 \mathrm{~K}$ can be calculated from the integral:

$$
\Delta k=\int_{558}^{1154} \frac{d k}{d T} d T=\int_{558}^{1154} \frac{K_{D}}{d T} d T=K_{D} \ln \frac{300}{1154}=0.0086 \ln \frac{300}{1154}=-0.012
$$

The reactivity reduction between the same temperatures for the reference core can be calculated directly from Table 28 as -0.002 , which is six times less than the values typical for fast oxidefueled, sodium-cooled reactors.

Although significantly smaller, the Doppler coefficient of the proposed fuel remains negative. Regarding the small magnitude of the Doppler effect, it is to be noted that other operating reactors also exhibit similar values. For U-235-fueled reactors using metal fuels, the Doppler effect is very small (less than $0.1 \mathrm{pcm} / \mathrm{K}$ ) and may even be positive [Hetrick, 1993]. The experimental breeder reactors EBR-I and EBR-II fall in this category. Hill et. al., [1995] reported the value of the Doppler coefficient for metal fueled IFR of $\sim-0.05 \phi / K$, which is comparable to the value calculated for the reference fuel of the actinide burner.

Because the ultimate goal is to achieve self-regulating reactor characteristics and inherent shutdown in ULOF, UTOP and ULOHS transients, the Doppler coefficient must be negative and fall within the range to satisfy the S-criteria. As discussed in Section 3.5.1, these criteria favor a small negative Doppler feedback. Therefore, the Doppler coefficient of $-0.07 \phi / \mathrm{K}$ in combination with the negative prompt fuel thermal expansion coefficient provides a very good starting point for further optimization to achieve self-controllability.

\subsubsection{Fuel Thermal Expansion Effect}

The fuel rods expand and affect the reactivity during fuel heat up, due to changes in the dimensions and specific density. Reactivity changes from fuel expansion provide prompt 
reactivity feedback in addition to the Doppler effect. Upon a temperature increase, both the diameter and length of the fuel rods increase. The increased fuel rod dimensions reduce the leakage from the core and lead to a reactivity increase. On the other hand, the specific density of the fuel is reduced leading to a reactivity reduction. Typically, the overall effect is a reactivity reduction.

A full core model was used to calculate the thermal expansion effect. All dimensions and concentrations throughout the core were kept fixed, except for the fuel, which was assumed to elongate its height into the upper gas plenum and increase its diameter, as indicated in Figure 71. Also, the fuel density change leads to changes in the number densities. To eliminate the effects of fuel temperature variations on other reactivity-related aspects, such as the Doppler coefficient and scattering fuel properties, the fuel temperature was held constant in all those calculations. Thus, the analysis yields only the effect of the thermal expansion of the fuel.

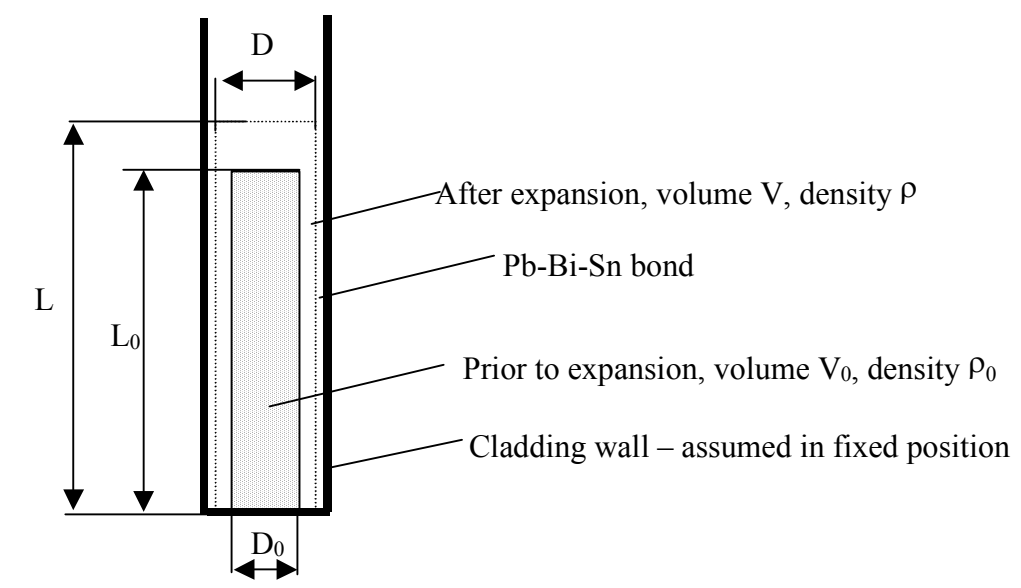

Figure 71. Thermal expansion model of fuel pin.

If the fuel linear thermal expansion coefficient is known, the expanded dimensions can be calculated as:

$$
\mathrm{L}=\mathrm{L}_{0}(1+\alpha \Delta \mathrm{T}) \text { and } \mathrm{D}=\mathrm{D}_{0}(1+\alpha \Delta \mathrm{T})
$$

for length and diameter, respectively. Further, one can derive the fuel density change to be proportional to volumetric change, i.e.,

$$
\frac{\rho}{\rho_{o}}=\frac{V_{o}}{V}=\left(\frac{1}{1+\alpha \Delta T}\right)^{3} .
$$

A large temperature change of $600^{\circ} \mathrm{C}$ (from 20 to $620^{\circ} \mathrm{C}$ ) was taken to maximize the fuel thermal expansion effect so that the computed reactivity change would be larger than the statistical uncertainty of the MCNP results. The average coefficient of thermal expansion for each of the fuel isotopes in the range $20-620^{\circ} \mathrm{C}$ was used for the calculations. For some isotopes, the coefficient of thermal expansion dependence on temperature was not available, values at room temperature were used. This assumption yields smaller dimensional changes, i.e., conservative results, since the thermal expansion and density changes increase with higher temperature. The coefficients of thermal expansion for the individual fuel nuclides, which were used in the analysis, are summarized in Table 29. 
Table 29. Coefficients of thermal expansion used in the calculations.

\begin{tabular}{|l|c|c|c|}
\hline Nuclide & CTE $(\mathbf{m} / \mathbf{m}-\mathbf{K})$ & Vol\% in mixture & Contribution to CTE \\
\hline $\mathrm{U}$ & $19 \times 10^{-6}$ & $5.07 \mathrm{E}-01$ & $5.63 \mathrm{E}-06$ \\
\hline $\mathrm{Th}$ & $11.1 \times 10^{-6}$ & $1.34 \mathrm{E}-01$ & $2.54 \mathrm{E}-06$ \\
\hline $\mathrm{Pu}$ & $37 \times 10^{-6}$ & $1.22 \mathrm{E}-01$ & $4.53 \mathrm{E}-06$ \\
\hline Zirconium & $6.0 \times 10^{-6}$ & $1.97 \mathrm{E}-01$ & $1.18 \mathrm{E}-06$ \\
\hline $\mathrm{Cm}$ & $8.7 \times 10^{-6}$ & $1.79 \mathrm{E}-04$ & $1.56 \mathrm{E}-09$ \\
\hline $\mathrm{Am}$ & $7.5 \times 10^{-6}$ & $3.10 \mathrm{E}-02$ & $2.33 \mathrm{E}-07$ \\
\hline $\mathrm{Np}$ & $30 \times 10^{-6}$ & $8.91 \mathrm{E}-03$ & $2.67 \mathrm{E}-07$ \\
\hline \multicolumn{2}{|l}{ Total CTE for the mixture } & $\mathbf{1 . 4 4 E - 0 5}$ \\
\hline
\end{tabular}

Because of the lack of data on the density of the proposed fuel, the theoretical density of the mixture of fuel nuclides was used. It was evaluated from the relation:

$$
\rho_{f}=\left(\sum_{i} \frac{w t \%_{i}}{\rho_{i}}\right)^{-1},
$$

where $\rho_{\mathrm{i}}$ and $\mathrm{wt}_{\mathrm{i}} \%_{\mathrm{i}}$ are specific theoretical densities and weight percents of individual constituents, respectively. For the expanded case, it is assumed that theoretical densities of individual constituents are decreased in proportion to volumetric change. Consultation with fuel specialists will be necessary to estimate the effect of pores within the fuel.

The total coefficient of thermal expansion to calculate the fuel radius and length change was evaluated based on the volume-averaged fractional contributions of individual constituents of the fuel mixture as indicated in Table 29. Note that uranium and plutonium provide the largest contribution to the overall thermal expansion.

The reactivity change with temperature is assumed to be linear. Thus, the thermal expansion coefficient per $1 \mathrm{~K}$ was obtained by dividing the reactivity change by the temperature difference. The results (see Table 30) show that the fuel thermal expansion effect is negative and that its magnitude is of the same order (albeit 15\% less) as the Doppler coefficient. In combination with the Doppler coefficient, the total value of the prompt negative fuel temperature feedback is about 4 times less than the typical values of the Doppler coefficient for liquid metal fast breeder reactors with oxide fuels. This is a sufficient value for the feedback, especially in view of the desirability for self-controllability (to be studied in the future), where a weak negative Doppler coefficient is desirable.

Table 30. Fuel thermal expansion coefficient.

\begin{tabular}{|l|l|l|}
\hline Case & $\mathbf{k}_{\text {eff }}$ & $\begin{array}{l}\text { Thermal exp. } \\
\text { coef. }(\mathbf{c} / \mathbf{K})^{*}\end{array}$ \\
\hline Cold fuel $\left(\right.$ at $\left.\mathrm{T}=20^{\circ} \mathrm{C}, \mathrm{R}_{\mathrm{f}}=0.274 \mathrm{~cm}, \mathrm{H}_{\mathrm{f}}=130 \mathrm{~cm}\right)$ & $1.0139 \pm 0.0003$ & \\
\hline Hot fuel $\left(\right.$ at $\left.\mathrm{T}=600^{\circ} \mathrm{C}, \mathrm{R}_{\mathrm{f}}=0.27636 \mathrm{~cm}, \mathrm{H}_{\mathrm{f}}=131.122 \mathrm{~cm}\right)$ & $1.0129 \pm 0.0003$ & \\
\hline Thermal expansion coefficient & & $-0.06 \pm 0.02$ \\
\hline
\end{tabular}

${ }^{*}$ Assumes $\beta_{\mathrm{eff}}=0.0028$, as calculated in the previous section; the thermal expansion coefficient is the linearized value between $20^{\circ} \mathrm{C}$ and $620^{\circ} \mathrm{C}$.

An open question on the thermal expansion coefficient to be resolved in the future is its efficacy for fuel in contact with the cladding. The calculations above assumed an open gap 
between the fuel and the cladding, allowing free movement of the fuel in both the radial and upward axial directions. The $\mathrm{Pb}-\mathrm{Bi}-\mathrm{Sn}$ bond was assumed to be squeezed up into the gas plenum upon fuel expansion. However, in case of fuel-cladding contact after burnup is accumulated, thermal expansion of the fuel will be controlled by the cladding thermal expansion, resulting in a different expansion behavior, both in magnitude and time scale, as it takes some time to transport heat to cladding. Thus, the thermal expansion-controlled reactivity feedback will be on a slower time scale than the Doppler reactivity feedback. These effects will be evaluated in future analyses, as will the incorporation of fuel bowing, which with the proper application of core constraints, can introduce a significant but comparatively slow negative reactivity feedback.

\subsection{Conclusions for Chapter 3}

\subsubsection{Summary and Conclusions of the Cross-Section Work}

A new cross-section library (minacxs1) was created that contained temperature dependent cross-section data for a specific set of minor actinides $(\mathrm{Np}, \mathrm{Am}$, and $\mathrm{Cm})$. The cross-section data was checked for consistency by comparing reactivity affects with existing room temperature cross-section data. The newly processed minor actinide cross-sections correlated well with known behavior, with the exception of Am-241. The ENDF5 (".50c") tables for Am-241 appear to be unreliable compared to the other tables, and the ORNL (".97c") data is inconsistent with the other tables (i.e., ".60c", ".82c", and ".83c") that are based on the ENDF6 data. Thus, the ".60c" data seems to correlate well with the ".82c" and ".83c" data, as one would expect since these tables are all processed from the same ENDF6 data set. From these results, and the information received from LANL, only ENDF6 data will be used in producing other temperature dependent tables and libraries.

\subsubsection{Conclusions of the Parametric Studies on Power and Burnup}

The conclusions drawn from the preceding studies are as follows:

- Nitride fuels have a better reactivity swing with burnup compared to metal fuel

- Thorium fuels have superior actinide destruction capabilities, and have better void coefficient properties

- While the average actinide destruction rate is higher at higher power for all fuels, the burnup potential increases rather than decreases

- The addition of uranium to denature the thorium fuels only slightly affects the actinide destruction rate

\subsubsection{Conclusions of the Lead-Bismuth and Sodium Comparison}

The choice of fuel for a fast reactor depends on the objective of the reactor. If the goal is to burn the greatest amount of actinides possible, then a non-fertile metal fuel is the best choice. The next choice for an actinide-burning reactor is the coolant to be used. In this report, we chose a non-fertile metal fuel, a metal fuel with uranium and thorium fertile material, and a nitride fuel with uranium and thorium. The reactivity swings and actinide burning capabilities for two different coolants (sodium and lead-bismuth) were compared. The comparison was based on a 
constant pitch to diameter ratio, similar physical and material fuel parameters, similar fuel constituents, and one variation in the amount of loaded TRU.

The reactivity swing of each coolant case varied, depending on the initially loaded plutonium and minor actinides. Using equal TRU loadings, the lead-bismuth-cooled cases had the highest excess reactivity at BOL and the longest fuel cycles. For the sodium cooled cases to achieve the same (or slightly better) cycle length than the lead-bismuth using fertile free fuel, the TRU loading needs to be increased from $20 \mathrm{wt} \%$ to $30 \mathrm{wt} \%$ plutonium and minor actinides. The result for the sodium-cooled cases is an increase in the mass of actinides discharged at the end-of-life, as compared to the lead-bismuth cooled cases. In the fertile Th- $\mathrm{Zr}$ based fuel, the TRU loading had to be increased from $20 \mathrm{wt} \%$ to $30 \mathrm{wt} \%$ to make the infinite lattice critical in the sodium coolant. As with the fertile free fuel, the $30 \mathrm{wt} \% \mathrm{Th}-\mathrm{Zr}$ fuel in sodium had a slightly longer cycle length than the $20 \mathrm{wt} \%$ lead-bismuth case, but will also have a larger mass of discharged actinides as compared to the lead-bismuth cooled case. The need for a higher loading of TRU in the sodium cases can be attributed to the somewhat softer spectrum and, therefore, higher capture to fission ratio than with the lead-bismuth coolant. Also important are the superior reflective properties of lead-bismuth compared to sodium, thus requiring less enrichment than sodium and resulting in a larger net actinide consumption at the end-of-life for the lead-bismuth.

Regarding actinide consumption rates, the coolants show similar effects; where the actinides are consumed at a rate of approximately $1 \mathrm{~g} / \mathrm{MWd}$ for the fertile-free fuel, and at a rate of approximately $0.5-0.9 \mathrm{~g} / \mathrm{MWd}$ for the fertile fuels. When compared to the generation rates from LWR's (at $0.303 \mathrm{~g} / \mathrm{MWd}$ ), the consumption rate of one actinide-burning reactor with fertile-free fuel should be able to accommodate three LWR's (assuming similar power outputs). However, the longer in-core residence times for the fertile-free lead-bismuth cases result in a higher total burnup at end-of-life, which can be up to 5 times higher than the sodium cases for similar initial TRU loadings. Likewise, the fertile cores using lead-bismuth have end-of-life TRU destruction rates that can be up to $40 \%$ higher than the sodium cases for similar initial TRU loadings. Higher TRU loadings for the sodium cooled cases will result in higher end-of-life discharges, and short in-core residence times for the fertile free fuel may be a concern based on the need for more frequent refueling.

The decrease in total TRU destruction at end-of-life for the low power option, as compared to the higher power option, is due to the increase in some minor actinides from generation and decay. It thus appears that a higher power will transmute more of the initial actinide inventory. Based on the linear reactivity model (Driscoll et al. 1990), a 3-batch refueling scheme would give $50 \%$ more burnup, which would further enhance the TRU transmutation. However, the cost of more frequent refueling may offset the gain in TRU destruction, and fluence limits will restrict the actual lifetime.

The plutonium content of the fuel is depleted in all cases, and the plutonium isotopics of the fuel are superior by way of proliferation resistance compared to the other fuel forms (based on the higher $\mathrm{Pu}-238$ and $\mathrm{Pu}-240$ percentages, and lower $\mathrm{Pu}-239$ percentage). However, the isotopic degradation is not so pronounced in the fertile fuels that contain uranium, thus favoring a thorium based fertile fuel. The higher weight percentage of Pu-238 and Pu-240 in the fuel would make them undesirable as a source for weapons grade material.

Based on the calculations performed, fast reactors can reduce the current inventory of plutonium and minor actinides found in spent LWR fuel, attain long core life if fertile material is used. However, the choice of coolant and power density can affect the total amount of TRU consumed. Our calculations have shown that when comparing reactivity coefficients (e.g., using 
"streaming" assemblies to make the void coefficient negative), reactivity swing, and the amount of TRU consumed, lead-bismuth-cooled fast reactors can outperform their sodium-cooled counterparts. . However, as was stated earlier, such a large pitch would not be used in a sodiumcooled reactor. Using a tighter pitch in the sodium case will harden the spectrum, which in turn will enhance the reactivity characteristics of the core. Nevertheless, based on previous calculations, and the results shown here, the lead-bismuth cooled fuel would also demonstrate an improvement in reactivity. Further calculations will be performed using a tighter pitch more typical of sodium cooled cores to verify if the above would still be applicable, and a comparison of optimized designs will be performed.

\subsubsection{Conclusions on Minor Actinide Burning Concept}

The concept of a lead or lead-bismuth-cooled dedicated MA burner with streaming fuel (metal MA-Pu-Zr) assemblies has been evaluated. The burner operates in a two-tier fuel cycle, where most of plutonium is burned in fertile-free LWR fuel assemblies and minor actinides are incinerated primarily in the dedicated MABR. Major findings are as follows:

- The two-tier scheme requires up to 3 times fewer dedicated actinide burning units and their associated reprocessing/ refabrication facilities compared to the strategy of transmutation of all-TRUs in one system, and hence significantly decreases the burner program cost.

- Increasing the minor actinide fraction in the TRU results in a reduction of the reactivity swing. In fact, a high MA loading can even achieve a reactivity increase with burnup in a fertile-free core due to the attractive combination of fission and capture cross sections of the major MAs - Np-237 and Am-241 - and their progeny in the buildup and decay chains.

- A large 1800MWth fertile-free core containing 37wt\% TRU with very high fraction of MA $(59 w t \%)$ from LWR spent fuel can be operated at an average pin linear heat rate of $367 \mathrm{~W} / \mathrm{cm}$ for a long period between refueling (compatible with current utility practice of 2 years) at a very small reactivity swing (less than $\beta_{\text {eff }}$ ).

- The innovative streaming fuel assembly makes it possible to attain a negative coolant void worth (for whole-core voiding), even at such high MA loadings as 59wt\% MA in the TRU and in a core of large dimensions (active height of $130 \mathrm{~cm}$ and equivalent core outside diameter of $3.7 \mathrm{~m}$ ). An increase of the core-average coolant temperature from the reference values of $450^{\circ} \mathrm{C}$ to $750^{\circ} \mathrm{C}$ (cladding temperature limit) leads to a reactivity insertion of only $0.4 \$$, which can be compensated by other reactivity feedbacks. Further optimization of the fuel assembly design to reduce the coolant temperature feedback so that the reactor can attain self-regulation characteristics similar to those in IFR designs is also possible.

- In spite of the large core size, the core exhibits very small power peaking and tight neutronic coupling due to its long neutron mean free path, thereby reducing concerns with potential instabilities in flux distribution, which are typically challenging for large fast reactor cores.

- Doppler and fuel thermal expansion coefficients are around zero due to the absence of fertile absorbers and a hard spectrum. To overcome this challenge, a reactivity feedback device based on prompt gamma heating, which can substitute for the fuel temperature feedback, has been proposed. However, significant R\&D would be required to confirm its effectiveness under all conditions. 
- The effective delayed neutron fraction is only half of that of the IFR metal cores, raising concerns over controllability of critical reactors with a dominant fraction of minor actinides. This is a major challenge for the MABR.

In summary, although significant progress in the design of a critical MA burner has been achieved in terms of a high actinide destruction rate with a small reactivity swing, and in overcoming the challenge of coolant void worth, less success was realized in fuel temperature feedback for reactor control. The lack of a prompt negative reactivity feedback, such as Doppler and fuel thermal expansion feedbacks, can be overcome using feedback devices based on an increase in the absorption from prompt gamma and neutron heating, such as described in this study. The major drawback was identified to be the small effective delayed neutron fraction, which cannot be increased in a fertile-free core, because it is primarily determined by the TRUs which are to be destroyed. However, the designer does not have a choice of TRU selection, as they are determined by the composition of the spent LWR fuel. Moreover, the composition of the TRUs in the core changes with burnup and during recycling, making it difficult to guarantee the $\beta_{\text {eff }}$ value over the cycle. Furthermore, preliminary burnup studies of recycled fuel have shown that maintenance of a small reactivity swing becomes difficult for the equilibrium core, unless the MA fraction in the TRU is increased further, challenging safety characteristics. Therefore, the path of actinide burning in a fertile-free core will not be further pursued and the main thrust of the investigation was shifted to TRU-burning cores with thorium as a fertile material to improve the safety characteristics. The results of these investigations to date are presented next.

\subsubsection{Conclusions from the MIT Study to Optimize both Actinide Burning and Low-Cost Electricity Production}

The concept of a Pb-Bi cooled critical reactor that can destroy actinides from spent LWR fuel while maintaining excellent safety and having the potential for being economical has been proposed and evaluated from the neutronics viewpoint. The analyses were performed for metallic thorium-based fuel (Th-U-Pu-MA-Zr) in a once-through cycle, assuming that the discharged fuel from the actinide burner reactor remains in temporary storage before multi-recycling is introduced. The major conclusions can be summarized as follows:

- Using thorium as a major fertile material is an effective means to reduce the large reactivity swing occurring in fertile-free cores while still allowing high actinide destruction rate per MWth. In addition, thorium use appreciably increases the Doppler feedback and reduces the coolant density reactivity coefficient.

- The actinide burner reactor destruction rate of actinides per MWth-yr is $63 \%$ of that of the ATW. This is a very appealing number considering the simplicity of the proposed reactor versus the more complex accelerator plus reactor system.

- The fast fluence on the cladding limit is a key limiting factor for a long life core. Two core configurations, which satisfy the fast fluence limit, are feasible for a target core power of 700MWth - a small core with 69 fuel assemblies and a refueling period of 4 years or a large core having 157 fuel assemblies targeted for a refueling period of 8 years. The latter option has been selected for the analyses, because it offers better use of space available for the core in the vessel (vessel dimensions are dictated by decay heat removal for fixed core power).

- The large core alternative requires introduction of measures to mitigate the coolant void worth. This was achieved by the employment of streaming fuel assemblies, in which streaming of neutrons in both radial and axial directions from the core center increases 
the leakage component of void reactivity. It has been shown that using streaming fuel assemblies with one row of peripheral streaming channels and a central streaming region results in negative coolant void worth and very small positive coolant temperature coefficient, which provides very good potential for a design with self-regulation characteristics, similar to the IFR. Streaming assemblies also reduce the power and neutron flux peaking, and thus the peak fast fluence.

- The constraint on peak discharge burnup is less limiting than the fast fluence limit for the metal fuel. The U-Th-Pu-MA-Zr fuel accumulates in the proposed reference core after 8 EFPYs of irradiation, a peak burnup of $\sim 160 \mathrm{MWd} / \mathrm{kg}$, which is well below the limit of $200 \mathrm{MWd} / \mathrm{kg}$.

- The discharged fuel from the actinide burner reactor satisfies proliferation constraints for both the plutonium and uranium compositions. The plutonium isotopics are significantly degraded from that of the PWR spent fuel vector making it virtually weapons unusable. The $12 \%$ proliferation limit on fissile uranium with U-233 content is satisfied if depleted uranium is mixed with thorium with $\sim 30 \mathrm{wt} \%$ of uranium in the $\mathrm{U}+\mathrm{Th}$ mixture.

- Both the Doppler and fuel thermal expansion feedbacks are negative and their values are comparable to those for IFR fuel. Thus, the magnitude of the fuel temperature feedback, together with a small coolant temperature reactivity coefficient, offer excellent potential for a design with self-regulating characteristics, capable of inherent shutdown in major transients without scram.

In summary, the proposed design of the reference 8-year life core for burning transuranics from spent LWR fuel appears to be very promising and deserving of future refined analyses and optimization because it offers high consumption of actinides, excellent safety characteristics, and has the potential to have low electricity generation costs due to its modularity, simplicity and high capacity factor. The latter claim will have to be verified by future economic studies and their feedback on neutronic and plant design to minimize cost while maintaining the safety and TRU consumption benefits. 


\section{Results of the Plant Engineering and Economics Studies}

\subsection{Thermal and Burnup Limits for the Cladding and Metal Fuel (INEEL, Dr. Jacopo Buongiorno)}

The purpose of this section is to estimate the operating temperature limits for the metal fuel and cladding of the lead-bismuth reactor, both at steady-state conditions and during transients. Temperature limits are important design constraints that affect the reactor economics and safety performance. These constraints are also summarized in Section 2 and then used in Section 4.3 below. The thermal limits of the reactor vessel are analyzed in Section 4.2.

The geometry of the fuel pin is illustrated in Figure 72. Two types of fuel are considered: the ternary alloy U-Pu-Zr (for breeding and long-lived cores) and the binary alloy $\mathrm{Zr}-\mathrm{Pu}$ (for pure actinide burning systems). The considerations on the U-Pu-Zr fuel (i.e., the reference fuel at the time this analysis was conducted) were extrapolated to the Th-U-Pu-Zr fuel (i.e., the current reference metal fuel for the reactor). Note that the nitride fuel was not considered because of the lack of basic information on its irradiation properties.

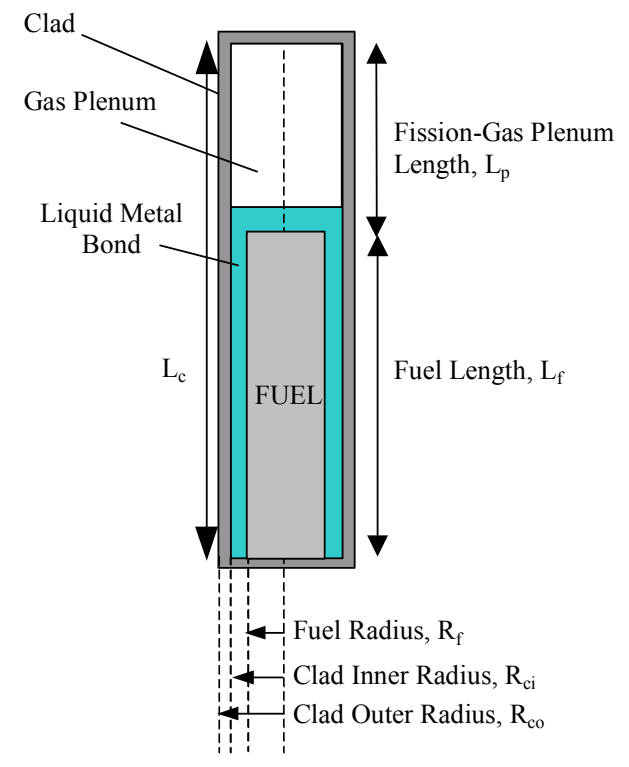

Figure 72. The fuel geometry.

The reference cladding material is the ferritic-martensitic stainless steel HT-9, somewhat similar in composition to the Russian steel EP-823 developed for heavy-liquid-metal applications. The cubic-centered crystalline structure of these ferritic-martensitic steels provides exceptional resistance to irradiation-induced swelling of the cladding, i.e., virtually no swelling up to 3.3$4.0 \times 10^{23} \mathrm{n} / \mathrm{cm}^{2}$ s or 150-200dpa (GE 1991, Dubberley et al. 2000a). The fuel and the cladding are thermally bonded by a thin layer of pure liquid lead to minimize the temperatures in the fuel. Lead is preferred as a bond material over other lead-alloys (e.g. $\mathrm{Pb}-\mathrm{Bi}$ or $\mathrm{Pb}-\mathrm{Bi}-\mathrm{Sn}$ ) because of its lower chemical reactivity with the cladding material HT-9. Note that traditionally metallic fuel for sodium-cooled fast reactors was bonded with sodium.

The temperature limits for the cladding will be determined on the basis of fuel-cladding 
mechanical interaction (FCMI), fission gas pressurization (FGP) and fuel-cladding chemical interaction (FCCI) considerations. Note that the issue of coolant corrosion is not addressed here, although it most certainly sets an additional constraint on the steady-state temperature limit of the cladding and possibly on the transient limit, as well. The information about the behavior of metallic fuel under irradiation is largely taken from the Na-cooled Integral Fast Reactor (IFR) literature and was extrapolated to the different materials and operating conditions of our system (e.g., lead bond vs. sodium bond, higher temperatures), where possible.

\subsubsection{Cladding - Steady-State (range of interest $<700^{\circ} \mathrm{C}$ )}

The limit ranges from 580 to $650^{\circ} \mathrm{C}$ depending on the fuel pin geometry and is set by FGP considerations, as explained in the following paragraphs.

FCMI. The most important characteristic of modern metal fuel is the low beginning-of-life smeared density, which allows unrestricted fuel swelling induced by the fission-gas-filled pores (Hofman et al. 1990, Pahl et al. 1992, Pitner 1993). For typical U-Zr and U-Pu-Zr IFR fuels, at about $1.0 \mathrm{at} \%$ burnup the pores begin to interconnect and, by $2 \mathrm{at} \%$ burnup, most fission gases are released to the gas plenum above the fuel slug (Seidel et al. 1986, Pahl et al. 1986). Once the gases are released, the fuel remains a spongy and very soft metallic matrix. The beginning-of-life smeared density is selected low enough (i.e., 75\%) to allow full swelling and porosity interconnection prior to fuel/cladding contact. Therefore, when fuel/cladding contact is finally made (because of further swelling, mostly due to liquid and solid fission products), the fuel readily creep-flows and the cladding is not significantly stressed ${ }^{\mathrm{a}}$. As a result, in estimating the steady-state cladding limits, FCMI can be neglected whenever the beginning-of-life smeared density is $75 \%$ or lower (Pahl et al. 1986, 1990a and 1990b, Porter et al. 1986, Walters 1999, Dubberley et al. 2000b).

FGP. The main source of stresses in the cladding is due to pressurization from fission gas release into the plenum (Pahl et al. 1986 and 1990a, Porter et al. 1986). Given the relatively high temperature at which the cladding operates, the dominant steady-state mechanical failure mechanism is the inception of tertiary thermal creep (also known as age softening), beyond which the cladding strain increases rapidly with time until failure occurs (Fox 1986). It was found that the tertiary-creep stress threshold for HT-9 is not a strong function of the operating time (in the range $>200$ days), but mostly of the operating temperature, as illustrated in Figure 73 . Note the cutoff at $650^{\circ} \mathrm{C}$, which represents the results of age-softening measurements performed with the Diamond Pyramid Hardness (DPH) technique (Fox 1986). The curve of Figure 73 can be utilized to evaluate the cladding temperature limit at steady-state as a function of burnup. For example, let us consider the stress history of a fuel pin of given geometry operating at a fixed temperature. As the pin is irradiated, the burnup increases, the FGP increases and so does the hoop stress in the cladding. Therefore, the stress history can be represented in Figure 73 as a vertical line starting at low values of the hoop stress (i.e., beginning-of-life). The burnup at which the stress history curve intersects the stress limit curve, is the maximum allowable burnup for that pin at that particular temperature. Or, equivalently, that is the maximum allowable temperature for that target burnup.

\footnotetext{
${ }^{a}$ Nevertheless, it is thought that at extremely high burnup ( $>25$ at $\left.\%\right)$ solid and liquid fission products could close most pores and thus harden the fuel again (Pahl et al. 1990, Ogata and Yokoo 2000). Under these circumstances, FCMI might become important.
} 


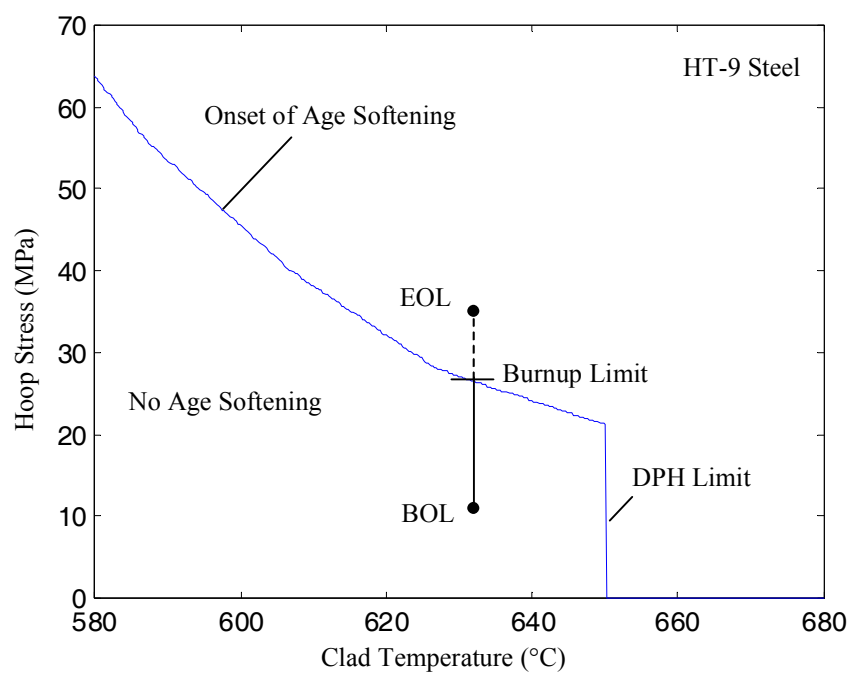

Figure 73. The stress-temperature limit curve for HT-9 (data from reference (Fox 1986)).

We shall now systematically implement this approach to establish the steady-state temperature-burnup limits as a function of the fuel composition, the cladding thickness, and the plenum-to-fuel-length ratio. Note that, for a given cladding temperature and fuel burnup, the linear heat generation rate level determines the service lifetime, but does not affect the cladding stresses, and thus does not affect the cladding temperature limit. For these reasons the linear heat generation rate will not be considered as a relevant variable in this analysis.

It is apparent that we need a model capable of generating the stress history as a function of the main variables (i.e., fuel composition, operating temperature, burnup, cladding thickness, and plenum-to-fuel-length ratio). The model must take into account elastic, thermal-expansion, thermal-creep, irradiation creep, and swelling effects. All the assumptions and equations of such a model are presented in Appendix B. The model assumes that the fuel/cladding gap rapidly closes with burnup and by then $80 \%$ of the fission-gas inventory is released in the fission-gas plenum, independent on the fuel composition. This should be a rather accurate assumption because the fission-gas release depends mostly on a geometric condition (i.e., the interconnection of the fuel pores) that should be roughly independent of the fuel composition. The model was benchmarked against actual irradiation data for sodium-bonded IFR fuel pins and was found to slightly over-predict the stresses and strains in the cladding.

Figures $74 \mathrm{a}$ and $74 \mathrm{~b}$ illustrate the cladding temperature/burnup limits for the $\mathrm{Zr}-\mathrm{Pu}$ fuel as a function of the cladding thickness $\left(\mathrm{t}_{\mathrm{c}}\right)$ and plenum-tofuel-length ratio $(\mathrm{P} / \mathrm{F})$, respectively. Similarly, Figures $75 \mathrm{a}$ and $75 \mathrm{~b}$ illustrate the cladding temperature/burnup limits for the U-Pu-Zr fuel as a function of the cladding thickness and plenum-to-fuellength ratio, respectively. In Figures 74 and 75, the fuel length, fuel outer diameter and cladding inner diameter are fixed and equal to their reference values

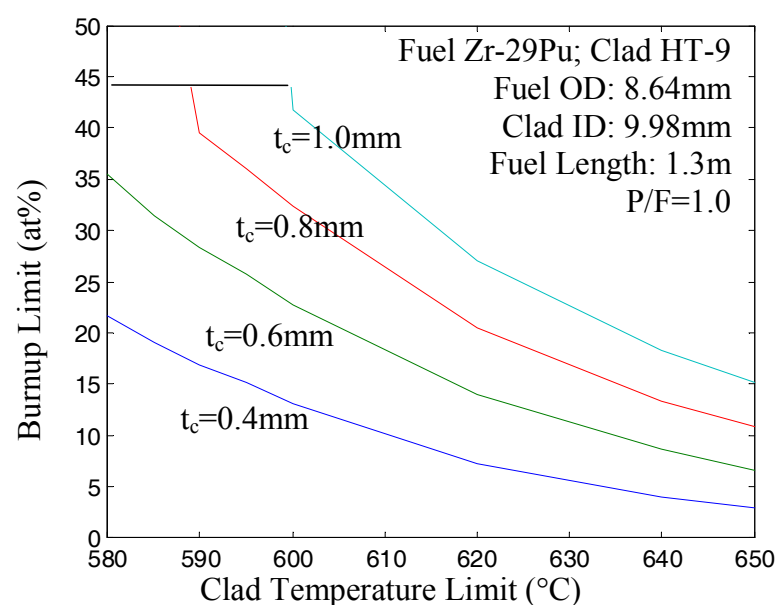

Figure 74a. Effect of the clad thickness on the temperature and burnup limits of the $\mathrm{Zr}$-Pu fuel. 
$1.3 \mathrm{~m}, 8.64 \mathrm{~mm}$ and $9.98 \mathrm{~mm}$, respectively. Therefore, the smeared density is also fixed at $(8.64 / 9.98)^{2}=75 \%$.

As expected, the burnup limit ${ }^{\mathrm{b}}$ decreases with increasing cladding temperature under all circumstances. Also, it increases with increasing cladding thickness and plenum-tofuel-length ratio. The burnup cutoff at about $44 \mathrm{at} \%$ for $\mathrm{Zr}-\mathrm{Pu}$ fuel and $35 \mathrm{at} \%$ for $\mathrm{U}-\mathrm{Pu}-\mathrm{Zr}$ fuel (not reported in Figures $75 \mathrm{a}$ and $75 \mathrm{~b}$ ) corresponds to the onset of cladding swelling (about 165dpa) and cannot be exceeded.

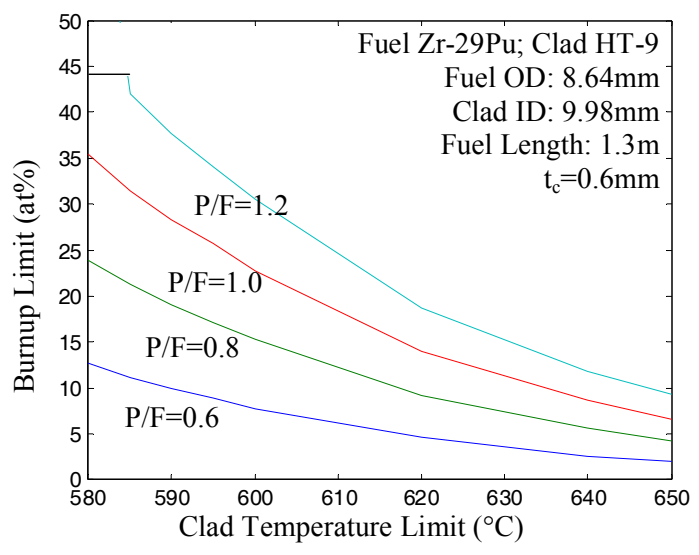

Figure 74b. Effect of the plenum-to-fuellength ratio on the temperature and burnup limits of the Zr-Pu fuel.

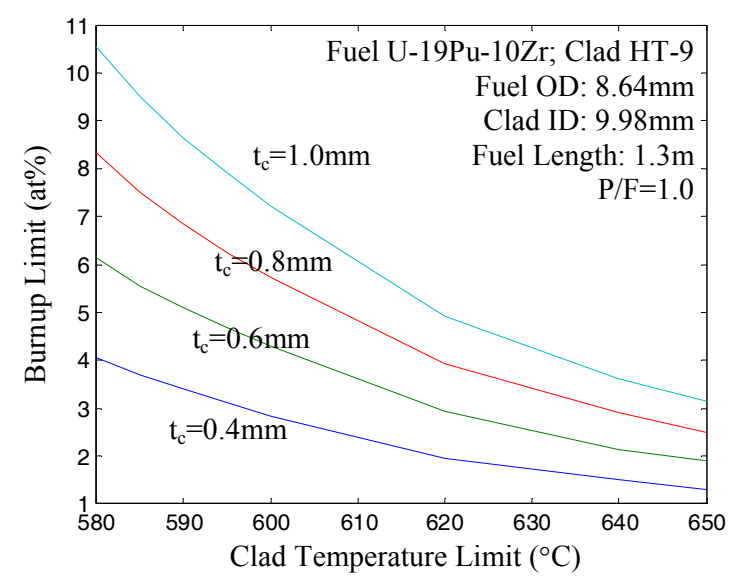

Figure 75a. Effect of the clad thickness on the temperature and burnup limits of the U-PuZr fuel.

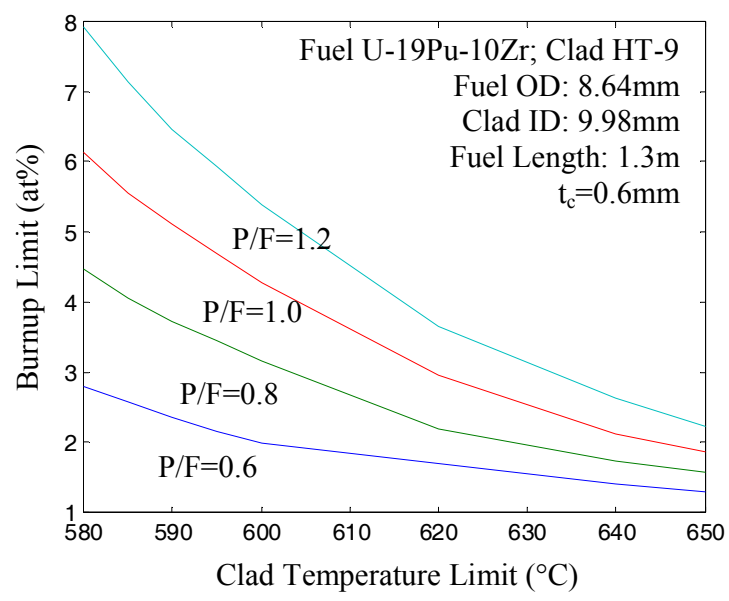

Figure 75b. Effect of the plenum-to-fuel-length ratio on the temperature and burnup limits of the U-Pu-Zr fuel.

\footnotetext{
${ }^{\mathrm{b}}$ All burnups are in at $\%$, where $1 \mathrm{at} \% \sim 10,000 \mathrm{MWd} / \mathrm{t}_{\mathrm{HM}}$, roughly independent of the fuel type and composition.
} 
Regarding the numerical value of the burnup limits, it is important to understand that the significant difference between the U-Pu-Zr and the $\mathrm{Zr}-\mathrm{Pu}$ fuels is just an effect of the heavy-metal inventory normalization, i.e., for given geometry a $\mathrm{Zr}-29 \mathrm{Pu}$ fuel pin contains almost 6 times less heavy metal mass than a U-19Pu-10Zr pin; therefore, for given fission energy extracted from the pin, its burnup (energy/mass of heavy metal) is about 6 times higher.

Nevertheless, the absolute burnup values of the U-Pu-Zr (for the reference fuel-pin geometry) are rather low if compared with the burnup achievable by the standard IFR fuel (i.e., 7 at $\%$ vs. 15at\%) (Dubberley et al. 2000a). The IFR fuel performs better because the stress level is dramatically reduced by the following design changes: 1) the IFR cladding diameter is much smaller (Cladding ID $=6.32 \mathrm{~mm}$ vs. $9.98 \mathrm{~mm}$ ) so that the diameter-to-thickness ratio is smaller, and 2) the IFR plenum-to-fuel-length ratio is much larger ( $\mathrm{P} / \mathrm{F}=1.9$ vs. 1.0) so that the FGP is smaller. When these design changes are implemented, the achievable burnup more than doubles, as illustrated in Figure 76. Therefore, it is recommended that this new geometry be adopted for the long-lived core designs with fertile-fuel, whose typical target burnup is in the 15-20at\% range (or $\left.150,000-200,000 \mathrm{MWd} / \mathrm{t}_{\mathrm{HM}}\right)$.

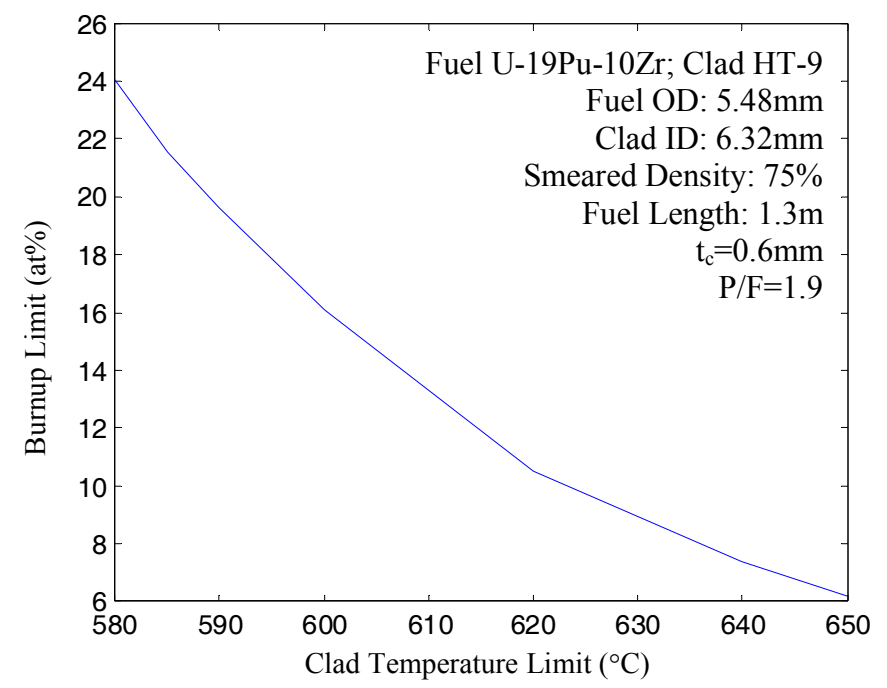

Figure 76. The temperature and burnup limits of the improved U-Pu-Zr fuel.

The burnup limits calculated above could be significantly improved with the development of advanced ferritic-martensitic steels. The effect of oxide dispersion in the ferritic matrix on the high-temperature mechanical strength ${ }^{\mathrm{c}}$ was explored in the US, Japan and Europe (Powell et al. 1986, Ukai et al. 1998, Huet 1985, Dubuisson et al. 1997). In these Oxide Dispersion Strengthening (ODS) steels the cubic-centered structure provides the swelling resistance while the dispersed oxides (e.g., yttrium oxides) provide enhanced high-temperature strength. The early grades of this class of alloys exhibited low ductility and large anisotropy in creep strength (Dubuisson et al. 1997, Ukai et al. 1998). However, these shortcomings were eliminated in Japan with a tungsten- and titanium-enriched martensitic ODS alloy of composition Fe-0.19C-10.6Cr$2.35 \mathrm{~W}-0.49 \mathrm{Ni}-0.93 \mathrm{Y}_{2} \mathrm{O}_{3}-0.43 \mathrm{Ti}$ that exhibits isotropic creep strength and acceptable ductility (i.e., over $10 \%$ total elongation at room temperature). The high-temperature creep strength of this alloy is exceptional, i.e., at $650^{\circ} \mathrm{C}$ it is three to four times larger than for HT-9 (Ukai et al. 1998). This would enable achievement of the $15-20 \mathrm{at} \%$ burnup target at $650^{\circ} \mathrm{C}$ in metal fuel pins with

${ }^{c}$ e.g., the creep resistance 
the geometry reported in Figure 76 , or alternatively, at $600^{\circ} \mathrm{C}$ with the geometry reported in Figures $75 \mathrm{a}$ and $75 \mathrm{~b}$.

Outstanding results could also be obtained with non-ODS $12 \mathrm{Cr}-8 \mathrm{Mo}$ steels, which exhibit twice-as-great creep resistance than HT-9 over a wide range of temperatures and negligible swelling up to 350dpa (!) (Tokiwai et al. 1993). Again it should be emphasized that the viability of either class of innovative steels (i.e., ODS or Cr-Mo steels) for our application depends also on their corrosion performance in lead or lead-bismuth coolant, which is unknown at this time.

FCCI. Diffusion of bond and fuel constituents (e.g., U, Pu, lanthanide fission products) into the cladding can alter the local chemistry of the cladding and give birth to alloys (e.g., Fe-U-Pu) whose melting point is below the operating temperature, thus thinning the cladding wall (Porter et al. 1986, Hofman et al. 1986, Pahl et al. 1990a). Also, diffusion of the cladding constituents to the fuel and bond can create a cladding region with altered mechanical characteristics because of the depletion of a certain element ${ }^{\mathrm{d}}$. However, at the relatively low temperatures of interest for steady-state operation $\left(<700^{\circ} \mathrm{C}\right)$, diffusion of $\mathrm{U}, \mathrm{Pu}$ or $\mathrm{Zr}$ to the cladding and diffusion of $\mathrm{Fe}$ and $\mathrm{Cr}$ to the fuel are small and cause little deterioration. At these temperatures, diffusion of the clad, fuel and bond constituents is hindered by the formation of a Zr-rich layer at the fuel/cladding interface $^{\mathrm{e}}$ (Hofman et al. 1986, Keiser and Dayananda 1993). It is speculated that this layer is formed by fuel restructuring ( $\mathrm{Zr}$ has a tendency to migrate to the fuel periphery, see Section 4.1.3 below) and/or by small amounts of $\mathrm{ZrO}_{2}$ deposited on the surface of the fuel slug during fuel casting in $\mathrm{ZrO}_{2}$ molds (Hofman et al. 1986, Keiser and Mariani 1999). In addition and most importantly, the melting point of the local alloys created by the (small) diffusion of $\mathrm{U}, \mathrm{Pu}$ and $\mathrm{Zr}$ into the cladding is above the steady-state operating temperatures of interest (i.e., 600 to $700^{\circ} \mathrm{C}$ ). Note that the role of $\mathrm{Zr}$ in this process is two-fold: 1) it forms the interfacial layer that reduces diffusion and 2) it generally increases the solidus of the local alloys. For these reasons, FCCI is not thought to be a key factor in the identification of the steady-state cladding temperature limit for sodium-bonded fuel (Holland et al. 1986, Pahl et al. 1990a).

Nevertheless, because the thermal bond in our fuel is pure lead, additional investigation is required to verify that lead does not readily diffuse into the cladding and does not form lowmelting alloys with the cladding constituents. An analytical approach could prove extremely complicated, because the problem is multi-component in nature $(\mathrm{Pb}, \mathrm{Fe}, \mathrm{Cr}, \mathrm{U}, \mathrm{Pu}, \mathrm{Zr})$. Moreover, the phase diagrams and inter-diffusion coefficients are not available and a "binary assumption" where lead, $\mathrm{U}, \mathrm{Pu}$ and $\mathrm{Zr}$ diffuse independently in the $\mathrm{Fe}-\mathrm{Cr}$ cladding matrix will not work (Keiser 2001). Clearly, an experimental investigation of this issue is needed. Here we shall just calculate the cladding weight loss by dissolution of iron and chromium in the lead bond. Assuming a fuel OD of $5.48 \mathrm{~mm}$ and a cladding ID of $6.32 \mathrm{~mm}$, the lead-bond inventory per unit fuel length is $0.78 \mathrm{~g} / \mathrm{cm}$. The solubility of $\mathrm{Fe}$ and $\mathrm{Cr}$ in lead at $650^{\circ} \mathrm{C}$ is about 4 and $3 \mathrm{ppm}$ in weight, respectively (Alden 1957). Assuming the lead bond saturates with dissolution products, the $\mathrm{Fe}$ and $\mathrm{Cr}$ weight losses per unit length are 3.1 and $2.3 \mu \mathrm{g} / \mathrm{cm}$, respectively. If the dissolution and deposition cycle is repeated 100 times over the fuel lifetime (e.g., because of shutdowns or temperature changes during transients), the Fe and $\mathrm{Cr}$ losses would amount to 310 and $230 \mu \mathrm{g} / \mathrm{cm}$, respectively or 156 and $116 \mu \mathrm{g} / \mathrm{cm}^{2}$ if normalized to the cladding area. Assuming a cladding

\footnotetext{
d e.g., it was observed that, within an austenitic steel clad, Ni readily migrates to the fuel leaving behind a brittle thin Ni-depleted region that even undergoes a transformation to the ferritic phase (Porter et al. 1986, Seidel et al. 1986).

${ }^{\mathrm{e}}$ To further suppress diffusion of fuel constituents to the clad, lining of the inner surface of the cladding with a layer of Zircaloy-2 was explored in Japan (Tokiwai et al. 1993).
} 
density of $7.7 \mathrm{~g} / \mathrm{cm}^{3}$ and weight composition of $12 \% \mathrm{Cr}$ and $88 \% \mathrm{Fe}$, the $\mathrm{Fe}$ and $\mathrm{Cr}$ depleted zones would extend 0.2 and $1 \mu \mathrm{m}$ into the cladding wall, respectively, which is a negligible distance given that the cladding wall thickness is $600 \mu \mathrm{m}$.

\subsubsection{Cladding - Transient (Range of Interest $>700^{\circ} \mathrm{C}$ )}

The limit is identified at $725^{\circ} \mathrm{C}$ and is set by FCCI considerations, as explained in the following paragraphs.

FCMI. After the fuel and cladding have made contact, significant mechanical interaction could, in principle, occur during transients, because of the differential thermal expansions or fuel phase changes. However, it was found that fuel with open interconnected porosity creep-flows so promptly that even during violent transients FCMI is negligible (Porter et al. 1986).

FGP. It is assumed that it is possible to exceed the temperature limits of Figure 73 for short periods of time typical of transients (i.e., few hours) without causing excessive thermal creep strains in the clad. This assumption needs to be verified experimentally.

FCCI. The Zr-rich layer at the fuel/cladding interface dissolves at high temperature and diffusion from and to the cladding proceeds rapidly (Hofman et al. 1986, Billone et al. 1986). Formation of local low-melting alloys thins the cladding wall, which then fails under the effect of the internal fission-gas pressurization. No melting of the cladding wall was observed below $725^{\circ} \mathrm{C}$ (i.e., the eutectic temperature of the U-Fe alloy) indicating that the presence of the zirconium raises the solidus of the potentially dangerous lower-melting alloys like $\mathrm{Fe}-\mathrm{Pu}$ (of eutectic temperature $480^{\circ} \mathrm{C}$ ). On the other hand at $825^{\circ} \mathrm{C}$, melting across the cladding occurred almost instantaneously. In between these two extremes, the following FCCI cladding penetration correlation is recommended by Tsai (1990):

$$
S=e^{A-\frac{Q}{R T}}
$$

where $\mathrm{S}$ is the penetration rate in $\mu \mathrm{m} / \mathrm{s}, \mathrm{R}$ is the gas constant $(8.31 \mathrm{~J} / \mathrm{mol} \cdot \mathrm{K}), \mathrm{T}$ is the cladding temperature in $\mathrm{K}, \mathrm{A}=11.65$ and $\mathrm{Q}=130.1 \mathrm{~kJ} / \mathrm{mol}$.

Then, the conservative $725^{\circ} \mathrm{C}$ limit can be applied to anticipated transients in which the operability of the fuel must be preserved (e.g., start-up, normal shutdown, loss-of-primary-heatsink), whereas a more realistic and sophisticated approach that makes use of Equation (1) and of a crack propagation model ${ }^{\mathrm{f}}$ should be applied for those extreme situations in which preservation of the fuel operability is not of primary importance, but rather public and plant personnel protection from the radiation exposure that would follow fuel failure is important.

Note that these conclusions apply to sodium-bonded fuels and again the effect of the lead bond needs to be evaluated. The same considerations of the steady-state FCCI analysis on the feasibility of an analytical approach to the problem apply here. Until some experimental results will be available, it is recommended that the $725^{\circ} \mathrm{C}$ limit be adopted even in the presence of a lead bond.

\footnotetext{
f e.g., the crack propagation model in (Roth and Biancheria 1986)
} 


\subsubsection{Fuel - Steady-State and Transient}

The limit is identified at about $1000^{\circ} \mathrm{C}$ and is set by restructuring considerations.

Restructuring of an initially mono-phase and homogenous metal fuel is primarily caused by the creation of different phases induced by the radial temperature gradient (Porter et al. 1990). The fuel constituents (e.g., $\mathrm{U}, \mathrm{Pu}, \mathrm{Zr}$ ) diffuse from one radial region to another because their chemical activity depends on the phase. For example, a U-19Pu-10Zr fuel rod whose surface temperature is below $600^{\circ} \mathrm{C}$ and centerline temperature is above $750^{\circ} \mathrm{C}$, will have the following three radial regions: $\gamma$-phase (innermost), $(\gamma+\zeta)$-phase (intermediate) $(\delta+\zeta)$-phase (periphery). Because the $\mathrm{Zr}$ chemical activity is maximum in the $(\gamma+\zeta)$-phase, the zirconium tends to migrate away from the intermediate region of the fuel and concentrate in the innermost and periphery regions. On the other hand, the $U$ chemical activity is minimum in the $(\gamma+\zeta)$-phase and therefore the uranium tends to concentrate to the intermediate region (Hayes and Hofman 1994, Sohn et al. 2000). No appreciable diffusion of plutonium has been reported (Pahl et al. 1986). It was already pointed out that $\mathrm{Zr}$ migration to the fuel/cladding interface is beneficial to reducing the FCCI via the formation of a diffusion-reducing layer. However, as far as the intermediate radial region of the fuel is concerned, the depletion of zirconium and the simultaneous concentration of uranium significantly lowers the fuel melting point (Pahl et al. 1990a). For example, for a metal fuel of initial (wt\%) composition $\mathrm{U}-19 \mathrm{Pu}-10 \mathrm{Zr}$ and melting point $\sim 1100^{\circ} \mathrm{C}$, the $\mathrm{Zr}$ content of the intermediate region can decrease down to only 1 or $2 \mathrm{wt} \%$ (Porter et al. 1990, Pahl et al. 1990a) resulting in a melting point of the restructured fuel of about $1000^{\circ} \mathrm{C}$, which should then be used as the thermal limit.

Restructuring is also expected for the fertile-free $\mathrm{Zr}-29 \mathrm{Pu}$ fuel as can be seen from the $\mathrm{Zr}-\mathrm{Pu}$ phase diagram of Figure 77. If the fuel centerline operates at about $800^{\circ} \mathrm{C}$ and the fuel surface at $600^{\circ} \mathrm{C}$, three $\mathrm{Zr}-\mathrm{Pu}$ phases are expected, the highand low-temperature phases being $\beta-Z r$ and $\alpha-\mathrm{Zr}, \quad$ respectively. The $\beta-Z r$ phase exhibits a larger density than the $\alpha-Z r$ phase and therefore it can be speculated that the zirconium will tend to diffuse away from the fuel innermost region. The melting point before restructuring is about $1600^{\circ} \mathrm{C}$, but it decreases with decreasing $\mathrm{Zr}$ concentration roughly at a rate of $14^{\circ} \mathrm{C}$ per $\mathrm{wt} \%$ of $\mathrm{Zr}$. Therefore, if a $1000^{\circ} \mathrm{C}$ fuel limit (which is very reasonable) is to be maintained for

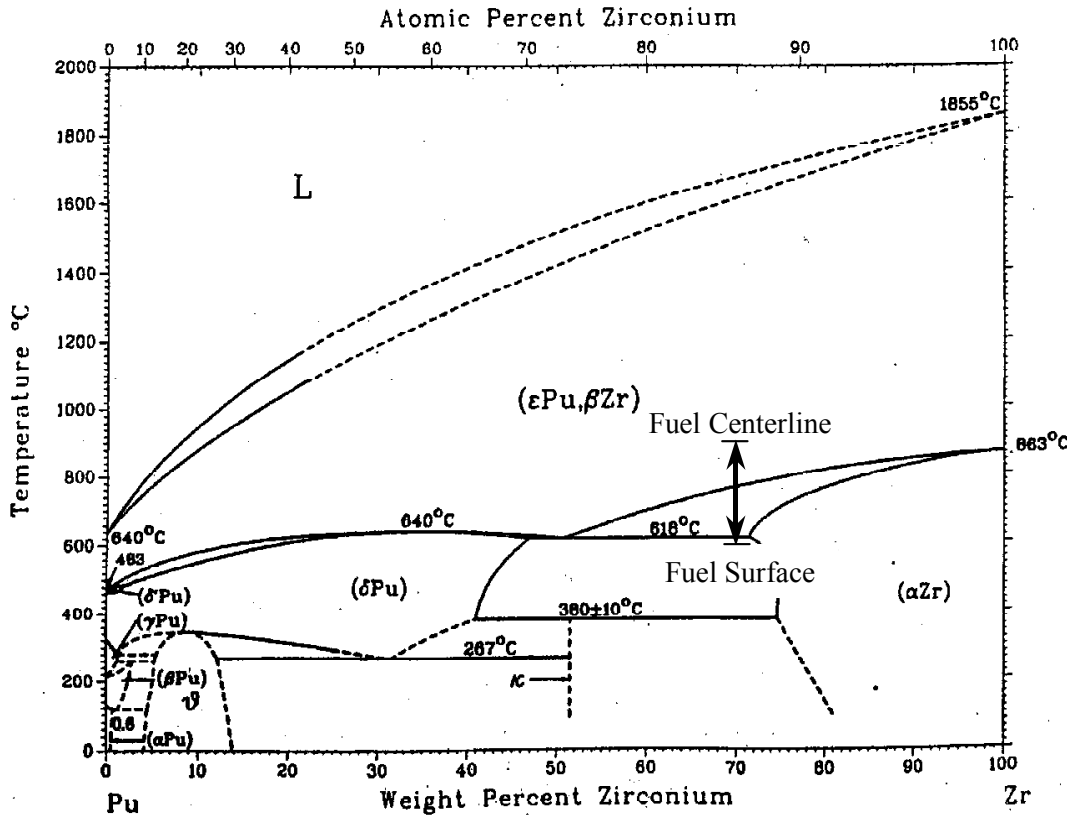

Figure 77. The phase diagram of $\mathrm{Zr}-\mathrm{Pu}$ (from Kassner and Peterson (1995)). 
this fuel, it must be demonstrated that the $\mathrm{Zr}$ concentration of the innermost region remains above approximately $30 \mathrm{wt} \%$.

It should be emphasized that the IFR experience and the thermal-hydraulic calculations in Buongiorno et al. (2000 and 2001) indicate that the fuel temperature limit ${ }^{\mathrm{g}}$ is not the most demanding design constraint, neither at steady-state nor in transient conditions, but rather cladding creep and FCCI are, respectively (see discussion above and reference (Pahl et al. 1990a)). Therefore, an accurate identification of the fuel thermal limit is not of crucial importance and we will assume $1000^{\circ} \mathrm{C}$ for all purposes.

Finally, it should be noticed that the micro-heterogeneities created by fuel restructuring are not expected to affect significantly the neutronic performance of the core because the mean-freepath of the high-energy neutrons is much larger than the characteristic radial extension of the restructured fuel zones.

\subsubsection{Section Summary}

The steady-state and transient temperature limits were estimated for the fertile and fertile-free metallic fuel and cladding. It was found that the steady-state cladding temperature limit ranges from 580 to $620^{\circ} \mathrm{C}$ depending on the cladding diameter and thickness, on the gas-plenum-to-fuel length ratio and on the fuel burnup. On the other hand, the transient cladding limit was identified at $725^{\circ} \mathrm{C}$. Finally, the fuel temperature limit was identified at $1000^{\circ} \mathrm{C}$ for both steady-state and transient conditions.

\subsection{Thermal Limits of the Guard Vessel (INEEL, Dr. Jacopo Buongiorno)}

For a reactor with an RVACS-type decay heat removal system with liquid lead-bismuth in the gap between the reactor vessel and the guard vessel, the static load is actually accommodated by the guard vessel, because the reactor vessel floats in the liquid lead-bismuth. Therefore, the focus of the structural analysis (here and in Section 4.5) must be applied to the guard vessel.

Under normal operating conditions the fission heat is removed through the steam generator/heat exchanger located between the core barrel and the reactor vessel. The guard vessel is maintained at relatively low temperatures by flow of the cold air in the collector. On the other hand, in a loss-of-primary-heat-sink situation the heat generated in the core is discharged to the outside environment through the guard vessel and therefore, it is then required to withstand substantially higher temperature levels (i.e., $>500^{\circ} \mathrm{C}$ ).

In this section a simplified structural analysis identifies the temperature limit of the guard vessel under these circumstances, as this is one of the constraints limiting the decay-heat removal capability and ultimately the reactor power rate.

${ }^{g}$ even if it were as low as $900^{\circ} \mathrm{C}$ 


\subsubsection{The ASME Code}

The guard vessel is to be designed according to the recommendations of the ASME Boiler and Pressure Vessel Code, Section III, Division 1, Subsection NH (Class 1 Components in Elevated Temperature Service), which regulates the design of pressure-retaining components whose operating temperature (under normal, transient or accidental conditions) is expected to exceed a certain threshold, e.g., $430^{\circ} \mathrm{C}$ or $800^{\circ} \mathrm{F}$ for SS316 (ASME 1998). The rules of Subsection NH are applicable to pressure-retaining components independent of the type of contained fluid (e.g., water, steam, helium, sodium) and thus are valid for heavy-liquid-metalcooled reactor applications, as well. The code specifies the allowable materials and the combined maximum temperature and time at which they can be operated. For example, use of SS-316 is permitted, but not above $816^{\circ} \mathrm{C}\left(1500^{\circ} \mathrm{F}\right)$ and, at any temperature above $430^{\circ} \mathrm{C}$, for not longer than $3 \times 10^{5}$ hours (total cumulative operation).

\subsubsection{Materials Selection}

As per Article NH-2000, only four materials are permitted for the design of Class 1 Components in Elevated Temperature Service: SS-316, SS-304, Ni-Fe-Cr (Alloy 800H) and $2 \frac{1}{4} \mathrm{Cr}-1 \mathrm{Mo}$. The austenitic stainless steel grade 316 (SS-316) is selected here as the reference material for the heavy-liquid-metal-cooled reactor vessel and the guard vessel, because of its better mechanical properties at high temperature and because of the previous experience in fast reactors applications (e.g., Superphenix, IFR, FFTF). However, note that from a corrosion standpoint, SS-316 is thought to be incompatible with heavy-liquid-metal coolants (in particular with $\mathrm{Pb}-\mathrm{Bi}$ ) at high temperature ( $\mathrm{Li} 1999$, Tsirlin et al. 1999, Weeks 1971). Therefore, it will be necessary to line the inner surface of the guard vessel with a thin layer of suitable corrosionresistant material (e.g., HT-9, EP-823, a refractory metal, a ceramic material). This will also prevent liquid-metal embrittlement of the guard vessel. It should be emphasized that the ASME code conservatively requires the designer to ignore the structural contribution of the liner.

\subsubsection{Service Loadings Levels}

The definition of the four main levels of service loadings (A, B, C and D) found in the ASME code is reported below for clarity.

Level A Service Loadings: any loadings arising from startup, operation in the design power range, hot standby and system shutdown, and excepting only those loadings covered by Level B, $\mathrm{C}$ and $\mathrm{D}$.

Level B Service Loadings: deviations from Level A Service Loadings that are anticipated to occur frequently enough that design should include capability to withstand the loadings without operational impairment. These events include any abnormal incidents not resulting in a forced outage and also forced outages for which the corrective action does not include any repair of mechanical damage.

Level C Service Loadings: deviations from Level A Service Loadings that require shutdown for correction of the loadings or repair of damaged system. The total number of postulated occurrences for such events may not exceed 25 .

Level D Service Loadings: combinations of loadings associated with extremely lowprobability postulated events whose consequences are such that the integrity and operability of 
the nuclear energy system may be impaired to the extent that only considerations of public health and safety are involved.

The two situations we are mostly interested in (normal operating conditions and loss-ofprimary-heat-sink accidents) fall under Service Levels A and C, respectively, in accordance with the IFR design practice.

\subsubsection{Stress Calculations}

The following assumptions are made:

1) Thermal stresses are neglected. According to the ASME code, thermal stresses associated with a radial temperature distribution in a cylindrical shell fall under the "secondary stresses" category and in Subsection NH should be considered for thermalstress ratcheting, only. Because the expected frequency of the loss-of-primary-heat-sink transient over the reactor lifetime is less than one (GE 1986), ratcheting effects should be negligible.

2) Thermal creep is not explicitly modeled as is already accounted for by the time- and temperature-dependent stress limits of the ASME Code Subsection NH (see below).

3) Discontinuity stresses at the beltline/head interface are neglected. This assumption is based on the calculations in Buongiorno et al. (1999) where it was shown that the limiting constraint is set by the primary membrane stresses (and not by primary local or secondary stresses). Moreover, it is possible to select the beltline-to-head-thickness ratio to minimize the discontinuity stresses, if needed.

4) As a result of assumptions 1) and 3), the structural analysis is conducted only for the primary membrane stresses.

The ASME code limits for primary membrane stresses in Class 1 Components in Elevated Temperature Service are:

$\begin{array}{lll}\mathrm{S}<\mathrm{S}_{\mathrm{mt}} & (\text { Level Service A \& B) } & \text { Eq.1 } \\ \mathrm{S}<\min \left\{1.2 \mathrm{~S}_{\mathrm{m}}, \mathrm{S}_{\mathrm{t}}\right\} & (\text { Level Service C }) & \text { Eq.2 }\end{array}$

where $\mathrm{S}$ is the primary membrane stress intensity defined as:

$$
S=\max \left\{\sigma_{r}-\sigma_{\vartheta}|,| \sigma_{z}-\sigma_{\vartheta}|,| \sigma_{r}-\sigma_{z} \mid\right\}
$$

$\sigma_{\mathrm{r}}, \sigma_{\vartheta}$ and $\sigma_{\mathrm{z}}$ are the radial, hoop and axial stress, respectively.

$\mathrm{S}_{\mathrm{mt}}, \mathrm{S}_{\mathrm{t}}$ are time- and temperature-dependent mechanical properties of SS-316 found in the ASME code (Mandatory Appendix I-14, Subsection NH). On the other hand, $\mathrm{S}_{\mathrm{m}}$ is defined in Section II, Part D, Appendix 2 as: 


$$
\mathrm{S}_{\mathrm{m}} \text { is the lesser of }\left\{\begin{array}{l}
1 / 3 \text { tensile strength at room temperature } \\
1 / 3 \text { tensile strength at operating temperature } \\
2 / 3 \text { yield strength at room temperature } \\
0.9 \text { yield strength at operating temperature }
\end{array}\right.
$$

The tensile and yield strengths of SS-316 as functions of temperature are also found in the code, so that $\mathrm{S}_{\mathrm{m}}$ can be readily calculated.

The reference geometry of the guard vessel is illustrated in Figure 78. The guard vessel diameter $D_{v}$ and length $L_{v}$ are fixed at about 6 and $19 \mathrm{~m}$, respectively (as these are the reference values utilized in the thermal-hydraulic analysis of Section 4.4). The main independent variable is the guard vessel thickness, $t_{v}$. The lower head is modeled as hemispherical shell of $6 \mathrm{~m}$ diameter. The upper plenum pressure $\mathrm{P}_{\mathrm{i}}$ is assumed to be $0.1 \mathrm{MPa}$ and so is the external pressure $\mathrm{P}_{0}$. The primary membrane radial, hoop and axial stresses at any location $\mathrm{z}$ are calculated from elementary equilibrium considerations and assuming hydrostatic behavior of the coolant pressure along the guard vessel. (With regard to Figure 78, note that in reality the guard vessel is not entirely filled with $\mathrm{Pb}-\mathrm{Bi}$, but rather contains the main reactor vessel with a $\mathrm{Pb}$-Bi-filled gap between the two. However, as far as the stresses in the guard vessel are concerned, the presence of the main vessel is irrelevant, because hydrostatic behavior of the $\mathrm{Pb}-\mathrm{Bi}$ fluid is assumed). The expressions for the primary membrane stresses are as follows:

$$
\begin{array}{ll}
\sigma_{r}=-\frac{P_{0}+P_{i}+\rho g z}{2} & \text { Eq.4 } \\
\sigma_{\vartheta}=\left(P_{i}+\rho g z-P_{0}\right) \frac{D_{v}}{2 t_{v}} & \text { Eq.5 } \\
\sigma_{z}=\left(P_{i}-P_{0}\right) \frac{D_{v}}{4 t_{v}}+g \rho\left(\frac{D_{v}}{3}+L_{v}\right) \frac{D_{v}}{4 t_{v}} & \text { Eq.6 }
\end{array}
$$

where $\rho$ and g are the coolant density (i.e., $\rho \sim 10,000 \mathrm{~kg} / \mathrm{m}^{3}$ for lead and lead-alloy coolants) and the gravity constant, respectively.

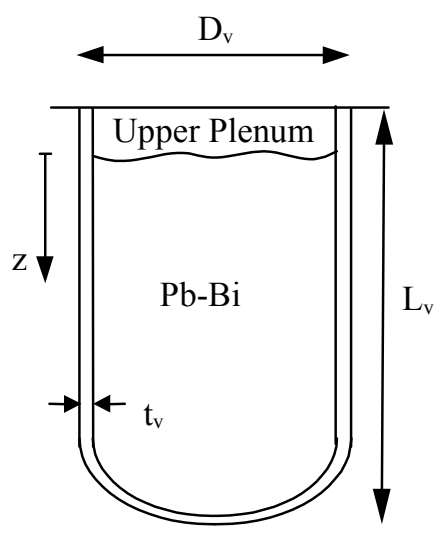

Figure 78. The guard vessel geometry. 


\subsubsection{Results}

For given loadings, the primary stresses decrease with the guard vessel thickness. Since $\mathrm{S}_{\mathrm{m}}$, $\mathrm{S}_{\mathrm{mt}}$ and $\mathrm{S}_{\mathrm{t}}$ generally decrease with temperature, the guard vessel temperature limits increase with the guard vessel thickness as shown in Figure 79, for both Service Levels A\&B and C. Note that, as already mentioned, SS316 cannot be operated above $430^{\circ} \mathrm{C}$ for longer than $3 \times 10^{5}$ hours $(\sim 34$ years). Thus, the guard vessel normal operating temperature needs to be maintained below $430^{\circ} \mathrm{C}$, if the anticipated reactor lifetime exceeds 34 years. On the other hand, remarkably high temperatures (as high as $750^{\circ} \mathrm{C}$ ) can be withstood by thick vessels $\left(\mathrm{t}_{\mathrm{v}}>10 \mathrm{~cm}\right)$ under Service Level $\mathrm{C}$ conditions for shorter times ( $<1,000$ hours) typical of loss-of-primary-heat-sink situations.

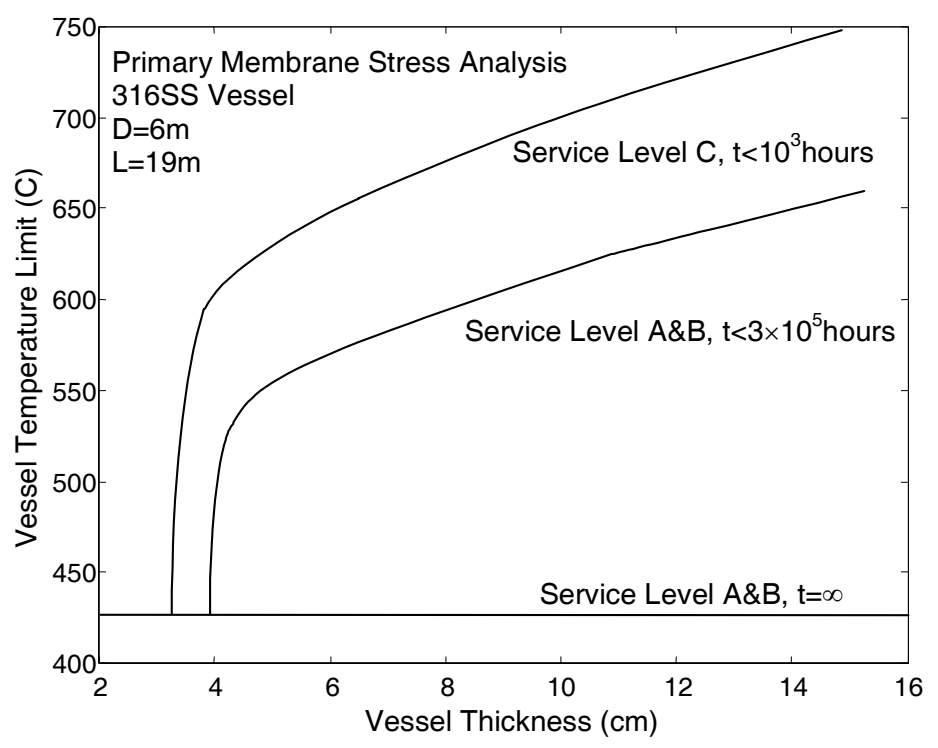

Figure 79. The guard vessel temperature limits.

The Service Level C curve of Figure 79 can be used in concert with a thermal-hydraulic model of the Decay Heat Removal System (DHRS) to evaluate the maximum allowable reactor power on the basis of the loss-of-primary-heat-sink transient (see Section 4.4).

\subsection{Technical/Economical Optimization of the Primary Circuit and Power Conversion Cycle (MIT, Prof. Neil Todreas, Vaclav Dostal)}

The goal of this section is to evaluate the various power generating systems that might be used with a lead-bismuth cooled reactor, i.e., minimum temperature drop. The three options discussed below are the steam, helium and supercritical $\mathrm{CO}_{2}$ cycles. Only forced circulation of the lead-bismuth in the primary coolant system was investigated during FY-01. The thermodynamic efficiency of the power conversion cycle is one of the key parameters that affect the bus-bar cost of electricity. In order to achieve the highest possible efficiency it is necessary to maximize the average core outlet temperature. This task is described in the core thermal hydraulics part of this work where the core features that affect the average core outlet temperature are addressed. The core thermal hydraulic analysis was performed using multiple channels with heat conduction between the channels, but no mass exchange. 
Once the highest possible average core outlet temperature is known, the second task is to transfer the heat from the primary circuit to the secondary coolant with maximum effectiveness. As will be discussed, the main limitation here is the fact that the intermediate heat exchanger (IHX) or steam generator (if a steam cycle is used) must be placed in the reactor vessel. Thus, the overall external dimensions of the IHX or steam generator are fixed. The key effort is then focused on the achievement of the highest possible IHX or steam generator outlet temperatures.

In the next section, the analysis and layout of the power generating cycles are discussed. The key figure of merit here is the cycle efficiency. The features of each cycle are then summarized and compared. Also, an attempt is made to estimate the amount of power consumed by the power station to obtain net efficiencies.

The last section discusses the economic features of the different power conversion cycles and presents comparisons among the cycles. Based on these comparisons, the optimum power conversion cycle for lead-bismuth forced convection was selected.

\subsubsection{Thermal Hydraulic Analysis of the Core with Forced Circulation}

Thermal hydraulic analysis of the core is performed in order to determine the temperature and pressure distribution within the core. From the plant design point of view the main task was to achieve the highest possible average core outlet temperature, compatible with the temperature constraints on the cladding and fuel. Due to the fact that a suitable subchannel code for the leadbismuth flowing through a square array does not exist, the thermal hydraulic analysis was performed for multiple channels with no mass exchange, but modeling the heat conduction among the channels. The overall method for this analysis is described in Dostal et al. [2001].

\subsubsection{Core Design}

The core design is based on the prior neutronic analysis (see Section 3) and fuel pin structural analysis (see Section 4.1). Table 24 in Section 3.4.4 lists the reference fuel composition and Table 25 lists the core parameters.

The Core Geometry. The core consists of 157 fuel assemblies, which are arranged in a $21 \mathrm{x}$ 21 square lattice. Streaming channels are located on the periphery of each fuel assembly and in the center, occupying the center $7 \times 7$ fuel rod positions (Figure 60). There are 312 fuel rods per fuel assembly. The friction of the coolant is higher in the corner and edge channels than in the central channels, which results in a lower mass flux in these channels and consequently higher coolant temperatures. To avoid these higher temperatures and equalize the flow through the core, the rod to wall pitch in these channels was increased by adding an extra $0.4 \mathrm{~mm}$ and reducing the dimensions of the streaming channels.

Core Power Distribution and Hot Channel Location. The core thermal power is 700 $\mathrm{MW}_{\text {th }}$. The power distribution within the core was obtained by neutronic analysis using MCNP4A. Three different peaking factors were used:

- Fuel-assembly power peaking factors as shown in Figure 61. The maximum fuel assembly power peaking factor is 1.16 .

- Pin power peaking factors within the fuel assembly, as shown Figure 62. The maximum local power peaking factor in the hot assembly is 1.015 . 
- The axial power profile as a function of the axial location is shown in Figure 63 and its values vary from 0.85 to 1.155 .

Additional heat deposition due to gamma heating of the walls surrounding the fuel assemblies is important since it contributes to the coolant temperature rise in the corner and edge subchannels. This heat rate was expected to be $1 \mathrm{~W} / \mathrm{g}$ and is assumed to be spatially uniform.

Oxide layer. Due to the corrosiveness of the lead-bismuth coolant, an oxide layer is intentionally formed on the surface of the cladding to protect it. This layer is taken into the account in the thermal hydraulic analysis of the core, since it increases the temperature of the cladding, which is the most important design constraint. This oxide layer is assumed to be 0.01 $\mathrm{mm}$ thick with a heat conductivity of $2 \mathrm{~W} / \mathrm{mK}$ as suggested in [Samsonov, 1973].

\subsubsection{Thermal Hydraulic Steady State Constraints}

The design constraints for the steady state are based on the structural analysis of the fuel pin, the fuel parameters, and the corrosion properties of the lead-bismuth. The design constraints, which apply to the thermal hydraulic design were introduced in Section 2.2 and are resummarized in Table 31. From a structural analysis point of view, it was decided to use for the cladding temperature limit a value of $600^{\circ} \mathrm{C}$ (see Section 4.1), which enables achievement of the 15-20 at.\% target burnup. The corrosion data for the lead-bismuth are not yet available, but are expected to allow the temperature specified in the structural analysis. There should be a limit on the maximum coolant velocity, since high coolant velocities are expected to result in the erosion of the protective oxide layers on the cladding and structural materials. This limit was set to $2 \mathrm{~m} / \mathrm{s}$ based on results of Fomitchenko [1998]. This limit is used to determine the maximum coolant mass flow rate through the core. The fuel melting point imposes a limit on the maximum fuel temperature. For the steady state operation this limit is set to $1000^{\circ} \mathrm{C}$. It has been shown in Dostal et al. [2001] that this limit is less restrictive than the cladding limit.

Table 31. Design constraints for the current reference core.

\begin{tabular}{|l|l|}
\hline Design constraint & Value \\
\hline Membrane cladding temperature limit & $600^{\circ} \mathrm{C}$ \\
\hline Fuel temperature limit & $1000^{\circ} \mathrm{C}$ \\
\hline Maximum coolant velocity & $2 \mathrm{~m} / \mathrm{s}$ \\
\hline
\end{tabular}

\subsubsection{Thermal Hydraulic Analysis - Methodology}

The objective of the core subchannel analysis is to obtain the temperature, pressure, and velocity distribution in the core. This is important to make sure that the core design limits are not violated. A detailed description of the computational methodology was presented in Dostal et al. [2001]. A brief explanation of the approach will be presented next.

Based on the core geometry determined by the neutronics and structural analysis, the core flow area is known. Using an estimated core inlet temperature for the calculation of the coolant density and an initial guess of the inlet velocity distribution, the core mass flow rate is estimated. The total core mass flow rate is calculated with the assumption that the mass flow rate is the same in all fuel assemblies. The final value of the core mass flow rate is then increased by five percent, which should be sufficient to account for the bypass mass flow rate, i.e., the coolant flowing in the gap between adjacent fuel assemblies. Assuming no significant mass exchange among the channels the temperature distribution within the core is calculated taking into the account heat 
conduction among the channels. The coolant temperature distribution is obtained from the heat balance of the core and the temperature profiles in the fuel elements determined from the heat transfer between the cladding and the coolant and the heat conduction within the fuel pin.

The coolant inlet temperature is adjusted in such a way that it will meet the maximum cladding temperature limit. The outlet core velocities are checked to confirm the coolant velocity limit is not exceeded, due to the change of the coolant density during heat up in the core. The coolant mass flow distribution is adjusted by adjusting the inlet channel velocities to satisfy equality of pressure drop for all channels.

The hot channel can either be a corner, edge, or center channel. The average value of the rod local radial peaking factors is the highest for the center channel, but the edge and corner channels are exposed to heat flow from the surrounding walls (from gamma and neutron heating) and have lower mass flow rates due to the higher friction pressure losses. The reason for the change of the rod to wall pitch was to equalize the velocity distribution within the fuel assembly. The corner and edge channels have much higher friction pressure losses than the center channels because of the additional friction on the walls, and an increase of flow area in these channels significantly reduces this pressure loss.

Temperature Distribution Calculation. The bulk coolant temperature in the channel is obtained from a heat balance in the channel, which considers the power from the fuel rods, the gamma heating from the walls, if any, and the heat gain or loss due to heat conduction. The bulk temperatures in the adjacent channels must be known to evaluate the heat conduction between the sub-channels. Because the bulk temperature is affected by the heat conduction, the solution needs to be obtained through an iterative process.

The control volume was chosen to be coolant centered. The power peaking factor was taken as the heat transfer surface averaged value of the peaking factors of the rods that contribute to the heat addition into the channel. The axial coolant temperature was evaluated using $10 \mathrm{~mm}$ steps from the heat balance.

The temperature distribution in the fuel rod was calculated for the rod with the highest peaking. The temperature at the surface of the oxide layer or at the surface of the cladding is calculated from Newton's law using the Westinghouse heat transfer correlation [Todreas and Kazimi 2000]. This correlation was formerly derived for triangular lattices and sodium coolant, but gives more conservative results than the Zhukov et al. correlation [1994], which was derived from lead-bismuth data, but for different parameters than used in this lead-bismuth cooled reactor. The temperature at the cladding outer and inner diameter is then calculated from Fourier's law of heat conduction. The cladding is made from stainless steel with a heat conductivity of $23 \mathrm{~W} / \mathrm{m} / \mathrm{K}$. The gap between the cladding and the fuel outer diameter is filled with liquid lead. The temperature at the fuel outer diameter is evaluated from Fourier's law. No convection or direct contact in the gap is taken into account. For the fuel conductivity the correlation proposed by Kim and used by Buongiorno et al. [1999] was utilized. The pore effect on the thermal conductivity was estimated from the equation proposed by Bauer et al. [Todreas and Kazimi 2000] for the porosity $\mathrm{P}=26 \%$ and spherical pores (i.e., $\varepsilon=1$ ).

Core Pressure Losses and Mass Flow Distribution. The pressure drop across the core was assumed to be uniform for all channels. From this condition one can evaluate the coolant velocities in the different channels, since the pressure losses, except the gravity pressure loss, are dependent on the square of the coolant velocity. The pressure loss across the core consists of: 
- Inlet pressure loss

- Two end fitting pressure losses

- Honeycomb grid pressure loss

- Outlet pressure loss

- Friction pressure loss

- Gravity pressure loss

Acceleration pressure loss was neglected. The pressure losses are evaluated based on the coefficients described in [Todreas and Kazimi 2000].

The mass flow rate across the core was evaluated from the coolant velocities, the number of channels in the fuel assembly, the channel-average coolant density, and the flow area of the channels. The assumption made here is that the flow distribution among the fuel assemblies is equal (i.e., all fuel assemblies have the same mass flow rate). The difference in mass flow rate between the subchannels of the same type due to the temperature related property differences was neglected. The temperature distribution within the core is fairly uniform and the error introduced by this simplification is overcome by the assumption of $5 \%$ bypass. The core mass flow rate can then be calculated from:

$$
\dot{\mathrm{m}}_{\text {core }}=(1+\mathrm{b}) \mathrm{n}_{\mathrm{fa}} \sum_{\mathrm{i}=1}^{4} \mathrm{n}_{\mathrm{i}} \bar{\rho}_{\mathrm{iLBE}} \mathrm{A}_{\mathrm{i}} \mathrm{v}_{\mathrm{i}}
$$

where: $\quad \mathrm{n}_{\mathrm{fa}} \quad$ is the number of the fuel assemblies in the core,

$\mathrm{b} \quad$ is the bypass fraction of the total mass flow rate, $b=0.05$,

$\mathrm{n}_{\mathrm{i}} \quad$ is the number of the channels of type $\mathrm{i}$,

$\bar{\rho}_{\text {iLBE }}$ is the average coolant density in the channels of type $i$,

$\mathrm{A}_{\mathrm{i}} \quad$ is the flow area of the channels of type $i$,

$v_{i} \quad$ is the average coolant velocity in the channels of type $i$.

The geometric characteristics of the channel types are summarized in Table 32.

Table 32. The geometric characteristics of the channel types.

\begin{tabular}{|l|c|c|c|c|c|c|}
\hline Channel Type & $\begin{array}{c}\text { \# of Channel Types } \\
\text { Fuel Assembly }\end{array}$ & $\begin{array}{c}\text { Flow } \\
\text { area } \\
\left(\mathbf{m m}^{2}\right)\end{array}$ & $\begin{array}{c}\text { Wetted } \\
\text { Perimeter } \\
(\mathbf{m m})\end{array}$ & $\begin{array}{c}\text { Heated } \\
\text { Perimeter } \\
(\mathbf{m m})\end{array}$ & $\begin{array}{c}\text { Equivalent } \\
\text { Hydraulic Diameter } \\
(\mathbf{m m})\end{array}$ & $\begin{array}{c}\text { Equivalent } \\
\text { Heated Diameter } \\
(\mathbf{m m})\end{array}$ \\
\hline Center & 260 & 51.16 & 23.625 & 23.625 & 8.661 & 8.661 \\
\hline Inner corner & 4 & 38.37 & 33.401 & 17.719 & 4.595 & 8.662 \\
\hline Edge & 96 & 29.49 & 21.588 & 11.813 & 5.464 & 9.986 \\
\hline Outer corner & 4 & 16.86 & 15.682 & 5.906 & 4.300 & 11.418 \\
\hline
\end{tabular}

\subsubsection{Summary of the Core Results}

As mentioned earlier, the aim of the core analysis is to evaluate the highest possible average core outlet temperature. Results for the case of forced circulation are shown in Table 33. The results are very promising. The average lead-bismuth outlet temperature is less than $50^{\circ} \mathrm{C}$ lower than the membrane cladding temperature, which sets the temperature limit. This small temperature difference is attributed mainly to the very flat power profile within the core and to the core power de-rating (compared to previous designs). A negative attribution occurs because of the reduction of the heat transfer surface per pin, due to the reduction of the pin diameter. Nevertheless, this negative effect is largely overcome by the flat power profile and lower core power. 
The velocity distribution within the core is fairly uniform as well. From the inlet velocity distribution it can be seen that there are no subchannel types with high or low mass flow rate in the core. This behavior is generally favorable, since the uniform flow distribution results in uniform heat removal from the core and enables a maximum utilization of the core capabilities.

Table 33. The forced circulation core thermal hydraulic results.

\begin{tabular}{|l|l|}
\hline INPUT & \\
\hline Reactor thermal power & $700 \mathrm{MW}_{\text {th }}$ \\
\hline Maximum coolant velocity & $2 \mathrm{~m} / \mathrm{s}$ \\
\hline Maximum cladding membrane temperature & $600^{\circ} \mathrm{C}$ \\
\hline Oxide layer thickness & $0.01 \mathrm{~mm}$ \\
\hline Oxide layer conductivity & $2 \mathrm{~W} / \mathrm{mK}$ \\
\hline \hline OUTPUT & \\
\hline Average reactor outlet temperature & $552.5^{\circ} \mathrm{C}$ \\
\hline Inlet core temperature & $461^{\circ} \mathrm{C}$ \\
\hline Maximum lead-bismuth temperature & $576.9^{\circ} \mathrm{C}$ \\
\hline Maximum fuel temperature & $684^{\circ} \mathrm{C}$ \\
\hline Total mass flow rate & $52,257.8 \mathrm{~kg} / \mathrm{s}$ \\
\hline Corner channels inlet velocity & $1.84 \mathrm{~m} / \mathrm{s}$ \\
\hline Edge channels inlet velocity & $1.97 \mathrm{~m} / \mathrm{s}$ \\
\hline Center channels inlet velocity & $1.89 \mathrm{~m} / \mathrm{s}$ \\
\hline Average corner channel heat transfer coefficient & $11.64 \mathrm{~W} / \mathrm{m}^{2} \mathrm{~K}$ \\
\hline Average edge channel heat transfer coefficient & $15.46 \mathrm{~W} / \mathrm{m}^{2} \mathrm{~K}$ \\
\hline Average center channel heat transfer coefficient & $22.73 \mathrm{~W} / \mathrm{m}^{2} \mathrm{~K}$ \\
\hline Total core pressure loss & $566.4 \mathrm{kPa}$ \\
\hline Core pumping power & $2.93 \mathrm{MW}$ \\
\hline
\end{tabular}

\subsubsection{Intermediate Heat Exchangers and Steam Generators}

Analysis of the IHXs and steam generators were performed to identify the key limitations on the secondary coolant heat removal capabilities and their effect on the overall efficiency. The main constraint was that IHXs and steam generators were designed to be fully placed within the reactor vessel. This increases the plant compactness, reduces the capital cost of the plant, and improves plant modularity. The reason for more detailed modeling of the IHX and steam generator was to assess the final temperature differences of the primary and secondary coolants.

The placement of the IHXs or steam generators in the reactor vessel imposes a constraint on their size. Only a certain amount of the annular gap between the core barrel and the liner can be filled with IHXs or steam generators. The rest must be left free for the additional reactor internals. In the case of forced circulation this is mainly the pumps or gas lift pumps. Even in the case of natural circulation, the entire gap cannot be filled due to modularity issues and maintenance problems. Another important factor is the cost of the IHXs or steam generators. Increasing the size of IHXs or steam generators would result in better heat transfer performance, but since the IHXs and steam generators are pressure vessels, the cost associated with increasing their size over reasonable dimensions is counter productive. In the case of natural circulation it might be desirable to reduce the height of the IHXs or steam generators in order to increase the elevation between the core and the IHXs or steam generators, and to reduce the friction drop in 
the IHXs or steam generators. However, this height is not as important for the forced circulation designs, and it was arbitrarily assumed to be $6.9 \mathrm{~m}$.

As described above, the overall external IHX or steam generator geometry is set. This introduces another constraint on the design. The lead-bismuth velocity in the IHXs or steam generators cannot exceed the limit of $2 \mathrm{~m} / \mathrm{s}$. The value of this velocity had to be checked during the design process.

\subsubsection{IHX and Steam Generator Geometry}

The IHXs and steam generators have triangular lattices, that have better heat transfer features than square lattice designs. The options of lead-bismuth in the tubes and lead-bismuth in the shell were investigated, in order to fully understand the heat removal system capabilities both configurations. Until now, only the configuration of lead-bismuth in the tubes and secondary coolant in the shell was considered suitable for the design. The main reason for this configuration was the effort to minimize corrosion due to better oxygen control and essentially no stagnant points when the lead-bismuth is placed in the tubes.

\subsubsection{Lead-Bismuth /Helium or Lead-Bismuth /Carbon Dioxide Intermediate Heat Exchanger}

The lead-bismuth /helium or lead-bismuth /carbon dioxide intermediate heat exchangers are single phase/single phase heat exchangers.

IHX Thermal Design. A detailed description of the thermal design of the IHX is presented in Dostal et al. [2001]. The heat transfer surface is given by the IHX geometry. Unknowns are the helium or $\mathrm{CO}_{2}$ temperature rise across the IHX. From this temperature difference one may find the pressure ratio of the Brayton cycle. For helium, this pressure ratio is the optimum pressure ratio (e.g., the pressure ratio at which the Brayton cycle achieves the highest efficiency). For the supercritical $\mathrm{CO}_{2}$ Brayton cycle, the pressure ratio is taken such that the cycle maximum pressure does not exceed $20 \mathrm{MPa}$. The pressure of $20 \mathrm{MPa}$ was set as a current design limit for the supercritical $\mathrm{CO}_{2}$ cycle as will be discussed later. For the known pressure ratio, the values of the secondary coolant inlet and outlet temperatures and the helium mass flow rate can be evaluated from the equations below. Since the temperatures are not independent of each other (based on one of them and the pressure ratio, the other one can be solved from the cycle analysis) only one of them is unknown. More important for the cycle design is the higher cycle temperature, so this one was picked up as an unknown. The second unknown is the secondary coolant mass flow rate, which can be obtained from an energy balance:

$$
\dot{\mathrm{m}}_{\mathrm{LBE}} \mathrm{c}_{\mathrm{pLBE}}\left(\mathrm{T}_{\mathrm{in}}-\mathrm{T}_{\text {out }}\right)_{\mathrm{LBE}}=\dot{\mathrm{m}}_{\mathrm{Se}} \mathrm{c}_{\mathrm{pSe}}\left(\mathrm{T}_{\text {out }}-\mathrm{T}_{\text {in }}\right)_{\mathrm{Se}}
$$

where: $\quad \dot{\mathrm{m}}_{\mathrm{LBE}}$ is the mass flow of the lead-bismuth through the IHX, equal to $\dot{\mathrm{m}}_{\text {core }}$,

$\mathrm{c}_{\mathrm{pLBE}}$ is the specific heat of the coolant,

$\mathrm{T}_{\text {in/out }}$ denotes the inlet or outlet temperatures, and,

LBE/Se denotes the fluid type (se can be either helium or carbon dioxide).

The outlet temperature of the helium or $\mathrm{CO}_{2}$ can be obtained from the heat transfer balance:

$$
\dot{\mathrm{Q}}=\overline{\mathrm{h}} \mathrm{S} \Delta \mathrm{t}_{\mathrm{ln}}
$$


where: $\dot{Q} \quad$ is the energy transferred in the heat exchanger from the lead-bismuth into the secondary coolant,

$\overline{\mathrm{h}} \quad$ is the average heat transfer coefficient evaluated at the average temperature for lead-bismuth in the tubes from:

$$
\overline{\mathrm{h}}=\frac{1}{\frac{1}{\mathrm{~h}_{\text {Se }}}+\frac{\mathrm{d}_{\text {out }}}{2 \mathrm{k}_{\text {steel }}} \ln \frac{\mathrm{d}_{\text {out }}}{\mathrm{d}_{\text {in }}}+\frac{\mathrm{d}_{\text {out }}}{2 \mathrm{k}_{\mathrm{O}}} \ln \frac{\mathrm{d}_{\text {in }}}{\mathrm{d}_{\mathrm{O}}}+\frac{\mathrm{d}_{\text {out }}}{\mathrm{h}_{\text {LBE }} \mathrm{d}_{\mathrm{O}}}}
$$

or, for lead-bismuth in shell from:

$$
\overline{\mathrm{h}}=\frac{1}{\frac{1}{\mathrm{~h}_{\text {LBE }}}+\frac{\mathrm{d}_{\mathrm{O}}}{2 \mathrm{k}_{\mathrm{O}}} \ln \frac{\mathrm{d}_{\mathrm{O}}}{\mathrm{d}_{\text {out }}}+\frac{\mathrm{d}_{\mathrm{O}}}{2 \mathrm{k}_{\text {stee }}} \ln \frac{\mathrm{d}_{\text {out }}}{\mathrm{d}_{\text {in }}}+\frac{\mathrm{d}_{\mathrm{O}}}{\mathrm{h}_{\mathrm{Se}} \mathrm{d}_{\text {in }}}}
$$

where: $\mathrm{h}_{\mathrm{Se}} \quad$ is the secondary coolant heat transfer coefficient,

$\mathrm{d}_{\text {out }} \quad$ is the outer IHX tube diameter,

$\mathrm{k}_{\text {steel }} \quad$ is the heat conductivity of the IHX tube material,

$\mathrm{d}_{\text {in }} \quad$ is the inner IHX tube diameter,

$\mathrm{k}_{\mathrm{O}} \quad$ is the oxide thermal conductivity,

$\mathrm{d}_{\mathrm{O}} \quad$ is the inner diameter of the IHX tube with the oxide layer on it,

$\mathrm{h}_{\mathrm{LBE}}$ is the $\mathrm{Pb}-\mathrm{Bi}$ heat transfer coefficient,

$\mathrm{S}$ is the heat transfer surface of the IHX, and,

$\Delta \mathrm{t}_{\mathrm{ln}} \quad$ is the logarithmic temperature difference calculated from:

$$
\Delta \mathrm{t}_{\ln }=\frac{\left(\mathrm{T}_{\text {inLBE }}-\mathrm{T}_{\text {outSe }}\right)-\left(\mathrm{T}_{\text {outLBE }}-\mathrm{T}_{\text {inSe }}\right)}{\ln \frac{\left(\mathrm{T}_{\text {inLBE }}-\mathrm{T}_{\text {outSe }}\right)}{\left(\mathrm{T}_{\text {outLBE }}-\mathrm{T}_{\text {inSe }}\right)}}
$$

where: $\mathrm{T}$ denotes temperatures of the fluids, in/out denotes the inlet or outlet temperature of the IHX, and, $\mathrm{LBE} / \mathrm{Se}$ denotes the type of fluids (Se stands for the secondary coolant, helium or carbon dioxide).

\subsubsection{Pb-Bi Steam Generator}

The lead-bismuth/steam generator is in general a single-phase/two-phase heat exchanger with single-phase/single-phase and single-phase/two-phase regions.

Steam Generator Thermal Design. A detailed description of the thermal design of the steam generator was presented in Dostal et al. [2001]. The heat transfer surface is defined by the steam generator geometry. As for the IHX, unknowns are the steam outlet temperature (inlet is provided from the cycle analysis) and the steam-water mass flow rate. Steam-water mass flow rate can be obtained from the following heat balance.

$$
\dot{\mathrm{m}}_{\mathrm{LBE}} \mathrm{c}_{\mathrm{pLBE}}\left(\mathrm{T}_{\mathrm{in}}-\mathrm{T}_{\text {out }}\right)_{\mathrm{LBE}}=\dot{\mathrm{m}}_{\mathrm{w}}\left(\mathrm{h}_{\text {out }}-\mathrm{h}_{\mathrm{in}}\right)_{\mathrm{w}}
$$


where: $\quad \dot{\mathrm{m}}_{\mathrm{LBE}}$ is the mass flow of the lead-bismuth through the steam generator, which is equal to $\dot{\mathrm{m}}_{\text {core }}$,

$\mathrm{c}_{\mathrm{pLBE}}$ is the specific heat of the coolant,

$\mathrm{T}_{\text {in/out }}$ denotes the inlet or outlet temperatures, and,

LBE/w denote the fluid type.

The outlet temperature of the steam can be obtained from the heat power transmitted in the steam generator. The steam generator was divided into following four different regions, and the average heat transfer coefficients were used for each region.

- The first section is the subcooled liquid region (single phase),

- The second represents the saturated fluid in the pre-dry-out region (two phase),

- The third is the saturated fluid in the post-dry-out region (two phase), and

- The fourth is the superheated steam region (single phase).

The basic equation for energy transferred in the steam generator is the same as for the IHX.

$$
\dot{\mathrm{Q}}_{\mathrm{i}}=\overline{\mathrm{h}}_{\mathrm{i}} \mathrm{S}_{\mathrm{i}} \Delta \mathrm{t}_{\ln \mathrm{i}}
$$

where: $\quad \dot{Q} \quad$ is the energy transmitted in the heat exchanger from the lead-bismuth into the water or steam,

$\overline{\mathrm{h}} \quad$ is the average heat transfer coefficient evaluated at the medium temperature for lead-bismuth in tubes from:

$$
\overline{\mathrm{h}}=\frac{1}{\frac{1}{\mathrm{~h}_{\mathrm{Se}}}+\frac{\mathrm{d}_{\mathrm{o}}}{2 \mathrm{k}_{\mathrm{O}}} \ln \frac{\mathrm{d}_{\mathrm{o}}}{\mathrm{d}_{\text {out }}}+\frac{\mathrm{d}_{\mathrm{o}}}{2 \mathrm{k}_{\text {steel }}} \ln \frac{\mathrm{d}_{\text {out }}}{\mathrm{d}_{\text {in }}}+\frac{\mathrm{d}_{\mathrm{o}}}{2 \mathrm{k}_{\mathrm{O}}} \ln \frac{\mathrm{d}_{\mathrm{in}}}{\mathrm{d}_{\mathrm{i}}}+\frac{\mathrm{d}_{\mathrm{o}}}{\mathrm{h}_{\mathrm{LBE}} \mathrm{d}_{\mathrm{i}}}}
$$

or, for lead-bismuth in shell from:

$$
\overline{\mathrm{h}}=\frac{1}{\frac{1}{\mathrm{~h}_{\text {LBE }}}+\frac{\mathrm{d}_{\mathrm{o}}}{2 \mathrm{k}_{\mathrm{O}}} \ln \frac{\mathrm{d}_{\mathrm{o}}}{\mathrm{d}_{\text {out }}}+\frac{\mathrm{d}_{\mathrm{o}}}{2 \mathrm{k}_{\text {steel }}} \ln \frac{\mathrm{d}_{\text {out }}}{\mathrm{d}_{\text {in }}}+\frac{\mathrm{d}_{\mathrm{o}}}{2 \mathrm{k}_{\mathrm{O}}} \ln \frac{\mathrm{d}_{\text {in }}}{\mathrm{d}_{\mathrm{i}}}+\frac{\mathrm{d}_{\mathrm{o}}}{\mathrm{h}_{\mathrm{Se}} \mathrm{d}_{\mathrm{i}}}}
$$

where: $h_{\mathrm{Se}}$ is the secondary coolant heat transfer coefficient,

$\mathrm{d}_{\text {out }} \quad$ is the outer steam generator tube diameter,

$\mathrm{k}_{\text {steel }} \quad$ is the heat conductivity of the steam generator tube material,

$\mathrm{d}_{\text {in }} \quad$ is the inner steam generator tube diameter,

$\mathrm{k}_{\mathrm{O}} \quad$ is the oxide layer thermal conductivity,

$d_{o} \quad$ is the outer diameter of the steam generator tube with the oxide layer,

di is the inner diameter of the steam generator tube with the oxide layer,

$\mathrm{h}_{\mathrm{LBE}}$ is the lead-bismuth heat transfer coefficient,

$\mathrm{S} \quad$ is the active surface of the steam generator,

$\Delta \mathrm{t}_{\ln } \quad$ is the logarithmic temperature difference (calculated form eq 3-4), and

i denotes the region (1-4) 


\subsubsection{IHX and Steam Generator Design Parameters}

The IHX and steam generator design values are shown in Tables 34 and 35 . The primary coolant flows through the IHX or steam generator at atmospheric pressure. The secondary coolants are pressurized. The helium pressure level is $7 \mathrm{MPa}$, the steam pressure is $15 \mathrm{MPa}$, and the supercritical $\mathrm{CO}_{2}$ pressure is $19.72 \mathrm{MPa}$.

Table 34. IHX and steam generator design parameters (lead-bismuth in tubes).

\begin{tabular}{|c|c|c|c|}
\hline \multirow[t]{2}{*}{ INPUT } & \multicolumn{2}{|c|}{ IHX } & Steam Generator \\
\hline & Helium & Carbon Dioxide & Water-Steam \\
\hline Power transmitted in the IHXs or SGs & $700 \mathrm{MW}_{\text {th }}$ & $700 \mathrm{MW}_{\text {th }}$ & $700 \mathrm{MW}_{\text {th }}$ \\
\hline Lead-bismuth mass flow rate & $52,257.8 \mathrm{~kg} / \mathrm{s}$ & $52,257.8 \mathrm{~kg} / \mathrm{s}$ & $52,257.8 \mathrm{~kg} / \mathrm{s}$ \\
\hline Lead-bismuth inlet temperature & $552.52^{\circ} \mathrm{C}$ & $552.52^{\circ} \mathrm{C}$ & $552.52^{\circ} \mathrm{C}$ \\
\hline Lead-bismuth outlet temperature & $461.0^{\circ} \mathrm{C}$ & $461.0^{\circ} \mathrm{C}$ & $461.0^{\circ} \mathrm{C}$ \\
\hline Secondary coolant inlet temperature & --- & --- & $280^{\circ} \mathrm{C}$ \\
\hline Secondary coolant pressure & $7 \mathrm{MPa}$ & $19.72 \mathrm{MPa}$ & $15 \mathrm{MPa}$ \\
\hline GEOMETRY & \multicolumn{2}{|c|}{ IHX } & Steam Generator \\
\hline Total number of tubes (4 bundles/reactor) & 26,976 & 34,412 & 25,556 \\
\hline Outer tube diameter & $16 \mathrm{~mm}$ & $18 \mathrm{~mm}$ & $18 \mathrm{~mm}$ \\
\hline Tube wall thickness & $1.62 \mathrm{~mm}$ & $4.11 \mathrm{~mm}$ & $3.31 \mathrm{~mm}$ \\
\hline Tube pitch & $18.4 \mathrm{~mm}$ & $18.9 \mathrm{~mm}$ & $18.9 \mathrm{~mm}$ \\
\hline Pitch to diameter ratio & 1.15 & 1.05 & 1.05 \\
\hline Tube length & $6.9 \mathrm{~m}$ & $6.9 \mathrm{~m}$ & $6.9 \mathrm{~m}$ \\
\hline Heat transfer surface & $9,356.1 \mathrm{~m}^{2}$ & $13,420.7 \mathrm{~m}^{2}$ & $9,971.6 \mathrm{~m}^{2}$ \\
\hline Outer tube bundle diameter $\left(\mathrm{d}_{\mathrm{to}}\right)$ & $5.2316 \mathrm{~m}$ & $5.2311 \mathrm{~m}$ & $5.2311 \mathrm{~m}$ \\
\hline Inner tube bundle diameter $\left(\mathrm{d}_{\mathrm{ti}}\right)$ & $3.3184 \mathrm{~m}$ & $3.3189 \mathrm{~m}$ & $3.3189 \mathrm{~m}$ \\
\hline Outer IHX/steam generator diameter $\left(\mathrm{d}_{\mathrm{o}}\right)$ & $5.25 \mathrm{~m}$ & $5.25 \mathrm{~m}$ & $5.25 \mathrm{~m}$ \\
\hline Inner IHX/steam generator diameter $\left(\mathrm{d}_{\mathrm{i}}\right)$ & $3.3 \mathrm{~m}$ & $3.3 \mathrm{~m}$ & $3.3 \mathrm{~m}$ \\
\hline Radius of the bend (R) & $0.4875 \mathrm{~m}$ & $0.4875 \mathrm{~m}$ & $0.4875 \mathrm{~m}$ \\
\hline Tube bundle angle $(\alpha)$ ( 4 bundles/reactor) & $60^{\circ}$ & $80^{\circ}$ & $60^{\circ}$ \\
\hline OUTPUT & \multicolumn{2}{|c|}{ IHX } & Steam Generator \\
\hline Secondary coolant mass flow rate & $702.9 \mathrm{~kg} / \mathrm{s}$ & $3,815.6 \mathrm{~kg} / \mathrm{s}$ & $315.5 \mathrm{~kg} / \mathrm{s}$ \\
\hline Secondary coolant inlet temperature & $353.89^{\circ} \mathrm{C}$ & $392.25^{\circ} \mathrm{C}$ & --- \\
\hline Secondary coolant outlet temperature & $545.82^{\circ} \mathrm{C}$ & $541.23^{\circ} \mathrm{C}$ & $551.1^{\circ} \mathrm{C}$ \\
\hline Logarithmic temperature difference & $36.22^{\circ} \mathrm{C}$ & $31.80^{\circ} \mathrm{C}$ & $\begin{array}{c}156.66 / 148.36 / \\
169.44 / 36.20^{\circ} \mathrm{C}^{*}\end{array}$ \\
\hline Secondary coolant velocity & $32.22 \mathrm{~m} / \mathrm{s}$ & $7.04 \mathrm{~m} / \mathrm{s}$ & $\begin{array}{c}0.14 / 0.15 / 0.97 / \\
1.33 \mathrm{~m} / \mathrm{s} \\
\end{array}$ \\
\hline Lead-bismuth velocity & $1.50 \mathrm{~m} / \mathrm{s}$ & $2.00 \mathrm{~m} / \mathrm{s}$ & $1.99 \mathrm{~m} / \mathrm{s}$ \\
\hline Total heat transfer coefficient & $2,065.8 \mathrm{~W} / \mathrm{m}^{2} \mathrm{~K}$ & $1,639.4 \mathrm{~W} / \mathrm{m}^{2} \mathrm{~K}$ & $\begin{array}{c}1,726.5 / 4,619.6 / \\
1,278.0 / 840.4 \\
\mathrm{~W} / \mathrm{m}^{2} \mathrm{~K}\end{array}$ \\
\hline Primary coolant heat transfer coefficient & $20,273.1 \mathrm{~W} / \mathrm{m}^{2} \mathrm{~K}$ & $26,753.3 \mathrm{~W} / \mathrm{m}^{2} \mathrm{~K}$ & $24,982.1 \mathrm{~W} / \mathrm{m}^{2} \mathrm{~K}$ \\
\hline Secondary coolant heat transfer coefficient & $2,788.0 \mathrm{~W} / \mathrm{m}^{2} \mathrm{~K}$ & $2,829.8 \mathrm{~W} / \mathrm{m}^{2} \mathrm{~K}$ & $\begin{array}{c}2,699.4 / 100,210.4 / 1,741 \\
3 / 1,017.8 / \\
4,313.0 \mathrm{~W} / \mathrm{m}^{2} \mathrm{~K}^{* *}\end{array}$ \\
\hline
\end{tabular}

The four numbers are for four different regions of the steam generators. They are given, in order, from the subcooled region to the superheated region. 
** The five numbers give the four values of water-steam heat transfer coefficient in different regions of the steam generator (from sub-cooled to superheated region); the fifth number is the average heat transfer coefficient.

Table 35. IHX and steam generator design parameters (lead-bismuth on the shell side).

\begin{tabular}{|c|c|c|c|}
\hline \multirow[t]{2}{*}{ INPUT } & \multicolumn{2}{|r|}{ IHX } & \multirow{2}{*}{\begin{tabular}{|c|} 
Steam Generator \\
Water-Steam
\end{tabular}} \\
\hline & Helium & Carbon Dioxide & \\
\hline Power transmitted in the IHXs or SGs & $700 \mathrm{MW}_{\text {th }}$ & $700 \mathrm{MW}_{\text {th }}$ & $700 \mathrm{MW}_{\text {th }}$ \\
\hline Lead-bismuth mass flow rate & $52,257.8 \mathrm{~kg} / \mathrm{s}$ & $52,257.8 \mathrm{~kg} / \mathrm{s}$ & $52,257.8 \mathrm{~kg} / \mathrm{s}$ \\
\hline Lead-bismuth inlet temperature & $552.52^{\circ} \mathrm{C}$ & $552.52^{\circ} \mathrm{C}$ & $552.52^{\circ} \mathrm{C}$ \\
\hline Lead-bismuth outlet temperature & $461.0{ }^{\circ} \mathrm{C}$ & $461.0^{\circ} \mathrm{C}$ & $461.0^{\circ} \mathrm{C}$ \\
\hline Secondary coolant inlet temperature & --- & --- & $280^{\circ} \mathrm{C}$ \\
\hline Secondary coolant pressure & $6.9 \mathrm{MPa}$ & $19.72 \mathrm{MPa}$ & $15 \mathrm{MPa}$ \\
\hline GEOMETRY & \multicolumn{2}{|c|}{ IHX } & Steam Generator \\
\hline Total number of tubes (4 bundles/reactor) & 26,976 & 22,436 & 13,012 \\
\hline Outer tube diameter & $16 \mathrm{~mm}$ & $18 \mathrm{~mm}$ & $22 \mathrm{~mm}$ \\
\hline Tube wall thickness & $1.62 \mathrm{~mm}$ & $4.11 \mathrm{~mm}$ & $4.04 \mathrm{~mm}$ \\
\hline Tube pitch & $18.4 \mathrm{~mm}$ & $20.2 \mathrm{~mm}$ & $26.4 \mathrm{~mm}$ \\
\hline Pitch to diameter ratio & 1.15 & 1.12 & 1.2 \\
\hline Tube length & $6.9 \mathrm{~m}$ & $6.9 \mathrm{~m}$ & $6.9 \mathrm{~m}$ \\
\hline Heat transfer surface & $9,356.1 \mathrm{~m}^{2}$ & $8,754.2 \mathrm{~m}^{2}$ & $6,205.3 \mathrm{~m}^{2}$ \\
\hline Outer tube bundle diameter $\left(\mathrm{d}_{\mathrm{to}}\right)$ & $5.2316 \mathrm{~m}$ & $5.2311 \mathrm{~m}$ & $5.2311 \mathrm{~m}$ \\
\hline Inner tube bundle diameter $\left(\mathrm{d}_{\mathrm{ti}}\right)$ & $3.3184 \mathrm{~m}$ & $3.3189 \mathrm{~m}$ & $3.3189 \mathrm{~m}$ \\
\hline Outer IHX/steam generator diameter $\left(\mathrm{d}_{\mathrm{o}}\right)$ & $5.25 \mathrm{~m}$ & $5.25 \mathrm{~m}$ & $5.25 \mathrm{~m}$ \\
\hline Inner IHX/steam generator diameter $\left(\mathrm{d}_{\mathrm{i}}\right)$ & $3.3 \mathrm{~m}$ & $3.3 \mathrm{~m}$ & $3.3 \mathrm{~m}$ \\
\hline Radius of the bend $(\mathrm{R})$ & $0.4875 \mathrm{~m}$ & $0.4875 \mathrm{~m}$ & $0.4875 \mathrm{~m}$ \\
\hline Tube bundle angle $(\alpha)$ (4 bundles/reactor) & $60^{\circ}$ & $60^{\circ}$ & $60^{\circ}$ \\
\hline OUTPUT & \multicolumn{2}{|c|}{$\overline{\mathrm{IHX}}$} & Steam Generator \\
\hline Secondary coolant mass flow rate & $678.5 \mathrm{~kg} / \mathrm{s}$ & $3,842.2 \mathrm{~kg} / \mathrm{s}$ & $318.4 \mathrm{~kg} / \mathrm{s}$ \\
\hline Secondary coolant inlet temperature & $356.83^{\circ} \mathrm{C}$ & $387.47^{\circ} \mathrm{C}$ & --- \\
\hline Secondary coolant outlet temperature & $549.77^{\circ} \mathrm{C}$ & $535.42^{\circ} \mathrm{C}$ & $543.50^{\circ} \mathrm{C}$ \\
\hline Logarithmic temperature difference & $27.90^{\circ} \mathrm{C}$ & $38.68^{\circ} \mathrm{C}$ & $\begin{array}{c}156.74 / 145.37 / \\
166.34 / 56.32^{\circ} \mathrm{C}^{*}\end{array}$ \\
\hline Secondary coolant velocity & $41.43 \mathrm{~m} / \mathrm{s}$ & $16.52 \mathrm{~m} / \mathrm{s}$ & $\begin{array}{c}0.24 / 0.27 / 1.67 / \\
2.30 \mathrm{~m} / \mathrm{s} \\
\end{array}$ \\
\hline Lead-bismuth velocity & $1.16 \mathrm{~m} / \mathrm{s}$ & $1.24 \mathrm{~m} / \mathrm{s}$ & $1.04 \mathrm{~m} / \mathrm{s}$ \\
\hline Total heat transfer coefficient & $2,681.83 \mathrm{~W} / \mathrm{m}^{2} \mathrm{~K}$ & $2,067.4 \mathrm{~W} / \mathrm{m}^{2} \mathrm{~K}$ & $\begin{array}{c}1,695.2 / 2,990.2 / \\
1,518.9 / 968.8 \\
\mathrm{~W} / \mathrm{m}^{2} \mathrm{~K}\end{array}$ \\
\hline Primary coolant heat transfer coefficient & $9,082.9 \mathrm{~W} / \mathrm{m}^{2} \mathrm{~K}$ & $11,306.8 \mathrm{~W} / \mathrm{m}^{2} \mathrm{~K}$ & $11,340.6 \mathrm{~W} / \mathrm{m}^{2} \mathrm{~K}$ \\
\hline Secondary coolant heat transfer coefficient & $5,838.43 \mathrm{~W} / \mathrm{m}^{2} \mathrm{~K}$ & $7,515.2 \mathrm{~W} / \mathrm{m}^{2} \mathrm{~K}$ & $\begin{array}{c}3,662.7 / 57,056.1 / \\
2,916.9 / 1,3920 / \\
5,144.8 \mathrm{~W} / \mathrm{m}^{2} \mathrm{~K}^{* *}\end{array}$ \\
\hline
\end{tabular}

The four numbers are for four different regions of the steam generators. They are given, in order, from the subcooled region to the superheated region.

${ }^{* *}$ The five numbers give the four values of water-steam heat transfer coefficient in different regions of the steam generator (from sub-cooled to superheated region); the fifth number is the average heat transfer coefficient. 
To illustrate the placement of the IHXs and steam generators, Figure 80 shows the crosssection of the IHX or steam generator. The dimensions of the IHXs and steam generators were selected in order to achieve reasonable final temperature differences of the secondary coolant and still leave enough space in the reactor vessel for pumps and additional internals. The performance of the IHXs and steam generators is well suited for this application. An additional increase of the heat transfer surface will not result in a significant gain of the cycle efficiency. However, in the case of natural circulation, which needs to be investigated, or when gas lift pumps are used, it is possible to increase the size of IHXs or steam generators and gain a few more degrees of secondary coolant temperature. Figure 81 shows the actual placement of the IHX or steam generator in the reactor vessel. The angle $\alpha$ was set to $60^{\circ}$ as a reasonable value, except for the $\mathrm{CO}_{2}$ case with lead-bismuth in the tubes, where $80^{\circ}$ was required to reduce the coolant velocity to $2 \mathrm{~m} / \mathrm{s}$ (Table 34 ). For the angle of $60^{\circ}$ there should be enough space for the pumps and other internals. Since these components have not been designed yet, the value of this angle is tentative.

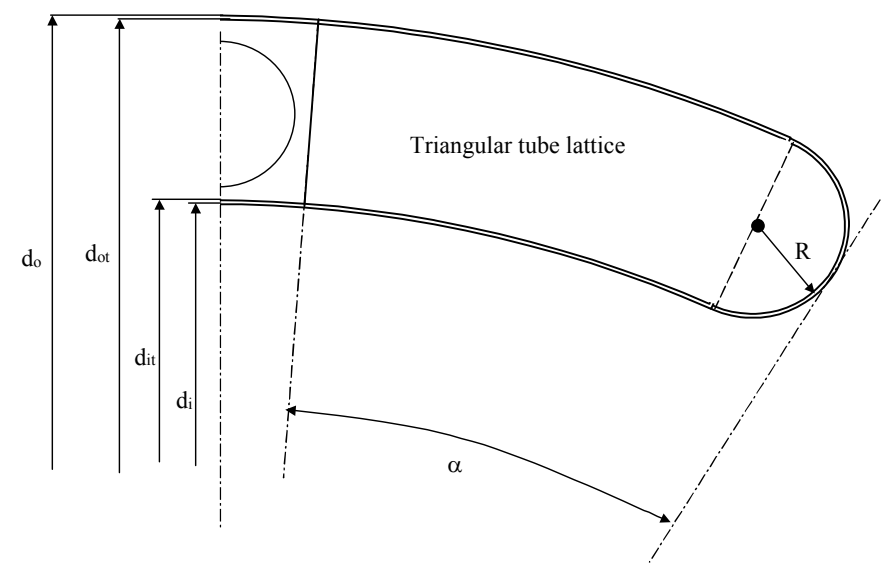

Figure 80. Schematic of $1 / 2$ of the IHX or steam generator.

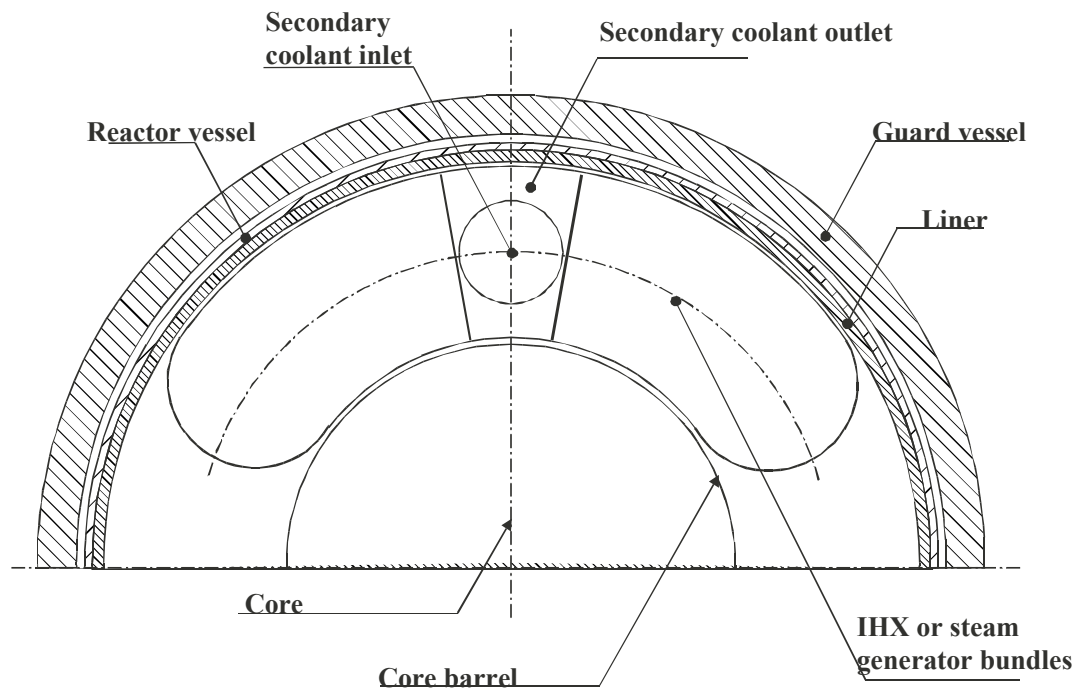

Figure 81. Cross-section of the reactor vessel showing the location of the IHX or steam generator. 
Discussion of the IHX and steam generator design. By examining the numbers in Tables 34 and 35, a few conclusions can be drawn. First, the configuration of the lead-bismuth in the shell performs better than the lead-bismuth in the tubes. The reason is that the surface heat transfer coefficient of the secondary coolant is significantly reduced when it is on the shell side because of the lower flow velocities, while the surface heat transfer coefficient of the primary coolant is practically independent of the $\mathrm{Pb}$ - $\mathrm{Bi}$ location (i.e., the lead-bismuth heat transfer coefficients are less influenced by velocity). This is shown especially in the helium case, where both designs have exactly the same geometry and the case of lead-bismuth in the shell achieves a higher helium outlet temperature. On the other hand, because this configuration increases the velocity of the secondary coolant, it also increases its pressure losses.

The better IHX and steam generator performance of the lead-bismuth in the shell configuration compared to lead-bismuth on the tube side for $\mathrm{CO}_{2}$ and steam is not as obvious as for the helium case from Tables 34 and 35. The reason is that it was impossible to keep the same geometry for both configurations, due to the lead-bismuth velocity limit when it was used in the tubes (very high lead-bismuth velocities can cause erosion problems). Since the steam generator and $\mathrm{CO}_{2}$ IHXs are at higher pressures than the helium IHX, the wall thickness of the tubes had to be increased. This resulted in a smaller tube inside diameter and a higher lead-bismuth velocity in the tubes. In order to avoid exceeding the design limit, more tubes and an unrealistically tight pitch to diameter ratio had to been used. Therefore, the $\mathrm{CO}_{2} \mathrm{IHX}$ had to be significantly enlarged. Because of space limitations, the use of $\mathrm{CO}_{2}$ in the shell side and lead-bismuth in the tubes is not possible in the current design of the core and reactor vessel. In the case of steam, use of lead-bismuth in the tubes is also highly unfavorable. When the configuration with the leadbismuth on the shell side was used, these problems disappeared and the IHX and steam generator performance with all three secondary coolants was almost equal.

Due to the reasons discussed above it is desirable to consider using the lead-bismuth on the shell side of the IHXs and steam generators. However, there are other factors that favor the leadbismuth on the shell side. The IHXs or steam generators separate the high-pressure secondary coolant from the nearly atmospheric lead-bismuth. With the lead-bismuth in tube configuration, both the tubes and the shell form the pressure boundary. In particular, a high pressure retaining shell will be difficult to design because it is not a cylinder. In the case of lead-bismuth in the shell, only the tubes have to be designed to withstand the secondary coolant pressure. In addition, the possibility of stagnant regions is not eliminated with the lead-bismuth in-tube application, since lead-bismuth stagnation can occur in the tube plena, as well as in the shell side of the IHX or steam generators. Thus, the reasons for placing the lead-bismuth in the tubes are not that strong. Since the current design of the core and reactor vessel appear to be acceptable and fulfill most of the design requirements, redesigning the entire reactor, just to place the lead-bismuth in the tubes does not seem reasonable.

\subsubsection{Power Conversion Cycles}

Selection of the optimum power conversion cycle, which best suits the reactor characteristics, is a very important step in the design process. Three candidates were investigated in this study. The first and most common option is the steam power conversion cycle, which might seem, at first glance, the best option for lead-bismuth cooled reactors for several reasons. The leadbismuth cooled reactor outlet temperatures are much higher than in the case of PWR or BWR reactors, thus it is possible to utilize a superheated steam cycle. Experience with the superheated steam cycle is extensive, hence there are very low design uncertainties or potential material difficulties. Such a cycle will achieve higher efficiencies than with fossil fuels, because fossil plants must include the boiler effectiveness, whereas the lead-bismuth cooled reactor penalty 
arises only from the reactor island power consumption. The disadvantages of the steam cycle are in the many support systems, heavy machinery, and in general the complicated configuration of the steam cycle. This motivates consideration of the Brayton cycle. For this lead-bismuth cooled reactor two different options of Brayton cycle were investigated.

The helium cycle offers a relatively cost effective and easily implemented option. The construction time of gas turbine cycles is in general very short in comparison with steam cycles. Further, gas cycles are more flexible in load follow service. However, gas cycles require high temperatures to operate with sufficient efficiency. Finally, operational experience with gas cycles is generally lower than that of steam cycles, so extensive research and development may be necessary. One advantage here is synergy with the Pebble Bed Modular Reactor (PBMR), which is currently pursuing a power conversion cycle with helium temperatures up to $850^{\circ} \mathrm{C}$. With this experience it would be possible to employ helium for the lead-bismuth cooled reactors as well.

The main disadvantage of the helium cycle is its low cycle efficiency compared to the steam cycle in the temperature range of current interest. In order to overcome this problem other working fluids were investigated. For the lower temperatures of about $500-550^{\circ} \mathrm{C}$, which are the current design temperatures for the lead-bismuth cooled reactor the supercritical $\mathrm{CO}_{2}$ Brayton cycle was found to be the most promising. A slight modification of the simple Brayton cycle, to a cycle with recompression, which will be described later, fulfills the need for a simple, high efficiency and low-cost power conversion cycle. This $\mathrm{CO}_{2}$ Brayton cycle option currently seems to be very promising and is an innovative option for the lead-bismuth cooled reactor.

\subsubsection{Steam Cycle}

The steam cycle uses superheated steam and one steam reheat stage. Before entering the steam generators the feed water is preheated by a five stage preheat system, with three lowpressure and two high-pressure feedwater heaters. Figure 82 shows the schematic of the steam cycle. Feedwater from the condenser is pressurized to $1 \mathrm{MPa}$ at the condenser pump and then passes to the open feedwater heater through the two closed feedwater heaters. The closed feedwater heaters utilize cascading of the condensed steam back to the condenser. The temperature at the open feedwater heater was chosen to be $180^{\circ} \mathrm{C}$. This temperature assures the removal of gases from the feedwater and allows for the same feedwater temperature differences for all feedwater heaters. After leaving the open feedwater heater, the feedwater is pressurized to $16 \mathrm{MPa}$ in the feedwater pump and then passes to the high-pressure feedwater heaters. The condensed steam from the high-pressure heaters is cascaded into the open feedwater heater. The final feed-water temperature at the outlet of the feedwater train is $280^{\circ} \mathrm{C}$. This feedwater then enters the steam generator. The steam produced in the steam generator is divided into two streams after leaving the steam generator. The first stream expands in the high-pressure turbine (HPT), the second stream reheats the main stream from the HPT, and then passes into the laststage high-pressure feed-water heater. The reheated steam continues expansion in the lowpressure turbine (LPT) and finally condenses in the condenser.

The steam cycle is not very sensitive to the characteristics of the components, except for the turbine efficiency. From experience with current steam turbines, an efficiency of $87 \%$ is a reasonable assumption. The turbine inlet pressure was set to $15 \mathrm{MPa}$ based on the reference plant. This pressure is common for fossil plants as well. The temperature in the condenser is assumed to be $30^{\circ} \mathrm{C}$. The turbine drives the generator, which has an efficiency of $98.5 \%$. Pump efficiencies were taken equal to $85 \%$. Figure 83 shows the steam cycle temperature-entropy diagram. 


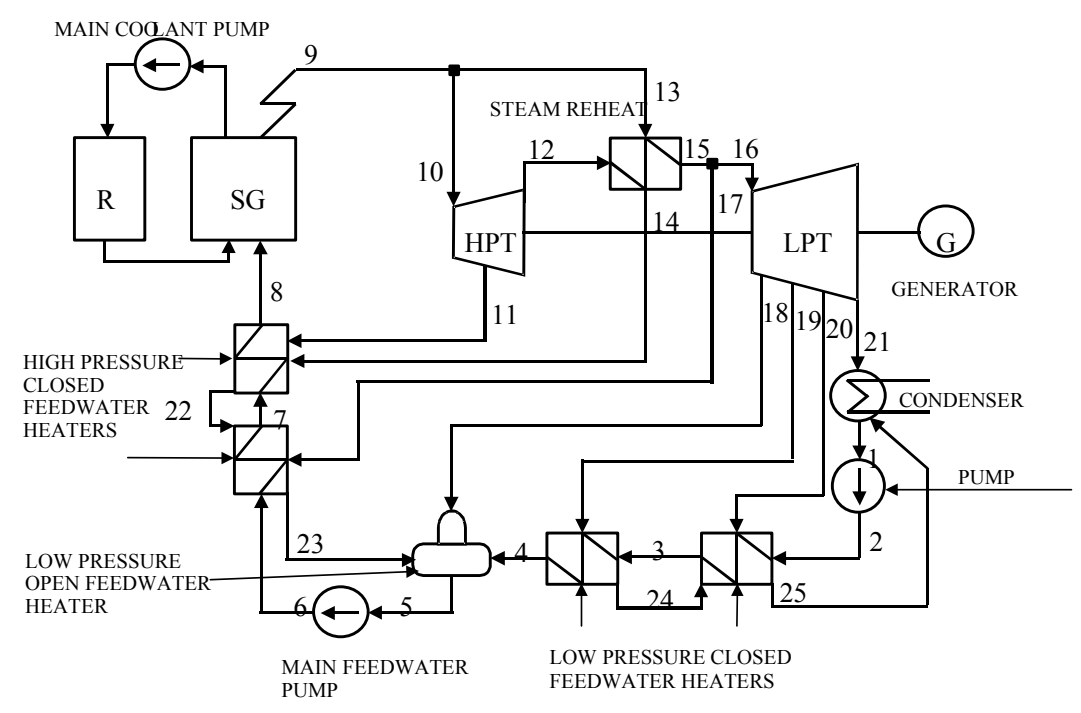

Figure 82. Plant layout of the lead-bismuth cooled reactor with the steam cycle.

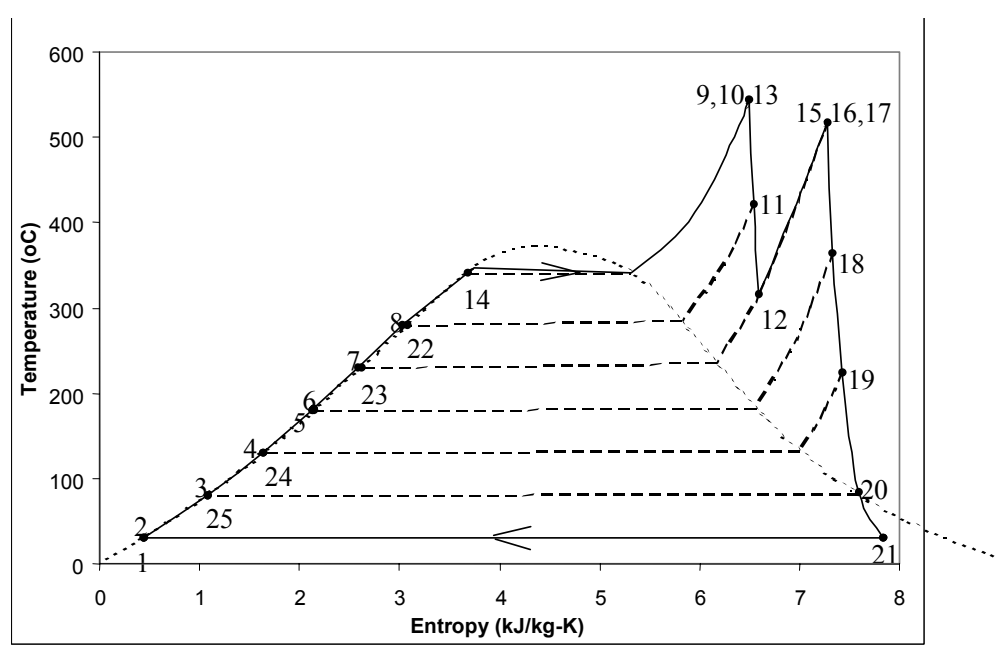

Figure 83. Temperature-entropy diagram of the steam cycle.

Steam cycle results. The main goal of the steam cycle analysis was the cycle efficiency. For the steam cycle described above, the cycle efficiency can be evaluated from:

$$
\eta_{\text {th }}=1-\frac{\dot{\mathrm{m}}_{1}\left(\mathrm{~h}_{21}-\mathrm{h}_{2}\right)}{\dot{\mathrm{m}}_{8}\left(\mathrm{~h}_{9}-\mathrm{h}_{8}\right)}
$$

The specified numbers denote the cycle points as described in Table 36 and Figure 83. Table 37 shows the most important cycle design values and the steam cycle efficiencies. The turbine is connected to the generator by a gearing with the mechanical efficiency of $98 \%$; the generator efficiency is taken as $98.5 \%$. 
Table 36. Steam cycle design point values.

\begin{tabular}{|c|c|c|c|c|c|}
\hline Point & $\begin{array}{c}\text { Temperature } \\
\left({ }^{\circ} \mathbf{C}\right)\end{array}$ & $\begin{array}{c}\text { Pressure } \\
\text { (MPa) }\end{array}$ & $\begin{array}{c}\text { Enthalpy } \\
(\mathrm{kJ} / \mathrm{kg})\end{array}$ & $\begin{array}{c}\text { Entropy } \\
(\mathrm{kJ} / \mathrm{kg}-\mathrm{K})\end{array}$ & $\begin{array}{c}\text { Mass flow } \\
\text { (kg/s) }\end{array}$ \\
\hline 1 & 30.00 & 0.0042 & 125.66 & 0.44 & 201.75 \\
\hline 2 & 30.02 & 1.0027 & 126.66 & 0.44 & 201.75 \\
\hline 3 & 80.00 & 1.0027 & 335.67 & 1.07 & 201.75 \\
\hline 4 & 130.00 & 1.0027 & 546.80 & 1.63 & 201.75 \\
\hline 5 & 180.00 & 1.0027 & 763.12 & 2.13 & 318.43 \\
\hline 6 & 182.75 & 16.0000 & 782.91 & 2.15 & 318.43 \\
\hline 7 & 230.00 & 16.0000 & 993.36 & 2.58 & 318.43 \\
\hline 8 & 280.00 & 16.0000 & 1232.57 & 3.03 & 318.43 \\
\hline 9 & 543.50 & 15.0000 & 3426.84 & 6.50 & 318.43 \\
\hline 10 & 543.50 & 15.0000 & 3426.84 & 6.50 & 260.13 \\
\hline 11 & 420.96 & 6.9186 & 3217.38 & 6.54 & 28.60 \\
\hline 12 & 517.00 & 3.0632 & 3493.50 & 7.27 & 231.52 \\
\hline 13 & 543.50 & 15.0000 & 3426.84 & 6.50 & 58.30 \\
\hline 14 & 342.13 & 15.0000 & 1611.01 & 3.69 & 58.30 \\
\hline 15 & 517.00 & 3.0632 & 3493.50 & 7.27 & 231.52 \\
\hline 16 & 517.00 & 3.0632 & 3493.50 & 7.27 & 209.09 \\
\hline 17 & 517.00 & 3.0632 & 3493.50 & 7.27 & 22.43 \\
\hline 18 & 364.76 & 1.0496 & 3188.89 & 7.33 & 7.35 \\
\hline 19 & 223.44 & 0.2867 & 2914.27 & 7.43 & 18.05 \\
\hline 20 & 84.38 & 0.0513 & 2651.75 & 7.60 & 14.73 \\
\hline 21 & 30.00 & 0.0042 & 2366.50 & 7.83 & 168.97 \\
\hline 22 & 280.00 & 6.9186 & 1263.21 & 3.07 & 86.19 \\
\hline 23 & 230.00 & 3.0632 & 1013.83 & 2.61 & 109.33 \\
\hline 24 & 130.00 & 0.2867 & 554.85 & 1.63 & 18.05 \\
\hline 25 & 80.00 & 0.0513 & 343.31 & 1.08 & 32.78 \\
\hline
\end{tabular}

Table 37. Steam cycle design values.

\begin{tabular}{|l|l|}
\hline Cycle characteristic & Design value \\
\hline Turbine inlet pressure & $15 \mathrm{MPa}$ \\
\hline Turbine inlet temperature & $543.5^{\circ} \mathrm{C}$ \\
\hline Reheat steam pressure & $3.06 \mathrm{MPa}$ \\
\hline Reheat steam temperature & $517^{\circ} \mathrm{C}$ \\
\hline Feedwater temperature into the steam generator & $280{ }^{\circ} \mathrm{C}$ \\
\hline Total mass flow rate & $318.43 \mathrm{~kg} / \mathrm{s}$ \\
\hline Cycle thermodynamic efficiency & $43.8 \%$ \\
\hline Generator efficiency & $98.5 \%$ \\
\hline Mechanical efficiency & $98 \%$ \\
\hline Cycle efficiency & $42.3 \%$ \\
\hline
\end{tabular}

\subsubsection{Helium Brayton Cycle}

The second option is the helium cycle. The selected cycle works with three compressors, two intercoolers and a recuperator. The parameters of the individual cycle components significantly affect the cycle thermal efficiency. Table 38 shows the characteristics of the cycle components, which were used for this helium cycle. These numbers should be achievable by current technology [Ballinger, 2001]. 
Table 38. Helium Brayton cycle component data.

\begin{tabular}{|l|l|}
\hline Compressor efficiencies (\%) & 85 \\
\hline Turbine efficiency (\%) & 90 \\
\hline Recuperator effectiveness (\%) & 92 \\
\hline Pressure drop across intercooler (\%) & 0.4 \\
\hline Pressure drop across precooler (\%) & 0.4 \\
\hline Pressure drop across recuperator (\%) & 1.8 \\
\hline Pressure drop across IHX (\%) & 2.5 \\
\hline
\end{tabular}

Helium Brayton Cycle Layout. The cycle layout is shown in Figure 84. The current layout is two shafts, three compressors, two intercoolers, a recuperator and a pre-cooler. Helium at $30^{\circ} \mathrm{C}$ enters the low-pressure compressor (LPC). After compression it is cooled to $30^{\circ} \mathrm{C}$ and passes to two high-pressure compressors (HPCs) with inter-cooling between them. After leaving the compressors, the helium enters the recuperator where it is heated by the helium that has left the turbine. From the recuperator the helium continues into the IHX and then to the high-pressure turbine (HPT), which provides work for the high-pressure compressors. Helium then passes into the low-pressure turbine (LPT), which provides work for the low-pressure compressor (LPC) and generator $(\mathrm{G})$, which has an efficiency of $98.5 \%$. After leaving the low-pressure turbine, the helium is cooled down to $30^{\circ} \mathrm{C}$ in the recuperator and pre-cooler. The maximum pressure of the cycle is $6.9 \mathrm{MPa}$. Figure 85 shows the temperature entropy diagram of the helium Brayton cycle and Table 39 contains the specified state point values.

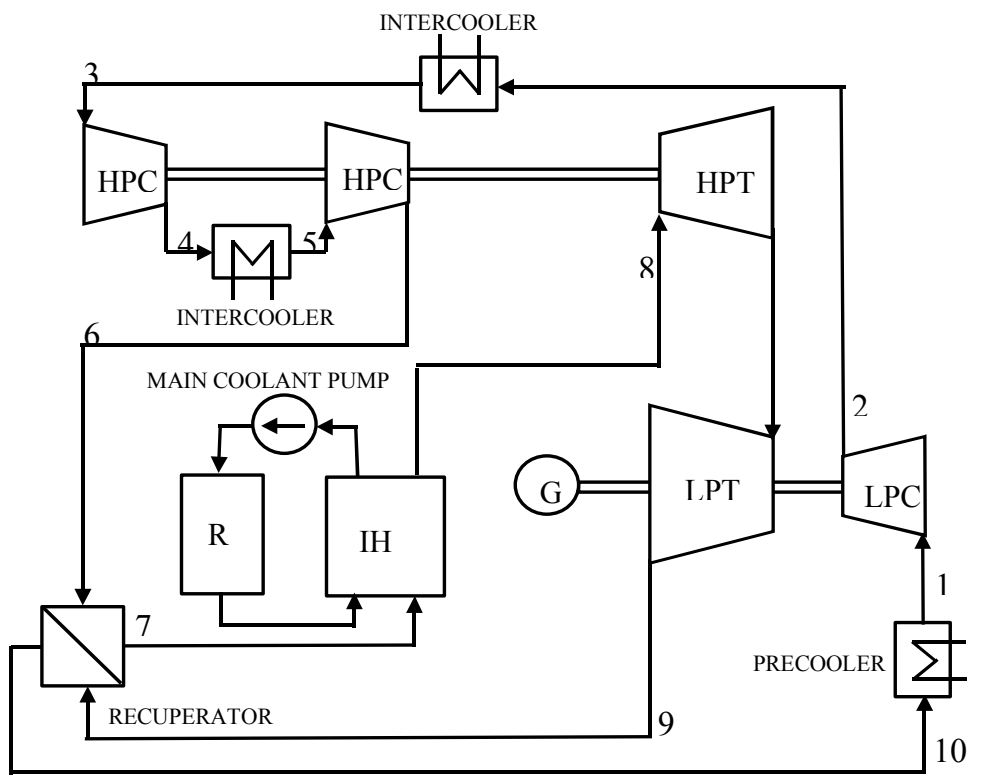

Figure 84. Plant layout of lead-bismuth cooled reactor with the helium cycle. 


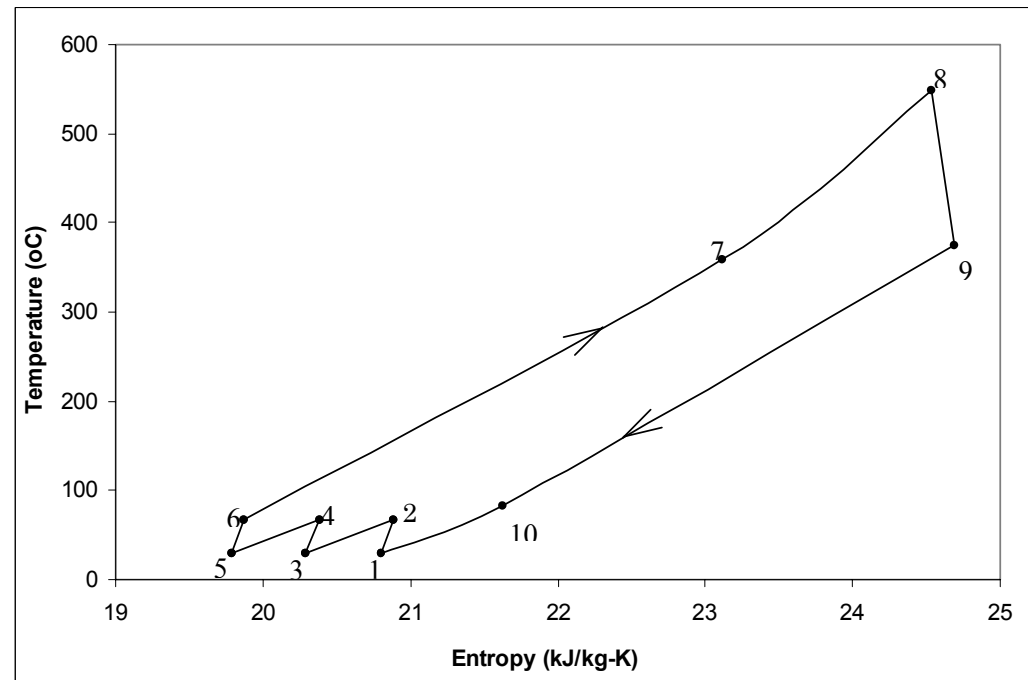

Figure 85. Temperature-entropy diagram of the helium Brayton cycle.

Table 39. Helium Brayton cycle design point values.

\begin{tabular}{|c|c|l|c|c|}
\hline Point & $\begin{array}{c}\text { Temperature } \\
\left({ }^{\mathbf{}} \mathbf{C}\right)\end{array}$ & $\begin{array}{c}\text { Pressure } \\
(\mathbf{M P a})\end{array}$ & $\begin{array}{c}\text { Enthalpy } \\
(\mathbf{k J} / \mathbf{k g})\end{array}$ & $\begin{array}{c}\text { Entropy } \\
(\mathbf{k J} / \mathbf{k g}-\mathbf{K})\end{array}$ \\
\hline 1 & 30.00 & 3.33 & 1590.25 & 20.80 \\
\hline 2 & 67.55 & 4.28 & 1788.16 & 20.89 \\
\hline 3 & 30.00 & 4.26 & 1593.25 & 20.29 \\
\hline 4 & 67.56 & 5.47 & 1792.04 & 20.40 \\
\hline 5 & 30.00 & 5.45 & 1597.09 & 19.78 \\
\hline 6 & 67.57 & 7.00 & 1797.00 & 19.87 \\
\hline 7 & 359.33 & 6.87 & 3310.13 & 23.12 \\
\hline 8 & 549.62 & 6.70 & 4296.97 & 24.53 \\
\hline 9 & 374.41 & 3.41 & 3378.07 & 24.69 \\
\hline 10 & 82.92 & 3.35 & 1590.25 & 21.63 \\
\hline
\end{tabular}

\subsubsection{Helium Cycle Results}

The main goal of the cycle analysis was to obtain the cycle efficiency. For the helium Brayton cycle described above, the cycle efficiency can be evaluated from:

$$
\eta_{\text {th }}=\frac{\mathrm{h}_{8}-\mathrm{h}_{9}-\left(\mathrm{h}_{6}-\mathrm{h}_{5}\right)-\left(\mathrm{h}_{4}-\mathrm{h}_{3}\right)-\left(\mathrm{h}_{2}-\mathrm{h}_{1}\right)}{\mathrm{h}_{8}-\mathrm{h}_{7}}
$$

The specified numbers denote the cycle points as described in Table 39 and Figure 85. Table 40 shows the most important cycle design values and the cycle efficiencies. The cycle is connected to the generator by gearing a the mechanical efficiency of about $98 \%$; the generator efficiency is taken as $98.5 \%$. 
Table 40. Helium cycle design values.

\begin{tabular}{|l|l|}
\hline Cycle characteristic & Design value \\
\hline Turbine inlet pressure & $7 \mathrm{MPa}$ \\
\hline Turbine inlet temperature & $549.6{ }^{\circ} \mathrm{C}$ \\
\hline Cycle pressure ratio & 2.1 \\
\hline Low pressure compressor inlet pressure & $3.33 \mathrm{MPa}$ \\
\hline Helium mass flow rate & $709 \mathrm{~kg} / \mathrm{s}$ \\
\hline Cycle thermodynamic efficiency & $32.8 \%$ \\
\hline Generator efficiency & $98.5 \%$ \\
\hline Mechanical efficiency & $98 \%$ \\
\hline Cycle efficiency & $31.7 \%$ \\
\hline
\end{tabular}

\subsubsection{Supercritical $\mathrm{CO}_{2}$ Brayton Cycle}

A closed Brayton cycle employing supercritical $\mathrm{CO}_{2}$ as the working fluid (also known as Feher cycle) was proposed, but not developed in 1967 [Feher 1967]. It can develop relatively high thermodynamic efficiencies (e.g., about 45\%) at modest turbine inlet temperatures (e.g., $\left.550^{\circ} \mathrm{C}\right)$ due to the low compressive power expended on the $\mathrm{CO}_{2}$ near its critical point $\left(31^{\circ} \mathrm{C}\right.$, 7.285 MPa) compared to nearly ideal gas working fluids such as helium. Also, experience with supercritical $\mathrm{CO}_{2}$ gas pipelines for oil recovery operations in the western US since about 1985, and with the $14 \mathrm{CO}_{2}$-cooled AGR units in the $\mathrm{UK}$ (core exit $\mathrm{T} \approx 650^{\circ} \mathrm{C} ; \mathrm{P}=4.2 \mathrm{MPa}$ ) in the same timeframe have also now established the previously lacking industrial experience base for the relevant technologies. Improvements in recuperator designs are also a relevant favorable development.

The cycle pressure is currently kept below $20 \mathrm{MPa}$ to ensure an easier introduction of the cycle. However, since higher pressures are used at the same temperatures for the supercritical steam cycle, it is expected that higher pressures will also be used in the future in the supercritical $\mathrm{CO}_{2}$ Brayton cycle, further improving the cycle efficiency.

Supercritical $\mathrm{CO}_{2}$ Cycle Layout. Difficulties would arise in the design of the recuperator if the simple Brayton cycle were used for supercritical $\mathrm{CO}_{2}$. It was found necessary to split the recuperator into separate high- and low- temperature components and to employ an intermediate recompression to avoid having a pinch point in the cold end of the recuperator, due to the different specific heats of the high and low pressure $\mathrm{CO}_{2}$. Figure 86 shows the temperature difference in the recuperator for one of the possible designs of the simple supercritical $\mathrm{CO}_{2}$ cycle. To avoid this, only around half of the total flow enters the main compressor. After being compressed this stream enters the low temperature recuperator. Before entering the high temperature recuperator, the main stream is merged with the recompressed stream. The total mass flow is then heated in the high temperature recuperator and subsequently in the intermediate heat exchangers. Then it enters the turbine. The turbo-machinery design is not definite, so here a two-shaft configuration is used, but this may change in the future. Following the expansion in the high and low-pressure turbines the working fluid enters the high temperature recuperator and subsequently, the low temperature recuperator. The temperature differences for both the highand low-temperature recuperators are shown in Figure 87. After leaving the low temperature recuperator the flow is split. About half of the flow is recompressed in the recompression compressor. The rest of the flow is cooled in the pre-cooler to the to the main compressor inlet temperature. Figure 88 shows the layout of the supercritical $\mathrm{CO}_{2}$ cycle. Figure 89 shows the temperature entropy diagram of the recompression supercritical $\mathrm{CO}_{2}$ cycle and Table 41 contains the specified state points of the current design. 


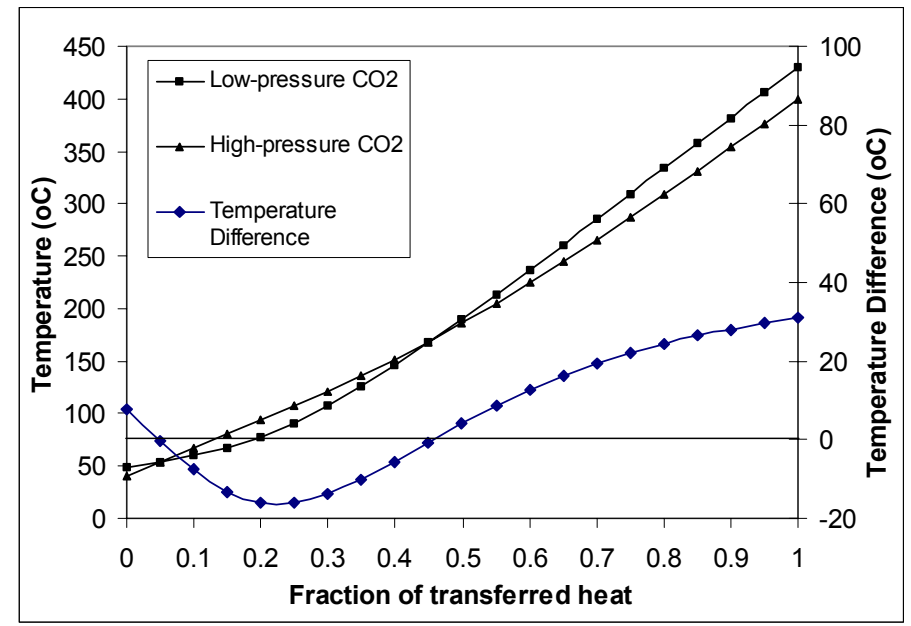

Figure 86. Pinch-point in the recuperator of the simple supercritical Brayton cycle.

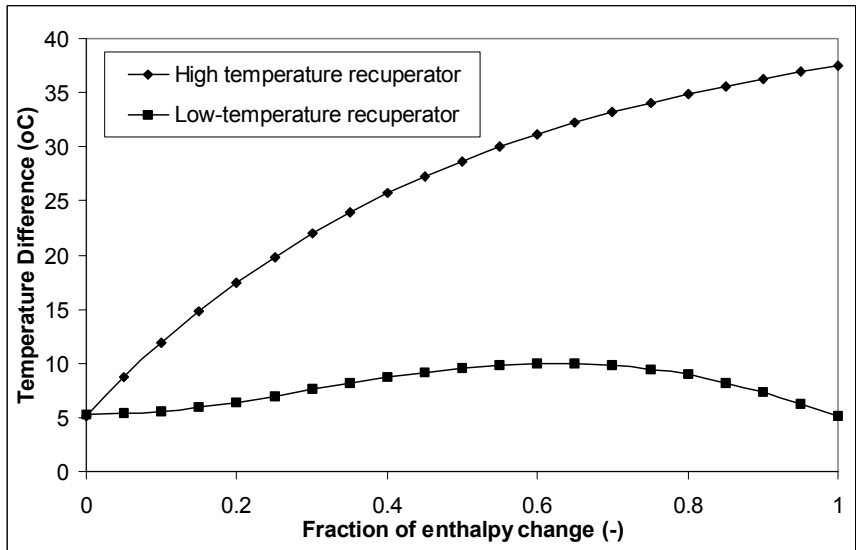

Figure 87. Temperature difference in the recuperators for the recompression cycle.

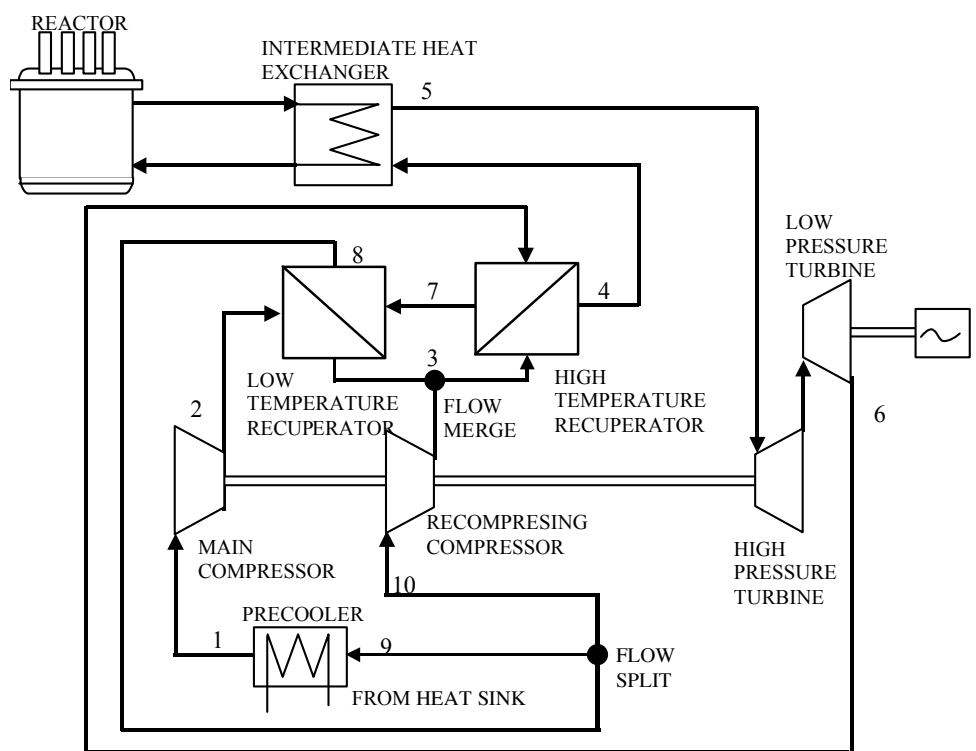

Figure 88. Plant layout of lead-bismuth cooled reactor with the supercritical $\mathrm{CO}_{2}$ cycle. 


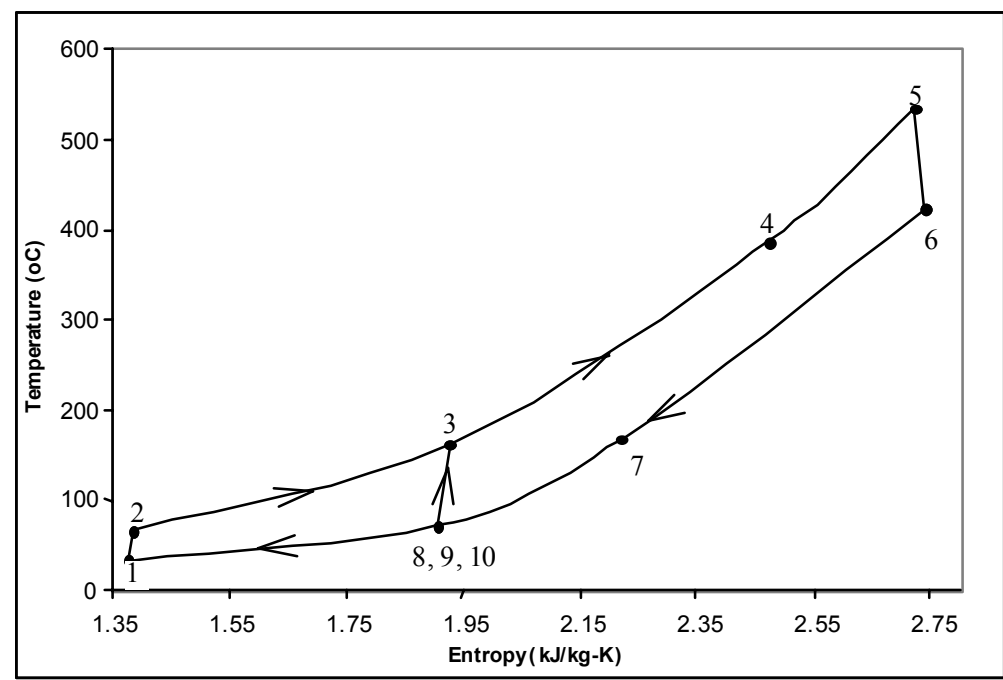

Figure 89. Temperature-entropy diagram of the supercritical $\mathrm{CO}_{2}$ Brayton cycle.

Table 41. Supercritical $\mathrm{CO}_{2}$ Brayton cycle design points.

\begin{tabular}{|c|c|c|c|c|c|}
\hline Point & $\begin{array}{c}\text { Temperature } \\
\left({ }^{\circ} \mathbf{C}\right)\end{array}$ & $\begin{array}{c}\text { Pressure } \\
(\mathbf{M P a})\end{array}$ & $\begin{array}{c}\text { Enthalpy } \\
(\mathbf{k J} / \mathbf{k g})\end{array}$ & $\begin{array}{c}\text { Entropy } \\
(\mathbf{k J} / \mathbf{k g}-\mathbf{K})\end{array}$ & $\begin{array}{c}\text { Mass flow } \\
(\mathbf{k g} / \mathbf{s})\end{array}$ \\
\hline 1 & 32.00 & 7.60 & 315.09 & 1.38 & 1959.52 \\
\hline 2 & 64.84 & 19.76 & 337.51 & 1.39 & 1959.52 \\
\hline 3 & 162.20 & 19.74 & 543.71 & 1.93 & 1959.52 \\
\hline 4 & 387.47 & 19.72 & 835.57 & 2.47 & 3842.20 \\
\hline 5 & 535.39 & 19.65 & 1017.28 & 2.72 & 3842.20 \\
\hline 6 & 424.01 & 7.63 & 895.81 & 2.74 & 3842.20 \\
\hline 7 & 167.38 & 7.62 & 603.94 & 2.22 & 3842.20 \\
\hline 8 & 71.32 & 7.61 & 482.29 & 1.91 & 3842.20 \\
\hline 9 & 71.32 & 7.61 & 482.29 & 1.91 & 1959.52 \\
\hline 10 & 71.32 & 7.61 & 482.29 & 1.91 & 1882.68 \\
\hline
\end{tabular}

Supercritical $\mathrm{CO}_{2}$ Cycle Results. The goal of the cycle analysis was to estimate the cycle efficiency. For the recompression supercritical $\mathrm{CO}_{2}$ Brayton cycle described above the cycle efficiency can be evaluated from:

$$
\eta_{\text {th }}=\frac{\dot{\mathrm{m}}_{5}\left(\mathrm{~h}_{5}-\mathrm{h}_{6}\right)-\dot{\mathrm{m}}_{1}\left(\mathrm{~h}_{2}-\mathrm{h}_{1}\right)-\dot{\mathrm{m}}_{10}\left(\mathrm{~h}_{3}-\mathrm{h}_{10}\right)}{\dot{\mathrm{m}}_{5}\left(\mathrm{~h}_{5}-\mathrm{h}_{4}\right)}
$$

The specified numbers denote the cycle points as described in Table 41 and Figure 89. Table 42 shows the most important cycle design values and the cycle efficiencies. The cycle is connected to the generator by gearing with a mechanical efficiency of about $98 \%$; the generator efficiency is taken as $98.5 \%$. 
Table 42. Recompression supercritical $\mathrm{CO}_{2}$ Brayton cycle design values.

\begin{tabular}{|l|l|}
\hline Cycle characteristic & Design value \\
\hline Turbine inlet pressure & $19.76 \mathrm{MPa}$ \\
\hline Turbine inlet temperature & $535.39{ }^{\circ} \mathrm{C}$ \\
\hline Cycle pressure ratio & 2.6 \\
\hline Main compressor inlet pressure & $7.6 \mathrm{MPa}$ \\
\hline Recompression compressor inlet pressure & $7.61 \mathrm{MPa}$ \\
\hline Recompressed fraction of mass flow rate & 0.49 \\
\hline Mass flow of the carbon dioxide & $3842.20 \mathrm{~kg} / \mathrm{s}$ \\
\hline Cycle thermodynamic efficiency & $45.7 \%$ \\
\hline Generator efficiency & $98.5 \%$ \\
\hline Mechanical efficiency & $98 \%$ \\
\hline Cycle efficiency & $44.1 \%$ \\
\hline
\end{tabular}

\subsubsection{Discussion of the Performance of of the Power Conversion Cycles}

The previous sections described the layout and thermal analysis of the three selected cycles. This section summarizes the cycle efficiencies and evaluates net efficiency of the lead-bismuth cooled reactor power station.

Based on current industry practice the self-power consumption of a PWR with a steam cycle is about $6.5 \%$ of the energy produced by the power station. For the case of a lead-bismuth cooled reactor, this power consumption is expected to be even slightly higher due to the heaters necessary for maintaining the lead-bismuth in a liquid state in the case of outages, although the decay heat might suffice. For example, the current design of the S-PRISM reactor developed by the General Electric Co. claims a cycle efficiency around $41.2 \%$, but the net power station efficiency is only $38 \%$. This corresponds to a self-power consumption of $7.9 \%$ [Boardman 2000]. Since the lead-bismuth cooled reactor does not have a three loop configuration as does the sodium cooled S-PRISM, one may expect that the power consumption of the lead-bismuth cooled reactor power station will be lower than in the case of the S-PRISM. As a base number for the in house power consumption of the lead-bismuth cooled reactor with the steam cycle, $7 \%$ was assumed.

For the helium and supercritical $\mathrm{CO}_{2}$ cycles cases, it is more difficult to evaluate the selfpower consumption. The current design of the PBMR is using numbers around $4 \%$ for the station power consumption. Since the helium cycle of the PBMR is nearly the same as for the leadbismuth cooled reactor and one would suppose the lead-bismuth cooled reactor to be more power demanding, hence a value of 5\% for the power consumption should be a reasonable estimate. For the supercritical $\mathrm{CO}_{2}$ cycle, which is significantly simpler, because no intercoolers and only two compressors are used, a further reduction of in in-house power consumption of $0.5 \%$ was assumed, resulting in consumption of $4.5 \%$ of the generated power.

Using the assumptions for in-house power consumption discussed above it is now possible to make a rough estimate of the efficiencies of the power station associated with the lead-bismuth cooled reactor employing the discussed power conversion cycles. Table 43 shows the estimated values leading to the evaluation of the net efficiency. It can be observed that the supercritical $\mathrm{CO}_{2}$ cycle achieves the best cycle and net efficiencies. Recall that this cycle works with the lowest temperature, but still is capable of achieving higher cycle efficiency than both of the other cycles. In addition, the low self-power consumption further improves the net efficiency. The 
steam cycle also offers a very interesting option and its net efficiency is relatively high. The helium cycle on the other hand is not suitable for lead-bismuth cooled reactors.

Table 43. Net efficiency evaluation.

\begin{tabular}{|l|c|c|c|c|c|c|c|}
\hline & $\begin{array}{c}\text { Thermal } \\
\text { power } \\
\left(\mathbf{M W}_{\text {th }}\right.\end{array}$ & Pressure & $\begin{array}{c}\text { Cycle } \\
\text { efficiency } \\
(\mathbf{M})\end{array}$ & $\begin{array}{c}\text { Gross } \\
\text { electric } \\
\text { power } \\
\mathbf{( M W}_{\mathbf{~}}\end{array}$ & $\begin{array}{c}\text { Self- } \\
\text { consumption } \\
\mathbf{( \% )}\end{array}$ & $\begin{array}{c}\text { Net electric } \\
\text { power } \\
\left(\mathbf{M W}_{\mathbf{e}}\right)\end{array}$ & $\begin{array}{c}\text { Net } \\
\text { efficiency } \\
\mathbf{( \% )}\end{array}$ \\
\hline Steam cycle & 700 & 15 & 42.3 & 296.1 & 7 & 275.4 & 39.3 \\
\hline Helium cycle & 700 & 7 & 31.7 & 221.9 & 5 & 210.8 & 30.1 \\
\hline $\begin{array}{l}\text { Supercritical } \\
\mathbf{C O}_{2} \text { cycle }\end{array}$ & 700 & 19.72 & 44.1 & 308.7 & 4.5 & 294.8 & 42.1 \\
\hline
\end{tabular}

\subsubsection{Economic Comparison of the Power Conversion Cycles}

Descriptions of the power conversion cycles were presented in the preceding sections. The gross and the net efficiency for all cycles were evaluated. The efficiencies were evaluated only for the case of forced circulation of lead-bismuth. The precise economic comparison of the cycles at this stage of design is a very difficult task. From the current results it is more reasonable to evaluate the potential of each power conversion cycle and address the main issues affecting the cycle cost.

From a core thermal hydraulic point of view, the core design is not affected by the choice of the power conversion cycle. The temperature and pressure distribution within the core as well as the mass flow rate are not affected by the choice of secondary coolant.

In the case of only the IHXs, the least expensive and best performing option is helium as a secondary coolant. The main reason for this is the lower pressure of the helium power conversion cycle in comparison with the other two cycles. The difference in cost between the steam generators and $\mathrm{CO}_{2}$ IHX should not be significant and both will cost more than the helium IHX. The steam cycle operates at lower pressure and has less active heat transfer surface, i.e., less tubes and cheaper tube bundles. On the other hand $\mathrm{CO}_{2}$ as a coolant is significantly less corrosive than water. This should tend to equalize the cost of the steam generators and the $\mathrm{CO}_{2} \mathrm{IHX}$.

The volumetric flow rate and the pressure of the working fluid in the secondary side piping affects the interconnecting piping cost. However, the advantage of the lower pressure of the helium is offset by the high volumetric flow rates in comparison with $\mathrm{CO}_{2}$ or water. But generally, this should not be a very important issue.

The most important part of the cost is the cost of the cycle itself. Since, as was described above, the only difference in the reactor island cost comes from IHXs or steam generators, the cost of the power conversion cycle is of great importance. From this point of view it is clear that the supercritical $\mathrm{CO}_{2}$ cycle should be the least expensive option. The cycle is very simple and compact. The utilization of high pressure makes the comparison more difficult, but one would expect the cost of the supercritical $\mathrm{CO}_{2}$ cycle to be lower than for helium because of the reduced number of components. Even if the cost of both cycles was taken the same and the helium would, in addition, receive credit for the lower cost of the IHX, still the lower efficiency of the helium 
power station on a lead-bismuth cooled reactor would make its specific cost $(\$ / \mathrm{kWe})$ significantly higher than in the case of the supercritical $\mathrm{CO}_{2}$ cycle. The huge difference in the net efficiency makes successful use of the helium power conversion cycle impossible. This cycle is not suitable for the lead-bismuth cooled reactor and its investigation should be abandoned.

Comparison of the steam cycle and supercritical $\mathrm{CO}_{2}$ cycle is not as straightforward. Here the pressures of both cycles are closer (15 MPa vs. $20 \mathrm{MPa})$, but the steam cycle gains some advantage here. The advantage of the steam cycle is also that it is a well-proven technology, so there would not be any difficulties with the design. The most difficult part of the design will be the steam generator. On the other hand the compactness and simplicity of the supercritical $\mathrm{CO}_{2}$ cycle favor it. The comparison of net efficiencies tells us that there is not a significant advantage of one cycle over the other although the $\mathrm{CO}_{2}$ cycle has a slightly higher efficiency. In summary, the cost difference due to the higher pressure of the supercritical $\mathrm{CO}_{2}$ plant should be largely overcome by its simplicity, and further improved by the slightly higher net efficiency.

Hence, for the reasons stated above the most suitable power conversion cycle for the leadbismuth cooled reactor is currently the supercritical $\mathrm{CO}_{2}$ recompression Brayton cycle and thus it should be used as the primary choice for the power conversion cycle. However, further investigation of the steam cycle, including utilization of higher pressure (possibly even supercritical) may improve the net efficiency of the steam cycle in such a manner that a detailed and very precise economical analysis will be necessary to resolve which cycle offers the better option. For this detail economical analysis a more final design is necessary.

\subsection{Analyses of Reactor Transients (INEEL, Cliff Davis)}

It should be emphasized that, because all the analyses in this section were undertaken early in FY-01, they were not performed for the reference core, vessel and power cycle designs described in Section 2 above (i.e., fertile-fuel core, $\mathrm{Pb}$-Bi forced circulation, $\mathrm{CO}_{2}$ power cycle), but for the older design utilized in FY-00, i.e., fertile-free fuel, natural circulation of the lead-bismuth coolant and steam power conversion cycle. Therefore, the results presented below should be taken only as a qualitative indication of the actual response of the reactor to the postulated transients. It is the intention of the authors to re-perform these analyses for the new reference design in FY-02.

The ATHENA code (Carlson et al. 1986) was used to determine core power limits for a lossof-feedwater transient (Buongiorno et al. 2000). The analysis determined transient power limits with the original Reactor Vessel Auxiliary Cooling System (RVACS) based on the Power Reactor Innovative Small Module (PRISM) design (General Electric 1986) design and an enhanced RVACS model designed to increase the power limit. Figure 1 in Section 2 shows the layout of the reactor and RVACS coolant circulation schemes. In the enhanced RVACS design, the wetted height of the reactor vessel was increased by $10 \%$, the gap between the reactor and containment vessel (in the earlier sections of this report the containment vessel was called the guard vessel) was narrowed and filled with lead bismuth, and fins were added to the outside of the containment vessel to double the effective heat transfer area. The transient power limits were found to be $660 \mathrm{MW}$ with the original RVACS model and $1050 \mathrm{MW}$ with the enhanced RVACS model. Any increase in core power above these limiting values caused the peak cladding temperature to exceed its transient limit. 
This year ATHENA was used to evaluate three distinct plant configurations, which are listed in Table 44. Configuration 1 simulates natural circulation of the primary coolant and a steam power conversion system. The original RVACS model was used. As noted above, this was the configuration analyzed last year and represented by the ATHENA model described in Section 4.4.1.

The second plant configuration evaluated was identical to the first except that forced circulation of the primary coolant was simulated. Two methods of achieving forced circulation were evaluated, one utilizing a centrifugal pump at the bottom of the downcomer and the other utilizing a gas lift pump that injected helium into the bottom of the chimney.

The third plant configuration was identical to Configuration 1 except that the secondary coolant was changed from water to helium.

The performance of different configurations of the actinide-burner reactor was evaluated during a wide range of transients, including loss of secondary heat sink with reactor scram (Section 4.4.2), loss of secondary heat sink without scram (Section 4.4.3), step change in load (Section 4.4.4), plant startup (Section 4.4.5), control rod ejection (Section 4.4.6), large rupture of the secondary coolant system (Section 4.4.7), primary coolant pump seizure (Section 4.4.8), loss of preheating of the secondary coolant (Section 4.4.9), and heat exchanger tube rupture (Section 4.4.10). The three configurations were evaluated for some, but not all, of the transients to reduce the total number of calculations required. A summary of results is presented in Section 4.4.11.

The relative transient performance of the three design configurations was evaluated by comparison with a transient cladding temperature limit of $750^{\circ} \mathrm{C}$ (Buongiorno et al. 2000). Section 4.1 describes a new analysis that shows that the transient cladding temperature limit should be $725^{\circ} \mathrm{C}$. The reduction in the temperature limit will affect the allowable reactor power, but will not affect the relative performance of the three design configurations. The cladding temperature limit was found to be more restrictive than the fuel and vessel temperature limits described in Sections 4.1 and 4.2.

The analysis described in Sections 4.4.2 through 4.4.11 is based on last year's reactor design (Buongiorno et al. 2000) and does not reflect the revisions described in Section 2.1. Analysis of transients in the revised design will be performed next year.

Table 44. Analyzed configurations of the actinide-burner reactor.

\begin{tabular}{|c|c|c|}
\hline Configuration & $\begin{array}{c}\text { Circulation of the Primary } \\
\text { Coolant }\end{array}$ & Secondary Coolant \\
\hline 1 & Natural & Water \\
\hline 2 & Forced & Water \\
\hline 3 & Natural & Helium \\
\hline
\end{tabular}

\subsubsection{ATHENA Model Description}

The ATHENA model used in this year's analysis is based on the model used in last year's analysis and is illustrated in Figure 90. The model simulates natural circulation of the primary coolant and a steam power conversion system (Configuration 1 of Table 44). The model represents the primary coolant system, the secondary coolant system, and the original RVACS based on the PRISM design (General Electric 1986). The primary coolant system is represented 
by Components 500 through 595 . The reactor core is represented by two parallel flow channels, one (Component 516) representing eight high-powered fuel assemblies and the other (Component 510) representing 149 fuel assemblies. The peaking factor of the eight high-powered bundles is 1.24. The axial power shape represents end-of-life conditions and has a maximum peaking factor of 1.12 (Hejzlar et al. 2000). Each control volume is approximately $1 \mathrm{~m}$ long except in the active core and steam generator, where smaller control volumes are used. For convenience, the cover gas above the normal liquid level is not explicitly modeled. Instead, a time-dependent volume (Component 595) is used to set the pressure of the system and to receive or supply fluid as the primary coolant heats or cools. A valve (Component 582) is used to represent the holes in the vessel liner. Opening the valve initiates the flow that occurs as the liquid level reaches the holes in the liner and spills over into the annular region (Component 585) between the liner and reactor vessel. The heat removed by the RVACS is enhanced significantly after spillover occurs. The opening time of the valve is treated parametrically. The average-powered and high-powered fuel rods, core barrel, and steam generator tubes are represented with heat structures. An oxide film was modeled on the inside of the heat exchanger tubes to represent fouling.

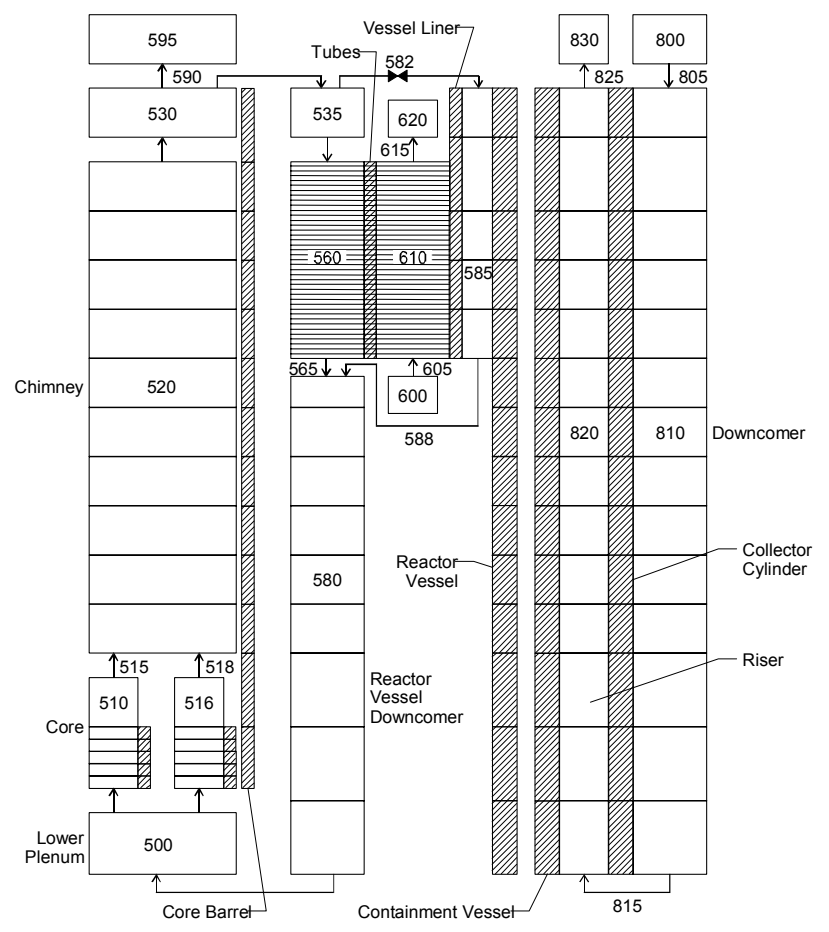

Figure 90. ATHENA model of the actinide-burner reactor.

The model shown in Figure 90 simulates natural circulation of the primary coolant. Forced circulation was simulated with a centrifugal pump and a gas lift pump. The centrifugal pump replaced the lowest volume of the reactor vessel downcomer (Component 580). The gas lift pump operated by injecting helium into the lowest volume of the chimney (Component 520).

The secondary coolant system is represented by Components 600 through 620 . The inlet flow to the secondary coolant system is supplied with a time-dependent junction (Component 605). The pressure in the secondary coolant system generator is set with a time-dependent volume (Component 620). The geometry of the model remains the same when the secondary coolant is changed from water to helium. Only initial and boundary conditions are adjusted to reflect the change in coolant. 
The RVACS is represented by Components 800 through 830 . The air supply and exhaust are represented with two time-dependent volumes (Components 800 and 830), which are set at atmospheric pressure. The model represents all the major heat structures associated with the RVACS, including the vessel liner, the reactor and containment vessels, and the collector cylinder. Radiation enclosure models are used to represent the radiation heat transfer between the reactor and containment vessels and between the containment vessel and the collector cylinder. The emissivity of these surfaces was set to 0.75 , which is representative of the average measured value during the PRISM test program (Hunsbedt and Magee 1988). The convection and conduction of the inert gas in the gap between the reactor and containment vessels was neglected. Insulation was applied to the outside surface of the collector cylinder. Additional details of the model, including benchmarking results, are described by Buongiorno et al. (2000).

Most of the transients analyzed this year did not simulate a reactor scram. Consequently, a best-estimate point reactor kinetics model was developed to calculate the transient reactor power. The point kinetics model was based on the calculations of Hejzlar et al. (2000). The ATHENA point kinetics model requires the delayed neutron fraction $(0.0025)$ and prompt neutron generation lifetime $(7.80 \mathrm{e}-6 \mathrm{~s})$. The reactivity feedback model was used to simulate the effects of changes in fuel temperature and moderator density. The input fuel temperature feedback coefficient was $-0.00083 \$ / \mathrm{K}$, which represented the combined effects of Doppler $(-0.0004 \$ / \mathrm{K})$ and fuel thermal expansion $(-0.00043 \$ / K)$. Table 45 shows the reactivity feedback due to changes in moderator density. The streaming tube design of the fuel assemblies results in a negative coolant void worth. Power-squared averaging was used to determine the weighting factors in the feedback model.

The ATHENA code version used in this analysis utilized the El-Boher and Lesin void correlation (1988) for cocurrent upflow of lead-

Table 45. Moderator density
feedback table.
\begin{tabular}{|c|c|}
\hline Density, kg/m & Reactivity, $\$$ \\
\hline 0.0 & -34.56 \\
\hline 6,000 & -5.513 \\
\hline 8,000 & -2.428 \\
\hline 10,250 & 0.0 \\
\hline 10,575 & $0.351^{\mathbf{3}}$ \\
\hline * Obtained by extrapolation. \\
\hline
\end{tabular}
bismuth and steam. The El-Boher and Lesin correlation was developed to predict the void fraction for the cocurrent upflow of several mixtures, including lead-bismuth and steam. The lead-bismuth tests on which the correlation was based were conducted at a nominal pressure of $0.35 \mathrm{MPa}$ and a nominal temperature of $170^{\circ} \mathrm{C}$. The lead-bismuth superficial velocity varied from 0.6 to $1.6 \mathrm{~m} / \mathrm{s}$. The ratio of steam superficial velocity to liquid superficial velocity varied from 0.35 to 5.8. Davis (2001) describes the implementation of the El-Boher and Lesin correlation into ATHENA using the code's drift flux model. For cocurrent upflow, the distribution parameter of the drift flux model was adjusted to obtain the same void fraction as predicted by the El-Boher and Lesin correlation for a given drift velocity. Davis used the Kataoka-Ishii (1987) correlation to predict the drift velocity, but more reasonable values of the distribution parameter for the thermal-hydraulic conditions of the actinide-burner reactor were obtained using the Zuber-Findlay (1967) churn-turbulent bubbly correlation. Thus, the ZuberFindlay drift velocity correlation was used for the calculations reported here. The code's normal drift flux correlations were used for cocurrent downflow and countercurrent flow. The El-Boher and Lesin correlation was important only for the steady-state gas lift pump calculations described in Section 4.4.2 and the heat exchanger tube rupture transient described in Section 4.4.10. 


\subsubsection{Loss of Heat Sink with Scram}

The performance of the three plant configurations summarized in Table $\mathbf{4 4}$ during a transient initiated by a loss of heat sink was evaluated. The initial conditions for the three plant configurations are summarized in Table 46. The core power was identical with each configuration. The results presented in Table 46 for Configuration 2 were obtained with a centrifugal pump. The speed of the centrifugal pump was adjusted to obtain a fluid velocity of 2 $\mathrm{m} / \mathrm{s}$ in the core. This velocity was selected as a significantly higher value than that obtained with natural circulation, but low enough to preclude erosion concerns. The principal effects of the higher primary flow rate were to reduce the temperature rise across the core and the core outlet fluid temperature compared to Configuration 1. Changing the secondary coolant to helium resulted in increased primary coolant temperatures because the heat transfer coefficient to helium was less than that to water in the subcooled and boiling regions.

Table 46. Initial conditions for the loss-of-heat-sink transient.

\begin{tabular}{|l|c|c|c|}
\hline Parameter & Configuration & \multicolumn{2}{l|}{} \\
\hline Primary coolant system: & $\mathbf{1}$ & $\mathbf{2}$ & $\mathbf{3}$ \\
\hline Core power, MW & & & \\
\hline Mass flow rate, $\mathrm{kg} / \mathrm{s}$ & 650 & 650 & 650 \\
\hline Core inlet temperature, ${ }^{\circ} \mathrm{C}$ & 17,409 & 53,995 & 17,299 \\
\hline Core outlet temperature, ${ }^{\circ} \mathrm{C}$ & 267 & 289 & 308 \\
\hline Maximum cladding temperature, ${ }^{\circ} \mathrm{C}$ & 518 & 370 & 563 \\
\hline Cover gas pressure, $\mathrm{MPa}$ & 603 & 410 & 647 \\
\hline Secondary coolant system: & 0.1 & 0.1 & 0.1 \\
\hline Pressure, MPa & & & \\
\hline Flow rate, $\mathrm{kg} / \mathrm{s}$ & 7.0 & 7.0 & 6.9 \\
\hline Inlet temperature, ${ }^{\circ} \mathrm{C}$ & 317 & 317 & 417 \\
\hline Outlet temperature, ${ }^{\circ} \mathrm{C}$ & 200 & 200 & 200 \\
\hline Collapsed liquid level, $\mathrm{m}$ & 316 & 316 & 500 \\
\hline RVACS: & 2.04 & 1.98 & 0.0 \\
\hline Power removed, $\mathrm{MW}$ & & & \\
\hline Air flow rate, $\mathrm{kg} / \mathrm{s}$ & 0.56 & 0.58 & 0.81 \\
\hline Air inlet temperature, ${ }^{\circ} \mathrm{C}$ & 14.4 & 15.2 & 15.8 \\
\hline Air exit temperature, ${ }^{\circ} \mathrm{C}$ & 38 & 38 & 38 \\
\hline
\end{tabular}

1. The collapsed liquid level is $0.0 \mathrm{~m}$ for single-phase gas.

A loss of secondary heat sink was simulated with each plant configuration. The transient was initiated by instantly reducing the inlet flow to the secondary coolant system and the fission power to zero at $0.0 \mathrm{~s}$. The loss of flow diminished the capacity of the secondary coolant system to remove heat, and within a few minutes the RVACS was the only system available for removing core decay power, which was based on an actinide-burning core with 200,000 MWdays/metric ton of burnup (Buongiorno et al. 1999). The primary coolant was assumed to expand to the elevation of the holes in the vessel liner 7 hours into the transient based on the timing in PRISM (Hunsbedt and Magee 1988).

The effect of forced circulation of the primary coolant depends on the availability of the pump during the transient. Consequently, two calculations were performed to investigate the effects of forced circulation. The pump continued to operate during the transient in the first 
calculation, but was tripped at the start of the transient in the second. The effects of forced circulation, both with and without an early pump trip, on maximum cladding temperature are compared to the results with natural circulation in Figure 91. The figure shows that the operation of the pump resulted in a higher peak cladding temperature during the transient than in the other cases. The higher cladding temperature occurred because the power required to pump the leadbismuth was significant compared to the core decay heat. For example, at the time of the temperature peak, the pumping power was about $1 \mathrm{MW}$, or $25 \%$ of the decay power. The addition of heat from the pump caused the primary coolant temperature to increase at a faster rate than in the case with natural circulation. The additional pump power more than compensated for the benefits of forced circulation, which included an increased RVACS heat removal rate (see Figure 92) due to the increased heat transfer coefficient on the primary side of the reactor vessel wall and the lower initial temperatures shown in Table 46.

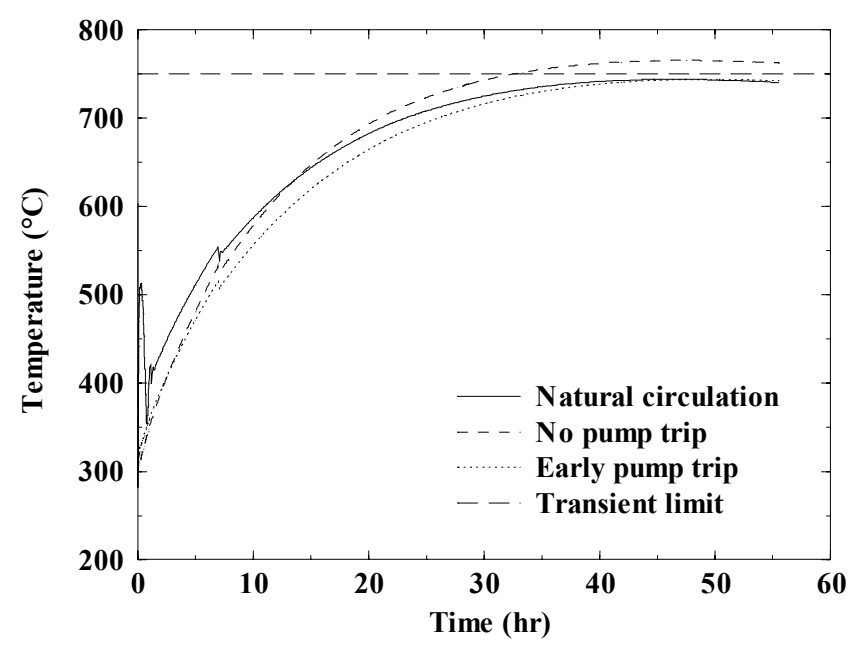

Figure 91. The effect of forced circulation on maximum cladding temperature following a loss of the secondary heat sink.

Figure 91 shows that the peak cladding temperature was nearly identical in the base case and the case with an early pump trip. The benefit of the lower initial temperature in this case was nearly offset by the reduction in natural circulation flow caused by the hydraulic resistance of the pump impeller.

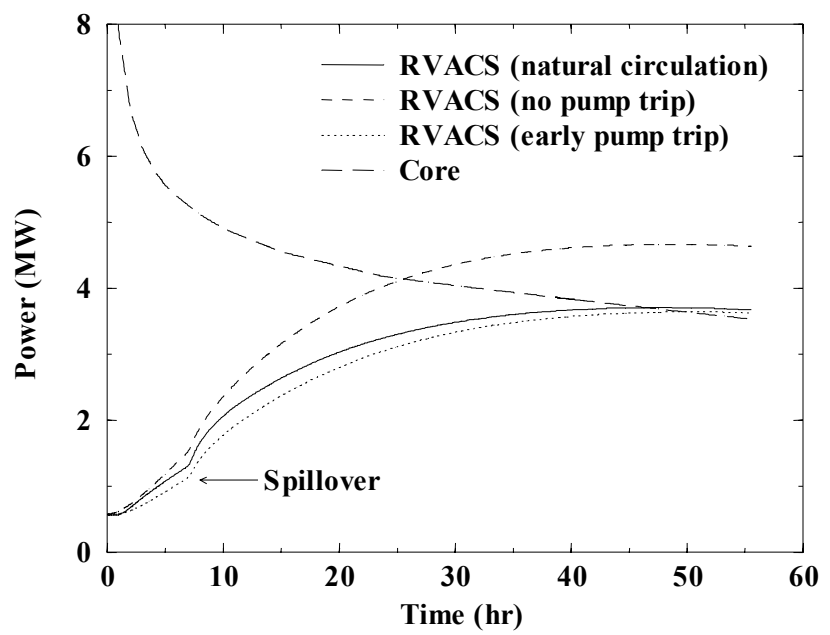

Figure 92. The effect of forced circulation on the power removed by RVACS following a loss of the secondary heat sink. 
Hand calculations were performed to determine the limiting core power that would result in a peak cladding temperature of $750^{\circ} \mathrm{C}$ during the loss-of-heat-sink transient. The limiting core power was $660 \mathrm{MW}$ for Configuration 1 (natural circulation) and Configuration 2 (forced circulation) with an early pump trip. The limiting core power was reduced by $6 \%$, to $618 \mathrm{MW}$, when the pump operated throughout the transient. Thus, it is better to trip the pump rather than operate it at full speed following a loss of secondary heat sink. Similar results are expected for an electromagnetic pump.

An additional calculation was performed to investigate if there was some benefit to operating the pump at reduced speed following a loss of secondary heat sink. In this calculation, the pump speed was reduced to about $35 \%$ of the normal operating speed following the loss of secondary flow. The primary coolant mass flow rate was also reduced to about $35 \%$ of the normal value. The pumping power was significantly reduced in this calculation compared to the case without a pump trip because it is proportional to the flow rate cubed. Because reduced power had to be removed by RVACS, the peak cladding temperature was $699^{\circ} \mathrm{C}$, which was significantly lower than the other cases evaluated. Thus, the limiting core power could be increased by at least $13 \%$ by running the pump at an intermediate speed during the transient. However, this approach is probably not worth pursuing because it is expensive to guarantee that pump power will be available for an extended period following a loss of secondary heat sink.

Full-power, steady-state calculations were also performed with a gas lift pump that injected helium into the chimney of the reactor vessel. The helium flow was adjusted to obtain a coolant velocity of $2.0 \mathrm{~m} / \mathrm{s}$ in the core. Because this coolant velocity was the same as obtained with the centrifugal pump, the steady-state results are almost identical to those shown in Table 46. The required helium flow rate was $1.1 \mathrm{~kg} / \mathrm{s}$, which resulted in an average void fraction in the chimney of 0.20 . The height of the reactor pool would have to be increased by approximately $1 \mathrm{~m}$ to accommodate the swell of the mixture level associated with helium injection compared to a design without gas injection. The use of gas lift pump would also complicate the design of the vessel liner. The normal helium flow rate should be sized so that the normal mixture level was beneath the elevation of the holes in the vessel liner. If the availability of the helium supply system cannot be guaranteed during a transient, the normal helium flow rate should be adjusted so that the mixture level swell during normal operation is less than the $0.24 \mathrm{~m}$ due to thermal expansion of the liquid between normal and emergency operating conditions (Buongiorno et al. 2000). Thus, the helium flow rate should be reduced below $1.1 \mathrm{~kg} / \mathrm{s}$ so that the mixture level swell during normal operation is less than $0.24 \mathrm{~m}$.

The effect of secondary coolant on a loss-of-heat-sink transient was expected to be small because the secondary provides cooling for only a few minutes and the transient lasts many hours. This expectation is confirmed by Figure 93, which shows the effect of secondary coolant on maximum cladding temperature. The cladding temperature was consistently higher with helium as the secondary coolant, but this difference diminished with time. With helium as the coolant, the cladding temperature was $45^{\circ} \mathrm{C}$ higher at the start of the transient, but the peak value was only $11^{\circ} \mathrm{C}$ higher. The effect of the helium coolant diminished with time because higher primary coolant temperatures resulted in more heat removal by RVACS, as shown in Figure 94. Hand calculations indicate that the core power limit was $641 \mathrm{MW}$ with helium as the secondary coolant, a $3 \%$ reduction from the base case.

However, as already mentioned, the reactor design changed considerably from FY-00 to FY01 (e.g., the core and vessel size changed, the fuel composition changed, the power cycle 
changed) and, thus, it was necessary to extrapolate the above results (valid for FY-00 design) to the new design (whose characteristics are summarized in Table 3). Hand calculations were performed and showed that the new power limit for the core with the transient cladding thermal limit of $725^{\circ} \mathrm{C}$ is $850 \mathrm{MW}_{\text {th }}$.

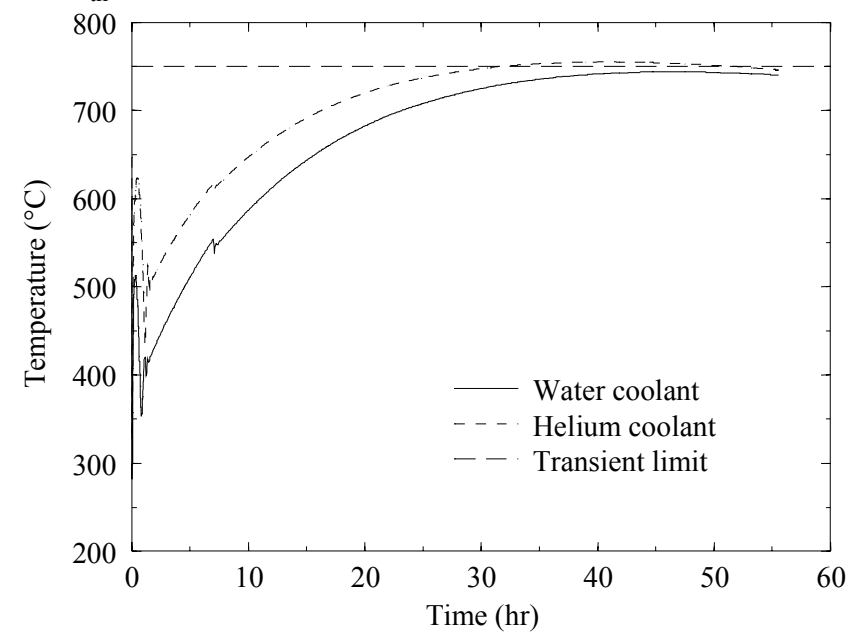

Figure 93. The effect of secondary coolant on maximum cladding temperature following a loss of secondary heat sink.

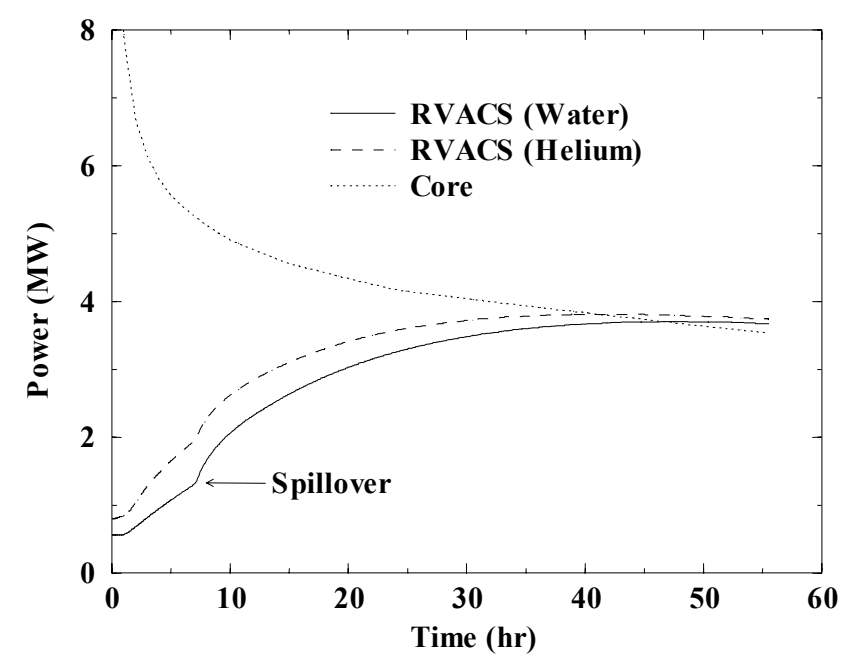

Figure 94. The effect of secondary coolant on power removed by the RVACS following a loss of the secondary heat sink.

\subsubsection{Loss of Heat Sink Without Scram}

The effect of a failure to scram following a loss of heat sink was determined for Configuration 1 of Table 44. The calculation was identical to that described in Section 4.4.2 except that the reactor kinetics model described in Section 4.4.1 was used to calculate the reactor power and no scram was modeled. The relative responses of the other two configurations are expected to be similar to those shown in Section 4.4.2.

The effect of scram on normalized core power is shown in Figure 95. The power quickly dropped to decay heat levels following scram. Without scram, the feedback associated with the 
temperature rise caused by the loss of heat sink resulted in a gradual reduction in the fission power. The reactor was essentially shut down by $1000 \mathrm{~s}$, with fission generating only $1 \%$ of the total power.

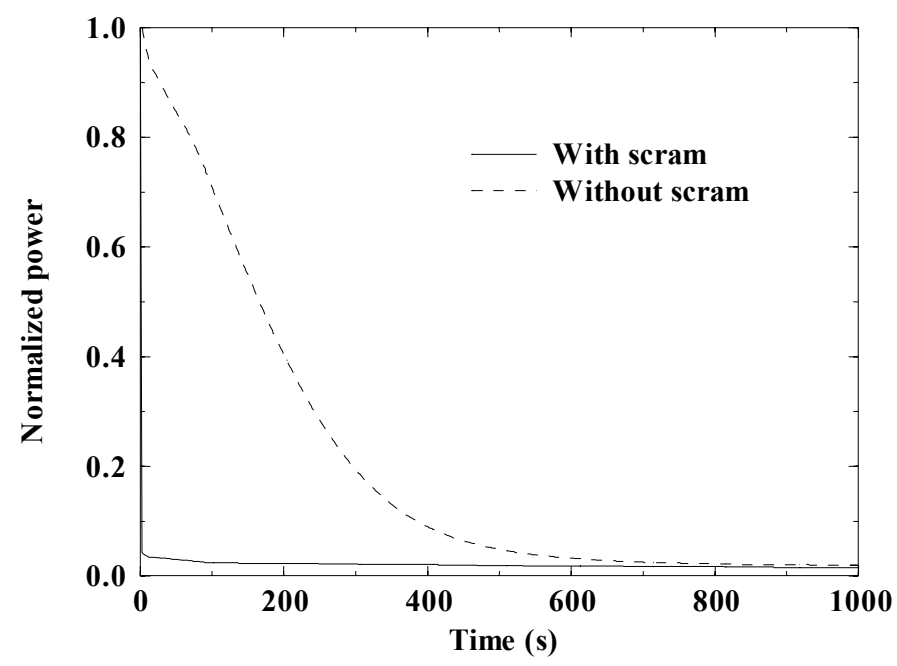

Figure 95. The effect of scram on normalized core power following a loss of heat sink.

The effect of scram on maximum cladding temperature is shown in Figure 96. The cladding temperatures were higher without scram, particularly early in the transient. However, the effect of scram diminished with time as the higher coolant temperatures caused RVACS to remove more power. The maximum cladding temperature exceeded the transient temperature limit near $19 \mathrm{hr}$. Hand calculations indicate that reducing the initial core power by $5 \%$ would allow the cladding temperature limit to be met even without scram.

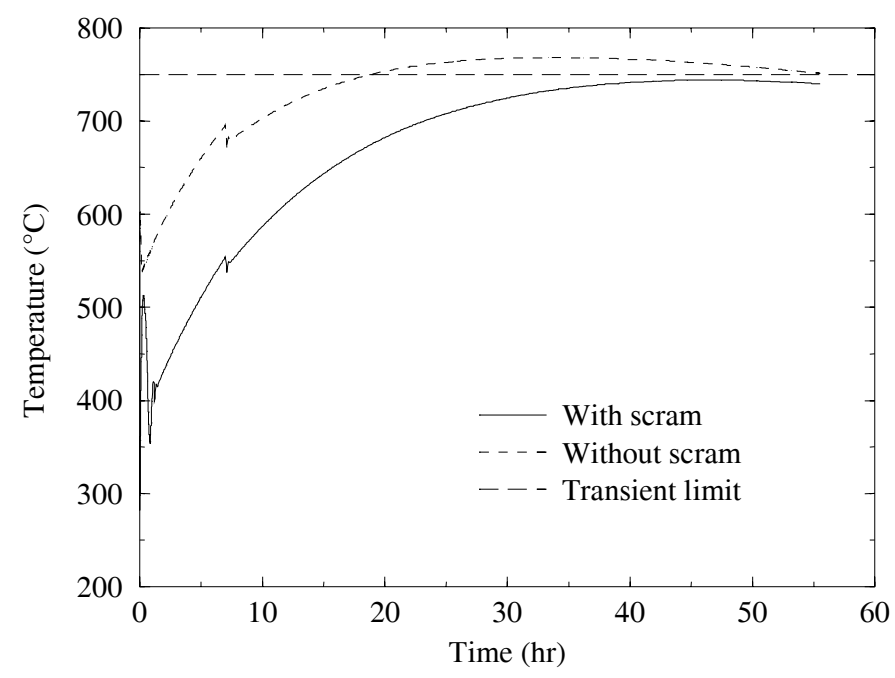

Figure 96. The effect of scram on maximum cladding temperature following a loss of heat sink.

\subsubsection{Step Change in Load}


ATHENA was used to simulate a step change in load for the three configurations of the actinide-burner reactor summarized in Table 44. The initial conditions for this transient were identical to those shown in Table $\mathbf{4 6}$ for the loss of heat sink. This transient was simulated using the point kinetics model described in Section 4.4.1. The purpose of the analysis was to determine whether the transient would challenge any safety limits, not to demonstrate the load following characteristics of the reactor.

A transient initiated by a step increase in load was calculated for Configuration 1 of Table 44. This transient was simulated by decreasing the pressure in time-dependent Volume 620 (see Figure 90), which represents the steam line and applies a pressure boundary condition to the steam generator, from 7.0 MPa to $6.928 \mathrm{MPa}$. The magnitude of the pressure change was selected to cause about a $10 \%$ increase in steam flow from the steam generator assuming that its pressure remained constant at $7.0 \mathrm{MPa}$ and a typical pressure drop of $0.35 \mathrm{MPa}$ (50 psi) between the steam generator and turbine header. Two calculations were performed to determine the sensitivity of the calculated results to feedwater flow rate. The first calculation assumed that the feedwater flow rate remained constant at its normal value. The second calculation simulated a $10 \%$ step increase in the feedwater flow. The control rods were not assumed to move in either calculation.

Note that the steam cycle pressure was increased during FY-01 from $7 \mathrm{MPa}$ to $15 \mathrm{MPa}$ to achieve higher thermal efficiency of the plant. The step-change-in-load analysis reported below was performed before this change was made, so it reflects the general behavior of the system, but does not reflect the specific behavior of the new 15.0 MPa system.

Figure 97 shows the effect of the step increase in load on the normalized reactor power. The reactor was operating at steady state prior to $10 \mathrm{~s}$, when the steam generator pressure was instantly reduced $0.072 \mathrm{MPa}$. The decrease in steam generator pressure caused the fluid temperature at the core inlet to decrease (see Figure 98), which resulted in a slight increase in reactor power until a new equilibrium power was obtained by $400 \mathrm{~s}$. The maximum power increase was $0.1 \%$ when the feedwater flow rate was held constant and was $2.4 \%$ when a $10 \%$ step change in feedwater flow was simulated at $10 \mathrm{~s}$. The increase in feedwater flow caused additional cooling of the moderator, and resulted in a higher equilibrium core power compared to the case with constant flow. However, the increase in power was much less than $10 \%$ because the increased feedwater flow eliminated the steam superheat, and in fact caused entrainment of some liquid into the steam line. 


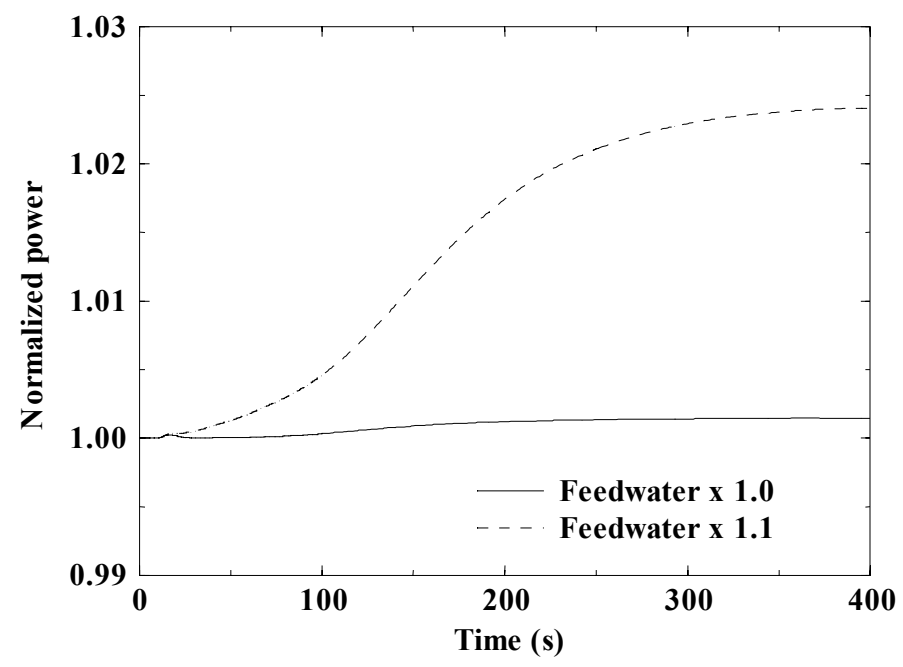

Figure 97. The effect of feedwater on core power during a transient initiated by a step change in load.

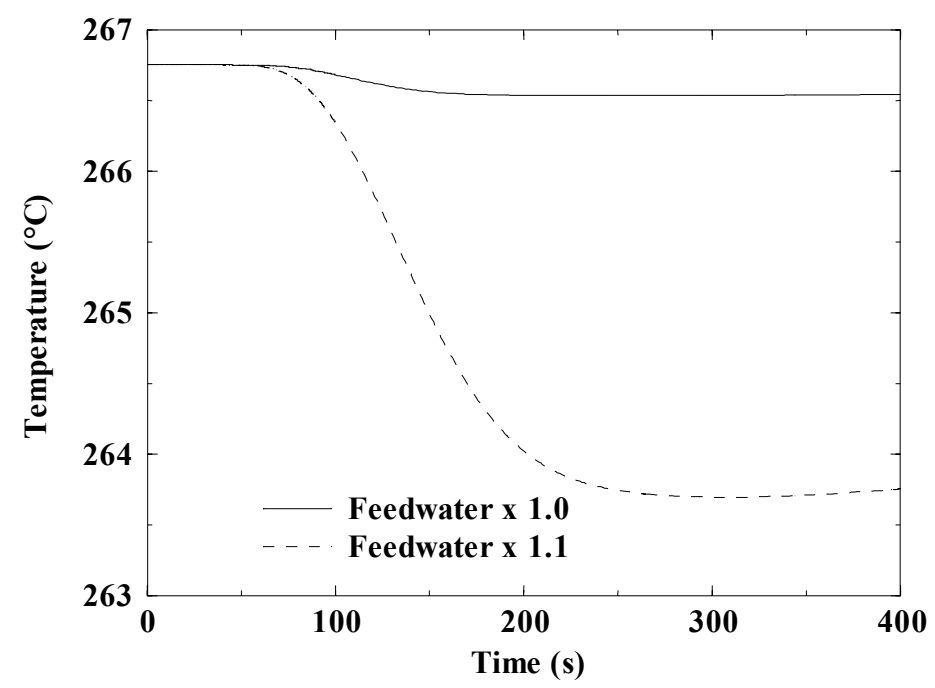

Figure 98. The effect of feedwater on fluid temperature at the core inlet during a transient initiated by a step change in load.

The effect of circulation mode during a step load change transient was determined by comparing results from the natural circulation case described previously and a case with circulation forced by a centrifugal pump. The feedwater flow was held constant in both cases. Figure 99 shows the liquid velocity in the core was significantly higher in the case with the pump. 


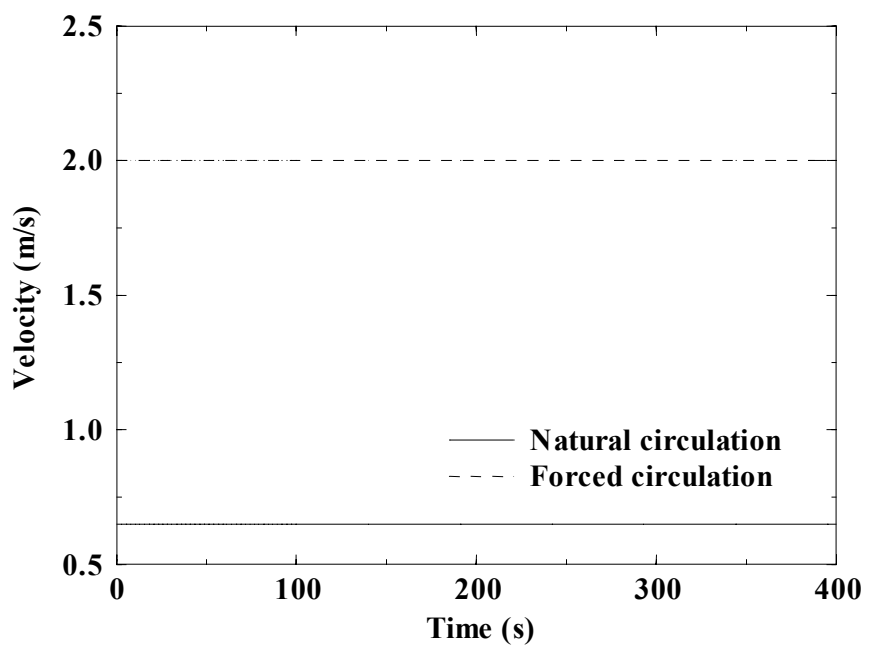

Figure 99. Core fluid velocity during a transient initiated by a step change in load.

Figure 100 shows that the equilibrium power was higher with pumped flow than with natural circulation. The maximum power increase was $0.4 \%$ with forced circulation compared to $0.1 \%$ with natural circulation. Forced circulation resulted in a larger heat transfer coefficient from the fuel rods to the coolant. The larger heat transfer coefficient resulted in a smaller increase in cladding and fuel temperatures for a given increase in power. The smaller increase in fuel temperature resulted in less reactivity feedback for a given change in moderator temperature and a higher equilibrium power. A small portion of the power increase was due to an increased heat transfer coefficient on the inside of the tubes in the forced circulation case. The increased heat transfer coefficient resulted in a bigger decrease in core inlet temperature (see Figure 101) for the same change in fluid saturation temperature corresponding to the $0.072 \mathrm{MPa}$ drop in secondary pressure.

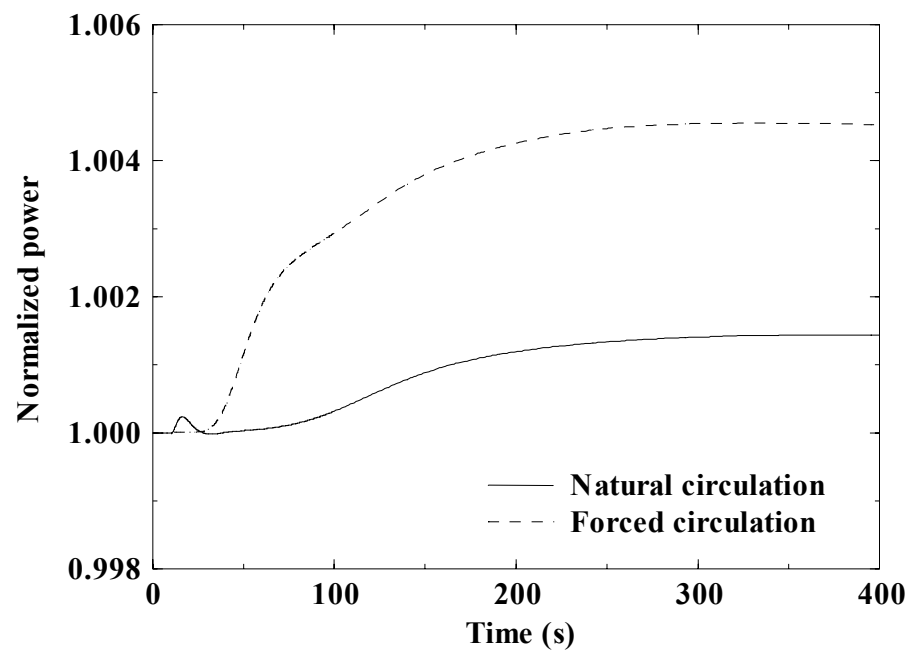

Figure 100. The effect of primary coolant flow rate on core power during a transient initiated by a step change in load. 


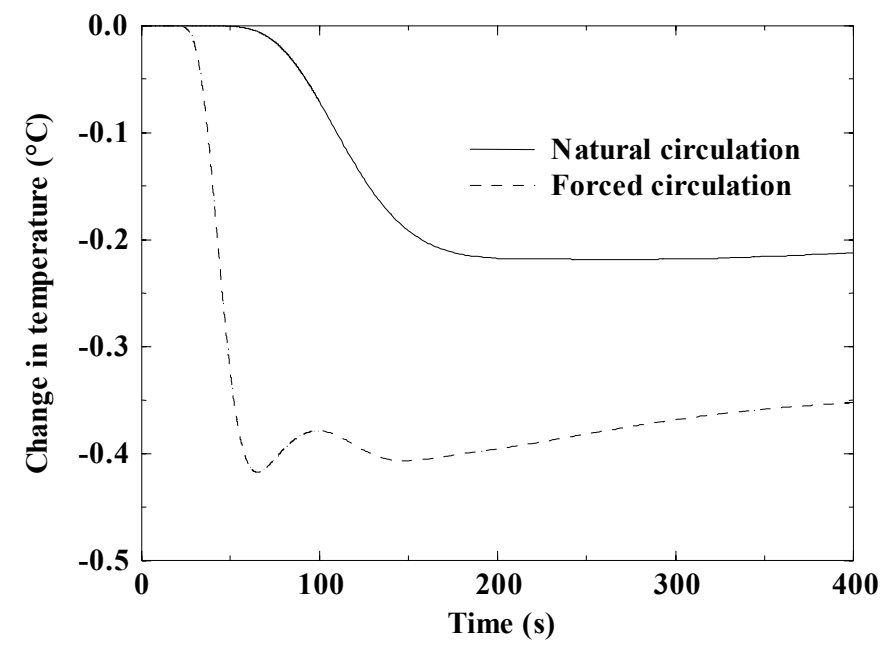

Figure 101. The effect of primary coolant flow rate on the change in core inlet fluid temperature during a transient initiated by a step change in load.

The effect of secondary coolant on normalized core power during a step change in load transient is shown in Figure 102. The first calculation was performed with water as the secondary coolant as discussed previously and the second calculation was performed with helium as the secondary coolant. In both cases, the transient was initiated by an instantaneous reduction in secondary pressure of $0.072 \mathrm{MPa}$ at $10 \mathrm{~s}$. The maximum power increase with helium was $0.7 \%$ versus $0.1 \%$ with water. The equilibrium core power was higher with helium as the secondary coolant because the instantaneous decrease in secondary pressure caused a larger decrease in the temperature of the secondary fluid, which resulted in a larger change in core inlet temperature as shown in Figure 103. For the case with water as the secondary coolant, the 0.072 $\mathrm{MPa}$ decrease in secondary pressure caused the saturation temperature of the secondary fluid to decrease by $0.7^{\circ} \mathrm{C}$ and the core inlet temperature to decrease by a smaller amount, $0.2^{\circ} \mathrm{C}$. With helium as the secondary coolant, the pressure change caused the secondary inlet temperature to decrease by $2.0^{\circ} \mathrm{C}$ (assuming an isentropic expansion), which caused the core inlet temperature to decrease by $1.0^{\circ} \mathrm{C}$.

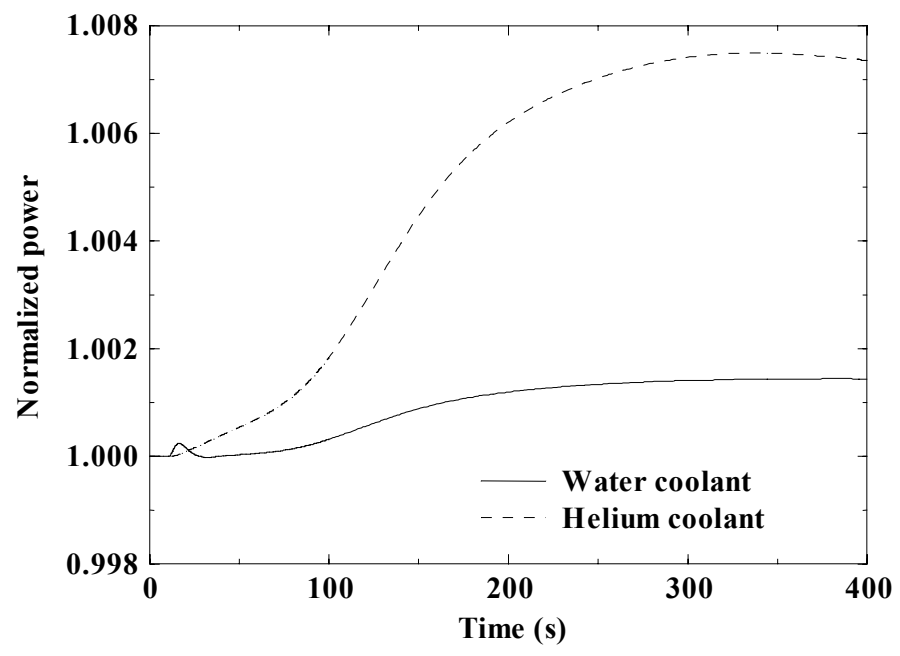

Figure 102. The effect of secondary coolant on core power during a transient initiated by a step change in load. 
The calculation with helium was essentially performed with a constant helium enthalpy at the inlet to the secondary side of the heat exchanger. If the calculation had been performed with a constant inlet temperature, the step change in pressure would have had a negligible effect on reactor power.

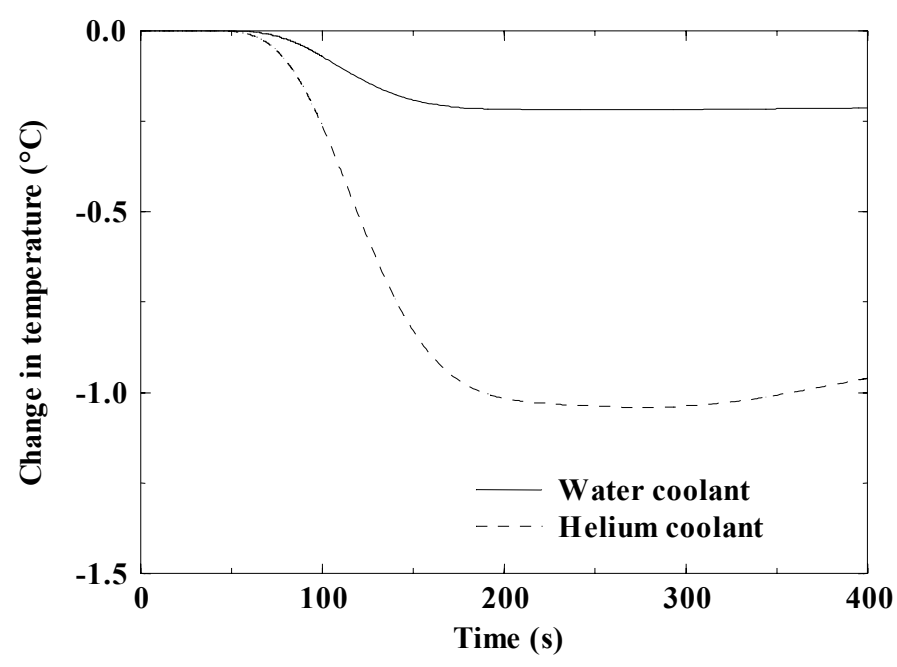

Figure 103. The effect of secondary coolant on the change in core inlet fluid temperature during a transient initiated by a step change in load.

The actinide-burner reactor shows less sensitivity to a transient initiated by a step change in load than current PWRs. For example, an instantaneous change in secondary pressure of 0.072 $\mathrm{MPa}$, which corresponds to approximately a $10 \%$ change in steam flow, caused the core power of the actinide-burning reactor to increase from $0.1 \%$ to $0.7 \%$, depending on the configuration. A step change in load corresponding to a $20 \%$ change in steam flow caused the power to increase by from 4 to $12 \%$ in a typical PWR (Westinghouse 1973). Of the options evaluated, the configuration with natural circulation of the primary coolant and water as the secondary coolant showed the smallest power excursion and thus showed the least susceptibility to load upset transients.

\subsubsection{Plant Startup}

ATHENA was used to simulate a plant startup transient from hot standby. The plant configuration analyzed utilized natural circulation of the primary coolant with a steam power conversion system (Configuration 1 of Table 44) because the startup of this configuration was judged to be the most challenging. The initial conditions for the transient are summarized in Table 47. The reactor was initially assumed to be critical and generating $0.1 \mathrm{MW}$. The secondary coolant system was initialized at its normal operating pressure and a low coolant level. A control system was used to adjust the feedwater flow rate so that the collapsed liquid level on the secondary side of the steam generator would follow a setpoint level that was a linear function of core power. The primary coolant system was initialized with no flow and with a constant fluid temperature corresponding to the saturation temperature of the secondary side. The calculation was performed with the model shown in Figure $\mathbf{9 0}$ and the point kinetics model described in Section 4.4.1. 
Table 47. Initial conditions for the plant startup transient.

\begin{tabular}{|l|l|}
\hline Parameter & Value \\
\hline Primary coolant system: & 0.1 \\
\hline Core power, $\mathrm{MW}$ & 0.0 \\
\hline Mass flow rate, $\mathrm{kg} / \mathrm{s}$ & 286 \\
\hline Temperature, ${ }^{\circ} \mathrm{C}$ & \\
\hline Secondary coolant system: & 7.0 \\
\hline Pressure, $\mathrm{MPa}$ & 0.1 \\
\hline Level, $\mathrm{m}$ & 0.0 \\
\hline Flow rate, $\mathrm{kg} / \mathrm{s}$ & 200 \\
\hline Inlet temperature, ${ }^{\circ} \mathrm{C}$ & \\
\hline
\end{tabular}

A constant reactivity insertion rate of $4.6 \times 10^{-5} \$ / \mathrm{s}$ was applied during the transient. This reactivity insertion rate, which corresponds to a complete withdrawal of the control rods from one fuel assembly in three hours, caused the average primary coolant temperature to increase at a rate near the design value of $56^{\circ} \mathrm{C} / \mathrm{hr}\left(100^{\circ} \mathrm{F} / \mathrm{hr}\right)$ for commercial PWRs.

The reactivity insertion due to the simulated control rod withdrawal is shown in Figure 104. The figure also shows the total reactivity insertion, which includes the effects of control rod movement and feedback due to moderator density and fuel temperature. The control rod withdrawal began at $0.0 \mathrm{~s}$ and continued until $7380 \mathrm{~s}$, when the reactor power approximately reached its normal operating value. The total reactivity was dominated by the effects of the control rod withdrawal early in the transient and reached a maximum of $0.05 \$$ at $1450 \mathrm{~s}$. The sensible heat produced by the reactor during the early portion of the transient (see Figure 105) was too small to result in significant changes in either fuel temperature or moderator density, which limited the feedback. After $1450 \mathrm{~s}$, the reactor power was high enough to cause significant feedback and the total reactivity began to decrease. The total reactivity was relatively small after $3000 \mathrm{~s}$, indicating that feedback effects were compensating for the control rod withdrawal.

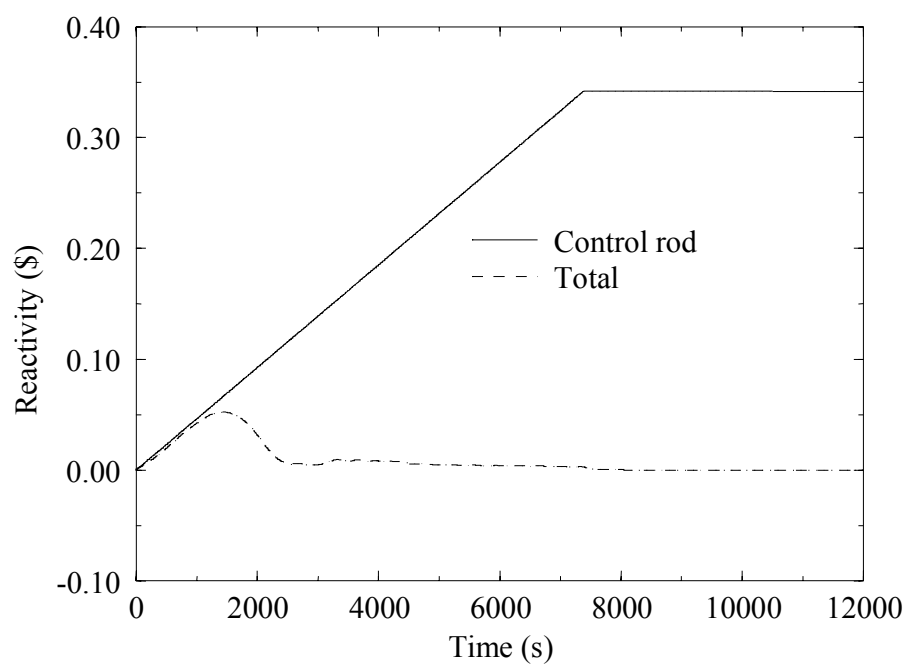

Figure 104. Reactivity insertion and feedback during a startup transient.

The reactor power calculated during the startup is shown in Figure 105. The decrease in slope at $2200 \mathrm{~s}$ was caused by feedback due to changes in moderator density and fuel temperature. The effects of control rod withdrawal and feedback were nearly balanced after 3000 
$\mathrm{s}$ and the power increased smoothly until the control rod withdrawal stopped at $7380 \mathrm{~s}$. The reactor power then approached the normal operating value of $650 \mathrm{MW}$.

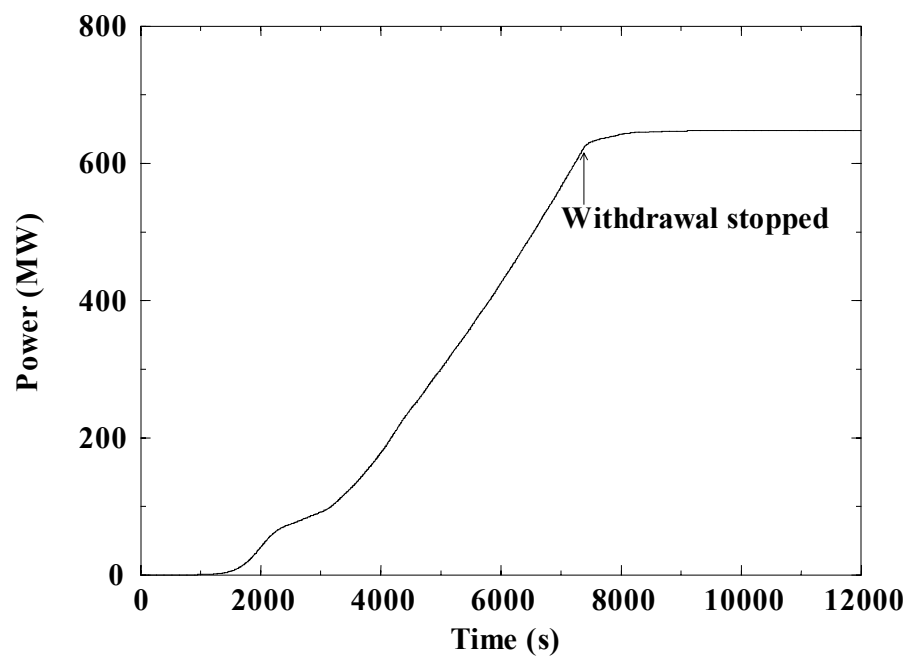

Figure 105. Reactor power during a startup transient.

Because the primary coolant was driven by natural circulation, the thermalhydraulic response of the primary coolant system was strongly affected by core power. Figure 106 shows the calculated fluid velocity in the core. The trends are similar to the trends in power discussed earlier. Figure $\mathbf{1 0 7}$ shows fluid temperatures at the inlet and outlet of the core. The outlet temperature was nearly constant until the sensible heat production in the core became significant near $1450 \mathrm{~s}$. The outlet temperature then increased until reaching its full-power, steady value near 7380 s. The temperature at the inlet remained near the saturation temperature of the secondary of the steam generator throughout the transient. The average fluid temperature increased at a rate of $52^{\circ} \mathrm{C} / \mathrm{hr}$ between 0.0 and $7380 \mathrm{~s}$.

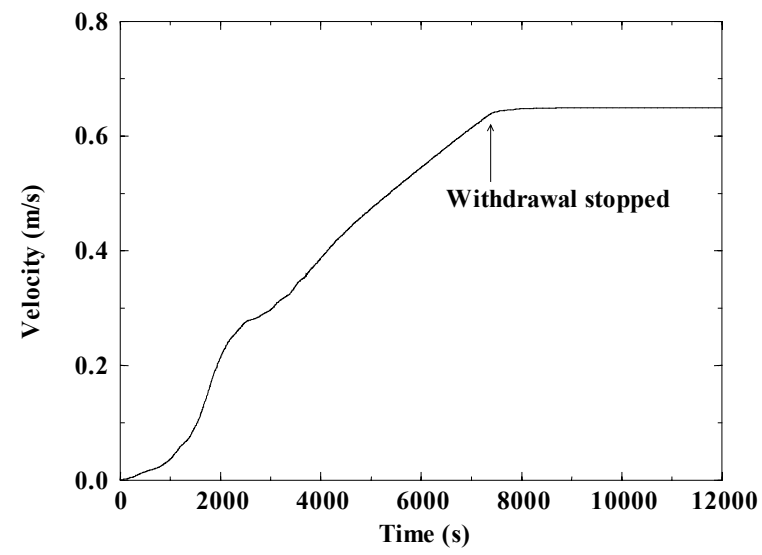

Figure 106. Fluid velocity in the core during a startup transient.

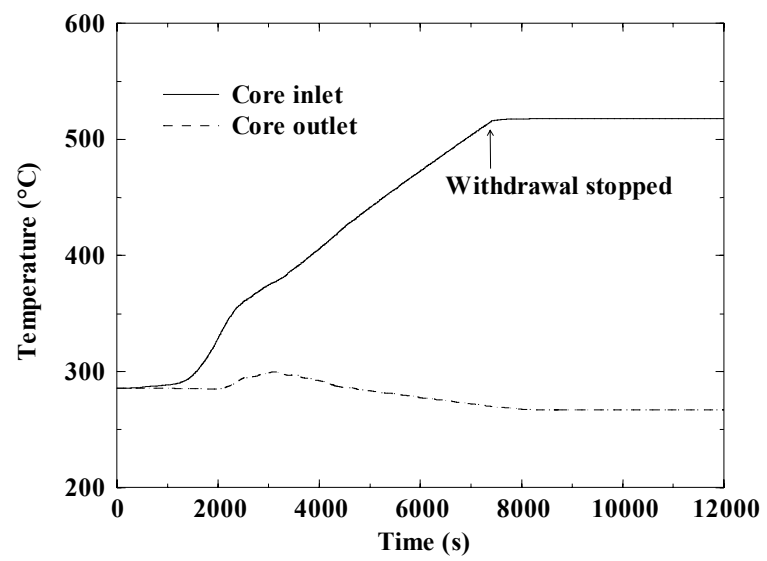

Figure 107. Fluid temperatures in the core during a startup transient. 
The response of the secondary coolant system is illustrated in Figures 108 and 109, which show collapsed liquid level and feedwater flow rate, respectively. Both parameters followed the reactor power as discussed previously. Although small oscillations were occasionally calculated in the feedwater flow rate, the overall response of the secondary system was stable.

The analysis showed that the actinide-burner reactor would be easy to start up. The system responded smoothly to control rod withdrawal between hot standby and full power. A simple feedwater control system was designed that allowed the secondary coolant system to smoothly follow the control rod withdrawal. Issues related to the startup of the plant from ambient to hot standby, including the thawing of the leadbismuth, were not addressed.

\subsubsection{Control Rod Ejection Accident Without Scram}

ATHENA was used to simulate a control rod ejection accident without scram for the three plant

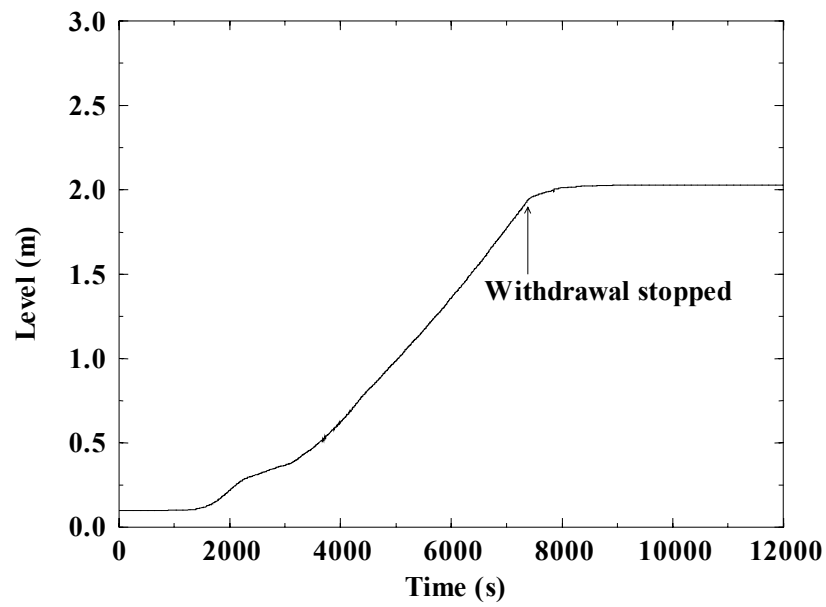

Figure 108. Collapsed liquid level in the steam generator secondary following a startup transient.

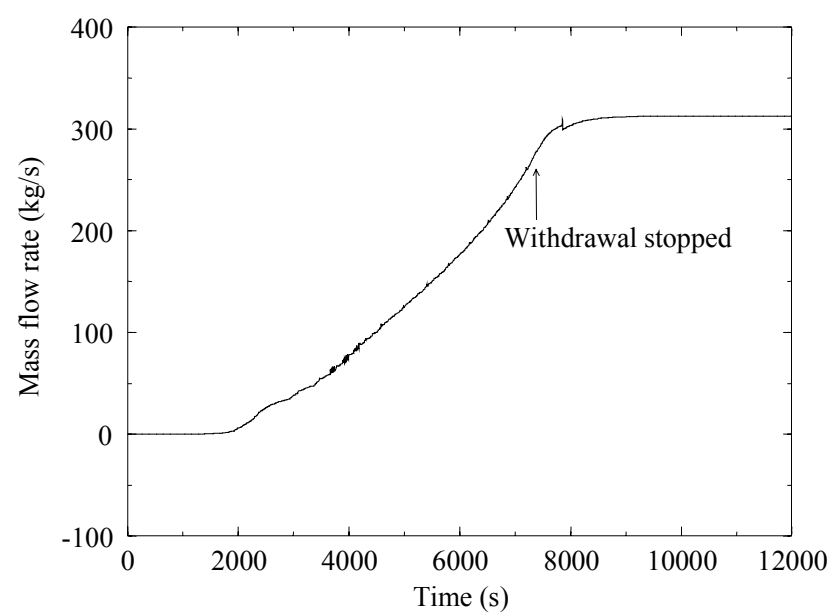

Figure 109. Feedwater flow rate during a startup transient.

configurations listed in Table 44. The initial conditions for this transient are shown in Table 46. The secondary coolant flow remained constant at its initial value during the transient. The control rod ejection was simulated by a step reactivity insertion of $0.5 \$$, corresponding to the worth of an average control rod (Hejzlar et al. 2000). The actinide-burner reactor contains 157 control rods, one for each fuel assembly, and each control rod contains 24 fingers.

The ejection of a control rod can cause severe power peaking in and near the affected fuel element. The point kinetics model described in Section 4.4.1 cannot calculate the localized neutronic effects of the control rod ejection. Thus, this analysis will concentrate on the neutronic and thermal-hydraulic response of the system.

Figure 110 shows the effect of the control rod ejection on the normalized reactor power. The reactor was operating at steady state prior to $10 \mathrm{~s}$, when $0.5 \$$ of reactivity was instantly added to the core. The step reactivity insertion caused the reactor power to increase rapidly. The power 
increase caused the density of the moderator to decrease and the temperature of the fuel to increase. The reactivity feedback caused the power to reach a maximum value near $80 \mathrm{~s}$. Although not shown in the figure, the power eventually returned to a steady value somewhat above the initial power.

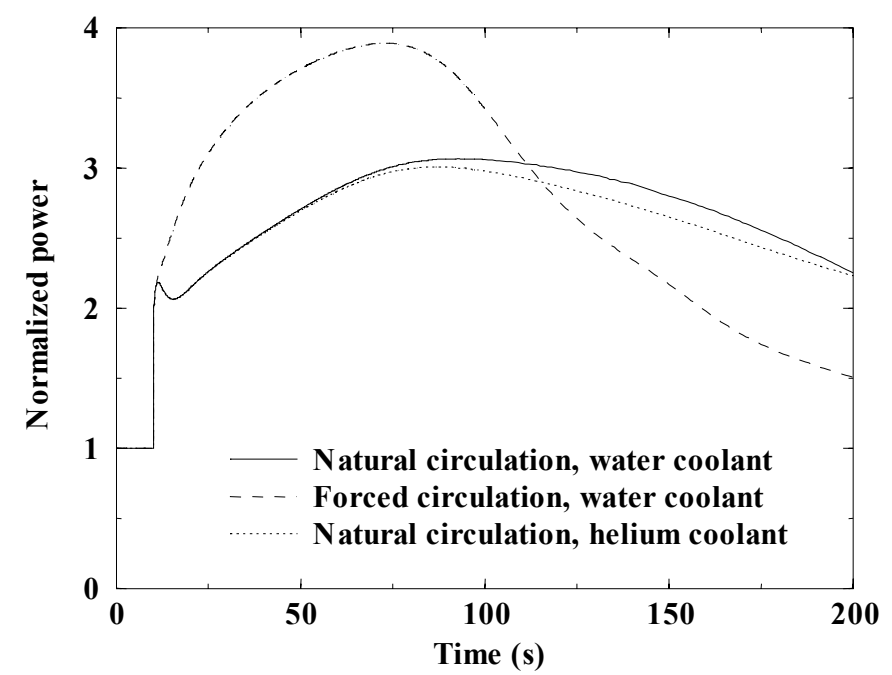

Figure 110. Normalized core power during a control rod ejection accident.

The maximum reactor power was significantly higher with forced circulation. The higher primary coolant flow rate associated with forced circulation caused a smaller increase in the outlet fluid temperature for a given change in power. The smaller increase in temperature caused a smaller decrease in moderator density (Figure 111) that resulted in less reactivity feedback. A higher maximum power was eventually required to compensate for the step insertion.

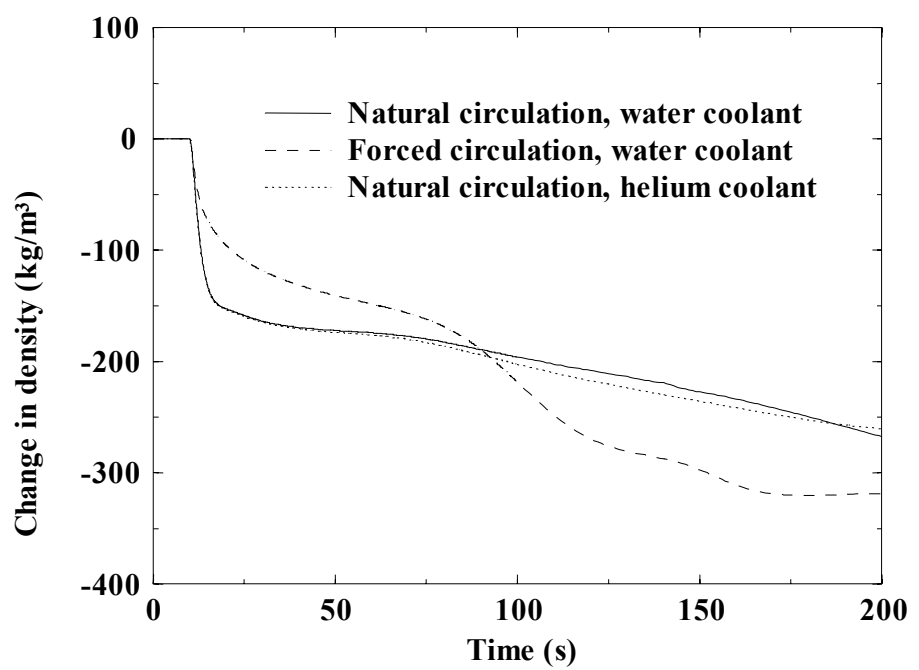

Figure 111. Change in average moderator density during a control rod ejection accident.

The increase in moderator temperature during the transient caused the moderator to expand, resulting in an increase in pool level and cover gas pressure. The maximum increase in pressure was $0.08 \mathrm{MPa}$ and occurred in the calculation with forced circulation. 
The effects of the rod ejection on the maximum cladding and fuel temperatures are shown in Figures 112 and 113. The power increase caused the cladding temperature to exceed the transient limit of $750^{\circ} \mathrm{C}$ at $13.1,74.1$, and $12.2 \mathrm{~s}$ for Configurations 1 through 3 , respectively. The fuel temperature always remained below the transient limit, which was assumed to be $1400^{\circ} \mathrm{C}$ based on last year's analysis (Buongiorno et al. 2000). Thus, the reactor trip system of the actinide-burner reactor needs to be able to insert significant shutdown reactivity before 2.2 to $64.1 \mathrm{~s}$, depending on the configuration, to prevent the cladding temperature from exceeding the transient limit during a rod ejection accident. The required amount of time for the actinide-burner reactor exceeds that typically assumed for PWRs. For example, Westinghouse (1973) assumed that significant shutdown reactivity was inserted at $1.1 \mathrm{~s}$ in the corresponding accident. Although the point kinetics model is not conservative for this analysis because it did not simulate the localized effects of power peaking, the results indicate that no stringent requirements will be placed on the trip system to protect the reactor against rod ejection accidents.

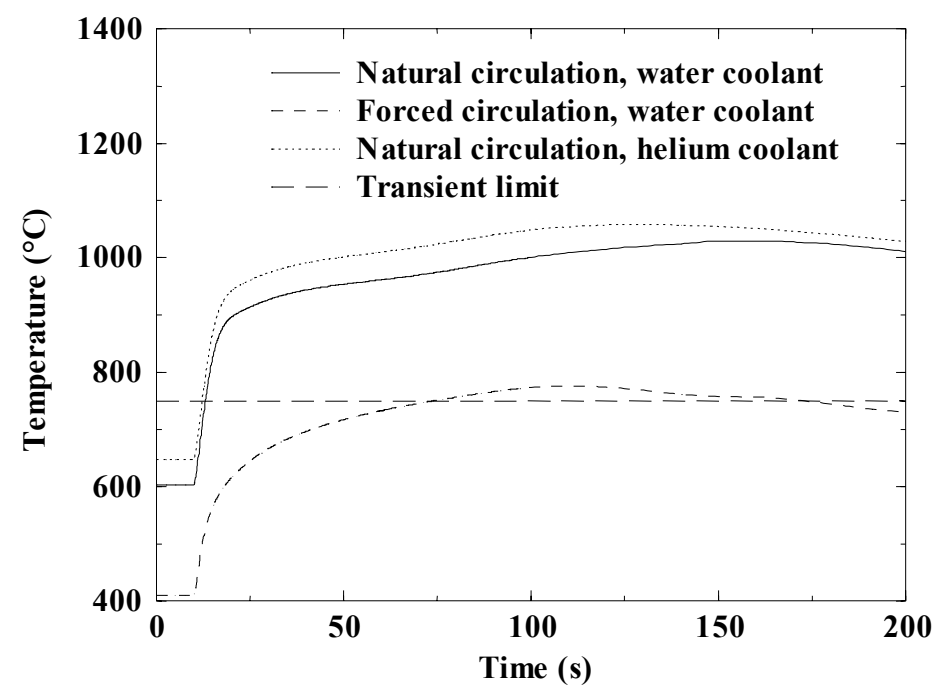

Figure 112. Maximum cladding temperature during a control rod ejection accident.

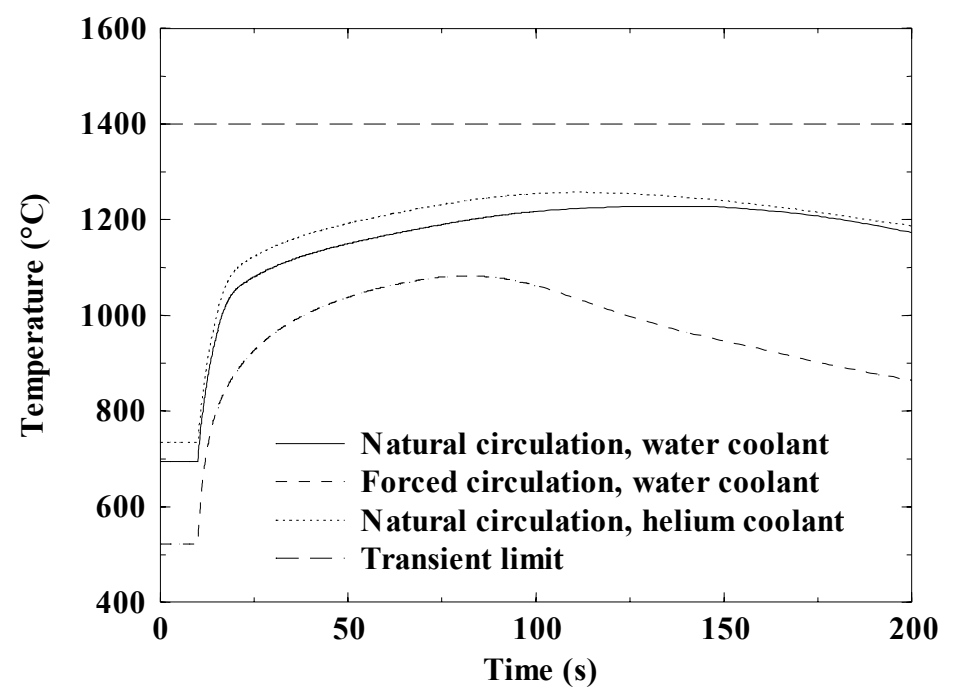

Figure 113. Maximum fuel temperature during a control rod ejection accident. 


\subsubsection{Large Rupture of the Secondary System Outlet Piping Without Scram}

ATHENA was used to simulate a large rupture of the secondary system outlet piping without scram for the three plant configurations listed in Table 44. The initial conditions for this accident are shown in Table 46. The actinide-burner reactor will contain multiple heat exchangers for redundancy and reliability. The multiple heat exchangers were combined into a single, equivalent heat exchanger in the ATHENA model. Consequently, the rupture simulated by the code was equivalent to the simultaneous blowdown of all heat exchangers, thus significantly increasing the effect of the accident. The accident was initiated at $0 \mathrm{~s}$ by an instantaneous rupture of four 16-in. schedule 40 pipes. The inlet flow to the secondary side of the heat exchanger was held constant for $10 \mathrm{~s}$ and then was set to zero to simulate the isolation of the feedwater/gas supply systems consistent with the general approach taken in simulating main steam line breaks in PWRs (Westinghouse 1973). Most PWRs use a venturi in each steam line to limit the flow during steam line breaks, but corresponding flow area reductions were not modeled in this analysis of the actinide-burner reactor.

Figure 114 shows the mass flow rate through the ruptured secondary coolant outlet piping for all threeplant configurations during the early portion of the transient. With water as the secondary coolant, the flow out the break was initially choked and the peak flow rate was more than 20 times the initial value. A significant amount of liquid was entrained out of the break during the first $5 \mathrm{~s}$ of the transient. Mostly steam flowed out of the break after 5 s.

As shown in Figure 115, the heat exchangers were blown down by $40 \mathrm{~s}$ when the secondary coolant pressure reached atmospheric pressure. With helium as the secondary coolant, there was no liquid to entrain and the peak mass flow rate was less than 5 times the initial value. Without the phase change associated with flashing and boiling that occurred in the calculations with water, the pressure rapidly decreased until the mass flow rate equalized with the inlet helium flow rate near $0.5 \mathrm{~s}$. The flow out the break then remained nearly constant until the inlet helium flow rate was terminated at $10 \mathrm{~s}$.

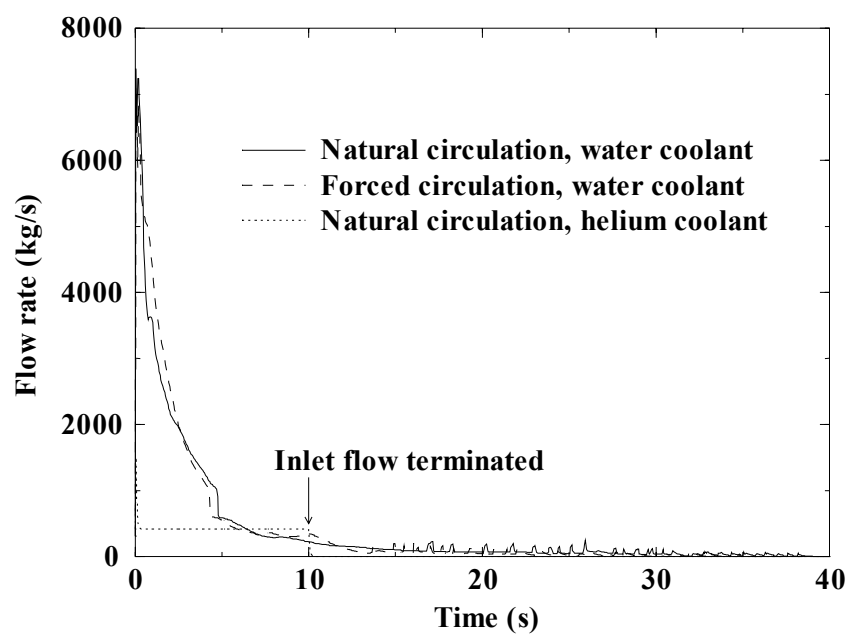

Figure 114. Break flow rate during a large rupture of the heat exchanger outlet piping.

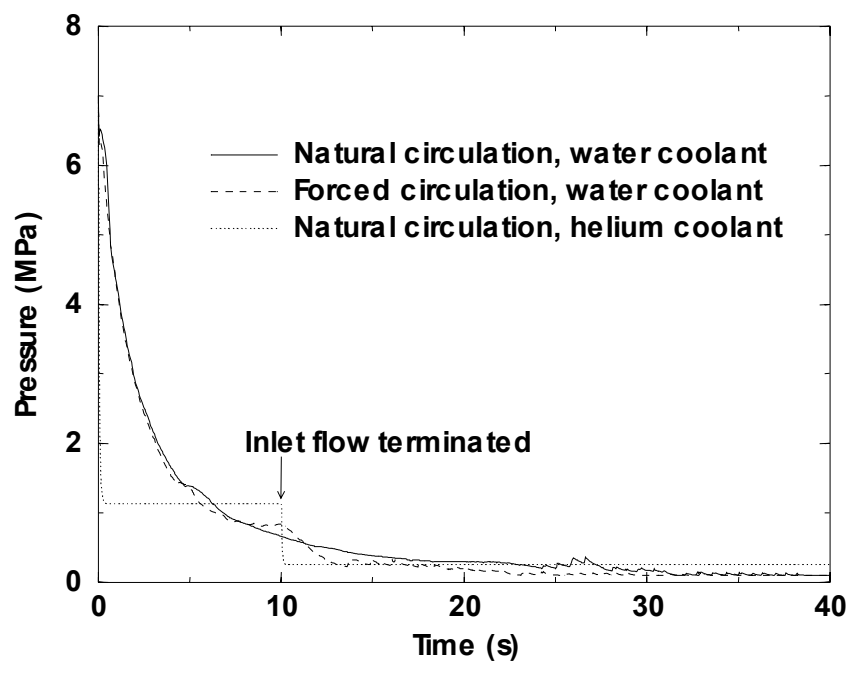

Figure 115. Secondary coolant pressure during a large rupture of the heat exchanger outlet piping. 
The effect of the rupture on the reactor power is shown in Figure 116. The reactor power began to increase almost immediately following the rupture in Configuration 1 . The decrease in secondary coolant temperature associated with the decrease in pressure resulted in enhanced heat transfer to the heat exchangers. This enhanced heat transfer cooled the lead-bismuth inside the heat exchanger tubes and caused an increase in the natural circulation flow rate through the core as shown in Figure 117. The increased flow rate resulted in a reduced moderator temperature at the outlet of the core. The resulting increase in moderator density caused the reactor power to begin increasing almost immediately following the rupture. In Configuration 2, the rupture did not cause an appreciable increase in flow, which was controlled by the primary coolant pumps. Consequently, the reactor power remained nearly constant until colder fluid from the heat exchanger reached the core. Only a minor increase in power was obtained in Configuration 3 because the initial increase in cooling by the heat exchanger was much smaller than in the cases with water coolant. The cooling associated with the rupture was over by $40 \mathrm{~s}$ for each configuration. By this time, the secondary coolant inlet flow had been terminated and the residual liquid inventory had been boiled away for the cases with water as the secondary coolant. Consequently, reactor temperatures increased (Figures 118 and 119) and the associated feedback reduced the power.

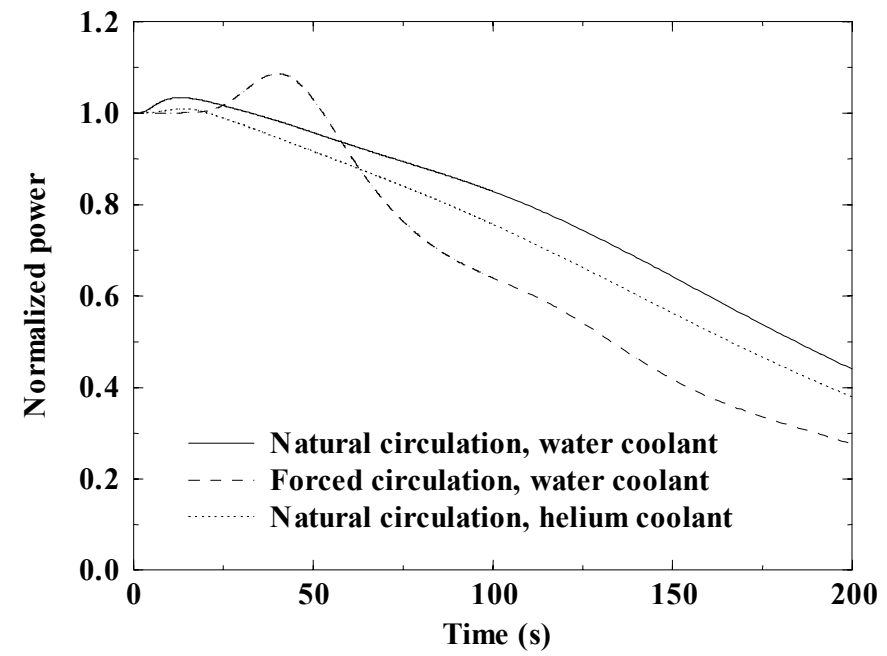

Figure 116. Normalized core power during a large rupture of the heat exchanger secondary outlet piping.

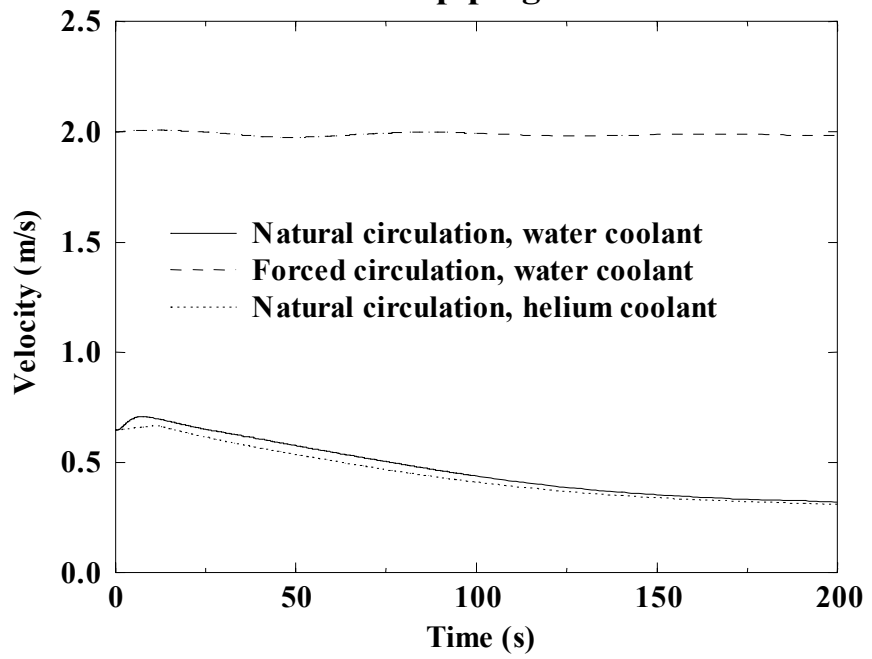

Figure 117. Core fluid velocity during a large rupture of the heat exchanger secondary outlet piping. 


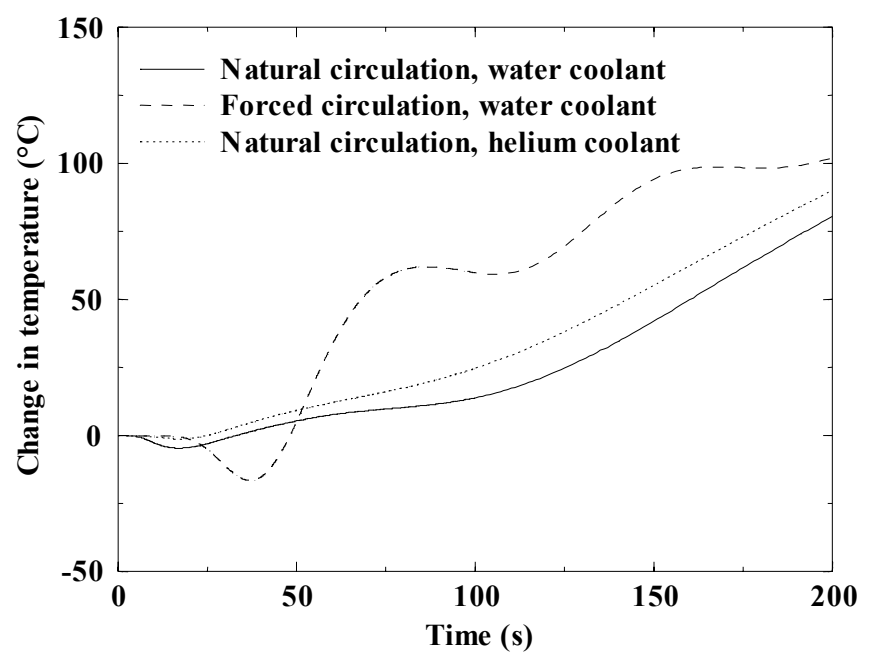

Figure 118. Change in average moderator temperature during a large rupture of the heat exchanger secondary outlet piping.

The peak cladding temperature was less than the transient limit for all three-plant configurations, as shown in Figure 119. The margins to the cladding temperature limit were consistent with the steady-state results shown in Table 46. Specifically, the most margin was obtained for the configuration with forced circulation and the least margin with helium as the secondary coolant.

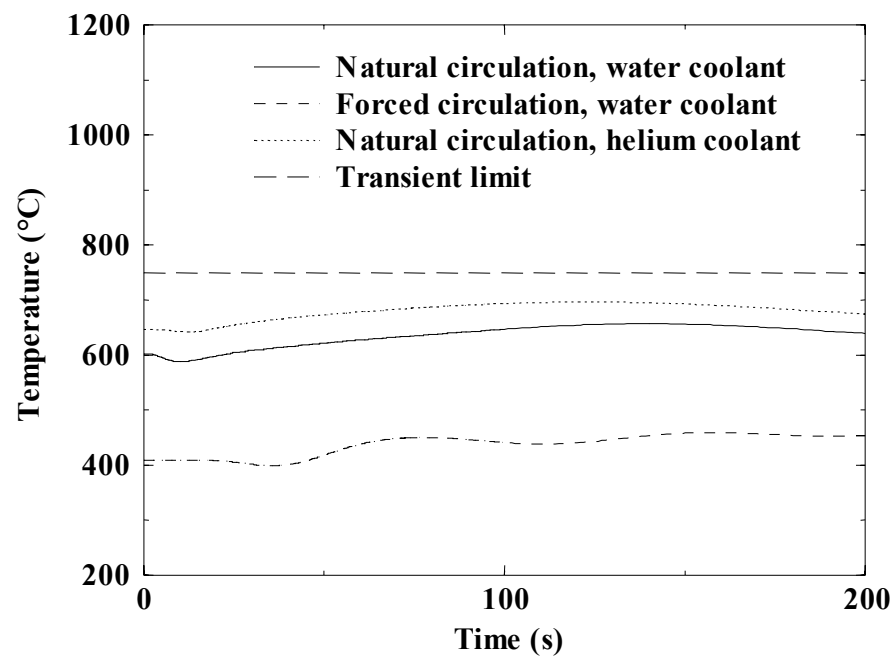

Figure 119. Maximum cladding temperature during a large rupture of the heat exchanger secondary outlet piping.

A very large rupture of the heat exchanger outlet piping does not pose serious consequences for the primary coolant system of the actinide-burner reactor. The rupture initially cools the primary coolant system, resulting in a small increase in core power. The peak cladding temperature remained below the transient limit of $750^{\circ} \mathrm{C}$ for the three plant configurations evaluated, even without a reactor scram. The configuration with forced circulation of the primary coolant and water secondary coolant resulted in the largest margin to the cladding temperature limit. The design does not require the use of flow restrictors in the outlet piping. 


\subsubsection{Primary Coolant Pump Seizure Without Scram}

Safety analysis reports for PWRs consider various loss-of-flow accidents, including partial loss of flow caused by tripping one primary coolant pump, complete loss of flow caused by tripping all coolant pumps, and seizure of the impeller of one coolant pump. The seizure of a single primary coolant pump, which is considered extremely unlikely, is the most severe of the loss-of-flow events and challenges limits for primary coolant pressure and cladding temperature.

ATHENA was used to simulate a simultaneous seizure of all the primary coolant pumps for the actinide-burner reactor, combined with a failure to scram. The actinide-burner reactor will contain multiple primary coolant pumps for reliability and redundancy. These pumps were combined into a single, equivalent pump in the ATHENA model. Consequently, the simulated seizure of the single pump in the ATHENA model corresponds to the simultaneous seizure of all primary coolant pumps in the reactor. Although the accident is not considered credible, it was analyzed because it is the most limiting of the loss-of-flow events. The plant configuration selected for analysis is Configuration 2 of Table 44, which utilizes forced circulation with a mechanical pump and water as the secondary coolant. The initial conditions for the calculation are presented in Table 46. The accident was initiated at $10 \mathrm{~s}$ by instantly reducing the speed of the pump impeller to zero. The feedwater flow was held constant.

The effect of the pump seizure on the coolant velocity in the core is shown in Figure 120. The pump seizure at $10.0 \mathrm{~s}$ caused the velocity to decrease rapidly until reaching a minimum value at $15.0 \mathrm{~s}$. The velocity then increased gradually as natural circulation was established.

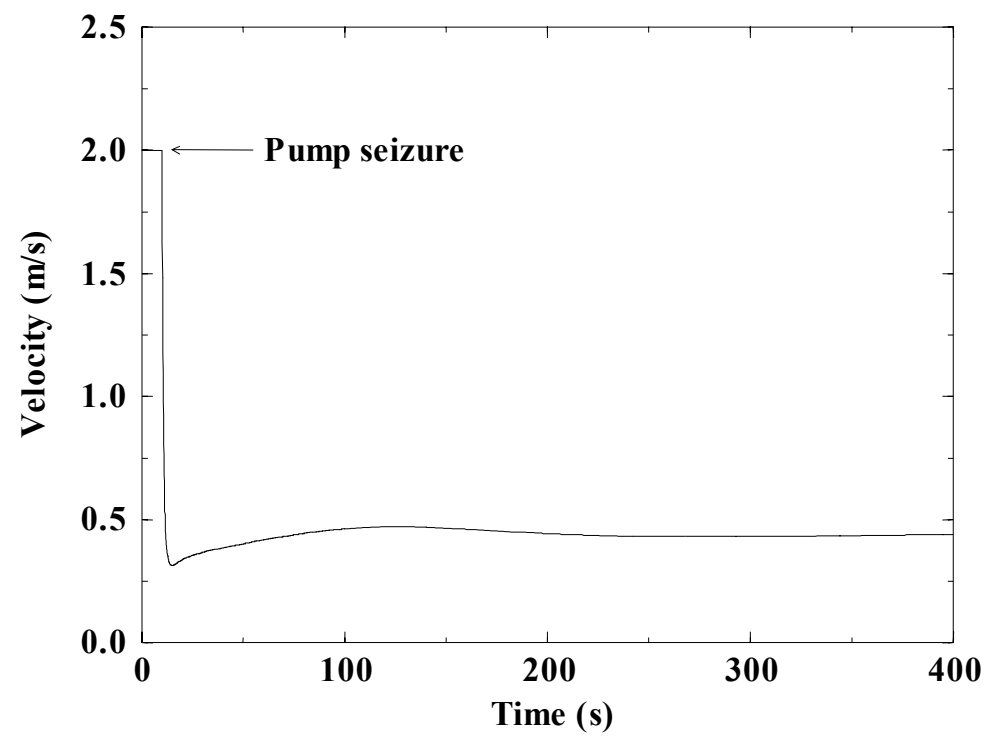

Figure 120. Core coolant velocity following a seizure of the primary coolant pump.

The effect of the pump seizure on the fluid temperatures at the inlet and outlet of the core is shown in Figure 121. The decrease in the flow rate caused the core outlet temperature to increase rapidly. Although the core inlet temperature eventually decreased slightly, the average moderator temperature clearly increased following the pump seizure. The reactivity feedback from the increase in temperature caused the core power to decrease as shown in Figure 122. By $400 \mathrm{~s}$, the power removed by the heat exchangers had come back into balance with that produced in the core and the system approached a new steady state. 


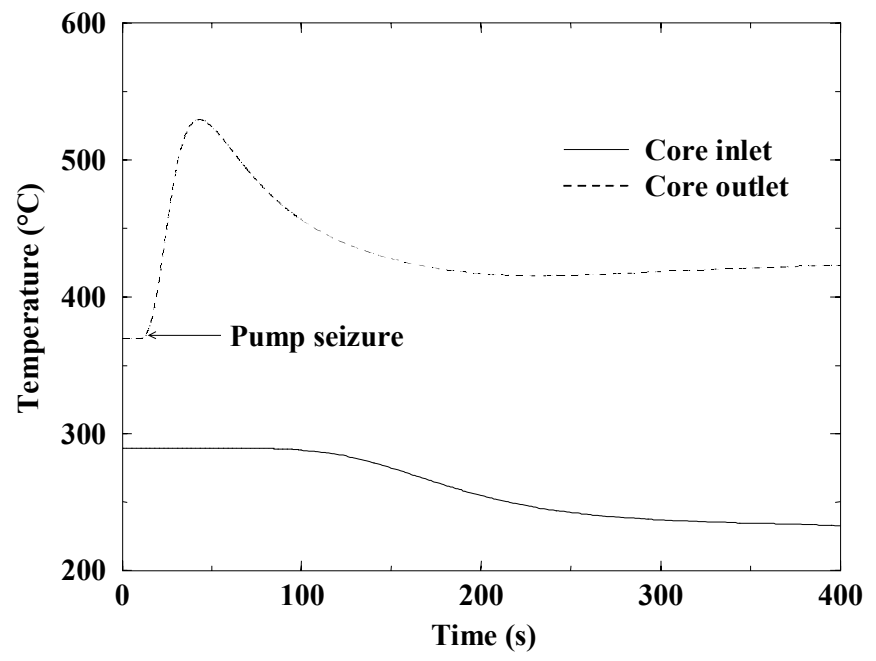

Figure 121. Primary coolant temperatures following a seizure of the primary coolant pump.

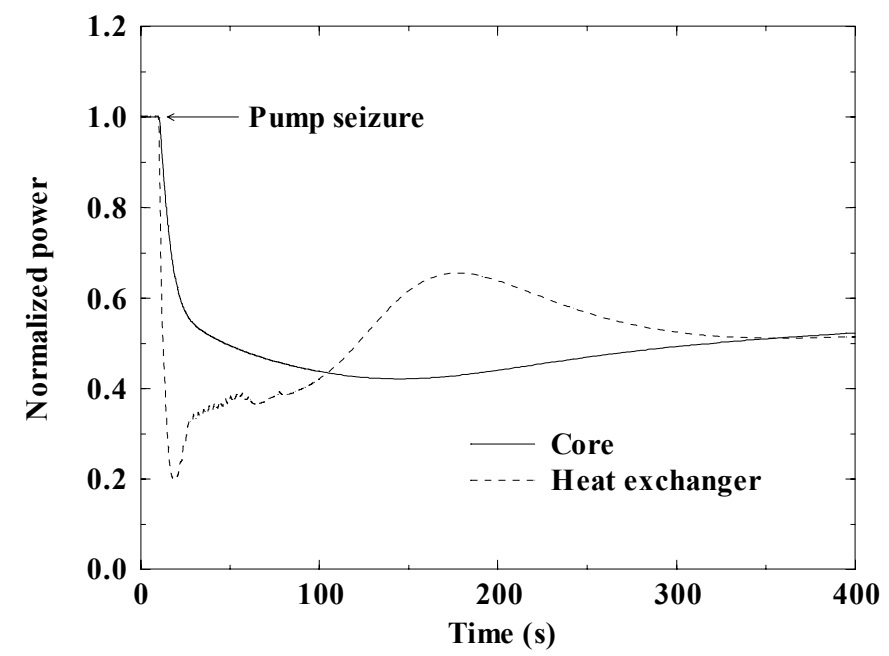

Figure 122. Core and heat exchanger powers following a seizure of the primary coolant pump.

At the end of the calculation, the steam superheat at the exit of the heat exchangers had vanished and liquid was being carried into the steam line. The liquid carryover began at $50 \mathrm{~s}$ and was a consequence of the assumption of constant feedwater flow. To protect the turbine, the feedwater control system should respond to the reduced core power by reducing flow within $50 \mathrm{~s}$ or the turbine should be tripped.

A comparison of Figures $\mathbf{9 9}$ and $\mathbf{1 2 0}$ shows that the natural circulation velocity was smaller following the pump seizure than that obtained previously. The decrease in the velocity was nearly equally caused by the increased hydraulic resistance associated with the seized impeller and the reduction in core power shown in Figure 122.

The peak cladding temperature remained well below the transient limit of $750^{\circ} \mathrm{C}$ as shown in Figure 123. The primary coolant pressure increased by less than $0.017 \mathrm{MPa}$ during the accident. 


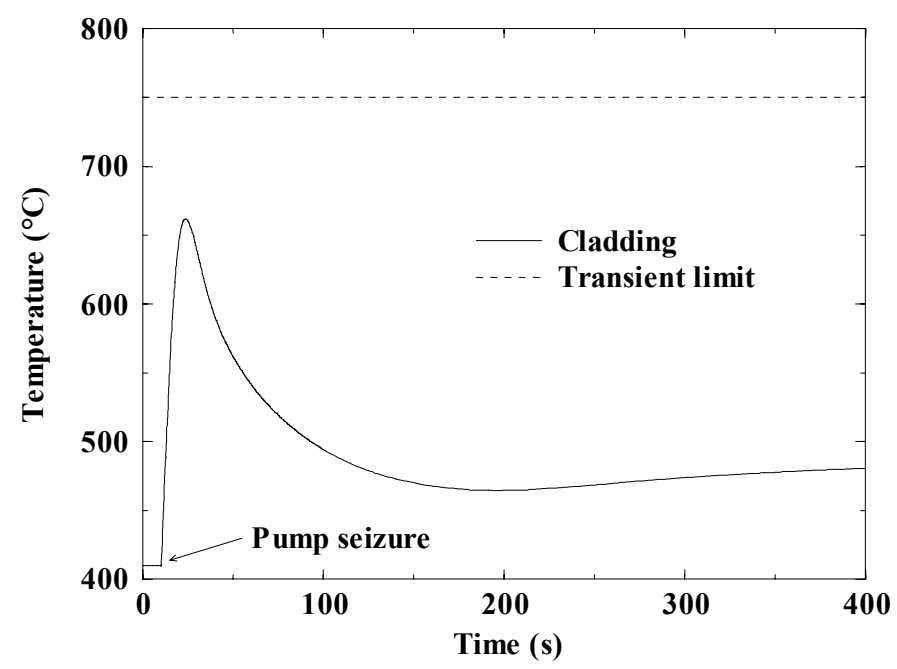

Figure 123. Maximum cladding temperature following a seizure of the primary coolant pump.

Loss-of-flow events do not cause serious consequences in the actinide-burner reactor. Even the simultaneous seizure of all primary coolant pumps combined with a failure to scram does not cause cladding temperature limits to be violated or large changes in coolant pressure. Flywheels to extend the coastdown of the pumps are not required. A feedwater control system will be required to protect the turbine.

\subsubsection{Loss of Preheating Without Scram}

Safety analyses of PWRs consider overcooling transients initiated by malfunctions that cause a decrease in feedwater temperature. This type of event is of particular concern for the actinideburner reactor because a decrease in the inlet temperature of the secondary coolant might cause the lead-bismuth to decrease below its freezing temperature of $125^{\circ} \mathrm{C}$. Freezing of the leadbismuth would cause a safety concern due to potential blockages of fuel assemblies as well as possible operational problems.

ATHENA was used to simulate a loss of preheating of the secondary coolant in the actinideburner reactor for the three configurations listed in Table 44. The accident was initiated at $10 \mathrm{~s}$ by instantly reducing the inlet temperature of the secondary coolant from $200^{\circ} \mathrm{C}$ to $5^{\circ} \mathrm{C}$. The secondary coolant inlet flow rate was held constant. Because the control system should reduce the flow rate of the secondary coolant following scram, no scram was assumed to maximize overcooling effects during the transient. The point kinetics model described in Section 4.4.1 was used to calculate reactivity feedback.

The effect of the decrease in secondary coolant inlet temperature on the fluid temperature at the core inlet is shown in Figure 124. The decrease in secondary coolant inlet temperature caused the fluid temperature at the outlet of the primary side of the heat exchanger to decrease. The colder fluid then reached the core after a delay that depended on the primary coolant flow rate. The core inlet temperature then decreased until reaching a minimum value between 200 and $300 \mathrm{~s}$. The minimum temperature was more than $80^{\circ} \mathrm{C}$ above the freezing point for all three configurations. The configuration with the least margin to freezing utilized natural circulation of the primary coolant and water as the secondary coolant because of its low initial temperature. 


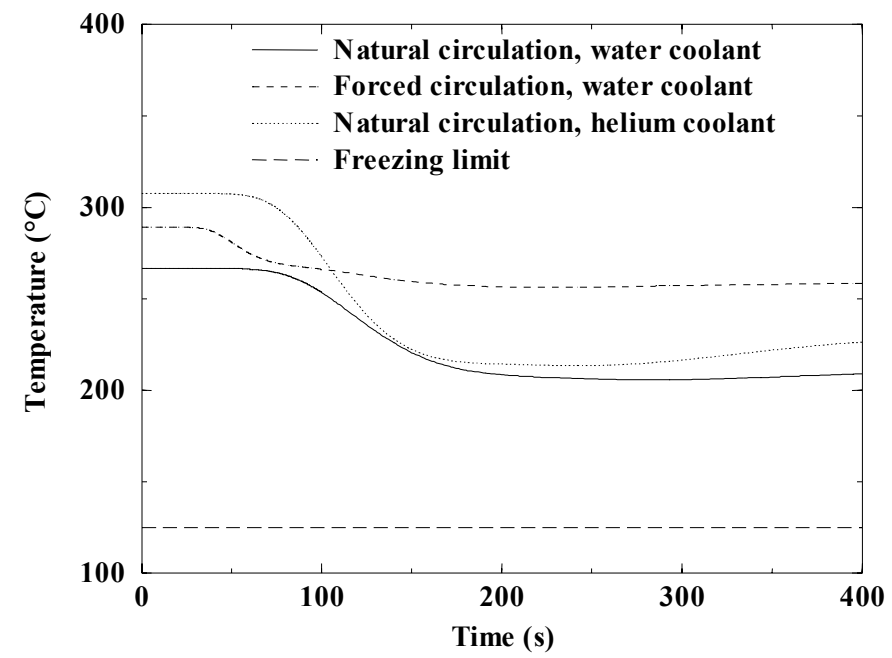

Figure 124. Core inlet temperature following a loss of preheating of the secondary coolant.

The decrease in core inlet temperature was much smaller than the decrease in secondary inlet temperature in all three configurations. The decrease in moderator temperature illustrated in Figure 124 caused the reactor power to increase as shown in Figure 125, which limited the decrease in temperature and provided additional margin from the freezing point. In addition, the primary coolant temperatures in the cases with water as the secondary coolant were as strongly coupled to the saturation temperature based on the secondary pressure, which remained constant, as to the secondary inlet temperature.

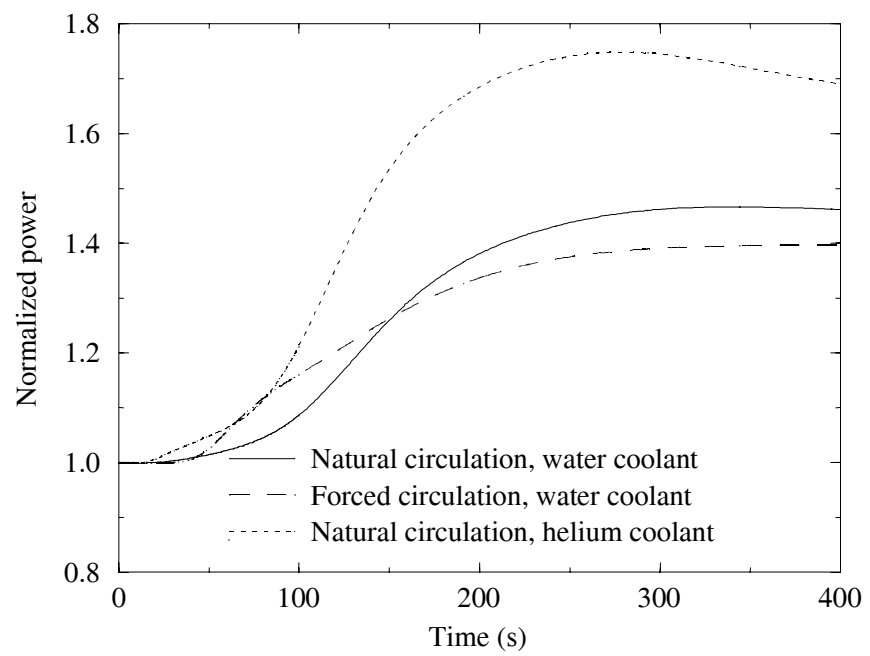

Figure 125. Normalized reactor power following a loss of preheating of the secondary coolant.

The increase in reactor power shown in Figure 125 caused the maximum cladding temperature to increase as shown in Figure 126. However, the maximum cladding temperature remained below the transient limit of $750^{\circ} \mathrm{C}$ for all three configurations. 


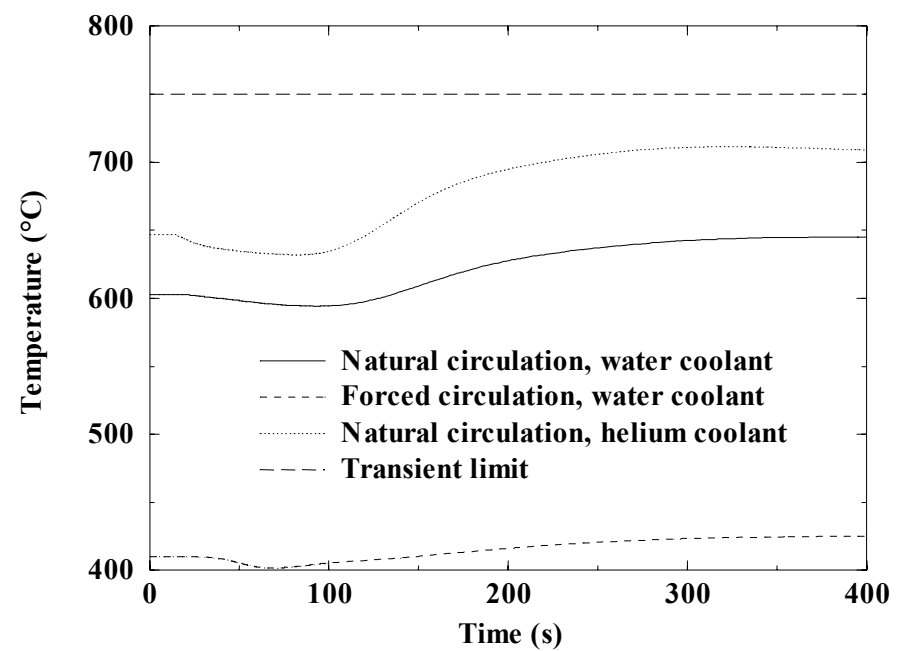

Figure 126. Maximum cladding temperature following a loss of preheating of the secondary coolant.

Figure 127 shows results from additional calculations performed to investigate the effect of a loss of preheating of the secondary coolant assuming that the reactor power remained constant, such as might occur if the control system moved control rods to compensate for the change in moderator temperature. The decrease in secondary coolant inlet temperature caused the leadbismuth temperature to drop below the freezing point with helium as the secondary coolant, but not with water.

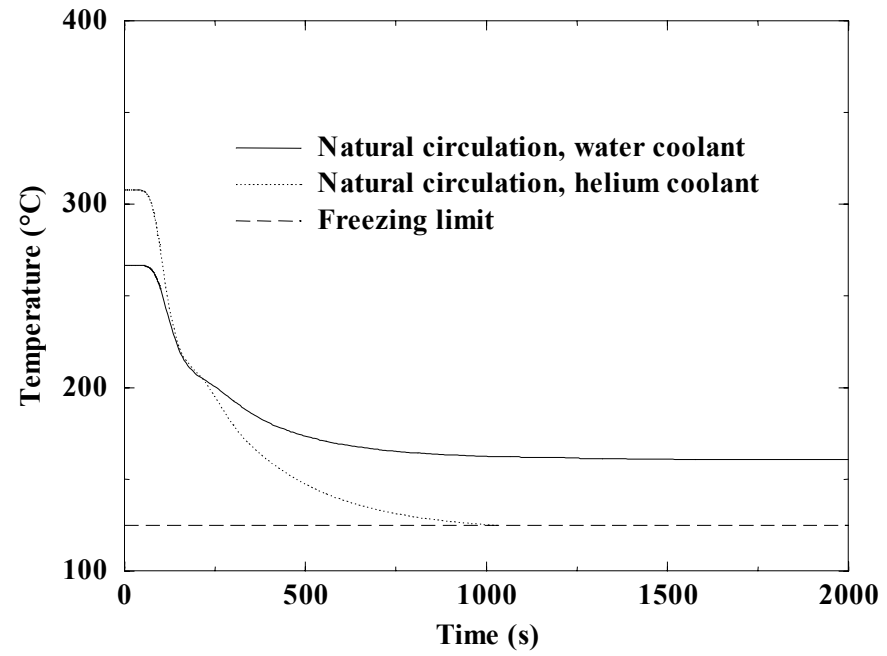

Figure 127. Core inlet temperature following a loss of preheating of the secondary coolant assuming that the power remains constant.

The actinide-burner reactor is not susceptible to overcooling accidents that might cause freezing of the lead-bismuth. The lead-bismuth temperature remained well above the freezing point following a complete loss of preheating assuming no movement of the control rods. If the control rods moved to compensate for reactivity feedback, freezing was calculated to occur with helium as the secondary coolant, but not with water. Of course, freezing could occur for the configurations with water coolant if a scram and a failure to reduce secondary flow followed a complete loss of preheating. Although this very unlikely event might be of operational concern, the scram should limit any safety concerns. 


\subsubsection{Heat Exchanger Tube Rupture Without Scram}

Safety analyses of PWRs consider steam generator tube rupture accidents, which result in a leak from the high-pressure primary side to the low-pressure secondary side of the steam generators. A tube rupture event in the actinide-burner reactor will result in flow in the opposite direction, from the high-pressure secondary side to the low-pressure lead-bismuth. This inflow of secondary coolant will pressurize the primary coolant system. A relief valve will be required to protect the reactor vessel from excessive pressure. The relief valve will have to discharge into a suppression pool or condenser to prevent release of radioactive polonium from the lead-bismuth to the atmosphere.

A computational complication arises for the configurations utilizing water as the secondary coolant. ATHENA solves continuity, energy, and momentum equations for two phases of a single working fluid, which is lead-bismuth for the actinide-burner reactor. If water enters the system, four phases will be present: liquid lead bismuth, a tiny amount of lead-bismuth vapor, liquid water, and steam. The code cannot model this situation mechanistically as it simulates only two fluid fields, one for a liquid and one for a gas. A major revision to the code would be required to model all four phases and the interactions between them. However, since the liquid water will quickly boil to steam, approximate quantitative results were obtained using the following three steps. First, the mass flow rate from the secondary side of the heat exchanger to the primary coolant system was calculated. The break flow was discharged into a time-dependent volume whose pressure was set to that of the primary coolant. Second, the flow of water into the primary coolant system was simulated using time-dependent junctions to inject an equivalent amount of noncondensable gas that was a mixture of air and helium. The mixture, which was $90.3 \%$ air by mass, had the same gas constant as steam and represented steam density to within five percent over the range of conditions encountered during the tube rupture. The mass flow rate of the injected nocondensable gas was thus equal to the water flow rate calculated during the first step. The volumetric flow rate of the injected gas was approximately equal to that of the water after it had boiled into steam. Finally, the ATHENA control system was used to perform a steady-state energy balance of the lead-bismuth/water mixture and remove the amount of energy from the lead-bismuth required to bring the water up to the lead-bismuth temperature.

ATHENA was used to simulate a heat exchanger tube rupture in the actinide-burner reactor for Configurations 1 and 2 of Table 44. The accident was initiated at $0.0 \mathrm{~s}$ by a double-ended rupture of a single heat exchanger tube at the lower tube sheet. The secondary coolant inlet flow rate and turbine header pressure were held constant during the transient. No scram was assumed and the point kinetics model described in Section 4.4.1 was used to calculate reactivity feedback. The pressure at the top of the reactor vessel was held constant using a time-dependent volume to simulate an open relief valve.

The total flow from the ruptured heat exchanger tube is shown in Figure 128 for Configuration 1 of Table 44. The flow rate was limited by choking at both ends of the break. About $75 \%$ of the total flow went through the lower tube sheet and into the reactor vessel downcomer (Component 580 in Figure 90). Less flow passed through the other side of the break because wall friction in the heat exchanger tube reduced the pressure at the choking plane. The decrease in break flow that began near $40 \mathrm{~s}$ was caused by a flow reversal, discussed below, that brought warmer lead-bismuth to the bottom of the heat exchanger that then heated the water at the bottom of the secondary side of the heat exchanger. The break was located at the lower tube 
sheet, and the increase in water temperature at that location caused a decrease in the choked flow rate.

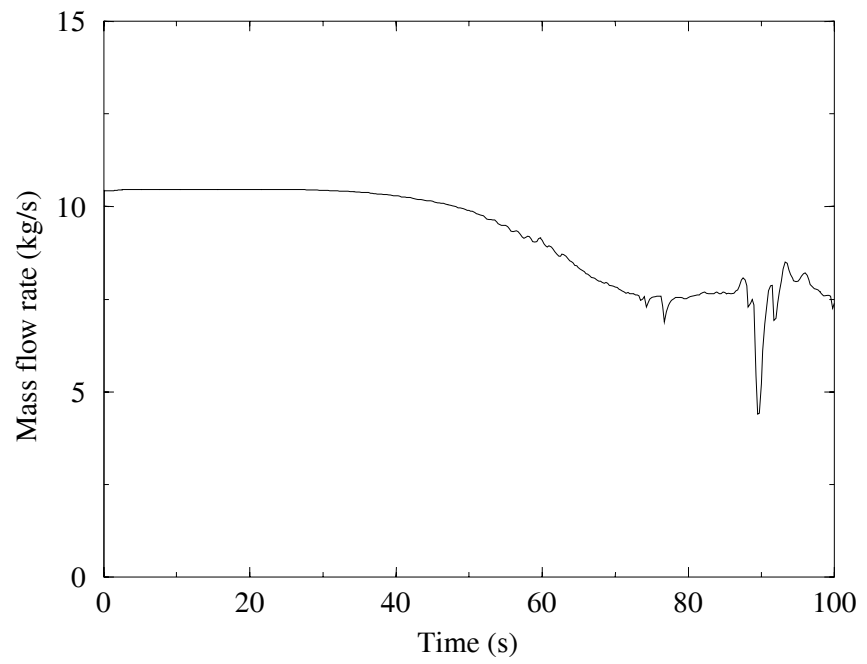

Figure 128. Total mass flow from the ruptured heat exchanger tube for Configuration 1.

The flow rate of water into the primary coolant system was simulated by the injection of noncondensable gases in ATHENA. Some of the injected gas passed up through the bypass path between the liner and the reactor vessel and out the simulated relief valve at the top of reactor vessel. However, the voiding caused by the remainder of the gas reduced the effective head of the primary flow path through the downcomer compared to that through the core. Consequently, the flow through the core reversed as illustrated in Figure 129. The gas from the tube sheet side of the break then flowed up through the gap between the liner and the reactor vessel and up through the heat exchanger tubes, into the gas space region at the top of the core, and out through the simulated relief valve. Consequently, no significant voiding occurred in the core.

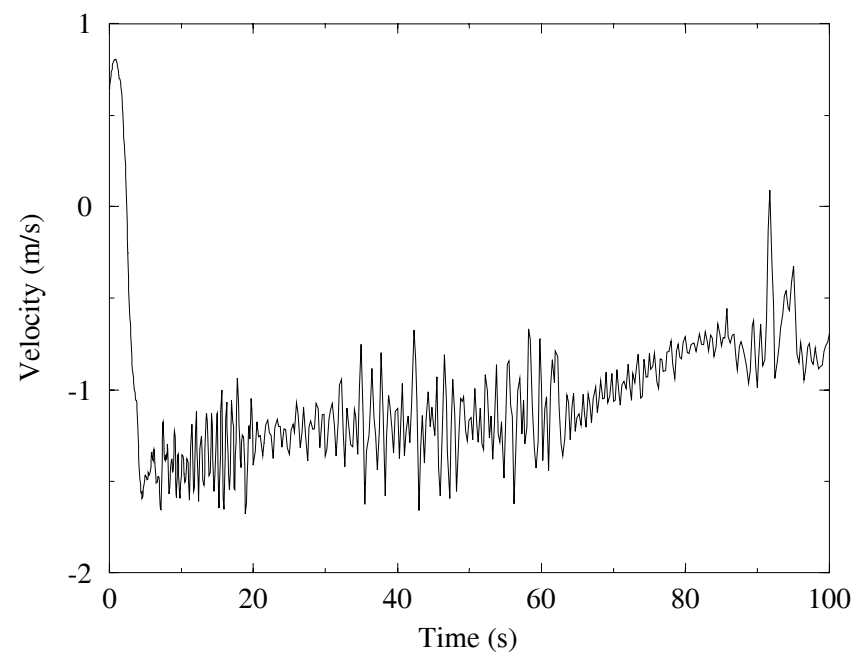

Figure 129. Coolant velocity through the core following the rupture of a single heat exchanger tube for Configuration 1.

Figure 129 shows that the absolute magnitude of the coolant velocity in the core decreased during the flow reversal. Consequently, the average cladding temperature increased as shown in Figure 130. The maximum cladding temperature also increased, but to a lesser extent than the average temperature, because the location of the maximum cladding temperature switched from 
near the top of the core to near the bottom. The peak cladding temperature remained well below the transient limit of $750^{\circ} \mathrm{C}$ even without reactor scram. The reactor power responded to the changes in moderator and fuel temperatures as shown in Figure 131.

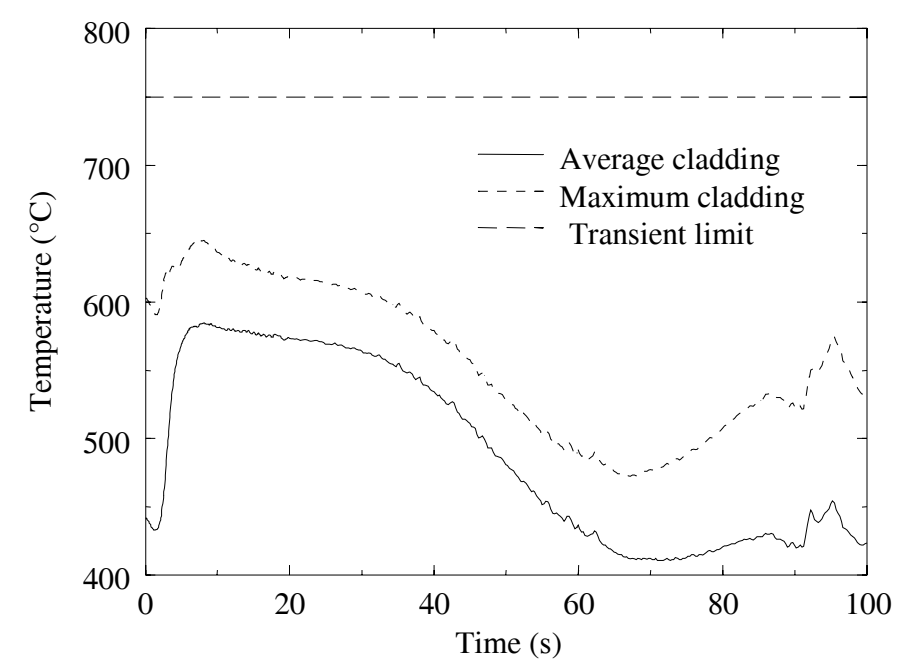

Figure 130. Average and maximum cladding temperature following the rupture of a single heat exchanger tube for Configuration 1.

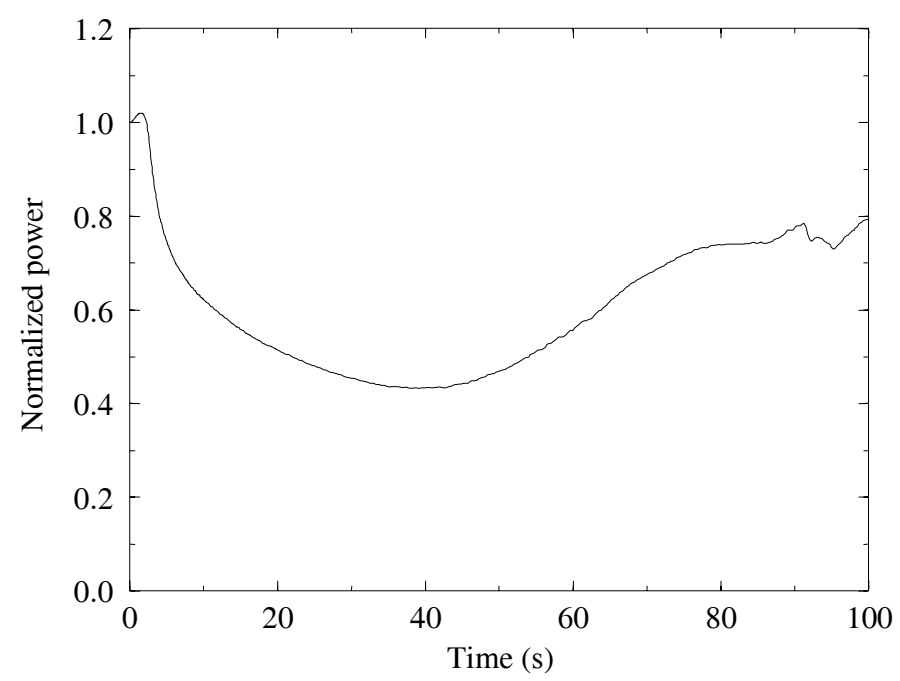

Figure 131. Reactor power following the rupture of a single heat exchanger tube for Configuration 1.

Calculations were not performed with Configuration 3 of Table 44, which was identical to Configuration 1 except that helium, rather than water, was used as the secondary coolant. However, the results with helium are expected to be qualitatively similar to those obtained with water. Specifically, the core flow reversal is expected because the density of helium is less than that of steam.

The total flow from the ruptured heat exchanger tube is shown in Figure 132 for Configuration 2 of Table 44. The results with operating primary coolant pumps were similar to those shown previously for Configuration 1, except that the flow rate remained nearly constant throughout the transient. The head produced by the operating primary coolant pumps caused the flow through the core to remain positive throughout the transient as shown in Figure 133. The 
reduction in density of the fluid outside of the core barrel caused a reduction in the flow rate, but not the flow reversal observed in Configuration 1. The calculated flow rate became oscillatory with a period near $10 \mathrm{~s}$. Only a small amount of gas was entrained downwards through the downcomer and to the core. Most of the gas flowed upwards through the gap between the liner and the reactor vessel and, to a lesser extent, upwards through the heat exchanger tubes during portions of the flow oscillations.

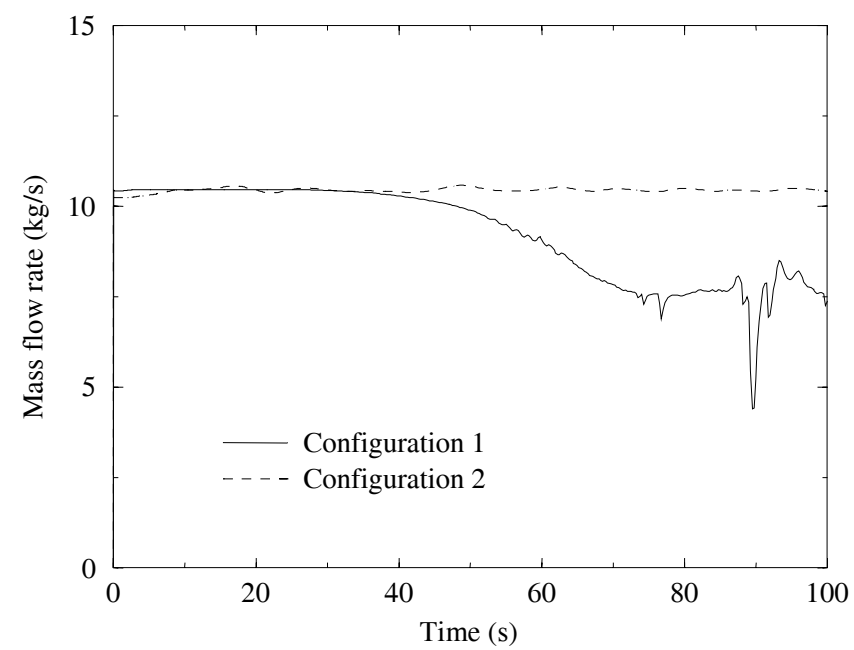

Figure 132. The effect of pump operation on total flow from the ruptured heat exchanger tube.

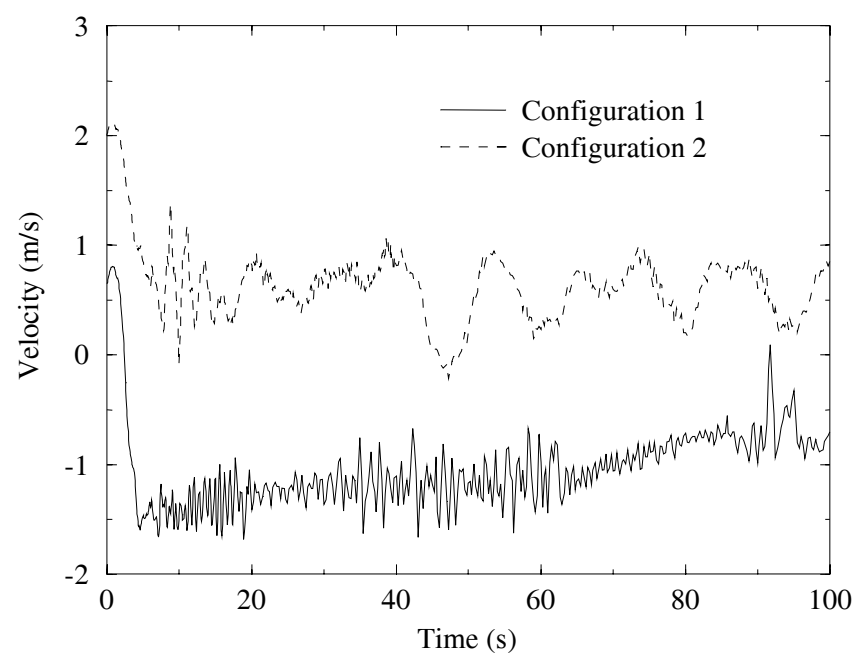

Figure 133. The effect of pump operation on coolant velocity in the core following the rupture of a single heat exchanger tube.

The fraction of gas that is carried down through the downcomer to the core is significantly affected by the drift flux correlations used in ATHENA. These correlations, which include Chexal and Lellouche (1986), Kataoka and Ishii (1987), Zuber-Findlay slug (1965), and ZuberFindlay churn-turbulent bubbly (1967), were primarily developed for two-phase mixtures of air and water or steam and water. These water-based correlations predict significantly different results from each other for flow in the downcomer of the actinide-burner reactor during the tube rupture accident. For example, the Kataoka-Ishii correlation predicts countercurrent flow in the downcomer, while the churn-turbulent bubbly correlation predicts cocurrent downflow. 
Furthermore, the application of these water-based correlations to a system with lead-bismuth and steam represents a significant extrapolation (Davis 2001). The calculated voiding in the core is subject to considerable uncertainty because of the uncertainties in the drift flux correlations.

To bound the possible effects of gas entrainment, a sensitivity calculation was performed in which the junctions between the outlet of the heat exchanger and the bottom of the reactor vessel downcomer (see Figure 90) were modeled with the one-velocity option, which forces the phases to flow at the same velocity. Figure 134 shows the effect of phase slip in the downcomer on the average void fraction in the core for Configuration 2. In the base calculation, the average void fraction was less than 0.001 because only a small fraction of the gas was entrained downwards through the downcomer. In the sensitivity calculation, void fraction was considerably larger, almost 0.05 , because gas was carried to the core by the

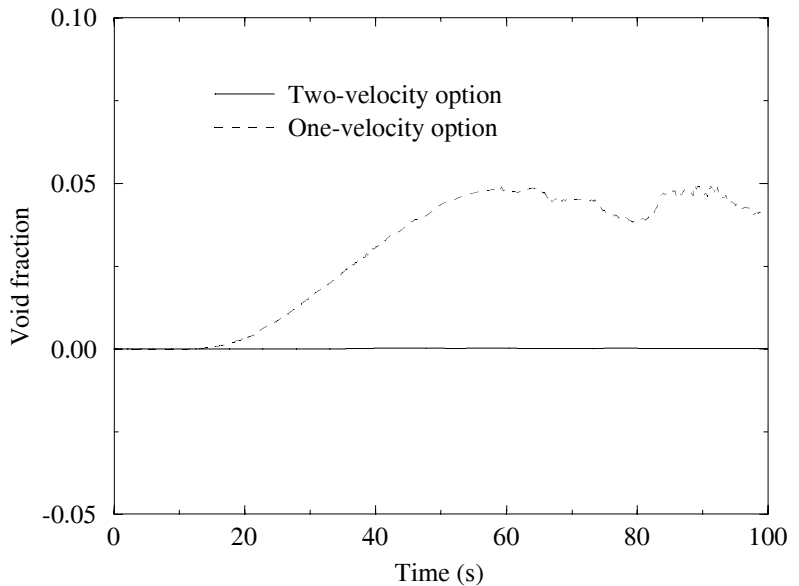

Figure 134. The effect of phase slip in the downcomer on average void fraction in the core following the rupture of a single heat exchanger tube for Configuration 2. downwards flow of liquid. However, nearly $90 \%$ of the gas still flowed upwards through the gap between the liner and the reactor vessel.

The effect of phase slip in the downcomer on core power is shown in Figure 135. In the base calculation, the power decreased primarily because of the reactivity feedback due to changes in moderator temperature. The power in the sensitivity calculation was eventually reduced below that of the base calculation because voiding in the core caused enough reactivity feedback to shut down the reactor. Thus, the sensitivity calculation demonstrates the effectiveness of the streaming tube design in case of core voiding during a heat exchanger tube rupture event.

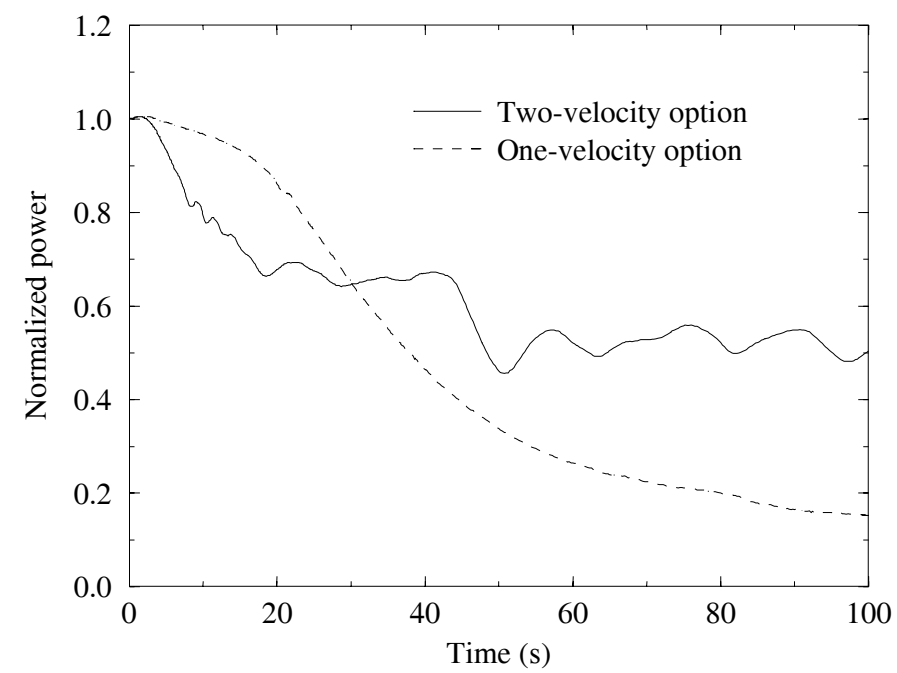

Figure 135. The effect of phase slip in the downcomer on normalized core power following the rupture of a single heat exchanger tube for Configuration 2. 
The effect of phase slip in the downcomer on maximum cladding temperature is shown in Figure 136. The tube rupture caused the cladding temperature to initially increase because the reduction in flow was greater than the reduction in power in both calculations. However, the peak cladding temperature remained well below the transient limit regardless of the phase slip in the downcomer.

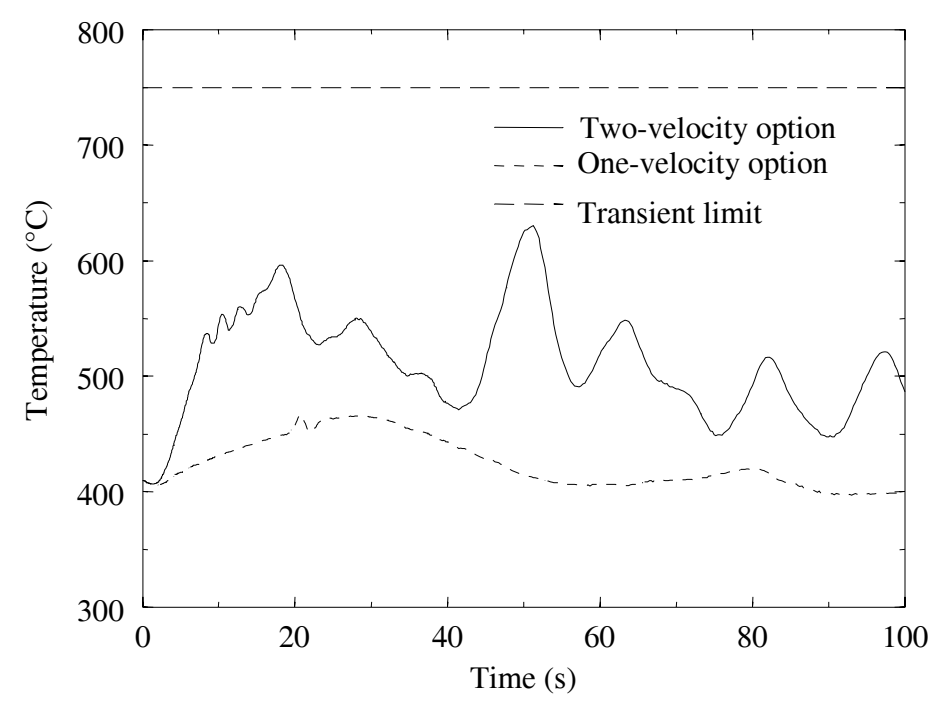

Figure 136. The effect of phase slip in the downcomer on maximum cladding temperature following the rupture of a single heat exchanger tube for Configuration 2.

The calculations described previously are thought to provide reasonable approximations to the behavior of a transient initiated by the rupture of a heat exchanger tube. However, the calculations are considered preliminary because of ATHENA's representation of the mixture of lead-bismuth and steam/water. The calculated results are also somewhat uncertain because of the use of water-based drift flux correlations for countercurrent flow and downflow and the extrapolation of the El-Boher and Lesin correlation beyond the range of its database for cocurrent upflow. For example, the lead-bismuth temperature exceeds the data on which the El Boher and Lesin correlation was based by as much as $250^{\circ} \mathrm{C}$, and the superficial liquid velocity in the bypass is almost a factor of two greater than the maximum value from the database. Test data will ultimately be required to reduce the uncertainty in the calculations due to the uncertainty in the drift flux correlations. However, the uncertainty in the thermal-hydraulics is ameliorated by the negative reactivity feedback associated with the streaming tube design.

\subsubsection{Summary of Transient Results}

The results of the transients described in the previous sections are summarized in Table 48. The table identifies each transient, including whether or not scram was assumed to occur, the peak cladding temperature and normalized power calculated during the transient, and whether or not scram is required to meet the transient cladding temperature limit of $750^{\circ} \mathrm{C}$. Results are presented for the three design configurations listed in Table 44. However, calculations were not completed for all transient/configuration combinations to reduce the total number of calculations performed. 
Table 48. Summary of transient results.

\begin{tabular}{|c|c|c|c|c|c|c|c|c|c|c|}
\hline \multirow[t]{2}{*}{ Transient } & \multirow[t]{2}{*}{ Scram? } & \multicolumn{3}{|c|}{$\frac{\text { Peak Cladding }}{\text { Temperature }\left({ }^{\circ} \mathrm{C}\right)}$} & \multicolumn{3}{|c|}{$\frac{\text { Peak Normalized }}{\text { Configuration }^{1}}$} & \multicolumn{3}{|c|}{$\begin{array}{c}\text { Scram Required? } \\
\text { Configuration }^{1}\end{array}$} \\
\hline & & 1 & 2 & 3 & 1 & 2 & 3 & 1 & 2 & 3 \\
\hline Plant startup & No & 602 & & & 1.00 & & & No & & \\
\hline Step change in load & No & 603 & 410 & 648 & 1.00 & 1.01 & 1.01 & No & No & No \\
\hline Loss of heat sink & Yes & 744 & $744^{2}$ & 755 & 1.00 & 1.00 & 1.00 & Yes & Yes & Yes \\
\hline Loss of heat sink & No & 769 & & & 1.00 & & & Yes & & \\
\hline Rod ejection & No & 1029 & 776 & 1058 & 3.07 & 3.89 & 3.01 & Yes & Yes & Yes \\
\hline Large secondary break & No & 657 & 466 & 697 & 1.03 & 1.09 & 1.01 & No & No & No \\
\hline Pump seizure & No & & 662 & & & 1.00 & & & No & \\
\hline Loss of preheating & No & 645 & 425 & 711 & 1.47 & 1.40 & 1.75 & No & No & No \\
\hline $\begin{array}{l}\text { Heat exchanger tube } \\
\text { rupture }\end{array}$ & No & 645 & 631 & & 1.02 & 1.00 & & No & No & \\
\hline
\end{tabular}

1. Configuration 1 employs natural circulation of the lead-bismuth and water as the secondary coolant. Configuration 2 uses centrifugal pumps in the primary coolant system and water as the secondary coolant. Configuration 3 uses natural circulation of the primary coolant and helium as the secondary coolant.

2. Assuming that the pumps were tripped early in the transient. The peak cladding temperature was $765^{\circ} \mathrm{C}$ if the pumps continued to operate during the transient.

The analysis showed that the actinide-burner reactor demonstrates good operating characteristics. The system was easy to start up and responded smoothly to control rod withdrawal between hot standby and full power. A simple feedwater control system was designed that allowed the secondary coolant system to smoothly follow the control rod withdrawal. Issues related to the startup of the plant from ambient to hot standby, including the thawing of the lead-bismuth, were not addressed. The actinide-burner reactor shows less sensitivity to a transient initiated by a step change in load than current PWRs. Scram was not required to protect the cladding temperature from a $10 \%$ step change in load. The cladding temperature remained well below the transient limit of $750^{\circ} \mathrm{C}$ for all three configurations evaluated. The analysis of the step change in load was performed to evaluate thermal margins, not load following capability. However, it is expected that the configuration with forced circulation would follow load quicker than the natural circulation designs because of the reduced particle transit time around the primary circuit.

The limiting transient for RVACS operation is initiated by a loss of heat sink. The limiting initial power for the RVACS described in Section 4.4.1 was 660 MW for Configuration 1. The initial value chosen for the analysis was $650 \mathrm{MW}$. The peak cladding temperature following a loss of secondary heat sink from an initial power of $650 \mathrm{MW}$ was $744^{\circ} \mathrm{C}$, slightly less than the transient thermal limit of $750^{\circ} \mathrm{C}$. With Configuration 2, the limiting initial power is also $660 \mathrm{MW}$ if the primary coolant pumps are tripped early in the transient. If the pumps continue running, the heat load on the RVACS is increased, resulting in a higher peak cladding temperature of $765^{\circ} \mathrm{C}$. A $6 \%$ reduction in initial power is required to meet the transient temperature limit if the primary coolant pumps continue to operate following a loss of heat sink. In either case, the transient power limit is more restrictive than the steady-state limit for the forced circulation configuration. The primary coolant pumps should be tripped following a loss of heat sink. The use of helium as the secondary coolant in Configuration 3 requires a $3 \%$ reduction in initial power to meet the transient temperature limit. 
The ejection of an average control rod in the actinide-burner reactor was simulated with a $0.5 \$$ reactivity step insertion. The analysis used a point kinetics model and did not account for any localized effects of the control rod ejection. Table $\mathbf{4 8}$ shows that the control rod ejection without scram results in a major (up to a factor of four) increase in reactor power. The power increase caused the cladding temperature to exceed the transient temperature limit 3.1,64.1, and $2.2 \mathrm{~s}$ after the ejection for Configurations 1 though 3, respectively. The amount of time available to insert the control rods exceeds that typically assumed for PWRs. Thus, requirements on actuation time of the scram system for the actinide-burner reactor should not be stringent.

A large rupture of the heat exchanger outlet piping does not pose serious consequences for the actinide-burner reactor. The rupture initially cools the primary coolant system, resulting in a small increase in core power. The peak cladding temperature remained well below the transient limit of $750^{\circ} \mathrm{C}$ for the three plant configurations evaluated, even without a reactor scram. The design does not require flow restrictors in the outlet piping. The analysis was more conservative than typically done for PWRs because of the assumed failure to scram and the assumed simultaneous rupture of the outlet piping from each heat exchanger.

Loss-of-flow events do not cause serious consequences in the actinide-burner reactor. The simultaneous seizure of all primary coolant pumps in Configuration 2 combined with a failure to scram does not cause cladding temperature limits to be violated or large changes in coolant pressure. Flywheels to extend the coastdown of the pumps are not required. A feedwater control system will be required to protect the turbine. The analysis was much more conservative than those typically done for PWRs, which assume the seizure of a single pump and that scram occurs.

The actinide-burner reactor is not susceptible to overcooling accidents initiated by a loss of preheating of the secondary coolant. The loss of preheating caused the reactor power to increase, but the peak cladding temperature remained below the transient temperature limit. The loss of preheating caused a decrease in the fluid temperature at the inlet to the core, but the lead-bismuth temperature remained well above the freezing point following a complete loss of preheating assuming no movement of the control rods. If the control rods moved to compensate for reactivity feedback, freezing was calculated to occur with helium as the secondary coolant, but not with water. Of course, freezing could occur for the configurations with water coolant if a scram and a failure to reduce secondary flow followed a complete loss of preheating. Although this very unlikely event might be of operational concern, the scram should limit any safety concerns.

A heat exchanger tube rupture in the actinide-burner reactor will result in flow from the highpressure secondary side to the low-pressure primary side. The inflow of secondary coolant will pressurize the primary coolant system. A relief valve will be required to protect the reactor vessel from excessive pressure. The relief valve will have to discharge into a suppression pool or condenser to prevent release of radioactive polonium from the lead-bismuth to the atmosphere. The rupture of a single heat exchanger tube caused a core flow reversal for Configuration 1, which utilized natural circulation of the primary coolant, but not for Configuration 2 which used forced circulation. The cladding temperature remained below the transient limit regardless of the circulation option. The calculations indicated that no gas or insignificant amounts of gas would be entrained to the core. A sensitivity calculation in which partial voiding of the core was forced shut down the reactor because of reactivity feedback associated with the streaming tube design. Test data will ultimately be required to reduce the uncertainty in the calculations due to the uncertainty in ATHENA's drift flux correlations, which are primarily based on air/water and steam/water data rather than on lead-bismuth data. Limitations in the code's representation of mixtures of lead/bismuth, water, and steam were also identified. 
The actinide-burner reactor provides reasonable protection for anticipated transients without scram. The reactor does not rely excessively on the scram system. The peak cladding temperature exceeded the thermal limit of $750^{\circ} \mathrm{C}$ only for those transients initiated by loss of heat sink and control rod ejection. Configuration 1 can meet the thermal limit following a loss of heat sink combined with a failure to scram if the initial power is reduced by $5 \%$. Reactivity feedback will shut down the reactor within $1000 \mathrm{~s}$ of the loss of heat sink. The amount of time available to scram the actinide-burner reactor following a control rod ejection exceeds that typically available for PWRs. Thus, stringent requirements on the scram system of the actinide-burner reactor should not be necessary. The control rod ejection accident is considered to be an extremely unlikely, or limiting, fault in a PWR. The transient calculated here, which includes a failure to scram, is expected to be beyond design basis in the actinide-burner reactor. Furthermore, the average control rod worth in designs that utilize fertile, long-lived cores is expected to be considerably less than the $0.5 \$$ assumed in this analysis.

All three configurations of the actinide-burner reactor have acceptable safety characteristics. Each configuration can be designed to meet the thermal limit of $750^{\circ} \mathrm{C}$ for all of the transients evaluated. However, Table 48 shows that the peak cladding temperatures are generally lowest for Configuration 2 and highest for Configuration 3. Configuration 2 also responded much better following the ejection of a control rod, as the time available to scram the reactor was more than $60 \mathrm{~s}$ longer than with the natural circulation designs. Configuration 3 was the only design that resulted in freezing of the lead-bismuth in the transient initiated by a loss of secondary preheating coupled with control rod movement that compensated for the change in moderator temperature.

Based on these results, Configuration 2 has the best safety characteristics of the designs evaluated and Configuration 3 has the worst characteristics. Thus, the best safety margins are obtained with water as the secondary coolant and with forced circulation of the primary coolant. Although the calculations described in Table 48 simulated centrifugal pumps, similar benefits are expected from the use of electromagnetic or gas lift pumps.

\subsection{Seismic Analysis Of The Guard Vessel (INEEL, Dr. Jacopo Buongiorno, Brian Hawkes)}

A linear-elastic seismic analysis of the guard vessel is presented in this section, based on the Design Response Spectrum approach for a $0.5 \mathrm{~g}$ earthquake. Four support types for the guard vessel were analyzed and it was found that the roll support exhibits the best overall performance. The variation of the normal-mode frequency and total peak stress intensity with the guard vessel diameter and thickness was also studied. It was found that the frequency of the first normal mode increases with increasing guard vessel diameter and thickness, while the total peak stress intensity decreases with increasing guard vessel thickness and is roughly independent of the guard vessel

diameter. Two new dimensionless groups are introduced that enable correlation of the frequency and stress-intensity data with adequate accuracy. It is proposed that these correlations be used for a quick estimate of the seismic response of any vessel of arbitrary size, material, and contained fluid, subject to an earthquake of arbitrary magnitude. Finally, the correlations are used to size the thickness of the guard vessel for the reactor investigated in this project.

To achieve the target reactor power of 300-350MWe it was necessary to increase the reactor vessel and guard vessel diameters to about 5.5 and $6 \mathrm{~m}$, respectively. However, ensuring that the stress levels are acceptable under both static and dynamic conditions for such large vessels is a 
serious technical challenge, especially because these vessels are filled with a high-density fluid. The static analysis of the guard vessel is reported in Section $\mathbf{4 . 2}$ where its temperature limits are estimated as functions of its thickness. On the other hand, the analysis of the guard vessel response to dynamic loadings generated by a seismic event is the objective of this section.

Although sporadic studies on this subject can be found in the literature, to the authors' knowledge this study is the first attempt to systematically evaluate the seismic performance of heavy-liquid-metal-reactor vessels and thus represents a useful design tool for the heavy-liquidmetal reactor community.

Note that for a reactor with an RVACS with liquid lead-bismuth in the gap between the reactor vessel and the guard vessel, the load (both static and seismic) is actually accommodated by the guard vessel, because the reactor vessel floats in the liquid lead-bismuth. Therefore, the recommendations from the seismic analysis must be applied to the guard vessel.

\subsubsection{Analysis Approach and Assumptions}

The guard vessel is made of austenitic stainless steel Grade 316, one of only four materials permitted by the ASME code for nuclear-reactor vessels operating at elevated temperature. The other three permitted materials are SS-304, Ni-Fe-Cr (Alloy 800H) and 21/4Cr-1Mo. Grade 316 is preferred because of its higher allowable stress at a given temperature and because of the previous experience with this material for fast reactor applications. Note that, although the guard vessel temperature may reach very high values for limited periods of time (e.g., up to $700^{\circ} \mathrm{C}$ during a loss-of-normal-heat-sink event), it is customary to ignore the simultaneous occurrence of two serious accidents (e.g., a major earthquake and a loss-of-normal-heat-sink event) as a second order effect with extremely low probability. Consequently, the seismic analysis can be conducted at the guard vessel steady-state temperature, which is conservatively assumed to be $420^{\circ} \mathrm{C}$. At this temperature, the rules of the ASME Boiler and Pressure Vessel Code, Section III, Division 1, Subsection NB (Class 1 Components) apply. These rules are applicable to pressureretaining components independent of the type of contained fluid and thus are valid for heavy-liquid-metal-cooled reactor applications (ASME 1998).

The guard vessel is modeled as a cylinder of outer diameter $\mathrm{D}$ and uniform wall thickness $\tau$ with a hemispherical lower head (Figure 137). $D$ and $\tau$ are the variables of the analysis. On the other hand, the guard vessel total height (from the bottom of the lower head to the top of the cylindrical shell) is selected and fixed at $19 \mathrm{~m}$, which is the length limit for transportation on U.S. railcars and also the reference value adopted in the thermalhydraulic analysis of Section 4.4. This length value is assumed only as a reference: the results of this study can be readily

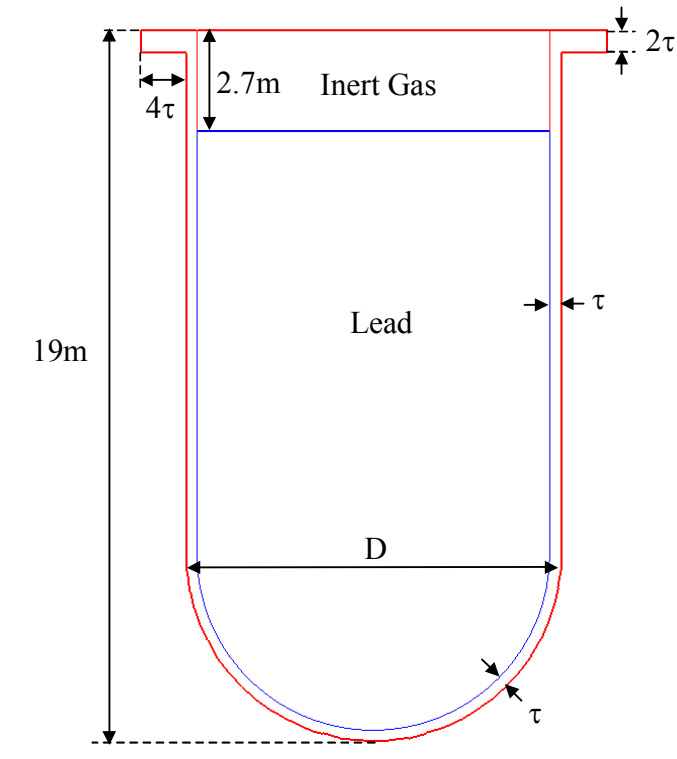

Figure 137. A schematic of the guard vessel. generalized to a guard vessel of any length, as shown in Section 4.5.4. The guard vessel is filled 
with a fluid of $10.2 \mathrm{~g} / \mathrm{cm}^{3}$ density (e.g., a lead alloy) up to an elevation of $2.7 \mathrm{~m}$ below the vessel top. (With regard to Figure 137, note that in reality the guard vessel is not entirely filled with $\mathrm{Pb}$ $\mathrm{Bi}$, but rather contains the main reactor vessel with a $\mathrm{Pb}$-Bi-filled gap between the two. However, for simplicity sake, the presence of the reactor vessel was ignored). The space between the fluid free surface and the guard vessel top is filled with an inert gas at atmospheric pressure to allow for expansion of the fluid during overheating transients. The guard vessel is equipped with a horizontal flange of width $4 \tau$ and thickness $2 \tau$. The connection between the flange and the reactor building, through which the earthquake is transmitted to the vessel, is realized by means of specified mechanical supports. Four types of supports were considered:

- Fixed Support (zero degrees of freedom): the flange is rigidly connected to the reactor building so that no translation or rotation of the flange is allowed.

- Roll Support (one degree of freedom): the flange is allowed to expand/shrink radially, but not to bend. Tangential displacements are not allowed.

- Hinge Support (one degree of freedom): the flange is allowed to bend (with the guard vessel circumference as the rotation axis), but no radial or tangential displacements are allowed.

- Hinge-and-Roll Support (two degrees of freedom): the flange is allowed to bend (with the guard vessel circumference as the rotation axis) and to expand/shrink radially. Again tangential displacements are not allowed.

A conceptual description of the four support types is illustrated in Figures 138a, b, $\mathbf{c}$ and $\mathbf{d}$.

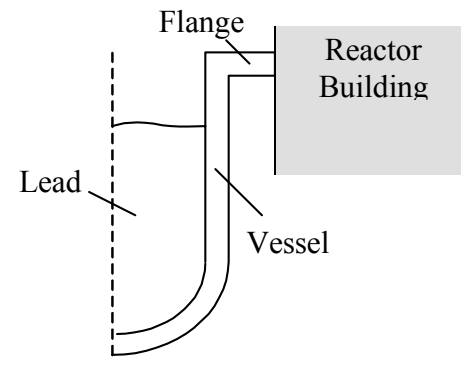

138a. The fixed support.

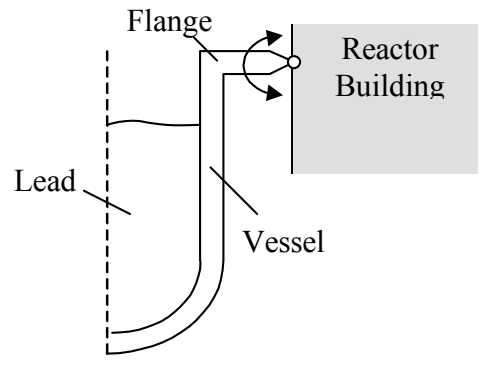

138c. The hinge support.

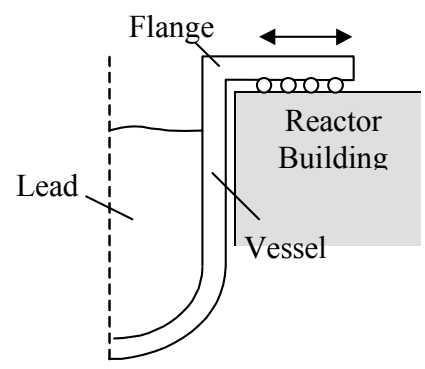

138b. The roll support.

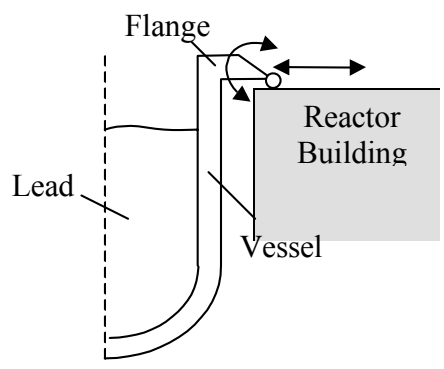

138d. The hinge-and-roll support.

Figure 138. The guard vessel supports.

The seismic analysis is conducted in the frequency domain according to the Design Response Spectrum (DRS) approach. In this approach, the guard vessel normal modes of vibration and their associated natural frequencies are calculated by means of a stress-strain elastic code (ABAQUS was used for this study). There are three sets of normal modes, associated with 
direction $\mathrm{x}$ (horizontal), $\mathrm{y}$ (horizontal) and $\mathrm{z}$ (vertical), respectively. However, note that the normal modes for the $\mathrm{x}$ and $\mathrm{y}$ directions are identical because the guard vessel and supports are symmetric about the longitudinal axis. Each normal mode of vibration can be effectively viewed as a simple harmonic oscillator with a characteristic natural frequency and a specified damping factor, for which the DRS can be utilized. The DRS is a (given) plot that characterizes the earthquake completely because it provides the maximum acceleration induced by the earthquake in any harmonic oscillator of given natural frequency and damping. Then, maximum accelerations are converted into maximum displacements by the simple relation:

$$
S_{d, k}=\frac{S_{a, k}}{\left(2 \pi f_{k}\right)^{2}}
$$

where $\mathrm{S}_{\mathrm{d}, \mathrm{k}}$ and $\mathrm{S}_{\mathrm{a}, \mathrm{k}}$ are the maximum displacements and acceleration of the $\mathrm{k}^{\text {th }}$ mode, respectively, and $f_{k}$ is the natural frequency of the $\mathrm{k}^{\text {th }}$ mode. Knowledge of the maximum displacement for each normal mode enables calculation of the stresses associated with that normal mode. These stresses are then combined to give the total stresses in the guard vessel during the earthquake.

The DRS approach is more general and more insightful than one where the time history of the ground motion is specified and then the stresses in the guard vessel are calculated as a function of time. The time history of the ground motion varies greatly from earthquake to earthquake and from location to location for a specific earthquake. On the other hand, the DRS approach based on the superposition of normal mode excitation lends itself to a clear and physically meaningful interpretation and also enables identification of possible design changes to improve the guard vessel seismic response.

It is necessary to specify three DRS plots, each characterizing the earthquake in the $\mathrm{x}, \mathrm{y}$ and $\mathrm{z}$ direction, respectively. The three DRS plots share the same shape, which is prescribed by the NRC Regulatory Guide 1.60 (NRC 1973a). However, two scaling parameters need to be specified for each direction (i.e., for each DRS plot): the Zero-Period Acceleration (ZPA, also known as the peak ground acceleration) and the damping factor (a measure of the ability of the structure to suppress the oscillations in that direction). A ZPA of $0.5 \mathrm{~g}$ was selected in this analysis for the horizontal directions $\mathrm{x}$ and $\mathrm{y}$ in accordance with the GE ALMR design (Gyorey et al. 1990). This is a rather high acceleration that should make the guard vessel licensable for most sites in the U.S. The Uniform Building Code (ICBO 1997) recommends the reduction of the vertical ZPA by a factor $1 / 3$ with respect to the horizontal ZPA, i.e., the ZPA in the $\mathrm{z}$ direction is $2 / 3 \times 0.5 \mathrm{~g}=0.33 \mathrm{~g}$. A damping factor of $3 \%$ is adopted for all directions, as recommended in reference (NRC 1973b). The DRS plots for directions $\mathrm{x}, \mathrm{y}$ and $\mathrm{z}$ are illustrated in Figure 139.

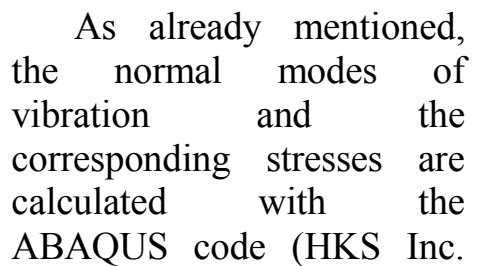
1998). ABAQUS is a finite

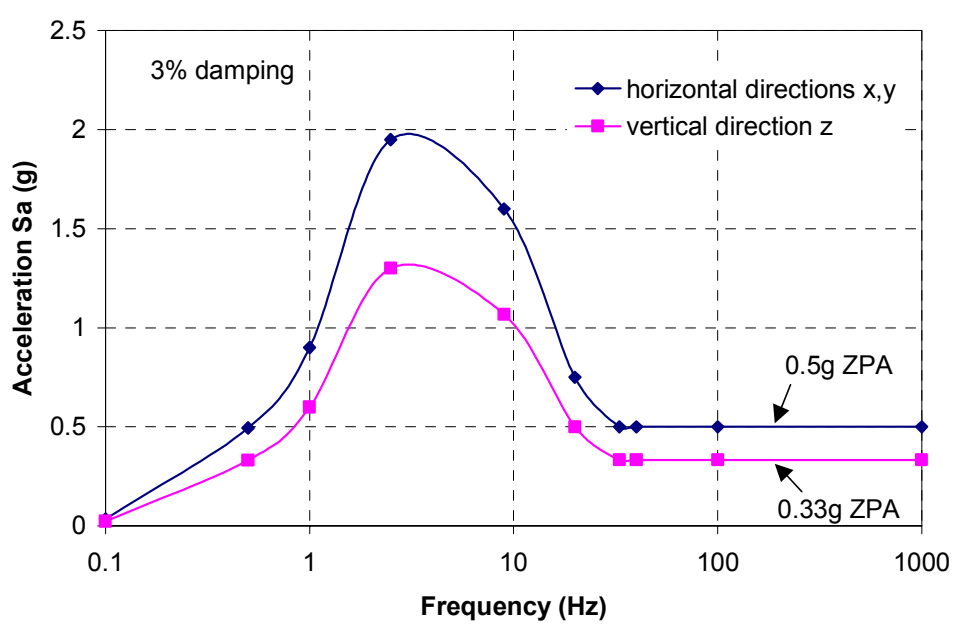

Figure 139. The Design Response Spectrum. 
element code suitable for performing the computational algorithm described above. For a seismic analysis based on the DRS approach, ABAQUS assumes that the system's response is linear. Note that if the excitation is so severe that nonlinear effects must be taken into account, the DRS analysis is not appropriate. The normal modes and their natural frequencies are calculated by means of the *FREQUENCY keyword. The acceleration DRS is specified in the code with the *SPECTRUM keyword. The peak stresses associated with each normal mode are computed and combined with the *RESPONSE SPECTRUM keyword. The combination of the peak stresses from different normal modes is not a simple linear summation, because this would be equivalent to assuming that all normal modes peak simultaneously, an excessively conservative assumption. Instead, it is assumed that the modes are completely independent and oscillate with a randomlydistributed relative phase lag. Therefore, to obtain the total peak stress $\sigma_{\mathrm{ij}}$ (i.e., the ij component of the stress tensor), the peak stresses from different normal modes are summed with the SUM=SRSS option to the *RESPONSE SPECTRUM keyword according to the following equation (HKS Inc. 1998):

$$
\sigma_{i j}=\sqrt{\sum_{k} \sigma_{i j, k}^{2}}
$$

where $\sigma_{\mathrm{ij}, \mathrm{k}}$ is the $\mathrm{ij}$ component of the stress tensor associated with the $\mathrm{k}^{\text {th }}$ normal mode.

To evaluate their acceptability, the total peak stresses are compared with the limits specified in the ASME code (Level D Service Loadings). For the elastic analysis, the ASME code prescribes that the general primary membrane stress intensity be at or below the lesser of $240 \%$ the allowable stress intensity of the material or $70 \%$ the ultimate strength of the material. The ASME code also prescribes that the primary stress intensity (general + local + bending) be at any point in the guard vessel below $150 \%$ the limit on the general primary membrane stress intensity. For simplicity sake, we conservatively assume that the primary stress intensity will meet the criterion for the general primary membrane stress intensity. The allowable stress intensity for SS316 at $420^{\circ} \mathrm{C}$ is $109.6 \mathrm{MPa}$ and the ultimate strength is $517.1 \mathrm{MPa}$ (ASME 1998), thus resulting in a limit of about 263.1MPa. Other SS-316 mechanical properties needed for the elastic analysis of the system (e.g., Young's modulus and Poisson's ratio at temperature) can be found in the ASME code. With regard to the contained fluid (i.e., lead) the Poisson's ratio is set equal to 0.5 and the Young's modulus is set equal to $1 / 10$ the room-temperature value to simulate the liquid nature of the fluid. With these assumptions, the contained fluid does not significantly contribute to the rigidity of the structure and most of the load is accounted for by stresses in the SS-316 only.

In modeling the guard vessel with ABAQUS particular attention is given to the issue of liquid sloshing at the top of the vessel. Sloshing concerns only a relatively small volume of fluid near the free surface. It was found that sloshing in a cylindrical pool can be effectively modeled by splitting the liquid mass into two masses (DOC 1963): one large mass fixed to the lower portion of the guard vessel and one small moving mass connected to the upper portion of the guard vessel by springs. The value of the moving mass $\mathrm{M}_{\mathrm{m}}$ and the total rigidity of the springs $\mathrm{K}_{\mathrm{s}}$ can be calculated as (DOC 1963):

$$
M_{m}=M_{t}\left[1-\frac{\tanh \left(\frac{\sqrt{3} D}{2 h}\right)}{\frac{\sqrt{3} D}{2 h}}\right]
$$




$$
K_{s}=M_{m} \frac{3.68 g}{D} \tanh \left(\frac{3.68 h}{D}\right)
$$

where $M_{t}$ is the total mass of the fluid, $h$ is the fluid depth (in our case about $16 \mathrm{~m}$ ) and $\mathrm{g}$ is the gravity acceleration. To evaluate the effect of sloshing on the seismic response of the vessel, an alternative model is also generated in which sloshing is eliminated by considering the entire fluid mass as fixed to the vessel.

The ABAQUS model of the system with sloshing (see Figure 140) comprises about 30,000 finite elements of which 15,360 represent the actual vessel, 1,152 the sloshing mass, 14,400 the fixed mass and 192 the spring elements connecting the sloshing mass with the guard vessel (each of rigidity equal to $\mathrm{K}_{\mathrm{s}} / 192$ ). The model without sloshing comprises about 25,000 finite elements of which 12,432 represent the actual guard vessel and 12,816 the fixed mass. No spring elements are present in the model without sloshing.

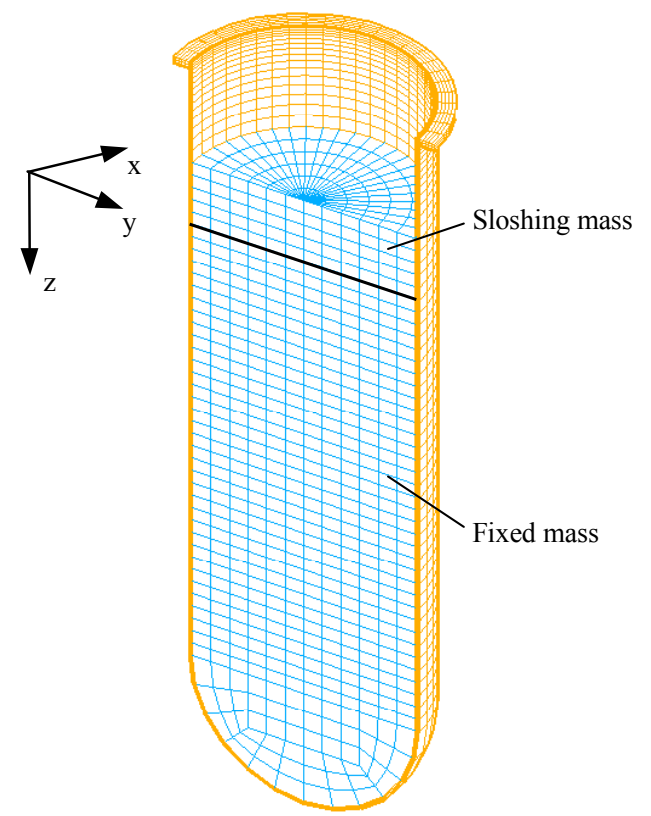

Figure 140. The finite-element model of the guard vessel with sloshing (the spring elements are not shown).

\subsubsection{Results}

The first set of calculations evaluates the importance of sloshing on the stresses in the guard vessel during the earthquake. For this purpose, a reference guard vessel configuration with fixed support, $6 \mathrm{~m}$ diameter and $10 \mathrm{~cm}$ thickness is analyzed with both the sloshing and non-sloshing models. It is found that the total peak stress intensity and first-mode frequency for the guard vessel with and without sloshing are $571.6 \mathrm{MPa}$ and $3.14 \mathrm{~Hz}$, and $600.5 \mathrm{MPa}$ and $3.20 \mathrm{~Hz}$, respectively. Thus, the effect of sloshing is to reduce the stress level in the vessel. On the other hand, the natural frequency of the first mode of vibration remains practically unchanged. Similar results are obtained for vessels with different support types. Therefore, because the model without sloshing is more conservative (with respect to the peak stresses) and computationally less expensive, it was used for the rest of the analysis. 
The second set of calculations evaluated the effect of the support type on the stresses, as well as on the normal-mode shape and frequency. A guard vessel configuration with $6 \mathrm{~m}$ diameter, $10 \mathrm{~cm}$ thickness and no sloshing was selected while the support type was varied (i.e., fixed, roll, hinge, hinge-and-roll). It is found that the fixed and roll supports share identical mode shape. The shape of their first three normal modes is illustrated in Figures 141a, $\mathbf{b}$ and $\mathbf{c}$. The hinge and hinge-and-roll supports also share identical mode shape, which are illustrated in Figures 142a, b and c. Note that the displacements in Figures 141 and 142 are greatly magnified for illustration purposes. For every support type, the first mode represents a simple lateral bending ${ }^{2}$. The second mode is torsional for the fixed and roll supports and axial (with a very odd nipple-like geometry) for the hinge and hinge-and-roll supports. The third mode is a higher-order lateral bending for all of the support types. The higher-order modes (not shown in Figures 141 and 142) are highfrequency displacement waves within the guard vessel for all of the support types.

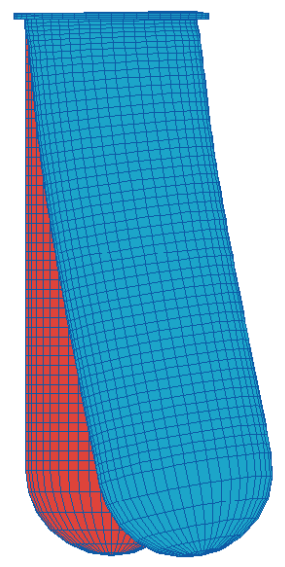

a. 1st Mode

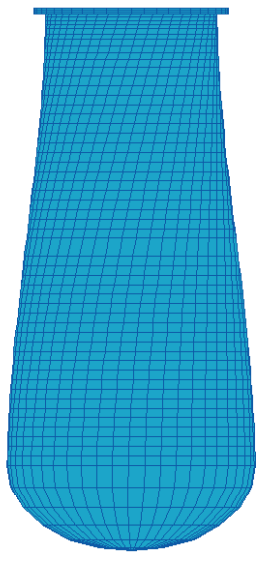

b. 2nd Mode

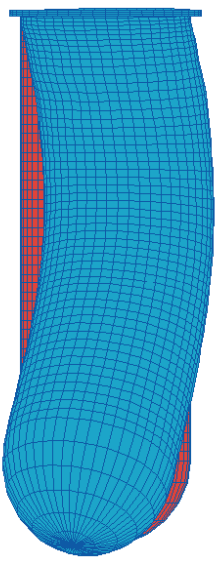

c. 3rd Mode

Figure 141. The shape of the normal modes of vibration for the fixed and roll supports.

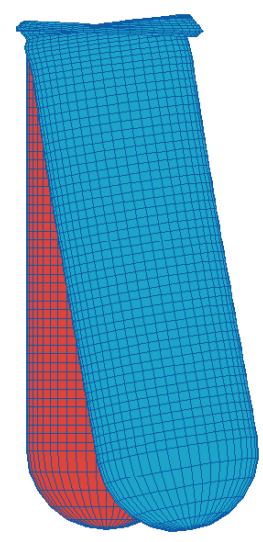

a. 1st Mode

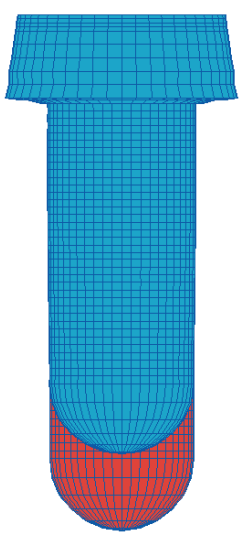

b. 2nd Mode

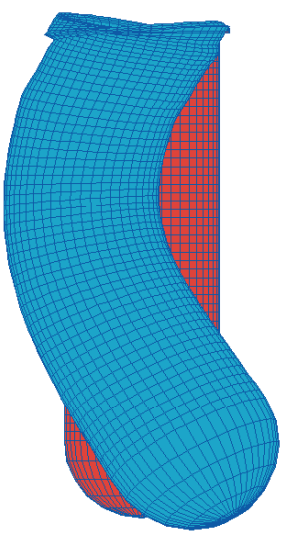

c. 3rd Mode

Figure 142. The shape of the normal modes of vibration for the hinge and hinge-and-roll supports.

\footnotetext{
${ }^{2}$ Because of the cylindrical symmetry of the system, there are actually two identical modes that share this same geometry.
} 
With regard to the first three modes, the similarity of the fixed and roll supports is expected because they both prevent bending of the flange. Analogously, the similarity between the hinge and hinge-and-roll supports is expected because they both allow for bending of the flange.

It is found that the first mode (i.e., simple lateral bending of the vessel) contributes the most to the total peak stress intensity, i.e., the first mode has the highest participation factor. As a result, for every support type the total peak stress intensity occurs immediately below the flange (in the cylindrical shell) where the guard vessel curvature (or, equivalently, the bending moment) associated with the first mode is maximum. The values of the total peak stress intensity for the different support types are reported in Table 49 along with the frequency of the first three modes. It can be seen that the support type yielding the lowest stress intensity is the fixed support, closely followed by the roll support. The hinge and hinge-and-roll supports exhibit much larger stresses. However, for this particular guard vessel size $(D=6 \mathrm{~m}, \tau=10 \mathrm{~cm})$ none of the support types yields stress intensities that satisfy the ASME limit for Level D Service Loadings for SS-316 at $420^{\circ} \mathrm{C}$. Note that at these stress levels (beyond the yield strength of the material) a linear elastic analysis is not accurate. Therefore, the results of Table 49 must be used as an indication only.

Table 49. Results of the support type comparison $(D=6 \mathrm{~m}, \tau=10 \mathrm{~cm})$.

\begin{tabular}{|c|c|c|c|c|}
\hline Support Type & $\begin{array}{c}\text { Total Peak Stress } \\
\text { Intensity (MPa) }\end{array}$ & $\begin{array}{c}\mathbf{1}^{\text {st }} \text { Mode } \\
\text { Frequency } \\
(\mathbf{H z})\end{array}$ & $\begin{array}{c}\mathbf{2}^{\text {nd }} \text { Mode } \\
\text { Frequency } \\
(\mathbf{H z})\end{array}$ & $\begin{array}{c}\mathbf{3}^{\text {rd }} \text { Mode } \\
\text { Frequency } \\
(\mathbf{H z})\end{array}$ \\
\hline Fixed & 600.5 & 3.20 & 12.9 & 13.1 \\
\hline Roll & 620.1 & 3.16 & 12.9 & 13.0 \\
\hline Hinge & 1978.8 & 1.77 & 8.14 & 12.4 \\
\hline Hinge-and-Roll & 2006.3 & 1.77 & 8.07 & 12.4 \\
\hline
\end{tabular}

It appears that, from a seismic standpoint, the fixed support performs best. However, the use of the fixed support in a nuclear reactor is impractical because it prevents unconstrained radial expansion/shrinkage of the guard vessel, and thus results in extremely high stresses upon guard vessel heating and cooling, e.g., during reactor startup and shutdown, respectively. To illustrate this behavior, a static ABAQUS calculation was performed to evaluate the stresses generated in a guard vessel of $6 \mathrm{~m}$ diameter, $10 \mathrm{~cm}$ thickness and with fixed support, upon heating from $20^{\circ} \mathrm{C}$ to $420^{\circ} \mathrm{C}$ (typical of reactor startup). It was found that under these conditions the maximum stress intensity in the guard vessel is $412.3 \mathrm{MPa}$, which greatly exceeds the ASME limit for Level A Service Loadings.

On the other hand, the roll support allows for unconstrained radial expansion/shrinkage of the guard vessel and also exhibits a seismic performance similar to the fixed support. For these reasons, in accordance with the LWR vessel practice, the use of the roll support is recommended also for heavy-liquid-metal-cooled-reactor vessels.

The third set of calculations studied the effect of the guard vessel size (i.e., D and $\tau$ ) on the seismic response. Table 50 reports the $\mathrm{D}$ and $\tau$ combinations considered for this purpose. For all combinations, the guard vessel is connected to the reactor building by means of a roll support and the contained fluid does not slosh.

The results of the analysis are reported in Table 51. It can be seen that, for a given diameter, the stress level decreases significantly with increasing thickness. On the other hand, for a given thickness, the dependence of the stress level on the diameter is more complicated, however not 
very strong. In the next section a simple model is presented that shows that the peak stress in the guard vessel is proportional to the ratio of the guard vessel cross-sectional moment of inertia to the guard vessel mass per unit length. This ratio significantly decreases with the guard vessel thickness but is roughly constant with respect to the guard vessel diameter, which explains the observed trends. The frequency of the first mode (also reported in Table 51) increases with the guard vessel thickness and diameter. These trends will also be explained in the next section.

Table 50. Case matrix for the vessel-size sensitivity analysis.

\begin{tabular}{|c|c|c|c|c|c|c|}
\hline & \multicolumn{5}{|c|}{$\tau(\mathrm{cm})$} \\
\hline & & 10.0 & 15.0 & 20.0 & 25.0 & 30.0 \\
\hline \multirow{4}{*}{$\underset{\varrho}{\Xi}$} & 4.0 & $\mathrm{X}$ & $\mathrm{X}$ & $\mathrm{X}$ & & $\mathrm{X}$ \\
\hline & 6.0 & $\mathrm{X}$ & $\mathrm{X}$ & $\mathrm{X}$ & & $\mathrm{X}$ \\
\hline & 8.0 & & & $X$ & $X$ & $X$ \\
\hline & 10.0 & & & $\mathrm{X}$ & $\mathrm{X}$ & $\mathrm{X}$ \\
\hline
\end{tabular}

Table 51. Results of the vessel-size sensitivity analysis.

\begin{tabular}{|c|c|c|}
\hline $\mathrm{D}(\mathrm{m}), \tau(\mathrm{cm})$ & $\begin{array}{c}\text { Total Peak Stress } \\
\text { Intensity }(\mathrm{MPa})\end{array}$ & $\begin{array}{c}\text { Frequency of the } \\
1^{\text {st }} \text { Mode }(\mathrm{Hz})\end{array}$ \\
\hline 4,10 & 547.4 & 2.65 \\
\hline 4,15 & 484.7 & 3.11 \\
\hline 4,20 & 299.9 & 3.52 \\
\hline 4,30 & 235.1 & 4.28 \\
\hline 6,10 & 619.1 & 3.16 \\
\hline 6,15 & 472.3 & 3.71 \\
\hline 6,20 & 347.5 & 4.28 \\
\hline 6,30 & 229.6 & 5.11 \\
\hline 8,20 & 330.3 & 4.71 \\
\hline 8,25 & 275.1 & 5.19 \\
\hline 8,30 & 181.3 & 5.63 \\
\hline 10,20 & 286.9 & 4.95 \\
\hline 10,25 & 216.5 & 5.47 \\
\hline 10,30 & 212.4 & 5.93 \\
\hline
\end{tabular}

Table 51 can be utilized as a lookup table for design of SS-316 reactor vessels of $19 \mathrm{~m}$ height, operating at $420^{\circ} \mathrm{C}$, containing a fluid of density $10.2 \mathrm{~g} / \mathrm{cm}^{3}$, connected to the reactor building by a roll support and subject to a horizontal $0.5 \mathrm{~g}$ and vertical $0.33 \mathrm{~g}$ earthquake. Of the fourteen $\mathrm{D}$ and $\tau$ combinations studied, only five (shaded in Table 51) exhibit stress levels below the Level D ASME limit of $263.1 \mathrm{MPa}$ for SS-316 at $420^{\circ} \mathrm{C}$. Again it should be emphasized that for the cases with peak stresses beyond the yield limit, a linear elastic analysis (like the one adopted in this study) is not accurate. Therefore, the results of Table $\mathbf{5 1}$ for these cases should be used as an indication only.

Note that there are ways to enhance the guard vessel seismic performance. For example, the first bending mode (and related stresses) can be suppressed by equipping the guard vessel with another roll support at the junction between the cylindrical shell and the hemispherical head, which would prevent lateral displacements of the bottom part of the vessel. This second roll support should also allow for axial expansion/shrinkage to prevent excessive stresses upon temperature transients. 


\subsubsection{Modeling Of The Seismic Response}

In this section it will be shown that, if two proper dimensionless groups are introduced, the results of the previous section can be generalized to the case of a vessel of arbitrary length, material, diameter, thickness and operating temperature, subject to an earthquake of arbitrary magnitude and containing a fluid of arbitrary (but high) density. The dimensionless groups are identified through the application of the beam theory to the bending normal modes of the vessel. Then two correlations are generated that satisfactorily predict the natural frequency of the first mode and the total peak stress intensity, respectively, and can be used for quick seismic calculations.

The vessel is modeled as an elastic beam of length $\mathrm{L}$, outer diameter $\mathrm{D}$, thickness $\tau$, made of a material with Young's modulus E, filled with a material of density $\rho$ and connected to the wall by a fixed support. The fixed support is adopted here because the application of the boundary conditions is straightforward. However, note that in terms of lateral bending the fixed support and the roll support are equivalent and therefore the results of this analysis can also be applied to a guard vessel with roll support. The geometry of the system is illustrated in Figure 143a and $143 b$.

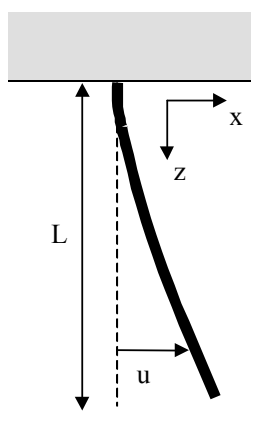

a. The system of coordinates.

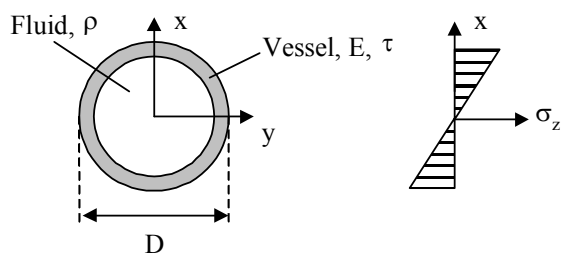

b. The beam cross section.

Figure 143. The beam geometry.

On the basis of simple elastic considerations (e.g., see Lalanne et al., 1983) it can be demonstrated that the motion equation of the beam is:

$$
E I \frac{\partial^{4} u}{\partial z^{4}}+m \frac{\partial^{2} u}{\partial t^{2}}=F
$$

where $\mathrm{u}$ is the lateral displacement, $\mathrm{t}$ is time, $\mathrm{m}$ is the beam mass per unit length, $\mathrm{I}$ is the beam cross-sectional moment of inertia, and $\mathrm{F}$ is the external force applied to the beam per unit length.

To calculate the shape of the normal modes and their frequency, Equation (5) has to be solved for $\mathrm{F}=0$ and with the following boundary conditions:

$$
\begin{cases}u(0, t)=0 & \text { (fixed support) } \\ \frac{\partial u}{\partial z}(0, t)=0 & \text { (fixed support) } \\ V(L, t)=0 & \text { (free end) } \\ M(L, t)=0 & \text { (free end) }\end{cases}
$$


where $\mathrm{V}$ and $\mathrm{M}$ are the shear force and the bending moment in the beam, respectively. The beam theory yields the following expressions for $\mathrm{V}$ and $\mathrm{M}$ in terms of $\mathrm{u}$ (Lalanne et al. 1983):

$$
\begin{aligned}
& V=-E I \frac{\partial^{3} u}{\partial z^{3}} \\
& M=E I \frac{\partial^{2} u}{\partial z^{2}}
\end{aligned}
$$

Therefore, Equations (8) and (9) effectively are conditions on the third and second spatial derivative of $\mathrm{u}$, respectively. If a solution of the form $\mathrm{u}(\mathrm{z}, \mathrm{t})=\mathrm{A}(\mathrm{z}) \mathrm{B}(\mathrm{t})$ is introduced in Equation (5) and the variables are separated, the following expression is obtained:

$$
\alpha^{4} \frac{1}{A} \frac{d^{4} A}{d z^{4}}=-\frac{1}{B} \frac{d^{2} B}{d t^{2}}
$$

where the parameter $\alpha$ is defined as:

$$
\alpha=\sqrt[4]{\frac{E I}{m}}
$$

Equation (12) indicates that a function of $\mathrm{z}$ only (the left-hand term) equals a function of $\mathrm{t}$ only (the right-hand term) for any values of $z$ and $t$. This implies that both terms are constant. We designate this constant as $\beta^{4}$. Equation (12) can then be split into two separate equations for only the $\mathrm{z}$ and $\mathrm{t}$ variable, respectively:

$$
\begin{aligned}
& \frac{d^{4} A}{d z^{4}}-\left(\frac{\beta}{\alpha}\right)^{4} A=0 \\
& \frac{d^{2} B}{d t^{2}}+\beta^{4} B=0
\end{aligned}
$$

Solution of these two equations is straightforward (they are both linear homogeneous differential equations with constant coefficients) and leads to the following two expressions:

$$
\begin{aligned}
& A(z)=A_{1} \sinh \left(\frac{\beta}{\alpha} z\right)+A_{2} \cosh \left(\frac{\beta}{\alpha} z\right)+A_{3} \sin \left(\frac{\beta}{\alpha} z\right)+A_{4} \cos \left(\frac{\beta}{\alpha} z\right) \\
& B(t)=\sin \left(\beta^{2} t+\varphi\right)
\end{aligned}
$$

where $A_{1}, A_{2}, A_{3}, A_{4}$ and $\varphi$ are arbitrary constants. The function $A(z)$ represents the spatial shape of the normal modes, which are modulated by $\mathrm{B}(\mathrm{t})$, an harmonic wave of angular frequency $\beta^{2}$ and phase $\varphi$. Setting the boundary conditions from Equations (6)-(9) into Equation (16) a system of four homogeneous linear equations in the four unknown $A_{1}, A_{2}, A_{3}$ and $A_{4}$ is obtained with the group $(\beta / \alpha) \mathrm{L}$ as a parameter: 


$$
\left\{\begin{array}{l}
A_{1}+A_{3}=0 \\
A_{2}+A_{4}=0 \\
A_{1} \cosh \left(\frac{\beta}{\alpha} L\right)+A_{2} \sinh \left(\frac{\beta}{\alpha} L\right)-A_{3} \cos \left(\frac{\beta}{\alpha} L\right)+A_{4} \sin \left(\frac{\beta}{\alpha} L\right)=0 \\
A_{1} \sinh \left(\frac{\beta}{\alpha} L\right)+A_{2} \cosh \left(\frac{\beta}{\alpha} L\right)-A_{3} \sin \left(\frac{\beta}{\alpha} L\right)-A_{4} \cos \left(\frac{\beta}{\alpha} L\right)=0
\end{array}\right.
$$

This system has non-zero solutions only for those values of $(\beta / \alpha) \mathrm{L}$ that satisfy the following equation (obtained by setting the determinant of the coefficient matrix of the system to zero):

$$
\cosh \left(\frac{\beta}{\alpha} L\right) \cos \left(\frac{\beta}{\alpha} L\right)+1=0
$$

Equation (22) is known as the characteristic equation of the system and can be readily solved with a standard numerical program (e.g., MATLAB or MATHCAD). Each solution corresponds to a normal mode and its frequency. The first two solutions of Equation (22) are:

$$
\begin{aligned}
& \frac{\beta_{1}}{\alpha} L=1.875 \\
& \frac{\beta_{2}}{\alpha} L=4.694
\end{aligned}
$$

Equations (23) and (24) indicate that the frequency f of the normal modes depends only on $\alpha$ and L as follows:

$$
f \propto \beta^{2} \propto \frac{\alpha^{2}}{L^{2}} \propto \frac{1}{L^{2}} \sqrt{\frac{E I}{m}}
$$

It is useful to develop an expression for I and $\mathrm{m}$. If the contribution of the fluid contained in the guard vessel to the bending moment is neglected ${ }^{3}$, the moment of inertia, I, can be readily calculated from its definition as:

$$
I=\int_{S} x^{2} d S=\frac{\pi}{4}\left[D^{4}-(D-2 \tau)^{4}\right]
$$

where $\mathrm{S}$ is the fraction of the beam cross-section area taken by the guard vessel material. The mass per unit length of the beam is:

$$
m \approx \rho \frac{\pi}{4}(D-2 \tau)^{2}
$$

\footnotetext{
${ }^{3}$ This is actually a good assumption because Newtonian fluids cannot transmit moments.
} 
where it was assumed that the mass of the contained fluid is much larger than the mass of the guard vessel (an excellent assumption in the case of heavy-liquid metals like lead or leadbismuth). Then Equation (25) becomes:

$$
f \propto \sqrt{\frac{E D^{2}}{\rho L^{4}} \cdot \frac{1-(1-2 \tau / D)^{4}}{(1-2 \tau / D)^{2}}}
$$

Therefore, the new dimensionless group $\mathrm{Bu}_{\mathrm{f}}$ is defined:

$$
B u_{f} \equiv \frac{f}{\sqrt{\frac{E D^{2}}{\rho L^{4}} \cdot \frac{1-(1-2 \tau / D)^{4}}{(1-2 \tau / D)^{2}}}}
$$

Equation (28) indicates that $\mathrm{Bu}_{\mathrm{f}}$ is a constant for the bending modes of any vessel. The physical meaning of $\mathrm{Bu}_{\mathrm{f}}$ is that of a normalized frequency of the guard vessel normal bending modes of vibration.

Let us now analyze the shape of the normal modes. After solving the system of Equations (18)-(21), function A becomes:

$$
A(z)=A_{1}\left\{\sinh \left(\frac{\beta}{\alpha} z\right)-\sin \left(\frac{\beta}{\alpha} z\right)-\frac{\cosh \left(\frac{\beta}{\alpha} L\right)+\cos \left(\frac{\beta}{\alpha} L\right)}{\sinh \left(\frac{\beta}{\alpha} L\right)-\sin \left(\frac{\beta}{\alpha} L\right)}\left[\cosh \left(\frac{\beta}{\alpha} z\right)-\cos \left(\frac{\beta}{\alpha} z\right)\right]\right\}
$$

$\mathrm{A}_{1}$ represents an amplitude factor proportional to the maximum displacement of the beam and can be set equal to unity for the purpose of studying the shape of the modes. A(z) is plotted in Figure 144 for $(\beta / \alpha) \mathrm{L}=1.875$ (the first mode) and $(\beta / \alpha) \mathrm{L}=4.964$ (the second mode). It can be seen that $\mathrm{A}(\mathrm{z})$ reproduces very well the shape of the $1^{\text {st }}$ and $3^{\text {rd }}$ modes (the bending modes) of the guard vessel with fixed (or roll) supports (see Figures 141a and 141c). Obviously, the torsional mode of Figure 141b cannot be reproduced with the beam theory, which does not account for torsional stresses.

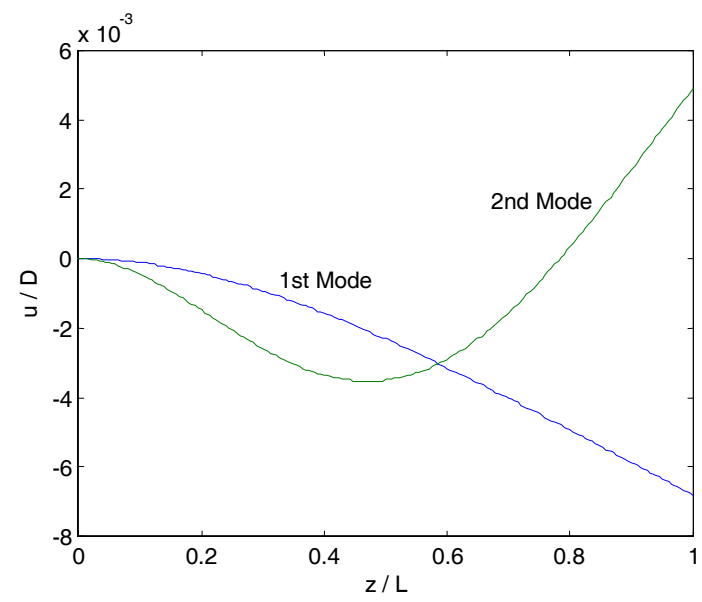

Figure 144. The shape of the bending normal modes. 
Let us now neglect the high-order modes ( $2^{\text {nd }}$ and higher) and calculate the peak stress intensity in the guard vessel on the basis of the first mode only. The beam theory is based on the assumption that the dominant stress component in the structure is the axial bending stress $\sigma_{z}$, which is assumed to be distributed linearly throughout the beam cross-section (see Figure 143b) according to the following equation (White et al. 1972):

$$
\sigma_{z}=-E \frac{\partial^{2} u}{\partial z^{2}} x
$$

Note that the $\sigma_{z}$ distribution exhibits a zero average over the beam cross-section, but does result in a bending moment. Furthermore, because all other stress components are neglected, the axial stress, $\sigma_{z}$, and the stress intensity, $S_{\mathrm{I}}$, are identical in the beam theory. Therefore, from Equation (31) it can be seen that the peak stress intensity, $S_{\mathrm{I}, \max }$, occurs at $\mathrm{x}= \pm \mathrm{D} / 2$ and, for the first mode, at $\mathrm{z}=0$ (where the curvature of the beam is maximum, see Figure 144):

$$
S_{I, \max }=E \frac{d^{2} A}{d z^{2}}(0) \frac{D}{2}
$$

Calculating the second derivative of A with respect to $\mathrm{z}$ from Equation (30) and substituting into Equation (32) one obtains:

$$
S_{I, \max }=A_{1} E D\left(\frac{\beta}{\alpha}\right)^{2} \frac{\cosh \left(\frac{\beta}{\alpha} L\right)+\cos \left(\frac{\beta}{\alpha} L\right)}{\sinh \left(\frac{\beta}{\alpha} L\right)-\sin \left(\frac{\beta}{\alpha} L\right)}
$$

But for a given mode (i.e., for a given value of $(\beta / \alpha) \mathrm{L})$, the factor containing the hyperbolic and trigonometric sines and cosines is constant. Also, from Equation (23) the factor $(\beta / \alpha)^{2}$ is inversely proportional to $\mathrm{L}^{2}$. Finally, $\mathrm{A}_{1}$ (the amplitude factor) is proportional to the maximum displacement in the guard vessel during the earthquake, $S_{d}$. Then, Equation (33) yields the following proportionality expression:

$$
S_{I, \max } \propto \frac{S_{d} E D}{L^{2}}
$$

Substituting Equation (1) and Equation (28) into Equation (34) the following expression is finally obtained:

$$
S_{I, \max } \propto \frac{S_{a} \rho L^{2}}{D} \cdot \frac{(1-2 \tau / D)^{2}}{1-(1-2 \tau / D)^{4}}
$$

Therefore, the new dimensionless group $\mathrm{Bu}_{\mathrm{s}}$ is defined: 


$$
B u_{s} \equiv \frac{S_{I, \max }}{\frac{S_{a} \rho L^{2}}{D} \cdot \frac{(1-2 \tau / D)^{2}}{1-(1-2 \tau / D)^{4}}}
$$

Equation (35) indicates that $\mathrm{Bu}_{\mathrm{s}}$ is a constant for the bending modes of any vessel. The physical meaning of $\mathrm{Bu}_{\mathrm{s}}$ is that of a normalized peak stress intensity.

To assess the validity of the model, the frequency and stress-intensity results of Table $\mathbf{5 1}$ are normalized according to the $\mathrm{Bu}_{\mathrm{f}}$ and $\mathrm{Bu}_{\mathrm{s}}$ groups and plotted against the guard vessel diameter (Figures 145 and 146) ${ }^{4}$. It can be seen that both $\mathrm{Bu}_{\mathrm{f}}$ and $\mathrm{Bu}_{\mathrm{s}}$ are roughly constant, as predicted by the model. The best fit of the data is obtained with a value of the constants of 0.0835 and 11.242 for $\mathrm{Bu}_{\mathrm{f}}$ and $\mathrm{Bu}_{\mathrm{s}}$, respectively, which was calculated according to the least-mean-squares method. Thus the correlations are:

$$
\begin{aligned}
& B u_{f}=0.0835 \\
& B u_{s}=11.242
\end{aligned}
$$

Figures 145 and 146 show that most of the data from Table 51 is predicted by the correlations with an uncertainty of $\pm 15 \%$. The actual standard deviation for $\mathrm{Bu}_{\mathrm{f}}$ and $\mathrm{Bu}_{\mathrm{s}}$ is about $6 \%$ and $11 \%$, respectively. Note that the correlations also correctly reproduce the trends observed in Table 51, i.e., the frequency increases with increasing guard vessel diameter and thickness (Figure 147) and the peak stress intensity decreases with the guard vessel thickness, but is roughly independent on the guard vessel diameter (Figure 148).

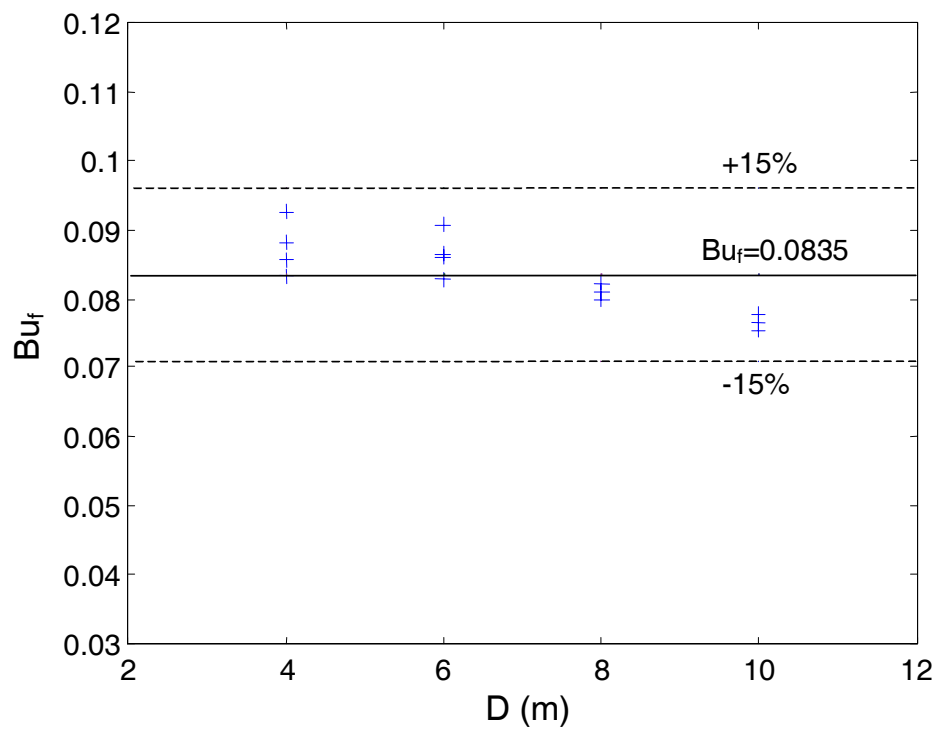

Figure 145. The frequency correlation.

\footnotetext{
${ }^{4}$ Identical results would be obtained if $\mathrm{Bu}_{\mathrm{f}}$ and $\mathrm{Bu}_{\mathrm{s}}$ were plotted against the other main variable of the analysis, the vessel thickness.
} 


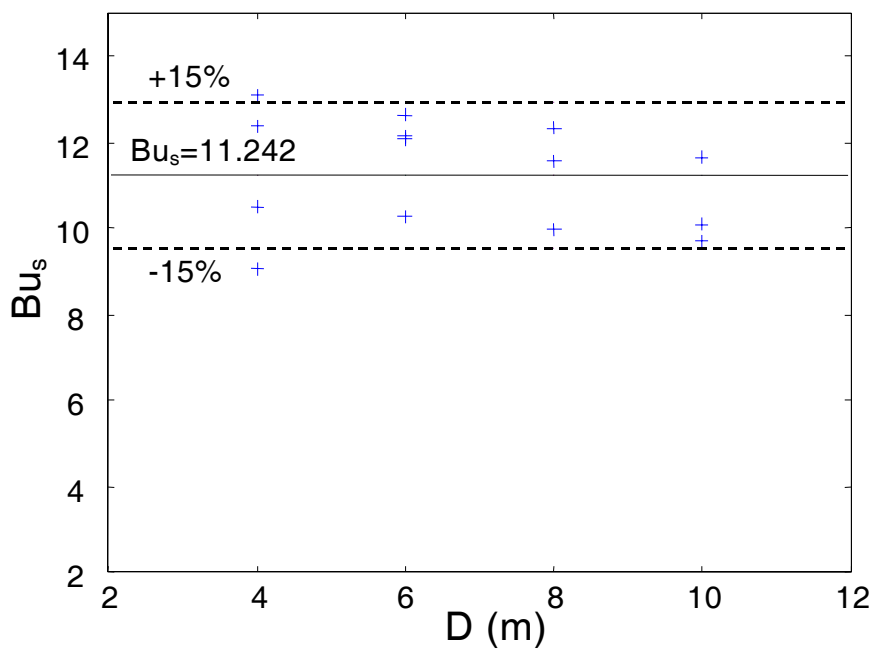

Figure 146. The stress-intensity correlation.

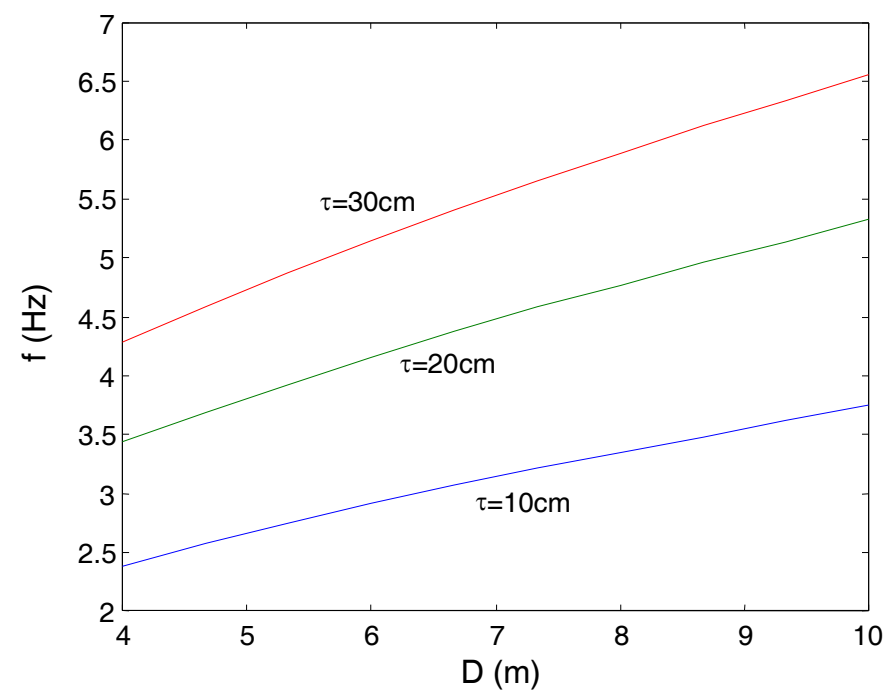

Figure 147. Variation of the of the frequency with $D$ and $\tau$.

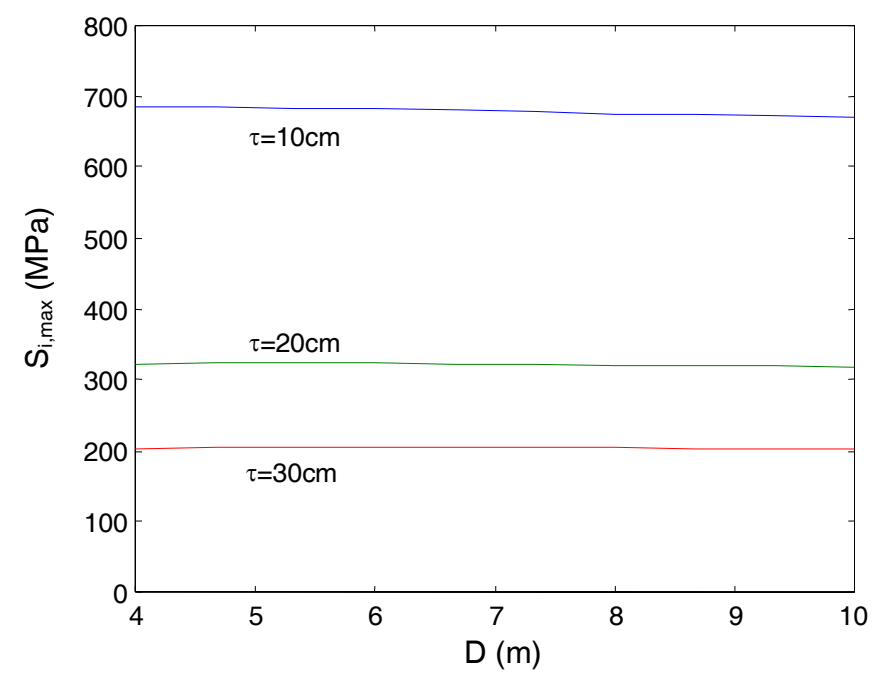

Figure 148. Variation of the of the peak stress intensity with $D$ and $\tau$. 
Equations (37) and (38) (in combination with the definitions of Equations (29) and (36)) enable calculation of the frequency and peak stress intensity for any guard vessel when $E, D, \rho$, $L, \tau$ and $S_{a}$ are specified. The correlations should be used as follows: first the frequency is calculated from Equation (37), then the acceleration $S_{a}$ corresponding to that frequency is found from the proper Design Response Spectrum plot. Then, the peak stress intensity is calculated from Equation (38). Finally, the peak stress intensity must be compared with the ASME limit for the material of interest to judge the acceptability of the stresses. Note that Equations (37) and (38) are (weakly) dependent on the guard vessel operating temperature via the Young's modulus E.

At the risk of sounding repetitive, we should once again emphasize that this study was based on a linear elastic analysis. Therefore, the results presented in Table $\mathbf{5 1}$ do not accurately reproduce the actual stress intensity and frequency for those $\mathrm{D}$ and $\tau$ combinations with peak stress intensity beyond the yield limit. However, those results would be correct if we were dealing with a (fictitious) material behaving linearly even beyond its yield limit. For the purpose of generating the correlations for $\mathrm{Bu}_{\mathrm{f}}$ and $\mathrm{Bu}_{\mathrm{s}}$, all data from Table 51 were utilized with the understanding that the predictions from these correlations are accurate only below the yield limit. Whenever the peak stress intensity predicted by Equation (38) is above the yield limit of the material, both the frequency and stress intensity predictions should be discarded.

\subsubsection{Applications Of The Correlations To The Reactor Guard Vessel}

Now the methodology described above is specifically applied to the guard vessel of the reactor studied in this project, which is made of SS-316, has a length of $19 \mathrm{~m}$, a diameter of $6.15 \mathrm{~m}$, and a plenum of $2.7 \mathrm{~m}$ (therefore, $\mathrm{L}=19-2.7 \approx 16 \mathrm{~m}$ ). The Young's modulus at operating temperatures is about $172 \mathrm{GPa}(\mathrm{E}=172 \mathrm{GPa})$, and a density of $10.2 \mathrm{~g} / \mathrm{cm}^{3}$ is assumed for the contained fluid. Using Equations (37) and (38) (along with the definitions in Equations (28) and (35)), and the DRS diagram of Figure 139, it is possible to calculate the total peak stress intensity in the guard vessel as a function of its thickness, as illustrated in Figure 149. Because the ASME limit is about $260 \mathrm{MPa}$, it is concluded that a guard vessel thickness of at least $25 \mathrm{~cm}$ is needed to withstand the $0.5 \mathrm{~g}$ design earthquake.

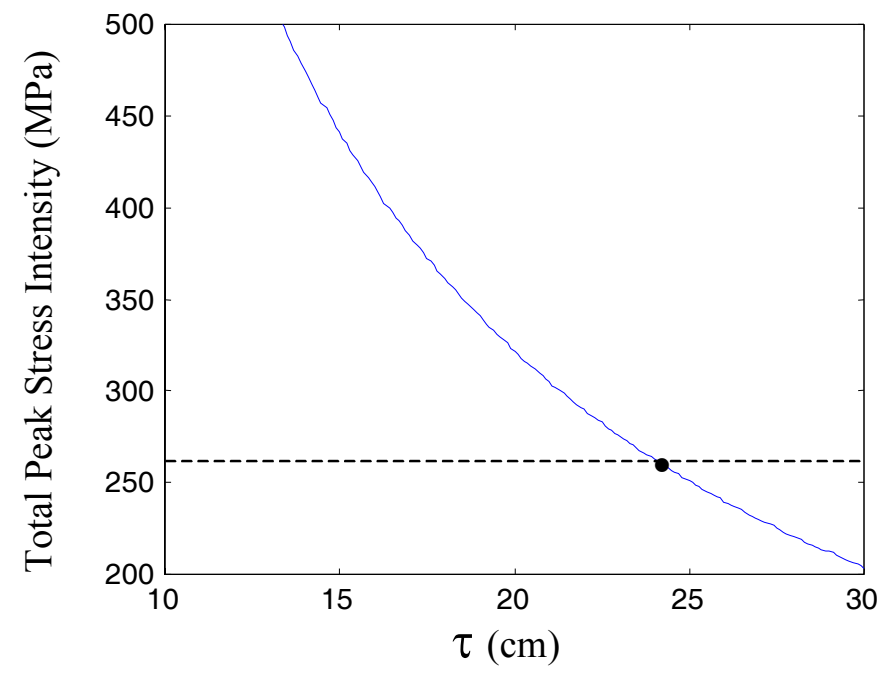

Figure 149. Stresses in the guard vessel 


\subsubsection{Conclusions}

The seismic linear-elastic analysis for the guard vessel of a heavy-liquid-metal reactor was undertaken based on the Design Response Spectrum approach and a $0.5 \mathrm{~g}$ earthquake. Four support types were analyzed and it was found that the (typical PWR) roll support exhibits the best overall performance. The variation of the normal-mode frequency and total peak stress intensity with the guard vessel diameter and thickness was also studied. It was found that the frequency of the first normal mode increases with increasing guard vessel diameter and thickness, while the total peak stress intensity decreases with increasing guard vessel thickness and is roughly independent of the guard vessel diameter. Two new dimensionless groups were introduced that enable correlation of the frequency and stress-intensity data with an average error of $6 \%$ and $11 \%$, respectively. It is proposed that these correlations can be used for quick estimate of the seismic response of a vessel of arbitrary size, material and contained fluid, subject to an earthquake of arbitrary magnitude. The correlations were used for sizing the guard vessel of the $\mathrm{Pb}-\mathrm{Bi}$ reactor investigated in this project and it was found that a $25 \mathrm{~cm}$ thickness ensures adequate seismic performance. 


\subsection{Results of the Materials Studies}

\subsection{Corrosion Tests at MIT (Prof. Ron Ballinger)}

The goal of this MIT task is to:

- Evaluate the compatibility of candidate structural materials with Pb-alloy coolant system under the proposed plant operation conditions,

- Develop and understanding of the key phenomena which control the interaction, and,

- To suggest a path forward for the development of materials that will be compatible at higher temperatures than the current limit of approximately $550^{\circ} \mathrm{C}$.

Figure 150 shows the relationship between operating temperature and the current state of the materials technology. The solubility of the elements in many of the structural materials increases as the temperature is increased. At the same time, the stability of the protective oxide films decreases. For current materials, the upper temperature limit is approximately $550^{\circ} \mathrm{C}$. In this regime Liquid Metal Corrosion (LMC) is an issue and active oxygen control is necessary for safe operation. Above $550^{\circ} \mathrm{C}$ operation will probably require the development of advanced alloys and/or more effective protection methods.

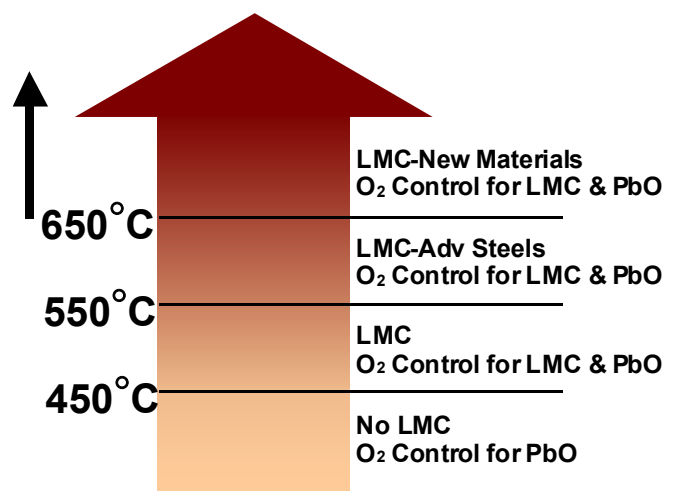

Figure 150. Relationship between operating temperature and technology requirements.

The joint program between INEEL and MIT is designed to develop materials and methods to extend the operating temperature regime for lead and $\mathrm{Pb}$-Bi operation. At MIT, the program is being carried out through an experimental program designed to explore the temperature limits of existing materials, to explore the behavior of selected high temperature materials and to suggest a path for advanced alloy development. The experimental program seeks to develop an understanding of the mechanisms by which lead and $\mathrm{Pb}$-Bi interact with structural materials. The alloy development program seeks to develop new materials that are more resistant to degradation at higher temperatures. In this report we provide details of progress during FY-01.

During this past year the effort has been focused on: (1) getting the existing rotating electrode system to the point that it is fully operational, (2) development and calibration of oxygen sensors for use in the program, (3) making progress in completion of the test matrix for the program, (4) construction of the second rotating electrode system, and (5) obtaining several model Fe-Si alloys for use in the alloy development program. 


\subsubsection{Experimental Facility}

The existing rotating electrode test facility is operational for testing at two oxygen potentials: (1) oxygen potential at the $\mathrm{Pb} / \mathrm{Pb}-\mathrm{O}$ equilibrium potential and above, and (2) at oxygen potentials limited by the oxygen potential over $\mathrm{ZrO}_{2}$. Additional modifications to the facility are being performed for testing at potentials between these two limits. The system is currently operational for temperatures not exceeding $600^{\circ} \mathrm{C}$. This is due to excessive lead condensation on chamber surfaces at temperatures above $600^{\circ} \mathrm{C}$. A work-around is being designed and implemented to address this issue.

During the past year it was discovered that operation at potentials between the $\mathrm{PbO}$ and $\mathrm{Cr}_{2} \mathrm{O}_{3}$ regions was being hampered by small leaks into the system from the outside and by small amounts of oxygen contamination present in the hydrogen being used to adjust the $\mathrm{H}_{2} / \mathrm{H}_{2} \mathrm{O}$ pressure ratio. The solution to the leakage problem was addressed by shifting from gasket and/or threaded joints to high vacuum flanges and welded connections.

The presence of residual oxygen in the hydrogen has proven more difficult to solve. Oxygen contamination in the argon carrier gas used for the system is removed by an oxygen getter system. However, hydrogen cannot be gettered using this system due to hydride formation. Therefore, the hydrogen contamination problem is being addressed in the short term through the use of 6-nines pure hydrogen, which is extremely expensive. In the longer term, a preheating system has been designed that will be installed in the system just prior to the entrance to the test chamber. All connections after the preheating system will be leak tested and/or welded. In other words, the gas stream will have the correct $\mathrm{H}_{2} / \mathrm{H}_{2} \mathrm{O}$ ratio to achieve the desired oxygen potential at the entrance to the pre-heater. However, there will still be some residual oxygen contamination that will not have combined with the hydrogen in the gas stream due to kinetics limitations. This gas stream will then be heated to $800^{\circ} \mathrm{C}$ in the pre-heater. At this temperature any residual oxygen will combine with the hydrogen to form water in equilibrium with the hydrogen partial pressure. This will not significantly alter the $\mathrm{H}_{2} \mathrm{O}$ concentration. The stream will then be cooled for injection into the test chamber.

The rotating electrode system is designed for operation at temperatures up to $800^{\circ} \mathrm{C}$. However, it has been discovered that at temperatures above $600^{\circ} \mathrm{C}$ the vapor pressure of lead is high enough to cause transport of lead to colder sections of the test chamber. A system is now being designed to mitigate this problem but, until this is accomplished, we are limiting our temperature of operation to less than $600^{\circ} \mathrm{C}$. The solution to the vapor transport problem will be the installation of a heated surface above the test crucible that will condense the vapor at a temperature that is above the melting point of lead and return it to the test crucible as liquid.

\subsubsection{Type 316 Stainless Steel Test Results}

Table 52 shows the updated test schedule for the program. Tests have been run using molybdenum and stainless steel (Type 316). The test temperature has been limited to less than $600^{\circ} \mathrm{C}$ as discussed above. In this section we present the results for the stainless steel tests.

A Type 316 stainless steel specimen was tested for 100 hours in the molten lead (containing the following impurities in ppm: Ag: 1, As: 1, Bi: 2.7, Cd: 4, Cu: 1, Fe: 1, Sb: 5, Sn 5, and Zn: 1) at a temperature of $583^{\circ} \mathrm{C}$. The rotational velocity was $200 \mathrm{rpm}$, which is equivalent to a maximum of $0.8 \mathrm{~m} / \mathrm{s}$. The $\mathrm{H}_{2} / \mathrm{H}_{2} \mathrm{O}$ pressure ratio for the test was approximately 1400 which, as 
Figure 151 illustrates, places the oxygen potential between the $\mathrm{Fe}_{3} \mathrm{O}_{4}$ and the $\mathrm{Cr}_{2} \mathrm{O}_{3}$ formation potentials.

Table 52. Experimental test matrix.

\begin{tabular}{|c|c|c|c|c|c|c|}
\hline Material & \multicolumn{3}{|c|}{ Temperature $\left({ }^{\circ} \mathrm{C}\right)$} & \multicolumn{3}{|c|}{ Rotating speed (rpm) } \\
\hline Molybdenum & \multirow{3}{*}{550} & \multirow{3}{*}{650} & \multirow{3}{*}{750} & & \multirow{4}{*}{$\begin{array}{l}300 \\
(1.2 \mathrm{~m} / \mathrm{s})\end{array}$} & \multirow{3}{*}{$\begin{array}{l}500 \\
(2 \mathrm{~m} / \mathrm{s})\end{array}$} \\
\hline Tantalum & & & & $(04 \mathrm{~m} / \mathrm{s})$ & & \\
\hline Tungsten & & & & & & \\
\hline $\begin{array}{l}\text { 316stainless } \\
\text { steel, HT-9 }\end{array}$ & & 650 & & & & \\
\hline
\end{tabular}

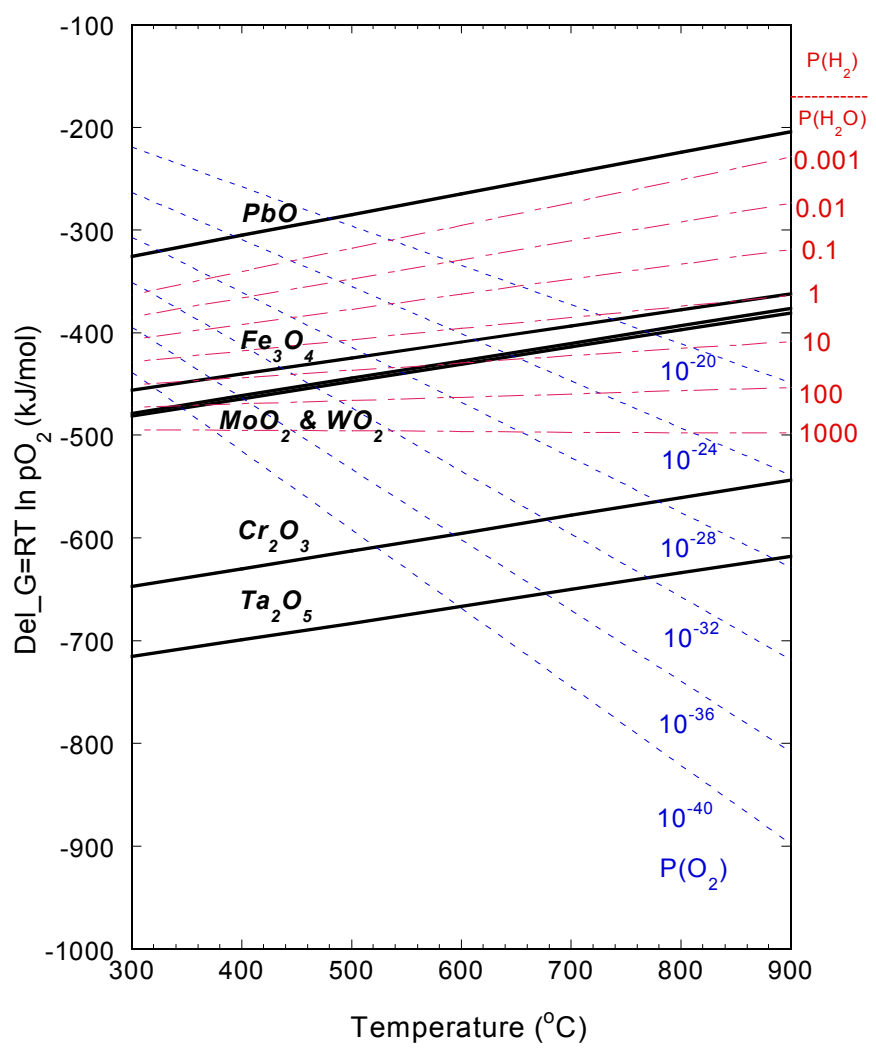

Figure 151. Ellingham diagram of $\mathrm{H}_{2} \mathrm{O}-\mathrm{O}_{2}-\mathrm{H}_{2}$ thermo-dynamic equilibrium.

General sample preparation. The sample was cut into small pieces $\left(\sim 1 \mathrm{~cm}^{2}\right)$ using a lowspeed diamond saw and mounted with epoxy. Grinding was performed using 320 and 600 grit water-cooled silicon carbide papers in accordance with standard metallographic procedures [ASM, 1985]. After grinding, the specimens were rough polished using 6, 3, and $1 \mu \mathrm{m}$ diamond solutions. Final polishing was made with a $0.05 \mu \mathrm{m} \mathrm{Al}_{2} \mathrm{O}_{3}$ suspension.

Scanning Electron Microscopy. Two types of samples were prepared for scanning electron microscope (SEM) analysis: (1) a sample polished to the last step $(0.05 \mu \mathrm{m})$ and, (2) an electrolytically etched sample using nitric acid as described in the optical microscopy section below. Figures 152 (back scatter) and 153 (secondary electron) show the SEM images of the as polished and polished and etched samples. The orientation of the sample is the through-thickness direction. Chemical analysis of various regions of the samples were performed using electron microprobe matrix analysis (EPMA). 


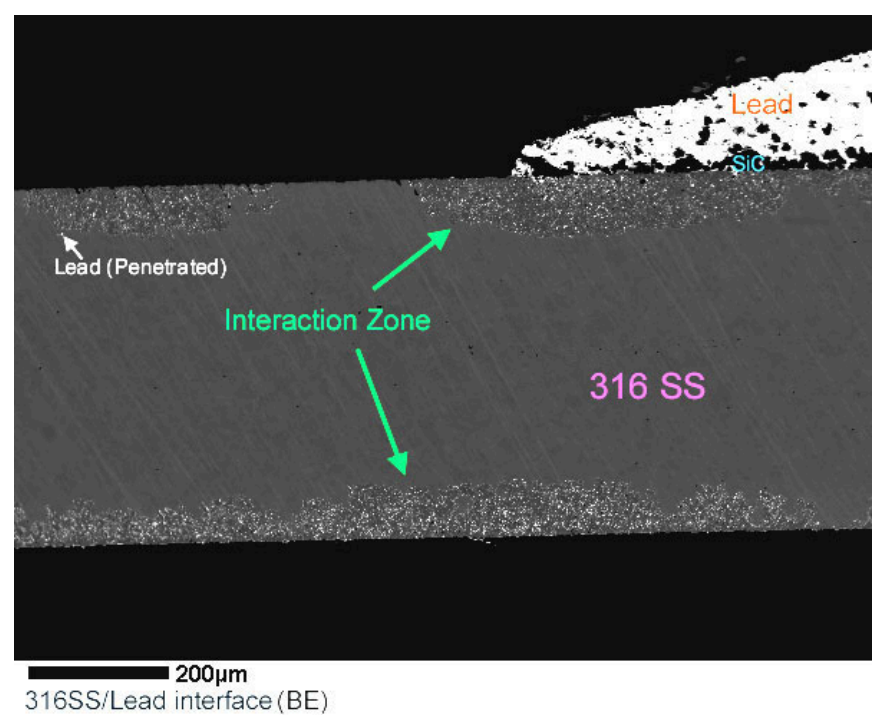

Figure 152. Backscattered electron image of Type 316 stainless steel sample showing the interaction zone.

Figure 153. Secondary electron image for the etched sample of Type 316 stainless steel.

After exposure the sample surface was characterized by: (1) an interaction zone where the lead has penetrated the sample to a depth of approximately $1 / 6$ the total thickness $(0.15 \mathrm{~mm} / 0.51$ $\mathrm{mm}$ ) of the sample. The interaction zone is characterized by grain boundary penetration/dissolution and the selective removal of nickel from the stainless steel composition. In fact, Figure 153, shows that the interaction zone allowed the subsequent removal of material from this zone during the etching process. While the penetration shown in Figures 152 and 153 appears to be irregular, the actual penetration is much more uniform. The appearance of irregularity is an artifact of material being pulled out during the polishing process.

Quantitative analysis. The interaction zone was analyzed using EPMA techniques. The system was calibrated using standard samples of $\mathrm{Pb}, \mathrm{Fe}, \mathrm{Cr}, \mathrm{Ni}$, and Mo. Table 53 shows the results of a typical analysis and Figure 154 shows a typical EPMA spectrum. Several analyses of similar regions yielded similar results. 
Table 53. Analysis results in $\mathrm{wt} \%$ for two points in the interaction zone.

\begin{tabular}{|l|l|l|l|l|}
\hline Point & $\mathrm{Fe}+\mathrm{Mn}+\mathrm{Si}$ & $\mathrm{Ni}$ & $\mathrm{Cr}$ & $\mathrm{Mo}$ \\
\hline $\begin{array}{l}\text { Interaction } \\
\text { Zone }\end{array}$ & $\mathrm{Bal}$ & 0.95 & 15.1 & 1.6 \\
\hline Base Nominal & $\mathrm{Bal}$ & $10-14$ & $16-18$ & $2-3$ \\
\hline
\end{tabular}

The results show a clear selective removal of nickel as has been observed by other investigators. What has not been discussed to any great extent by other investigators is the method by which the lead penetrates the surface. It appears that the lead has penetrated the material along the grain boundaries. A more detailed microstructural analysis of the material is now being performed to further investigate this. However, it may be that the starting material was partially sensitized, or that sensitization occurred during exposure. Sensitization would have resulted in chromium depletion at the grain boundaries with subsequent enrichment by nickel. Selective removal of nickel would then have encouraged grain boundary penetration. A more extensive analysis is now in progress to determine the extent of the lead penetration and interaction.

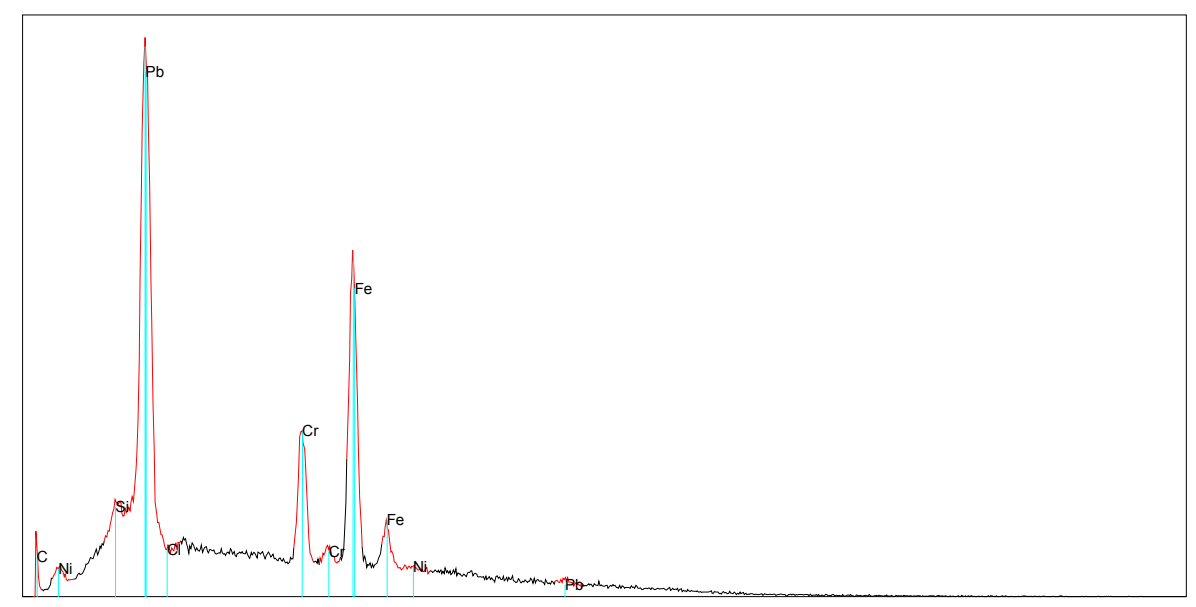

Figure 154. EPMA profile in the interaction zone shown in Figure 152.

Optical microscopy. To further explore the nature of the grain boundary penetration as well as the effect of test on the evolution of the grain boundary, three samples were prepared and compared to each other. Samples in the as received condition, a sample held at $580^{\circ} \mathrm{C}$ for 100 hours without exposure to lead (actually in air), and the sample tested in lead. Samples were electrolytically etched using $\mathrm{HNO}_{3} / \mathrm{H}_{2} \mathrm{O}$ for $15 \mathrm{sec}$ above $0.5 \mathrm{~A}$ [Vander Voort, 1986]. The preliminary results of this analysis are shown in Figures 155 through 158. Figures 155 through 157 show that the high temperature exposure $\left(580^{\circ} \mathrm{C} / 100 \mathrm{hr}\right)$ does not change the grain size, as would be expected for exposures below the re-crystallization temperature. Figures 155 through 157 show micrographs of the sample disk surface. Figure 158 shows the through-thickness orientation and shows a region where material has been removed by the exposure. While more detailed analysis is necessary, it appears that the material removal process is a combination of both inter-granular penetration as well as matrix removal. As Figure 158 shows, the interaction "front" is inter-granular in some regions but now all. Some evidence of matrix dissolution is also present. Further analysis is in progress. This analysis will include a determination of the degree of sensitization which may have resulted during the sample exposure. 


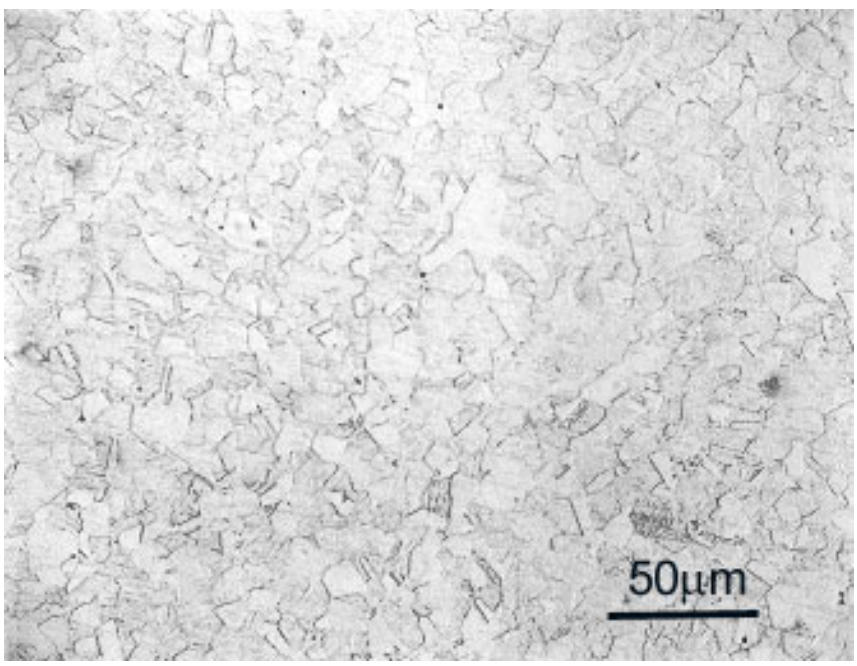

Figure 155. Optical microscopy of as received sample of Type 316 stainless steel.

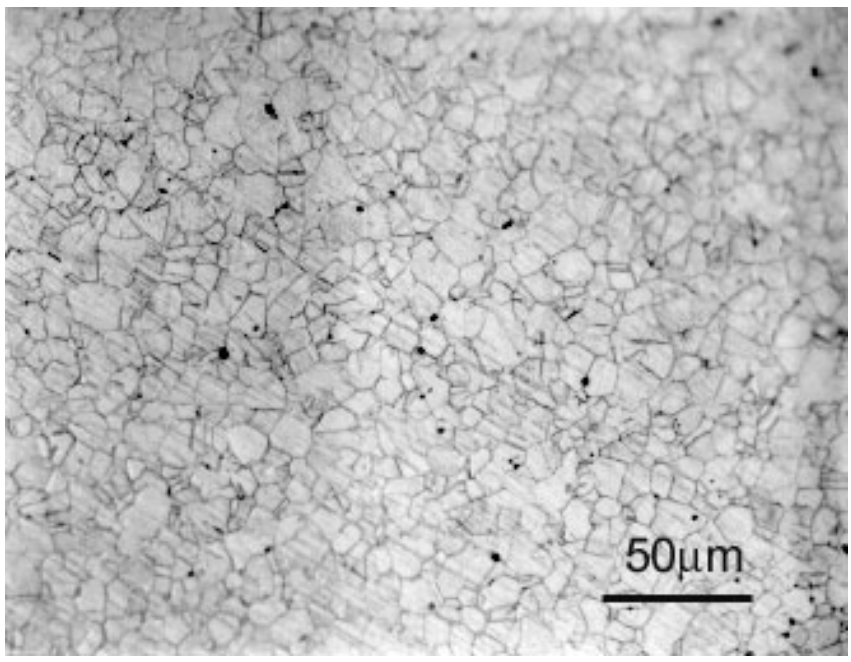

Figure 156. Optical micrograph of heat-treated Type 316 stainless steel sample at $580^{\circ} \mathrm{C}$ in air for $100 \mathrm{hr}$.

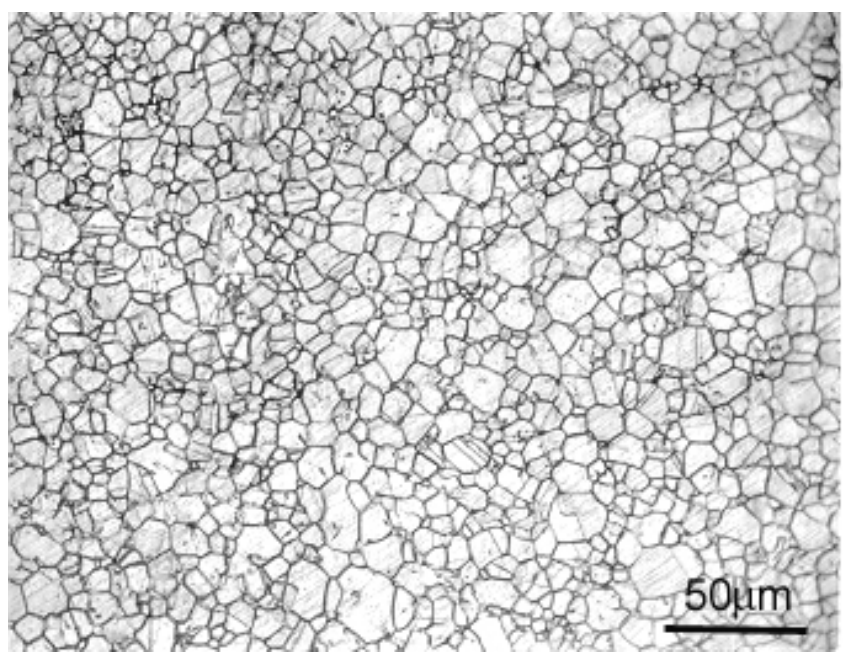

Figure 157. Optical micrograph of tested 316 stainless steel sample in lead at $580^{\circ} \mathrm{C}$ for 100 hr. 


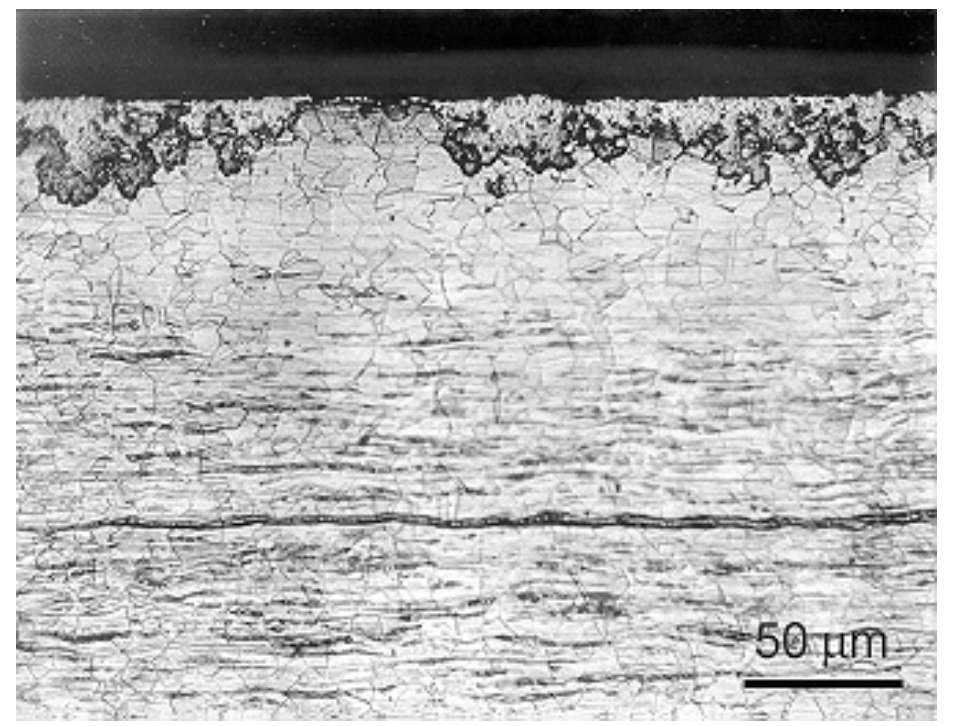

Figure 158. Cross-sectional view (same as figure 154) for the Type 316 stainless steel sample tested in the lead at $580^{\circ} \mathrm{C}$ for $100 \mathrm{hr}$.

Mechanical Properties. Specimens exposed to lead were found during sectioning to be noticeably embrittled, and therefore easier to cut. This is an indication that lead may have penetrated further into the material than the gross analysis conducted thus far would indicate. Tensile tests are planned for the near future to further explore this possibility. Test specimens for a thin sheet (0.02 inch) are being prepared in accordance with ASTM standard E8 [ASTM, 1992]. Specimens will be taken from the rolling direction. Figure 159 shows the rolling direction of specimen and the design for the tensile test.
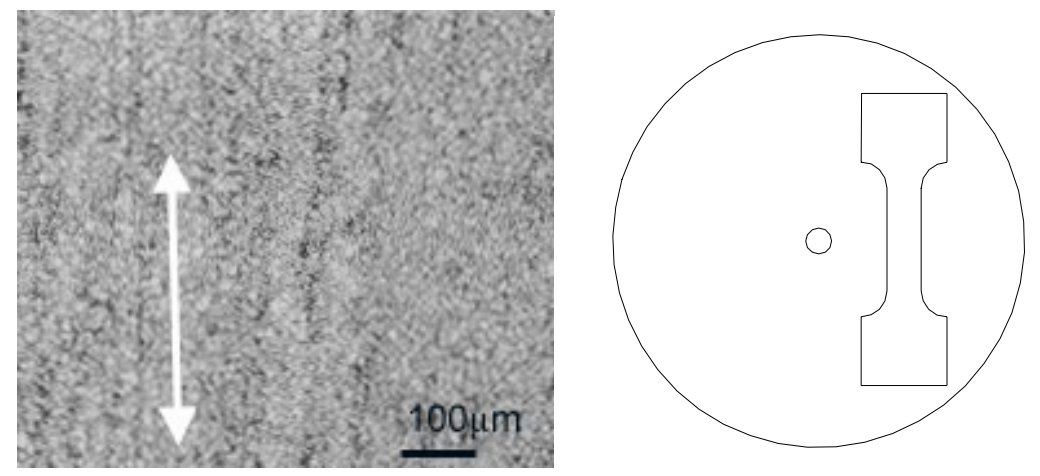

Figure 159. (a) Rolling direction of the disk sample (b) Tensile test specimen.

\subsubsection{Second Rotating Electrode Test Facility}

The second rotating electrode facility has been completed and is undergoing initial startup. It is anticipated that testing with this facility will begin within two weeks. 


\subsubsection{Sensor Development and Calibration}

Oxygen sensors based on the $\mathrm{Bi}-\mathrm{BiO}_{2}$ system have been developed for the program. Calibration of these sensors was planned for this year. However, difficulties in the achievement of a known intermediate oxygen potential (between the $\mathrm{PbO}$ and $\mathrm{Cr}_{2} \mathrm{O}_{3}$ potentials) has hampered this task. As has been discussed above, this problem has been addressed, in part, and will be fully addressed in the near future. As soon as this is completed the calibration process will be completed. Additionally, we are working with Los Alamos National Laboratory as part of the calibration process. We anticipate that "commercially" available electrodes will be available to us-fabricated by the Los Alamos facility and calibrated at MIT-in the near future.

\subsubsection{Alloy Development}

New materials and/or film control schemes will need to be developed for operation at temperatures above $550^{\circ} \mathrm{C}$. Figure 160 illustrates the relationship between temperature and reaction rates. As the temperature is increased the stability of the oxide film decreases and the dissolution rates increase for a given alloy composition. An extension of then operating temperature range will thus require either a material with reduced solubility or a material with a more stable film. More than likely, at least for the 550-650 temperature range, both methods will be employed. In this task we are focused on an expansion of the stable film regime.

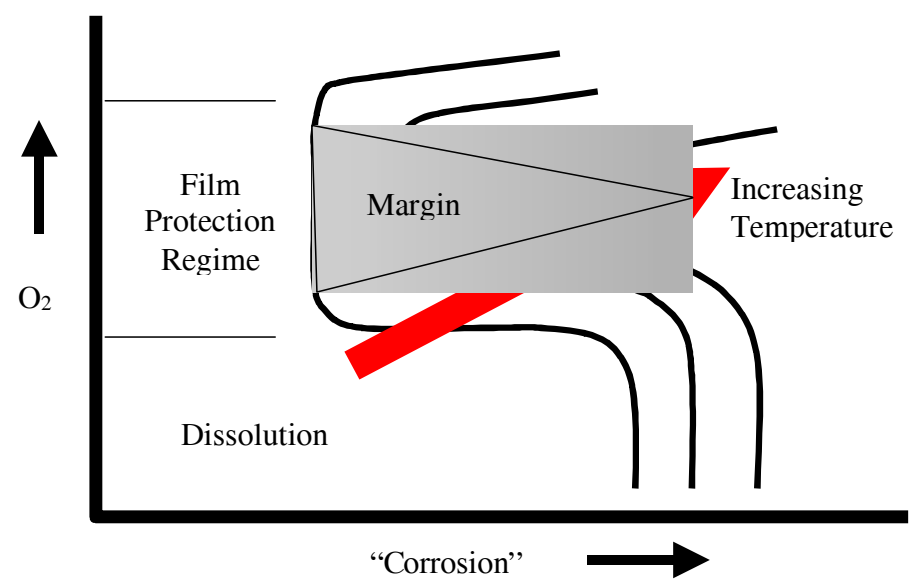

Figure 160. Schematic of the effect of temperature on corrosion of material exposed to heavy metal coolants

The Russian experience for lead and $\mathrm{Pb}-\mathrm{Bi}$ systems has resulted in the development of alloy EP-823. EP-823 has a somewhat similar chemistry to the US steel labeled HT-9 and contains relatively high levels of silicon. As a part of the EP-823 development process, the central role of the silicon was identified. Silicon is thought to promote the formation of a stable oxide film on the surface which prevents dissolution. However, the role of silicon has not been clearly quantified due to potential influences of other elements in the composition.

In this task we are seeking to understand the fundamental role of silicon in the film formation process on $\mathrm{Fe}$. To this end, three high purity $\mathrm{Fe}-\mathrm{Si}$ alloys have been procured with silicon contents ranging from zero to $3.82 \%$. Tests will be conducted as a function of temperature and oxygen potential to explore the roll of increasing silicon on film formation. The Fe-Si alloys have been received and are now being characterized prior to testing. 


\subsection{Results of the INEEL Materials Studies (Dr. Eric Loewen and Philip MacDonald)}

In collaboration with the Massachusetts Institute of Technology, the INEEL is investigating the corrosion characteristics of typical structural metals. This section reports the results of the FY-01 corrosion experiments. Section 5.5.1 presents information on our experimental apparatus. Section 5.2.2 presents the scanning electron microscope (SEM) results. Issues associated with the temperature control of the test rig and uses of our mass spectrometer are discussed in Sections 5.2.3 and 5.2.4.

Experiments conducted in the U. S. during the 1950s determined that the corrosion rate of reactor structural steels by molten lead-bismuth or other lead-alloys depends mainly on the solubility of the structural material immersed in the liquid metal, which is a strong function of temperature. The dissolution process can be affected by diffusion barriers, primarily metal oxides or other adsorbed/absorbed species. Mass transfer occurs in these systems due to solubility concentration gradients due to thermal gradients in the system.

The overall purpose of the current program is to explore the effect of oxygen potential on the corrosion behavior of selected structural materials and to make use of this understanding to suggest the composition of more resistant advanced alloys. However, the purpose of the initial research was to examine material compatibility issues for candidate alloys under various relatively extreme oxidizing and reducing conditions and to verify some of the earlier work in the field. In parallel to the corrosion studies, a program to develop accurate oxygen potential measurement probes was undertaken in order to allow for future testing at intermediate oxygen potentials. When such a probe is developed, we will run additional experiments at other oxygen potentials. The initial experiments were run with lead shot that was readily available. However, it was later discovered that the lead shot used in the initial experiments was alloyed with significant amounts of arsenic and antimony. This problem was corrected and the program continued. Never the less, we believe that the experiments with high levels of arsenic and antimony provide some useful information about what might happen when significant levels of aggressive contaminants are present in a liquid metal cooled reactor and we have, therefore, included those results in this report. Subsequent experiments were run with relatively pure lead. However, the mass spectrometer indicated the presence of small amounts of carbon during some of the experiments.

Table 54 presents an overview of the experiments performed to date and the key variables in each of those experiments. For experiments at high oxygen potentials, oxygen was injected at a level of $10 \mathrm{ppm}$ in the Argon carrier gas. In the reducing experiments hydrogen was injected. To better understand the experimental conditions listed in Table 54, see Figure 161, which shows the standard free energy of formation of oxides as a function of temperature. The free energy of formation was calculated using HSC Chemistry normalized for one gram atom of $\mathrm{O}_{2}$. An "Oxygen control band" is identified in Figure 161, which characterizes the potential region between the $\mathrm{PbO}$ formation potential and the chromium oxide formation potential. This region would be suitable for operation of Fe-based systems containing chromium (stainless steels) while, at the same time minimizing the formation of $\mathrm{PbO}$ based "sludge" in the system. The formation of lead oxide is less favorable than the formation of chromium and iron oxides. During the oxidizing experiments, the excess $\mathrm{O}_{2}$ in the system produced $\mathrm{PbO}$, as expected from Figure 161 . Therefore, the calculated oxygen potential was approximately $10^{-27}$ atm (Runs 3, 7X, and 7Y). Because the $\mathrm{O}_{2}$ injection was constant, a fine powder of $\mathrm{PbO}$ was produced, except in cases where carbon was present, which was subsequently removed from the cell. Gas injection 
conditions were maintained throughout the experiment. At the conclusion of each experiment the lead was drained from the cell and the metallic coupons removed for analysis.

As mentioned above, reducing conditions were established by hydrogen injection. Verification of reducing conditions was assured by continuous monitoring with a mass spectrometer. Based on Figure 161 and the results of the mass spectrometer, the oxygen potential was between $10^{-27}$ and $10^{-40}$ atm.

Table 54. Overview of INEEL lead corrosion experiment runs.

\begin{tabular}{|c|c|c|c|c|c|c|}
\hline $\begin{array}{l}\text { Run } \\
\text { No. }\end{array}$ & $\mathbf{P O}_{2}$ & $\begin{array}{l}\text { Temp } \\
\left({ }^{\circ} \mathrm{C}\right)\end{array}$ & $\begin{array}{l}\text { Time } \\
\text { (hr) }\end{array}$ & Melt & Metal Samples & Comments \\
\hline $1^{\mathrm{a}}$ & Oxidation & 600 & 3 & $\begin{array}{l}\mathrm{Pb}, \mathrm{As}, \\
\mathrm{Sb}^{\mathrm{a}}\end{array}$ & $316,410, \mathrm{~F}-22, \mathrm{Zr}$ & $\begin{array}{l}\text { Initial run to validate safety } \\
\text { systems and overall } \\
\text { operability. }\end{array}$ \\
\hline 2 & Oxidation & 650 & 7 & $\begin{array}{l}\mathrm{Pb}, \mathrm{As}, \\
\mathrm{Sb}^{\mathrm{a}}\end{array}$ & $316,410, \mathrm{~F}-22, \mathrm{Zr}$ & $\begin{array}{l}\text { Two-day run to validate re- } \\
\text { melting lead after freezing. }\end{array}$ \\
\hline 3 & Oxidation & 500 & 100 & $\begin{array}{l}\mathrm{Pb}, \mathrm{As}, \\
\mathrm{Sb}^{\mathrm{a}}\end{array}$ & $316,410, \mathrm{~F}-22, \mathrm{Zr}$ & $\begin{array}{l}\text { First long-duration run, used } \\
\text { industrial gasses to establish } \\
\text { oxidation conditions. }\end{array}$ \\
\hline 5 & Reducing & 500 & 100 & $\begin{array}{l}\mathrm{Pb}, \mathrm{As}, \\
\mathrm{Sb}^{\mathrm{a}}\end{array}$ & $316,410, \mathrm{~F}-22, \mathrm{Zr}$ & $\begin{array}{l}\text { Used new mass spectrometer } \\
\text { to establish reducing } \\
\text { conditions with } \mathrm{H}_{2} \text { injection. }\end{array}$ \\
\hline 7 & Reducing & 500 & 100 & $\mathrm{~Pb}^{\mathrm{b}}$ & $316,410, \mathrm{~F}-22, \mathrm{Zr}, \mathrm{HT} 9$ & $\begin{array}{l}\text { Replicate of Experiment 5, } \\
\text { with pure lead, but some } \\
\text { carbon in the melt. }\end{array}$ \\
\hline $7 \mathrm{X}$ & Oxidation & 500 & 100 & $\mathrm{~Pb}^{\mathrm{b}}$ & 316, 410,F-22, Zr, HT9 & $\begin{array}{l}\text { Replicate of Experiment } 3 \text {, } \\
\text { with pure lead, but some } \\
\text { carbon in the melt. }\end{array}$ \\
\hline $7 \mathrm{Y}$ & Oxidation & 500 & 100 & $\mathrm{~Pb}^{\mathrm{b}}$ & $316,410, F-22$, Zr, HT9 & Replicate of Experiment 7. \\
\hline
\end{tabular}

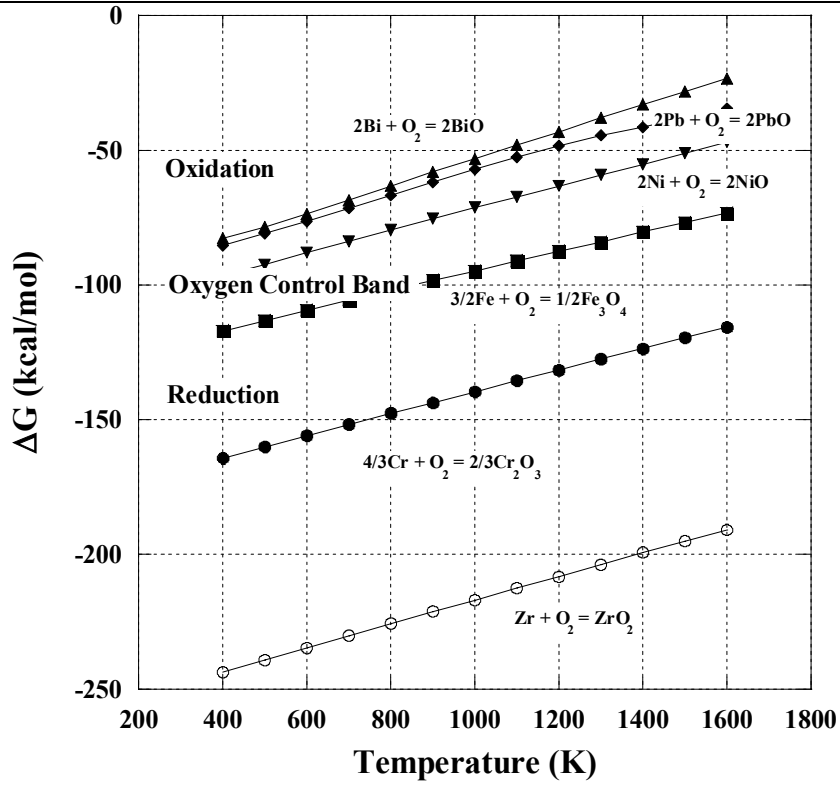

Figure 161. Ellingham diagram of typical metal oxidation reactions. 


\subsubsection{Apparatus}

The metallic specimens were supplied by Metal Samples, Inc in the form of $3.175 \mathrm{~cm}$ diameter disks $0.318 \mathrm{~cm}$ thick. The specimens were polished to a $0.3 \mu \mathrm{m}$ finish and then were weighed. The nominal chemical composition of each coupon is listed in Table 55, along with Energy Dispersive X-ray analysis (EDX) results performed at INEEL. It should be noted that the EDX results do not exactly match the alloy compositions specified by Metal Samples, Inc. This may have been due to the smaller area analyzed in the EDX analysis as compared to bulk analysis performed by the vendor. However, the EDX results are in generally good agreement with the material specifications and, therefore, should be approximately correct for post-test analysis. The coupons, separated by $1 / 4$-inch aluminum spacers, were placed on the gas injection lance and inserted into the INEEL dynamic corrosion cell shown in Figure 162.

The INEEL corrosion test facility achieves "loop-type" behavior by inducing flow in a riser/down-comer

arrangement. Flow is induced in the riser by gas injection with a lance. A resistance furnace, controlled by Type-K thermocouples, is used to heat the experimental apparatus. Process gas is supplied from standard high-pressure gas bottles.

Inside the corrosion cell (Figure 162) is an open-ended pipe (shroud) that separates the cell into three regions: a riser located inside the shroud, a down-comer located between the shroud and the vessel wall, and an upper plenum region located above the top of the shroud. The injected inert gas flows up through the riser, reducing the

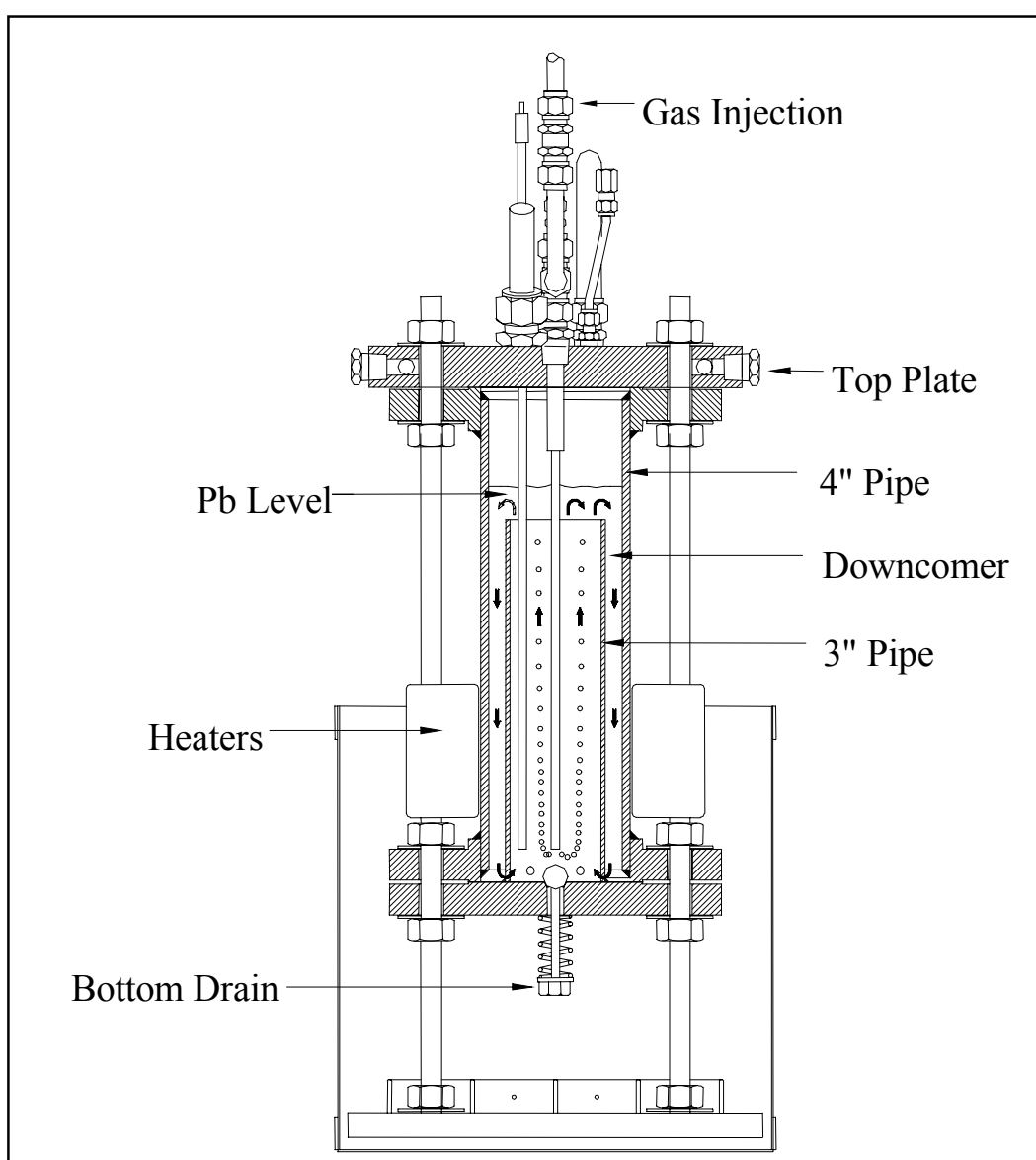

Figure 162. Gas lift corrosion cell cross section.

hydrostatic head in the riser. This causes the liquid lead to flow up through the riser, down the down-comer, and back into the riser through a gap at the bottom of the shroud. The inert gas is separated from the molten lead in the upper plenum region and removed through the top of the vessel. Injecting a reductive or oxidative gas, which makes up a small part of the inert gas injected into the corrosion cell, can control the oxidation potential in the corrosion cell. The bulk of gas flow is inert argon, used to control the velocity of fluid in the down-comer. 


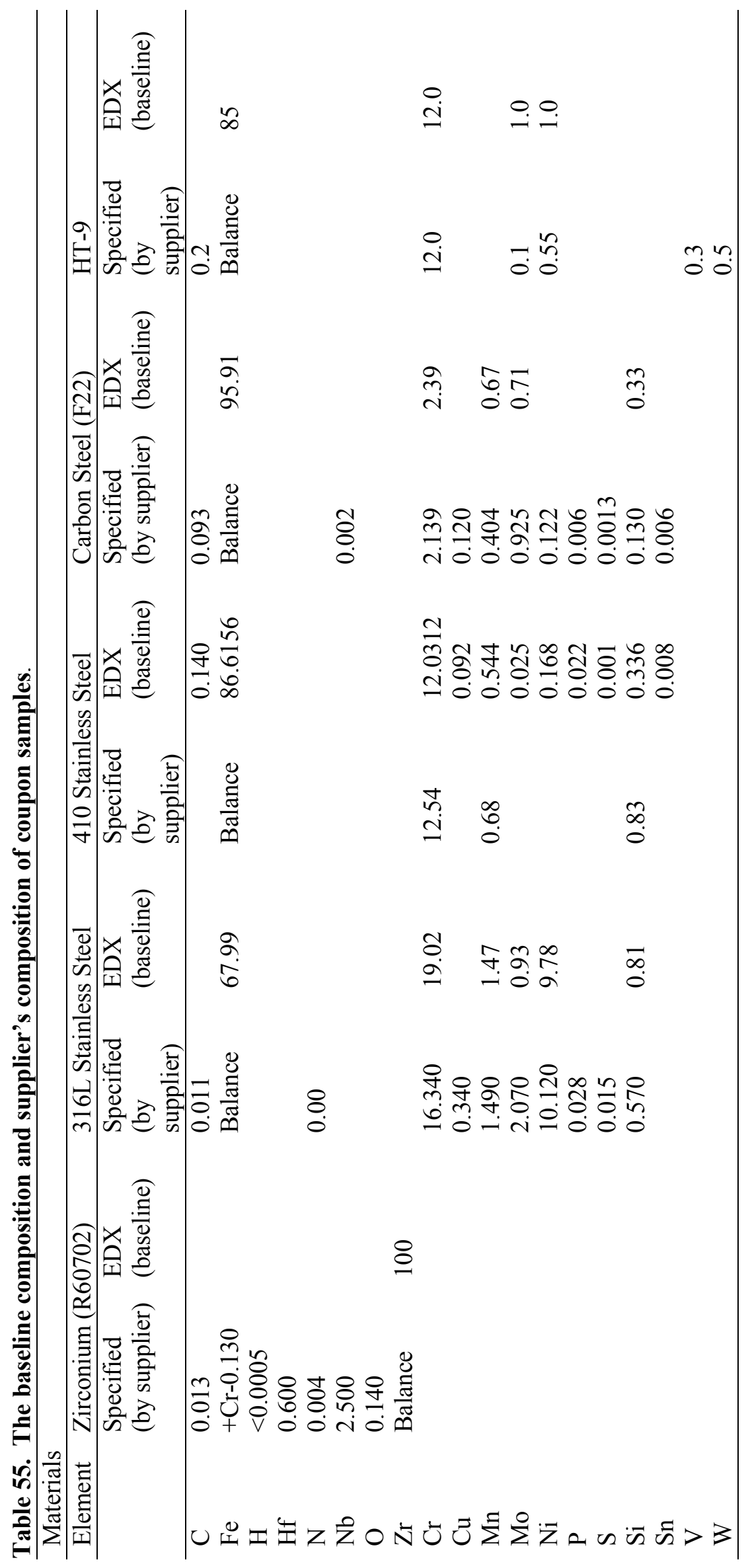




\subsubsection{SEM Results}

After the experiments, the coupons were cross-sectioned and mechanically polished inward from the cross section surface. Detailed corrosion and interaction morphologies were obtained by using a scanning electron microscope (SEM), (Philips XL, with a 20-keV electron beam). Energy Dispersive X-ray (EDX) analysis (EDAX Phoenix) was used to analyze the chemical composition of the interaction layers. To avoid uncertainties in the analysis of the lead and arsenic due to peak overlap, the L-line was used for arsenic, the M-line for lead. This likely introduced additional uncertainty in the accuracy of the chemical analysis but was unavoidable. This technique offered a compositional analysis of each layer, and a measure of any penetration into the base metal.

\subsubsection{Zirconium Coupons}

Figure 163 shows the top surfaces of an as-received zirconium coupon (upper left) and coupons polished and then tested in Experiments 5, 7, and 7X. The zirconium coupons could be polished only to a finish of $1.0 \mu \mathrm{m}$ due to the softness of the surface. After the corrosion tests, the excess lead was removed from the surfaces by rapidly heating the coupons on a hot plate to $400^{\circ} \mathrm{C}$, then wiping the surface with a soldering sponge. This technique easily removed most of the surface lead. Other techniques tried, such as placing the corrosion coupons into hot mineral oil or hot sand, failed to remove most of the lead that adhered to the coupon's surface. The right and lower micrographs in Figure 163 show the surfaces of the zirconium coupons exposed to the experimental conditions in Tests 5, 7, and 7X, respectively. Also listed are the compositions of any unusual features. The results show that the lead did not adhere well to the coupon surfaces.

Figure 164 presents five SEM micrographs of the cross sections of the zirconium coupons tested under each of the experimental condition listed in Table 54. The SEM micrographs show back-scatter images with magnifications ranging from 250 to 1000 times. The SEM images are labeled, providing information on the composition of each unique area. These results show that the zirconium alloy retains an oxide scale over the complete range of the oxygen control band (i.e. under both oxidizing and highly reducing conditions). It is likely that the oxide films that we see on these SEM photographs were there from the beginning. It will be essentially impossible to reduce the oxide during the reducing chemistry tests given the small level of oxygen contamination that exists in the hydrogen that we are using, and the fact that the free energy of formation of zirconium oxide is so low, e.g. well below that of chrome oxide. (As is shown in Figure 161, the free energy for the formation of $\mathrm{ZrO}_{2}$ is significantly below the oxides of $\mathrm{Ni}, \mathrm{Cr}$, $\mathrm{Fe}$ and $\mathrm{Pb}$.) The SEM results listed on Figure 164 suggest that the zirconium oxide films were not stoichiometric, but strongly deficient in oxygen. However, these results are probably not accurate because beam broadening in the EDX analysis will cause the volume observed to include metal under the surface oxide layer. The specimens from Tests 7 and $7 \mathrm{Y}$ also have lead on their top surfaces that contains inclusions of silicon and carbon. It is believed that these inclusions are due to the use of $\mathrm{SiC}$ in the final polishing process.

Note that in the tests with significant antimony and arsenic contamination (Experiments 3 and 5) there is no observable attack of the zirconium surface by those materials. The stainless steel specimens discussed below experienced significant attack by the arsenic and antimony under reducing chemistry conditions. 


\section{$\operatorname{Zr}$ (alloy)}

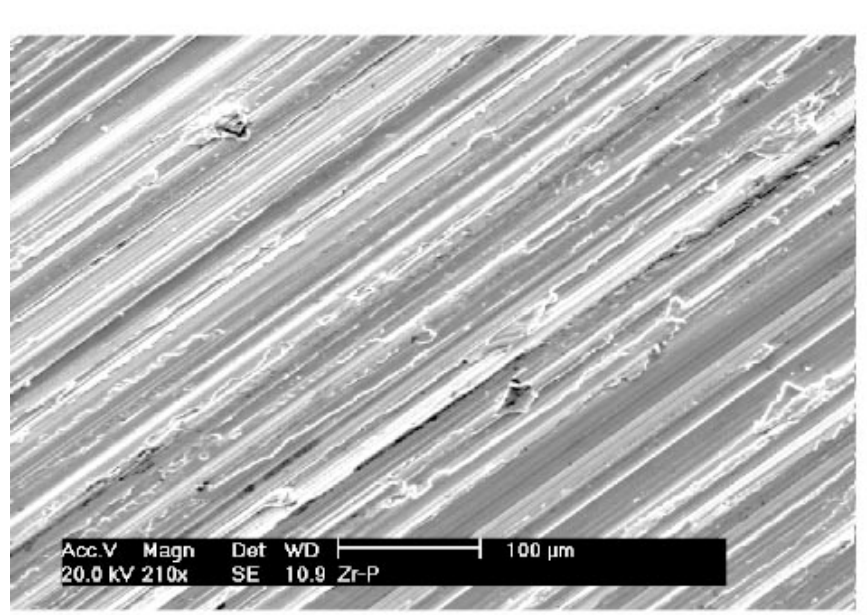

$\mathrm{Zr}$ as received before polishing

\section{Exp 7: Reducing with pure $\mathrm{Pb}$}

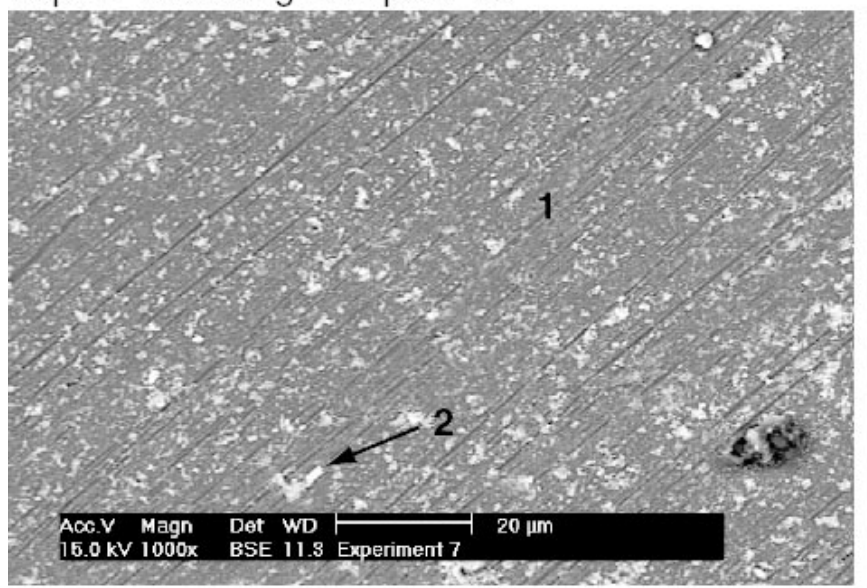

1. $\mathrm{Zr} 60 \%, \mathrm{O}_{2} 23 \%, \mathrm{~Pb} 14 \%, \mathrm{Sb} 3 \%$

2. $\mathrm{Zr} 35 \%, \mathrm{~Pb} 28 \%, \mathrm{O}_{2} 24 \%, \mathrm{Si} 5 \%, \mathrm{Al} 3 \%$,

$\mathrm{Fe} 3 \%$ As $1 \%$, Sb $1 \%$
Exp 5: Reducing with $\mathrm{Sb}$ and $\mathrm{As}$

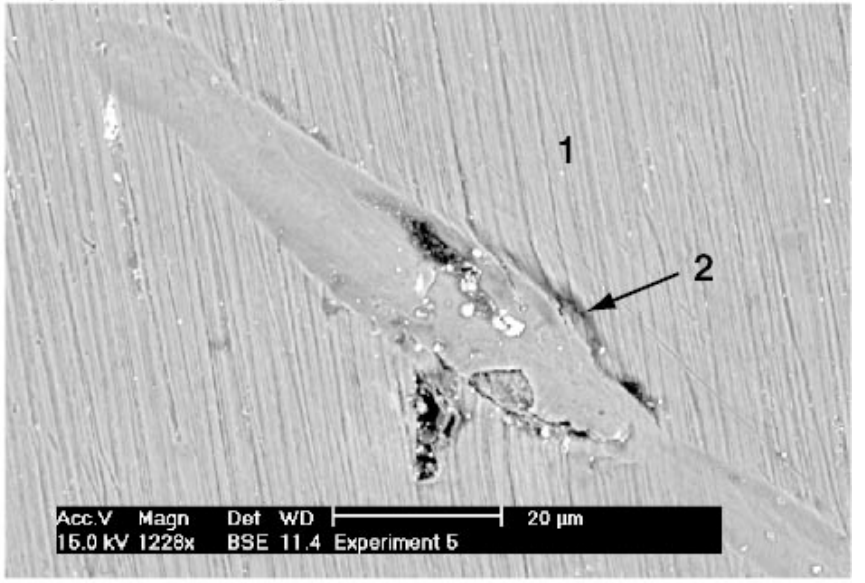

1. Base metal

2. $\mathrm{Pb}$

\section{Exp 7x: Oxidizing with pure $\mathrm{Pb}$}

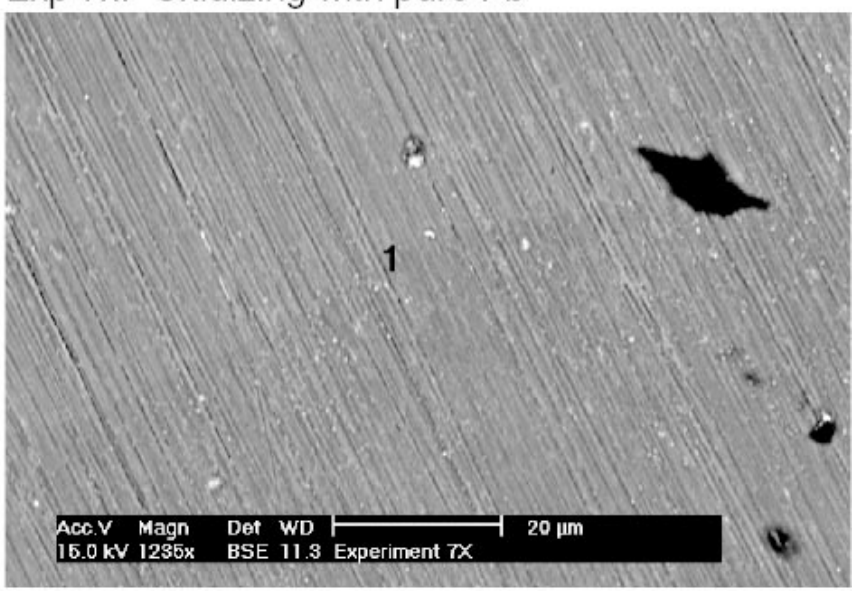

1. Base metal

Figure 163. Top surfaces of the zirconium alloy specimens. The picture on the top left shows the surface of a zirconium alloy specimen before pre-test polishing. The specimens shown on the right and in the lower part of the figure were polished to a $1.0 \mu \mathrm{m}$ finish before the experiments. These surfaces were subsequently cleaned, but not polished after the experiments. 


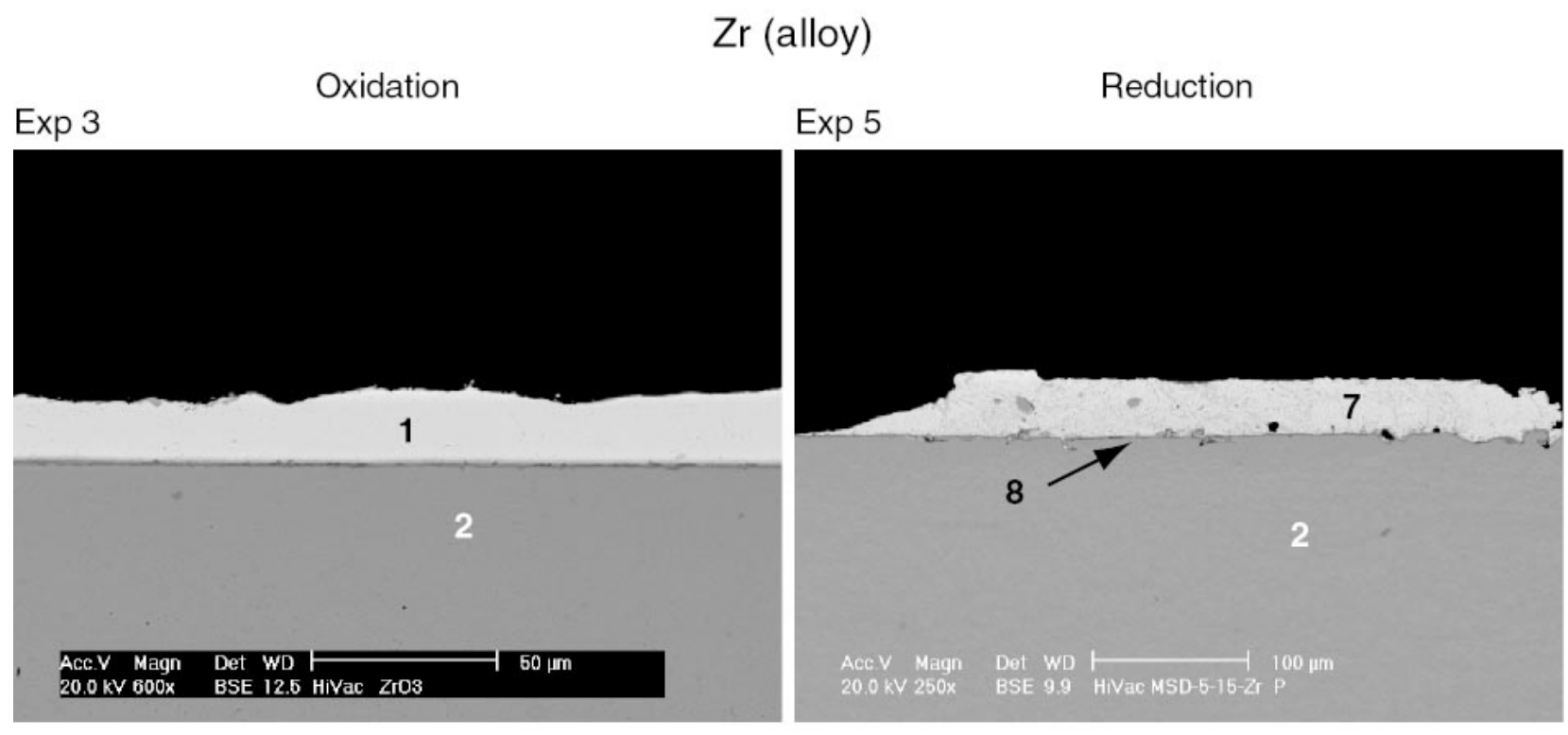

Exp 7x

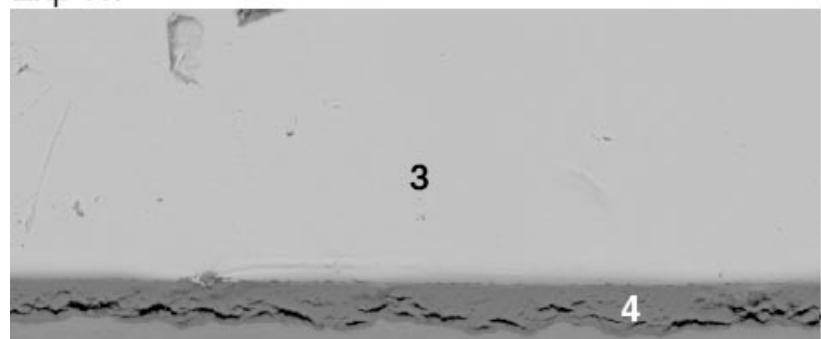

2
Exp 7

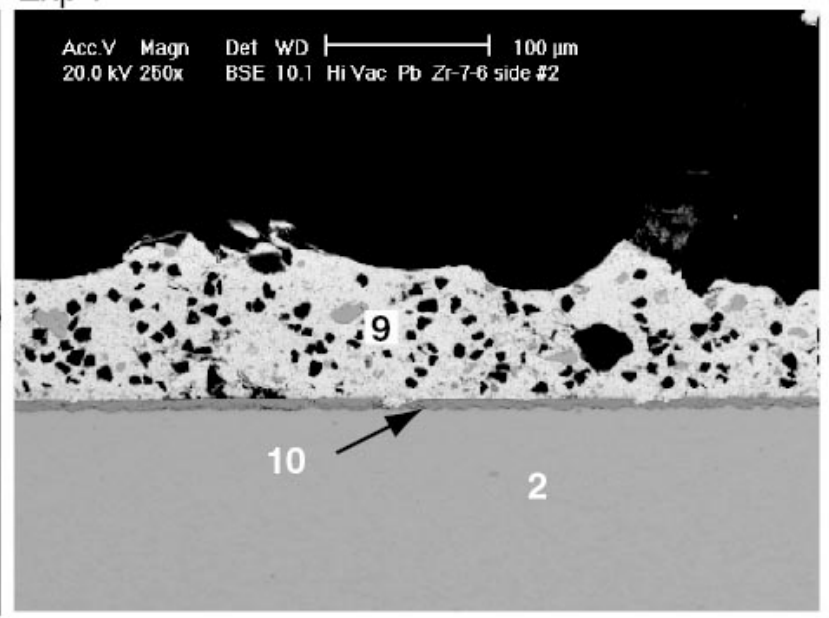

SEM Normalized (wt $\%$ )

1. $\mathrm{Sb} 53 \%, \mathrm{~Pb} 32 \%$, As $15 \%$

2. $\mathrm{Zr} 100 \%$

3. $\mathrm{Pb} 100 \%$

4. $\mathrm{Zr} 89 \%, \mathrm{O}_{2} 11 \%$

5. $\mathrm{Pb} 100 \%$, inclusions of $\mathrm{Si}$ and $\mathrm{C}$

6. $\mathrm{Zr} 87 \%, \mathrm{O}_{2} 13 \%$

7. $\mathrm{Pb} 96 \%, \mathrm{O}_{2} 4 \%$

8. $\mathrm{Zr} 94 \%, \mathrm{O}_{2} 6 \%$

9. $\mathrm{Pb} 100 \%$, inclusions of $\mathrm{Si}$ and $\mathrm{C}$

10. $\mathrm{Zr} 91 \%, \mathrm{O}_{2} 9 \%$

Figure 164. SEM photos of polished cross sections of the zirconium alloy specimens. 


\subsubsection{Type 316 Stainless Steel Coupons}

Figure 165 shows top surface views of the Type 316 stainless steel coupons. The upper left micrograph shows the $0.3 \mu \mathrm{m}$ mirror finish of the samples before testing. The subsequent micrographs show specimen surfaces after exposure to high temperature lead (under the experimental conditions listed in Table 55), after removing most of the lead that had adhered to the surface. Subsurface holes are observed over the entire surface of the coupon exposed to the lead with significant arsenic and antimony contamination in Experiment 5. A suitable explanation for this phenomenon has not yet been identified. These voids seem to appear at the grain boundaries, have irregular shapes, and indicate an inter-metallic-phase interaction with the arsenic and antimony. Note at Location 2 (Experiment 5) that the surface material is a mixture with significant antimony, nickel, iron, and chrome present. This picture indicates an attack of the metallic surface by contaminants under the reducing conditions.

\section{L Stainless Steel}

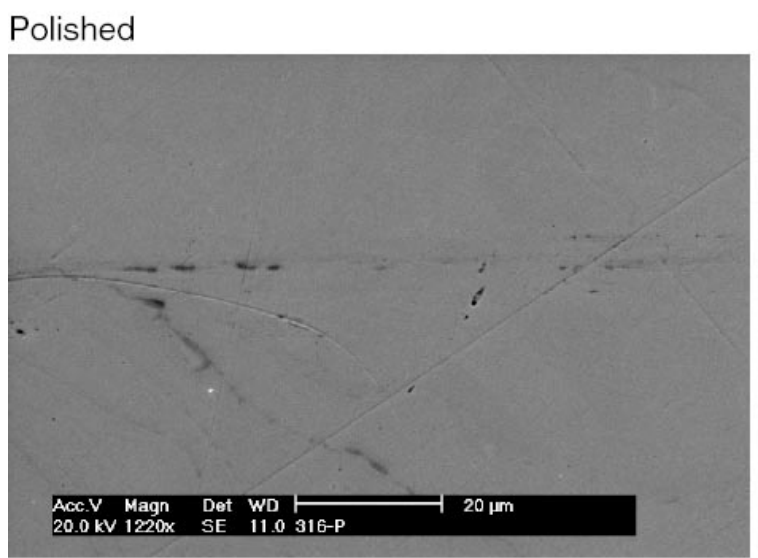

Polished to $0.3 \mu \mathrm{m}$

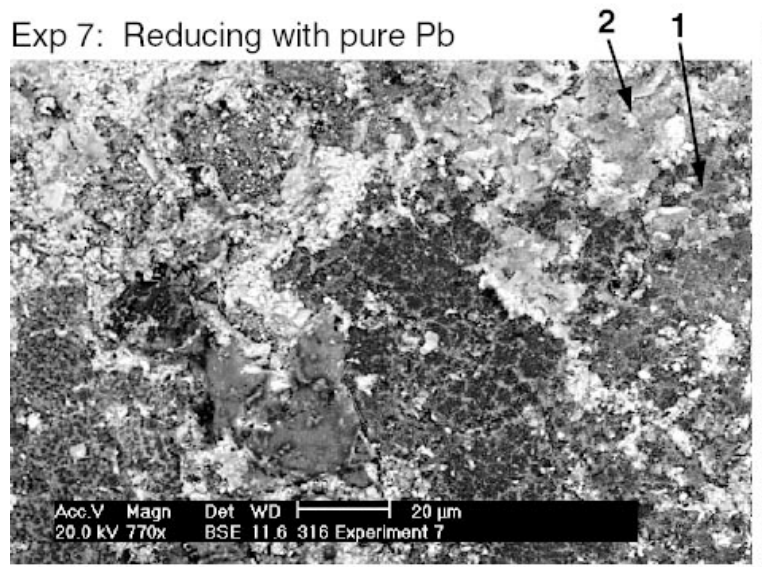

1. Fe $66 \%$, Cr $19 \%$, As $7 \%, \mathrm{Ni} 6 \%, \mathrm{Mn} 2 \%$

2. $\mathrm{Pb} 90 \%, \mathrm{Fe} 6 \%, \mathrm{Cr} 2 \%, \mathrm{Ni} 1 \%, \mathrm{Mn} 0.5 \%$

\section{Exp 5: Reducing with $\mathrm{Sb}$ and $\mathrm{As}$}

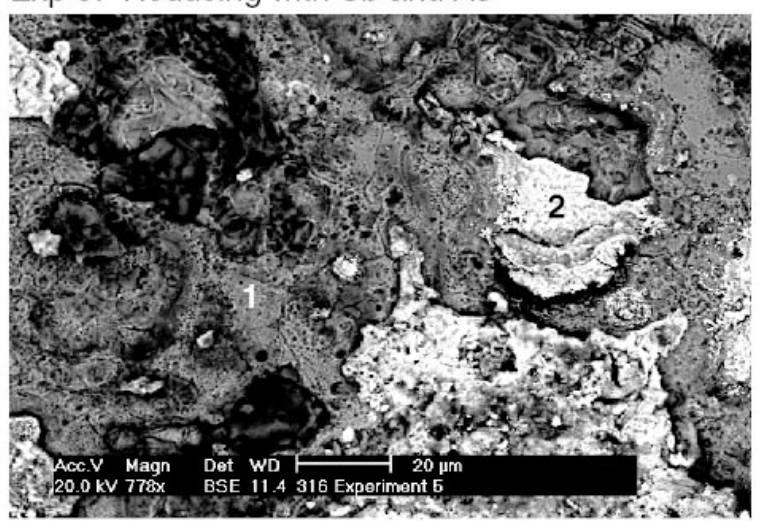

1. $\mathrm{Fe} 70 \%, \mathrm{Cr} 17 \%, \mathrm{Ni} 10 \%, \mathrm{Mn} 2 \%$

2. Sb $51 \%$, Ni $29 \%$, Fe $13 \%$, Cr $5 \%$, As $1 \%$ Mn $1 \%$

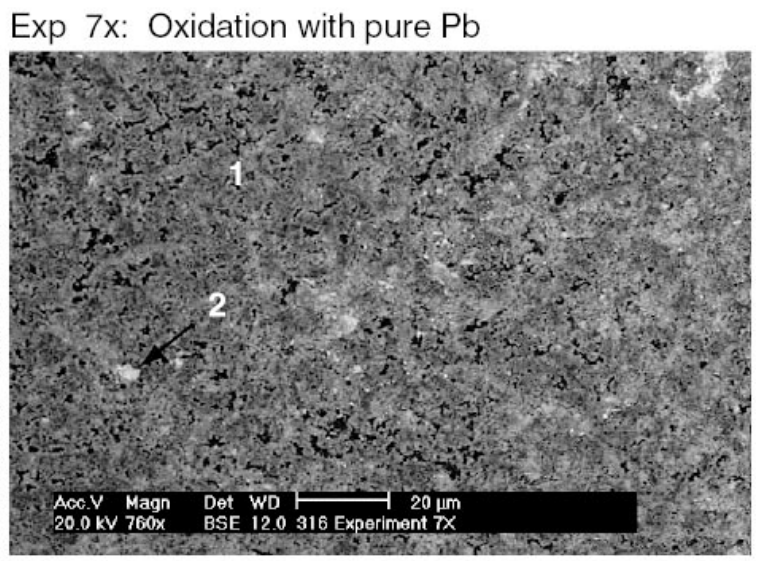

1. Basemetal (porus)

2. $\mathrm{Pb} 94 \%, \mathrm{Fe} 4 \%, \mathrm{Cr} 1 \%, \mathrm{Sb} 1 \%$

Figure 165. Top surfaces of the Type 316L stainless steel specimens. The pre-test surface is shown in the upper left and the surfaces after Experiments 5, 7, and $7 \mathrm{X}$ and after cleaning are shown in the right hand and lower figures. 
Five SEM cross-section micrographs of the Type 316 stainless steel coupons from each of the four experimental conditions are presented in Figure 166. The cross-section from Experiment 5, run under reducing conditions with a significant amount of arsenic and antimony present, shows two relatively large interaction zones with significant levels of arsenic (labeled Layers 6 and 7 on the photograph). These interaction zones are not present when essentially the same test with arsenic and antimony contamination is run under oxidizing conditions. They also do not occur, of course, when the arsenic and antimony are not present in the molten lead (Experiments 7, 7X, and $7 \mathrm{Y})$. When the chemistry is reducing, the arsenic and antimony contamination in the molten lead seem to accelerate solid-state diffusion of arsenic, antimony, and lead into the base metal, while at the same time supporting the diffusion of some of the constituents in the base metal into the liquid lead (most of the nickel is removed from both layers and most of the chrome is gone from Layer 6). It is also possible that these layers are produced by the selected removal of $\mathrm{Ni}$ and replacement by the contaminants. Of all of the elements in stainless steel, $\mathrm{Ni}$ has the highest solubility in liquid lead. Below the two FeAs layers is what appears to be a thin "front" of lead and antimony attacking the base metal. It is probable, but not certain, that the original base metal surface was at the interface of Layers 5 and 6.

Experiment $7 \mathrm{X}$, with highly oxidizing conditions and no arsenic and antimony contamination, resulted in some iron, chrome, and nickel in the lead on the surface of the specimen. Experiment 7, with reducing conditions and no arsenic or antimony contamination, also produced a mixture of iron, lead, chrome and nickel on the surface of the specimen. However, it is not clear whether the base metal constituents in the surface lead from those experiments came from the specimen, adjacent specimens, or the vessel. Figure 166 also shows that for those tests run without contaminants (Experiments 7, 7X, and 7Y), the molten lead/base metal interaction zones are much more extensive than for the zirconium alloy specimens.

\subsubsection{Type 410 Stainless Steel Coupons}

Figure 167 shows the polished and after-experiment SEM micrographs of the top surfaces of the Type 410 stainless steel coupons from Experiments 5 and 7. Consistent with the Type 316 stainless steel results from Experiment 5 discussed above, there was significant attack of the specimen surfaces. What is unusual with the Type 410 stainless steel is that severe attack of the surfaces also occurred during Experiment 3 (oxidation, not shown in Figure 167). As will be shown in the SEM cross sections, the Type 410 stainless steel coupons in Experiment 3 experienced what appears to be severe erosion, which could not be adequately quantified with either the cross sections nor the surface SEM analysis.

SEM micrographs of the polished cross-sections of the Type 410 stainless steel coupons from the five experiments are shown in Figure 168. Exposure of the coupon to lead containing oxygen in Experiment 3 resulted in the polished surface being removed, apparently by severe erosion. This result was not expected, so no markers were available to determine the depth of removal. At the end of the experiment, both the polished and unpolished sides of the coupon looked similar. The cross-section from Experiment 3 also showed a chrome-poor region near the surface of the base metal (not shown in Figure 168) and contained a surface layer primarily of FeAs, with small amounts of tin, nickel, chrome, and lead. Under the conditions of Experiment 5 (reducing chemistry with arsenic and antimony contaminants), two FeAs layers were formed, similar to the layers formed on the Type 316 stainless steel specimen. Last, the Experiment 7 conditions resulted in relatively little interaction between the specimen and the molten lead. 


\section{L Stainless Steel}

Oxidation

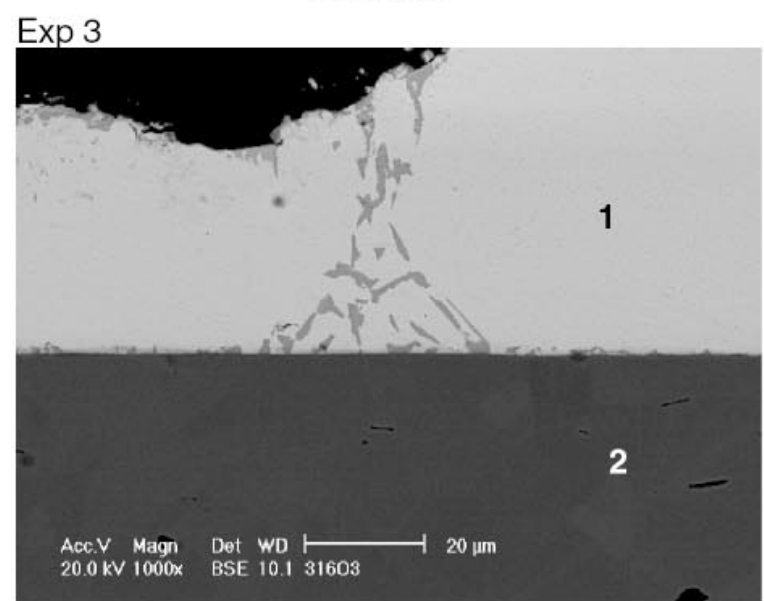

\section{$\operatorname{Exp} 7 x$}

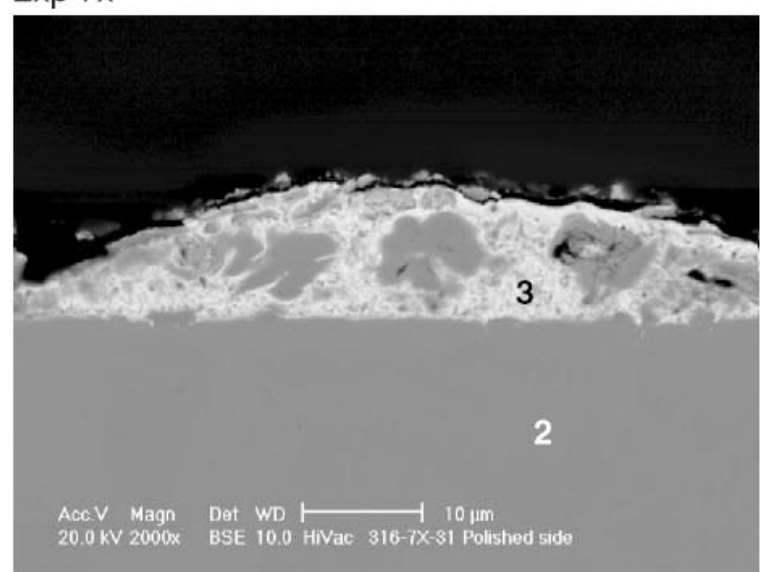

\section{Exp 7y}

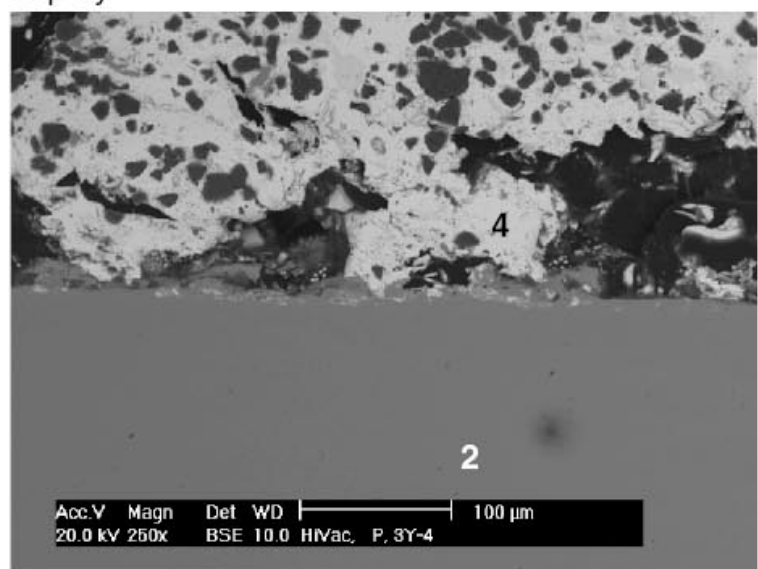

Reduction

\section{Exp 5}

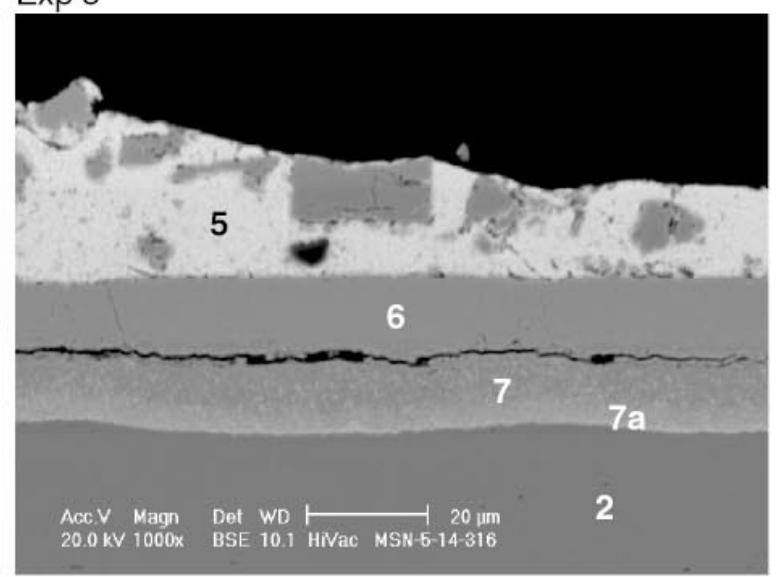

Exp 7

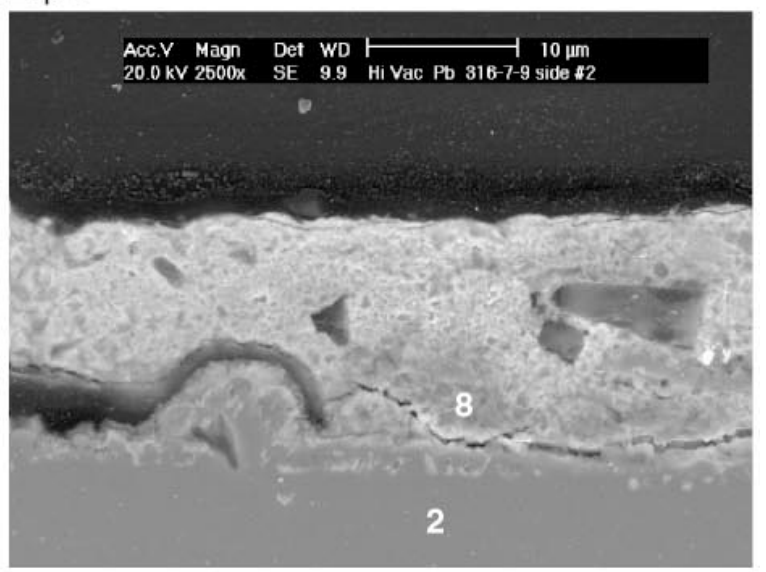

SEM Normalized (wt $\%$ )

1. $\mathrm{Pb} 97 \%, \mathrm{Sb} 2 \%, \mathrm{Fe} 1 \%$

2. Fe $70 \%$, Cr $17 \%$, Ni $12 \%$, Mo $1 \%$, Si $0.2 \%$

3. $\mathrm{Pb} 68 \%, \mathrm{Fe} 29 \%$, Cr $2 \%$, Ni $1 \%$

4. $\mathrm{Pb} 100 \%$ with $\mathrm{C}$ and $\mathrm{Si}$ inclusions from polishing

5. $\mathrm{Pb} 90 \%, \mathrm{Sb} 5 \%$, As $5 \%$ with inclusions from layer 6

6. As $51 \%, \mathrm{Fe} 44 \%, \mathrm{Ni} 3 \%, \mathrm{Cr} 1 \%$, $\mathrm{Sb} 1 \%, \mathrm{Mn} 0.5 \%$

7. $\mathrm{Fe} 37 \%$, As $30 \%$, Cr $20 \%, \mathrm{~Pb} 10 \%$, Ni $3 \%$

7a. Sb $40 \%$, Fe $20 \%$, Ni 10\%, As $11 \%$ $\mathrm{Cr} 9 \%, \mathrm{~Pb} 9 \%, \mathrm{Mn} 1 \%$

8. Fe $55 \%, \mathrm{~Pb} 36 \%, \mathrm{Cr} 5 \%, \mathrm{Ni} 4 \%$

Figure 166. SEM photos of polished cross sections of the Type 316 stainless steel specimens. 


\section{Stainless Steel}

Polished surface

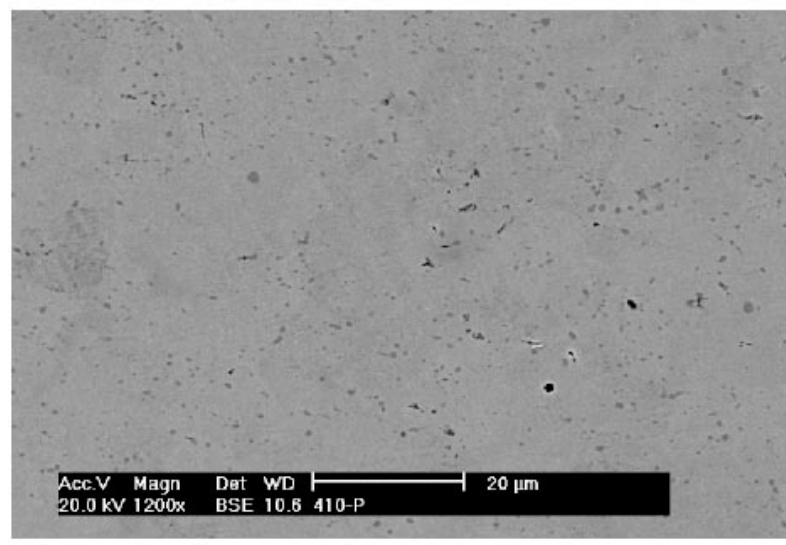

$0.3 \mu \mathrm{m}$ finish

Exp 5: Reducing with $\mathrm{As}$ and $\mathrm{Sb}$

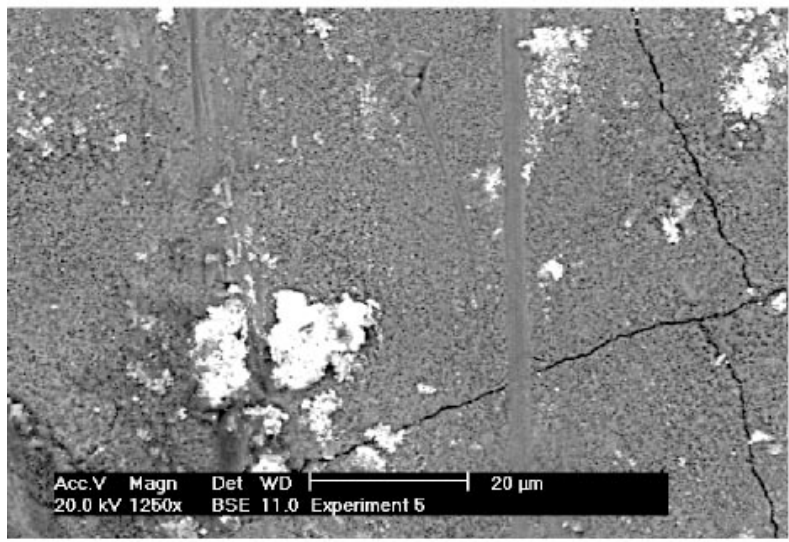

Exp 7: Reducing with pure $\mathrm{Pb}$

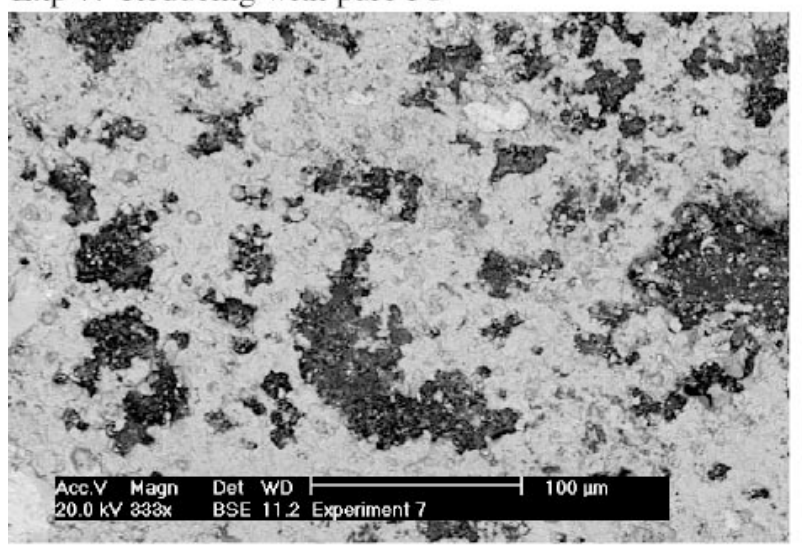

Exp 5: Reducing with As and $\mathrm{Sb}$

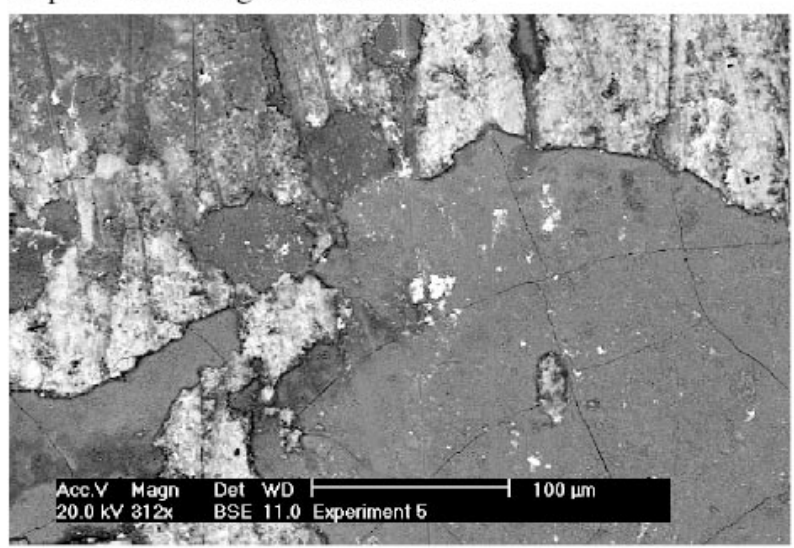

Exp 7: Reducing with pure $\mathrm{Pb}$

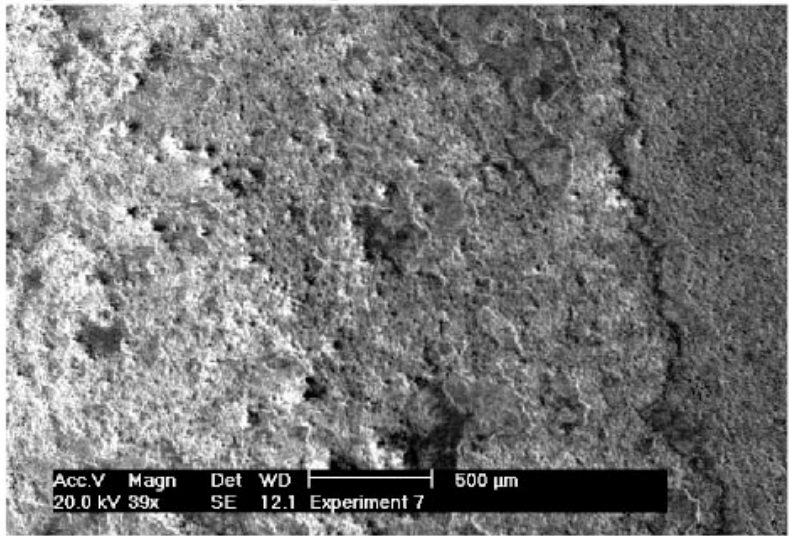

Exp 7: Reducing with pure $\mathrm{Pb}$

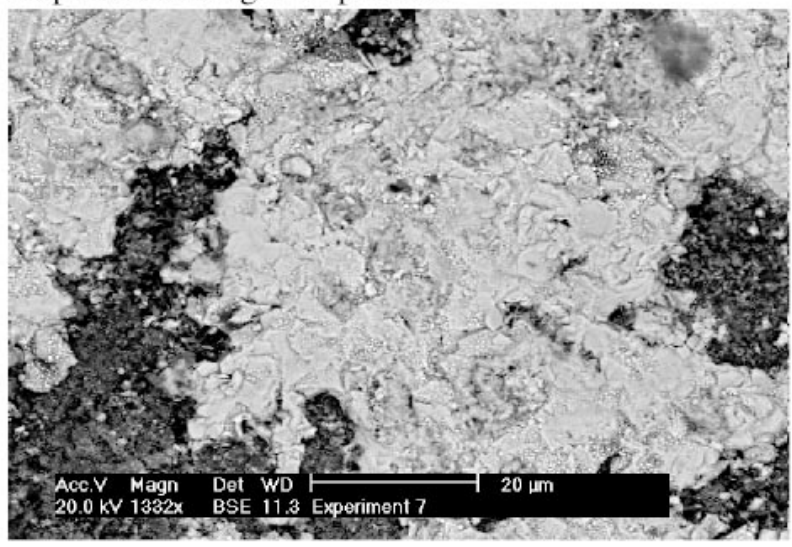

01-GA50949-07

Figure 167. Top surfaces of the Type 410 stainless steel specimens. The picture on the top left shows the surface before testing, the remaining photographs show the surfaces after Experiments 5 and 7 and after cleaning. 


\section{Stainless}

Oxidation

Exp 3: With As and Sb

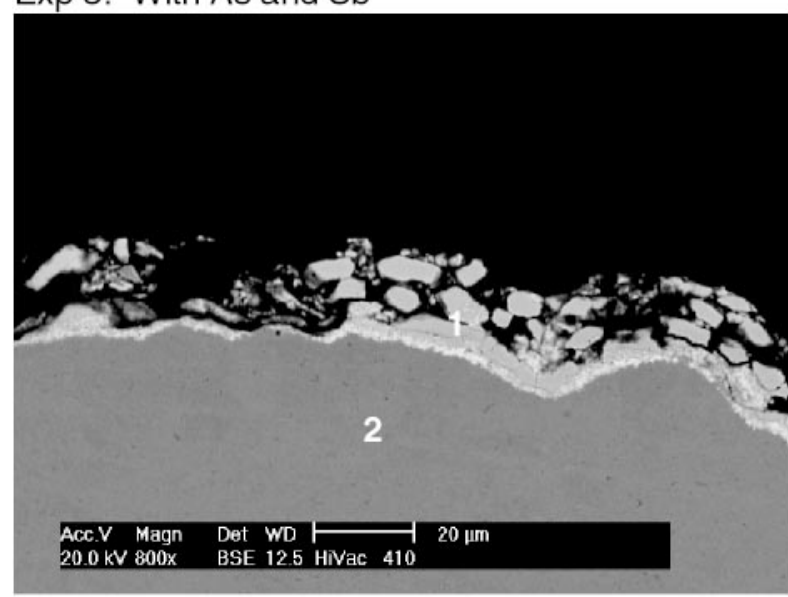

Exp 7X: Pure $\mathrm{Pb}$

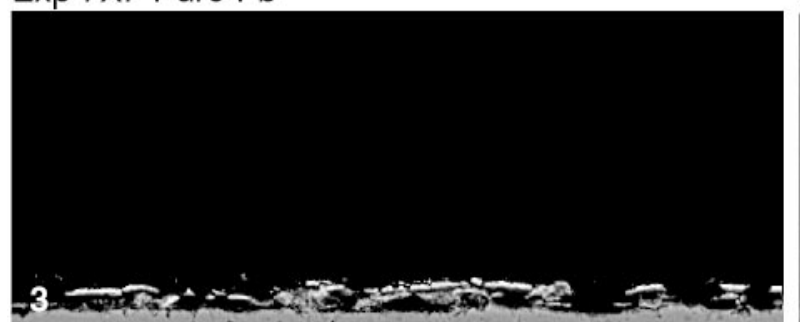

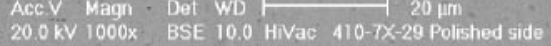

Reduction

Exp 5: With As and Sb

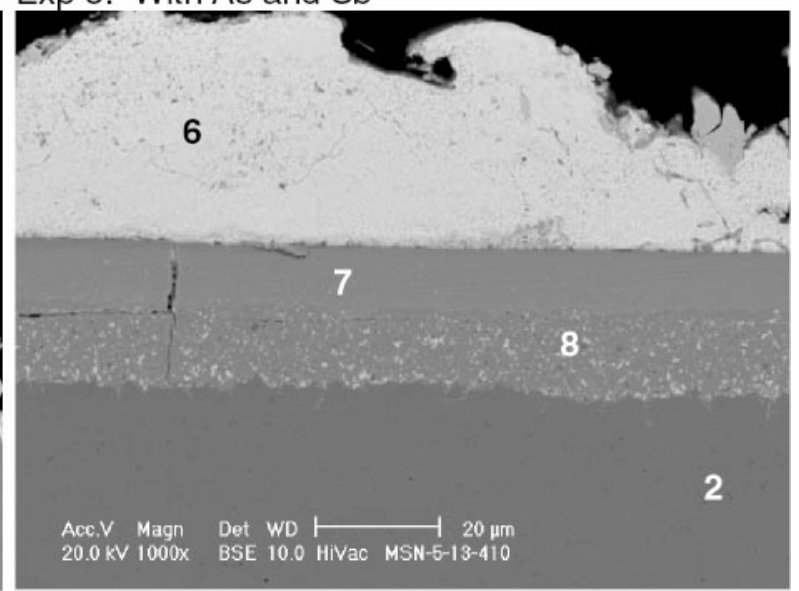

Exp 7: Pure $\mathrm{Pb}$

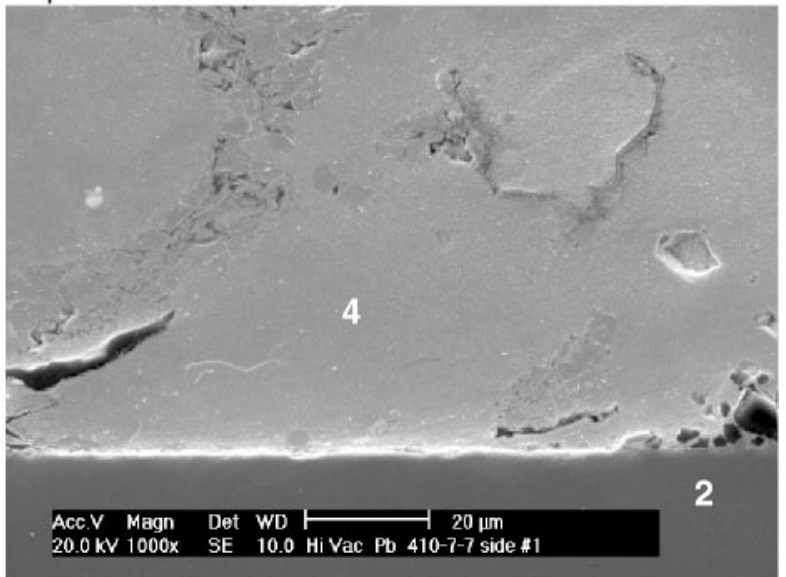

SEM Normalized Compostions (wt $\%$ )

1. As $52 \%$, Fe $39 \%$, Sn $4 \%$, Ni $3 \%$, $\mathrm{Cr} 1 \%, \mathrm{~Pb} 1 \%$

2. $\mathrm{Fe} 89 \%$, Cr $11 \%$, Si $0,4 \%$

3. $\mathrm{Fe} 66 \%, \mathrm{~Pb} 21 \%, \mathrm{O}_{2} 6 \%, \mathrm{Cr} 3 \%$, $\mathrm{Sb} 2 \%$, Si $1 \%$

4. $\mathrm{Pb} 100 \% \mathrm{Si}$ and $\mathrm{C}$ incursions

5. $\mathrm{Fe} 77 \%, \mathrm{~Pb} 15 \%, \mathrm{O}_{2} 7 \%, \mathrm{Cr} 1 \%$

6. $\mathrm{Pb} 99 \%, \mathrm{Sb} 1 \%$

7. As $52 \%, \mathrm{Fe} 43 \%$, Ni $2 \%, \mathrm{Cu} 1 \%$, $\mathrm{Sb} 1 \%, \mathrm{Cr} 1 \%$

8. Fe $50 \%$, As $32 \%, \mathrm{Cr} 13 \%, \mathrm{~Pb} 3 \%$, Sb $1 \%$, Si $0.5 \%$ 


\subsubsection{Carbon Steel (F-22) Coupons}

The carbon steel samples performed notably different than the other metal samples. Figure 169 shows the top surface micrographs of the carbon steel coupons. Severe attack of the surfaces is revealed when the post experiment surfaces are compared with the original polished samples. In addition, when the zirconium, Type 316 stainless steel, and Type 410 stainless steel coupons were recovered from the cooled corrosion cells, the residual lead could be relatively easily removed from the surfaces by hand; whereas, the lead deposits on the surfaces of the carbon steel coupons could not be removed. The SEM micrographs from the cross-sectioned carbon steel coupons provide some insight into this adhesion phenomenon.

Figure 170 presents the micrographs of the polished carbon steel coupon cross-sections for each experimental condition. (For the carbon steel coupons, we omitted EDS analysis for carbon since we used carbon to coat the samples, and the oxygen peak was not far enough above the noise level to use for a quantitative value.) We observed a puzzling phenomenon in the case of the coupon exposed in Experiment 3 (oxidizing conditions with arsenic and antimony contaminants). Subsurface voids appeared just below the polished layer. Present opinion is that these voids occurred when the carbon or chrome migrated into the molten lead. There is a layer made up primarily of lead and iron, with some antimony and arsenic just above the remaining base metal. Above that is a layer primarily made up of FeAs with nickel and a small amount of antimony. There is also some penetration of lead to a distance of approximately $2 \mu \mathrm{m}$ into the base metal (not shown well on the photo).

For the conditions in Experiment 5 (reducing chemistry conditions with arsenic and antimony contaminants), the SEM analysis shows three distinct layers. The top layer comprises mostly lead, with a small amount of antimony and arsenic. The next layer from the top (Layer 8 in the figure) is mostly FeAs, with small amounts of nickel and antimony. The bottom layer (Layer 9 on the figure) is also mostly FeAs, but with small amounts of lead, chrome, antimony, and manganese. These layers are somewhat similar to the layers observed on the Type 316 and 410 stainless steel specimens tested in Experiment 5.

Results for the experiments without contaminants are also shown in Figure 170. The interaction layers between the base metal and the molten lead are relatively thin, on the order of 5 to 10 microns. Also, the composition of the interaction layers is similar in all three experiments, suggesting that the molten lead chemistry (oxidation or reduction) did not have much effect. However, as mentioned above, the lead is well adhered to the base metal and does contain some inclusions of silicon and carbon, probably left from the $\mathrm{SiC}$ polishing paste used to prepare the specimens. Layers 5, 10, and 7 appear to be either iron or iron/chrome oxide layers with some lead. 


\section{Carbon Steel (F-22)}

Polished sample

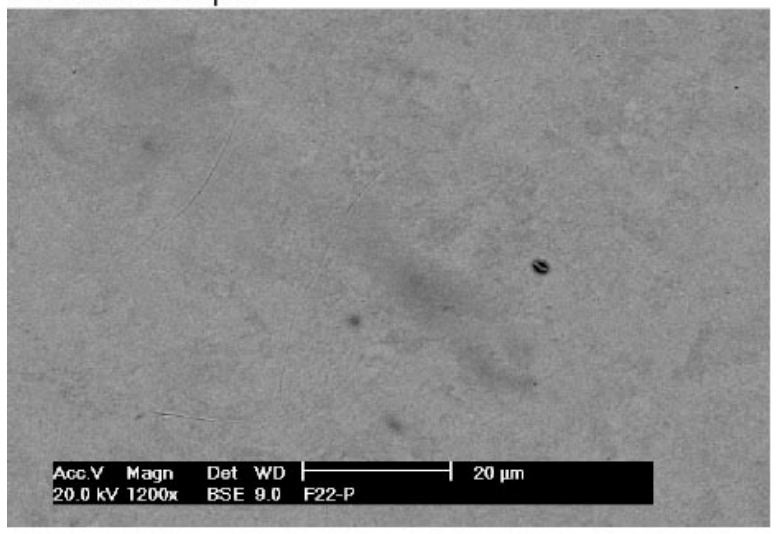

Exp 5: Reducing with As and Sb

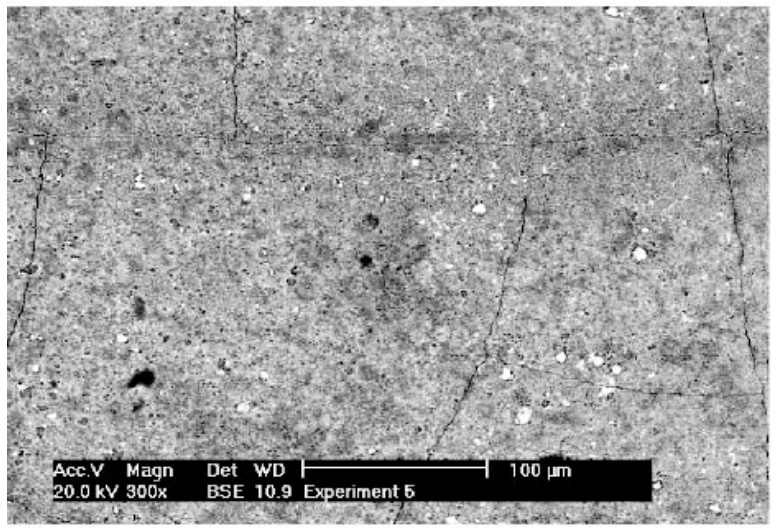

Exp 5: Reducing with As and $\mathrm{Sb}$

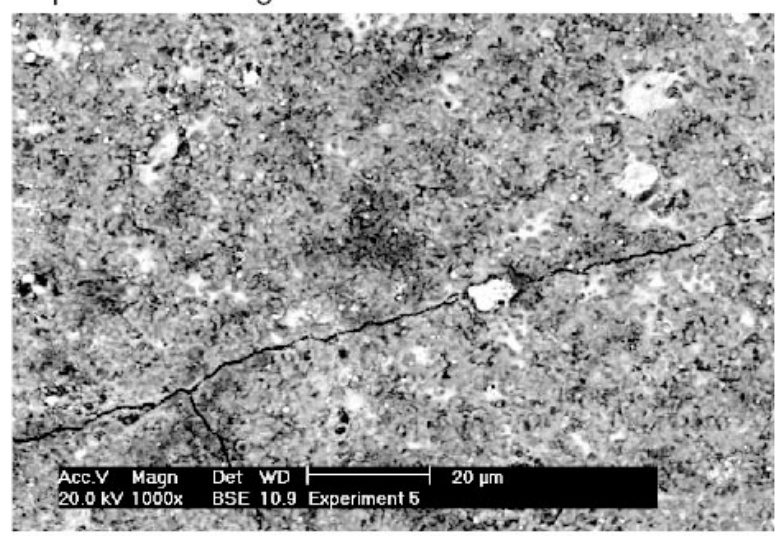

Exp 7X: Oxidation with pure $\mathrm{Pb}$

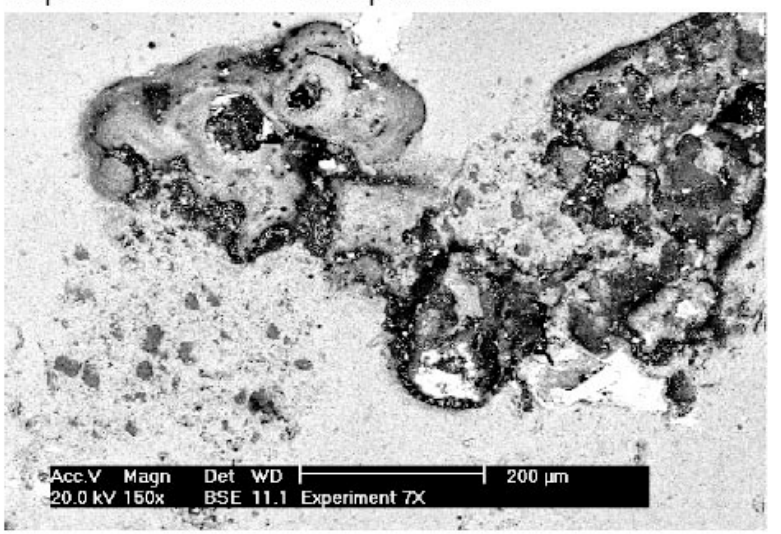

Exp 7X: Oxidation with pure $\mathrm{Pb}$

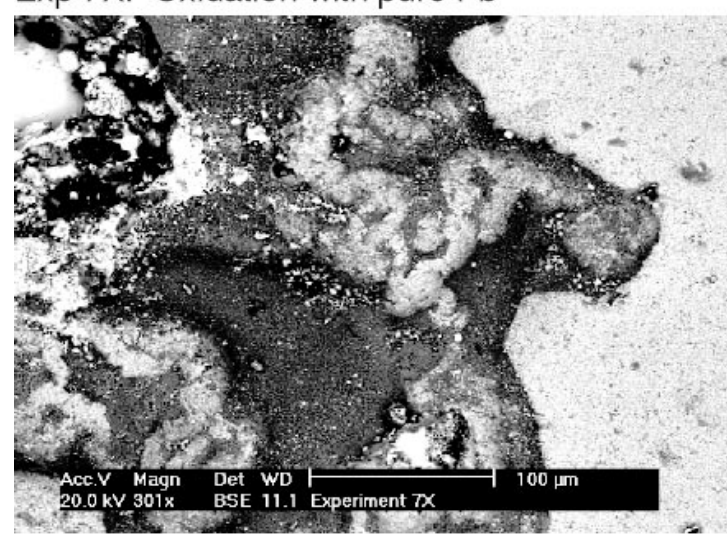

Exp 7X: Oxidation with pure $\mathrm{Pb}$

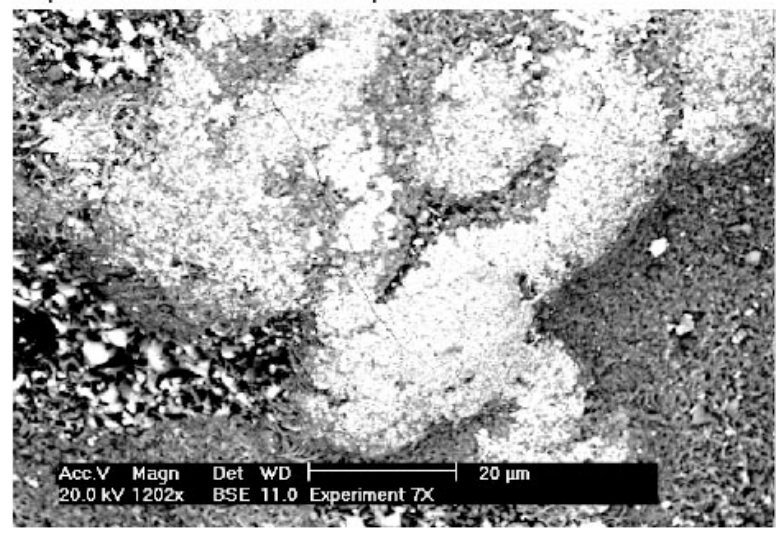

Figure 169. Top surfaces of the F-22 carbon steel specimens. The picture on the top left shows the surface before testing, the remaining photographs show the surfaces after Experiments 5 and $7 \mathrm{X}$ and after cleaning. 


\section{Carbon Steel (F22)}

\section{Oxidation}

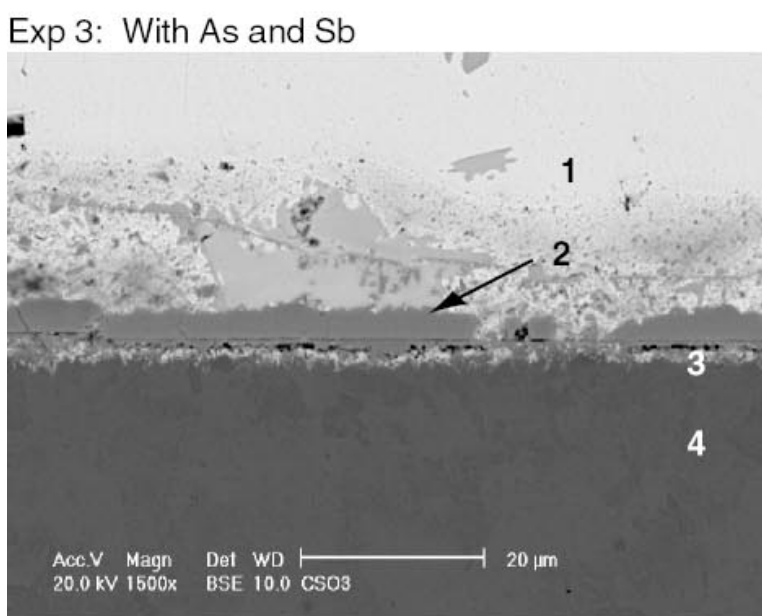

Exp 7X: Pure $\mathrm{Pb}$

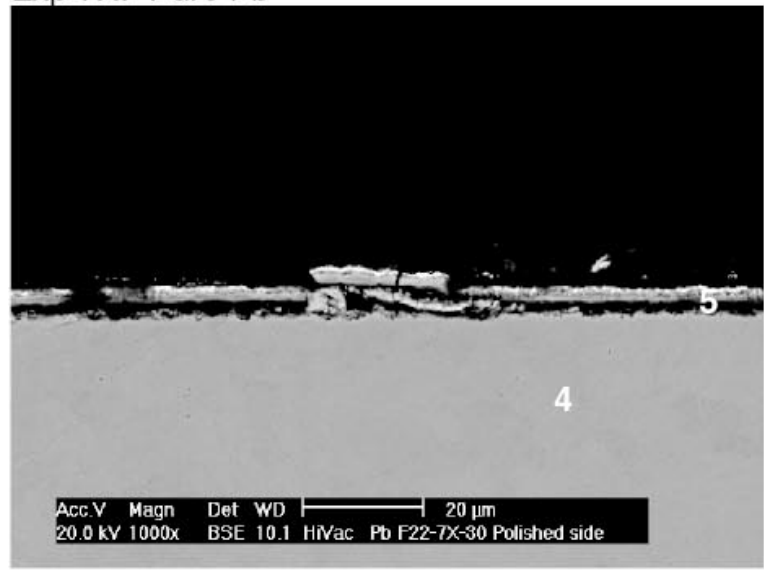

Exp7Y: Pure Pbs

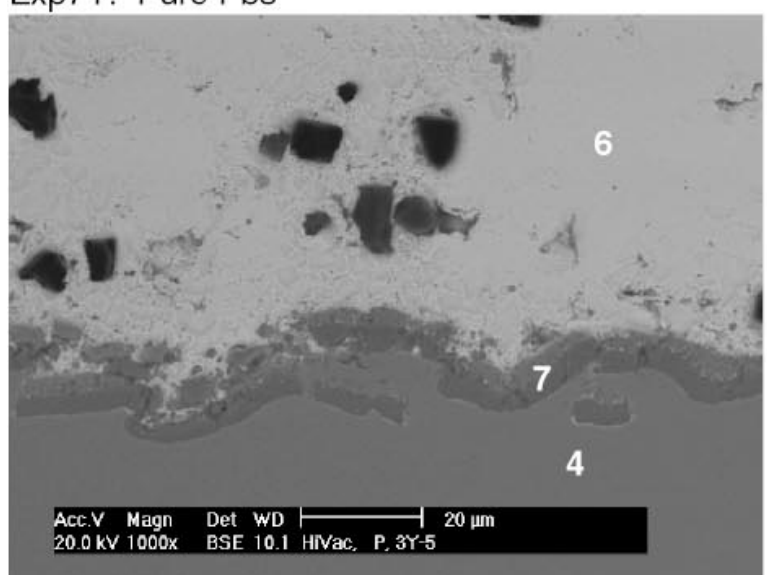

Reduction

Exp 5: With As and Sb

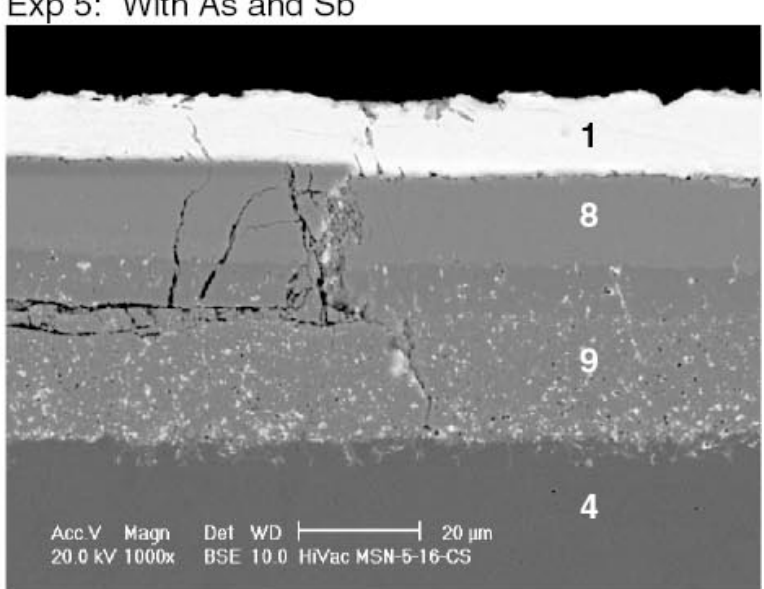

Exp 7: Pure $\mathrm{Pb}$

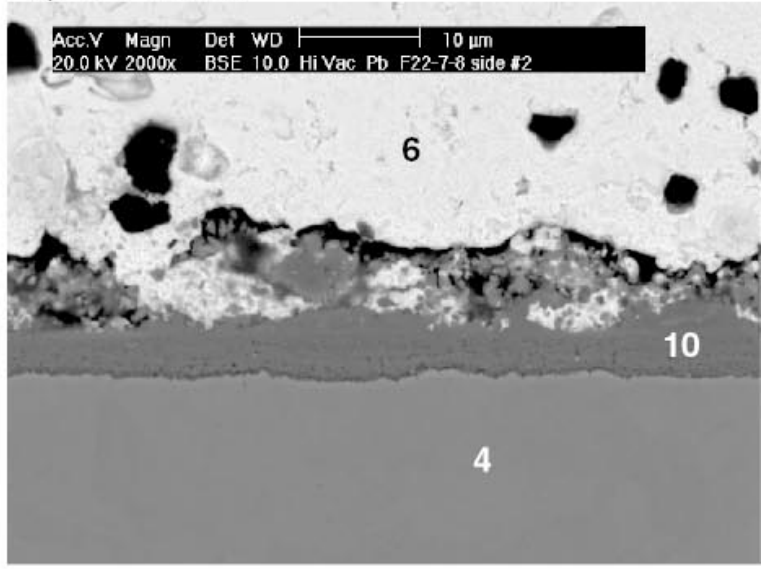

SEM Normalized Compostions (wt $\%$ )

1. $\mathrm{Pb} 100 \% \mathrm{As}$ and $\mathrm{Sb}$ inclusions

2. As $50 \%, \mathrm{Fe} 43 \%, \mathrm{Ni} 6 \%, \mathrm{Sb} 1 \%$

3. $\mathrm{Pb} 50 \%, \mathrm{Fe} 36 \%, \mathrm{Sb} 8 \%$, As $3 \%$

4. $\mathrm{Fe} 97 \%, \mathrm{Cr} 2.27 \%$, Mn $0.44 \%$

5. $\mathrm{Fe} 82 \%, \mathrm{~Pb} 12 \%, \mathrm{O}_{2} 6 \%$

6. $\mathrm{Pb} 100 \% \mathrm{Si}$ and $\mathrm{C}$ inclusions

7. $\mathrm{Fe} 78 \%, \mathrm{~Pb} 10 \%, \mathrm{O}_{2} 7 \%, \mathrm{Cr} 4 \%$

8. As $52 \%, \mathrm{Fe} 45 \%$, Ni $2 \%$, Sb $1 \%$

9. Fe $63 \%$, As $31 \%, \mathrm{~Pb} 2 \%, \mathrm{Cr} 2 \%$, Sb $1 \%$, Mn $1 \%$

10. Fe. $86 \%, \mathrm{O}_{2} 9 \%$, Cr $3 \%, \mathrm{~Pb} 2 \%$

Figure 170. SEM photographs of polished cross sections of F-22 carbon steel specimens. 


\subsubsection{HT-9 Coupons}

HT-9 samples cut from a non-irradiated fuel channel box arrived from Argonne West after Experiments 3 and 5 were completed. We placed the samples in subsequent experiments to obtain corrosion information of this stainless steel designed for sodium fast reactor use. The samples placed in the corrosion cell had a nominal thickness of 0.042 " by 1.0 " by 1.3 ". The samples were not polished before corrosion testing.

Figures 171 and 172 show the top surfaces and the cross section SEM photographs, respectively. The SEM results show that HT-9 experienced little corrosion, less than observed with the other metals, and no major interaction layers. Layers 1, 4, and 7 again appear to be iron/chrome oxide layers with some lead present. Surprisingly, we also observed antimony in Layer 1, despite the fact that we used pure lead in Experiment 7X. The presence of the antimony may be a residual from previous experiments in the same cell.

\subsubsection{Lance Tips}

As discussed in Section 5.2.2 above, stirring of the molten lead is accompanied by injecting an inert gas (argon) into the center of the corrosion cell near the bottom with a lance. The lance is a 0.25 -in.-OD steel tube with the inert gas continuously forced down its center. The coupons are located on the lower outside section of the lance, exposed to the experimental conditions of the corrosion cell, as shown in Figure 162.

This metal offers further insight into the corrosion behavior of the molten lead, so we performed SEM cross-section analysis on the post-run lance tips from Experiments 3 and 5 (the oxidation and reducing chemistry experiments with arsenic and antimony contamination). The chemical composition of the lance was unknown. The lance tip was cut off the lance, and mounted and polished down to $\sim 200 \mu \mathrm{m}$. Figure 173 presents the SEM micrograph of the lance cross-sections. There was essentially no lead or interaction zone on the inside surface of the lance where the gas was being injected. On the outside surface we see one FeAs interaction zone in the oxidation experiment (Zones 2 and 5 in the left hand lower figures) and two FeAs interaction zones in the reducing experiment (Zones 5 and 6 in the right hand, lower photograph). The upper zone contains a small amount of nickel and the lower zone contains some antimony and lead. These results are similar to what was observed for the F-22 carbon steel material. 


\section{HT-9 Stainless Steel}

As received sample

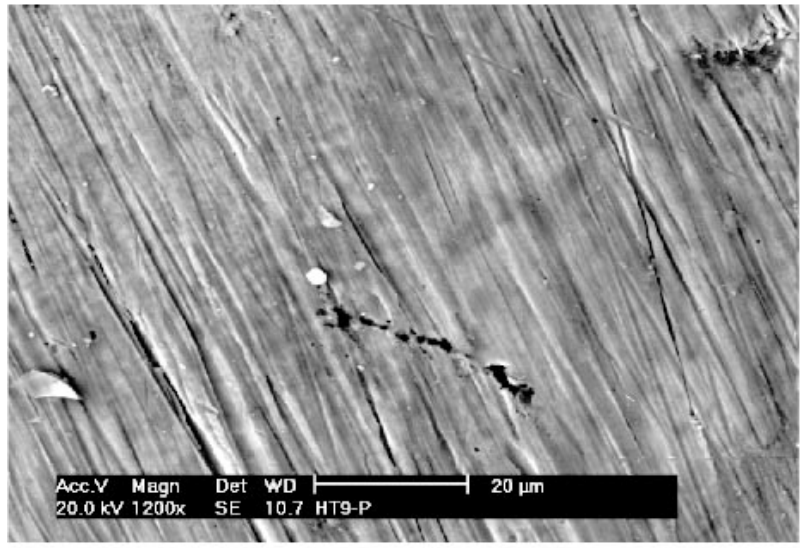

Exp 7: Reducing with pure $\mathrm{Pb}$

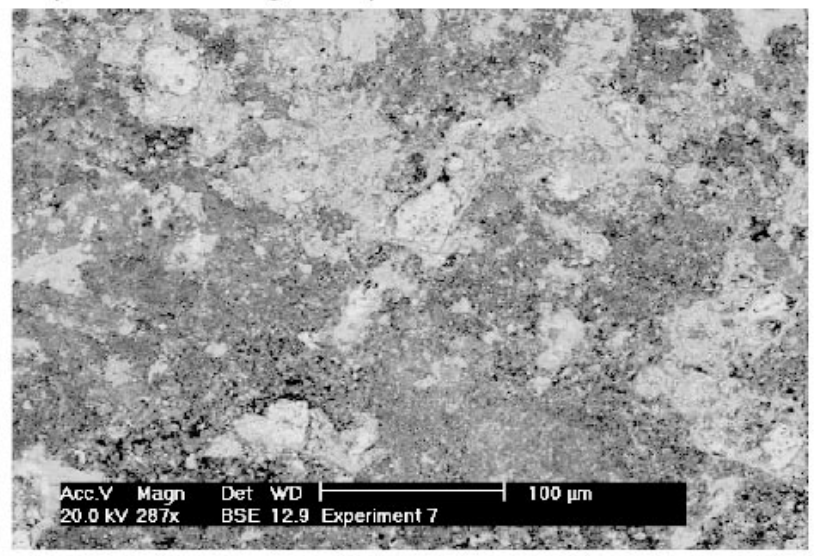

Exp 7: Reducing with pure $\mathrm{Pb}$

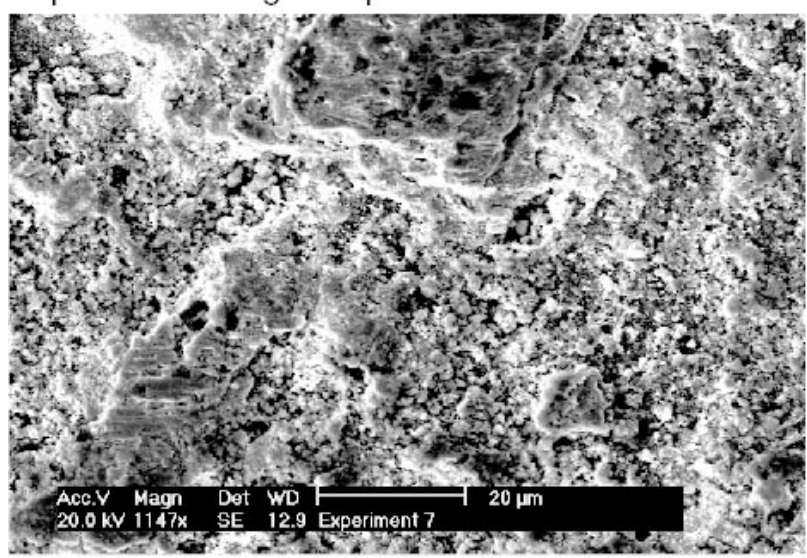

Exp 7X: Oxidizing with pure $\mathrm{Pb}$

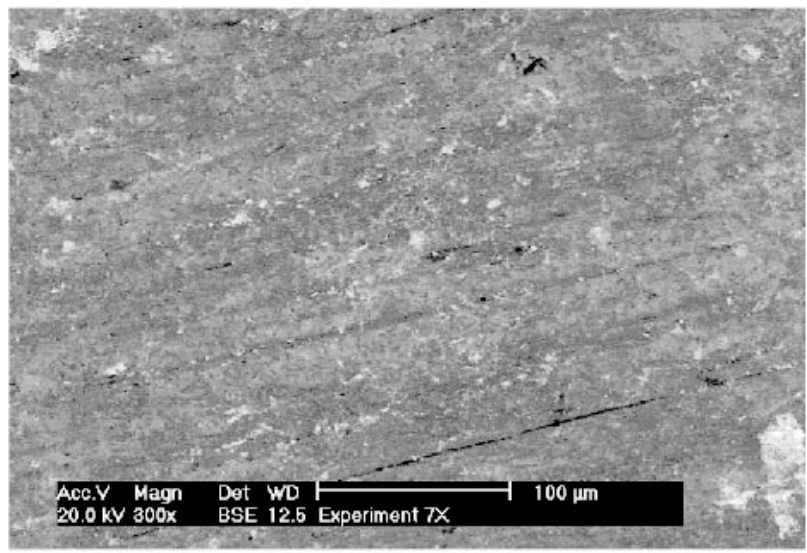

Exp 7X: Oxidizing with pure $\mathrm{Pb}$

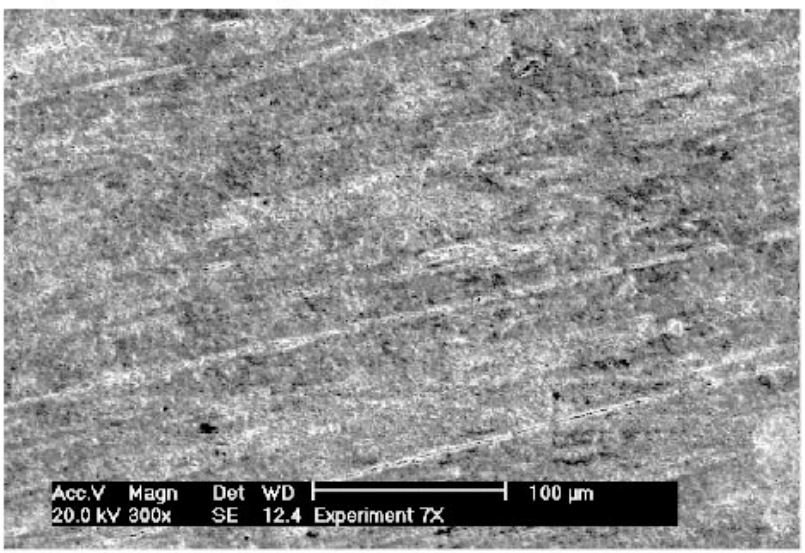

Exp 7X: Oxidizing with pure $\mathrm{Pb}$

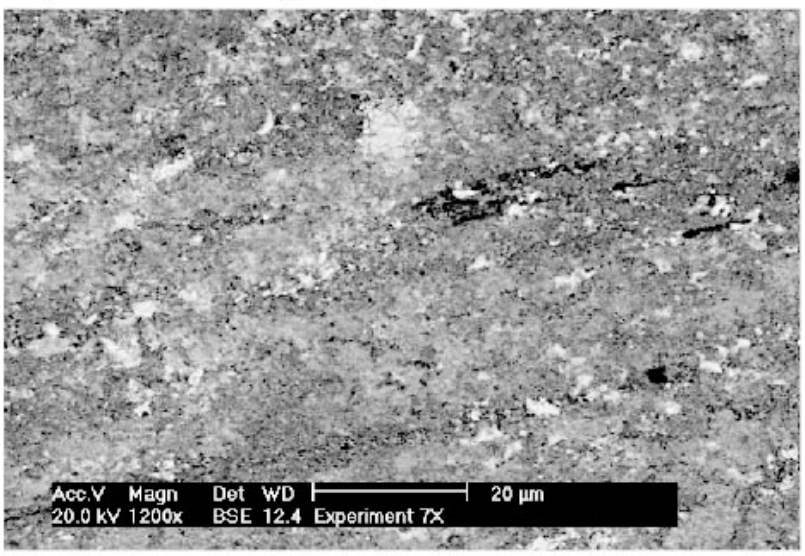

Figure 171. Top surfaces of the Type HT-9 stainless steel specimens. The picture on the top left shows the surface before testing, the remaining photographs show the surfaces after Experiments 7 and $7 X$ and after cleaning. 


\section{HT-9 Stainless Steel}

Oxidation

Exp 7X: Pure $\mathrm{Pb}$
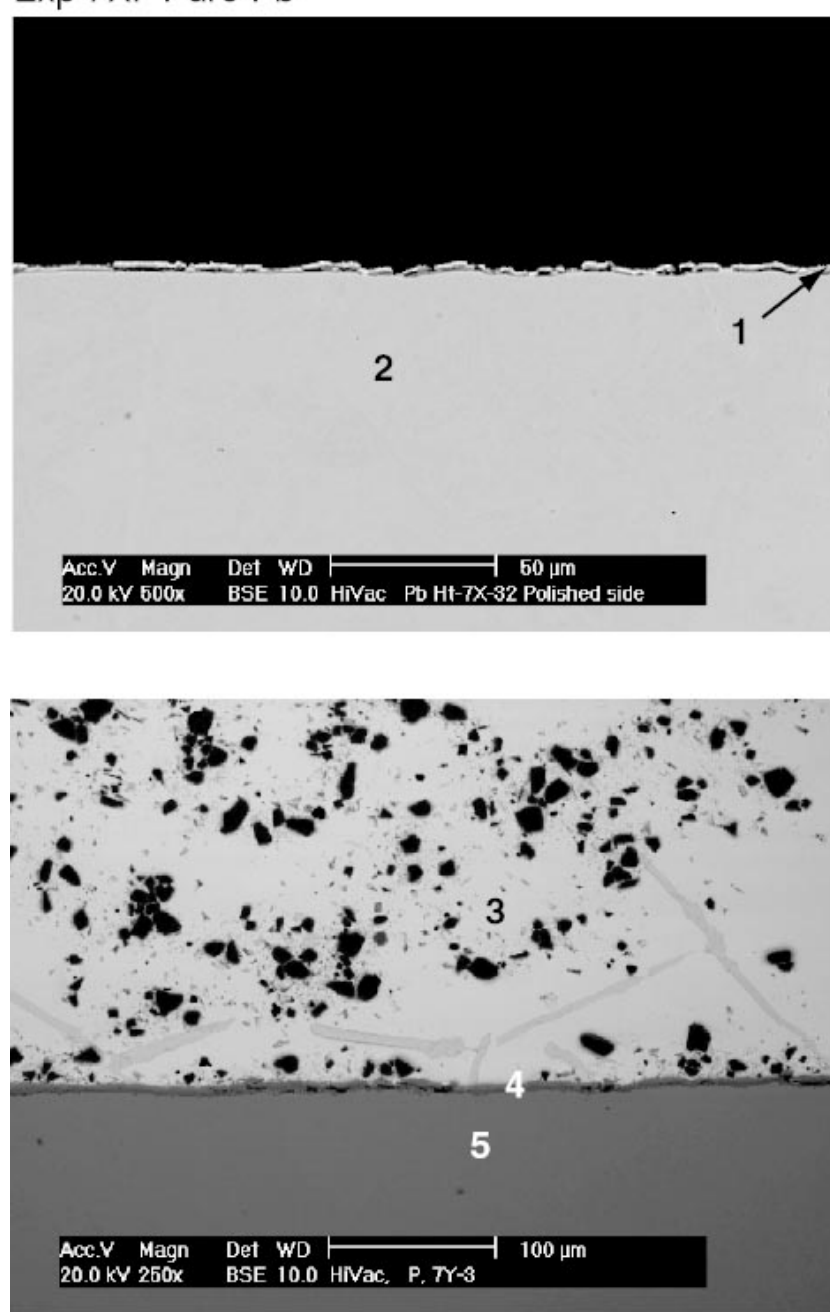

Reduction

Exp 7: Pure $\mathrm{Pb}$

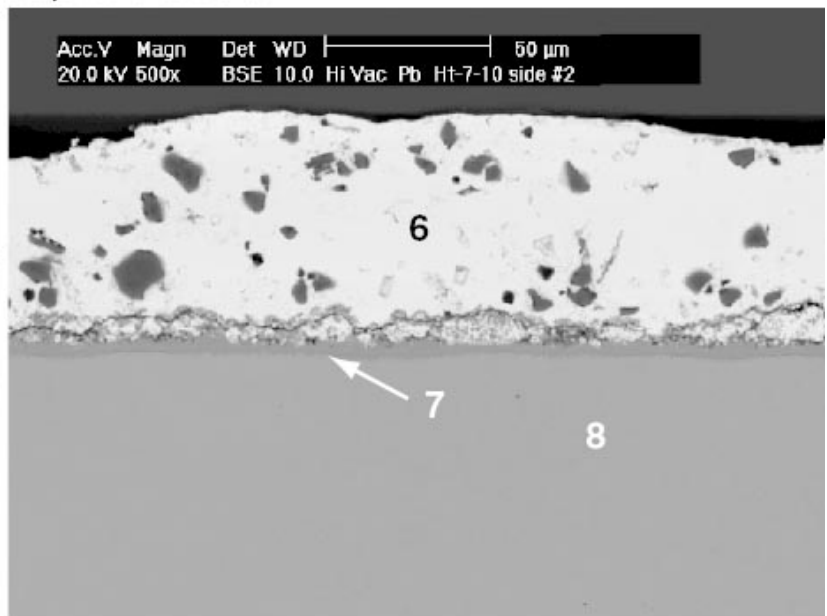

SEM Normalized (wt $\%)$

1. $\mathrm{Fe} 62 \%, \mathrm{~Pb} 20 \%, \mathrm{O}_{2} 7 \%, \mathrm{Cr} 5 \%, \mathrm{Sb} 5 \%$, Si $1 \%$

2. Fe $85 \%$, Cr $12 \%$, Mo $1 \%$, Mn $1 \%$, Si $0.5 \%$

3. $\mathrm{Pb} 100 \%, \mathrm{Si}$ and $\mathrm{C}$ inclusions from polishing material

4. $\mathrm{Fe} 73 \%, \mathrm{Cr} 15 \%, \mathrm{O}_{2} 7 \%, \mathrm{~Pb} 4 \%, \mathrm{Si} 1 \%$

5. $\mathrm{Fe} 87 \%, \mathrm{Cr} 12 \%, \mathrm{Mn} 1 \%$, Si $0.3 \%$

6. $\mathrm{Pb} 100 \% \mathrm{Si}$ and $\mathrm{C}$ inclusions from polishing material

7. $\mathrm{Fe} 90 \%, \mathrm{O}_{2} 6 \%, \mathrm{~Pb} 3 \%, \mathrm{Cr} 1 \%$

8. Fe $85 \%$, Cr $12 \%$, Mo $1 \%$ Mn $1 \%$, Si $0.5 \%$

Figure 172. SEM photos of polished cross sections of Type HT-9 stainless steel specimens. 


\section{Carbon Steel Lance}

Run 3 Oxidation
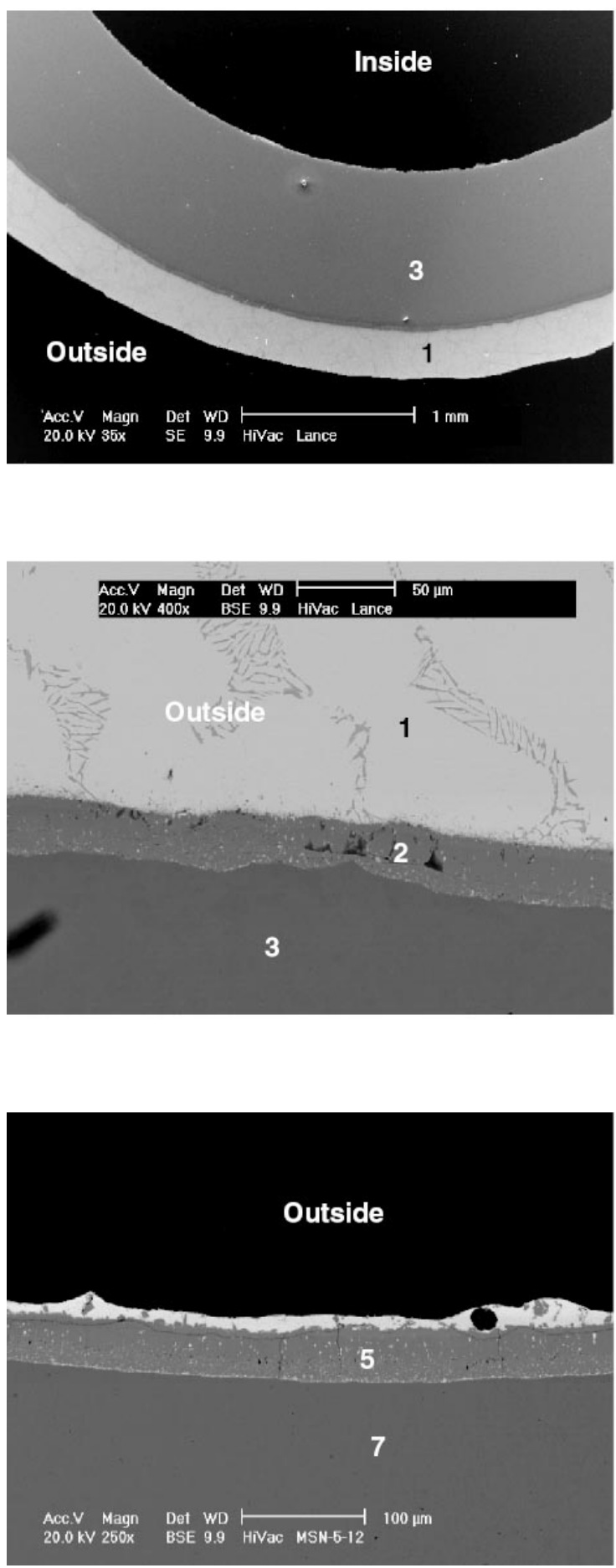

Run 5 Reduction
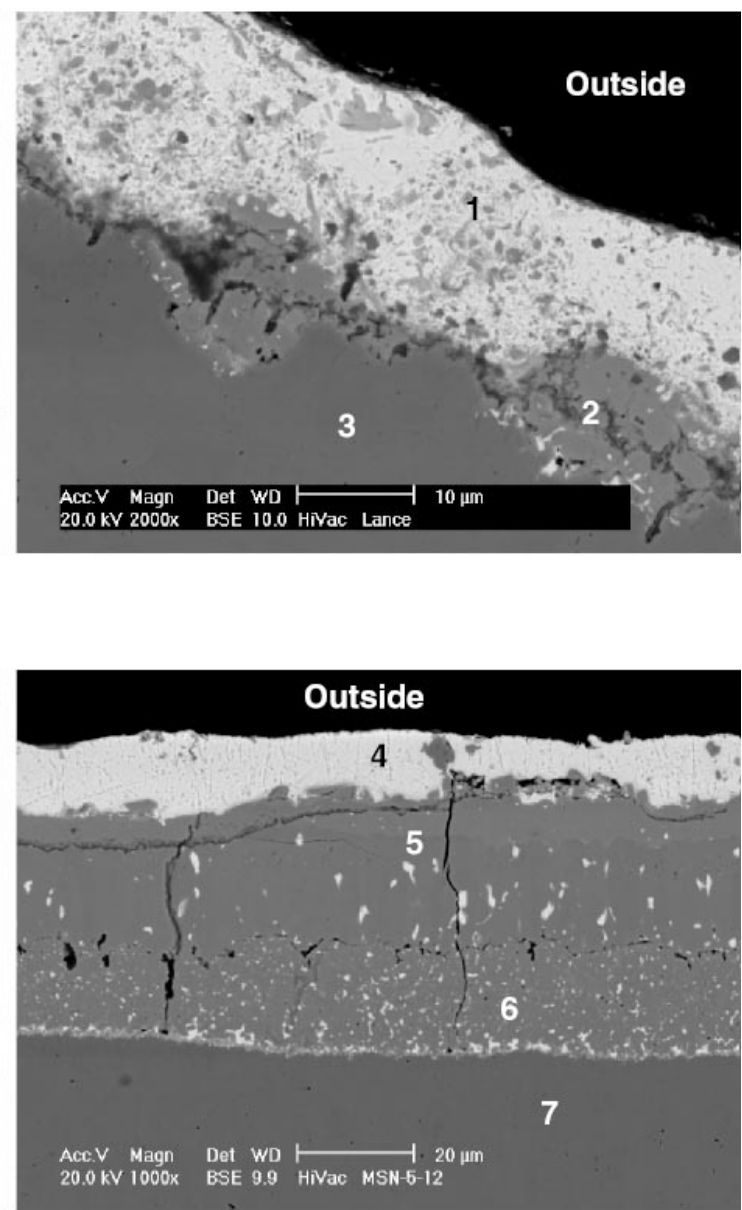

SEM Normalized Compostions (wt \%)

1. $\mathrm{Pb} 95 \%, \mathrm{Sb} 5 \%$

2. As $58 \%$, Fe $42 \%$

3. Fe $100 \%$

4. $\mathrm{Pb} 98 \%, \mathrm{Sb} 2 \%$

5. As $52 \%, \mathrm{Fe} 45 \%$, Ni $3 \%$

6. Fe $60 \%$, As $33 \%, \mathrm{Sb} 5 \%, \mathrm{~Pb} 2 \%$

7. $\mathrm{Fe} 100 \%$

Figure 173. SEM photographs of polished cross sections of the iron lance tips from Experiments 3 and 5. The upper left hand photograph shows a 36 magnification of both surfaces of the lance from Experiment 3, indicating that lead and reaction layers were only found on the outside of the lances. The remaining photographs at higher magnification show the outside surface lead and interaction layers. 


\subsubsection{Temperature Control}

The corrosion cells were heated with resistance heaters located about $2 \mathrm{~cm}$ from the outside surfaces. This type of heating is expected to produce relatively isothermal regions inside the corrosion cells. The temperature data were obtained from the experiments by placing thermocouples (Type-K) with "washer-ends" onto the sides of the corrosion cells. The thermocouple data were recorded using National Instruments Corporation's Virtual-Bench software.

Figure 174 shows a heat-up curve for Experiment 5, which is typical of all of the experiments. These data show that the heat-up rate of the experimental apparatus was approximately $100^{\circ} \mathrm{C} / \mathrm{hr}$. All the experiments were heated slowly to a temperature below the liquidus point of the lead, and then the system was allowed to soak (come to thermal equilibrium). After the lead was melted the heat-up was continued with a rapid heat-up rate $\left(\geq 200^{\circ} \mathrm{C} / \mathrm{hr}\right.$ ). Once the lead was molten, additional lead was added (see the drop in temperature on Figure 174) to bring the bath level to approximately 2 to $3 \mathrm{~cm}$ above the shroud. Superimposed onto Figure 174 is the cool down curve for the same experiment. After the molten lead is drained from the corrosion cell, both the upper and lower heaters are turned off. These data show that the cool down for an empty corrosion cell is approximately $200^{\circ} \mathrm{C} / \mathrm{hr}$.

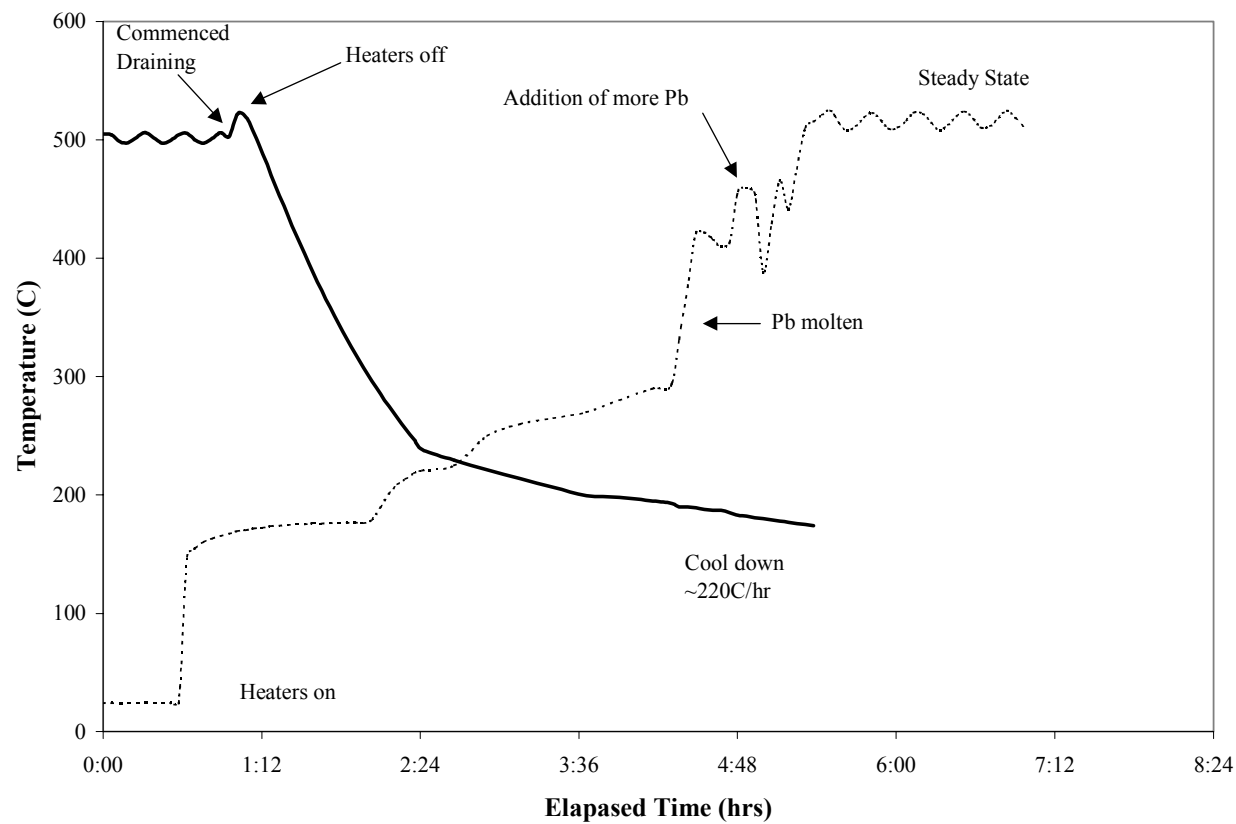

Figure 174. Typical heat-up and cool down curves from one of the gas lift corrosion cells. (Data presented is from Experiment 5.)

Figure 175 shows the axial temperature profile for three of the experiments. The figure shows a very step temperature gradient at the top of the corrosion cell. This is due to the watercooling used on the top flange to keep Teflon seals from melting. However, the axial profile inside the lead is relatively isothermal as expected by the heating and bath stirring. 


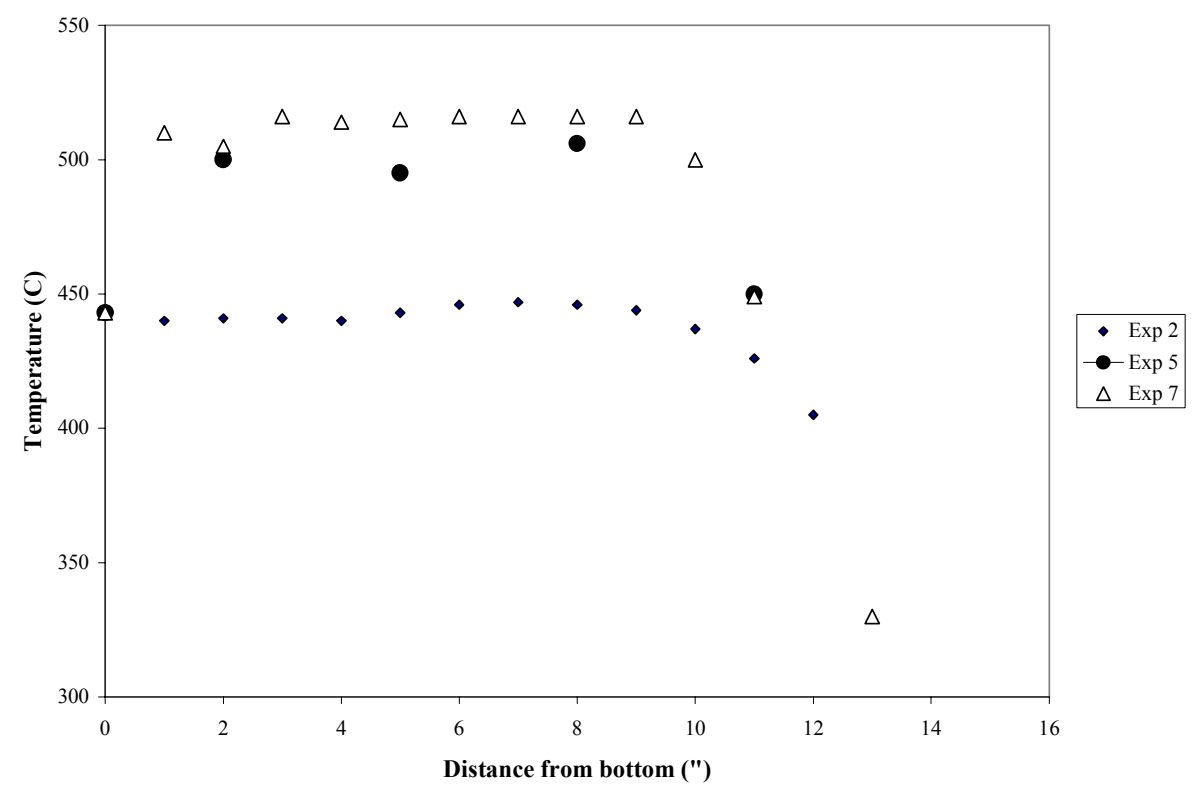

Figure 175. Typical corrosion cell axial temperature profile during steady state conditions.

\subsubsection{Mass Spectrometer Results}

A mass spectrometer (AERO VAC ${ }^{\mathrm{TM}} 2900$ Sampling System) was available for Experiments $5,7,7 \mathrm{X}$, and $7 \mathrm{Y}$ to determine the composition of the gas emitted from the corrosion cell. The AV2900 is a turn-key system consisting of a computer-controlled residual gas analyzer system that integrates a specifically designed heated oven-enclosure housing - the Atmospheric Pressure Sampling System (APSS) and the AERO VAC ${ }^{\mathrm{TM}} 1600$ Mass Spectrometer/RGA. The sampling system comes mounted in a portable cart, with a 2-stage fractionation-free manifold system, special heated inlet, AERO VAC ${ }^{\mathrm{TM}} 1600$ RGA, turbo-molecular pump with mechanical backing pump, separate mechanical sampling pump, temperature-controlled oven, high-vacuum ion gauge, dual convection gauges with digital readout controller, and a Windows-based data acquisition and control software and instruction manual. Figure 176 shows a typical analog scan from Experimental Run 5 showing a large hydrogen peak at atomic Mass Number 2, an argon peak at atomic Mass Number 40 (Mass 20 is double ionized argon), and water peaks at Mass Number 18. These data were captured every two minutes during Experiment 5 and every 12 minutes during Experiments 7, 7X, and 7Y.

Before and after the experiments, we passed a known calibration gas through the corrosion cell and analyzed it with the mass spectrometer. The calibration data were used to determine the sensitivity factors, $\mathrm{k}$, for each gas constituent, so we could determine the concentrations during the experiment. The sensitivity factor $\mathrm{k}$ is calculated using the following expression:

$$
k=\frac{x_{s}}{1-x_{s}} \times \frac{I_{A r}}{I_{s}}
$$

where:

$$
\mathrm{k}=\text { gas relative sensitivity factor (in argon), }
$$




$$
\begin{array}{lll}
\chi_{\mathrm{s}} & = & \text { mol } \% \text { of gas of interest (standard), } \\
\mathrm{I}_{\mathrm{Ar}} & = & \text { ion signal for Mass } 40 \text { of argon in amps for known standard, and } \\
\mathrm{I}_{\mathrm{s}} & = & \text { ion signal for gas of interest in amps for known standard. }
\end{array}
$$

The calculated $\mathrm{k}$ values are shown in Table 56 for hydrogen and oxygen. These values for $\mathrm{H}_{2}$ are within $12 \%$ for the two different standards used. No comparison can be made for $\mathrm{O}_{2}$ since only one certified standard was available. The k values are used to calculate the $\mathrm{H}_{2}$ or $\mathrm{O}_{2}$ concentrations during the experiments.

Table 56. K values from the calibration gas scans.

\begin{tabular}{llllllll}
\hline Data & $\mathbf{I}_{\mathbf{A r}}$ & $\mathbf{I}_{\mathbf{H}}$ & $\mathbf{I}_{\mathbf{O}}$ & $\chi_{\mathbf{H}}$ & $\chi_{\mathbf{O}}$ & $\mathbf{k}_{\mathbf{H} 2}$ & $\mathbf{k}_{\mathbf{O 2}}$ \\
\hline $2-\mathrm{Pure} \mathrm{Ar}$ & $4.63 \mathrm{e}-10$ & $7.76 \mathrm{e}-12$ & $6.67 \mathrm{e}-12$ & $1 \mathrm{ppm}$ & $1 \mathrm{ppm}$ & $5.967 \mathrm{e}-5$ & $6.94 \mathrm{e}-5$ \\
$5 \% \mathrm{H}_{2}$ in $\mathrm{Ar}$ & $4.43 \mathrm{e}-10$ & $1.01 \mathrm{e}-9$ & $4.65 \mathrm{e}-12$ & $5 \%$ & $1 \mathrm{ppm}$ & 0.0231 & - \\
$1.97 \% \mathrm{H}_{2}$ in $\mathrm{Ar}$ & $4.67 \mathrm{e}-10$ & $3.63 \mathrm{e}-10$ & $4.24 \mathrm{e}-12$ & $1.97 \%$ & $1 \mathrm{ppm}$ & 0.0258 & - \\
$1.95 \% \mathrm{O}_{2}$ in $\mathrm{Ar}$ & $4.22 \mathrm{e}-10$ & $3.77 \mathrm{e}-12$ & $1.83 \mathrm{e}-11$ & $1 \mathrm{ppm}$ & $1.95 \%$ & - & 0.4586 \\
\hline
\end{tabular}

The mass spectrometer continuously recorded data during the experiments for five gas constituents of interest: $\mathrm{Ar}, \mathrm{N}_{2}, \mathrm{O}_{2}, \mathrm{H}_{2}$, and $\mathrm{H}_{2} \mathrm{O}$. Two methods of data capture were used. Actual analog scans were recorded, one of which is presented in Figure 176. Also, a time-based scan was used during the experiments to track trends in the gas phase of the corrosion cell. Figure 177 is the time-based scan taken during Experiment 5, showing an 8-hour segment. The ion current measured is in proportion to the amount of gas present in the sample, with the exception of hydrogen. The mass spectrometer is overly sensitive to hydrogen, resulting in a higher peak than appropriate. The actual concentration of hydrogen was about 2 vol\%, with the balance argon.

Typical Analog Scan Taken on October 21, 2000.

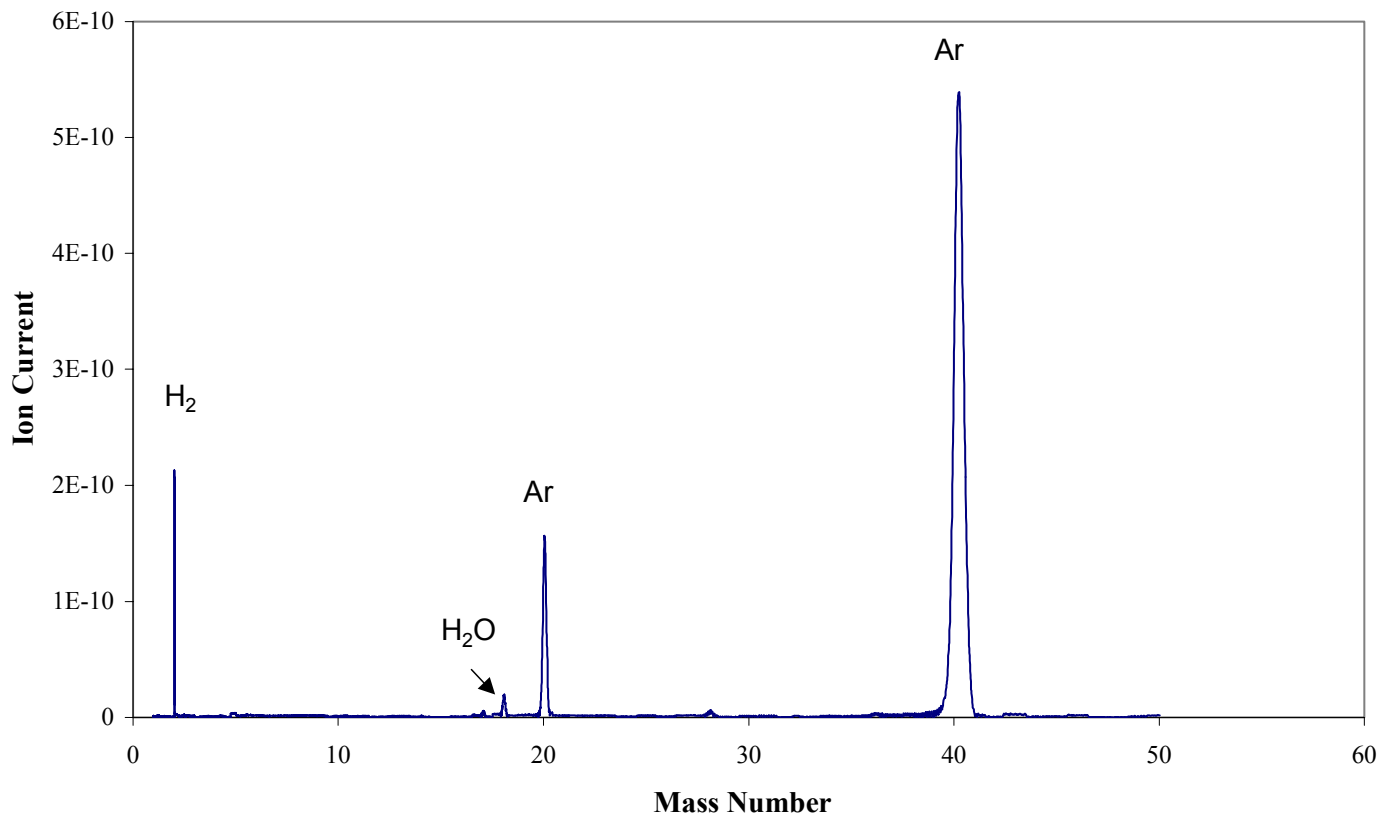

Figure 176. Typical analog scan from mass spectrometer. 


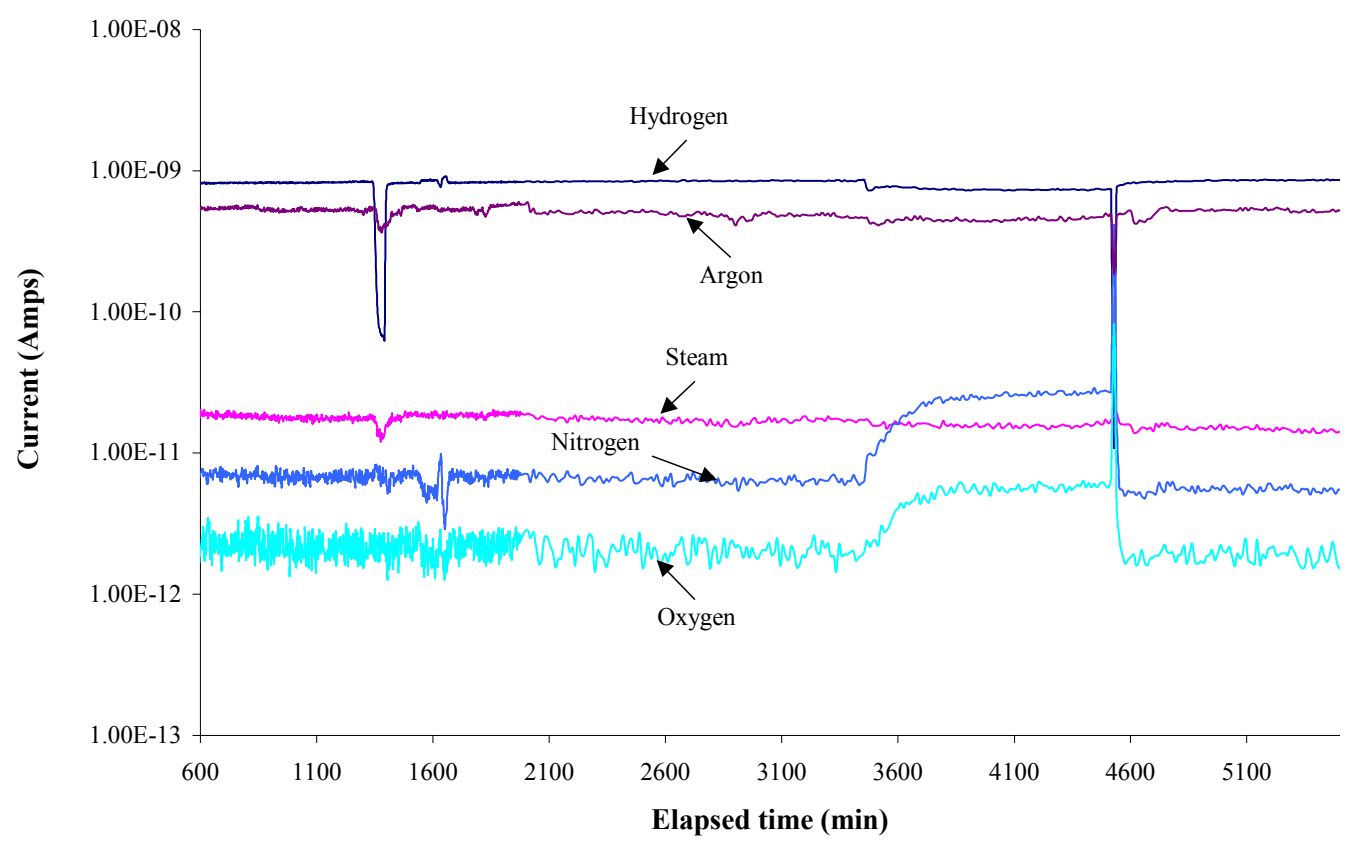

Figure 177. Mass spectrometer time based scan during sampling.

The ion current versus time data plotted in Figure 177 illustrates how the molten lead chemistry can be monitored with the mass spectrometer. The hydrogen flow was secured at time 1400. The plot shows a decrease in the hydrogen concentration and a corresponding decrease in the water generation, since the hydrogen-oxygen reaction to produce water was reduced at time 1400. The hydrogen flow was then reestablished and equilibrium conditions were obtained shortly thereafter. At time $\sim 3400$, the system was opened to take bath measurements. The ingress of air can be seen due to the increase of oxygen and nitrogen. Once the system was sealed, the excess hydrogen flow removed the oxygen and reestablished the reducing conditions.

Table 57 presents the steady-state gas concentrations for the three experiments from the $\mathrm{k}$ factors calculated in Table 56.

Table 57. Bulk gas compositions during steady-state in volume percent (normalized).

\begin{tabular}{lllll}
\hline Gas & $\begin{array}{l}\text { Run 5 } \\
\text { Reducing }\end{array}$ & $\begin{array}{l}\text { Run 7 } \\
\text { Reducing }\end{array}$ & $\begin{array}{l}\text { Run 7X } \\
\text { Oxidation }\end{array}$ & $\begin{array}{l}\text { Run 7Y } \\
\text { Oxidation }\end{array}$ \\
\hline $\mathrm{Ar}$ & 95.95 & 92.31 & 98.25 & 98.13 \\
$\mathrm{H}_{2}$ & 3.88 & 5.90 & 0.01 & 0.04 \\
$\mathrm{O}_{2}$ & 0.17 & 0.18 & 1.75 & 1.82 \\
\hline
\end{tabular}

For the reducing experiments ( 5 and 7$)$, the calculated $\mathrm{O}_{2}$ concentrations $(0.17$ and 0.18 vol.\%, respectively) are certainly higher than the planed oxygen partial pressure $\left(\mathrm{PO}_{2}\right)$ of $10^{-27}$ atm. The vendor of the mass spectrometer has stated the lower detection limit for $\mathrm{O}_{2}$ in the system is 5 to $10 \mathrm{ppm}$. This makes it impossible to measure exact partial pressures of oxygen in the range of interest. However, the mass spectrometer is still a useful experimental tool, since the ratio of the hydrogen and oxygen ion currents $\left(\mathrm{I}_{\mathrm{H} 2} / \mathrm{I}_{02}\right)$ will indicate whether the molten lead chemistry is oxidizing or reducing. For example, during Experiment 7, reducing conditions, the 
average $\mathrm{I}_{\mathrm{H} 2} / \mathrm{I}_{02}$ ratio is 65.1 . Contrast this to Experiment $7 \mathrm{Y}$, oxidation conditions, where the average $\mathrm{I}_{\mathrm{H} 2} / \mathrm{I}_{02}$ ratio is 0.48 . This two order of magnitude difference allows some form of control between the two experimental extremes currently under study. The mass spectrometer will also provide information such as bulk gas phase trending during an experiment and detection of air leaks in the system.

\subsubsection{Lead Chemistry}

The composition of the lead before and after the experiments is presented in Table 58. The drained lead was not reused from experiment to experiment. This parameter is important when evaluating lead corrosion data, because the solubility of the base metal into the molten lead, and the penetration/diffusion of the contaminants in the lead into the corrosion coupons, affects the corrosion results. The experiments were all run in a corrosion cell (Figure 162) constructed of Type 316 stainless steel. Material from the corrosion cell may also be present in the post-test lead.

Table 58. Composition of lead before and after the experiments.

\begin{tabular}{|c|c|c|c|c|c|c|}
\hline & $\begin{array}{l}\text { Pre- } \\
\text { experiment } \\
(3,5)\end{array}$ & $\begin{array}{l}\text { Pre- } \\
\text { experiment } \\
(3,5)\end{array}$ & $\begin{array}{l}\text { Post- } \\
\text { experiment } \\
3^{\mathbf{a}^{\mathrm{a}}}\end{array}$ & $\begin{array}{l}\text { Post- } \\
\text { experiment } \\
3^{\mathrm{a}}\end{array}$ & $\begin{array}{l}\text { Pre- } \\
\text { experiment }^{\mathbf{b}} \\
(7,7 \mathrm{X}, 7 \mathrm{Y})\end{array}$ & $\begin{array}{l}\text { Post- } \\
\text { experiment } \\
7 Y\end{array}$ \\
\hline & $\begin{array}{l}\text { Metal } \\
\text { (wt.\%) }\end{array}$ & $\begin{array}{l}\text { Metal } \\
\text { (wt.\%) }\end{array}$ & $\begin{array}{l}\text { Metal } \\
(w t . \%)\end{array}$ & $\begin{array}{l}\text { Dust } \\
(w t . \%)\end{array}$ & Metal & Metal \\
\hline $\mathrm{Pb}$ & Balance & Balance & Balance & Balance & Balance & Balance \\
\hline $\mathrm{Sb}$ & 4 & 2.14 & 9.00 & 15 & $<0.1 \mathrm{ppm}$ & $<16 \mathrm{ppm}$ \\
\hline Sn & 0.054 & -- & 0.113 & 10 & $<0.1 \mathrm{ppm}$ & $<16 \mathrm{ppm}$ \\
\hline As & 0.7 & 0.53 & 9.00 & 5 & $<0.1 \mathrm{ppm}$ & $<3 \mathrm{ppm}$ \\
\hline $\mathrm{O}_{2}$ & 0.0062 & -- & 0.0121 & 5.4 & -- & -- \\
\hline $\mathrm{Cr}$ & -- & -- & -- & -- & -- & $<0.5 \mathrm{ppm}$ \\
\hline $\mathrm{Fe}$ & -- & -- & -- & -- & -- & $1^{\mathrm{c}} \mathrm{ppm}$ \\
\hline $\mathrm{Ni}$ & -- & -- & -- & -- & $<0.1 \mathrm{ppm}$ & 1.4 ppm \\
\hline \multicolumn{7}{|c|}{$\begin{array}{l}\text { a. MIT analysis. } \\
\text { b. INEEL ICP analysis. } \\
\text { c. The measurements from the majority of the previously molten lead ranged from } 0 \text { to } 2 \mathrm{ppm} \text {. There was } \\
12 \text { to } 50 \mathrm{ppm} \text { iron in the } \mathrm{PbO} \text {, which was about } 3.3 \% \text { of the total lead removed after the test. } \\
\text {-- Measurement not taken. }\end{array}$} \\
\hline
\end{tabular}

As part of the MIT/INEEL collaboration on this research, we sent three samples to MIT for analysis from Experiment 3: the pre-experiment lead, the post-test drained metal, and the dust collected in the off-gas system. The MIT Plasma Science and Fusion Center sent the samples to an outside source that performed LECO and glow discharge mass spectrometry analysis of these samples. For comparison, the INEEL ICP laboratory also analyzed the pre-experiment lead shot used in Experiments 3 and 5 (second column of Table 59). The INEEL and MIT results are not consistent. However, the arsenic concentrations are closely linked to the antimony concentrations in the pre-experiment material used in Experiments 3 and 5. The arsenic is always about onefourth the concentration of the antimony. The results from the INEEL analysis are, in general consistent with the amounts of antimony and arsenic used in lead shot. However, the MIT LECO measurements gave the oxygen content, which, in the case of the dust sample, showed the expected stoichiometric amount expected for lead oxide. 
Also, in the INEEL analysis there appears to be one measurement, possibly one shot pellet, that has an extra high amount of antimony. The concentration of antimony in that pellet was more than twice the average value of the other four analyses. In fact, the level of 5.6\% is above the solid-state solubility limit of antimony in lead. This pellet would solidify with some eutectic two-phase composition. The minor phase would have a high concentration of antimony. Therefore, we conclude that all the results in Table 59 from both MIT and INEEL for Experiments 3 and 5 are suspect.

Metallic Solubility. Mass transfer is one factor that governs molten lead attack of steels and other metals, that is, the transfer of the structural materials into the molten-lead and by the molten lead. If the solubility of the structural materials in the lead is at saturation, then further dissolution is limited. This is why we used a large molten-lead mass relative to the sample weight. The highest solubility in molten lead of the metals tested is Ni (2 at.\% or about $5000 \mathrm{ppm}$ at $\left.550^{\circ} \mathrm{C}\right)$, followed by $\mathrm{Cr}$ and $\mathrm{Fe}\left(0.2\right.$ at. $\%$ or about $500 \mathrm{ppm}$ and $10^{-3}$ at. $\%$ or about $2.5 \mathrm{ppm}$ at $600^{\circ} \mathrm{C}$, respectively). The solubility of all materials in molten lead varies with temperature. Therefore, transport (flow) of material in solution from a higher solubility (higher temperature) region to a lower solubility (lower temperature) region may result in precipitation of the metallic material at the lower temperature locations. We investigated the metallic coupons under nearly isothermal conditions; therefore, we analyzed the solubility of $\mathrm{Ni}, \mathrm{Cr}$, and $\mathrm{Fe}$ in the post-test lead to determine if saturated conditions existed. Table 59 shows that the iron, chrome, and nickel in Experiment $7 \mathrm{Y}$ remained below the soluble limit, indicating the transfer of those metals from the coupons was not inhibited. However, there is an inconsistency between the amount of $\mathrm{Ni}$ observed in the post-experiment analysis of Experiment $7 \mathrm{Y}$ and that which one would expect due to the higher solubility of Ni. Relatively little $\mathrm{Ni}$ was observed in the $\mathrm{Pb}$. The combination of a higher solubility of Ni in the samples and the use of a Type 316 Stainless Steel test cell should have resulted in Ni being present in the post-test analysis at a higher level than all of the other constituents.

\subsubsection{Summary of the INEEL Corrosion Test Results}

Results of the corrosion research at the INEEL show that the type of material (alloy), molten lead chemistry conditions, and lead-purity affect the corrosion of structural materials in contact with molten lead. Five metal alloys were exposed to molten lead for about 100 hours at $500^{\circ} \mathrm{C}$. We have observed various types of corrosive or chemical attack on the solid metal alloy test coupons by the liquid lead and its contaminants. Zirconium was by far the least affected of the metal alloys tested. Some specific conclusions follow.

The SEM cross-section micrographs of the zirconium specimens, regardless of the experimental conditions, show that an oxide layer is retained, that apparently helps protect the base metal. A very low $\left(<10^{-50} \mathrm{~atm}\right)$ oxygen partial pressure is needed to dissolve these oxide layers. The oxygen partial pressure for the reducing experiments probably never got below $10^{-30}$ atm and, of course, was relatively high in the oxidizing experiments. There was very little damage to the zirconium specimens in any of the experiments.

The SEM cross-sectional views of the Type 316 stainless steel specimens tested under oxidizing conditions, show that the original polished surfaces remained relatively intact. The SEM photographs of the Type 410 stainless steel specimens tested under oxidizing conditions indicate some surface attack (apparent formation of an iron/chrome oxide layer containing lead) when the arsenic and antimony contamination was not present and significant erosion of the 
surface when the arsenic and antimony was present. The SEM micrographs of the F-22 carbon steel samples tested under oxidizing conditions when the arsenic and antimony contamination was not present show the formation of a thin iron oxide layer containing lead. $\mathrm{FeAs}$ and $\mathrm{FePb}$ reaction layers appeared during the experiment with oxidizing conditions and arsenic and antimony contamination.

For the Type 316 and 410 stainless steel and F-22 carbon steel specimens exposed to reducing chemistry conditions and molten lead with significant arsenic and antimony contamination (Experiment 5), the SEM cross-sections show significant attack by the lead, arsenic, and antimony, forming a multi-layered scale, as shown in Figures 166, 168, and 170. The top light layer is the lead. The next two layers are comprised of mixtures of mostly FeAs, with small quantities of the base metal alloying elements in the upper FeAs layer and more representative quantities of the chrome and significant lead in the lower FeAs layer. At the interface of the Type 316L stainless steel lower FeAs layer and the base metal is a very thin layer rich in antimony, iron, nickel, arsenic, chrome, and lead.

For the Type 316 and 410 stainless steel and F-22 carbon steel specimens exposed to reducing chemistry conditions and lead without significant arsenic and antimony contamination, (Experiment 7), the SEM cross-sections show significant attack of the Type 316 and F-22 carbon steel surfaces by the molten lead, but little attack of the Type 410 stainless steel surface.

Development of an understanding of the interactions between arsenic, antimony, and lead and the iron-base materials would require a much more detailed investigation. A number of potential explanations are possible. However, for each potential explanation there are contradictions and/or unknowns that make a complete analysis difficult. The reaction layers under reducing conditions consist of a two-layer morphology where the primary constituents are iron and arsenic. The outer layer, exposed to the liquid metal, is essentially FeAs. FeAs is an intermetallic compound that could be confirmed by X-ray analysis. The inner layer, adjacent to the un-reacted metal, is mostly iron and arsenic, but contains a higher fraction of iron then the FeAs composition. Nickel is essentially absent from the layers. An important question that needs to be answered is where has the nickel gone to? If the nickel was rejected to the metal during the process there should have been a layer enriched in nickel. If the nickel was dissolved in the lead, indicating that the arsenic replaced the nickel in the matrix (even though the amount of nickel available would have been less than the amount of arsenic present) then the nickel content of the lead bath should have reflected this. Due to the nature of the setup no accurate mass balance could be performed. Additionally, sufficiently accurate measurements of the specimen dimensions, such that the nature of the layer growth (penetration, replacement, etc.) could be determined, was not possible. Another possibility is that the nickel may have been transported to a lower temperature part of the cell and precipitated. Verification of this would require destructive analysis of the cell.

Thus, while a complete analysis of the interaction of arsenic with the Fe-Ni-Cr alloys would yield some very interesting, and potentially very important, fundamental understanding, the present results do not allow for a complete analysis. Additionally, since actual lead-bismuth systems will not contain arsenic and antimony, pursuit of an explanation may not be important to the solution of the immediate materials issues in lead-bismuth systems. 


\subsection{Oxygen Probe Development (Drs. Galen Smolik and Eric Loewen)}

This section summarizes the activities and results associated with the development of an oxygen potential probe to support the molten metal corrosion experiments. An initial probe design used a 10-mm diameter yttria-stabilized zirconia tube. The configuration of the $45 \mathrm{~mm}$ long probe contained in a closed-end alumina tube with a water- cooled flange was illustrated in the previous annual report. Problems were encountered maintaining the seal at the water-cooled flange and good contact at the inner and outer platinized surfaces of the closed-end zirconia tube. A second design was pursued using automotive oxygen sensors. This approach would benefit from the processing experience established in preparing the platinum contacts and leads on the automobile sensors. A couple of different models of the automobile sensors were tested. The sensors were mounted and contained on stainless steel extension tubes to allow the use of a Pt-air reference junction. These probes were tested in low oxygen bearing gases, other gas mixtures and given a limited exposure in a Pb-Bi melt at the INEEL. Some probes were also provided to the KALLA Laboratory in Germany for comparison and calibration with their probes. The results and conclusion from these activities are reported below.

\subsubsection{Test Results from Initial $\mathrm{Y}_{2} \mathrm{O}_{3}$-stabilized Zirconia Probe}

Several test runs were performed with the $\mathrm{Y}_{2} \mathrm{O}_{3}$-stabilized zirconia probe. The alumina enclosure tube was inserted and heated in a resistance heated tube furnace. The probe assemble was purged with argon and a calibration gas containing $1 \mathrm{ppm}$ oxygen in helium. Emf recordings were then taken as the probe was heated to various temperatures ranging up to $800^{\circ} \mathrm{C}$. On several occasions the emf signal would undergo sudden changes. These changes were often found to be associated with a loss of the seal at the gasket between the flange and the alumina tube. On a few occasions it appeared as if good contact between the platinum lead and the internal surface of the $\mathrm{Y}_{2} \mathrm{O}_{3}$-stabilized zirconia tube was lost.

On one run with the 1-ppm oxygen reference gas we obtained consistent measurements for eight hours. Plots of temperature and potential are shown in Figure 187 for this run. The system was initially maintained under vacuum during the heat-up to $600^{\circ} \mathrm{C}$. The 1-ppm standard was then introduced at 300 minutes into the run. The potential increased abruptly indicating a decrease in the oxygen activity. The potential stabilized quite rapidly at $600^{\circ} \mathrm{C}$ and at the other higher temperatures of 700 and $800^{\circ} \mathrm{C}$. Oxygen potentials are calculated at the various temperatures assuming the Nernst relationship. These calculated potentials are shown in Figure 187 and are significantly below $1 \times 10^{-6}$ atmosphere expected from the reference gas. They also do not show the linear temperature dependence expected from the Nernst relationship. We expect that the very low oxygen content of the reference gas reacted with some reducing agent, perhaps some organic species out-gassed from the gasket material. The several factors causing a lack of consistency in cell performance caused us to realize the need for a new cell design and the use of better cell such as one that would use vacuum tight seals at the flange. 


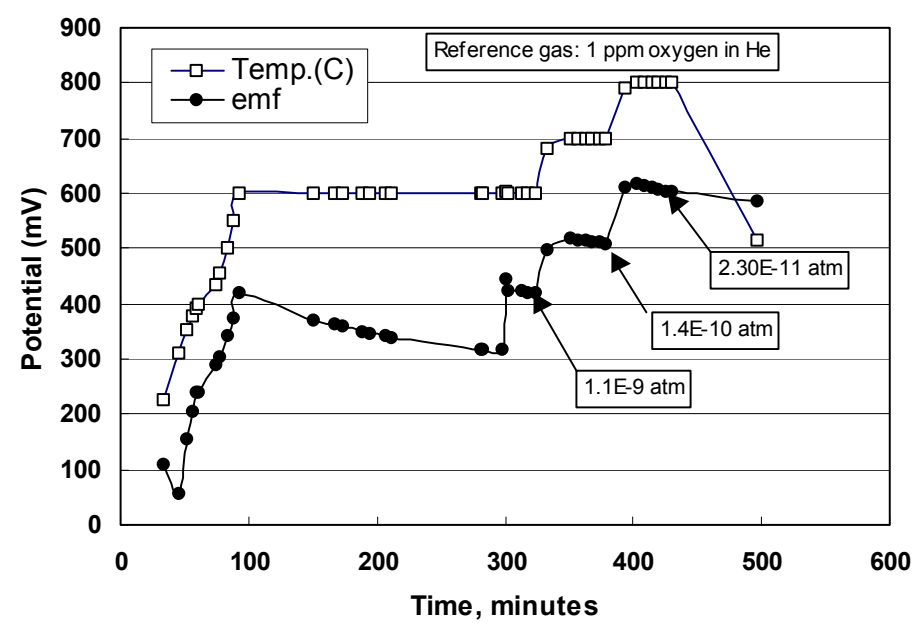

Figure 178. Potential and temperature plots from a run with the INEEL probe using a reference gas with 1 ppm oxygen in helium.

\subsubsection{Design of Probes Using Automotive Oxygen Sensors}

We obtained two different types of off-the-shelf automobile sensors to use as the ceramic substrate and contact leads for an oxygen probe. One sensor manufactured by Bosch was identified as Model SG-300. The other sensor was a generic sensor identified as SG-12. We removed the protective metallic tip from the sensors, exposing the ceramic cone containing the ceramic electrolyte, the platinum contacts, and a protective porous ceramic layer. The sensor cones were already mounted in a metal fixture that threads into the engine exhaust manifold. We mounted these metal fixtures onto stainless steel tubes as shown in Figure 179. The illustration also shows an insulated lead connecting to the platinum contact inside the sensor and a shielded thermocouple. The thermocouple junction was directly attached on sensor metal fixture. The schematic in Figure 179 illustrates the Pt-air reference junction at the internal region of the sensor. The gas or molten metal for which the oxygen activity is to be measured contacts the outer surface of the cone-shaped $\mathrm{Zr}_{2} \mathrm{O}_{3}-\mathrm{Y}_{2} \mathrm{O}_{3}$ electrolyte.

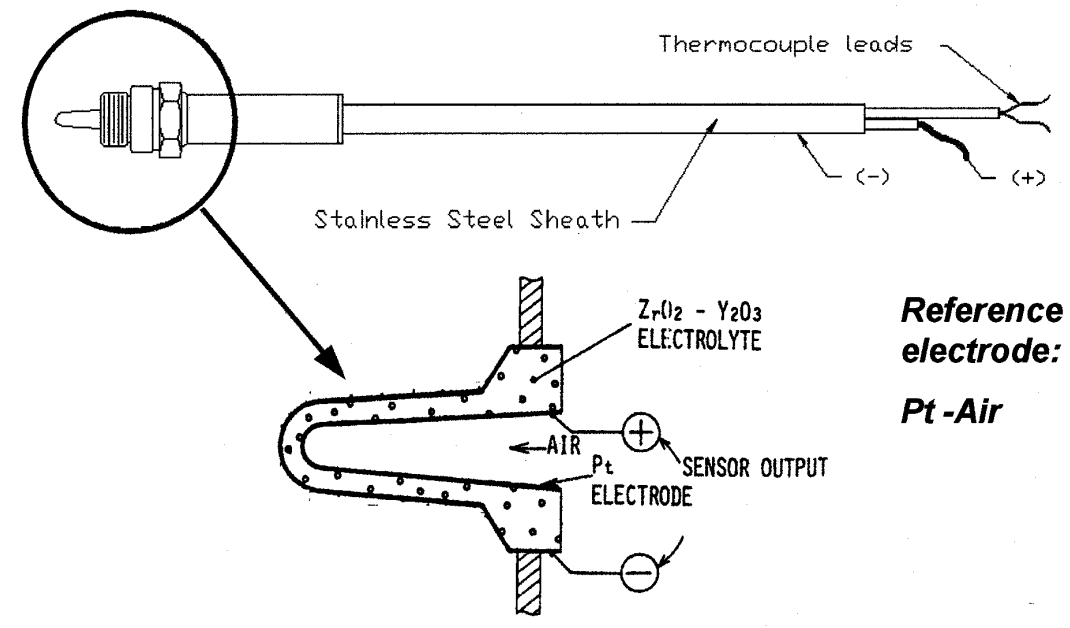

Figure 179. Illustration of oxygen probes prepared from automotive oxygen sensors. 


\subsubsection{Experimental Results from the Newly Designed Oxygen Sensors}

Four different types of experiments were conducted with the new oxygen sensors designed from the automotive sensors: 1) Tests performed in gas environments in the large $\mathrm{Pb}-\mathrm{Bi}$ corrosion cell, 2) A test in a Pb-Bi melt in the large test cell, 3) Tests in the KALLA facility in Germany, and 4) Tests in gas mixtures in a small cell equipped with an ultra-high vacuum (UHV) seal on the top flange. These will each be discussed separately.

\subsubsection{Gas Exposure Experiment Performed in the Large Corrosion Cell.}

The top flange of the corrosion cell was modified to accommodate ports for the oxygen probes. Figure 180 shows the protrusion of the sensors through the bottom of the top flange plate. The two different types of automobile sensors, extending only a short distance through the top plate, still have their protective metal shield. The yellow tube is the earlier design probe, i.e., the one using a closed end $\mathrm{Y}_{2} \mathrm{O}_{3}$-stabilized zirconia tube. We attempted to use spring loading to maintain pressure on the internal platinum contact. The smaller white ceramic tube contains the Pt lead and thermocouple attached to the end of the zirconia tube. A thermocouple and a gas inlet tube are the other penetrations. In addition, automotive oxygen sensors of each type were threaded into the bottom of the test cell.

Figure 181 shows the top flange plate mounted onto the test cell. An O-ring was used to seal the flange plate to the test chamber. The chamber was initially purged with argon. The two sensors at the top near the water-cooled flange never reached high enough temperatures to provide meaningful readings. Although measurements varied somewhat between the two automotive sensors at the bottom, they

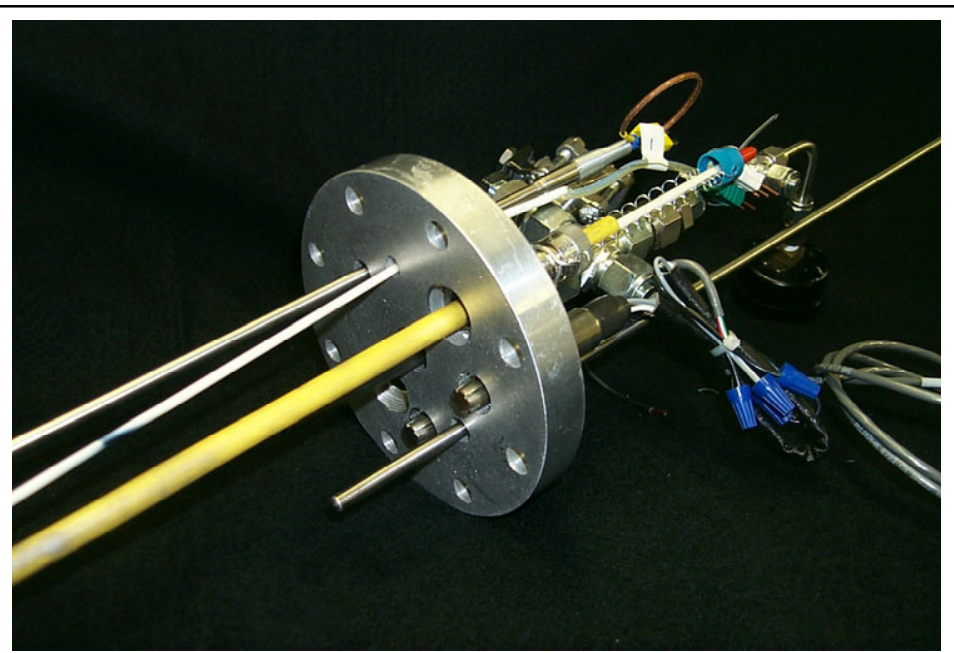

Figure 180. Top flange plate for the large corrosion cell showing penetrations with various types of oxygen sensors.

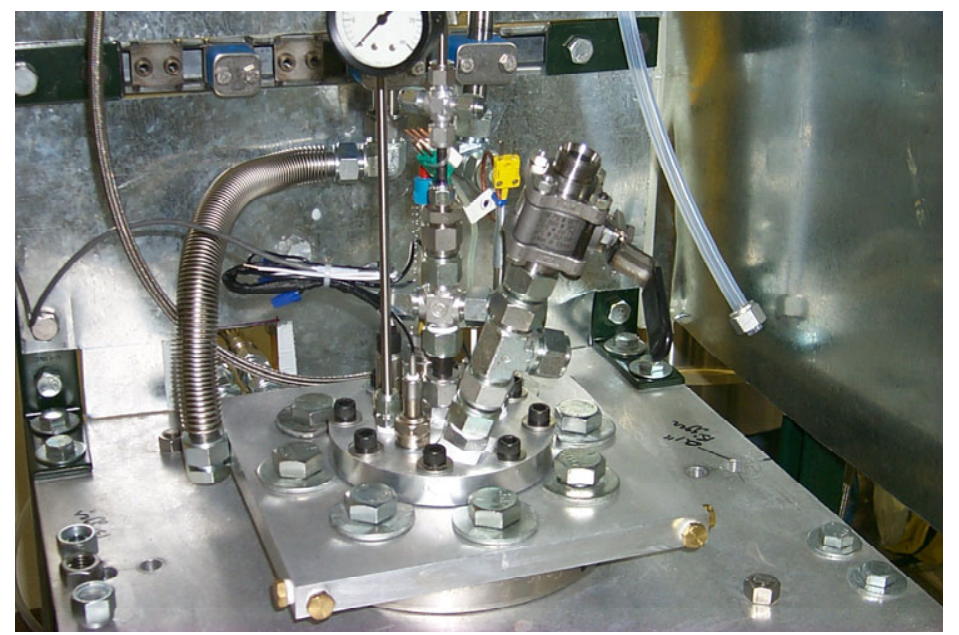

Figure 181. Photograph showing a top view of the corrosion cell containing the oxygen sensors.

generally provide similar readings and trends as the test gas was changed. Measurements from the yellow $\mathrm{Y}_{2} \mathrm{O}_{3}$-stabilized zirconia tube were quite different than the measurements from the 
automobile probes, which we attribute to contact problems at the platinum junctions. The use of this probe was therefore discontinued. Temperatures at the bottom of the cell near the two oxygen sensors were about $465^{\circ} \mathrm{C}$. We found that readings from these two sensors were affected by the flow rate of argon through the test chamber. The potential increased as the flow rate was increased. This indicates a decrease in oxygen activity with higher flow rate. These trends are what we would expect when a system leaks and oxygen penetrates into the test cell. Emf recordings increased dramatically to values of around $1000 \mathrm{mV}$ when a $2 \% \mathrm{H}_{2}$ - Ar mixture was introduced at a significant flow rate, i.e., around $400 \mathrm{sccm}$. These trends and results, repeated on two separate runs, are shown in Figure 191. The plots show the rather good agreement between the two different types of sensors. The potentials of approximately $45 \mathrm{mV}$ at $465^{\circ} \mathrm{C}$ with argon flow of about $400 \mathrm{sccm}$ would indicate an oxygen pressure of around 0.01 atmosphere. This strongly supports that air was leaking into the cell. We believe that the air leaks could have occurred at the drain plug at the bottom of the cell. On the other hand potentials of approximately $1000 \mathrm{mV}$ indicate that the small hydrogen introduction decreased the oxygen activity to around $10^{-20}$ atmosphere. This demonstrates the strong reduction potential of this gas.
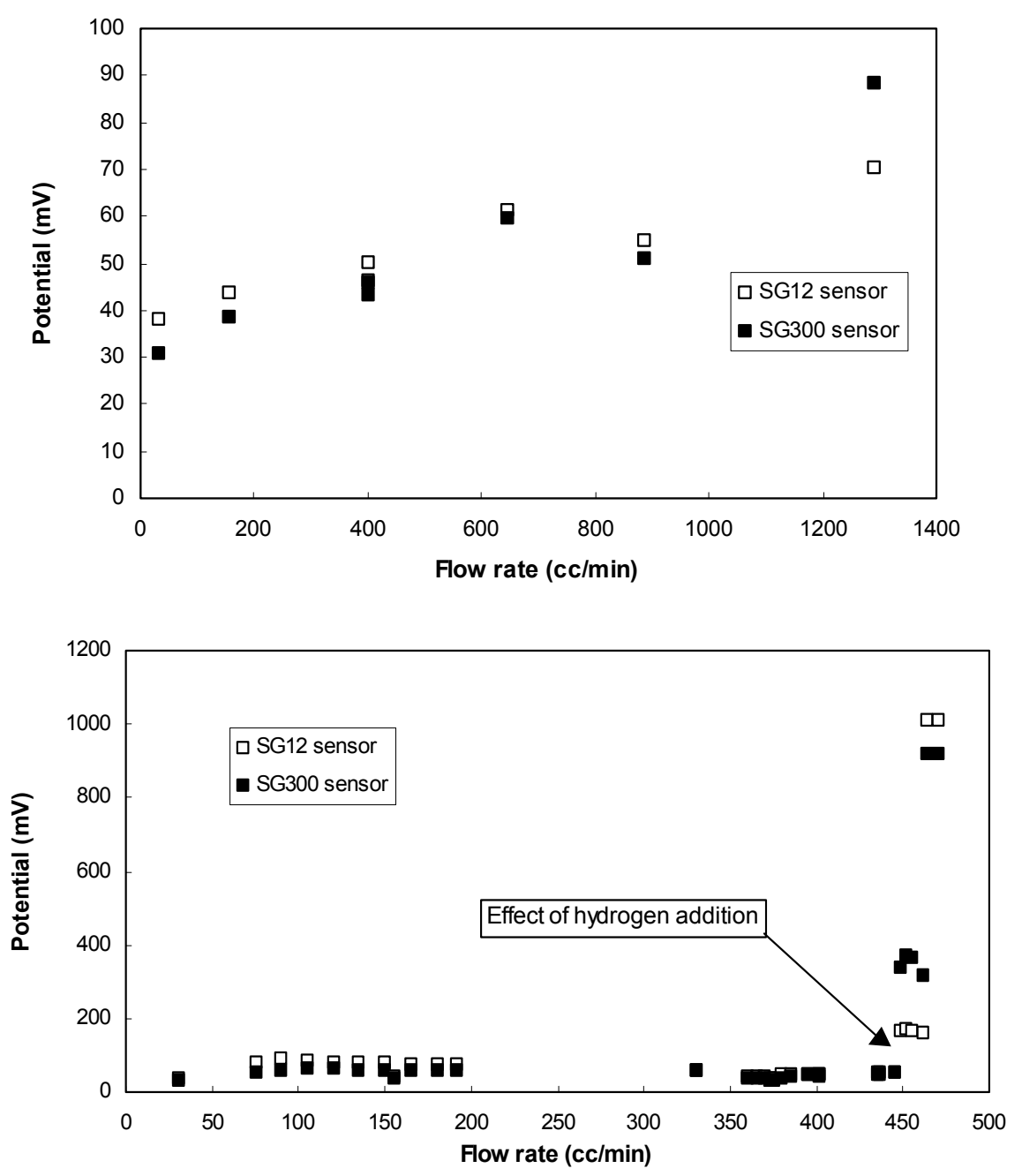

Figure 182. Plot showing influence of flow upon potential (top). Plot showing the strong of hydrogen upon oxygen potential (bottom). 


\subsubsection{Test in Molten Pb-Bi Melt at the INEEL}

A test was run using the automotive sensors in a $\mathrm{Pb}$ - $\mathrm{Bi}$ mixture consisting of $52 \mathrm{w} / \mathrm{o}$ lead and $48 \mathrm{w} / \mathrm{o}$ bismuth. A sensor of each type was threaded the bottom of the test cell while a SG-12 sensor was positioned in the gas phase about $12 \mathrm{~cm}$ above the level of the melt. Potentials were recorded after the charge was melted while it was injected with nitrogen, then with a $2 \%$ oxygenargon mixture, then purged overnight with nitrogen and finally injected with $2 \%$ hydrogen-argon mixture.

The potentials recorded from the three sensors during this time are shown plotted in Figure 183. Sensor 1 (the Bosch SG-300) and Sensor 2 (the SG-12 model) remained between 515 to $525^{\circ} \mathrm{C}$ during the run. The third sensor of the SG-12 type in the gas phase operated around $415^{\circ} \mathrm{C}$. During the initial nitrogen lance the recording from the two sensors in the melt were quite similar. When oxygen was introduced both sensors showed an increase in potential and then a gradual decrease over a couple of hours. Potentials from the SG-12 type sensor decreased relative to those from the Bosch SG-300 sensor and ultimately decreased to less than one-half during the overnight nitrogen purge.

When hydrogen was introduced the next morning the sensor in the gas phase increased to values of over $1000 \mathrm{mV}$. Neither sensor in the melt showed much response to the hydrogen purge, instead they continued their downward trend. This suggests that the decrease in oxygen activity in the gas phase did not reduce the activity in the molten metal. Perhaps a significant amount of oxide formed during the oxygen treatment and enough time was not allowed to have the hydrogen reduce the oxide and attain equilibrium and thus change the activity in the melt. We cannot explain the different response between the two sensors, nor do we know if the integrity of the sensors changed due to the molten metal exposure. However, a plot of the potentials in Figure 184 shows that the ranges from the Bosch SG-300 sensor for each gas treatment phase lie within the temperature versus potential envelope established by KALLA.

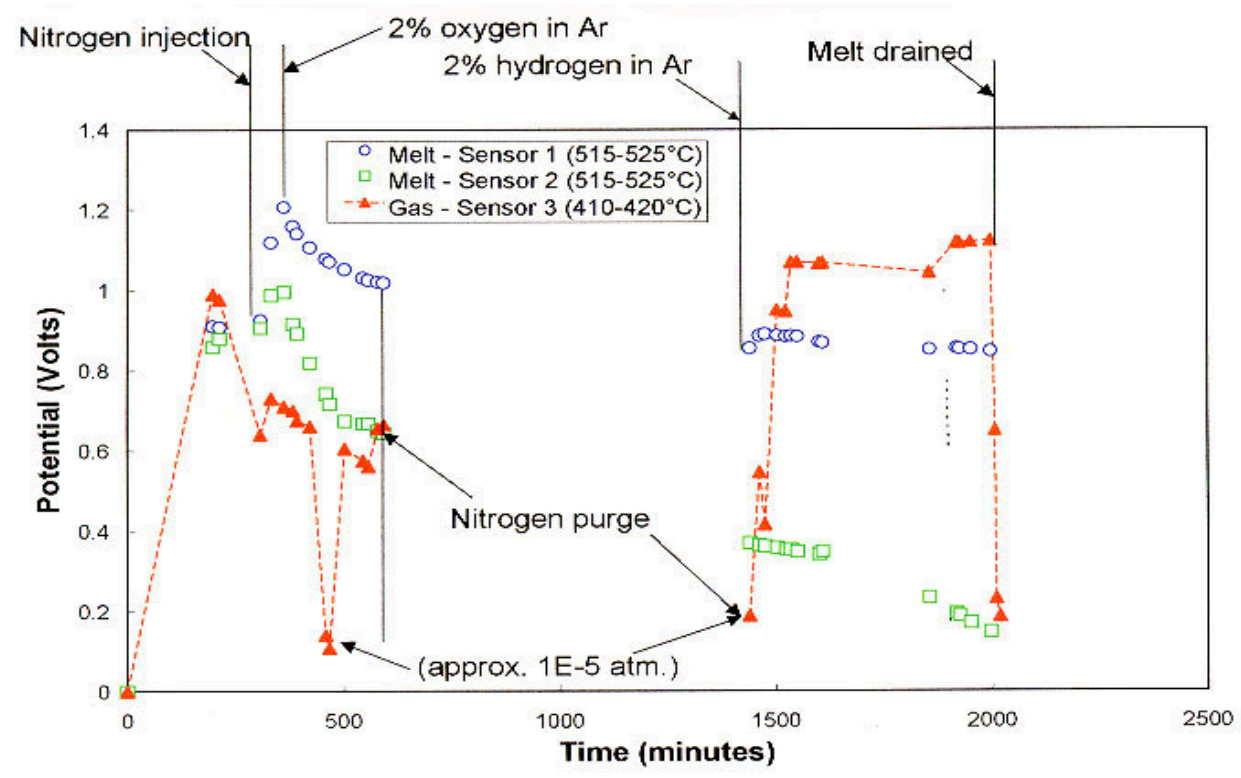

Figure 183. Potentials recorded on oxygen sensors during a test run with a lead-bismuth melt. 


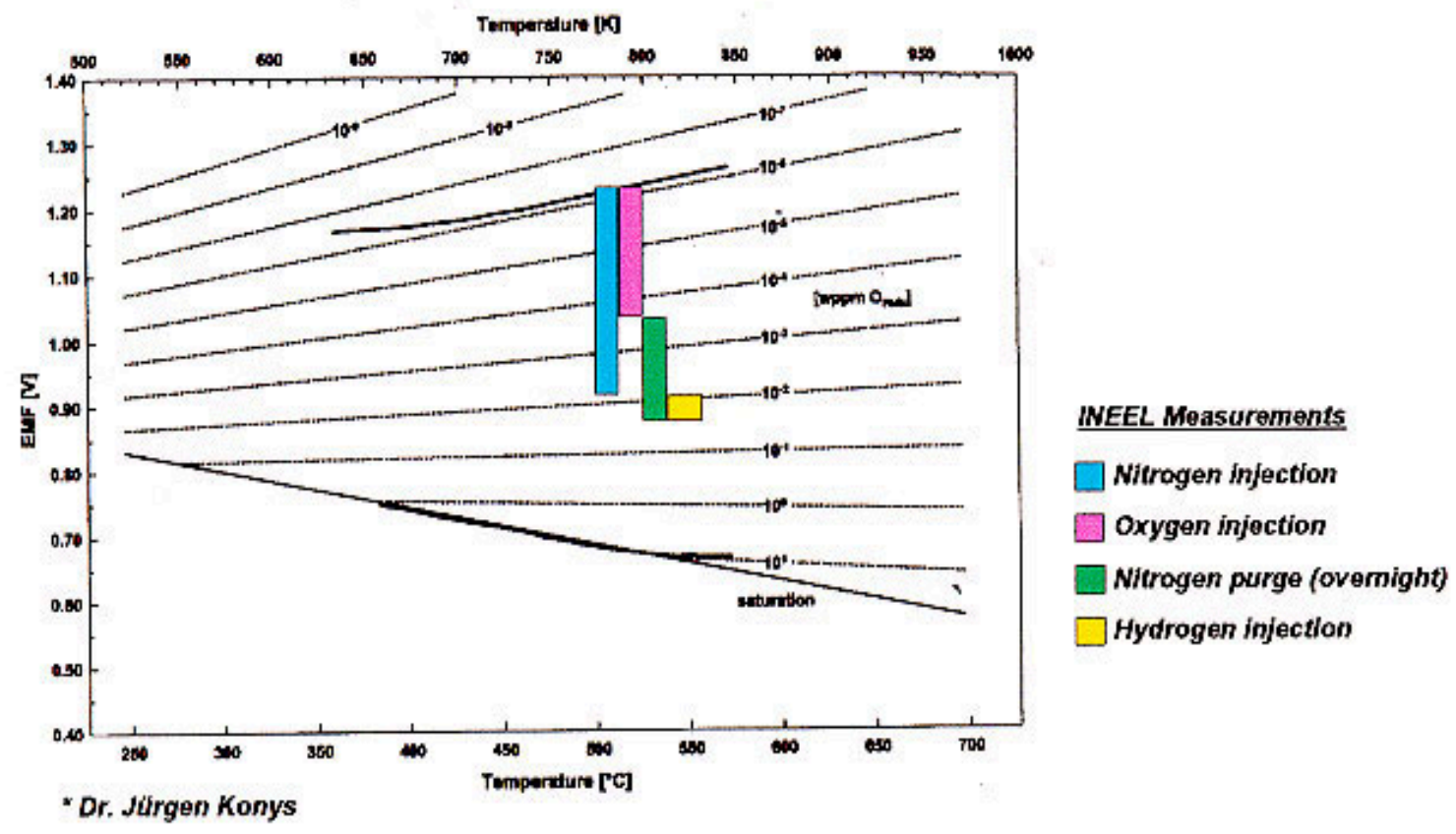

Figure 184. Plot of potentials from INEEL sensors compared with potential versus temperature envelope from KALLA.

\subsubsection{Results from INEEL Sensors Sent to KALLA}

Two of each type of the automotive sensors prepared as probes shown in Figure 179 were sent to KALLA in Germany to be compared with the performance of their probes and calibrated in a system with a known oxygen activity. The performance in a gas phase with defined $\mathrm{H}_{2}$ to $\mathrm{H}_{2} \mathrm{O}$ ratios were used to compared the different types of probes. KALLA reported good agreement between the dependency of the emf and expected oxygen partial pressures for the various probes, however, the probes showed different offset values. Potential measurements in a flowing lead-bismuth loop were lower than expected for all probes including their own. They have therefore assembled a stagnant system for calibration and are currently setting up to test several probes at one time. We hope to thusly obtain calibrated probes to provide a means for cross checking oxygen activities for our studies.

\subsubsection{Tests of New Probes in Small Calibration Cell}

A small cell about $3.5-\mathrm{cm}$ diameter $\mathrm{x} 18-\mathrm{cm}$ depth was prepared from stainless steel tubing. This cell is shown in Figure 185 to the right and was fitted with a UHV top flange using Con-Flat seals with a copper gasket. The top flange was water-cooled and the gas inlet and outlet ports were welded to ensure no leakage.

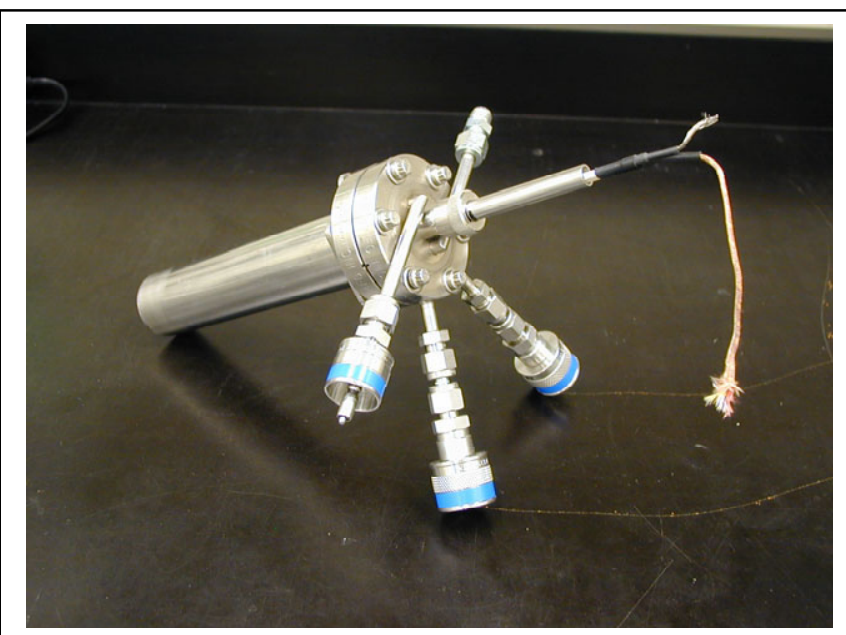

Figure 185. Small calibration cell and oxygen probe prepared from automobile sensors. 
A series of tests were run over several days with different gases and flow rates. The results from these tests are shown in Table 63. The cell was positioned in a small vertically mounted tube furnace with the temperature maintained near $700^{\circ} \mathrm{C}$. The thermocouple attached to the top end of the sensor, however, was a couple of inches above the hot zone indicated a temperature of about $490^{\circ} \mathrm{C}$ throughout the test series. The stainless steel surfaces of the chamber and tubes containing the sensor had an initial un-oxidized metallic condition. We found that this initial condition influenced emf outputs for gases with low oxygen content. The data in Table 63 show that when the flow of such gases was shut off or reduced, the potential generally increased. We believe this reflects the consumption of a very small amount of oxygen as the internal surfaces are oxidized.

We then exposed the cell to a gas containing 2 percent oxygen for about 2.5 hours. The readings then became quite stable irrespective of flow rate. The potential of about $44 \mathrm{mV}$ applied to the Nernst equation provides an oxygen pressure of about 0.01 atmosphere. This is close to our input gas composition. After the oxidation or passiviation from the oxygen bearing gas, we obtained more stable indications from the gases with low oxygen partial pressures. However, we still observed some small changes in emf output when the flow rates were changed but these changes were a lot smaller, e.g., 10 $\mathrm{mV}$, and slower than observed from the initial test.

The condition of the oxygen sensor after the exposures in the gases is shown in Figure 186. Oxidation of the stainless steel components is apparent. The second photograph shows a close-up of the sensor showing the network of the platinumsubstrate contact revealed after the outer porous ceramic was removed by grinding. We found that the platinum contact for the Bosch sensors had better coverage and adherence than the other types of automobile sensors. In conclusion we found that the metallic condition of components in environments of low oxygen partial pressures need to be considered. The surfaces should be oxidized or passivated.
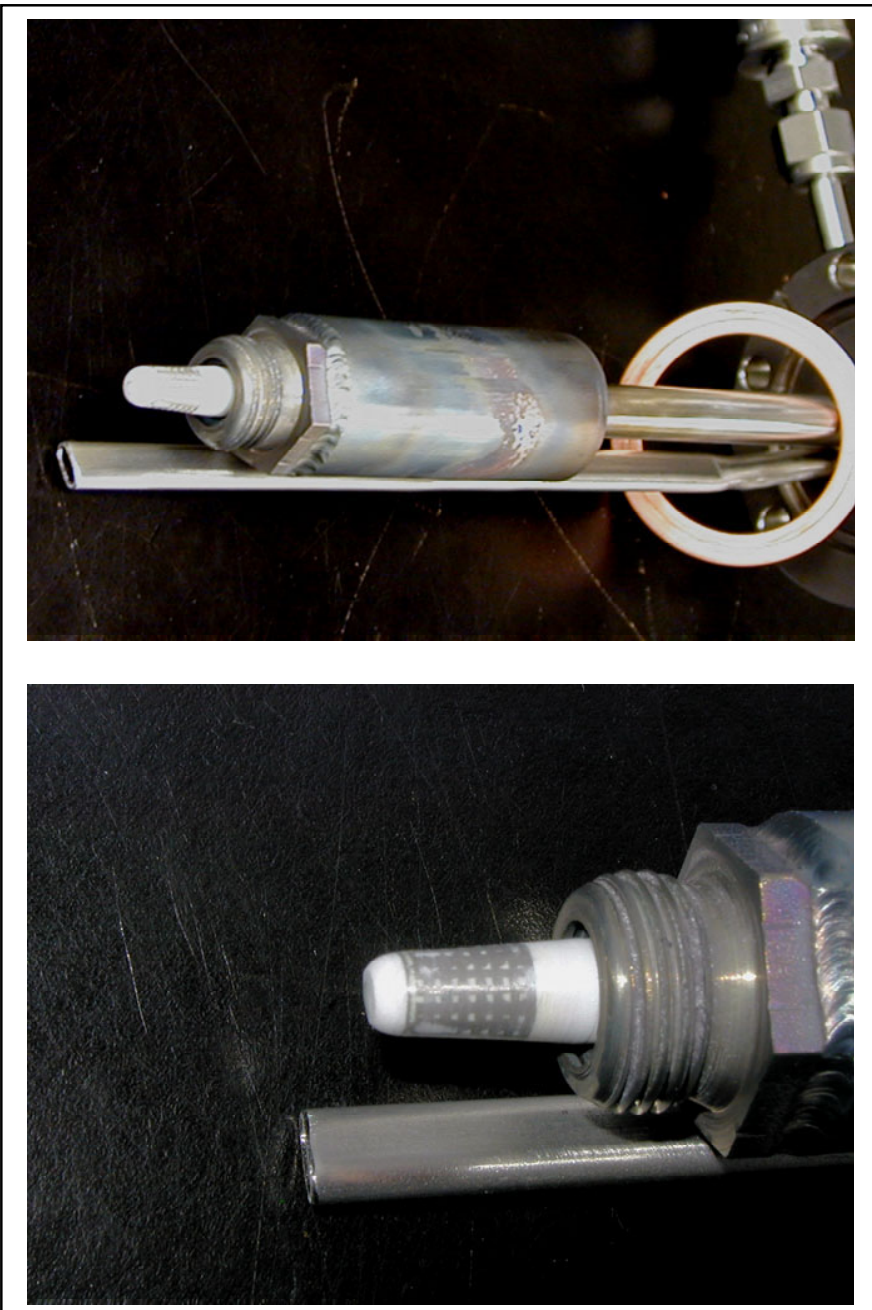

Figure 186. Oxygen sensor exposed to the various gases in the small calibration cell. Note the oxidized surfaces developed during the exposure to low oxygen environments and the good platinum contact on the Bosch probe. 
Table 63. Description of activities and emf recordings from $\mathrm{O}_{2}$ probe in small calibration cell.

\begin{tabular}{|c|c|c|c|c|}
\hline Activities & $\begin{array}{l}\text { Flow rate, } \\
\text { Sccm }\end{array}$ & $\begin{array}{l}\text { Emf, } \\
\text { mV }\end{array}$ & Time & $\begin{array}{l}\text { Calculated } \\
\mathrm{PO}_{2} \text {, } \\
\text { atmosphere }\end{array}$ \\
\hline \multirow[t]{2}{*}{ Purge with Praxair Ar (99.9999\%) } & 155 & $\sim 1000$ & initial & \\
\hline & & $\sim 750$ & after 6 hours & \\
\hline \multirow[t]{2}{*}{ Switch to standard grade of $\mathrm{Ar}$} & 155 & $\sim 840$ & initial & \\
\hline & & $\sim 685$ & after 14 hours & \\
\hline Shut off flow & 0 & $\sim 735 \uparrow$ & after 2 minutes & \\
\hline Restart flow & 155 & $\sim 699 \downarrow$ & after 2 minutes & \\
\hline Increase flow rate & 600 & $\sim 670 \downarrow$ & after 2 minutes & \\
\hline Decrease flow rate & 155 & $\sim 685 \uparrow$ & after 5 minutes & \\
\hline Continued flow & 155 & $\sim 671 \downarrow$ & after 1.2 hours & \\
\hline Shut off flow & 0 & $\sim 716 \uparrow$ & after 2 minutes & \\
\hline Restart flow & 155 & $\sim 680 \downarrow$ & after 5 minutes & \\
\hline By-passed flow meter with std. Ar & Est. as $\sim 150$ & $\sim 710$ & after 1.5 hours & \\
\hline \multirow{2}{*}{$\begin{array}{l}\text { Shut off flow } \\
\text { Restart flow }\end{array}$} & $\sim 150$ & $\sim 770 \uparrow$ & after 3 minutes & \\
\hline & $\sim 150$ & $\sim 795 \uparrow$ & after 15 minutes & \\
\hline Shut off flow & $\sim 150$ & $\sim 825 \uparrow$ & after 2 minutes & \\
\hline Restart flow & $\sim 150$ & $\sim 789 \downarrow$ & after 2 minutes & \\
\hline \multirow{2}{*}{$\begin{array}{l}\text { Increase flow rate } \\
\text { Decrease flow rate }\end{array}$} & $\sim 600$ & $\sim 595 \downarrow$ & after 10 minutes & \\
\hline & $\sim 155$ & $\sim 857 \uparrow$ & after 50 minutes & \\
\hline \multirow[t]{2}{*}{ Start purge with $2 \% \mathrm{O}_{2}$ in argon } & 400 & $\sim 49.7$ & initial & \\
\hline & & $\sim 46.5$ & after 1 hour & \\
\hline Shut off flow & 0 & $\sim 49.1 \uparrow$ & after 10 minutes & \\
\hline Restart flow & 400 & $\sim 44.0 \downarrow$ & after 1.5 hours & \\
\hline \multirow{2}{*}{$\begin{array}{l}\text { Shut off flow } \\
\text { Restart flow }\end{array}$} & 0 & $\sim 44.3 \rightarrow$ & after 10 minutes & \\
\hline & 400 & $\sim 44.0 \rightarrow$ & after 5 minutes & 0.012 \\
\hline \multirow[t]{2}{*}{ Switch to standard grade of $\mathrm{Ar}$} & 155 & $\sim 68$ & initial & \\
\hline & & $\sim 165$ & after 15 minutes & \\
\hline Increase flow rate & 500 & $\sim 177 \uparrow$ & after 10 minutes & \\
\hline Decrease flow rate & 155 & $\sim 172 \downarrow$ & after 5 minutes & \\
\hline Shut off flow & 0 & $\sim 198 \uparrow$ & after 5 minutes & \\
\hline \multirow{2}{*}{$\begin{array}{l}\text { Restart flow } \\
\text { Purged overnight } \\
\end{array}$} & 155 & $\sim 171 \downarrow$ & after 10 minutes & \\
\hline & $\sim 10$ & $\sim 159 \downarrow$ & after 15 hours & \\
\hline \multirow[t]{2}{*}{ Start purge with $1 \mathrm{ppm} \mathrm{O}_{2}$ in $\mathrm{He}$} & 155 & $\sim 135$ & initial & \\
\hline & & $\sim 180 \uparrow$ & after 30 minutes & $3.1 \mathrm{E}-6$ \\
\hline Increase flow rate & 500 & $\sim 192 \uparrow$ & after 15 minutes & $1.7 \mathrm{E}-6$ \\
\hline Decrease flow rate & 155 & $\sim 184 \downarrow$ & after 10 minutes & $2.4 \mathrm{E}-6$ \\
\hline \multirow[t]{2}{*}{ Purge with Praxair Ar (99.9999\%) } & 155 & $\sim 152$ & initial & \\
\hline & & $\sim 172 \uparrow$ & after 10 minutes & $4.7 \mathrm{E}-6$ \\
\hline Increase flow rate & 500 & $\sim 182 \uparrow$ & after 10 minutes & $2.8 \mathrm{E}-6$ \\
\hline Decrease flow rate & 155 & $\sim 175 \downarrow$ & after 10 minutes & $4.4 \mathrm{E}-6$ \\
\hline
\end{tabular}




\subsubsection{Conclusions and Future Plans}

We find that the oxygen probes developed from automotive sensors show promise. They seem particularly sensitive to measuring oxygen activities in the gas phase. We found that the condition of metallic components, i.e., un-oxidized or passiviated, and flow rates strongly influence the emf readings in environments with very low oxygen contents. The low amounts of oxygen may be gettered by the reactive surfaces. This is a consideration that needs to be kept in mind when using these techniques in experimental measurements.

The performance and calibration of the oxygen sensors in molten metals still needs to be accomplished. We anticipate obtaining collaborative results from the sensors that we supplied to KALLA. They are continuing to evaluate their performance in molten metal systems. 


\section{Results of the Coolant Activation Studies}

One of the important issues associated with using lead-bismuth as a reactor coolant is the radiological hazard associated with activation of the lead-bismuth in such a reactor. Polonium210 (an extremely toxic alpha-emitter of approximately 140 days half-life) is formed from ${ }^{209} \mathrm{Bi}$ by neutron capture according to the following reaction:

$$
{ }^{209} \mathrm{Bi}+n \rightarrow{ }^{210} \mathrm{Bi} \underset{t_{1 / 2}=5 \text { days }}{\stackrel{\beta^{-}}{\rightarrow}}{ }^{210} \mathrm{Po} \underset{t_{1 / 2}=138 \text { days }}{\stackrel{\alpha}{\longrightarrow}}{ }^{206} \mathrm{~Pb}
$$

In a typical lead-bismuth cooled reactor the primary system is sealed and segregated from the secondary system by the steam generator. As a result, polonium is retained in the lead-bismuth eutectic during normal operating conditions and can cause problems only if coolant leakage occurs. However, some polonium migrates to the cover gas in the reactor plenum and will diffuse outside the primary system when the reactor is opened for refueling and maintenance. Recent studies within the framework of the Los Alamos National Laboratory ATW project [Li 1998] indicate that exposure of plant personnel to polonium can be maintained within tolerable limits even in the event of a massive release of the cover gas or coolant into the reactor room. Nevertheless, due to its long half-life, ${ }^{210}$ Po may limit access to the surfaces on which it deposits, thus increasing maintenance costs and/or collective doses.

Considerable experience in dealing with polonium related issues has been gained in the past 30 years in Russia where several submarines were equipped with lead-bismuth cooled nuclear reactors [Pankratov 1992, Zrodnikov 1999]. A polonium technology was developed that includes special polonium filters for air cleaning, polonium adsorbing adhesive films for decontamination of large surfaces, special respirators, and pressurized suits for maintenance of contaminated areas [Pankratov 1992].

The polonium hazard can be significantly reduced by continuous on-line polonium extraction from the reactor coolant because the rate of polonium release under any circumstance is proportional to the polonium concentration in the lead-bismuth melt. Even small rates of polonium extraction can result in a considerable reduction of the polonium concentration in leadbismuth. However, it should be emphasized that, despite the construction of several submarine lead-bismuth reactors in the former Soviet Union, there is no industrially established and proven polonium extraction technology in the West. The development of such technology is the objective of the proposed work.

When generated in the lead-bismuth, polonium rapidly forms a rather stable compound with lead, known as lead polonide, PbPo [Feuerstein 1992, Gromov 1996], which is then the initial chemical species all polonium extraction systems ought to focus upon. Five chemical/physical mechanisms of $\mathrm{PbPo}$ removal from the lead-bismuth are being evaluated in this project:

1) Polonium Hydride Stripping. Formation of the volatile polonium hydride from the reaction of hydrogen gas with polonium-contaminated lead-bismuth:

$$
\mathrm{PbPo}+\mathrm{H}_{2} \rightarrow \mathrm{H}_{2} \mathrm{Po}+\mathrm{Pb}
$$

2) $\mathrm{PbPo}$ Distillation. Direct high temperature evaporation of the lead polonide. 
3) Alkaline Extraction. Formation and separation of sodium polonide from the reaction of molten sodium hydroxide with polonium contaminated lead-bismuth:

$$
\mathrm{PbPo}+4 \mathrm{NaOH} \leftrightarrow \mathrm{Na}_{2} \mathrm{Po}+\mathrm{Na}_{2} \mathrm{PbO}_{2}+2 \mathrm{H}_{2} \mathrm{O}
$$

4) Electro-deposition (or electroplating). Deposition of the lead polonide induced by the application of an electric field.

5) Formation of Rare-Earth Polonides. Removal of polonium by forming solid polonide species with Praseodymium or Thulium.

In the following sections, a summary of the work done at the INEEL and MIT in the areas of polonium hydride stripping, alkaline extraction, formation of rare-earth polonides, electrodeposition of polonium, and modeling of polonium removal systems is reported. Polonium hydride stripping is analyzed in some detail, while only preliminary considerations are made for the formation of rare-earth polonides.

\subsection{Chemistry and Kinetics of Polonium Hydride (MIT, Prof. Ken Czerwinski, Chris Larsen)}

The formation and release of polonium hydride upon mixing of a high temperature LBE melt with steam was studied at MIT as part of the feasibility study of an LBE/water direct contact heat transfer fast reactor [Buongiorno 2000]. The following reaction was investigated:

$$
\mathrm{PbPo}+\mathrm{H}_{2} \mathrm{O} \rightarrow \mathrm{H}_{2} \mathrm{Po}+\mathrm{PbO}
$$

which can be obtained from Eq.2 by subtracting the lead/lead oxide equilibrium:

$$
\mathrm{Pb}+\mathrm{H}_{2} \mathrm{O} \leftrightarrow \mathrm{H}_{2}+\mathrm{PbO}
$$

Samples of pure bismuth were irradiated in the MIT research reactor to produce Po- 210 . They were then mixed with pure lead, and melted. The specific activity of polonium in $\mathrm{Pb}-\mathrm{Bi}$ melt was measured by dissolving small masses in $\mathrm{HNO}_{3}$, which were counted in a liquid scintillation counter. The process allowed minimal vapor release in the dissolving process and multiple samples to be analyzed, yielding an accurate assessment of the specific activity of polonium in the $\mathrm{Pb}-\mathrm{Bi}$ eutectic. The results indicate little quenching in scintillation counting of samples; the total alpha activity of polonium in the melt was then calculated to be $9.024 \times 10^{8} \mathrm{~Bq}$, resulting in a specific activity of $66.1 \mathrm{mCi} / \mathrm{kgKnowledge}$ of the specific activity of the $\mathrm{Pb}$ - $\mathrm{Bi}$ melt was important for the measurement of the free energy of Equation 6.4, as well as the vapor pressure of $\mathrm{PbPo}$ in the system.

The free energy of Equation 6.4 was measured in the experimental apparatus illustrated in Figure 187, consisting of a high pressure/high temperature stainless steel autoclave hosting an LBE bath. The cell is equipped with heaters, thermocouples, a temperature controller, a pressure gage and a stirrer and is connected to two gas tanks and two high-efficiency $\mathrm{H}_{2} \mathrm{Po}$ traps in series. A controlled gas mixture was injected in the autoclave and then released through the traps. The associated polonium release was measured by alpha-counting of the trapping solution (e.g., by means of a liquid scintillator or by electroplating on nickel planchets) and, combined with knowledge of the system temperature, enabled calculation of the free-energy of formation of the polonium hydride as a function of temperature, as plotted in Figure 188. All the details of this experimental investigation can be found in a separate publication [Radiochimica Acta 2001]. 
Note that the free energy of Equation 6.2 can also be obtained by subtracting the free energy of Equation 6.5 from that of Equation 6.4, as illustrated in Figure 197. The result is:

$$
\Delta \mathrm{G}(\mathrm{T})=24.9+0.047 \mathrm{~T}
$$

where $\Delta \mathrm{G}$ is the free-energy variation $(\mathrm{kJ} / \mathrm{mol})$ of Eq.6.2 and $\mathrm{T}$ is in $\mathrm{K}$. Knowledge of the free energy enables calculation of the equilibrium concentration of the species involved, but does not provide information on the rate at which the reaction takes place. Therefore the kinetics of the reaction of Equation 6.2 is being investigated so that a realistic evaluation of a polonium removal system based on $\mathrm{H}_{2} \mathrm{Po}$ stripping can be obtained. The preliminary results are discussed below.

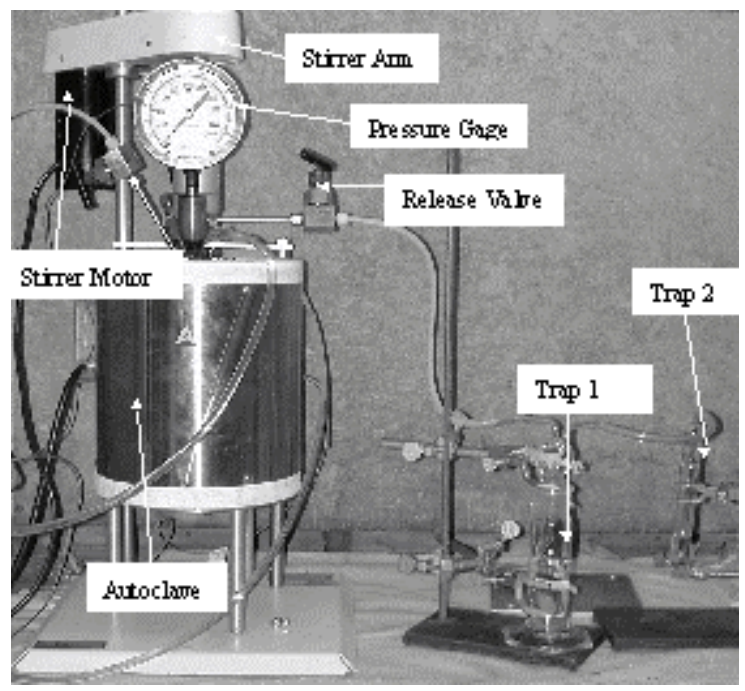

Figure 187: The reaction cell for investigation of polonium hydride stripping.

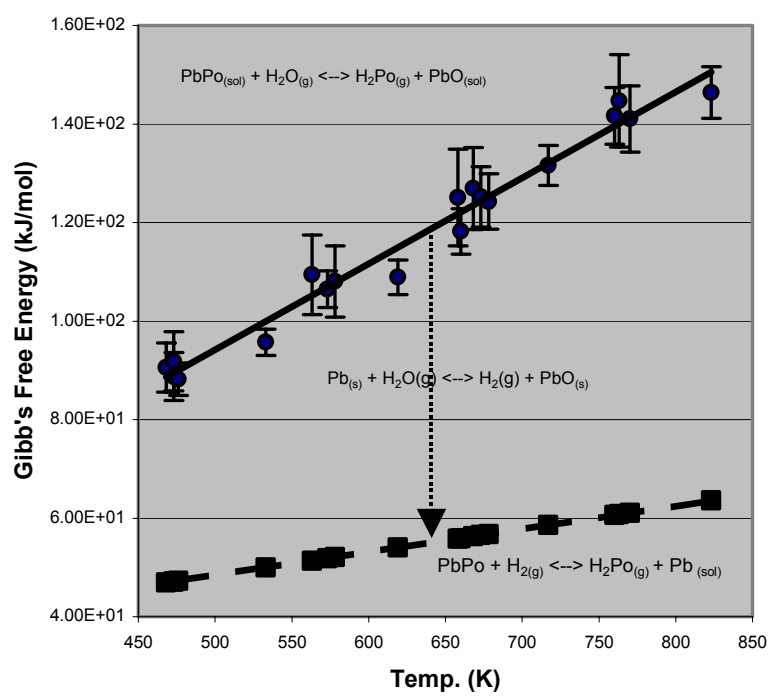

Figure 188: Gibb's Free Energy of $\mathrm{H}_{2} \mathrm{Po}$ $(\mathrm{kJ} / \mathrm{mol})$ vs. Temperature $\left({ }^{\circ} \mathrm{K}\right)$

The rate of release of polonium is being experimentally investigated in order to determine the kinetics equilibrium constant for various temperatures and mixtures of hydrogen-argon mixed gases. Procedures are very similar to that of the thermodynamic experiments mentioned previously and used the same apparatus as shown in Figure 187.

Prior to initializing the kinetics experiments, a NIST traceable Po-209 standard in solution was utilized to determine the combined electroplating and detector efficiencies. The efficiency of the two processes in series has been experimentally determined to be $10.2 \% \pm 0.5 \%$, resulting from a detector efficiency of $28.0 \%$, and an electroplating efficiency of $36.4 \% \pm 1.8 \%$. These results are reasonable considering previous experimentation using polonium. [Buongiorno 2000]. The Po-209 plated nickel planchets were used as a reference in the alpha spectroscopy counting during the polonium hydride kinetics experiments.

Considering the kinetics of polonium hydride release, argon gas samples were collected at time intervals of $5,15,30,60$, and 120 minutes, and at temperatures of $425^{\circ} \mathrm{C}$ and $500^{\circ} \mathrm{C}$. Subsequently, the samples were processed by electroplating and dry counted. Initial counts 
indicate that the kinetic equilibrium to occured between 40-45 minutes, for the specific temperatures and conditions. This approximation will be verified in upcoming measurements, as the kinetics data retrieval will continue at incremental temperatures with $1,000 \mathrm{ppm}$ and $10,000 \mathrm{ppm}$ hydrogen gas. Subsequent to alpha counting of all the samples and the data analysis, the kinetics equilibrium constant will be reported for varying temperatures versus gas mixture ratios.

Since the liquid scintillation counter yielded several count levels below background for samples of hydrogen-argon mixed gases at higher temperatures, electroplating and then dry counting will be utilized until the count levels exceed the background level. Therefore, more time must be devoted to electroplating and counting, as compared to liquid scintillation counting. After the completion of the kinetics experiments, the effect of the addition of rare earths to the system will be determined as discussed in Section 6.3.

\subsection{Polonium Removal By Alkaline Extraction (INEEL, Dr. Jacopo Buongiorno, Dr. Eric Loewen)}

The alkaline extraction method was originally proposed by the Russians (Orlov et al. 1998). The following reaction occurs when a mass of polonium-contaminated lead-bismuth is put in contact with a $\mathrm{NaOH}$ melt:

$$
\mathrm{PbPo}+4 \mathrm{NaOH} \leftrightarrow \mathrm{Na}_{2} \mathrm{Po}+\mathrm{Na}_{2} \mathrm{PbO}_{2}+2 \mathrm{H}_{2} \mathrm{O}
$$

Addition of $\mathrm{KOH}$ to $\mathrm{NaOH}$ results in the formation of a low melting point eutectic, which would enable operating the purification system at a relatively lower temperature (down to $250^{\circ} \mathrm{C}$ ). Neither KOH nor the molten lead-bismuth (which acts as a polonium carrier) seems to participate in the chemical reaction (Yefimov et al. 1998). The reaction was found to change with the concentration of oxygen and oxides in the lead-bismuth coolant, being larger at low concentrations and vice versa.

The Russians have not published detailed information on this polonium extraction method, and several questions are still open:

- The basic chemistry of alkaline extraction is largely unexplored in the West,

- The effect of alkaline extraction on the lead-bismuth chemical characteristics (i.e., oxygen and oxides activity, impurity concentration) is not known, and,

- It remains to be determined whether this method can be applied on a large scale.

During FY-2001 a reaction cell was deployed at the INEEL to investigate the chemistry of the alkaline reaction. Experiments will start in FY-2002 with tellurium, a chemical surrogate of polonium. The use of tellurium requires some explanation. The two elements belong to the same chemical group and share similar general chemical properties (Greenwood and Earnshaw 1984), as testified by the similarities of their pH-potential diagrams (Pourbaix 1966), and the crystalline properties of their intermetallic compounds (Bagnall 1966; Witteman et al. 1960). Moreover, tellurium was successfully used in lieu of polonium by the Russians in alkaline extraction experiments (Yefimov et al. 1998). All of the above lead us to believe that tellurium is suitable for screening of polonium extraction techniques. We plan to use tellurium just to prove the concept qualitatively. We believe this approach is a quicker (yet insightful) approach to assessing the potential of promising extraction techniques. However, it should be emphasized that direct 
experiments with actual polonium will be necessary should the development of a poloniumextraction system be more aggressively pursued in the future.

The cell accommodates a molten $\mathrm{NaOH}$ bath (or, alternatively, a $\mathrm{NaOH}-\mathrm{KOH}$ bath) that is mixed with controlled amounts of lead-bismuth (or, alternatively, pure lead) of known tellurium concentration. Inert gas bubbling through the melt ensures effective mixing of the species. Note that because of their immiscibility and considerable density difference, the alkaline and leadbismuth melts would tend to separate along a horizontal interface if active mixing were not provided. Three main independent variables are identified:

1. The system temperature $\left(200-550^{\circ} \mathrm{C}\right)$, as this affects the thermodynamics of the reaction.

2. The tellurium concentration in the lead-bismuth melt prior to contact with the $\mathrm{NaOH}$ bath $\left(10^{-3}-10^{-1} \mathrm{~mol} / \mathrm{kg}\right)$. It is anticipated that the reaction product inventory will be proportional to this variable.

3. Oxygen activity of the lead-bismuth melt $(<10 \mathrm{ppm})$. As already mentioned, an effect of the oxygen concentration on the chemistry of the reaction has been observed. Hydrogen additions to the inert gas will enable control of the lead-bismuth oxygen potential by means of the hydrogen/oxygen/water chemical equilibrium, as explained in (Buongiorno et al. 2001). Moreover, an oxygen probe currently under development at the INEEL and MIT may be utilized to directly measure the lead-bismuth oxygen potential, if it is properly calibrated (Loewen et al. 2000, Lim and Ballinger 2000).

The cell is equipped with heaters, thermocouples, compressed gas supply, and a gas mass spectrometer that enable control of the independent variables. A drawing of the reaction cell is illustrated in Figure 189. The fluids are contained in a removable crucible. Materials being tested for the crucible are nickel, graphite and alumina, which can withstand high temperature $\mathrm{NaOH}$ with minimal corrosion (Huntington Alloys 1979, Nelson 1987) and are known to be entirely compatible with leadbismuth at temperatures up to $1000^{\circ} \mathrm{C}$ (Weeks 1971).

A sample will be extracted from the alkaline and lead-bismuth melts for analysis of the chemical species at the end of each experimental run (characterized by a unique set of the

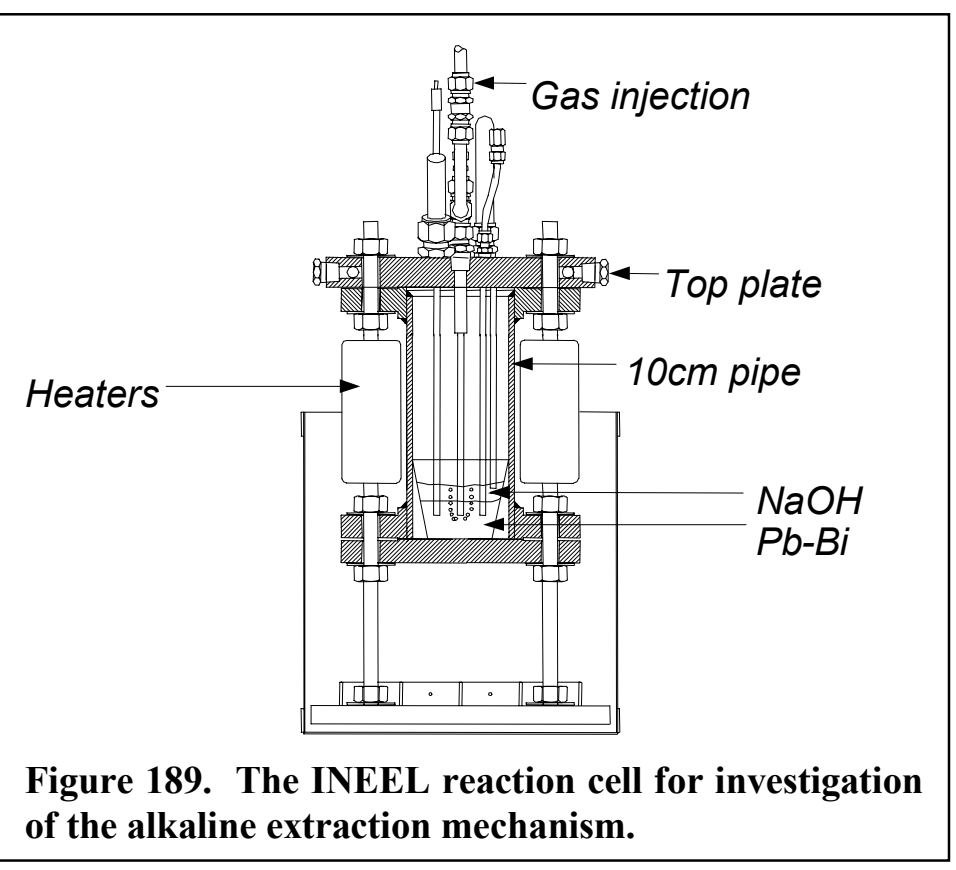
of the alkaline extraction mechanism. independent variables), e.g., by means of an ICP and an SEM. The following data will be collected:

- Equilibrium activities of the chemical species as functions of the three independent variables. This will enable calculation of the free-energy variation of the reaction.

- Tellurium removal efficiency vs. time. This will enable calculation of the reaction kinetic constant. 
- Characterization of residual alkaline species in the lead-bismuth after the treatment.

Analysis of the crucible will provide insight of the interaction between the species and the structural materials. At this point, only two test runs were conducted to confirm the expected performance of the cell components (e.g., heaters, gas injectors, gas spectrometer, thermocouples), and assess the interaction of the lead-bismuth/sodium hydroxide melt with the crucibles.

\subsection{Rare Earth Filtering (MIT, Prof. Ken Czerwinski, Chris Larsen)}

It is known that the rare earths form very stable complexes with polonium [Ershova 1973, Abakumov 1976, Greenwood 1984]. For example, praseodymium polonide and thulium polonide display a melting point of $1253^{\circ} \mathrm{C}$ and $2200^{\circ} \mathrm{C}$, respectively. Polonites of praseodymium $\left(\mathrm{Pr}_{2} \mathrm{O}_{2} \mathrm{PoO}_{3}\right)$ were also formed from polonium vapor and polonium oxide. The resulting material was stable up to $960^{\circ} \mathrm{C}$. These data indicate that polonium could theoretically be removed from the lead-bismuth when the rare earth polonium species are significantly more stable than the $\mathrm{PbPo}$. For example, this could be done by forcing the lead-bismuth flow through filters made of a metal or oxide sponge of $\operatorname{Pr}$ or Tm. This process is somewhat similar to how the water is cleaned up in a LWR ion-exchange resin filter.

It is necessary to collect data on sorption of polonium into thulium and praseodymium foils and oxide solids immersed in the lead-bismuth containing polonium. This will be done by means of the same equipment currently utilized for the polonium hydride studies (see Figure 187). The effect of temperature and oxygen potential will be evaluated. In addition to evaluating the kinetics and thermodynamic of the formation of polonium species with thulium and praseodymium, the surface area of the foils and oxides will be determined, to facilitate modeling. Also, the residual concentration of rare earths in the lead-bismuth coolant will be measured after polonium removal. These data are important because rare earths have a relatively large capture cross-section and, if present in the lead-bismuth coolant pumped back to the reactor, they might significantly worsen the neutron economy of the core even at low concentrations. Furthermore, because of their high chemical potential, rare earths can readily reduce the protective iron and chromium oxide layers on the reactor structural materials thus accelerating corrosion.

Following a literature search and a review of the approach, initial experiments were performed with praseodymium chips to understand its behavior at high temperatures and in the presence of air, moisture, and mixed gases. The praseodymium chips, as anticipated, oxidized in minutes in the presence of air. The praseodymium chip was relatively non-corrosive in a high temperature eutectic of lead-bismuth. However, these experiments were done in a simple system, and might not necessary reflect the behavior of praseodymium in an impeller stirred system. In future work, praseodymium disks will be purchased and used for radiochemistry measurements with polonium inside a pressurized system. Lastly, the thermodynamics and kinetics experiments will be repeated with the incorporation of praseodymium into the system once the kinetics experiments have been completed. 


\subsection{Electro-Deposition Of Polonium (INEEL, Dr. Jacopo Buongiorno)}

The conceptual design of a reaction cell for the investigation of polonium electro-deposition on a metal electrode is presented in this section.

It is found in the literature that Po exists in a lead-bismuth bath mostly as the solid compound $\mathrm{PbPo}$. The electro-deposition technique is based on the assumption that at least some polonium exists also in ionic form, e.g., as per the following equilibrium:

$$
\mathrm{PbPo} \leftrightarrow \mathrm{Pb}^{2+}+\mathrm{Po}^{2-}
$$

If indeed an ionic form of Po is present in the lead-bismuth bath, it should exhibit a non-zero mobility when an electric field is applied to the bath by means of two electrodes. The $\mathrm{Po}^{2-}$ ions would migrate to the cathode where they release two electrons, whereas the $\mathrm{Pb}^{2+}$ ions would migrate to the anode where they acquire two electrons, according to the two half-reactions:

$$
\begin{aligned}
& \mathrm{Po}^{2-} \rightarrow \mathrm{Po}+2 \mathrm{e}^{-} \\
& \mathrm{Pb}^{2+}+2 \mathrm{e}^{-} \rightarrow \mathrm{Pb}
\end{aligned}
$$

which realize the following overall reaction:

$$
\mathrm{Pb}^{2+}+\mathrm{Po}^{2-} \rightarrow \mathrm{Pb}+\mathrm{Po}
$$

This reaction decreases the concentration of the $\mathrm{Po}$ and $\mathrm{Pb}$ ions in the bath, thus driving reaction (6.8) to the right, which supplies new ions, and so forth.

If the system (bath + electrodes) is maintained at a temperature below the Po melting point $\left(254^{\circ} \mathrm{C}\right)$, it is expected that the metallic Po will stick to the cathode. Then the Po can be extracted from the system simply by periodically removing and cleaning the cathode.

This Po extraction techniques can be investigated with the electrolytic cell illustrated in Figure 190.

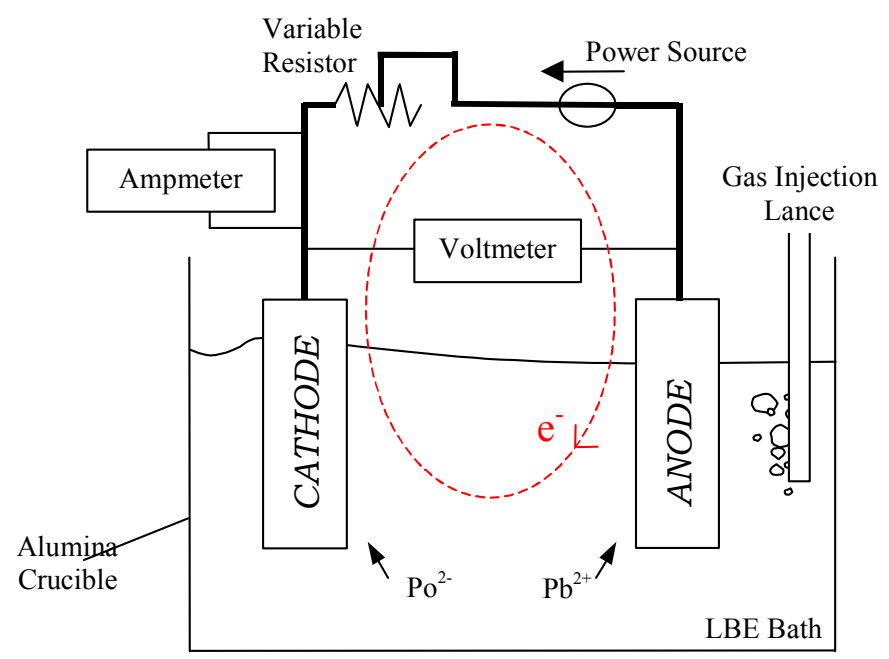

Figure 190. Schematic of the electrolytic cell. 
The crucible is made of alumina, which is compatible with lead-bismuth up to $1090^{\circ} \mathrm{C}$ (Gitzen 1970) and provides electric insulation of the cell from the surroundings. The electric current circulating within the cell and the voltage applied to the bath will be measured directly with an amp-meter and a voltmeter, respectively. A simple commercial battery $(<5 \mathrm{~V})$ can be used as the power source. A variable resistor in series to the power source enables control of the voltage actually applied to the bath.

Because the lead-bismuth is a liquid metal, the electric resistance of the bath is small, i.e., estimated to be about $1 \mathrm{~m} \Omega$ based on lead-bismuth resistivity (Lyon 1951) data and typical electrode geometry. Therefore, to maintain reasonably low currents in the circuit $(<1 \mathrm{~A})$, it is necessary to control the voltage applied to the bath in the range $<1 \mathrm{mV}$. This relatively low voltage should not impair Po collection because reaction (6.11) is expected to be thermodynamically spontaneous ${ }^{5}$ at the temperatures of interest $\left(<400^{\circ} \mathrm{C}\right)$ and therefore it does not need to be actively driven by the application of large voltages. The role of the voltage is mostly to drive the ion migration to the electrodes where they acquire or loose electrons. Note that, even under these low voltage conditions, most of the current through the bath is expected to be from electronic conduction (the normal mechanism of conduction in metals) and not from ion migration associated with reaction (6.11). This implies that Po yields at the cathode will be small.

The electrodes are cylindrical bars and should be made of a good conductive material so that the resistance within the electrode is negligible with respect to the resistance in the bath and thus the voltmeter reading is in fact the voltage applied to the bath. The electrode material should be also compatible with lead-bismuth at the temperatures of interest $\left(<400^{\circ} \mathrm{C}\right)$. For example, suitable electrode materials are iron and chromium as they exhibit relatively low solubility in lead and lead-bismuth (Lim 1999). Note that the electrode material does not participate in reaction (6.11).

A mixture of argon and hydrogen is bubbled through the bath to eliminate the lead-bismuth oxides that could reduce the mobility of the polonium ions.

It is proposed that the experiments be first conducted with Te, a chemical surrogate of Po. A justification for using tellurium in lieu of polonium is provided in Section 6.2. The following design parameters are identified:

1) Electrode diameter: $0.6 \mathrm{~cm}(1 / 4 ")$ and $0.3 \mathrm{~cm}\left(1 / 8^{\prime \prime}\right)$. For a given voltage, varying the electrode diameter enables variation of the local electric field, i.e., the smaller the electrode diameter the higher the electric field at the electrode surface.

2) Electrode distance, $x=10 \mathrm{~cm}$. Because the resistance across the bath is not the dominating resistance in the circuit, it is anticipated that the Te yield at the cathode will not be very sensitive to this parameter.

\footnotetext{
${ }^{5}$ From basic electrochemical potential data for the half-reactions (6.9) and (6.10) and making use of the Nernst equation (assuming unity activity for the metals and $10^{-10}$ for the ions), it was evaluated that the cell electrochemical potential for reaction (6.11) at room temperature is about $0.7 \mathrm{~V}$, which is positive and thus indicates that the reaction is spontaneous (at least at room temperature).
} 
3) System temperature: 200,300 and $400^{\circ} \mathrm{C}$. Because the melting point of Te is $449^{\circ} \mathrm{C}$, it is expected that the metallic Te collected at the cathode will remain solid and stick to the cathode.

4) Collection time: 10 minutes, 1 hour, 3 hours. It is desirable to measure the rate at which tellurium is collected at the cathode as a function of time.

5) Voltage applied to the bath: $<1 \mathrm{mV}$, if possible.

Experimental Procedure. Each run comprises the following sequence of operations:

$>$ Solid $\mathrm{Pb}, \mathrm{Bi}$ and Te are accommodated in the crucible.

$>$ The crucible is heated up to $500^{\circ} \mathrm{C}$ to ensure melting of all species.

$>$ The argon-hydrogen mixture is bubbled through the bath to ensure mixing of the species and reduction of $\mathrm{Pb}$ and $\mathrm{Bi}$ oxides.

$>$ The temperature is lowered to $400^{\circ} \mathrm{C}$.

$>$ The electrodes are lowered into the bath.

$>$ The flow or argon-hydrogen is interrupted or, alternatively, the gas injection lance is extracted from the bath. This ensures that the bath is stagnant and that ionic migration within the bath is not disturbed.

$>$ A small lead-bismuth sample is sucked from the bath by means of a vacuum pump to measure the initial Te concentration in the bath.

$>$ The electrodes are energized.

$>$ The current and voltage across the bath are measured.

$>$ The electrodes are de-energized and extracted for analysis while the lead-bismuth is molten.

$>$ The system is cooled to room temperature.

$>$ The crucible is removed and the lead-bismuth analyzed.

\subsection{Modeling Of Polonium Removal Systems (INEEL, Dr. Jacopo Buongiorno)}

In this section the relevant figures of merit for a generic polonium removal system are identified. Then, a simplified analysis of a polonium removal system based on formation and separation of the polonium hydride is presented as an example of application of the figures of merit.

\subsubsection{Figures Of Merit Of A Polonium Removal System}

A polonium balance over the control volume represented by the total lead-bismuth inventory of a lead-bismuth-cooled nuclear reactor yields the following equation:

$$
\frac{d N}{d t}=\Gamma_{p r o d}-\Gamma_{d e c}-\Gamma_{e x t r}
$$

where $\mathrm{N}$ is the total number of ${ }^{210} \mathrm{Po}$ moles in the lead-bismuth coolant and $\Gamma_{\text {prod, }}, \Gamma_{\text {dec }}$ and $\Gamma_{\text {extr }}$ are the production, the decay and the extraction terms defined below.

${ }^{210} \mathrm{Po}$ is created in the reactor core by neutron activation of ${ }^{209} \mathrm{Bi}$. Neglecting the intermediate radionuclide ${ }^{210} \mathrm{Bi}$, whose half-life is 5 days, the rate of ${ }^{210} \mathrm{Po}$ production in the coolant can be readily calculated as: 


$$
\Gamma_{\text {prod }}=\sigma \Phi N_{B i, c}
$$

where $\Phi$ is neutron flux, $\sigma$ the ${ }^{209} \mathrm{Bi}$ capture cross section and $\mathrm{N}_{\mathrm{Bi}, \mathrm{c}}$ the number of ${ }^{209} \mathrm{Bi}$ moles in the core.

${ }^{210} \mathrm{Po} \alpha$-decays with a half-life of approximately 140 days (i.e., $\lambda_{\operatorname{dec}} \sim 5.8 \times 10^{-8} \mathrm{~s}^{-1}$ ). The radioactive decay term can be expressed as:

$$
\Gamma_{\text {decay }}=\lambda_{\text {dec }} N
$$

It is assumed that a lead-bismuth mass flow rate $\dot{m}$ is sent to a polonium extraction system whose removal efficiency is $\varepsilon$. Therefore the extraction term can be calculated as:

$$
\Gamma_{e x t r}=\varepsilon \dot{m} \frac{N}{M_{P b B i}}
$$

where $\mathrm{M}_{\mathrm{PbBi}}$ is the total lead-bismuth mass inventory in the reactor pool.

Then, the asymptotic polonium inventory is from Equation (6.12):

$$
N_{\infty}=\frac{\sigma \Phi N_{B i, c}}{\lambda_{d e c}+\frac{\varepsilon \dot{m}}{M_{P b B i}}}
$$

The degree of polonium extraction, F, can be defined as the ratio of the polonium inventory for $\dot{m}=0$ (no extraction) to that for $\dot{m} \neq 0$ :

$$
F=\frac{\lambda_{d e c}+\frac{\varepsilon \dot{m}}{M_{P b B i}}}{\lambda_{d e c}}=1+\frac{\varepsilon \dot{m}}{\lambda_{d e c} M_{P b B i}}
$$

Because $\lambda_{\text {dec }}$ is a physical constant and $\mathrm{M}_{\mathrm{PbBi}}$ is not usually selected on the basis of coolant activation considerations, $\mathrm{F}$ can be maximized only by increasing the product $\varepsilon \dot{m}$, which is then a measure of the polonium system performance. If we further assume that only limited space is available for the polonium extraction system near the reactor, the correct figure of merit becomes $\eta=\varepsilon \mathrm{G}$ where $\mathrm{G}$ is the lead-bismuth mass flux (mass flow rate per unit flow area) in the extraction system.

\subsubsection{Simplified Analysis Of A Polonium Hydride Exchanger}

When generated in the LBE, polonium rapidly forms a rather stable compound with lead, known as lead polonide, $\mathrm{PbPo}$. The polonium hydride is formed from the reaction of hydrogen gas with polonium-contaminated LBE: 


$$
\mathrm{PbPo}+\mathrm{H}_{2} \rightarrow \mathrm{H}_{2} \mathrm{Po}+\mathrm{Pb}
$$

With:

$$
\Delta \mathrm{G}(\mathrm{T})=24.9+0.047 \mathrm{~T}
$$

where $\Delta \mathrm{G}$ is the free-energy variation $(\mathrm{kJ} / \mathrm{mol})$ and $\mathrm{T}$ is in $\mathrm{K}$.

Polonium hydride is a very volatile and unstable gas. Therefore, the reaction of Equation (6.18) can be in principle utilized as the basis for a polonium extraction system where a stream of pure hydrogen gas and a $\mathrm{Pb}-\mathrm{Bi}$ mass are put in contact to induce formation of the polonium hydride, which readily gets entrained by the hydrogen. The gaseous mixture is then processed separately, e.g., the mixture can be bubbled through an alkaline aqueous solution of $\mathrm{pH}>12$, which was shown to exhibit $\mathrm{H}_{2} \mathrm{Po}$ trapping efficiencies in excess of $99 \%$ (Buongiorno et al. 2001). A schematic of a mass exchanger that realizes this concept is illustrated in Figure 191.

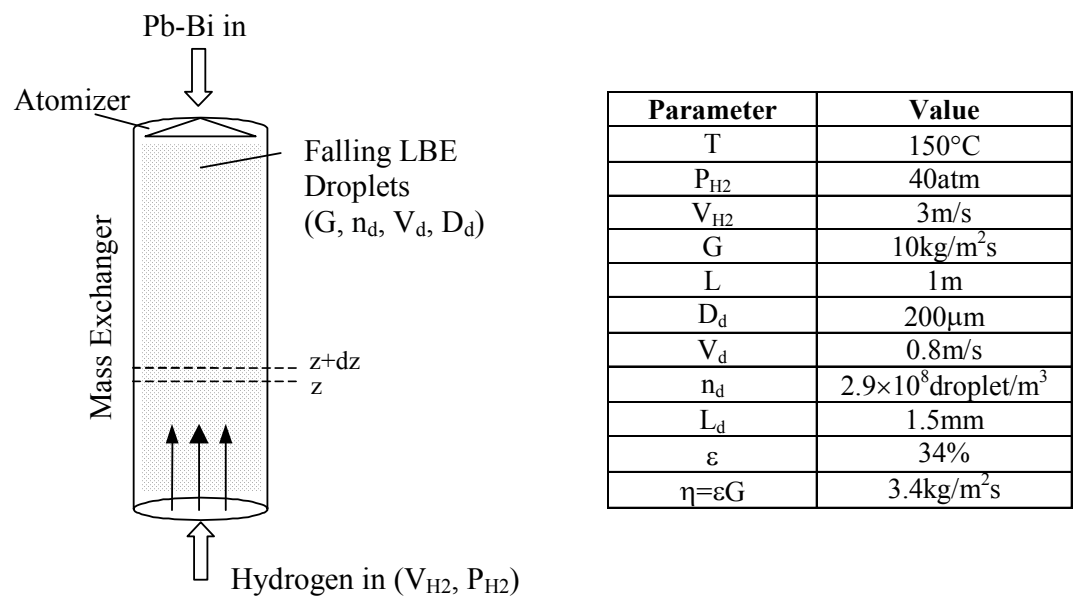

Figure 191. Schematic of a polonium hydride exchanger.

To maximize the mass transfer area, the liquid $\mathrm{Pb}-\mathrm{Bi}$ is atomized into fine droplets that fall in countercurrent flow with the hydrogen stream. To evaluate the performance of this system, let us define the following quantities: $\mathrm{G}$ is the $\mathrm{Pb}$-Bi mass flux $\left(\mathrm{kg} / \mathrm{m}^{2} \mathrm{~s}\right), \mathrm{n}_{\mathrm{d}}$ the droplet concentration $\left(\right.$ droplets $\left./ \mathrm{m}^{3}\right), \mathrm{D}_{\mathrm{d}}$ the droplet diameter, $\mathrm{V}_{\mathrm{d}}$ the droplet velocity, $\mathrm{V}_{\mathrm{H} 2}$ the hydrogen velocity, $\mathrm{P}_{\mathrm{H} 2}$ the hydrogen pressure and $\mathrm{S}$ the mass exchanger flow area. With reference to an axial region of thickness $\mathrm{dz}$ about $\mathrm{z}$ and indicating by $\mathrm{a}_{\mathrm{Po}}$ and $\mathrm{C}_{\mathrm{Po}}$ the polonium hydride concentration in hydrogen $\left(\mathrm{mol} / \mathrm{m}^{3}\right)$ and the polonium concentration in $\mathrm{Pb}-\mathrm{Bi}(\mathrm{mol} / \mathrm{kg})$, respectively, the following mass transfer equations can be written:

$$
\left\{\begin{array}{l}
V_{H 2} S a_{P o}(z)+n_{H 2 P o} n_{d} S d z=V_{H 2} S a_{P o}(z+d z) \Rightarrow V_{H 2} \frac{d a_{P o}}{d z}=n_{H 2 P o} n_{d} \\
G S C_{P o}(z+d z)=n_{H 2 P o} n_{d} S d z+G S C_{P o}(z) \Rightarrow G \frac{d C_{P o}}{d z}=n_{H 2 P o} n_{d}
\end{array}\right.
$$

where $\mathrm{n}_{\mathrm{H} 2 \mathrm{Po}}$ is the rate of polonium hydride release from a single $\mathrm{Pb}-\mathrm{Bi}$ droplet (mol/s) and can be readily evaluated as: 


$$
n_{H 2 P_{o}}=\pi D_{d}^{2} h_{m}\left(a_{P o, s}-a_{P_{o}}\right)
$$

$\mathrm{a}_{\mathrm{Po}, \mathrm{s}}$ is the polonium hydride concentration in hydrogen at the droplet surface and $\mathrm{h}_{\mathrm{m}}$ is the droplet mass transfer coefficient which can be evaluated from the Ranz-Marshall correlation, recommended in (Incropera and De Witt 1990) for mass transfer from falling droplets:

$$
\frac{h_{m} D_{d}}{D_{A B}}=2+0.6 \mathbf{R e}_{d}^{0.5}\left(\frac{\mu_{H 2}}{\rho_{H 2} D_{A B}}\right)^{0.33}
$$

where $\mathrm{Re}_{\mathrm{d}}$ is the droplet Reynolds number:

$$
\operatorname{Re}_{d}=\frac{\rho_{H 2}\left(V_{d}+V_{H 2}\right) D_{d}}{\mu_{H 2}}
$$

and $\mu_{\mathrm{H} 2}$ and $\rho_{\mathrm{H} 2}$ are the hydrogen viscosity and density, respectively. $\mathrm{D}_{\mathrm{AB}}$ is the binary diffusion coefficient of $\mathrm{H}_{2} \mathrm{Po}$ in hydrogen. Because no data are available on the thermo-physical properties of $\mathrm{H}_{2} \mathrm{Po}, \mathrm{D}_{\mathrm{AB}}$ was assumed equal to the diffusion coefficient of $\mathrm{H}_{2} \mathrm{O}$ (which is molecularly homologous to $\mathrm{H}_{2} \mathrm{Po}$ ) in hydrogen and scaled to the pressure and temperature of interest.

Treating $\mathrm{H}_{2} \mathrm{Po}$ as an ideal gas, $\mathrm{a}_{\mathrm{Po}, \mathrm{s}}$ is related to the local $\mathrm{H}_{2} \mathrm{Po}$ partial pressure $\mathrm{P}_{\mathrm{H} 2 \mathrm{Po}, \mathrm{s}}$ as:

$$
a_{P o, s}=\frac{P_{H 2 P o, s}}{R T}
$$

where $\mathrm{R}$ is the universal gas constant and $\mathrm{T}$ is the system absolute temperature. Assuming chemical equilibrium at the droplet surface (i.e., neglecting the reaction kinetics), $\mathrm{P}_{\mathrm{H} 2 \mathrm{Po}, \mathrm{s}}$ can be calculated from the equilibrium constant of Equation (6.18), $\mathrm{k}$, as:

$$
k=e^{-\frac{\Delta G(T)}{R T}}=\frac{P_{H 2 P O, s}}{C_{P o} P_{H 2}}
$$

where the chemical activity of liquid lead was set equal to unity. The free energy variation $\Delta \mathrm{G}$ is from Equation (6.19).

Combining Equation (6.25) and (6.26), one gets:

$$
a_{P o, s}=\frac{C_{P o} P_{H 2}}{R T} e^{-\frac{\Delta G}{R T}}
$$

Back-substituting Equation (6.27) into (6.22), (6.21) and (6.20), the following system of two linear homogeneous ordinary differential equations in the two unknown $\mathrm{a}_{\mathrm{Po}_{0}}$ and $\mathrm{C}_{\mathrm{Po}_{0}}$ is obtained:

$$
\left\{\begin{array}{l}
V_{H 2} \frac{d a_{P o}}{d z}=n_{d} \pi D_{d}^{2} h_{m}\left(\frac{P_{H 2}}{R T} e^{-\frac{\Delta G}{R T}} C_{P_{o}}-a_{P o}\right) \\
G \frac{d C_{P o}}{d z}=n_{d} \pi D_{d}^{2} h_{m}\left(\frac{P_{H 2}}{R T} e^{-\frac{\Delta G}{R T}} C_{P_{o}}-a_{P o}\right)
\end{array}\right.
$$


which can be readily integrated with the boundary conditions $\mathrm{a}_{\mathrm{Po}}(0)=0$ and $\mathrm{C}_{\mathrm{Po}}(\mathrm{L})=\mathrm{C}_{\mathrm{Po}, \mathrm{i}}$ (where $\mathrm{C}_{\mathrm{Po}, \mathrm{i}}$ is the polonium concentration in $\mathrm{Pb}-\mathrm{Bi}$ at the mass exchanger inlet, $\mathrm{z}=\mathrm{L}$ ) to yield:

$$
\begin{aligned}
& a_{P_{o}}(z)=\frac{G C_{P_{O}, i}}{V_{H 2}} \frac{1-e^{-(\beta-\alpha) z}}{\frac{\beta}{\alpha}-e^{-(\beta-\alpha) L}} \\
& C_{P_{o}}(z)=C_{P_{O}, i} \frac{\frac{\beta}{\alpha}-e^{-(\beta-\alpha) z}}{\frac{\beta}{\alpha}-e^{-(\beta-\alpha) L}}
\end{aligned}
$$

The following definitions were adopted:

$$
\begin{aligned}
& \alpha \equiv n_{d} \pi D_{d}^{2} h_{m} \frac{P_{H 2}}{G R T} e^{-\frac{\Delta G}{R T}} \\
& \beta \equiv n_{d} \pi D_{d}^{2} h_{m} \frac{1}{V_{H 2}}
\end{aligned}
$$

The polonium removal efficiency of the mass exchanger, $\varepsilon$, is defined as:

$$
\varepsilon \equiv \frac{C_{P_{o, i}}-C_{P_{o}}(0)}{C_{P o, i}}
$$

and can be easily calculated from Equation (6.31) as:

$$
\varepsilon=\frac{1-e^{-(\beta-\alpha) L}}{\frac{\beta}{\alpha}-e^{-(\beta-\alpha) L}}
$$

It was demonstrated in Section 6.5.1 that the radioactivity reduction resulting from a polonium extraction system actually depends on the product of $\varepsilon$ and $G$ (see Equation (6.17)). Therefore, the performance index $\eta \equiv \varepsilon \mathrm{G}$ is defined, for which the following equation holds:

$$
\eta=G \frac{1-e^{-(\beta-\alpha) L}}{\frac{\beta}{\alpha}-e^{-(\beta-\alpha) L}}
$$

Note that via $\alpha$ and $\beta, \eta$ depends on the following variables: $P_{H 2}, T, V_{H 2}, G, D_{d}, L, V_{d}$ and $n_{d}$. However, only $\mathrm{P}_{\mathrm{H} 2}, \mathrm{~T}, \mathrm{~V}_{\mathrm{H} 2}, \mathrm{G}, \mathrm{D}_{\mathrm{d}}$ and $\mathrm{L}$ are independent ${ }^{\mathrm{a}}$.

$\mathrm{V}_{\mathrm{d}}$ can be calculated by equating the hydrogen drag force to the droplet weight:

$$
\frac{\pi}{6} D_{d}^{3} \rho_{d} g=C_{D} \frac{\pi}{4} D_{d}^{2} \frac{\rho_{H 2} V_{r}^{2}}{2}
$$

\footnotetext{
${ }^{a} \mathrm{G}$ and $\mathrm{D}_{\mathrm{d}}$ can be controlled by proper design of the atomizer.
} 
where $\rho_{\mathrm{d}}=10^{4} \mathrm{~kg} / \mathrm{m}^{3}$ is the droplet density and $\mathrm{V}_{\mathrm{r}}=\mathrm{V}_{\mathrm{H} 2}+\mathrm{V}_{\mathrm{d}}$ is the hydrogen/droplet relative velocity. Solving for $\mathrm{V}_{\mathrm{r}}$ one gets:

$$
V_{r}=\sqrt{\frac{4}{3} \frac{D_{d} \rho_{d} g}{C_{D} \rho_{H 2}}}
$$

Ishii and Kataoka (1979) recommend the use of the following expression for the drag coefficient $\mathrm{C}_{\mathrm{D}}$ for a droplet in highly dispersed flow:

$$
C_{D}=\frac{10.67}{\operatorname{Re}_{d}^{0.5}}
$$

valid for $5<\operatorname{Re}_{d}<1000$. Equation (6.37) is an implicit equation in $V_{d}$ (because $\operatorname{Re}_{d}$ depends on $V_{d}$ ) and its solution requires iteration. Note that, for a given $\mathrm{D}_{\mathrm{d}}$, the value of $\mathrm{V}_{\mathrm{H} 2}$ should be kept below $\mathrm{V}_{\mathrm{r}}$ to allow the $\mathrm{Pb}$-Bi droplets to fall.

$\mathrm{n}_{\mathrm{d}}$ is obtained from the continuity equation:

$$
G=\frac{\pi}{6} D_{d}^{3} \rho_{d} n_{d} V_{d} \Rightarrow n_{d}=\frac{G}{\frac{\pi}{6} D_{d}^{3} \rho_{d} V_{d}}
$$

We are now ready to use Equation (6.36) to analyze the performance of the mass exchanger (i.e., $\eta$ ) as a function of the independent variables. The variation of $\eta$ with the hydrogen pressure and the system temperature is illustrated in Figure 192 for arbitrary values of $\mathrm{L}, \mathrm{D}_{\mathrm{d}}, \mathrm{V}_{\mathrm{H} 2}$ and $\mathrm{G}$. As expected, $\eta$ decreases with temperature because formation of the polonium hydride is thermodynamically favored at low temperature (i.e., $\frac{d \Delta G}{d T}>0$ ). Also, $\eta$ increases with the hydrogen pressure as expected from Equation (6.27). We shall then select $\mathrm{T}=150^{\circ} \mathrm{C}$ (i.e., $25^{\circ} \mathrm{C}$ above the freezing temperature of $\mathrm{Pb}-\mathrm{Bi}$ ) and $\mathrm{P}_{\mathrm{H} 2}=40 \mathrm{~atm}$ as our reference values.

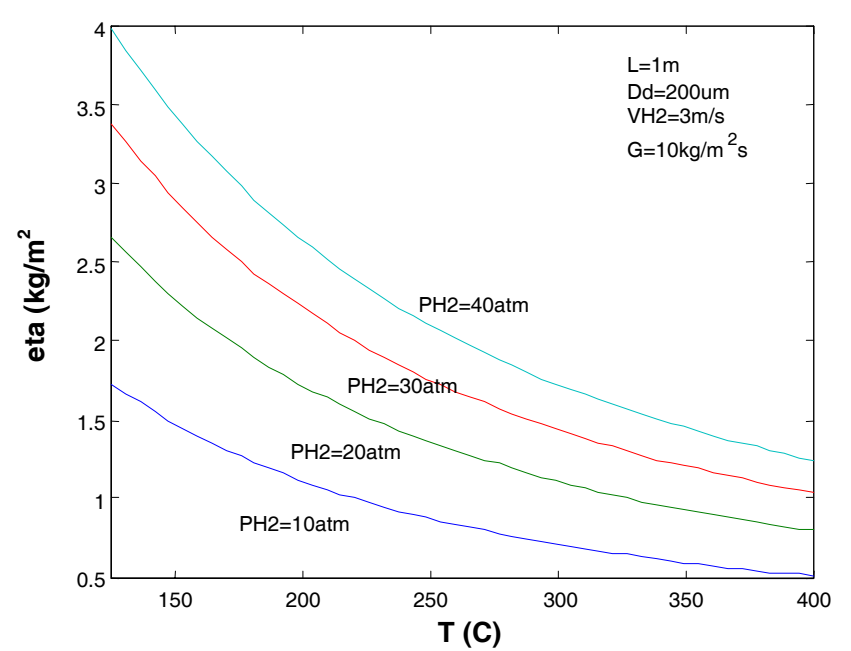

Figure 192. Temperature and pressure effects on the mass exchanger performance.

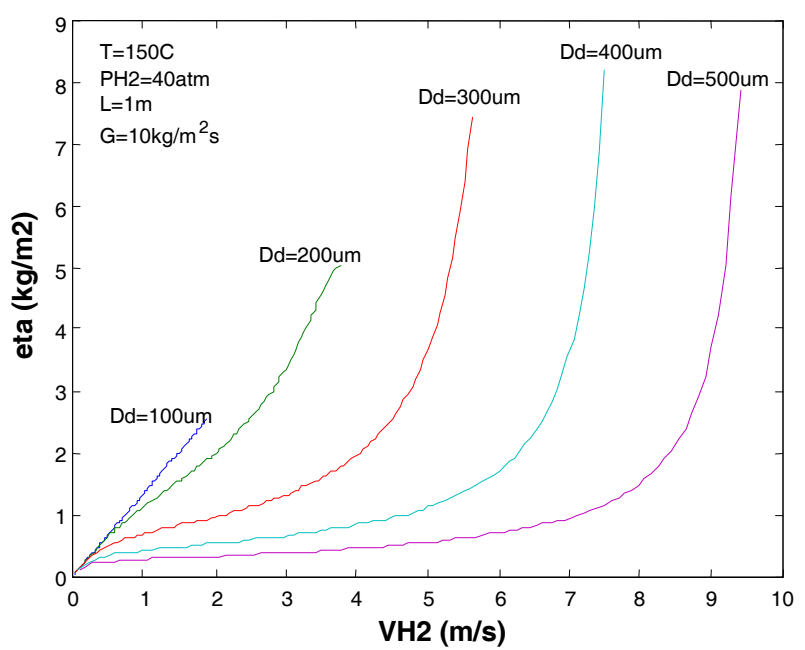

Figure 193. The droplet size and hydrogen velocity effects on the mass exchanger performance. 
In Figure 193, $\eta$ is plotted as a function of the hydrogen velocity and the $\mathrm{Pb}-\mathrm{Bi}$ droplet diameter for reference values of $\mathrm{P}_{\mathrm{H} 2}$ and $\mathrm{T}$ and arbitrary values of $\mathrm{L}$ and $\mathrm{G}$. Note that, as already mentioned, for a given droplet diameter, the hydrogen velocity must be kept below a maximum acceptable value corresponding to complete droplet suspension. It can be seen that for given droplet diameter, $\eta$ increases with the hydrogen velocity. This is expected because a higher hydrogen velocity results in a lower droplet velocity, a higher droplet concentration and consequently a larger mass transfer area. On the other hand, in the region of low hydrogen velocity, $\eta$ decreases with the droplet size because a smaller droplet size results in larger droplet concentration and again in a higher mass transfer area. Although Figure 193 indicates that larger values of $\eta$ can be attained by increasing the hydrogen velocity and the droplet diameter, we select the intermediate values $\mathrm{D}_{\mathrm{d}}=200 \mu \mathrm{m}$ and $\mathrm{V}_{\mathrm{H} 2}=3 \mathrm{~m}$ as reference. This translates into a droplet velocity of about $0.8 \mathrm{~m} / \mathrm{s}$.

Finally, in Figure $194 \eta$ is plotted as a function of the mass exchanger length for several different values of G. It can be seen that, at low $\mathrm{L}, \eta$ increases with $\mathrm{G}$ due to the increase of droplet concentration (i.e., for given $D_{d}$ and $V_{d}, n_{d}$ increases with $G$ ). On the other hand, as $\mathrm{L}$ increases, $\eta$ approaches an asymptotic value independent of $\mathrm{G}$. This is due to the fact that, if the channel is long enough, the polonium hydride concentration in hydrogen reaches the saturation value corresponding to $\mathrm{C}_{\mathrm{P}, \mathrm{i}}$ regardless of the droplet concentration (i.e., regardless of $G, V_{d}$ and $D_{d}$ ). It is thought that the selection of $\mathrm{L}=1 \mathrm{~m}$ and $\mathrm{G}=10 \mathrm{~kg} / \mathrm{m}^{2} \mathrm{~s}$ as reference values

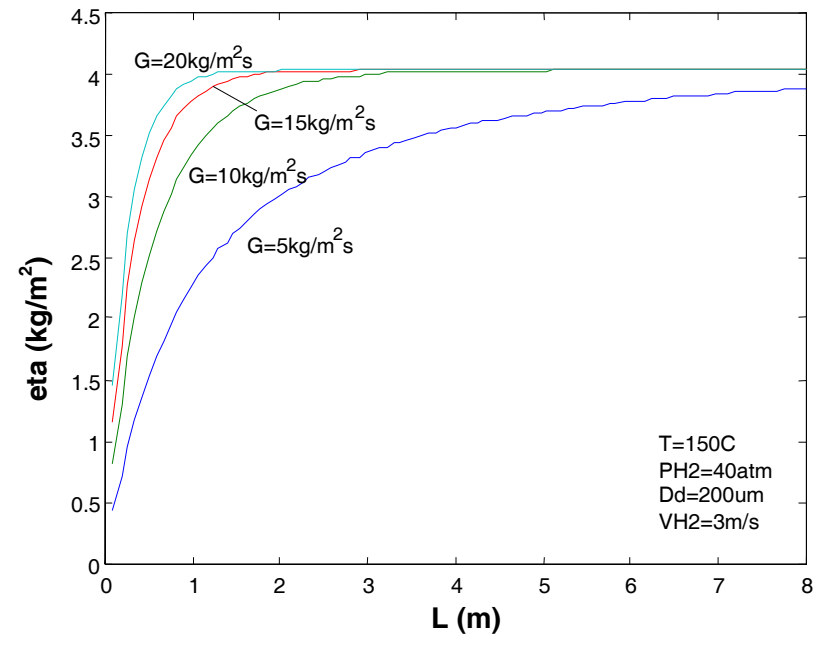

Figure 194. The Pb-Bi mass flux and channel length effects on the exchanger performance.

provides an adequate compromise of system compactness and high performance. A summary of the reference values of the mass exchanger is reported in Figure 191 above. Note that with the selection of the parameters of Figure 191 the average droplet-to-droplet distance $L_{d}=n_{d}{ }^{1 / 3}$ is about $1.5 \mathrm{~mm}$. Because it is $L_{d}>>D_{d}$, significant mass transfer area reduction due to droplet coalescence should not occur in the system.

In Section 6.5.1 it is shown that the effect of a polonium extraction system is to reduce the alpha-activity of the lead-bismuth coolant by a factor F. To illustrate the effectiveness of the polonium hydride mass exchanger approach, let us assume $S=2 \mathrm{~m}^{2}$ and $\mathrm{M}_{\mathrm{LBE}}=10^{6} \mathrm{~kg}$. Then, for $\eta=3.4 \mathrm{~kg} / \mathrm{m}^{2} \mathrm{~s}$, Equation (6.17) yields $\mathrm{F} \approx 120$, i.e., the polonium activity is reduced by over two orders of magnitude. 
A schematic of the entire polonium extraction system is illustrated in Figure 195. It is anticipated that the polonium-rich lead-bismuth coming from the reactor pool (or from the target coolant loop) is at relatively high temperature and low pressure, i.e., probably $\sim 400^{\circ} \mathrm{C}$ and $1 \mathrm{~atm}$, respectively. Before it enters the mass exchanger, a cooler and a pump bring the lead-bismuth to the extraction system operating conditions (i.e., $150^{\circ} \mathrm{C}$ and $40 \mathrm{~atm}$, respectively). At the mass exchanger inlet the lead-bismuth is atomized into fine droplets, falls against the up-flowing hydrogen stream, is drained out of the mass exchanger, passes through a depressurization valve to reduce the pressure back to its nominal value and is finally redirected to the reactor pool ${ }^{\mathrm{b}}$ (or to the target cooling loop). On the other hand, the hydrogen gas exiting the mass exchanger is bubbled through a pool of alkaline aqueous solution (also operating at $150^{\circ} \mathrm{C}$ and $40 \mathrm{~atm}$ ) that traps the polonium hydride. The clean hydrogen is then re-circulated to the mass exchanger by a gas compressor.

It should be emphasized that the system described above presents major technical and safety challenges. The use of high-pressure hydrogen is a safety issue per se because of its chemical reactivity with oxygen, naturally present in the air of the reactor compartment. In addition, the hydrogen line from the mass exchanger to the $\mathrm{H}_{2} \mathrm{Po}$ trapping station is heavily contaminated with polonium, which would aggravate the consequences of a hydrogen/oxygen explosion. Moreover, the highly alkaline trapping solution, besides being corrosive, needs to be periodically regenerated by removing the accumulated polonium. This can probably be done by reducing the alkalinity of the solution and thus inducing precipitation of solid polonium (as per the $\mathrm{pH}$ potential diagram of polonium), but it will likely require an additional dedicated loop (not shown in Figure 195). Finally, the feasibility of a lead-bismuth atomizer with the required performance needs to be demonstrated.

\footnotetext{
${ }^{\mathrm{b}}$ Because the $\mathrm{Pb}-\mathrm{Bi}$ mass flow rate in the polonium extraction system is expected to be much smaller then the total $\mathrm{Pb}$-Bi mass flow rate in the reactor pool, it is anticipated that mixing the two $\mathrm{Pb}$-Bi streams will not significantly affect the core coolant temperature.
} 


\title{
7. Summary of the Accomplishments to Date and Plans for FY-02
}

\author{
Neutronics - Major Accomplishments To Date
}

- Completed plutonium plus minor actinide burning, and pure minor actinide burning core designs (MIT lead)

- Completed the U-235 enriched core design (MIT lead)

- Started the Th-U-Pu-MA-Zr metal fuel core design for optimized actinide burning and low-cost electricty production (MIT lead)

- Produced new temperature dependent cross-section libraries to support reactivity calculations (INEEL lead)

- Completed the parametric study on power versus burnup and actinide destruction rates (INEEL lead)

- Completed the performance comparison of the sodium and lead-bismuth cooled large pitch to diameter ratio cores (INEEL lead)

\section{Neutronics - Major Remaining Work}

- Comple the performance comparison of sodium and lead-bismuth cooled cores for the small pitch to diameter ratio cores (INEEL lead)

- Optimize the core design and fuel for actinide burning and low cost electrical production

- This will include evaluations of metallic (MIT lead, completed), nitride (INEEL lead), and oxide (INEEL lead) fuel (FY-02)

- Integrate the inherent safety features, with the goal of achieving the same (or better) safety performance as the IFR project (FY-02)

- Verify that the reactivity coefficients and the delayed neutron fractions will be acceptable through all phases of the burnup (FY02-FY03)

- Compare the performance indices of the three different fuel types and core configurations; including a qualitative economic analysis (FY-03)

\section{Plant Engineering - Major Accomplishments To Date}

- Upgraded the RELAP-ATHENA code to perform calculations for heavy-liquid metal systems. (INEEL)

- Evaluated the thermal-mechanical limits of the metallic fuel, cladding and reactor vessel on the basis of simplified structural analyses of the fuel pin and reactor vessel. (INEEL)

- Performed thermal-hydraulic design, analysis, and preliminary economic evaluations of the following indirect-cycle plant configurations for steady operation (MIT):

1. Natural circulation: steam cycle and helium cycle,

2. Forced circulation: steam cycle, helium cycle, and, supercritical $\mathrm{CO}_{2}$ cycle. 
- Analyzed key operational transients and accidents for the following indirect-cycle plant configurations (INEEL):

1. Natural circulation: steam cycle and helium cycle

2. Forced circulation: steam cycle

- Performed a seismic analysis of the reactor vessel and guard vessel. (INEEL)

- Performed a complete feasibility study and conceptual design of a direct-cycle Pb-Bicooled reactor with in-vessel steam generation. (MIT)

\section{Plant Engineering - Major Remaining Work}

- Upgrade the RELAP-ATHENA code for thermal-hydraulic evaluation of the reactor with a supercritical $\mathrm{CO}_{2}$ power cycle. (INEEL)

- Assess the technical feasibility of the supercritical $\mathrm{CO}_{2}$ power cycle. (MIT)

- Transient analysis of the reactor with a supercritical $\mathrm{CO}_{2}$ power cycle. (INEEL)

- Assess the technical feasibility of the gas-lift pump approach. (INEEL)

- Refine the economic analysis of the more promising reactor configuration(s). (MIT)

- Select and analyze optimal design (INEEL/MIT)

\section{Corrosion Studies - Major Accomplishments To Date}

- Performed seven $\mathrm{Pb}$-corrosion experiments. Four of the experiments were 100 hours in duration at about $500^{\circ} \mathrm{C}$. (INEEL)

- Performed four oxygen probe development experiments using zirconium oxide probes. (INEEL)

- Added the following experimental capabilities at May Street North facility (INEEL):

1. Purchased, assembled, calibrated and made operational a mass spectrometer to measure the gas constituents in the corrosion cell.

2. Designed, constructed, and deployed a second corrosion cell.

3. Designed, constructed, and deployed an $\mathrm{O}_{2}$ probe calibration cell.

- Built a second spinner test facility (MIT)

- Ran one experiment (MIT)

\section{Corrosion Studies - Major Remaining Work:}

- Perform many more corrosion experiments (with the two cells at both MIT and INEEL) to fill in the on going factorial design so that a corrosion model can be built.

- Calibrate the INEEL developed $\mathrm{O}_{2}$ probes in Germany. This will enable better experimental control.

- Calibrate the MIT oxygen probes.

\section{Coolant Activation - Major Accomplishments To Date}


- Measured the vapor pressure of lead polonide and the Gibbs free energy for the formation of polonium hydride. (MIT)

- Collected data on the kinetics of polonium hydride release. (MIT)

- Modeled polonium separation by polonium hydride stripping and direct lead polonide evaporation. (INEEL)

- Designed, constructed and tested a reaction cell to explore a polonium extraction technique based on the formation and separation of sodium-polonide from the reaction of sodium hydroxide with polonium contaminated lead-bismuth. (INEEL)

- Developed a conceptual design of a reaction cell for polonium electro-deposition experiments. (INEEL)

\section{Coolant Activation - Major Remaining Work}

- Use the INEEL reaction cell to collect data on the alkaline extraction and electrodeposition techniques. (INEEL)

- Study the effects of rare-earth additions to the lead-bismuth coolant on the release of polonium. (MIT)

- Establish the relevant figures of merit for promising polonium removal systems. (INEEL/MIT)

\section{Other Pertinent Project Data}

Student Involvement:

- Plant engineering: 3 PhD candidates (J. Buongiorno, D. Kim, and V. Dostal)

- Corrosion: 1 PhD candidate (J. Lim)

- Polonium studies: 1 MS candidate (C. Larson)

Proposals Submitted:

- 3 FY-01 NERI proposals, none funded:

- Fuel performance and irradiation

- Polonium removal studies

- Corrosion studies

- 4 JNC proposals, one funded:

- Pebble bed reactor

- Polonium removal studies (will receive funding)

- Corrosion studies

- Imaging techniques in heavy liquid metals

- 4 Generation IV Concepts Submitted:

○ Direct Contact (J. Buongiorno)

- Indirect Contact (P. MacDonald)

- Pebble Bed (P. MacDonald)

- Minor Actinide Burner (P. Hejzlar) 


\section{References}

- Abakumov, A., and N. F. Reznikova. "Synthesis and Thermal Stability of Yttruim, Dysprosium, and Praseodymium Polonites". Radiokhimiya. Vol.18, No.3, pp.378-82. 1976.

- Abdelrahman M. S. and Abdurrahman N. M., UTXS: The University of Texas Neutron Cross Section Library: Generation and Validation," ANS Transactions, Vol. 79, November 1998.

- Adamov, E., Orlov, V., Filin, A., Leonov, V., Sila-Novitski, A., Smirnov, V., and Tsikunov V., 1997. "The Next Generation of Fast Reactors," Nuclear Engineering and Design, Vol. 173, pp. 143-150.

- Alden, T. H. "The Solubility of Nickel and Chromium in Liquid Lead". MIT, M.S. Thesis. 1957.

- Amodeo, R. J., and N. M. Ghoniem. "Development of Design Equations for Ferritic Alloys in Fusion Reactors". Nuclear Engineering and Design/Fusion, vol.2, 97-110. 1985.

- ASME. Boiler \& Pressure Vessel Code. An International Code. Section III, Division 1, Subsections NB and NH. (1998)

- $\quad$ ASTM Standards, Section 3, Vol 03.01, ASTM 1992

- Bagnall, K. The Chemistry of Selenium, Tellurium and Polonium, Elsevier Publishing Company, 1966.

- Billone, M. C., Y. Y. Liu, E. E. Gruber, T. H. Hughes, and J. M. Kramer. "Status of Fuel Element Modeling Codes for Metallic Fuels". Proceedings of the International Conference on Reliable Fuels for Liquid Metal Reactors, Tucson (AZ), September 7-11, 1986.

- Boardman C. E., "Optimizing the Size of the Super-Prism Reactor, ICONE 8, April 2-6, Baltimore, 2000

- Brady M. C. and England T. R., "Delayed Neutron Data and Group Parameters for 43 Fissioning Systems," Nuclear Science and Engineering, Vol. 103, p. 129, 1989.

- Briesmeister, J. F., Ed., "MCNP ${ }^{\mathrm{TM}}$ - A General Monte Carlo Code N-Particle Transport Code, Version 4C," Los Alamos National Laboratory, LA-13709-M, April 2000.

- Briesmeister, J. F., Ed., "MCNP - A General Monte Carlo Code for Neutron, Photon and Electron Transport, Version 3A/3B/4A/4B," Los Alamos National Laboratory, LA-7396-M, 1986, Revised in 1988, 1991 and 1997.

- Buongiorno, J., N. E. Todreas, and M. S. Kazimi. Thermal Design of Lead-Bismuth Cooled Reactors for Actinide Burning and Power Production. Nuclear Engineering Department, MIT. Report MIT-ANP-TR-066. July,1999.

- Buongiorno, J., N. E. Todreas, and M. S. Kazimi. Conceptual Design of a Lead-Bismuth Cooled Fast Reactor with In-Vessel Direct-Contact Steam Generation. MIT, Nuclear Engineering Department. Technical Report MIT-ANP-TR-079. March 2001.

- Buongiorno, J., R. Ballinger, C. Davis, D. Kim, M. Driscoll, P. Hejzlar, S. Herring, M. Kazimi, P. MacDonald, K. McCarthy, N. Todreas, V. Shah, and K. Weaver, 1999, "Design of an Actinide Burning, Lead-Bismuth Cooled Reactor that Produces Low Cost Electricity," INEEL/EXT-99-00693, MIT-ANP-TR-065, July.

- Buongiorno, J., R. Ballinger, K. Czerwinski, M. Driscoll, J. Lim, P. Hejzlar, M. Kazimi, D. Kim, N. Todreas, C. Davis, S. Herring, P. MacDonald, E. Loewen, A. Shieh, G. Smolik, and K. Weaver, 2000. "Design of an Actinide Burning, Lead or Lead-Bismuth Cooled Reactor that Produces Low Cost Electricity," Annual Project Status Report, INEEL/EXT-200000994, MIT-ANP-PR-071, Idaho National Engineering and Environmental Laboratory, July.

- Buongiorno, J., K. R. Czerwinski, and C. L. Larson. "Discussion on Polonium Extraction Systems for Pb-Bi-Cooled Nuclear Reactors". Transactions of Global 2001- Systems: Paris, France. 30 May 2001. 
- Carlson, K. E., P. A. Roth, and V. H. Ransom, 1986, ATHENA Code Manual Vol. I: Code Structure, System Models, and Solution Methods, EGG-RTH-7397, September.

- Chexal, B. and G. Lellouche, 1986, "A Full-Range Drift-Flux Correlation for Vertical Flows (Rev. 1)," EPRI NP-3989-SR, Electric Power Research Institute.

- Chodak P., Driscoll M. J., Miller M. M. and Todreas N. E., "Destruction of Plutonium Using Non-Uranium Fuels in Pressurized Water Reactor Peripheral Assemblies," Report MIT-NFCTR-001, MIT, Department of Nuclear Engineering, January, 1997.

- Croff, A. G., "A User's Manual for the ORIGEN2 Computer Code", Oak Ridge National Laboratory, ORNL/TM-7175, 1980.

- Czerwinski., K. R. , J. Buongiorno, and C. L. Larson. "Experimental Investigations on Vapor Pressure of Lead Polonide at Low Temperature \& Thermodynamics of Polonium Hydride". Radiochimica Acta. Sept. 2001.

- Davis, C. B., 2001, "Assessment of the ATHENA Code for Calculating the Void Fraction of a Lead-Bismuth/Steam Mixture in Vertical Upflow," Nuclear Technology, pp. 187-193, February.

- Dobbin K. D., Nelson N. V., Kessler S. F., Omberg R. P., and Wootan D. W., "Evaluating the Efficacy of the Minor Actinide Burner," Global 93 Conference, Seattle, USA, September 1993.

- DOC, U.S. Department of Commerce. Nuclear Reactors and Earthquakes. Report TID 7024. Chapter 6, pp.183-187. (1963)

- Dostal V., Todreas N. E., Hejzlar P., and Kazimi M. S., "Plant Design and Cost Assessment of a Forced Circulation Lead-Bismuth Cooled Reactor with Conventional Power conversion Cycles", MIT-ANP-TR-082, August, 2001

- Driscoll M.J. and Hejzlar P., "A Negative Reactivity Feedback Device for Actinide Burner Cores," Transactions of the American Nuclear Society, Vol. 84, Milwaukee, June 17-21, pp. 242-243, p. 241, 2001.

- Driscoll M.J. and Kim D., "The Need for Actinide Burner Reactor Fuel Cycle Cost Reduction," Trans. Am. Nucl. Soc., Vol. 82, June 2000.

- Driscoll, M. J., Downar, T. J., and Pilat, E. E., 1990. The Linear Reactivity Model for Nuclear Fuel Management, American Nuclear Society.

- Dubberley, A. E., C. E. Boardman, K. Yoshida, and T. Wu. "SuperPRISM Oxide and Metal Fuel Core Designs". ICONE-8002. Proceedings of ICONE-8, $8^{\text {th }}$ International Conference on Nuclear Engineering. Baltimore, MD USA. April 2-6, 2000a.

- Dubberley, A. E., C. E. Boardman, A. J. Lipps, and T. Wu. "SuperPRISM Metal Core Margins to Severe Core Damage". ICONE-8001. Proceedings of ICONE-8, $8^{\text {th }}$ International Conference on Nuclear Engineering. Baltimore, MD USA. April 2-6, $2000 \mathrm{~b}$.

- Dubuisson, P., R. Schill, M. P. Hugon, I. Grislin, and J. L. Seran. "Behavior of an Oxide Dispersion Strengthened Ferritic Steel Irradiated in Phenix". Effects of Radiation on Materials: $18^{\text {th }}$ Symposium. ASTM STP 1325. 1997.

- El-Boher, A., S. Lesin, Y. Unger, and H. Branover, 1988, "Experimental Studies Of LiquidMetal Two-Phase Flows In Vertical Pipes," Proceedings of the $1^{\text {st }}$ World Conference on Experimental Heat Transfer, Fluid Mechanics and Thermodynamics, Dubrovnik (Yugoslavia), September.

- Eriksson M. and Piaszczyk C., "Reliability Assessment of the LANSCE Accelerator System," NEA/OECD Workshop on Utilization and Reliability of High Power Accelerators in Mito, Japan, 13-15 Oct, 1998.

- Ershova, Z. V., A. S. Avakumov, and M. L. Malyshev. "Reaction of Vaporous Polonium with Some Chemical Elements". Radiokhimiya. Vol.15, No.5, pp.688-93. 1973.

- Feher, E. G., "The Supercritical Thermodynamic Power Cycle", Advances in Energy Conversion Engineering, August 13-17, 1967. 
- Feuerstein, H., J. Oschinski, and S. Horn. "Behavior of Po-210 in Molten Pb-17Li”. Journal of Nuclear Materials 191-194, 288-291. 1992.

- Forsberg C.W., Hopper C.M. and Vantine H.C., "What is Nonweapons-Usable U-233?" Trans. Am. Nucl. Soc., Vol. 81, p. 62, Long Beach, California, November 14-18, 1999.

- Fomitchenko, P. A., "Physics of Lead-Cooled Reactors," Proceedings of the 1998 Frédéric Joliot Summer School in Reactor Physics, Cadarache, France, August 17-26, 1998.

- Fox, G.L. "Design Limits for HT-9 Cladding Using Stress-Induced Aging Data". Proceedings of the International Conference on Reliable Fuels for Liquid Metal Reactors, Tucson (AZ), September 7-11, 1986.

- Fujimura K., Kawashima K., and Watari Y., Minor Actinide Burning LMFBR Core System to Enhance Safety Characteristics," Global 93 Conference, September 1993.

- GE. PRISM. Preliminary Safety Information Document. Report GEFR-00793, UC-87Ta. Vol.II, pp.5.7-1. 1986.

- GE Nuclear Energy. ALMR Summary Plant Design Description. 1991.

- General Electric, 1986 "Preliminary Safety Information Document," GEFR-00793, UC-87Ta, November.

- Gitzen, W. H. Alumina as a Ceramic Material, pp.103-110. American Ceramic Society. 1970.

- Greenspan, E., Elias, E., Kastenberg, W. E., and Stone, N., 1998. "Non-Proliferating Liquid Metal Cooled Reactors for Developing Countries," Technical Report CNTWM98-2, Univ. of California at Berkeley, Berkeley, CA.

- Greenwood, N. N., and A. Earnshaw. Chemistry of the Elements. Pp.882-919. Pergamon Press 1984.

- Gyorey, G. L., R. W. Hardy, and P. M. Magee. "Safety Design for the Advanced LiquidMetal-Cooled Reactor". Nuclear Safety, Vol.31, No.3, pp.323-335. (1990)

- Harvey, P.D. Engineering Properties of Steel. American Society for Metals. pp.328-331. 1982.

- Hayes, S. L., and G. L. Hofman. "Constituent Redistribution Modeling in U-Zr Fast Reactor Fuel”. Trans. Am. Nucl. Soc. Vol.71, pp.178-179. 1994.

- Hejzlar, P., M. J. Driscoll, and M. S. Kazimi, 2000, "Conceptual Reactor Physics Design of a Lead-Bismuth-Cooled Critical Actinide Burner," Topical Report MIT-ANP-TR-069, Massachusetts Institute of Technology, Dept. of Nuclear Eng., February.

- Hejzlar, P., Driscoll, M., and Kazimi, M., 1999a. "Void Reactivity Performance in LeadBismuth-Cooled Reactors for Actinide Transmutation," Topical Report MIT-ANP-TR-068, Massachusetts Institute of Technology, Cambridge, MA.

- Hejzlar, P., Driscoll, M., and Kazimi, M., 1999b. "Neutronic Design for a Pb-Bi-Cooled Actinide Burner Fast Reactor," Transactions of the American Nuclear Society, Vol. 81, pp. 271-273.

- Hejzlar P., Driscoll M. J. and Kazimi M. S., "Conceptual Neutronic Design of a LeadBismuth-Cooled Actinide Burning Reactor," Nuclear Science and Engineering, Vol. 139, pp.1-18, 2001a.

- Hejzlar P., Driscoll M. J., and Kazimi M. S., and N.E. Todreas, "Minor Actinide Burning in Dedicated Lead-Bismuth Cooled Fast Reactors," ICONE-9, $9^{\text {th }}$ International Conference on Nuclear Engineering, Nice, France, April 8-12, $2001 \mathrm{~b}$.

- Hejzlar P., Todreas N. E., and Kazimi M. S. and Driscoll M.J., Evaluation of a Once-Through lead-Bismuth-Cooled Reactor Concept, Topical Report MIT-ANP-TR-081, MIT, Dep. of Nuclear Engineering, July 2001c.

- Hetrick D. L., Dynamics of Nuclear Reactors, American Nuclear Society, La Grange Park, Illinois, 1993. 
- Hill R. N., D. C. Wade, J. R. Liaw, and E. K. Fujita, "Physics Studies of Weapons Plutonium Disposition in the Integral Fast Reactor Closed Fuel Cycle," Nucl. Sci. Eng. Vol., 121, pp. 17-31, 1995.

- Hill, R. N., J. E. Cahalan, H. S. Khalil, and D. C. Wade. "Development of Small, Fast Reactor Core Design Using Lead-Bismuth Coolant". Proc. Global '99 Int. Conf. On Future Nuclear Systems. Jackson Hole (WY), USA. 1999.

- HKS Inc. ABAQUS / Standard User's Manual. Section 6.3.7. Version 5.8. (1998)

- Hofman, G. L., A. G. Hins, D. L. Porter, L. Leibowitz, and E. L. Wood. "Chemical Interaction of Metallic Fuel with Austenitic and Ferritic Stainless Steel Cladding". Proceedings of the International Conference on Reliable Fuels for Liquid Metal Reactors, Tucson (AZ), September 7-11, 1986.

- Hofman, G. L., R. G. Pahl, C. E. Lahm, and D. L. Porter. "Swelling Behavior in U-Pu-Zr Fuel”. Metallurgical Transactions A. Vol.21A, pp.517-528. 1990.

- Holland, J. W., A. E. Wright, T. H. Bauer, A. J. Goldman, A. E. Klickman, and R. H. Sevy. "Post-test Examination Results of Recent TREAT Tests on Metal Fuel". Proceedings of the International Conference on Reliable Fuels for Liquid Metal Reactors, Tucson (AZ), September 7-11, 1986.

- Huet, J. J. "Fabrication and Mechanical Properties of Oxide Dispersion Strengthening Ferritic Alloy Canning Tubes for Fast Reactor Fuel Pins". Nuclear Technology. Vol.70, pp.215. 1985.

- Hunsbedt, A. and P. M. Magee, 1988, "Design and Performance of the PRISM Natural Convection Decay Heat Removal System," Proceedings of the International Topical Meeting on Safety of Next Generation Power Reactors, Seattle, Washington, May 1-5.

- Huntington Alloys, Inc. Resistance to Corrosion. pp.31-35. $3^{\text {rd }}$ Edition. 1979.ICBO, International Conference of Building Officials. Uniform Building Code ${ }^{T M}$. Vol.2, Chapter 16, Div. IV, Section 1631. (1997)

- Incropera, F. P., and D. P. De Witt. Fundamentals of Heat and Mass Transfer. pp.A-24. $3^{\text {rd }}$ Edition. John Wiley \& Sons, Inc. 1990.

- Ishii, M., and I. Kataoka. "Drag Coefficient and Relative Velocity in Bubbly, Droplet or Particulate Flows". AIChE Journal. 25, 843. 1979.

- Kassner, M. E., and D. E. Peterson (eds.). Phase Diagrams of Binary Actinide Alloys, ASM International, Materials Park (OH), p. 423, 1995.

- Kataoka, I. and M. Ishii, 1987, "Drift Flux Model for Large Diameter Pipe and New Correlation for Pool Void Fraction," International Journal of Heat Mass Transfer, Vol. 30, No. 9, pp. 1927-1939.

- Keiser, D. D. Jr., and M. A. Dayananda. "Interdiffusion between U-Zr Fuel and Selected FeNi-Cr Alloys". Journal of Nuclear Materials. Vol.200, pp.229-243. 1993.

- Keiser, D. D. Jr., and R. D. Mariani. "Zr-Rich Layers Electrodeposited onto Stainless Steel Cladding During the Electrorefining of EBR-II Fuel”. Journal of Nuclear Materials. Vol.270, pp.279-289. 1999.

- Keiser, D. D. Jr. Argonne National Laboratory (ANL-W). Private communication with J. Buongiorno. January 24, 2001.

- Kim D., Kazimi M. S., Todreas N. E., and Driscoll M. J., "Economic Analysis of the Fuel Cycle of Actinide Burning Systems," Topical Report MIT-NFC-TR-019, MIT, Dep. of Nuclear Engineering, February 2000.

- Krivitski I., "Utilization of Fast Reactor with Uranium-Free Fuel for Minor Actinides Transmutation," International Meeting on Advances in Reactor Physics and Mathematics, Pittsburgh, PA, May 7-11, 2000.

- Kuraishi H., Sawada T., and Ninokata H., "Inherent and Passive Safety Sodium-Cooled Fast Reactor Core Design with Minor Actinide and Fission Product Incineration," Nucl. Sci.Eng., Vol. 138, pp. 205-232,2001. 
- Lalanne, M., P. Berthier, J. D. Hagopian, and F. Nelson. Mechanical Vibrations for Engineers, pp.97-98. John Wiley \& Sons. (1983)

- Li, N. Active Control of Oxygen in Molten Lead-Bismuth Eutectic Systems to Prevent Steel Corrosion and Coolant Contamination. Report LA-UR-99-4696. Los Alamos National Laboratory. 1999.

- Lim, J. "Solubility of structural Materials in Liquid Lead-Bismuth". NED-MIT, private communication. 1999.

- Lim, J., and R. G. Ballinger. "Development of a Facility for the Study of Liquid-MetalStructural Interaction". Trans. Am. Nuc. Soc., vol.83, pp.310. November 2000.

- Loewen, E. P., C. B. Davis, and P. E. MacDonald. "A Technique for Dynamic Corrosion Testing in Liquid Lead Alloys". ICONE-8245, Proceedings of ICONE-8. Baltimore, MD USA. April 2-6, 2000a.

- $\quad$ Lyon. R.N. Liquid-Metals Handbook, pp.42-43. Navy Press, June 1952.

- MacDonald P. E. et al., Design of an Actinide Burning, Lead or Lead-Bismuth Cooled Reactor that Produces Low Cost Electricity, Annual Project Status Report, Idaho National Engineering Laboratory, INEEL/EXT-2000-00994 and MIT, Dep. of Nucl. Eng., MIT-ANPPR-071, July 2000.

- MacFarlane, R. E., and Muir, D. W., 1994. "The NJOY Nuclear Data Processing System, Version 91," LA-12740-M, Los Alamos National Laboratory, Los Alamos, NM.

- Meyer, J. Notes of the 22.314 Structural Mechanics in Nuclear Engineering Course. MIT. 1998.

- Metals Handbook, $9^{\text {th }}$ ed. Vol. 9, Metallography and Microstructures, ASM 1985

- Moore R. L., Schnitzler B. G., Wemple C. A., Babcock R. S., and Wessol D. E., "MOCUP: MCNP-ORIGEN2 Coupled Utility Program", INEL-95/0523, Idaho National Engineering Laboratory, September 1995.

- Nelson, J. K. "Corrosion by Alkalies and Hypochlorite" in Metals Handbook $9^{\text {th }}$ Edition, Volume 13, Corrosion. pp. 1174-1178. ASM International. 1987.

- Nikitin K., Saito M., Artisyuk V., Chmelev A., and Apse V., "Advanced U-Np-Pu Fuel to Achieve Long-Life Core in Heavy Water Reactor," Annals of Nuclear Energy, Vol. 26, pp. 1319-1329, 1999.

- NRC, U.S. Nuclear Regulatory Commission. Design Response Spectrum for Seismic Design of Nuclear Power Plants. Regulatory Guide 1.60. (1973a)

- NRC, U.S. Nuclear Regulatory Commission. Damping Values for Seismic Design of Nuclear Power Plants. Regulatory Guide 1.61. (1973b)

- Ogata, T., and T. Yokoo. "Irradiation Performance of a Prototypical Metallic Fuel for Fast Reactors". ICONE-8237. Proceedings of ICONE-8, $8^{\text {th }}$ International Conference on Nuclear Engineering. Baltimore, MD USA. April 2-6, 2000.

- Orechwa, Y., and S. T. Yang. "Development of an LMR Core Design Using Metallic Fuel". Proceedings of the International Conference on Reliable Fuels for Liquid Metal Reactors, Tucson (AZ), September 7-11, 1986.

- Orlov, Y., E. Yefimov, J. Stbbins, M. Bjornberg, X. He, W. Gregory, and N. Li, "LANL/IPPE/EDO-GP Collaboration Programs on Liquid Lead-Bismuth technology". Notes of the ATW Technical Review at MIT, Boston, MA, USA, January 15-16, 1998.

- Pahl, R. G., C. E. Lahm, R. Villareal, W. N. Beck, and G. L. Hofman. "Recent Irradiation Tests of Uranium-Plutonium-Zirconium Metal Fuel Elements". Proceedings of the International Conference on Reliable Fuels for Liquid Metal Reactors, Tucson (AZ), September 7-11, 1986. 
- Pahl, R. G., D. L. Porter, C. E. Lahm, and G. L. Hofman. "Experimental Studies of U-Pu-Zr Fast Reactor Fuel Pins in the Experimental Breeder Reactor-II". Metallurgical Transactions A. Vol.21A, pp.1863-1870. 1990a.

- Pahl, R. G., R. S. Wisner, M. C. Billone, and G. L. Hofman. "Steady-State Irradiation Testing of U-Pu-Zr Fuel to >18at\% Burnup". International Fast Reactor Safety Meeting, Snowboard, Utah. Session 2, Vol.IV, pp.129-137. 1990b.

- Pahl, R. G., D. L. Porter, D. C. Crawford, and L. C. Waters. "Irradiation Behavior of Metallic Fast Reactors Fuels". Journal of Nuclear Materials, vol.188, pp.3-9. 1992.

- Pankratov, D., B. F. Gromov, M. A. Solodjankin, E. I. Yefimov, V. N. Stepanov, G. I. Toshinsky, V. V. Kalchenko, V. V. Stekolnikov, V. S. Stepanov, L. N. Moskvin, O. G. Panov, and Y. A. Prokhorov. "The Experience in Handling Lead-Bismuth Coolant Contaminated by Polonium-210". Transactions of the ANS. Vol.67, Supplement No.1. p.256. September 1992.

- Parker, T.D. "Strength of Stainless Steels at Elevated Temperature". Metals Engineering Quarterly. Vol.8, No.2, pp.47-66. 1968.

- Pitner, A.L. "Metal Fuel Test Program in the FFTF". Journal of Nuclear Materials. Vol.204, pp.124-130. 1993.

- Porter, D.L., B. R. Seidel, L. C. Walters, and G. L. Hofman. "Factors Controlling Metal Fuel Lifetime". Proceedings of the International Conference on Reliable Fuels for Liquid Metal Reactors, Tucson (AZ), September 7-11, 1986.

- Porter, D. L., C. E. Lahm, and R. G. Pahl. "Fuel Constituent Redistribution during the Early Stages of U-Pu-Zr Irradiation". Metallurgical Transactions A. Vol.21A, pp.1871-1876. 1990.

- Poston D. I. and H. R. Trellue, MONTEBURNS 1.0, An Automated, Multi-step Monte Carlo Burnup Code System," PSR-455, RSICC Peripheral Shielding Routine Collection, September 1999.

- Pourbaix, M., Atlas of Electrochemical Equilibria in Aqueous Solutions, pp.554-576. Pergamon Press, 1966.

- Powell, R. W., G. D. Johnson, M. L. Hamilton, and F. A. Garner. "LMR Cladding and Duct Materials Development". Proceedings of the International Conference on Reliable Fuels for Liquid Metal Reactors, Tucson (AZ), September 7-11, 1986.

- Roth, T. S., and A. Biancheria. "A Model to Predict the Failure of Liquid-Metal-Reactor Fuel Pins during Transient Overpower Conditions". Proceedings of the International Conference on Reliable Fuels for Liquid Metal Reactors, Tucson (AZ), September 7-11, 1986.

- Salvatores M., "Fast Reactor Calculations," in CRC Handbook of Reactors Calculations, CRC Press, Boca Raton, 1986.

- Samsonov, E. G. V., "The oxide handbook", (Originally, Russian, translated by C. N. Turton and T. I. Turton), Plenum Press, London, 1973.

- Seidel, B. R., D. L. Porter, L. C. Walters, and G. L. Hofman. "Experience with EBR-II Driver Fuel". Proceedings of the International Conference on Reliable Fuels for Liquid Metal Reactors, Tucson (AZ), September 7-11, 1986.

- Shirakata K., Sanda T., and Nakashima F., "Spatial Neutronic Decoupling of Large Fast Breeder Reactor Cores," Nuclear Science and Engineering, Vol. 131, pp. 187-198, February 1999.

- Sohn, Y. H., M. A. Dayananda, G. L. Hofman, R. V. Strain, and S. L. Hayes. "Analysis of Constituent Redistribution in the $\gamma$ (bcc) U-Pu-Zr Alloys under Gradients of Temperature and Concentrations". Journal of Nuclear Materials. Vol.279, pp.317-329. 2000.

- Takano H., Fujine Y. and Saito J., "Minor Actinide Transmutation in Fission Reactors," Proceedings of $1^{\text {st }}$ International Information Exchange Meeting on Actinide and Fission Product Separation and Transmutation, Mito City, Japan, November 1990. 
- Todreas, N. and E., Kazimi, M., S., "Nuclear Systems I", Third printing, Taylor \& Francis, 2000.

- Tokiwai, M., M. Horie, K. Kako, and M. Fujiwara. "Development of New ferritic Steels as Cladding Material For Metallic Fuel Fast Breeder Reactor". Journal of Nuclear Materials. Vol.204, pp.56-64. 1993.

- Tommasi J., Massara S., and Pillon S. and Rome M., "Minor Actinide Destruction in Dedicated Reactors," Fifth NEA International Information Exchange Meeting, Mol, Belgium, 25-27 November, 1998.

- Tommasi J. and Massara S., "L.M.F.R. Dedicated Cores for Transmutation: Critical versus Subcritical Systems Comparison," Proc. Global '99 Int. Conf. on Future Nuclear Systems, Jackson Hole, WY, August 1999.

- Toshinsky G.I., "LMFBR Operation in the Nuclear Cycle Without Fuel Reprocessing," Proc. of Int. Topical Meeting on Advanced Reactors Safety, Vol. 1., pp. 39-44, Orlando, June 1997.

- Tsai, H. "Fuel/Cladding Compatibility in Irradiated Metallic Fuel Pins at Elevated Temperatures". International Fast Reactor Safety Meeting, Snowboard, Utah. Session 2, Vol.II, pp.259-267. 1990.

- Tsirlin, M., Sh. Lesin, and H. Branover. "Some Aspects of Structural Materials Compatibility with Liquid Lead-Containing Coolants". Trans. Am. Nuc. Soc., vol.80, pp.196-197. June 1999.

- Ukai, S., T. Nishida, T. Okuda, and T. Yoshitake. "Development of Oxide Dispersion Strengthened Steels for FBR Core Application, (II) Morphology Improvement by Martensite Transformation". Journal of Nuclear Science and Technology. Vol.35, No.4, pp.294-300. 1998.

- Vander Voort G. F. ed., Applied Metallography, Van Nostrand Reinhold Company Inc., New York, 1986

- Wade D. C. and E. K. Fujita, "Trends Versus Reactor Size of Passive Reactivity Shutdown and Control Performance," Nuclear Science and Engineering, Vol. 103, pp. 182-195, 1989.

- Wade D. C. and R. N. Hill, "The Design Rationale of the IFR," Progress in Nuclear

- Wakabayashi T., Takahashi K., and Yanagisawa T., "Feasibility Studies on Plutonium and Minor Actinide Burning in Fast Reactors," Nucl. Technol., Vol. 118, pp. 14-25, 1997.

- Walters, L. C. "Thirty Years of Fuels and Materials Information from EBR-II". Journal of Nuclear Materials. Vol.270, pp.39-48. 1999.

- Waltar A. E. and Reynolds A. B., Fast Breeder Reactors, Pergamon Press, New York, 1981.

- Weaver, K. D., Herring, J. S., and MacDonald, P. E., 2000. "Performance Modeling of Metallic and Nitride Fuels in Advanced Lead-Bismuth Cooled Fast Reactors," Proceedings of ICONE-8, Baltimore, MD.

- Weaver, K. D., Herring, J. S., and Macdonald, P. E., 2001. "Performance Comparison of Metallic, Actinide Burning Fuel in Lead-Bismuth and Sodium Cooled Fast Reactors," Proceedings of ICONE-9, Nice, France.

- Weeks, J. R. "Lead, Bismuth, Tin and their Alloys as Nuclear Coolants". Nuclear Engineering and Design, 15, pp.363-372. 1971.

- Westinghouse Nuclear Energy Systems, 1973, Reference Safety Analysis Report, Volume VI, RESAR 41, December.

- White, R. N., P. Gergely, and R. G. Sexsmith. Structural Engineering. Vol.1, pp.188-193. John Wiley \& Sons. (1972).

- Witteman, W., A.Giorgi, D.Vier. "The Preparation and Identification of Some Intermetallic Compounds of Polonium". J. Phys. Chem., Vol.64, No.4, pp.434-440, 1960. 
- Wright R. F., J. S. Tulenko, G. J. Schoessow, R. G. Connel, M. A. Dubecky Jr., and T. Adams, "Thermal Bonding of Light Water Reactor Fuel Using Nonalkaline Liquid Metal Alloy,” Nuclear Technology, 115, pp. 281-292, 1996.

- Yamaoka M. and Wakabayashi T., "Study on Super-Long-Life Cores Loaded with Minor Actinide Fuel,” Nucl. Eng. Des., Vol. 154, pp. 239-250, 1995.

- Yefimov, E., D. Pankratov, S. Ignatiev. "Removal and Containment of High-Level Radioactive Polonium from Liquid Lead-Bismuth Coolant". Proceedings of the Materials Research Society Symposium. Vol.506, p.679-686. 1998.

- Zhukov A. V., Sorokin A. P., Smirnov V. P., and Papandin M. V., "Heat Transfer in LeadCooled Fast Reactor (LCFR)", Proceedings of the 1994 International Topical Meeting on Advanced Reactors Safety, Pittsburgh, USA, 1994.

- Zrodnikov, A. V., V. I. Chitaykin, B. F. Gromov, G. I. Toshinsky, U. G. Dragunov, and V. S. Stepanov. "Applications of Reactors Cooled by Lead-Bismuth Alloy in Nuclear Power Energy". Proceedings of Global '99: International Conference on Future Nuclear Systems. Jackson Hole, WY USA. August-September 1999.

- Zuber, N. and J. Findlay, 1965, "Average Volumetric Concentrations in Two-Phase Flow Systems," Journal of Heat Transfer, Vol. 87, pp. 453-468, November.

- Zuber, N., F. W. Staub, G. Bijwaard, and P. G. Kroeger, 1967, "Steady-State and Transient Void Fraction in Two-Phase Flow Systems," GEAP-5417, General Electric Company. 


\section{Appendix A. Publication History Of The Lead- Cooled Actinide Burning Reactor Project}

\section{Theses}

- J. Buongiorno, " Conceptual Design of a Lead-Bismuth Cooled Fast Reactor with InVessel Direct-Contact Steam Generation," Doctoral Thesis, Dept. of Nuclear Engineering, M.I.T., September 2000.

\section{$\underline{\text { Topical Reports }}$}

- J. Buongiorno, P. Hejzlar, N.E. Todreas, M.J. Driscoll and M.S. Kazimi, "Actinide Transmutation by Lead-Bismuth Cooled Reactors," MIT-ANP-TR-065, MIT Nuclear Engineering Dept., June 1999.

- J. Buongiorno, N.E. Todreas and M.S. Kazimi, "Thermal Design of Lead-Bismuth Cooled Reactor for Actinide Burning and Power Production," MIT-ANP-TR-066, MIT Nuclear Engineering Dept., July 1999.

- P. Hejzlar, M.J. Driscoll and M.S. Kazimi, "Void Reactivity Performance in LeadBismuth Cooled Reactor for Actinide Transmutation," MIT-ANP-TR-068, MIT Nuclear Engineering Dept., August 1999.

- D. Kim, M.S. Kazimi, N.E. Todreas and M.J. Driscoll, "Economic Analysis of the Fuel Cycle of Actinide Burning Systems," MIT-NFC-TR-019, MIT Nuclear Engineering Dept., February 2000.

- P. Hejzlar, M.J. Driscoll, and M.S. Kazimi, "Conceptual Reactor Physics Design of a Lead-Bismuth-Cooled Critical Actinide Burner," MIT-ANP-TR-069, MIT Nuclear Engineering Dept., February 2000.

- D. Kim, N.E. Todreas, M.S. Kazimi and M.J. Driscoll, "Plant Design and Cost Estimation of a Natural Circulation Lead-Bismuth Reactor with Helium Power Conversion Cycle," MIT-ANP-TR-074, MIT Nuclear Engineering Dept., November 2000.

- J. Buongiorno, N.E. Todreas, M.S. Kazimi and K.R. Czerwinski "Conceptual Design of a Lead-Bismuth Cooled Fast Reactor with In-Vessel Direct-Contact Steam Generation," MIT-ANP-TR-079, CANES/MIT Nuclear Engineering Dept., March 2001.

- R.G. Ballinger, J.Y. Lim and M.S. Kazimi "A Review of US Research Activities on Material Compatibility Issues in Nuclear Systems Using Heavy Liquid-Metal Coolant and Needs for Improved Materials," MIT-ANP-TR-080, CANES/MIT Nuclear Engineering Dept., June 2001.

- Hejzlar P., Todreas N.E., Kazimi M.S. and Driscoll M.J., "Evaluation of a Once-Through lead-Bismuth-Cooled Reactor Concept," MIT-ANP-TR-081, MIT Nuclear Engineering Dept., July 2001.

- V. Dostal, N.E. Todreas, P. Hejzlar, and M.S. Kazimi, "Plant Design and Cost Assessment of a Forced Circulation Lead-Bismuth Cooled Reactor with Conventional Power Conversion Cycles", MIT-ANP-TR-082, MIT Nuclear Engineering Dept., August 2001.

- V. Dostal, M.J. Driscoll, P. Hejzlar, and N.E. Todreas, "Optimum Power Conversion Cycle Selection of a Forced Circulation Lead-Bismuth Cooled Reactor", MIT-ANP-TR083, MIT Nuclear Engineering Dept., To be submitted in September 2001. 


\section{$\underline{\text { Journal Papers }}$}

- K. D. Weaver, P. E. MacDonald, and J. S. Herring, "Reactivity and Isotopic Assessment of Fertile Fuels for Proliferation-Resistant, Actinide-Burning Lead or Lead-Bismuth Cooled Fast Reactors", Submitted to the Journal of Nuclear Engineering and Design, January 2001.

- Davis, C. B., "Assessment of the ATHENA Code for Calculating the Void Fraction of a Lead-Bismuth/Steam Mixture in Vertical Upflow", Nuclear Technology, Vol. 133, pp. 187-193, February 2001.

- Davis, C., D. Kim. N.E. Todreas, M.S. Kazimi, "Plant Design and Economic Analysis of a Lead-Bismuth Cooled Actinide Burner Reactor," Submitted to Nuclear Engineering and Design, Feburary, 2001

- Buongiorno J., M.S. Kazimi, N.E. Todreas, "Heavy-Metal Aerosol Transport in a LeadBismuth Cooled Fast Reactor with In-Vessel Direct-Contact Steam Generation," Submitted to Nuclear Technology, April 2001.

- Buongiorno, J., and B. D. Hawkes, "Seismic Analysis of Heavy-Liquid-Metal-Cooled Reactor Vessels". Submitted to Nuclear Technology, June 2001.

- Czerwinski. K.R., J. Buongiorno, C.L. Larson. "Experimental Investigations on Vapor Pressure of Lead Polonide at Low Temperature \& Thermodynamics of Polonium Hydride". Submitted to Radiochimica Acta. April 2001.

- Hejzlar, P., M.J. Driscoll, M.S. Kazimi, "Conceptual Neutronic Design of a LeadBismuth Cooled Actinide Burning Reactor," Accepted for publication in Nuclear Science \& Engineering, Vol. 139, pp. 1-18, October 2001.

\section{Conference Papers}

- P. Hejzlar, M.J. Driscoll and M.S. Kazimi, "Reactor Physics Design Challenges of a lead-bismuth Cooled Actinide Burner Reactor,"_Transactions of the American Nuclear Society, Vol. 80, pp. 192-194 June 1999.

- P. Hejzlar, M.J. Driscoll, and M.S. Kazimi, "Neutronic Design for a Pb-Bi-Cooled Actinide Burner Fast Reactor," Transactions of the American Nuclear Society, Vol. 81, pp. 271-273, 1999.

- J. Buongiorno, M.S. Kazimi and N.E. Todreas, "Natural Circulation Potential of leadbismuth Cooled Reactors for Production and Actinide Burning," Transactions of the American Nuclear Society, Vol. 8, pp. 191-192, June 1999.

- J. Buongiorno, N.E. Todreas, M.S. Kazimi, M.J. Driscoll and P. Hejzlar, "Key Features of an Integrated Lead-Bismuth Cooled Reactor Based on Water/Liquid Metal Direct Heat Transfer,"_Transactions of the American Nuclear Society, Vol 81, pp. 360, Long Beach, CA, November 14-18, 1999.

- J.Buongiorno, N.Todreas, M.Kazimi. "Void Fraction Prediction for the LeadBismuth/Water Direct Contact Nuclear Reactor". Proceedings of ICONE-8, $8^{\text {th }}$ International Conference on Nuclear Engineering, No. 8739, April 2-6, 2000, Baltimore, MD USA.

- C. B. Davis and A. S. Shieh, "Overview of the Use of ATHENA for Analysis of LeadBismuth Cooled Reactors", Proceedings of the $8^{\text {th }}$ International Conference on Nuclear Engineering (ICONE-8), April 2-6, 2000, Baltimore, MD.

- E. P. Loewen, C. B. Davis, and P. E. MacDonald, "A Technique for Dynamic Corrosion Testing in Liquid Lead Alloys" Proceedings of the $8^{\text {th }}$ International Conference on Nuclear Engineering (ICONE-8), April 2-6, 2000, Baltimore, MD. 
- K. D. Weaver, J. S. Herring, and P. E. MacDonald, "Performance Modeling of Metallic and Nitride Fuels in Advanced Lead-Bismuth Cooled Fast Reactors," Proceedings of the $8^{\text {th }}$ International Conference on Nuclear Engineering (ICONE-8), April 2-6, 2000, Baltimore, MD.

- Driscoll, M. J., and Dohyoung Kim, "The Need for Actinide Burner Reactor Fuel Cycle Cost Reduction," Transactions of the American Nuclear Society, Vol. 82, June 2000.

- Lim, J., and R. G. Ballinger "Development of a Facility for the Study of Liquid-MetalStructural-Material Interaction", Trans. Am. Nucl. Soc. Vol. 83, pg. 310 November, 2000.

- Buongiorno J., N.E. Todreas and M.S. Kazimi, "Thermal-Hydraulic Modeling of a Water/Liquid-Metal Direct Contact Heat Transfer Reactor," Trans. Am. Nucl. Soc. Vol. 83, pg. 395-397, November 2000.

- Hejzlar, P., M.J. Driscoll and M.S. Kazimi, "Consequence of Fuel Choice for Spent Fuel Characteristics for Once-Through Heavy Metal Cooled Fast Reactors," Trans. Am. Nucl. Soc. Vol. 83, pg. 39-41, November 2000.

- J. Buongiorno, N. E. Todreas, and M. S. Kazimi. "Thermal Design of a Lead-Bismuth Cooled Fast Reactor with In-Vessel Direct-Contact Steam Generation”. ICONE-9772. Proceedings of ICONE-9, the $9^{\text {th }}$ International Conference on Nuclear Engineering. Nice, France. April 8-12, 2001.

- Hejzlar, P., M.J. Driscoll, M.S. Kazimi and N.E. Todreas, "Minor Actinide Burning in Dedicated Lead-Bismuth Cooled Fast Reactors," Track 8 - \#336, The Proceedings of ICONE 9, April 8-12, 2001-Nice, France.

- Weaver, K.D., J.S. Herring and P.E. MacDonald. "Performance Comparison of Metallic, Actinide Burning Fuel in Lead-Bismuth and Sodium Cooled Fast Reactors," ICONE-409 Proceedings of ICONE-9, the $9^{\text {th }}$ International Conference on Nuclear Engineering. Nice, France. April 8-12, 2001.

- Driscoll, M.J., and P. Hejzlar, "A Negative Reactivity Feedback Device for Actinide Burner Cores," Trans. Am. Nucl. Soc., Vol. 84, pg. 241-242, June 2001

- J.Buongiorno, B.D.Hawkes. "Seismic Response of Lead- and Lead-Bismuth-Cooled Reactor Vessels". Proceedings of the SMiRT-16 Conference. Washington D.C., August 12-17, 2001.

- Buongiorno, J., C. L. Larson, and K. R. Czerwinski. "Discussion on Polonium Extraction Systems for Pb-Bi-Cooled Nuclear Reactors". Proceedings of the Global 2001 International Conference. Paris (France), September 9-13, 2001.

- Buongiorno, J. "Temperature Limits for the Fuel and Cladding of Heavy-Liquid-MetalCooled Reactors". Proceedings of the Global 2001 International Conference. Paris (France), September 9-13, 2001.

- Weaver, K.D., J.S. Herring and P.E. MacDonald. "A Comparison of Long-Lived, Proliferation Resistant Fast Reactors," Proceedings of the Global 2001 International Conference. Paris (France), September 9-13, 2001.

- Buongiorno, J., "Temperature Limits for Heavy-Liquid-Metal Reactor Vessels". Summary submitted for the ANS Winter Meeting, Reno, NV, November 2001.

- Hejzlar, P., N.E. Todreas, M.S. Kazimi, M.J. Driscoll, "Challenges of Minor Actinide Burning in Critical Lead-Bismuth Cooled Reactors," Summary submitted for the ANS Winter Meeting, Reno, NV, November 2001.

- Dostal, V., P. Hejzlar, M.J. Driscoll, N.E. Todreas, "A Supercritical CO2 Brayton Cycle for Advanced Reactor Applications" Summary submitted for the ANS Winter Meeting, Reno, NV, November 2001.

- Lim, J., P. W. Stahle and R.G. Ballinger, "A Test System for Experimental Studies of Liquid-Metal-Structural-Material Interaction", Summary submitted for the ANS Winter Meeting, Reno, NV, November 2001. 


\section{Awards}

- J.Buongiorno received the ANS Mark Mills national award in recognition of the "best original technical paper contributing to the advancement of science and engineering related to the atomic nucleus", September 2001.

- "Void Fraction Prediction for the Lead-Bismuth/Water Direct Contact Nuclear Reactor" by J. Buongiorno, N. Todreas and M. Kazimi received the Best Technical Paper of the Thermal-Hydraulic Track award at the $8^{\text {th }}$ International Conference on Nuclear Engineering (ICONE-8), Baltimore MD, April 2000.

\section{$\underline{\text { Invited Presentations and Seminars }}$}

- J.Buongiorno. "Evaluation of Polonium Extraction Technology for Lead-Bismuth Cooled Fast Reactors", presentation at the Russia-Japan LBE Workshop held at the Tokyo Institute of Technology in Tokyo (Japan). February 2001.

- J.Buongiorno. "Conceptual Design of a Lead-Bismuth Cooled Fast Reactor with InVessel Direct-Contact Steam Generation". Seminar held at the Department of Engineering Physics of the University of Wisconsin at Madison. February 2001.

- E. Loewen, "Dynamic Corrosion Testing at the INEEL", Limited distribution proceedings, Dec. 13, 2000, Lead-Bismuth Technology International Meeting, Japan Nuclear Cycle Development Institute, Tokyo and Mito, Japan

- P. E. MacDonald, "Design of an Actinide Burning, Lead or Lead-Bismuth Cooled Reactor That Produces Low Cost Electricity", Limited distribution proceedings, Dec. 12, 2000, Lead-Bismuth Technology International Meeting, Japan Nuclear Cycle Development Institute, Tokyo and Mito, Japan

- P. Hejzlar, M. J. Driscoll, and N. E. Todreas, "Impact of Fuel Choices On Spent Fuel Characteristics for Once-Through Heavy Metal Cooled Reactors", Proceedings are not yet published, Nov. 23-Dec. 1, IAEA Technical Meeting, IAEA, ANL, Argonne, IL

- D. Kim, M. S. Kazimi, M. J. Driscoll, and N. E. Todreas, "The Economics of Transmutation Fuel Cycles", Proceedings not yet published, Nov. 23-Dec. 1, IAEA Technical Committee Meeting, IAEA, ANL, Argonne, IL 


\section{Appendix B. The Strain And Stress Model In The Cladding}

\section{B.1. General Assumptions}

1) Fuel-cladding interaction is neglected. It was noted that by reducing the initial smeared density of the metallic fuel and thus allowing for unrestricted fuel swelling, it is possible to greatly reduce the fuel-cladding mechanical interaction up to considerable burnups, i.e., 1520at\% (Pahl et al. 1990a, 1990b and 1992).

2) Plastic strains are neglected. The accuracy of this assumption will be tested by verifying that the cladding stresses do not exceed the yield limit of the cladding material at temperature.

3) Elastic, thermal, swelling, irradiation creep and thermal creep strains are considered.

4) Fuel deformation is modeled by specifying the fuel outer radius and axial expansion as a function of burnup.

\section{B.2. Geometry}

The reference geometry is illustrated in Figure 72 of Section 4.1. The free volume occupied by the fission gases is $\mathrm{V}_{\mathrm{fg}}$ and is calculated as:

$$
V_{f g}=\pi R_{c i}^{2} L_{c}-\pi R_{f}^{2} L_{f}-V_{b o n d}
$$

where the volume of the bond is calculated from the (known) bond mass and density.

\section{B.3. Time Nodalization and Initial Conditions}

The specified irradiation time is nodalized in equally spaced intervals (typically 1000). The fuel and cladding dimension at Beginning-Of-Life (BOL) are known and indicated by the subscript " 0 ": $\mathrm{R}_{\mathrm{f} 0}, \mathrm{R}_{\mathrm{c} i 0}, \mathrm{R}_{\mathrm{co} 0}, \mathrm{~L}_{\mathrm{f} 0}, \mathrm{~L}_{\mathrm{c} 0}, \mathrm{~L}_{\mathrm{p} 0}, \mathrm{~V}_{\mathrm{fg} 0}$. To calculate $\mathrm{V}_{\mathrm{fg} 0}$, it is assumed that at BOL the liquid metal bond level equals the fuel level (i.e., no bond above the fuel slug).

The density of the as-fabricated fuel $\rho_{\mathrm{fo}}$ is calculated as:

$$
\rho_{f 0}=\frac{1}{\sum_{i} \frac{w_{i}}{\rho_{i}}}
$$

where $\mathrm{w}_{\mathrm{i}}$ is the nominal weight fraction of the $\mathrm{i}$-th fuel component (e.g., zirconium, uranium, plutonium) and $\rho_{\mathrm{i}}$ its nominal density (as a pure substance). For the metallic alloys of interest, this approach yields a rather accurate estimate of the as-fabricated fuel density (Hill et al. 1999).

The mass of initially loaded heavy metals, $\mathrm{M}_{\mathrm{HM}}$ is:

$$
M_{H M}=\pi R_{f 0}^{2} L_{f 0} \rho_{f 0} \sum_{i H M} w_{i H M}
$$


where $\mathrm{w}_{\mathrm{iHM}}$ is the weight fraction of the $\mathrm{i}$-th heavy metal.

The linear heat generation rate q' and thus the fuel rod power $\dot{q}$ are known. The fast neutron flux $\Phi\left(\mathrm{E}_{\mathrm{n}}>0.1 \mathrm{MeV}\right)$ on the cladding is also known as a function of the power density in the fuel. The conversion factor between the fast flux and the dose rate $\dot{\delta}(\mathrm{dpa} / \mathrm{s})$ is: $1 \mathrm{dpa} / \mathrm{s}=2 \times 10^{21} \mathrm{n} / \mathrm{cm}^{2} \mathrm{~s}$, as recommended in (Pahl et al. 1990a).

Finally the cladding temperature $T_{c}$ is specified. It should be emphasized that knowledge of the temperature distribution in the fuel is not needed, because fuel expansion (primarily due to fission products-induced swelling) is specified (both in the radial and axial directions) as a function of burnup only.

\section{B.4. Definitions}

Four vectors are defined for the cladding. The cladding displacement vector, $\underline{D}_{D}$ is defined as:

$$
\underline{D}_{D} \equiv\left(\begin{array}{c}
u_{c i} \\
u_{c o} \\
\varepsilon_{z}
\end{array}\right)
$$

where $\mathrm{u}_{\mathrm{ci}}$ and $\mathrm{u}_{\mathrm{co}}$ are the cladding inner and outer radial displacement, respectively and $\varepsilon_{\mathrm{z}}$ is the axial strain. Note that $\mathrm{u}_{\mathrm{ci}}$ and $\mathrm{u}_{\mathrm{co}}$ are in length units, whereas $\varepsilon_{\mathrm{z}}$ is a dimensionless quantity.

With these definitions the cladding inner radius, outer radius and length at any time during the irradiation are, respectively:

$$
\begin{array}{ll}
\mathrm{R}_{\mathrm{ci}}=\mathrm{R}_{\mathrm{ci}}+\mathrm{u}_{\mathrm{ci}} & \text { B. } 5 \\
\mathrm{R}_{\mathrm{co}}=\mathrm{R}_{\mathrm{co} 0}+\mathrm{u}_{\mathrm{co}} & \text { B.6 } \\
\mathrm{L}_{\mathrm{c}}=\mathrm{L}_{\mathrm{c} 0}\left(1+\varepsilon_{\mathrm{z}}\right) & \text { B. } 7
\end{array}
$$

The cladding external force vector, $\underline{F}_{\mathrm{E}}$ is defined as:

$$
\underline{\mathrm{F}}_{\mathrm{E}} \equiv\left(\begin{array}{c}
2 \pi \mathrm{R}_{\mathrm{ci} 0} \mathrm{P}_{\mathrm{i}} \\
-2 \pi \mathrm{R}_{\mathrm{co0} 0} \mathrm{P}_{\mathrm{B}} \\
\pi \mathrm{R}_{\mathrm{ci} 0}^{2} \mathrm{P}_{\mathrm{i}}-\pi \mathrm{R}_{\mathrm{co} 0}^{2} \mathrm{P}_{\mathrm{B}}
\end{array}\right)
$$

where $\mathrm{P}_{\mathrm{B}}$ and $\mathrm{P}_{\mathrm{i}}$ are the $\mathrm{Pb}-\mathrm{Bi}$ coolant and cladding internal pressure, respectively. Note that the third component of $\underline{F}_{E}$ (i.e., $F_{z}$ ) is in $N$, while the first two are in $N / m . P_{B}$ is known (and usually equal to about $0.1 \mathrm{MPa}$ in liquid metal systems). As for $\mathrm{P}_{\mathrm{i}}$, it is assumed that the as-fabricated fuel rod is filled with a known pressure of inert gas $\left(\mathrm{P}_{\mathrm{i} 0}\right.$ at room temperature, $\left.\mathrm{T}_{\mathrm{ref}}=20^{\circ} \mathrm{C}\right)$. Additional cladding pressurization is induced by the build-up of fission gases in the plenum. Therefore the total cladding pressurization can be calculated as:

$$
P_{i}=\frac{T_{c}}{T_{r e f}} \frac{V_{f g 0}}{V_{f g}} P_{i 0}+\frac{N_{f g} R T_{c}}{V_{f g}}
$$


where $\mathrm{R}$ is the ideal gas constant $(8.31 \mathrm{~J} / \mathrm{mol} \cdot \mathrm{K}), \mathrm{T}_{\mathrm{c}}$ is the cladding absolute temperature and $\mathrm{N}_{\mathrm{fg}}$ is the cumulative number of fission gas moles released to the gas plenum at time $t_{k}$. $\mathrm{N}_{\mathrm{fg}}$ is calculated as:

$$
N_{f g}=F_{f g} n_{f g} \dot{q} t_{k}
$$

where $\mathrm{n}_{\mathrm{fg}}=1.31 \times 10^{-3} \mathrm{~mol} / \mathrm{MWd}$ (roughly independent on the fuel) from previous estimates (Hejzlar et al. 2000) and $\mathrm{F}_{\mathrm{fg}}$ is the fraction of fission gases generated in the fuel that are released to the plenum. $\mathrm{F}_{\mathrm{fg}}$ is a known fuel-dependent function of the burnup.

The cladding strain vector, $\underline{D}_{\mathrm{S}}$ is defined as:

$$
\underline{D}_{S} \equiv\left(\begin{array}{c}
\varepsilon_{r} \\
\varepsilon_{\theta} \\
\varepsilon_{z}
\end{array}\right)
$$

where $\varepsilon_{\mathrm{r}}, \varepsilon_{\theta}$ and $\varepsilon_{\mathrm{z}}$ are the radial, hoop and axial strain, respectively. Note that $\varepsilon_{\mathrm{z}}$ in Equation B.4 and B.11 are the same.

The cladding stress vector, $\underline{F}_{\mathrm{S}}$ is defined as:

$$
\underline{F}_{S} \equiv\left(\begin{array}{c}
\sigma_{r} \\
\sigma_{\theta} \\
\sigma_{z}
\end{array}\right)
$$

where $\sigma_{\mathrm{r}}, \sigma_{\theta}$ and $\sigma_{\mathrm{z}}$ are the radial, hoop and axial stress, respectively.

\section{B.5. Fundamental Equations}

In general, static structural mechanics problems can be solved by establishing three sets of equations: 1) the displacement/strain relations, 2) the equilibrium equations and 3) stress/strain relations. In our case these are, respectively:

1) $\underline{D}_{S}=C \underline{D}_{D}$

where, from the definition of $\varepsilon_{\mathrm{r}}$ and $\varepsilon_{\theta}$, the matrix $\mathrm{C}$ is:

$$
\mathrm{C}=\left[\begin{array}{ccc}
-\frac{1}{\mathrm{R}_{\mathrm{co} 0}-\mathrm{R}_{\mathrm{ci} 0}} & \frac{1}{\mathrm{R}_{\mathrm{co} 0}-\mathrm{R}_{\mathrm{ci} 0}} & 0 \\
\frac{1}{\mathrm{R}_{\mathrm{co} 0}+\mathrm{R}_{\mathrm{ci} 0}} & \frac{1}{\mathrm{R}_{\mathrm{co} 0}+\mathrm{R}_{\mathrm{ci} 0}} & 0 \\
0 & 0 & 1
\end{array}\right]
$$

2) $\underline{F}_{E}=\pi\left(R_{c o 0}^{2}-R_{c i 0}^{2}\right) C^{T} \underline{F}_{S}$

B. 15 
where $\mathrm{C}^{\mathrm{T}}$ is the transposed matrix of $\mathrm{C}$.

This force equilibrium condition was derived from Equation B.13 and the principle of virtual work, i.e., virtual work done by the external forces equal virtual work done by the internal stresses (Meyer 1998).

3) $\underline{D}_{S}=A \underline{F}_{S}+\underline{D}_{S}^{\prime}=\frac{1}{E}\left[\begin{array}{ccc}1 & -v & -v \\ -v & 1 & -v \\ -v & -v & 1\end{array}\right] \underline{F}_{S}+\underline{D}_{S}^{\prime}$

where E and $v$ are the cladding Young's and Poisson's modulus, respectively, which are assumed to be known functions of temperature. The burnup dependence of the moduli is neglected. The vector D's represents the cladding non-elastic strains and is the sum of four components: a) thermal expansion strains, b) irradiation swelling strains, c) irradiation creep strains and d) thermal creep strains:

$$
\underline{D}_{S}^{\prime}=\underline{D}_{T}+\underline{D}_{I S}+\underline{D}_{I C}+\underline{D}_{T C}
$$

The expressions for these four terms are as follows:

a) $\underline{D}_{T}=\varepsilon_{T}\left(\begin{array}{l}1 \\ 1 \\ 1\end{array}\right)$

where:

$$
\varepsilon_{T}=\int_{T_{r e f}}^{T_{c}} \alpha(T) d T=\bar{\alpha}\left(T_{c}-T_{r e f}\right)
$$

and $\bar{\alpha}$ is the average linear thermal expansion coefficient.

b) $\underline{D}_{I S}=\varepsilon_{I S}\left(\begin{array}{l}1 / 3 \\ 1 / 3 \\ 1 / 3\end{array}\right)$

where swelling is assumed to be isotropic and $\varepsilon_{\mathrm{IS}}$ is the volumetric irradiation swelling expansion, which is a known material-dependent function of the fast neutron fluence or dose.

c) From creep theory (e.g., see (Meyer 1998)): 


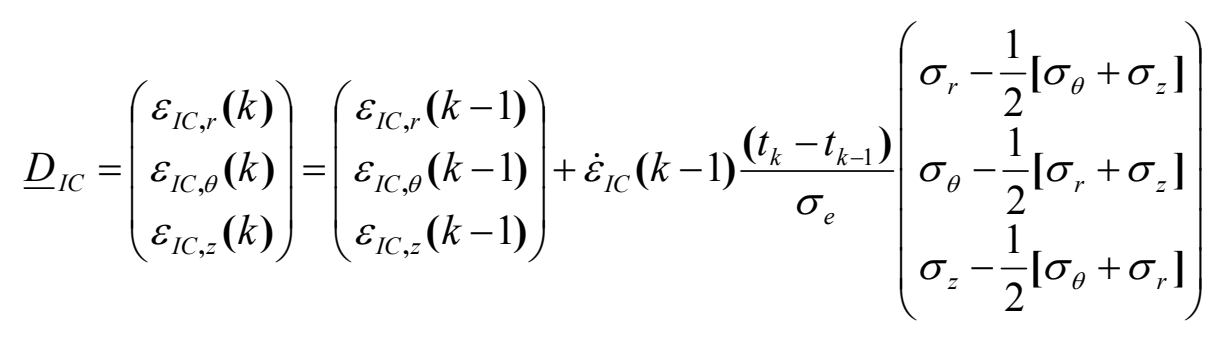

where $\sigma_{\mathrm{e}}$ is the Von Mises equivalent stress:

$$
\sigma_{e} \equiv \sqrt{\frac{1}{2}\left[\left(\sigma_{r}-\sigma_{\vartheta}\right)^{2}+\left(\sigma_{z}-\sigma_{\vartheta}\right)^{2}+\left(\sigma_{r}-\sigma_{z}\right)^{2}\right]}
$$

and $\dot{\varepsilon}_{I C}$ is a known material-dependent function of $\sigma_{\mathrm{e}}$ and $\Phi$ (or, equivalently, the dose rate, $\dot{\delta}$ ). Note that in Equation B.21 all the stresses (including $\sigma_{\mathrm{e}}$ ) are calculated at $\mathrm{t}_{\mathrm{k}-1}$.

d) The expression of the thermal creep strains is identical to that of the irradiation creep strains in c), except that $\dot{\varepsilon}_{I C}$ is replaced by $\dot{\varepsilon}_{T C}$, a known material-dependent function of $\mathrm{T}_{\mathrm{c}}$ and $\sigma_{\mathrm{e}}$.

\section{B.6. Computational Algorithm}

For any time node $t_{\mathrm{k}}$ the following calculations are performed:

- The burnup is calculated from knowledge of the fuel rod power and initial mass of heavy metals. Note that the burnup can be expressed in terms of $\mathrm{MWd} / \mathrm{t}_{\mathrm{HM}}$ or at $\%$. The conversion factor between the two is 1 at $\% \approx 10,000 \mathrm{MWd} / \mathrm{t}_{\mathrm{HM}}$.

- From knowledge of the fuel and cladding dimensions (at $t_{k-1}$ ) the cladding pressurization and thus the external force vector $\underline{F}_{\mathrm{E}}$ is calculated.

- From Equation B.15 the stress vector $\underline{F}_{\mathrm{S}}$ is calculated as:

$$
\underline{F}_{S}=\frac{1}{\pi\left(R_{c o 0}^{2}-R_{c i 0}^{2}\right)}\left(C^{T}\right)^{-1} \underline{F}_{E}
$$

- The strain vector $\underline{D}_{S}$ is readily calculated from Equation B.16. Note that $\underline{D}_{s}^{\prime}$ at $t_{k}$ is calculated from Equation B.17 through B.22, which do not require knowledge of the conditions at $t_{k}$. Thus $\underline{D}_{S}^{\prime}$ is a known term in Equation B.16.

- The displacement vector $\underline{D}_{\mathrm{D}}$ is calculated inverting Equation B.13.

Validation of the Model. It is desirable to benchmark the model against actual fuel irradiation data. A series of tests of three HT-9-clad sodium-bonded and sodium-cooled metallic fuel rods (IFR test X441, (Pahl et al. 1992)) is selected for this purpose. The geometry and operating conditions of these fuel rods are reported in Table B.I. It can be seen that the operating conditions are identical for the three rods and so are the cladding radius, thickness and length. However, the three rods differ by the fuel slug length, i.e., the plenum-to-fuel volume ratio is different.

The benchmarking parameter is the EOL cladding hoop strain due to swelling, irradiation and thermal creep, because this is the well-characterized data reported in (Pahl et al. 1992). 
Table B.I. Operating conditions of the IFR test fuel rods.

\begin{tabular}{|l|l|}
\hline Parameter & Value \\
\hline $\mathrm{R}_{\mathrm{co} 0}$ & $2.92 \mathrm{~mm}$ \\
\hline $\mathrm{R}_{\mathrm{ci} 0}$ & $2.54 \mathrm{~mm}$ \\
\hline $\mathrm{t}_{\mathrm{c}}\left(=\mathrm{R}_{\mathrm{co} 0}-\mathrm{R}_{\mathrm{ci} 0}\right)$ & $0.38 \mathrm{~mm}$ \\
\hline $\mathrm{R}_{\mathrm{f} 0}$ & $2.20 \mathrm{~mm}$ \\
\hline $\mathrm{L}_{\mathrm{c} 0}(\mathrm{Rod} \# 1 / 2 / 3)$ & $35.7 / 30.0 / 24.2 \mathrm{~cm}$ \\
\hline $\mathrm{L}_{\mathrm{f} 0}(\operatorname{cm}$ \\
\hline $\mathrm{L}_{\mathrm{p} 0}($ Rod $\# 1 / 2 / 3)$ & $39.2 / 44.9 / 50.7 \mathrm{~cm}$ \\
\hline Fuel Alloy & $\mathrm{U}-19 \mathrm{Pu}-10 \mathrm{Zr} \mathrm{wt} \%$ \\
\hline$\rho_{\mathrm{f} 0}($ calculated $)$ & $16,110 \mathrm{~kg} / \mathrm{m}^{3}$ \\
\hline $\mathrm{M}_{\mathrm{HM}}($ Rod $\# 1 / 2 / 3)$ & $78.6 / 66.0 / 53.3 \mathrm{~g}$ \\
\hline Smeared Density & $75 \%$ \\
\hline Cladding Material & $\mathrm{HT}-9$ \\
\hline Peak Linear Power & $51 \mathrm{~kW} / \mathrm{m}$ \\
\hline Peak Cladding Temperature & $600^{\circ} \mathrm{C}$ \\
\hline Peak Burnup & $12.7 \mathrm{at} \%\left(127,000 \mathrm{MWd} / \mathrm{t}_{\mathrm{HM}}\right)$ \\
\hline $\mathrm{P}_{\mathrm{B}}$ & $0.1 \mathrm{MPa}$ \\
\hline $\mathrm{P}_{\mathrm{i} 0}$ & $0.3 \mathrm{MPa}$ \\
\hline
\end{tabular}

The thermo-physical properties of the sodium bond were taken from (Incropera and De Witt 1990). When not directly available, the mechanical and thermo-physical properties of HT-9 were assumed to be equal to those of SS410, a ferritic/martensitic steel of composition similar to HT-9. The elastic moduli $\mathrm{E}$ and $v$ as a function of temperature were taken from (Parker 1968); the yield strength and the linear average thermal expansion coefficient as a function of temperature were found in (Harvey 1982).

\section{B.7. Cladding and Fuel Constitutive Equations}

The volumetric irradiation swelling expansion was derived from the data in (Pahl et al. 1990a, GE 1991):

$$
\varepsilon_{\mathrm{IS}}=\left\{\begin{array}{l}
0 \text { for } \delta<165 \mathrm{dpa} \\
0.002(\delta-165) \text { for } \delta \geq 165 \mathrm{dpa}
\end{array}\right.
$$

Equation B.24 states that irradiation swelling in HT-9 has an incubation dose of 165dpa and occurs at a rate of $0.2 \% / \mathrm{dpa}$ thereafter.

The irradiation creep equation is taken from (Amodeo and Ghoniem 1985):

$$
\dot{\varepsilon}_{I C}=A_{I C} \sigma_{e} \dot{\delta}
$$

where $\mathrm{A}_{\mathrm{IC}}$ was found to be in the range $1.0 \times 10^{-7}$ to $2.9 \times 10^{-6} \mathrm{dpa}^{-1} \mathrm{MPa}^{-1}$. Here the upper limit is conservatively adopted.

\footnotetext{
${ }^{6}$ The smeared density is defined as $R_{f 0}^{2} / R_{c i 0}^{2}$.
} 
The secondary thermal creep equation is also taken from (Amodeo and Ghoniem 1985):

$$
\dot{\varepsilon}_{T C}=\frac{A_{T C}}{k_{B} T_{c}}\left(\sigma_{e}-\sigma_{0}\right)^{3} e^{-\frac{Q_{T C}}{k_{B} T_{c}}}
$$

where $\mathrm{k}_{\mathrm{B}}$ is the Boltzmann's constant $\left(8.6207 \times 10^{-5} \mathrm{eV} / \mathrm{K}\right), \mathrm{T}_{\mathrm{c}}$ is in $\mathrm{K}, \mathrm{Q}_{\mathrm{TC}}=1.23 \mathrm{eV}$, $\mathrm{A}_{\mathrm{TC}}=6.2588 \times 10^{-9} \mathrm{eV} /(\mathrm{s} \cdot \mathrm{MPa})$ and the thermal creep threshold stress is (in MPa):

$$
\sigma_{0}=-1.5065 \mathrm{~T}_{\mathrm{c}}+1366.39
$$

The fast neutron flux $\left(\mathrm{E}_{\mathrm{n}}>0.1 \mathrm{MeV}\right)$ on the cladding of the $\mathrm{U}-19 \mathrm{Pu}-10 \mathrm{Zr}$ fuel is calculated as:

$$
\Phi=a \frac{\dot{q}}{M_{H M}}
$$

where $\mathrm{a}=1.16 \times 10^{10}\left(\mathrm{n} / \mathrm{cm}^{2} \mathrm{~s}\right) /\left(\mathrm{W} / \mathrm{kg}_{\mathrm{HM}}\right)$ is derived from the data in (Pahl et al. 1990a).

The fuel deformation as a function of the burnup BU is calculated based on the assumption that the cladding/fuel gap closes at $2 \mathrm{at} \%$ burnup for the U-Pu-Zr fuel and remains closed thereafter (Pahl et al. 1990a). Also, it was found that fuel expansion prior to fuel/cladding contact is anisotropic with the radial and hoop strains growing at a rate twice as large as the axial strain. After fuel/cladding contact is made, the axial strain grows at a rate of $0.1 \% / a t \%$ burnup. Therefore the following equations hold for the fuel:

$$
\begin{aligned}
& \mathrm{R}_{\mathrm{f}}=\left\{\begin{array}{l}
\mathrm{R}_{\mathrm{f} 0}+\left(\mathrm{R}_{\mathrm{ci}}-\mathrm{R}_{\mathrm{f} 0}\right)(\mathrm{BU} / 0.02) \text { for } \mathrm{BU}<0.02 \\
\mathrm{R}_{\mathrm{ci}} \text { for } \mathrm{BU} \geq 0.02
\end{array}\right. \\
& \varepsilon_{\mathrm{z}, \mathrm{f}}=\left\{\begin{array}{l}
1 / 2\left(\mathrm{R}_{\mathrm{f}}-\mathrm{R}_{\mathrm{f} 0}\right) / \mathrm{R}_{\mathrm{f} 0} \text { for } \mathrm{BU}<0.02 \\
\varepsilon_{\mathrm{z}, \mathrm{f}}(2 \mathrm{at} \%)+0.1(\mathrm{BU}-0.02) \text { for } \mathrm{BU} \geq 0.02
\end{array}\right.
\end{aligned}
$$

where $\varepsilon_{\mathrm{z}, \mathrm{f}}$ is the fuel axial strain. Analogous expressions hold for the $\mathrm{Zr}$ - $\mathrm{Pu}$ fuel with the threshold burnup level being $6 \mathrm{at} \%$.

Regarding the fission gas release from the fuel, the following correlation is based on the U19Pu-10Zr data in (Pahl et al. 1990b):

$$
F_{f g}=0.8\left(1-e^{-B U / 0.02}\right)
$$

Note that because only the peak heat generation rate data are given in reference (Pahl et al. 1992), Equation B.10 needs to be modified as follows:

$$
N_{f g}=F_{f g} n_{f g}\left(\dot{q} / P_{a x}\right) t_{k}
$$

where $\mathrm{P}_{\mathrm{ax}}$ is the axial peaking factor, which is not given for the fuel rods of interest. Therefore it is arbitrarily assumed that $\mathrm{P}_{\mathrm{ax}}=1.4$. 


\section{B.8. Results}

The cladding equivalent stress for rods \#1,2 and 3 is plotted in Figure B.1 along with the yield strength of HT-9 at $600^{\circ} \mathrm{C}, \mathrm{S}_{\mathrm{y}}$. As expected, the stresses in the cladding increase with burnup due to the release of fission gases from the fuel. Also, the stresses in rod \#1 are higher due to the smaller plenum length. However, it can be seen that the cladding remains within the elastic range $\left(\sigma_{\mathrm{e}}<\mathrm{S}_{\mathrm{y}}\right)$ for all rods at the burnup level considered.

The hoop elastic, thermal expansion, irradiation and thermal creep strains in the cladding of Rod \#1 are illustrated in Figure B.2. The sum of these terms equals by definition the total hoop strain $\varepsilon_{\theta}$ of Equation B.11. Note that, because the neutron dose to the cladding remains below $100 \mathrm{dpa}$, no swelling strains are expected. Further, it can be noted that, among the irreversible strains (in general swelling, thermal and irradiation creep), the irradiation creep strain is dominant at these burnup levels.

The results of the benchmark are reported in Table B.II. The model appears to systematically overpredict the hoop strain, but given the uncertainties in the axial peaking factor and especially in the HT-9 irradiation creep equation, the agreement is considered satisfactory.

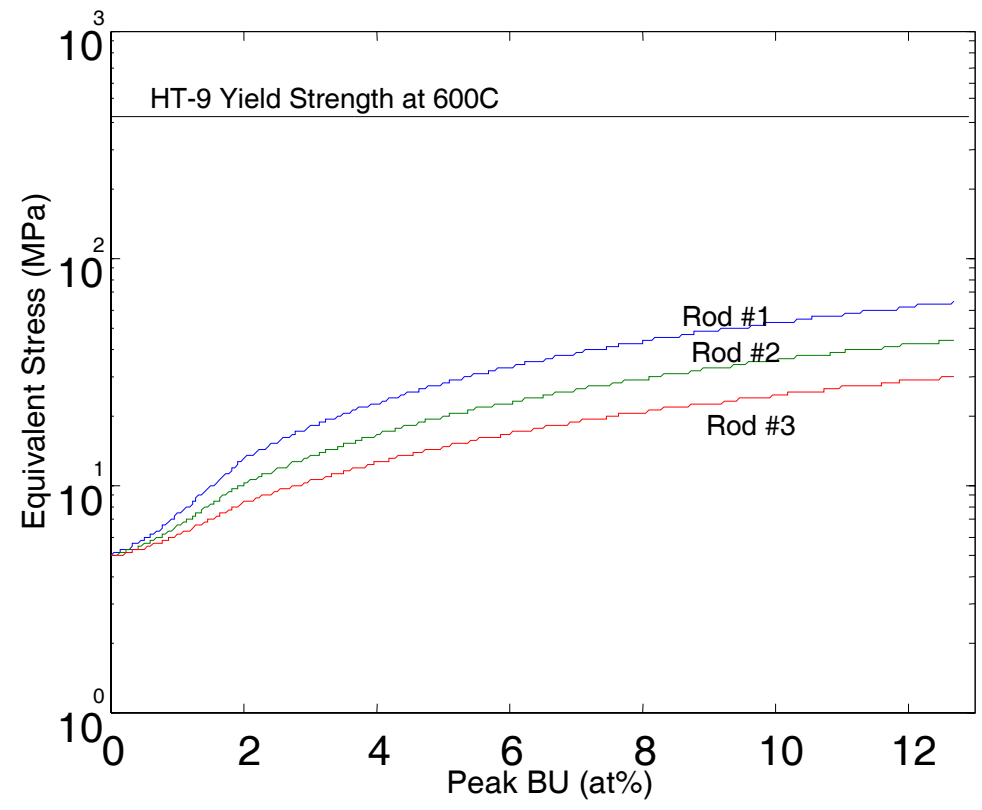

Figure B.1. Stresses in the cladding. 


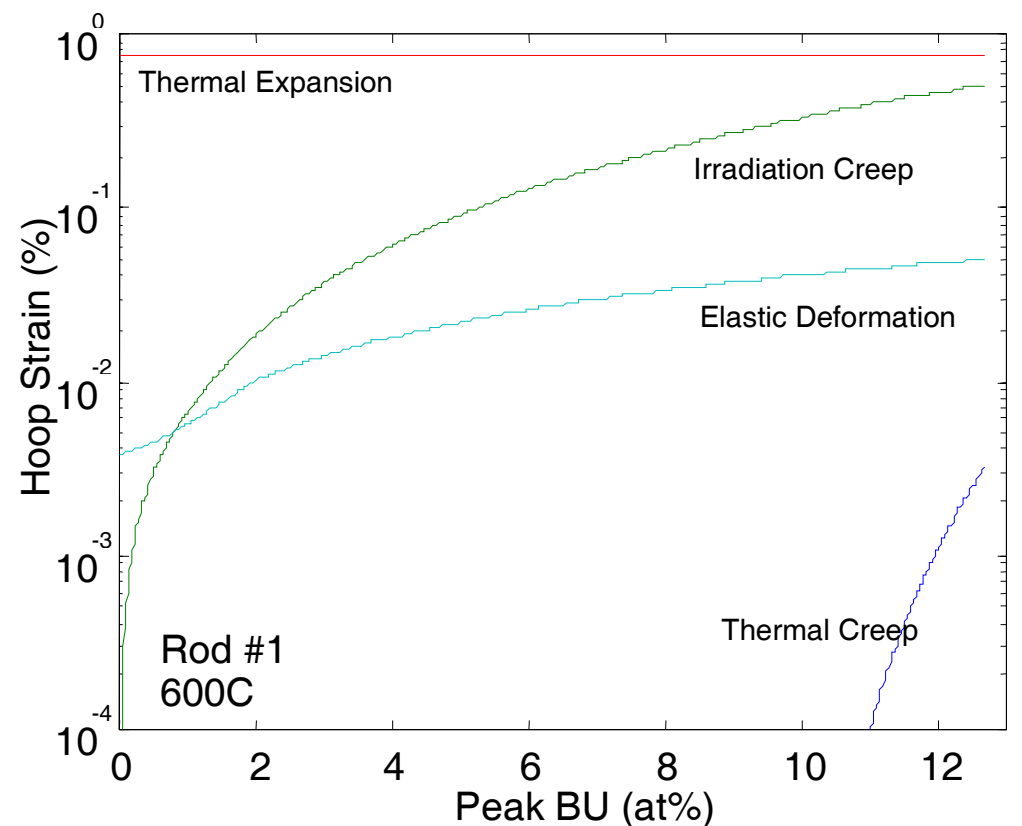

Figure B.2. Strains in the cladding.

Table B.II. EOL hoop strain due to irradiation and thermal creep in HT-9-clad sodium-bonded and sodium-cooled metallic fuel rods irradiated at $12.7 \mathrm{at} \%$ peak burnup.

\begin{tabular}{|c|c|c|}
\hline Rod \# & $\begin{array}{l}\text { Hoop Strain, \% } \\
\text { (calculated) }\end{array}$ & $\begin{array}{l}\text { Hoop Strain, \% } \\
\text { (measured) }\end{array}$ \\
\hline 1 & 0.52 & 0.32 \\
\hline 2 & 0.36 & 0.28 \\
\hline 3 & 0.26 & 0.17 \\
\hline
\end{tabular}

